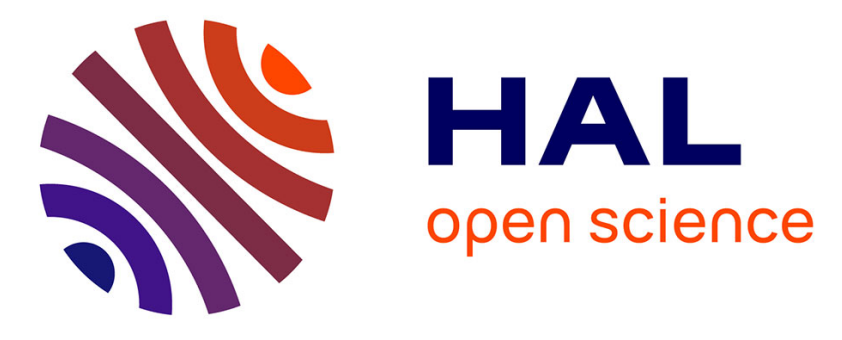

\title{
L'Aven d'Orgnac, valorisation touristique, apports scientifiques
}

Jean-Jacques Delannoy, Christophe Gauchon, Stéphane Jaillet

\section{To cite this version:}

Jean-Jacques Delannoy, Christophe Gauchon, Stéphane Jaillet. L'Aven d'Orgnac, valorisation touristique, apports scientifiques. Coordinateurs: Fabien Hobléa; Emmanuel Reynard; Jean Jacques Delannoy. Collection EDYTEM, pp.184, 2007, Collection Edytem, Cahiers de Géographie $n^{\circ}$ 5, ISBN 2-9520432-4-8. halsde-00786450

\section{HAL Id: halsde-00786450 https://hal.science/halsde-00786450}

Submitted on 8 Feb 2013

HAL is a multi-disciplinary open access archive for the deposit and dissemination of scientific research documents, whether they are published or not. The documents may come from teaching and research institutions in France or abroad, or from public or private research centers.
L'archive ouverte pluridisciplinaire HAL, est destinée au dépôt et à la diffusion de documents scientifiques de niveau recherche, publiés ou non, émanant des établissements d'enseignement et de recherche français ou étrangers, des laboratoires publics ou privés. 


\section{Collection EDYTEM \\ Environnements, Dynamiques et Territoires de la Montagne}

\section{Cahiers de Géographie}

Numéro 5 - Année 2007
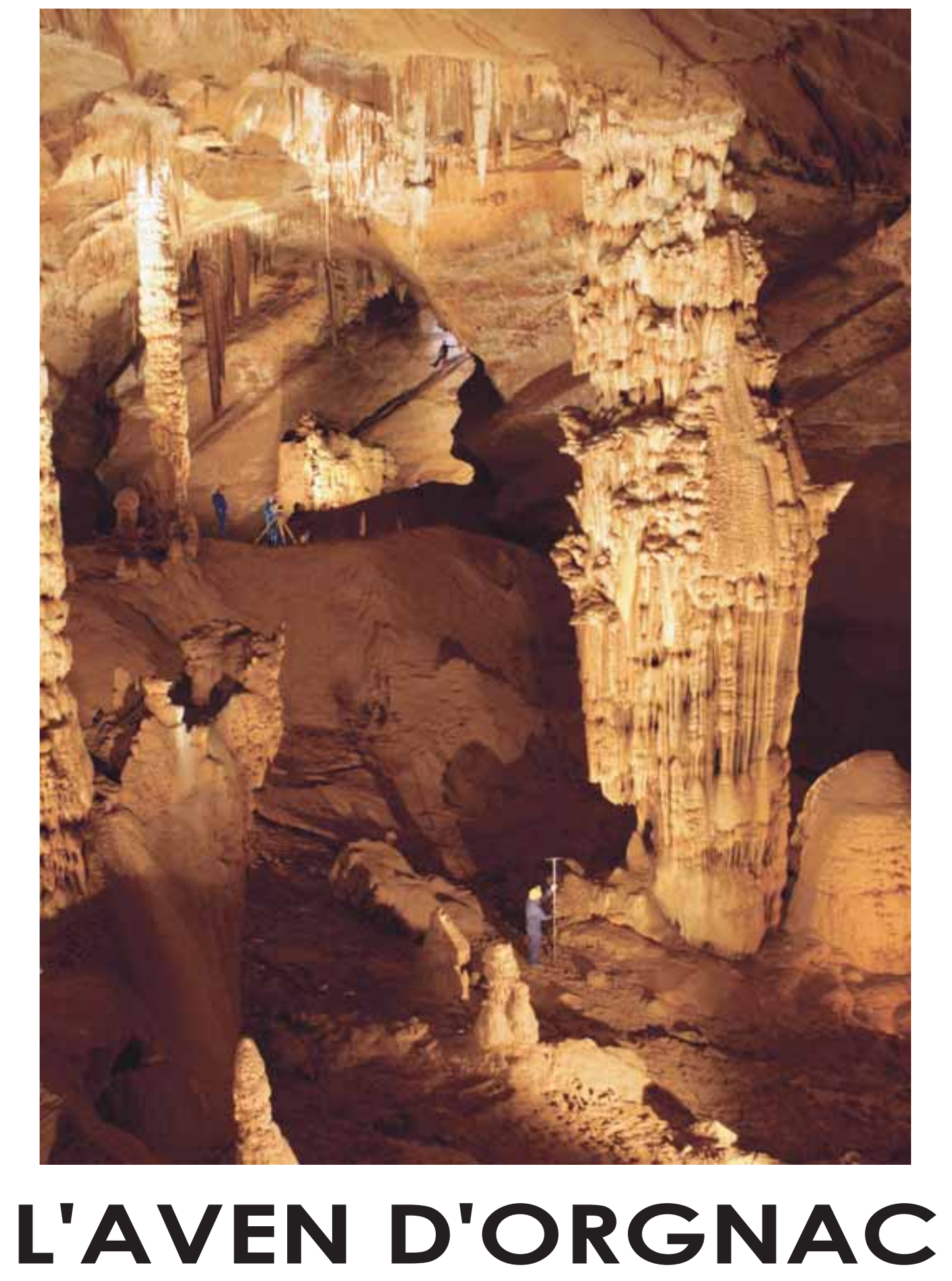

VALORISATION TOURISTIQUE, APPORTS SCIENTIFIQUES 



\section{Collection \\ Laboratoire}

Année 2007

\section{Cahiers de Géographie}

Numéro 5

\section{L'aven d'Orgnac valorisation touristique, apports scientifiques}




\section{Photo de couverture :}

Les Salles Rouges de l'aven d'Orgnac constituent le terme de la visite touristique. Un son et lumière y met en valeur les volumes, les formes et les stalagmites massives d'un paysage qui compte parmi les plus éloquents qui soient offerts au touriste souterrain en France, le tout à plus de cent mètres sous la surface de la terre. Les dimensions de la salle sont impressionnantes : plus de $40 \mathrm{~m}$ de large et autant de hauteur sans compter les cheminées. La paroi du fond est à $110 \mathrm{~m}$ de la plate-forme d'où la photo a été prise, et les colonnes stalagmitiques comptent parmi les plus grandes du monde.

Ce site concentre à lui seul une grande partie des thématiques et des travaux de recherches mis en œuvre à l'aven d'Orgnac. Les formes pariétales présentent des banquettes-limites exemplaires (banquettes pentées à gauche du personnage au fond sur la corde). Elles sont les témoins de la phase paragénétique du creusement du réseau à des époques très anciennes. La réalisation d'un modèle 3D par lasergrammétrie (utilisation d'un Lidar terrestre, personnages au centre de la salle) a permis de les étudier finement. Les dépôts détritiques (essentiellement argileux) ont été sondés (personnage au premier plan) à la tarière sur plus de $10 \mathrm{~m}$ de profondeur.

Dans le domaine des circulations fluides, les Salles Rouges sont également très intéressantes. Le CO y est piégé une partie du temps et le renouvellement de l'air dépend des conditions météorologiques externes. En période de crue, l'eau peut aussi remonter du karst profond. Ainsi, en septembre 2002 lors d'un épisode pluvieux exceptionnel, les Salles Rouges ont été ennoyées jusqu'à la plateforme.

Paysage souterrain exceptionnel, porteur d'une information scientifique riche et variée, les Salles Rouges ont été au cœur de la réorganisation de l'offre touristique lors de «l'opération Grand Site ». 


\section{L'aven d'Orgnac valorisation touristique, apports scientifiques}

René UGHETTO, maire d’Orgnac-l’Aven

Introduction

Problématique d'étude

Jean-Jacques DELANNOY

Chapitre 1

L'aven d'Orgnac : identification d'un haut lieu du tourisme souterrain Vincent BIOT, Mélanie DUVAL et Christophe GAUCHON

La gestion des réseaux d'Orgnac-Issirac : un exemple original de valorisation de réseaux souterrains fragiles et à haute valeur patrimoniale

Stéphane TOCINO

Chapitre 2

L'aven d'Orgnac : une caverne privilégiée pour l'élaboration des connaissances karstologiques Christophe GAUCHON et Françoise PRUD'HOMME

Bibliographie scientifique sur l'aven d'Orgnac.

Françoise PRUD'HOMME

L'aven d'Orgnac : un grand réseau paragénétique, étude spéléogénétique des grands volumes karstifiés

Stéphane JAILLET, Jean Jacques DELANNOY, Jean-Loïc BERSIHAND, Matthieu NOURY, Benjamin SADIER et Stéphane TOCINO

L'aven d'Orgnac : étude des remplissages, mémoires des dynamiques spéléogéniques post-paragénétiques Benjamin SADIER, Anne-Sophie PERRROUX, Yves PERRETTE, Jean-Jacques DELANNOY, Yves QUINIF et Olivier KAUFMANN

Chapitre 5

L'aven d'Orgnac : suivi environnemental et modèle de fonctionnement actuel du milieu souterrain karstique au service du développement durable.

François BOURGES, Alain MANGIN, Pierre GENTHON, Dominique D’HULST et Françoise GAUQUELIN

\section{Chapitre 6}

L'aven d'Orgnac : un jalon karstique pour la reconstitution paléogéographique de l'interfluve Ardèche/Cèze

Jean-Jacques DELANNOY, Stéphane JAILLET, Serge FUDRAL, Dominique GASQUET, Olivier KAUFMANN, Maxime SABAUT et Estelle PLOYON

Conclusion

Perspectives pluridisciplinaires

Jean-Jacques DELANNOY 


\section{ANNEXES MÉTHODOLOGIQUES}

Annexe 1

Topographie et Modèle Numérique de Terrain 2,5D

Benjamin SADIER

Annexe 2

Volume souterrain 3D et laserscanning

Stéphane JAILLET

Annexe 3

Cartographie géomorphologique des sols

Jean-Jacques DELANNOY

Annexe 4

Sédimentologie endokarstique

Anne-Sophie PERROUX

Annexe 5

Datations U / Th des stalagmites

Yves QUINIF

Annexe 6

Tomographie électrique

Olivier KAUFMANN

Annexe 7

Métrologie et climatologie souterraine

François BOURGES

Annexe 8

3D et réalité virtuelle

Estelle PLOYON 


\section{PRÉFACE}

Il m'est agréable aujourd'hui de préfacer cet ouvrage tant celui-ci démontre la volonté de la commune d'Orgnac-l'Aven, propriétaire et gestionnaire du site, de concilier les deux missions que se doit de réaliser tout responsable de sites naturels et touristiques, à savoir associer préservation et présentation à un large public d'un lieu pittoresque.

Le travail réalisé ici pour la protection et le développement de ce fameux site, mémoire du temps, qu'est l'aven d'Orgnac, a toujours privilégié un fonctionnement interdisciplinaire fondé sur l'écoute afin de trouver le consensus indispensable à l'avancement des projets.

Deux axes principaux ont tout de suite été identifiés :

- comprendre le fonctionnement aérodynamique et la genèse de cette cavité pour ainsi pouvoir mieux protéger et mieux transmettre au public,

- associer les différents acteurs du territoire touristique et culturel et les aspirations de celles et ceux qui y vivent ou qui le découvrent, tout en essayant de conjuguer leurs aspirations et les champs du possible sans porter atteinte à l'intégrité du site. Tel a été le cheminement qui a conduit la labellisation de ce Grand Site de France, le 13 juin 2004. Ici peut-être a-t-on prouvé qu'il est possible de concilier protection et valorisation touristique.

En ayant soin de placer l'homme au cœur du dispositif, du chercheur à l'hôtesse d'accueil et au guide, médiateurs du site, du visiteur à l'habitant, nous avons délibérément choisi de privilégier l'écoute et le dialogue.

Le travail réalisé montre le besoin de réunir tous les champs disciplinaires afin d'appréhender la totalité du sujet ; ainsi agents de l'État, chercheurs, concepteurs, gestionnaires du site, utilisateurs, ont œuvré en symbiose pour parvenir à ce résultat. Bien entendu, aucune réussite n'est définitive, de nouveaux travaux sont engagés : classement du site en surface, nouveaux équipements, nouvelles stratégies de communication, nouveau positionnement du Musée de Préhistoire, tout cela inscrit dans un programme de développement à long terme.

Cet ouvrage confirme parfaitement la nécessité de transversalité des actions et nous espérons que la continuité de celles-ci, avec notamment le travail du laboratoire Edytem dont nous tenons ici à souligner le professionnalisme, nous permettront de nouvelles avancées.

Merci donc à celles et ceux qui nous ont accompagnés ou nous accompagnent dans cette aventure. C'est peut-être cela la réussite de la mise en place d'un tourisme vraiment durable.

Pour la municipalité d'Orgnac-l'Aven,
le Maire,
René Ughetto 


\title{
Introduction
}

\section{PROBLÉMATIQUE D’ÉTUDE}

\author{
par Jean-Jacques DELANNOY
}

1 Laboratoire EDYTEM - Université de Savoie

Cavité majeure tant par la diversité de ses paysages souterrains que par l'ampleur de ses réseaux, l'aven d'Orgnac a été, depuis une dizaine d'années, l'objet de nouvelles recherches qui soulignent à nouveau l'importance de cette cavité aussi bien sur le plan karstogénique, géomorphologique que géographique. Cet ouvrage a pour objet de présenter les résultats des nouvelles recherches qui ont été engagées dans le cadre de l'Opération Grand Site et qui se poursuivent aujourd'hui dans le cadre de différents programmes de recherche en partenariat avec la municipalité d'Orgnacl'Aven et la DIREN Rhône-Alpes. La labellisation « Grand Site de France » en 2004 de l'aven d'Orgnac est le fruit d'une forte volonté locale de repenser, dès le milieu des années 1990, la gestion de cette cavité en s'appuyant sur la forte valeur patrimoniale des réseaux notamment non touristiques qui, depuis les années 1970, sont classés tant pour leur dimension esthétique que pour le caractère remarquable des volumes souterrains. Compte tenu de ce classement, la municipalité a sollicité l'accord de la DIREN pour le réaménagement de la partie touristique et la réalisation de visites guidées dans la partie non aménagée et classée de la cavité. La DIREN Rhône-Alpes a eu l'intelligence de se saisir de l'instrument «Opération Grand Site » pour lancer de nouvelles recherches sur la cavité. Celles-ci ont été, dans un premier temps, consacrées à la climatologie de la cavité, et plus particulièrement à la présence saisonnière parfois importante de $\mathrm{CO}_{2}$ qui avait pour effet de contraindre les visites touristiques et le projet de développement de l'offre aux réseaux non aménagés. Un important travail de recherche a été réalisé par le laboratoire souterrain de Moulis (A. Mangin, D. D'Hulst et P. Genthon) et le bureau d'étude Géologie Environnement Conseil (F. Bourges). C'est sur la base du modèle climatique de la cavité proposé par cette équipe qu'ont été pensés la restructuration du site d'Orgnac (déplacement des parkings...) et le réaménagement de la partie touristique. C'est également sur la base des recherches menées par ces chercheurs que la DIREN a donné son accord à des visites strictement encadrées des réseaux non aménagés d'Orgnac II et d'Orgnac III (arrêté préfectoral de 1999). L’Opération Grand Site, menée de concert par la DIREN, la municipalité et le Syndicat Intercommunal d'Exploitation et de Gestion des Réseaux de l'Aven d'Orgnac-Issirac, met rapidement en avant que les dernières connaissances disponibles sur la cavité remontent au milieu des années 1960 . Afin de renouveler ces connaissances, un programme de recherche est lancé par la DIREN. Celui-ci avait essentiellement pour objet de définir les différentes étapes spéléogéniques de la cavité, de les caler autant que possible chronologiquement et de mettre en avant les mémoires karstogéniques et environnementales contenues dans les morphologies endokarstiques et les remplissages. C'est dans le cadre de ce programme qu'ont débuté les premiers travaux du laboratoire sur cette cavité. Cette opportunité était d'autant plus intéressante que le laboratoire était déjà impliqué dans l'étude karstogénique de la toute proche grotte Chauvet et que les recherches sur cette cavité avaient mis en avant le déficit de nouvelles recherches morphogéniques et karstogéniques sur ce secteur de l'Ardèche. C'est dans ce cadre que les recherches menées par le Laboratoire de Géographie de l'Université de Savoie (LGUS) puis par le laboratoire EDYTEM ont été engagées et progressivement développées. Cette implication du laboratoire dans l'étude d'Orgnac n'aurait pu se faire sans l'appui sans faille de Françoise Gauquelin de la DIREN Rhône-Alpes qui a porté le dossier Grand Site auprès du ministère, d'Alain Mangin du laboratoire souterrain de Moulis et de François Bourges (Géologie Environnement Conseil), tous deux fortement impliqués dans les études climatologiques de la cavité, de Gilbert Mantovani, investi dans le réaménagement touristique de la cavité et avec lequel nous avions déjà partagé des recherches spéléogéniques (site de Choranche), de Joël Ughetto, gestionnaire du site d'Orgnac, de la municipalité d'Orgnac et de son maire, René Ughetto, ainsi que de la municipalité d'Issirac. Nous espérons que cet ouvrage soit à la hauteur de leur confiance et de leur soutien. 
L'implication du laboratoire EDYTEM sur Orgnac répondait également à la volonté de développer sur le sud-Ardèche un « site-atelier de recherche » permettant, autour d'objets karstiques de très fortes valeurs patrimoniales (aven Orgnac, grotte Chauvet, gorges de l'Ardèche, Pont d'Arc...), de croiser différentes regards et approches de la géographie. Il s'agissait ici de mettre en avant la pertinence de l'interdisciplinarité dans la définition des valeurs patrimoniales des objets naturels et de modes de gestion combinant protection et valorisation. Cette dimension transversale des recherches menées au sein d'EDYTEM sur les objets karstiques est celle qui a été privilégiée dans l'étude de l'aven d'Orgnac et dans l'organisation de cet ouvrage. Plusieurs recherches doctorales et de master ont été menées sur le site d’Orgnac : il s'agit des travaux d'A-S. Perroux sur les remplissages détritiques d'Orgnac (2005), de B. Sadier sur la géomorphologie des salles d'Orgnac et les concrétions translatées, de M. Noury sur la morphogenèse de la Salle de Joly, de J.-L. Bersihand sur les remplissages et la morphologie des Salles Rouges, de M. Sabaut sur l'étude géomorphologique de l'anticlinal du bois de Ronze et de M. Duval sur le tourisme souterrain. L'ensemble de ces travaux doivent beaucoup à l'important soutien apporté par le personnel travaillant sur le site d'Orgnac; nous pensons ici tout particulièrement à Joël Ughetto, Stéphane Tocino, Frédéric Fiorentino, Philippe Barth, Lydia Gambéri A. de C. et Françoise Prud'homme. Le partenariat développé entre le site d'Orgnac et le laboratoire s'est traduit par plusieurs actions de divulgation scientifique et plus particulièrement par l'exposition réalisée par le Musée régional de Préhistoire d'Orgnac, en 2002-2003, sur « Le calcaire et l'eau ». Le travail réalisé sur Orgnac doit beaucoup à Stéphane Jaillet qui a coordonné avec efficacité et dévouement les nombreuses missions de recherche tant en surface que sous terre ainsi qu'à Estelle Ployon qui a développé de nouveaux modes de représentation de la cavité et de son environnement géologique (modèles 3D). Enfin, les recherches menées sur Orgnac ont permis de développer des partenariats scientifiques de grande qualité, notamment avec nos collègues du département de géologie de la Faculté polytechnique de Mons (Belgique) : Yves Quinif et Olivier Kaufmann.

Cet ouvrage a pour volonté de présenter les principaux résultats des travaux réalisés depuis une petite dizaine d'années sur Orgnac. Aux recherches géographiques, spéléogéniques et géomorphologiques menées par les membres du laboratoire d'EDYTEM, ont été associés les travaux menés par F. Bourges et A. Mangin sur la climatologie de la cavité et leurs implications dans le réaménagement du site d'Orgnac et de la partie touristique.
Objet central des recherches, l'ouvrage débute par la présentation de l'aven en tant que haut lieu du tourisme karstique et souterrain. Ce premier chapitre permet d'appréhender la place et le rôle sans cesse précurseur de cette cavité dans le développement et la structuration de l'offre touristique régionale notamment autour des valeurs patrimoniales du karst ; ce chapitre présente également la genèse de l'Opération Grand Site qui a été menée avec efficacité grâce à une dynamique regroupant les élus locaux, les services de l'État (DIREN) et les chercheurs impliqués dans ce projet.

Le deuxième chapitre est consacré aux recherches qui ont été menées dans l'aven d'Orgnac; au même titre que la portée touristique de cette cavité, cet aven a été très tôt l'objet de recherches spéléogéniques novatrices. Le caractère exceptionnel de cette cavité tant par l'ampleur des volumes souterrains, la diversité des paysages, l'importance du concrétionnement que par la géométrie des réseaux et des formes souterraines, a très vite interpellé les spéléologues et les scientifiques. Sur bien des aspects, l'aven d'Orgnac ne répondait pas aux « standards » habituels morphogéniques, sédimentologiques et spéléogéniques et il n'est pas étonnant que cette cavité ait été au cœur de nouveaux concepts et approches du karst souterrain. Il est intéressant de relever que très tôt, l'étude de l'aven d'Orgnac s'est posée en tant que vecteur d'informations sur l'évolution géomorphologique régionale (R. de Joly, B. Gèze...), en tant que support paléoclimatique (J.-Cl. Duplessy) et en tant que «modèle » d'un fonctionnement spéléogénique particulier (paragénétisme de $\mathrm{Ph}$. Renault)... axes qui sont au cœur des recherches actuelles sur le karst. Cet article qui présente en détail le caractère précurseur des recherches menées dans cette cavité est complété par une riche synthèse bibliographique des travaux réalisés sur le site d'Orgnac.

Les quatre contributions qui suivent présentent les recherches menées depuis une dizaine d'années sur Orgnac en karstologie et en climatologie souterraine. Le chapitre sur la climatologie souterraine présente sous forme synthétique le long suivi métrologique réalisé par $\mathrm{F}$. Bourges et $\mathrm{A}$. Mangin à partir duquel a été conçu le modèle de fonctionnement aérologique de la cavité ; ce modèle permet d'appréhender la présence du $\mathrm{CO}_{2}$ dans l'aven ainsi que ses variations de concentration dans les différents réseaux souterrains. C'est sur la base de ce modèle qu'ont été repensés les aménagements extérieurs de l'aven et posés les systèmes de ventilation de la partie touristique (Salles Rouges). Sur bien des aspects, ce modèle s'applique à de nombreuses cavités de 
l'Ardèche ayant connu une spéléogenèse similaire à celle des réseaux d'Orgnac, responsable de la présence d'importants colmatages argileux. Les trois autres contributions reposent sur l'analyse morphogénique de l'aven et du karst environnant. L'ordre de ces chapitres est le reflet de la démarche que nous avons menée sur ce site : (i) l'étude des morphologies et sédiments endokarstiques a permis de travailler sur les emboitements, à la fois d'ordre spatial et temporel, des différents événements qui ont marqué l'évolution de l'aven; l'objectif étant de poser un canevas spéléogénique rendant compte de l'ensemble des observations et relevés réalisés dans la cavité ; (ii) ce canevas spéléogénique a été ensuite confronté aux données issues de l'étude géomorphologique des paysages exokarstiques afin de dégager des dynamiques paléogéographiques cohérentes; (iii) les moteurs de ces dynamiques ont été ensuite recherchés sur la base de travaux récents et en cours sur l'Ardèche et la vallée du Rhône. Cette démarche a ainsi permis de reconstituer la genèse de l'aven d'Orgnac sur les cinq derniers millions d'années et de mettre en avant l'importance de la transgression pliocène dans la spéléogenèse de la cavité (paragénétisme) et de l'évolution plioquaternaire dans la dynamique des soutirages souterrains, en grande partie responsables de la physionomie actuelle des réseaux d'Orgnac et de leur ampleur. L'ampleur des réseaux, la compréhension du rôle des soutirages et de leurs dynamiques et l'importance du concrétionnement rendant parfois délicate la compréhension morphogénique ont limité, en partie, nos ambitions initiales de travailler sur l'ensemble du réseau et sur le concrétionnement. Cet ouvrage constitue une première synthèse des nouvelles recherches menées sur l'aven d'Orgnac. Les recherches en cours seront l'objet d'articles à venir, voire d'un nouveau recueil de synthèse. Quoi qu'il en soit, cet ouvrage met clairement en avant l'importance de l'aven d'Orgnac dans la karstogenèse régionale et dans la compréhension des dynamiques morphogéniques qui se sont développées durant le Néogène puis le Quaternaire sur les plateaux calcaires du Bas-Vivarais et dans les gorges qui les recoupent (Cèze, Ardèche). Cet ouvrage permet également de mettre en avant le rôle majeur d'une action de valorisation du karst souterrain : l'Opération Grand Site a été un moteur essentiel pour repenser de nouveaux champs du tourisme souterrain, pour poser la place de l'aven d'Orgnac dans la restructuration actuelle de l'offre touristique régionale et pour relancer les recherches sur le mode souterrain et la spéléogenèse. Que tous ceux qui ont contribué à la réussite de cette opération et ont eu confiance dans notre démarche scientifique soient ici remerciés. 


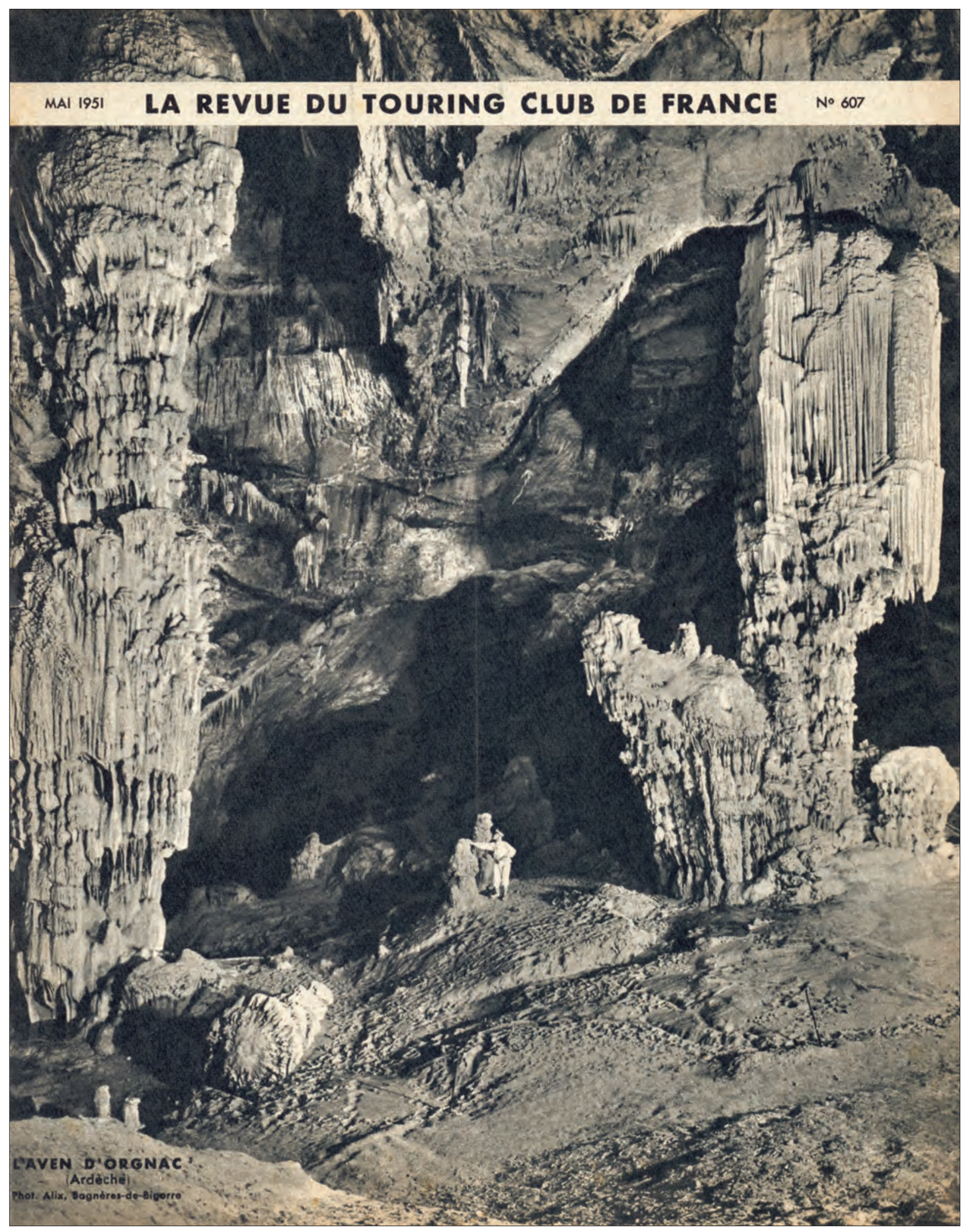




\title{
L'AVEN D'ORGNAC
}

\section{IDENTIFICATION D’UN HAUT LIEU DU TOURISME SOUTERRAIN}

\author{
par Vincent $\mathrm{BIOT}^{\prime}$, Mélanie DUVAL ${ }^{l}$, Christophe GAUCHON ${ }^{l}$
}

1 Laboratoire EDYTEM - Université de Savoie

Lorsqu'en 1948 la maison Michelin édita une carte des grottes touristiques de France, c'est un dessin de la grande salle de l'aven d'Orgnac qui fut choisi pour figurer sur la jaquette. Ce choix n'était pas anodin car, sans affirmer que la valeur esthétique d'Orgnac fût supérieure à celle d'autres cavernes ouvertes à la visite, il mettait en exergue cet aven ouvert dans les semaines qui avaient précédé la guerre et qui symbolisait le renouveau du tourisme souterrain après les grandes innovations des années 1890-1900. Si les années 1945-1970 allaient être marquées par l'ouverture au public de plusieurs dizaines d'autres cavernes, l'aven d’Orgnac conserva une dimension emblématique liée au volontarisme de ses gérants qui ne se démentit jamais. Et c'est ainsi que des initiatives répétées ont permis à l'aven de conserver tout son lustre et de concilier l'ancrage dans le tissu local, l'efficacité économique et le souci du respect du site ; on peut alors poser comme hypothèse que l'aven d'Orgnac a illustré et illustre encore les principes du tourisme durable, et ce bien avant que ce terme même ait été inventé. Même si toute l'histoire de l'aven d'Orgnac n'est pas écrite dès sa découverte, le contexte dans lequel se déroule son exploration n'est pas anodin et il nous semble intéressant de revenir d'abord sur ce point, qui va conditionner la mise en tourisme du lieu. Mais l'une des spécificités de l'aven d'Orgnac tient aussi dans le souci constant de sa protection et dans la façon dont ce souci n'a cessé depuis plus de 70 ans de se combiner avec l'activité touristique. Or cette synergie ne se développe pas seulement à l'échelle du site, mais s'inscrit aussi dans l'ensemble de la région du sud-Ardèche avec toute une série d'allers-retours dont Orgnac tire profit tout autant qu'en profite la région.

\section{I - L'EXPLORATION ET LA MISE EN TOURISME DE L'AVEN D'ORGNAC}

\section{a - La découverte et la décision d'aménagement}

Bizarrement, c'est peut-être sur les hauteurs du causse Méjean que commence, le 11 juin 1927, l'histoire de l'aven d'Orgnac ; ce jour-là, en effet, l'aven Armand ouvre enfin au public. Pendant les trente années qui se sont écoulées depuis sa découverte, Édouard-Alfred Martel s'est démené pour faire aboutir ce projet : ni la guerre, ni la disparition de Louis Armand en 1922, ni l'extinction de la Société Spéléologique de France ni la vieillesse (Martel a alors 68 ans) n'ont eu raison de cette farouche volonté de créer, au beau milieu des Grands Causses, l'attraction touristique majeure qui fut l'un des buts de sa vie. Le site est isolé, le puits d'entrée est profond de 75 mètres, un tunnel de 208 mètres de long doit être creusé, mais tous ces obstacles sont surmontés et l'exploitation touristique rencontre immédiatement le succès.

Et lorsqu'en 1929 Robert de Joly reprend le flambeau de la spéléologie française et crée le Spéléo-Club de France, l'exemple de l'aven Armand est dans tous les esprits. Les statuts du S.-C.F. citent parmi les buts de l'association « la recherche d'abîmes à exploiter touristiquement $»$; en lien avec le Touring-Club de France, R. de Joly va parcourir toutes les régions karstiques du pays et donner son avis sur différents projets d'aménagements touristiques (photo 1). La découverte d'un "nouvel aven Armand» devient un objectif avoué des recherches spéléologiques... et ce sera l'aven d'Orgnac. Il est vrai que les deux gouffres présentent de telles similitudes dans leur configuration et 


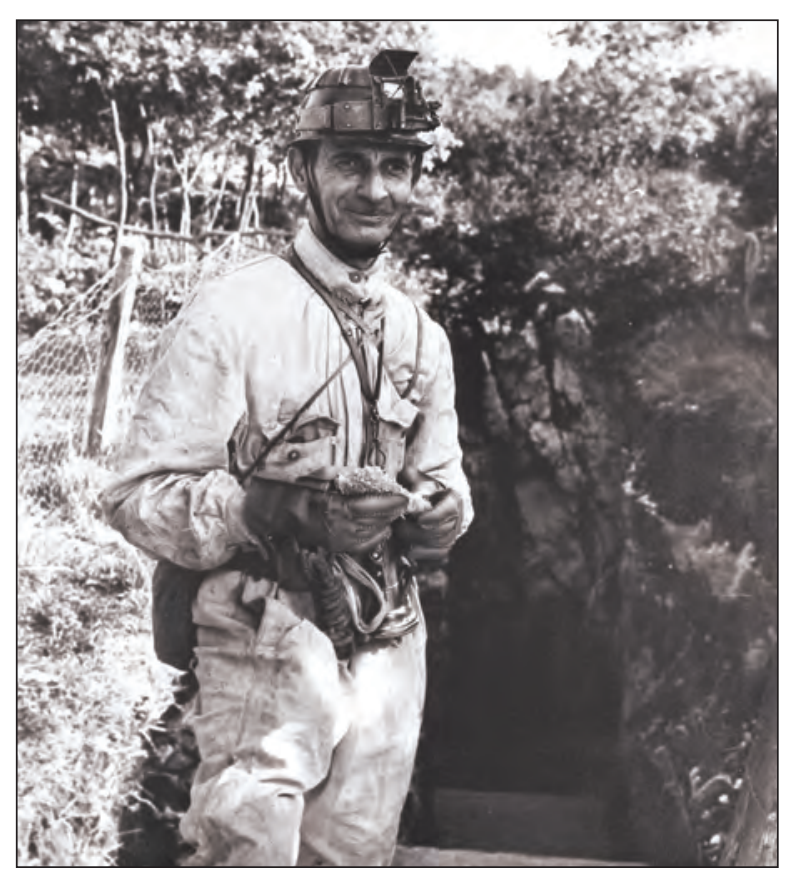

Photo 1

Robert de Joly s'apprêtant à descendre sous terre.

(Archives Mairie d'Orgnac)

même dans le style du concrétionnement (les fameuses stalagmites piles d'assiettes) qu'ils appellent d'euxmêmes la comparaison.

Depuis 1926, R. de Joly arpentait donc les karsts du Gard et y réalisait des dizaines d'explorations. En mars 1933, il a revisité la grotte de Saint-Marcel, puis le printemps et l'été 1935 le voient de retour autour des gorges de l'Ardèche. Le 19 août 1935, les habitants d'Orgnac le mènent auprès de l'aven du Bertras qu'il explore avec quatre co-équipiers (Glory, Latour, Petit et Chagnard) jusqu'au fond des Salles Rouges.

Aussitôt sorti, il fait dresser un procès-verbal signé par trois conseillers municipaux qui certifient l'authenticité de l'exploration « de l'aven de BERTRAS où à notre connaissance ils sont les premiers à être descendus ». Puis, De Joly informe de sa découverte la municipalité d'Orgnac qui se révèle être propriétaire du gouffre (photo 2). Car tout de suite dans son esprit a germé le projet d'un aménagement touristique. Et le soir même, il prend encore le temps d'écrire au maire et ne lésine pas sur les comparaisons flatteuses pour le convaincre de l'intérêt de sa découverte : «Une découverte comme "BERTAS" est UNIQUE dans une vie d'explorateur souterrain : M. É.-A. MARTEL le spéléologue bien connu, aujourd'hui à la retraite, a eu dans sa vie l'aven "ARMAND», PADIRAC étant peu de chose à côté. M. A. VIRÉ un autre savant a eu St. SOL LACAVE. Sans craindre de me tromper, «BERTAS» est mieux encore, parce que plus varié » (orthographe, majuscules et guillemets sont d'origine. Source: Archives municipales). Le rapprochement avec l'aven Armand apparaît donc sous la plume de R. de Joly dès la première description écrite de l'aven d'Orgnac !
Le maire de l'époque, Paul Delarque, prête à ce chant des sirènes une oreille attentive et plutôt bienveillante puisqu'il décide de commencer l'aménagement, sans pour autant prévoir de crédit, au moins dans un premier temps... Cette réceptivité est décisive; elle s'inscrit dans un tissu local dynamique et novateur. Les vignerons d'Orgnac n'ont-ils pas été les premiers dans le département à créer une cave coopérative dès 1924 ? Si ce n'est pas le lieu ici de chercher les raisons de cet état d'esprit, il est intéressant de noter qu'Orgnac se signale ainsi dans les années 1920-1930 comme un lieu d'innovation sociale et économique appelé à faire école dans la région.

La séance du conseil municipal du 9 février 1936 est largement consacrée à l'aven. Tout d'abord, un crédit de 1200 francs est voté pour les premiers travaux, après quoi (sic) le maire expose ses motivations : « La récente découverte faite sur le territoire de la commune présentant (...) un intérêt exceptionnel, est de nature à attirer dans la région de nombreux touristes et il peut en résulter pour la commune une importante source de revenus ». Moyennant quoi il convainc le conseil de la nécessité de créer une route d'accès à l'aven et de creuser un tunnel «qui conduirait directement les visiteurs au fond du puits ». Plus de deux années sont consacrées à conduire les études préparatoires et à réunir des subventions du haut-commissariat au tourisme car les édiles d'Orgnac répètent à l'envi qu'il y $\mathrm{a}$ 《 un intérêt national à aménager cet aven » (séance du 28 novembre 1936, entre autres). Un prêt est contracté, et la commune fait savoir dès février 1937 «qu'elle assurera elle-même l'exploitation de l'aven ». Enfin, les travaux commencent à l'automne 1938 : un tunnel de $120 \mathrm{~m}$ de long permet d'accéder à la première salle, le cheminement intérieur est tracé, l'installation électrique alimentée par un groupe électrogène reste discrète. Le 17 décembre 1938, Robert de Joly est nommé directeur d'exploitation de l'aven et sa rémunération fixée à $15 \%$ du chiffre d'affaires.

Photo 2

Le maire d'Orgnac, Robert de Joly et une partie du conseil municipal réunis pour décider de l'avenir de l'aven. (Archives Mairie d'Orgnac).

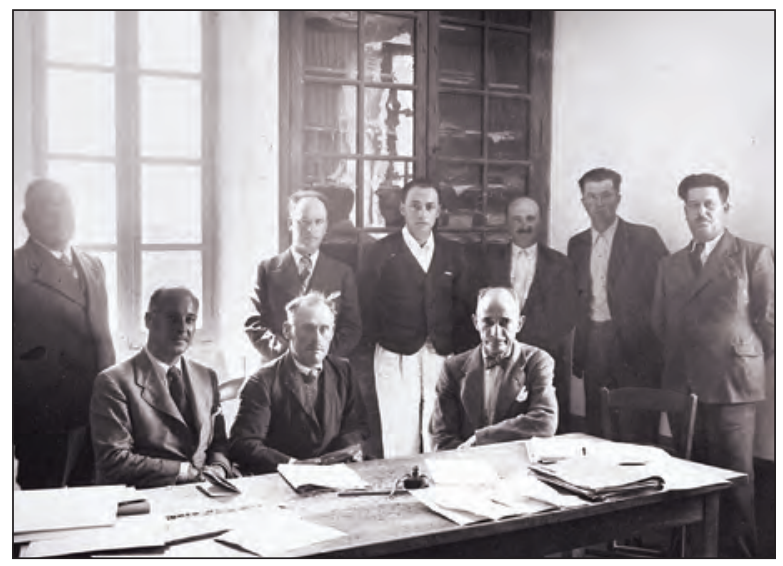




\section{b - Les moteurs du processus de décision}

Trois facteurs se sont donc avérés décisifs dans la mise en tourisme de l'aven.

Tout d'abord, la personnalité même de Robert de Joly : lorsque celui-ci explore l'aven d'Orgnac, il est président du Spéléo-Club de France qu'il a relevé après l'interruption de la première guerre mondiale; sa notoriété est grande dans la région qui va de l'Ardèche à la bordure des Grands Causses. Son entregent, son sens de l'initiative, sa force de conviction et, il faut le dire aussi, son caractère autoritaire jouent un rôle décisifdans le lancement du projet. D'emblée, il prend une option de bail sur le terrain où s'ouvre l'aven, ce qui démontre sa foi dans le devenir touristique du site, même si par la suite c'est la mairie qui prendra l'exploitation à son compte. Dans une note dactylographiée non datée et conservée dans les archives de la mairie d'Orgnac, De Joly retrace les efforts qu'il a déployés pour parachever l'aménagement de l'aven, insistant sur les démarches effectuées «(À MES FRAIS)» (graphie d'origine). C'est lui entre autres qui obtient de l'Automobile-Club du Gard les premières plaques émaillées qui indiqueront l'aven aux automobilistes.

La simultanéité entre l'exploration et la décision d'aménagement de l'aven d'Orgnac est exceptionnelle et remarquable en termes de mise en tourisme : l'aven d'Orgnac est tout à la fois découvert en tant que cavité souterraine et inventé en tant que ressource touristique nouvelle, avec une identité des acteurs assez rare. Sitôt exploré, l'aven est identifié comme une source possible de nouveaux revenus pour la commune.

Ensuite, la qualité des paysages souterrains est systématiquement mise en avant dans l'argumentaire que déploie R. de Joly. La beauté et la qualité du concrétionnement, la perspective créée par l'ouverture de l'aven vue depuis le fond de la salle sont autant d'atouts esthétiques, et l'aménagement paraît relativement facile : le tunnel d'accès est en effet deux fois plus court que celui qui mène dans la grande salle de l'aven Armand, après quoi le cheminement dans la salle ne pose pas de grands problèmes. La comparaison avec l'aven Armand n'est pas ici fortuite : elle fait partie du processus de décision puisqu'en 1936, « M. le Maire [d’Orgnac] et quelques conseillers ont tenu à aller visiter l'aven Armand et ont pu se rendre compte que l'aven d'Orgnac présentait un intérêt touristique plus considérable » (séance du conseil municipal du 1er novembre 1936). Or l'aven Armand reçoit déjà 27000 visiteurs par an! Le tourisme souterrain a déjà atteint une certaine maturité, les entrepreneurs s'appuient sur l'étude des sites déjà aménagés pour estimer la pertinence de leur projet, même si la comparaison reste largement empirique.

Enfin, la situation géographique d'Orgnac est fréquemment invoquée comme un facteur très favorable à l'aménagement de l'aven et nous y reviendrons dans la troisième partie. Car dans cette région du sud de l'Ardèche, il n'y a alors aucune cavité naturelle bénéficiant d'un aménagement touristique moderne. Si l'on observe une carte du tourisme souterrain de l'époque, rien de plus proche que la grotte des Demoiselles aménagée depuis 1930 et distante de plus de 90 kilomètres ! Et dans une région touristique qui est en train de se structurer, la découverte de l'aven d'Orgnac est une occasion unique de combler cette lacune. Non seulement De Joly voudrait être à Orgnac ce que Martel fut à l'aven Armand, mais il souhaite aussi devenir le promoteur du tourisme dans le Bas-Vivarais comme Martel l'avait été dans les Grands Causses.

\section{c - L'ouverture au public}

Le 11 juillet 1939, voici donc venu le grand moment de l'inauguration, en présence du ministre de l'agriculture et de plusieurs parlementaires. Car l'événement est d'importance: l'inauguration s'accompagne d'une grande publicité et l'aven accueille 7243 visiteurs pendant l'été 1939, dont 4379 pour le seul mois d'août. Le succès est donc au rendez-vous, mais la guerre va très rapidement infléchir cette courbe de fréquentation et obliger à revoir à la baisse les projets d'aménagement. Toutefois, les affaires reprennent très vite (photo 3), comme en témoigne cette lettre de Robert de Joly à un correspondant genevois E. Buri, en date du 27 juin 1946 : « Ici Orgnac m’occupe beaucoup. Il y vient un

Photo 3

Les premières visites de l'après-guerre à l'aven d'Orgnac (Archives Mairie d'Orgnac)

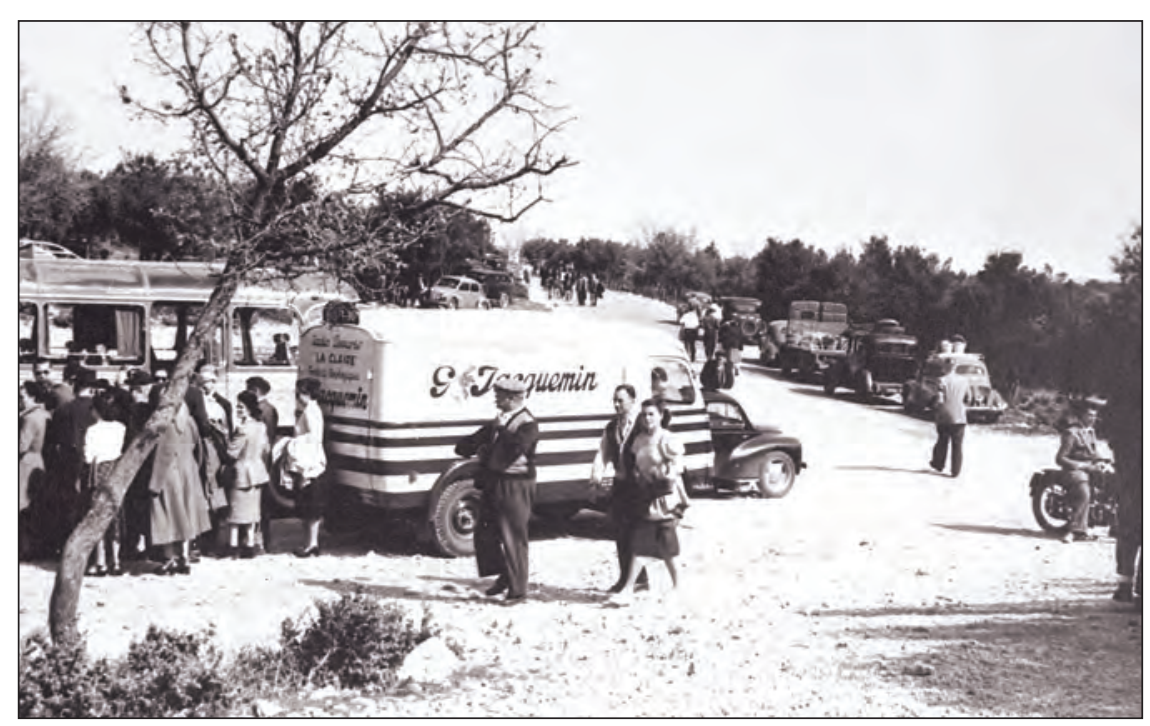


monde fou, on se bat pour entrer plus vite et renverse (sic) notre garde champêtre à l'entrée du tunnel » (Source : Archives de la mairie d'Orgnac). Que ce soit en 1939 ou après 1945, R. de Joly déploie une activité infatigable pour multiplier les articles dans les journaux et les revues les plus variés ; la revue de presse est ainsi des plus éclectiques, depuis Le Petit Parisien (10 mai 1939) au Nouvelliste de Lyon (18 et 19 avril 1939), depuis Tourisme et Travail (mars 1946) jusqu'au Glacier français (1948). L'aven d'Orgnac est cité dans des récits à l'eau de rose parus dans « À tout cœur », il fait l'objet de poèmes mis en chansons, des émissions de radio sont diffusées depuis la Salle de Joly... Cette médiatisation orchestrée par De Joly alimente un puissant courant d'intérêt autour de l'aven d'Orgnac et explique, en partie au moins, le succès touristique.

Dans une publication de la fin des années 1940, Robert de Joly fait part du projet de construction d'un hôtelrestaurant « au sommet de la colline, près de l'aven » (s.d., p.8) alors que l'idée de construire un lotissement à proximité de l'aven est également dans l'air ; dans le même opuscule, il évoque aussi l'aménagement à venir « des parties basses et des salles latérales»(p. 42). Mais aucun de ces projets ne se concrétisera, et le site restera à peu près en l'état jusqu'à la fin des années 1990 : un bâtiment d'accueil est inauguré en 1948, puis un ascenseur est installé en 1965 pour faciliter la remontée depuis la Salle de Joly. La courbe ci-dessous montre donc que les affaires reprirent vite dès la fin de la guerre, et l'année 1966 marque un premier sommet avec le franchissement du seuil des 100000 visiteurs annuels (figure 1). Mais cette situation plutôt idyllique allait bientôt rencontrer quelques puissantes turbulences.
En effet, l'histoire de l'aven d'Orgnac ne s'arrête pas à la phase initiale d'exploration et d'exploitation. Dans les années 1960, la chatière qui se trouvait au fond de la Salle Nord est franchie, et les réseaux II, III et IV sont découverts en 1965 et 1966, multipliant le développement du réseau par cinq (Trébuchon, $p$. 127) et livrant de nouvelles salles toutes plus vastes et plus richement ornées les unes que les autres. Or ces explorations se déroulent dans une atmosphère très conflictuelle qui oppose les spéléologues auteurs de ces découvertes et la mairie d'Orgnac. Jean Trébuchon a lui-même narré de façon aussi précise que savoureuse cette période complexe et ce n'est pas le lieu ici d'y revenir en détail. Mais la tension de ces années 1965-1975 va faire peser de lourdes incertitudes sur le site touristique lui-même: dans leur conflit avec la mairie d'Orgnac, les spéléologues vont en effet trouver un appui auprès de la commune d'Issirac qui possède des terrains sous lesquels se développent les réseaux d'Orgnac III et IV. Cette phase assez pénible continue à associer l'exploration proprement dite, que la mairie d'Orgnac voudrait bien pouvoir stopper, et la valorisation touristique. En effet, l'enjeu majeur de ce conflit apparaît rapidement: les projets pharaoniques supposent que soit ouvert un second accès aux réseaux profonds de façon à exploiter, indépendamment de l'aven d'Orgnac, une autre partie du réseau. Cet enjeu est perceptible à travers l'implication des autorités, absolument unique dans l'histoire de la spéléologie d'exploration: le 3 août 1965, surlendemain de la découverte des nouveaux réseaux, une visite en est organisée pour le sous-préfet, le conseil municipal et la presse, soit au total une quarantaine de personnes. Et

Figure 1

Évolution de la fréquentation touristique des réseaux aménagés de l'aven d'Orgnac (1941 - 2005).

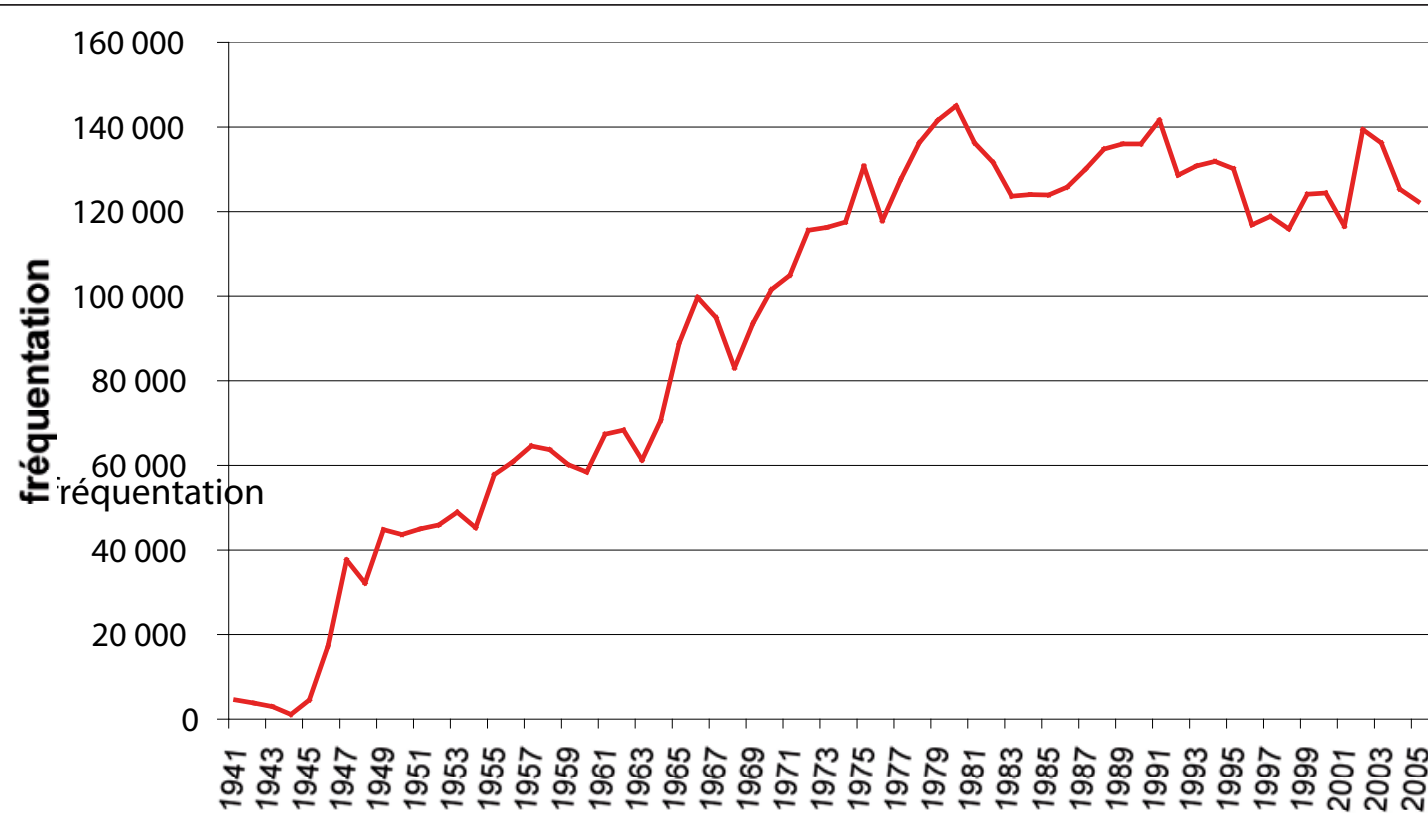

année 
le 12 septembre 1975, au moment de rendre les ultimes arbitrages, les réseaux non aménagés sont à nouveau visités par le secrétaire d'État au tourisme et par le préfet de l'Ardèche (Le Progrès du 12 octobre 1975).

Tous ces projets sont définitivement abandonnés en 1976 après un très long bras de fer, et la normalisation des relations entre les deux communes impliquées est actée par une convention signée en 1978 : Issirac renonce à toute entreprise unilatérale et percevra en compensation un pourcentage sur les recettes de l'aven d'Orgnac, déduction faite des recettes de l'aven-grotte de la Forestière. Ouvert en 1968, situé à 2 kilomètres à vol d'oiseau au nord-ouest d'Orgnac, ce site touristique est en effet géré par la mairie d'Issirac, propriétaire à titre privé des terrains sur la commune d'Orgnac-l'Aven. Mais, à dire vrai, ces péripéties parfois déplaisantes n'ont pas d'impact négatif sur la fréquentation touristique de l'aven. Dans une lettre du 13 décembre 1971, J. Trébuchon pensait même que les découvertes des années 1965-1966 avaient valu à l'aven une publicité qui avait alimenté le flux croissant des visiteurs.

Quoi qu'il en soit, la fréquentation continue à se développer jusqu'à un pic autour de 145000 visiteurs atteint en 1980 (figure 1). Depuis lors, la fréquentation a diminué et semble avoir rencontré un palier autour de 120000 visiteurs annuels. C'est-à-dire que, par rapport à son plus haut niveau, l'aven a perdu environ $17 \%$ de sa clientèle. Or la plus grande partie des grottes touristiques françaises ont maintenu une meilleure croissance pendant les années 1980, ont connu leur meilleure fréquentation autour de 1990 puis ont subi une érosion un peu plus marquée sur les 15 dernières années : le gouffre de Padirac a ainsi perdu environ $21 \%$ et les grottes de Choranche environ $22 \%$ de leur fréquentation. De ce point de vue, la trajectoire de l'aven d'Orgnac est donc un peu particulière. Les gestionnaires ont été confrontés plus tôt que d'autres à une certaine obsolescence du site, et à une marginalisation croissante face à une activité touristique qui se centrait de plus en plus sur les gorges ; l'année 1980 a en effet été marquée par la création de la Réserve naturelle des gorges de l'Ardèche et par un déplacement du centre de gravité du tourisme vers l'axe Vallon / Saint-Martin. Mais ces difficultés relativement précoces par rapport au reste du tourisme souterrain ont permis aux gestionnaires de réagir peut-être plus précocement, en imaginant dès 1983 un réaménagement du circuit de visite, même s'il n'interviendra que bien plus tard. La longévité du site passe aussi par ces différents accidents de parcours et par la capacité des acteurs à réagir et à redonner au site une attractivité qui semblait s'estomper.

Ainsi, lorsque la convention entre Orgnac et Issirac est reconduite le 28 février 1996, une nouvelle disposition (article 4) prévoit l'organisation de visites du « nouveau réseau (...) sous la conduite de guides compétents », ce qui constitue une nouvelle étape dans la mise en tourisme de l'aven, même si les modalités sont très différentes de ce que l'on observe dans les réseaux anciens et de ce que les projets envisageaient naguère dans les nouveaux réseaux. Dans ce texte, aucune mention n'est faite de l'aménagement ou du nonaménagement des réseaux. Mais il apparaît rapidement que la simple convention n'offre pas un cadre satisfaisant pour la mise en place de ce « nouveau concept » (id.) et les statuts d'un Syndicat Intercommunal d'Exploitation et de Gestion des Réseaux de l'Aven d'Orgnac sont déposés en préfectures en juin et juillet 1998.

\section{II - LES GRANDS MOMENTS DE LA PATRIMONIALISATION}

Avant même l'ouverture de l'aven au public, le souci de la protection du site accompagne sa mise en valeur touristique et il en ira ainsi jusqu'aujourd'hui. Le 18 février 1939 en effet, le conseil municipal, saisi d'une demande d'acquisition de terrains communaux, décide de restreindre la vente de parcelles «afin d'assurer la conservation du site aux environs immédiats du site » (Source : archives municipales); cette attention précoce à la qualité paysagère est remarquable car, dans la mise en tourisme d'un site souterrain, il n'était pas évident à l'époque que les promoteurs prennent aussi en compte l'environnement extérieur. Mais ce n'est là qu'un avant-goût des mesures qui viendront s'ajouter les unes aux autres à partir de 1946 et qui feront toujours le pari de la qualité comme garant de la réussite touristique.

Trois événements ou séries d'événements ont fait de l'aven d'Orgnac un site à part sur le plan du rapport entre tourisme et valorisation du patrimoine.

\section{a - Orgnac, site classé}

Tout d'abord, la protection institutionnelle à travers la procédure de classement s'est développée en trois temps, avec une extension progressive du périmètre classé. En 1946, seul le réseau classique est reconnu : la Salle de Joly, les Salles Rouges et la Salle Nord. À la demande des services de l'architecture et avec l'accord du conseil municipal (séance du 15 avril 1945), en application de la loi de 1930, l'aven d'Orgnac est classé au titre des monuments naturels et sites. Ce premier classement sera opposé, dès 1947-1949, à la construction d'un lotissement à proximité immédiate de l'aven.

En 1974, le périmètre de classement est étendu à l'ensemble des réseaux découverts, mais ce classement ne concerne que les tréfonds, utilisant ainsi une disposition du droit français qui laisse la possibilité de dissocier la surface et les tréfonds d'une parcelle (ou ici d'un ensemble de parcelles). La 
surface, couvrant environ 230 hectares, est inscrite à l'inventaire des sites, ce qui correspond à un moindre degré de protection. Cette dissociation entre la surface et les réseaux en profondeur, unique en France à notre connaissance, s'explique par un dosage des contraintes dans le contexte local, mais pose plus fondamentalement le problème du périmètre classé, en plan et en coupe, propice à la protection d'un réseau souterrain. En 1974 toutefois, aucun réseau des dimensions d'Orgnac n'était intégralement protégé en France. Il s'agissait donc à l'époque, d'un compromis novateur qui cherchait à rendre possible la protection d'un grand réseau.

Enfin, en 2005-2006, la Direction régionale de l'Environnement instruit un dossier pour une nouvelle extension de périmètre du classement, passant de 230 à 390 hectares et ré-associant la surface et les réseaux souterrains (figure 2). Ce nouveau périmètre marque une extension dans la compréhension des ressources patrimoniales du karst, ne se limitant plus au seul aven d’Orgnac mais intégrant deux autres cavités du secteur (l'une touristique : l'aven de la Forestière ; l'autre non aménagée : la Baume de Ronze) comme autant de formes complémentaires de l'aven, et un site archéologique majeur dans la région, le site d'Orgnac III. Les formes de surface, caractéristiques des plateaux karstiques des gorges de l'Ardèche, sont considérées comme parties prenantes du site classé. Pour la première fois, un objet spéléologique se trouverait ainsi légalement intégré dans son environnement paysager et morphologique à des fins de protection, même en l'absence de lien direct entre les différentes cavités par exemple, et à des fins de compréhension, à travers les procédés de mise en valeur pédagogique de Baume de Ronze ou du site d’Orgnac III. En Suisse, en Autriche ou en Slovénie, il n'y aurait là rien d'extraordinaire car cela correspond

Figure 2

Proposition d'extension du périmètre de classement de surface au titre des sites. En orange : les réseaux de l'aven d'Orgnac classés en 1974 ; liseré jaune : périmètre inscrit en 1974 ; liseré orange : le classement proposé en 2006 (source : DIREN).

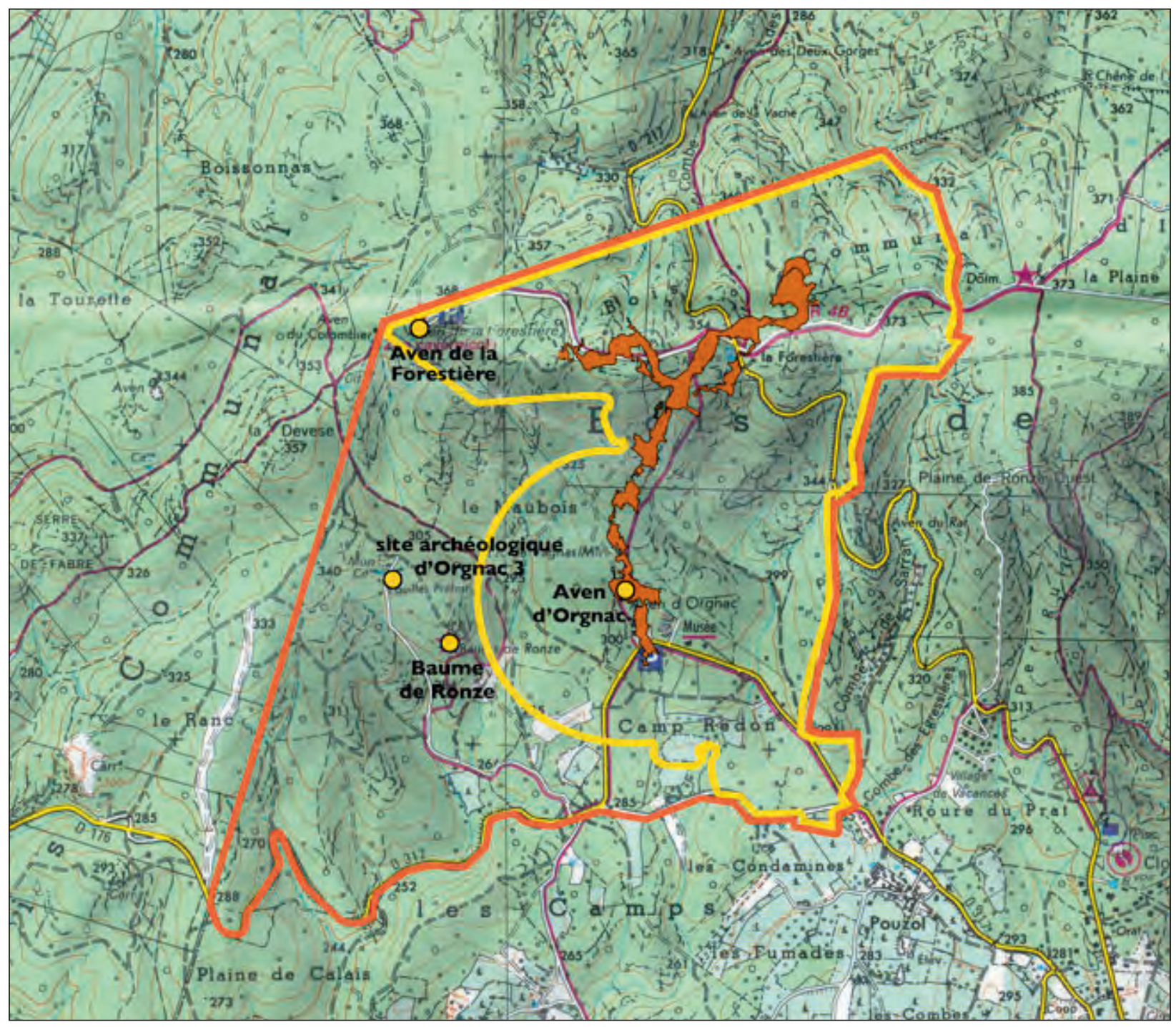


à une pratique courante, mais en France cela reste assez unique. Ici, cette nouvelle extension du périmètre classé prend place dans la préparation d'un dossier de candidature de 18 cavités au patrimoine mondial de l'Humanité; selon les critères de l'UICN, qui expertisera ce dossier pour l'UNESCO, la protection légale dont bénéficiait jusque-là l'aven d'Orgnac était insuffisante, et c'est cette exigence de «mise aux normes » qui explique cette nouvelle procédure.

Il s'agit donc là du seul réseau karstique en France dont le périmètre de protection a ainsi été redéfini à trois reprises, de façon à tenir compte à la fois des avancées de l'exploration (redéfinition 1974) et de l'évolution des conceptions en matière de protection (redéfinition 2005-2006).

\section{b - L’accès réglementé}

Ensuite, sur la base de ces dispositions réglementaires et suite à la création d'un SIVU par les communes d'Orgnac et d'Issirac, le préfet de l'Ardèche prit le 12 juillet 1999 un arrêté «réglementant l'accès, les visites et les études des réseaux II et III (pour partie) de l'Aven d'Orgnac ». Cet arrêté s'appuie pour commencer sur l'article 12 de la loi de 1930 qui par ailleurs ne prévoit en aucun cas une quelconque réglementation de la fréquentation (texte de l'article 12 de la loi : «Les propriétaires des monuments naturels ou des sites classés ne peuvent ni détruire ni modifier l'état des lieux ou leur aspect, sauf autorisation spéciale donnée par le ministre des beaux-arts, après avis des commissions départementale et supérieure »). L'arrêté de 1999 se compose de onze articles, dont les quatre premiers définissent les modalités de fréquentation, qui visent à protéger tout à la fois les réseaux euxmêmes (nombre de visiteurs, encadrement, balisage du parcours) et les visiteurs (teneur maximale en $\mathrm{CO}_{2}$ en particulier, sans doute pour éviter un secours qui à son tour porterait préjudice à la cavité). L'article $1^{\mathrm{er}}$ précise que l'arrêté s'applique uniquement aux réseaux II et III (pour partie) « le reste de la cavité non ouverte au public demeurant en protection intégrale $»$. Ce sont ici les galeries et les salles d’Orgnac IV qui sont concernées, mais de façon tout à fait énigmatique car le verbe « demeurer » ne renvoie à aucun texte antérieur (!) et la « protection intégrale » ne repose sur aucune définition en droit français de l'environnement.

En réalité, l'ensemble des réseaux II, III et IV étaient de fait interdits à toute visite, ou presque, depuis les années 1970 ; l'arrêté préfectoral de 1999 valide et encadre une certaine libéralisation de la fréquentation des réseaux, mais par cette formulation de l'article $1^{\text {er }}$, présente comme une mesure de « protection intégrale » ce qui n'était qu'une mesure de restriction de l'accès édictée par les seuls propriétaires, en l'occurrence les communes d'Orgnac et d'Issirac. Quoi qu'il en soit, l'arrêté de 1999 participe donc de cette articulation entre protection de l'environnement karstique et activité touristique, puisque les réseaux II et III sont désormais ouverts à la visite. Il s'agit là aussi d'un cas unique, car aucune cavité naturelle en France n'est régie par un arrêté préfectoral (en revanche, les communes ont souvent pris des arrêtés réglementant l'accès à telle ou telle cavité, s'appuyant en général sur le code des communes et sur l'obligation qui est faite au maire d'assurer la sécurité sur son territoire); le seul équivalent pourrait être l'arrêté préfectoral de 1999 réglementant l'accès à la montagne dans le département de la Haute-Savoie. Mais ce dernier suscita une levée de boucliers car il se présentait surtout comme un interdit, alors que l'arrêté concernant Orgnac ouvrait à la fréquentation une porte fermée depuis un quart de siècle ! Dans le cas présent, l'arrêté préfectoral de 1999, en instaurant une régulation des modalités de fréquentation, prépare la réflexion qui se concrétisera dans l'Opération Grand Site dont c'est là la finalité ; dans ce sens, l'O.G.S. légitimera a posteriori cet arrêté plutôt atypique.

\section{c - L'Opération Grand Site}

Enfin, en 2004, l'aven d'Orgnac se voyait reconnu « Grand Site de France » par le ministère de l'Écologie, aux côtés de la pointe du Raz, du pont du Gard et de la montagne Sainte-Victoire.

Lancées depuis le début des années 1980, les Opérations Grands Sites ont pour objectif majeur d'assurer le maintien (ou la reconstitution) de la qualité de sites « naturels», essentiellement des sites ouverts, tout en assurant un développement local principalement axé sur le tourisme. Ce programme se présente donc comme une démarche originale concernant les sites classés, reconnus d'intérêt national voire universel. La loi de 1930 sur les sites classés ne prévoyant pas de mesures d'accompagnement budgétaire pour assurer la restauration et l'entretien des sites, l'Opération Grand Site va permettre de mettre autour de la table l'ensemble des partenaires concernés : collectivités locales et territoriales, services de l'État, gestionnaires et utilisateurs. L'O.G.S. se présente avant tout comme une opération; celle-ci vise à corriger certains dysfonctionnements observés sur des sites classés et faisant l'objet de fréquentation touristique considérée comme importante. À ce titre, il ne s'agit pas d'une mesure de protection entraînant son lot de servitudes supplémentaires mais d'un programme de réhabilitation (Duval et Gauchon, 2007).

À l'échelle de l'aven d'Orgnac, la réalisation de cette O.G.S. résulte d'un faisceau de circonstances où se retrouvent volonté locale et intérêt des services de l'État. Dès 1996, un projet de réhabilitation de l'aven d'Orgnac émerge. Au commencement, la municipalité, gestionnaire du site, souhaite procéder à un réaménagement de son circuit souterrain. Les 
tréfonds de l'aven étant classés, un dossier est déposé à la DIREN, laquelle se saisit de l'instrument O.G.S. pour lancer un programme d'études essentiellement climatologiques dans la cavité. Ces études préalables aboutiront à la signature d'une convention d'O.G.S. en 2000, à l'inauguration du nouveau site en 2003 et à sa labellisation Grand Site en 2004.

À l'inverse de l'O.G.S. des gorges de l'Ardèche qui peine à se réaliser depuis 1989, l'O.G.S. conduite sur le site d'Orgnac se caractérise par sa rapidité d'exécution. Cette spécificité s'explique autant par le nombre réduit d'acteurs en présence, que par un consensus autour des aménagements à réaliser ou encore par les caractéristiques même du site. Ainsi, à la lecture des sites français ayant fait l'objet d'une O.G.S., l'aven d'Orgnac apparaît comme étant l'un des deux seuls sites fermés à entrée payante. Seule grotte française ayant fait l'objet d'une O.G.S., ses problématiques d'aménagement diffèrent de celles rencontrées par d'autres sites O.G.S. comme le cirque de Gavarnie, la vallée de la Clarée, etc., autant de sites ouverts, non payants, confrontés à des problèmes de régulation des flux touristiques.
Aussi, au regard des autres sites O.G.S., l'aven d'Orgnac se positionne sur un registre quelque peu différent. Il est alors essentiellement question de requalification du site touristique, aussi bien à l'échelle des aménagements intérieurs que des infrastructures touristiques en surface.

Les différents volets de cette O.G.S. s'articulent alors autour de :

1) la requalification du circuit touristique souterrain : suppression du cheminement pour remonter à la surface et remontée en ascenseur, l'objectif étant d'améliorer la fluidité et de gommer toute forme de pénibilité,

2) la requalification des aménagements en surface (photos 4) : restructuration des bâtiments d'accueil, mise en place d'un volet scientifique, suppression d'une partie des parkings bitumés situés à la verticale des réseaux,

3) la mise en place d'un nouveau circuit de visite associant la visite de l'aven et du Musée régional de Préhistoire, lesquels sont pensés conjointement et dépendent de la même billetterie.

Photos 4

Les aménagements en surface réalisés dans le cadre de l'Opération Grand Site
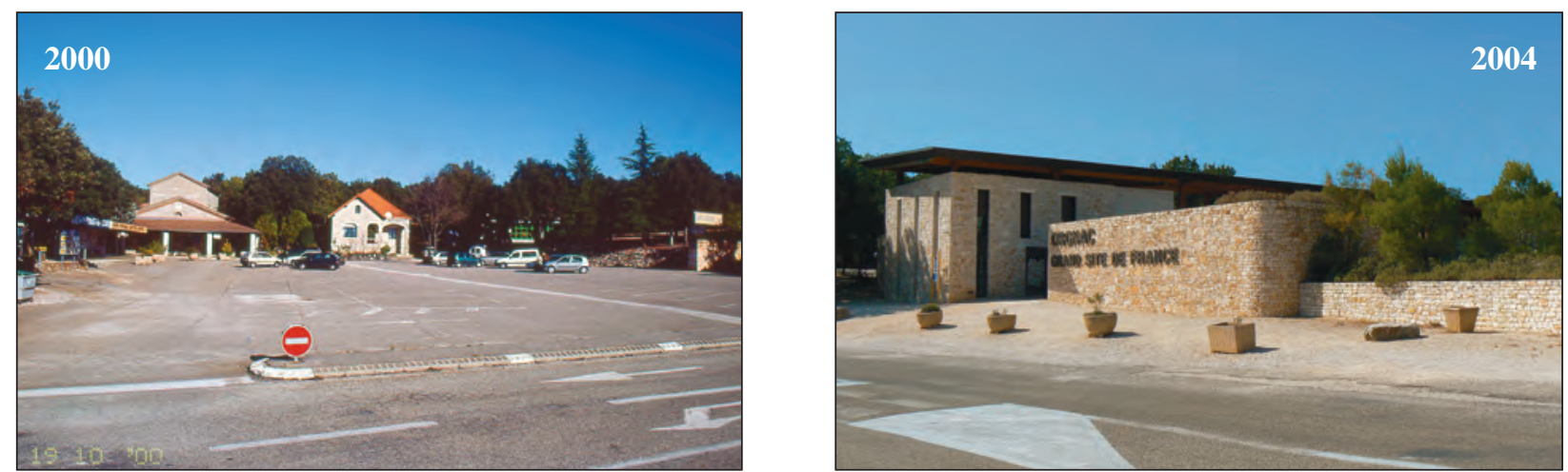

Billetterie et bâtiment d'accueil des visiteurs ont été refondus dans un aménagement global : l'étagement en terrasses et l'utilisation de la pierre garantissent l'intégration paysagère du site dans son environnement sub-méditerranéen.

Les visiteurs sont donc invités à flâner entre l'aven, le musée, la boutique et la buvette, à l'écart de la circulation automobile. Les parkings qui occupaient toute l'esplanade ont été déplacés de l'autre côté de la route et sous les chênes.

Néanmoins, la grande galerie sous portiques reste le seul secteur ombragé dans la zone d'attente des visiteurs et ses dimensions s'avèrent insuffisantes en période estivale (clichés Philippe Bastian et Françoise Prud'homme).
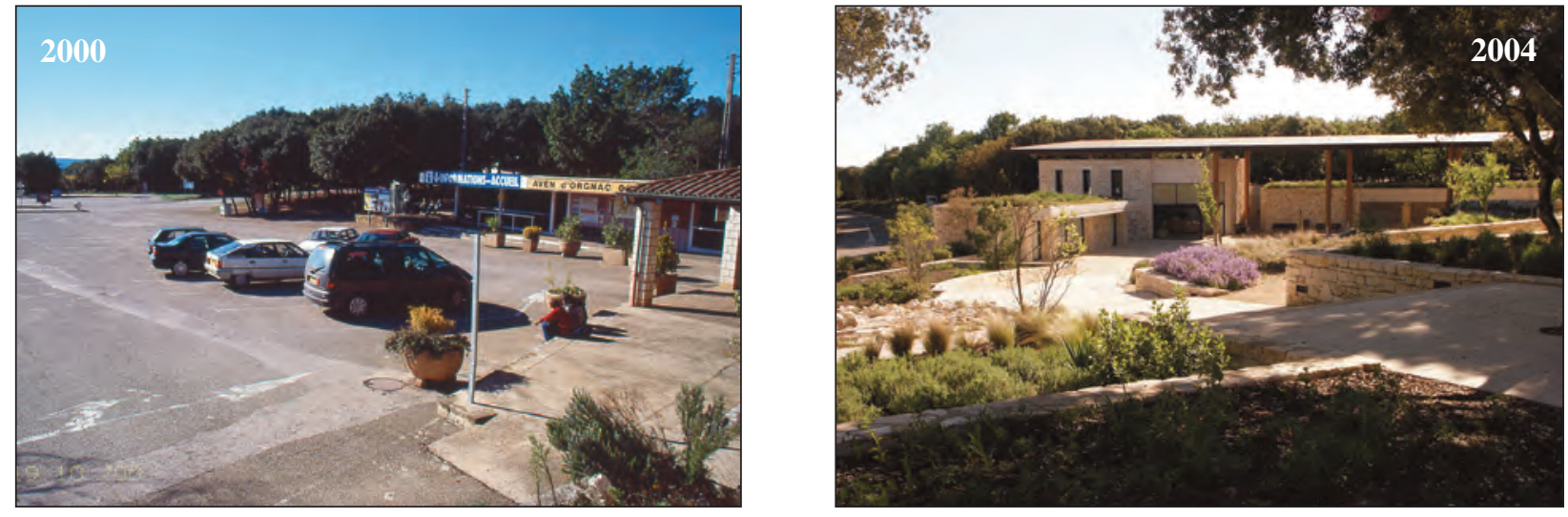
Cette requalification touristique est parachevée par la remise du label « Grand Site de France » qui certifie ainsi que le site est «préservé et géré suivant les principes du développement durable, conciliant préservation $\mathrm{du}$ paysage et de « l'esprit des lieux », qualité de l'accueil du public, participation des habitants et des partenaires à la vie du Grand Site » (site R.G.S.F., dossier de presse, octobre 2004, p. 5).

\section{d - Un gouffre au statut unique}

Ainsi, entre les années 1930 et aujourd'hui, se sont co-construits un site touristique notable à l'échelle régionale et un ensemble à haute valeur patrimoniale dont la protection et la valorisation sont allées croissantes.

Quatre étapes peuvent alors être identifiées dans ce processus (figure 3 ).

Figure 3

Quatre phases sont identifiables autour de l'aven d'Orgnac.

Chaque flèche en couleur marque une nouvelle étape.

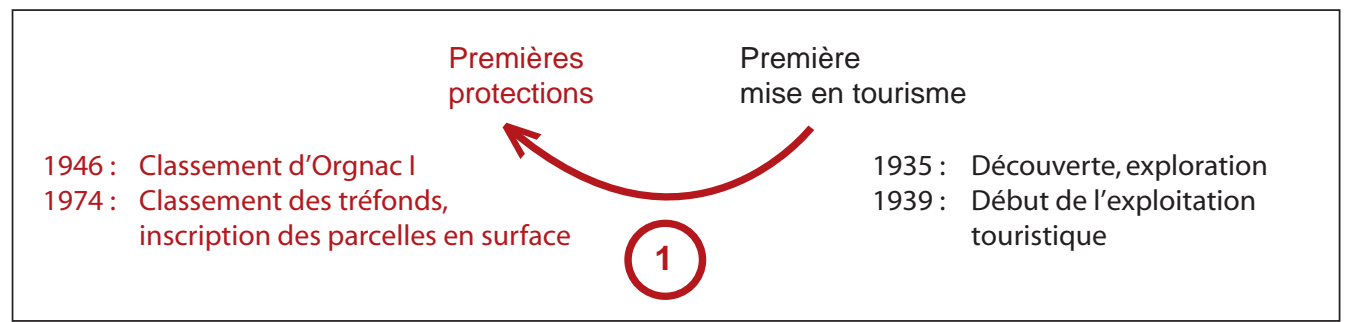
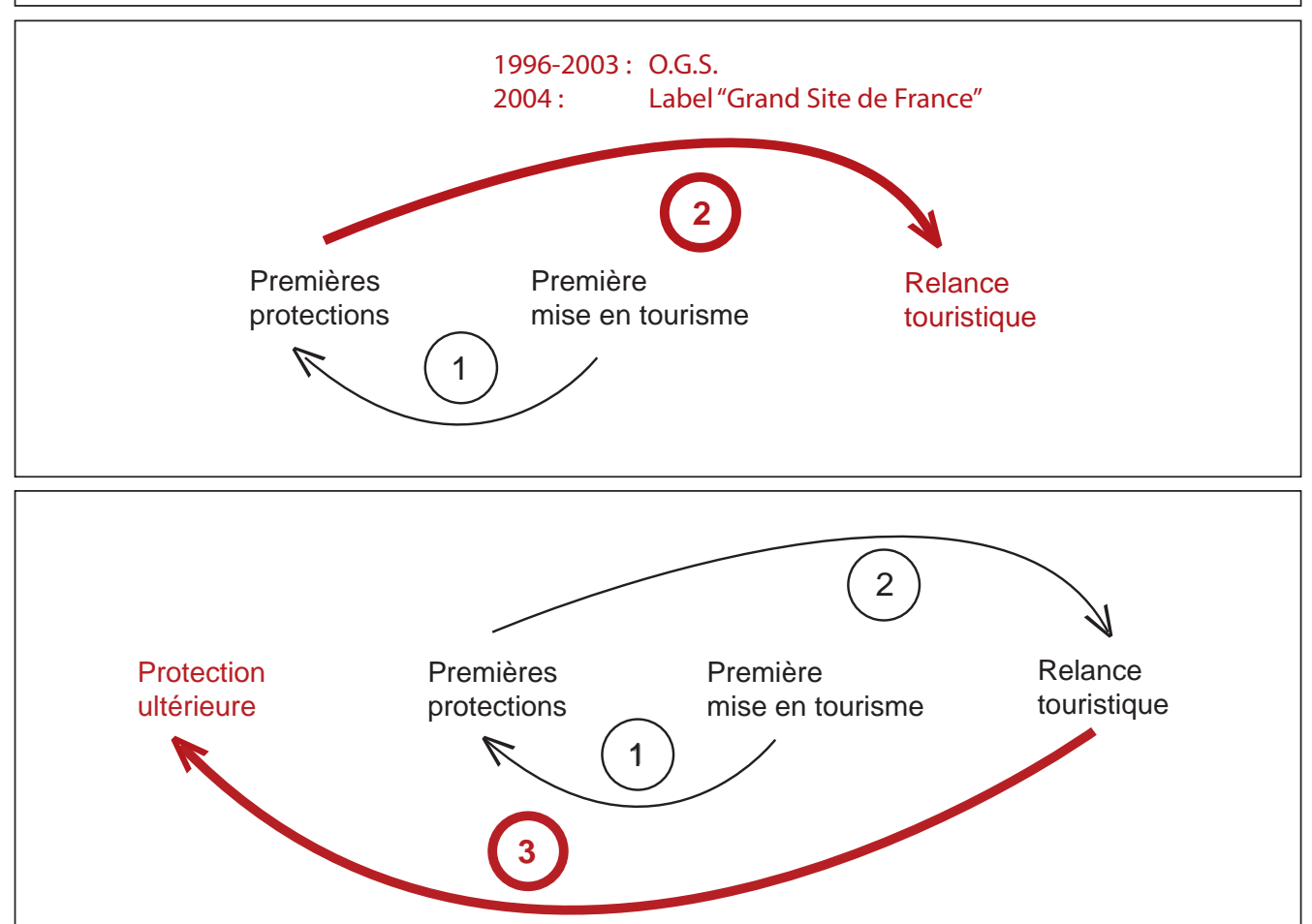

2005 : Révision du périmètre de classement

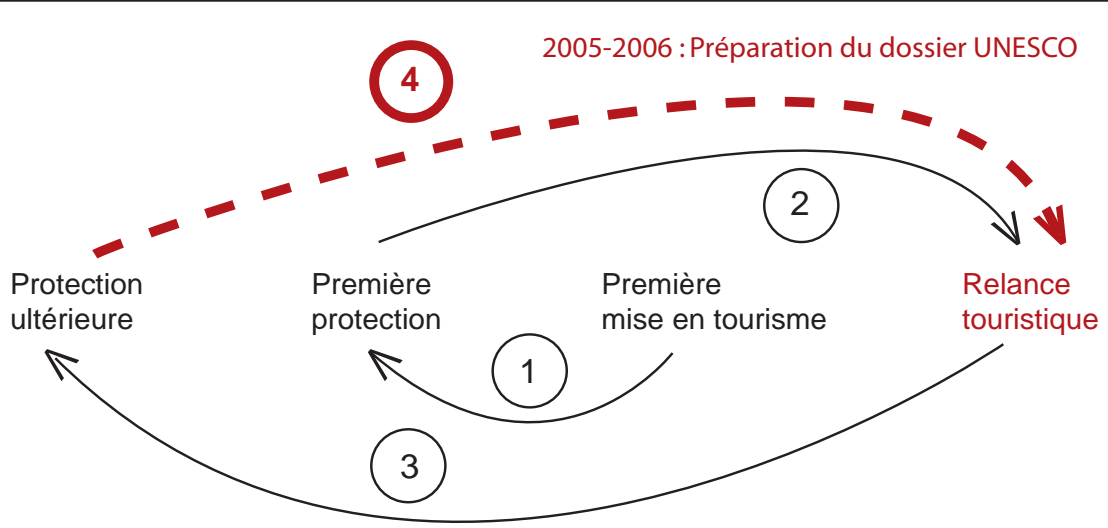


Mais ces différentes procédures ne sont pas indépendantes les unes des autres et témoignent au contraire d'une grande cohérence en termes de projet pour le site. Rétrospectivement, on voit qu'elles sont liées entre elles, qu'elles se préparent les unes les autres et se justifient a posteriori (figure 4). Bien plus que d'une fuite en avant, il s'agit là d'un effort soutenu pour se maintenir à un niveau d'excellence, ou pour le retrouver lorsque l'appareil a manifestement trop vieilli comme ce fut le cas au milieu des années 1990. La baisse du nombre d'entrées combinée à des indices de dégradation physique du site (sous terre et en surface) ont fonctionné alors comme des signaux d'alarme forts que les gérants ont bien compris comme autant d'injonctions à requalifier l'ensemble. Un demi-siècle de fonctionnement touristique et d'accueil du public, même avec un certain nombre d'améliorations notables au fil du temps, avaient marqué l'aven du sceau d'une obsolescence de plus en plus visible. C'est la prise de conscience de cette situation, combinée au statut patrimonial de la cavité, qui expliquent l'accélération des procédures de requalification et de labellisation observables depuis une dizaine d'années.

Comment expliquer une telle superposition de mesures de protection, une telle convergence d'attentions vers l'aven d'Orgnac, très éloignées des pratiques habituelles en matière de protection du karst en France? Tout d'abord, il faut invoquer des causes historiques, propres à la mise en tourisme du site et à la façon dont $\mathrm{R}$. de Joly conduisit le conseil municipal à s'approprier la nouvelle découverte. Cet attachement très fort explique l'attention que les conseils municipaux successifs porteront, jusqu'aujourd'hui, à la préservation de l'aven et de l'intégrité de ses paysages.

À cette position de départ vint s'ajouter la crise des années 1965-1975 liée à la découverte des nouveaux réseaux (photo 5) et à leur éventuel aménagement. De

Figure 4

Sucession et interrelations des mesures de protection et de labellisation.

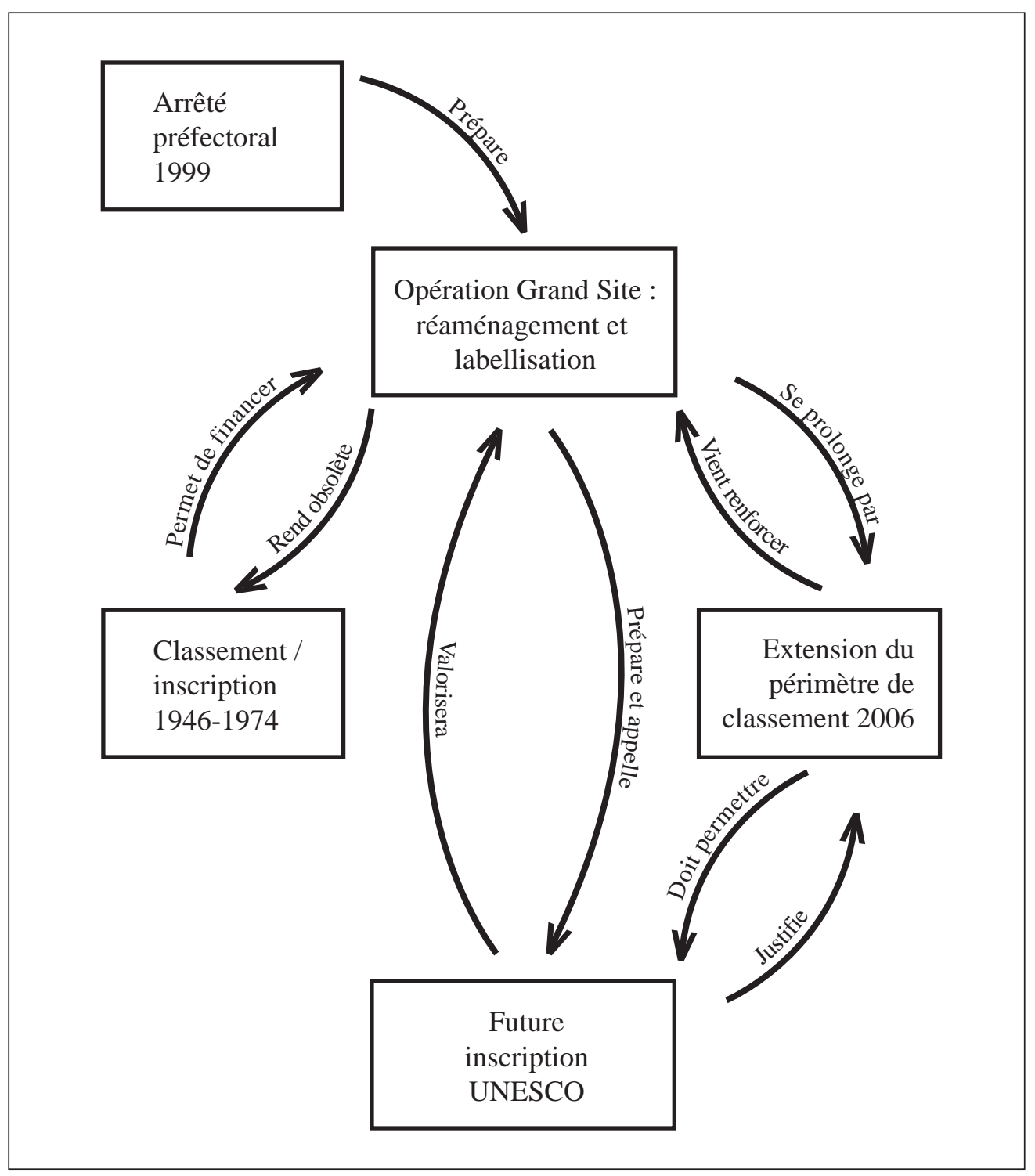




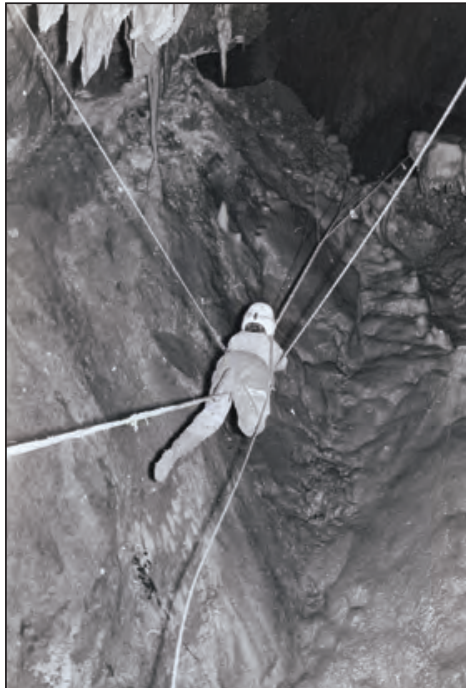

Photo 5

L'exploration des nouveaux réseaux a conduit l'équipe de spéléologues sous le domaine privé de la commune d'Issirac : passage du Puits de la Tyrolienne (photo Claude Laamoureux).

ce point de vue, il est évident que le classement de 1974 visait à bloquer tout nouvel aménagement, et c'était bien là ce qu'en attendait la mairie d'Orgnac qui fut à l'initiative de ce classement (conseil municipal du 21 avril 1973) alors qu'elle n'avait fait qu'approuver celui de 1946 ! Car si la ressource touristique et patrimoniale préexiste à cette phase conflictuelle, et si la crise n'a donc pas été une condition préalable à la valorisation et à la protection de l'aven, cette période a aussi consolidé le lien qui s'était tissé entre la commune et l'aven. La construction patrimoniale incorpore fréquemment de tels conflits qui ne laissent pas seulement des traces négatives mais participent aussi de façon positive à ce processus.

Ces explications d'ordre historique se combinent avec le statut foncier particulier de l'aven : l'aven s'ouvre en effet sur des terrains communaux d'Orgnac et les réseaux anciens explorés en 1935 se développent eux aussi sous des terrains communaux: entre 1935 et les années 1960, la mairie d'Orgnac possédait donc la pleine maîtrise foncière du site. Cette situation singulière favorisa l'appropriation collective de l'aven et facilita l'aménagement puisqu'il n'était besoin d'aucune convention avec d'autres ayants droit. Les découvertes des années 1960 vinrent bouleverser cette situation et introduisirent un nouvel acteur qui dès lors ne sortira plus du jeu : la commune d'Issirac, sise dans le département voisin du Gard, était en effet propriétaire des terrains situés au nord de l'aven (on parle du « domaine privé » des communes qui possèdent souvent des terrains au-delà des limites administratives de leur territoire). Cette complication explique que les arrêtés impliquant les deux communes soient du ressort des deux préfectures du Gard et de l'Ardèche, alors que les textes réglementaires concernant l'aven ne dépendent que de la préfecture de l'Ardèche ! S'appuyant sur le code civil, la commune d'Issirac put donc revendiquer la pleine et entière jouissance de ses terrains, en surface et en profondeur, y compris l'aspiration légitime à en tirer un profit (fructus). Le classement de 1974, dans la mesure où il réduisit les prérogatives liées au droit de propriété, permit de revenir au statu quo ante, même si la commune d'Issirac sera, on l'a vu, associée à la gestion.

Ce souci conjoint de la conservation et de la valorisation du patrimoine karstique se retrouve dans la promotion touristique réalisée par l'aven. Si l'inscription «site classé » apparaît dans les années 70-80 sur les dépliants de l'aven, il faut attendre le début des années 90 pour voir figurer, en complément du nom, la mention " 3 étoiles" qui fait allusion à la distinction décernée par le guide Michelin mais donne aussi une valeur supplémentaire au site en jouant sur l'analogie avec un classement de type hôtelier. Plus tard, les prospectus s'orneront du label "Grand Site", précisant même «seule grotte labellisée de France » pour que ni la rareté ni le prestige du label n'échappent à personne.

Photo 6

Cette photo du secteur de

l'Orfèvrerie (Orgnac III)

permet d'appréhender

les volumes des réseaux

d'Orgnac et la diversité

des paysages souterrains

(photo Jean-Pierre Petit).,

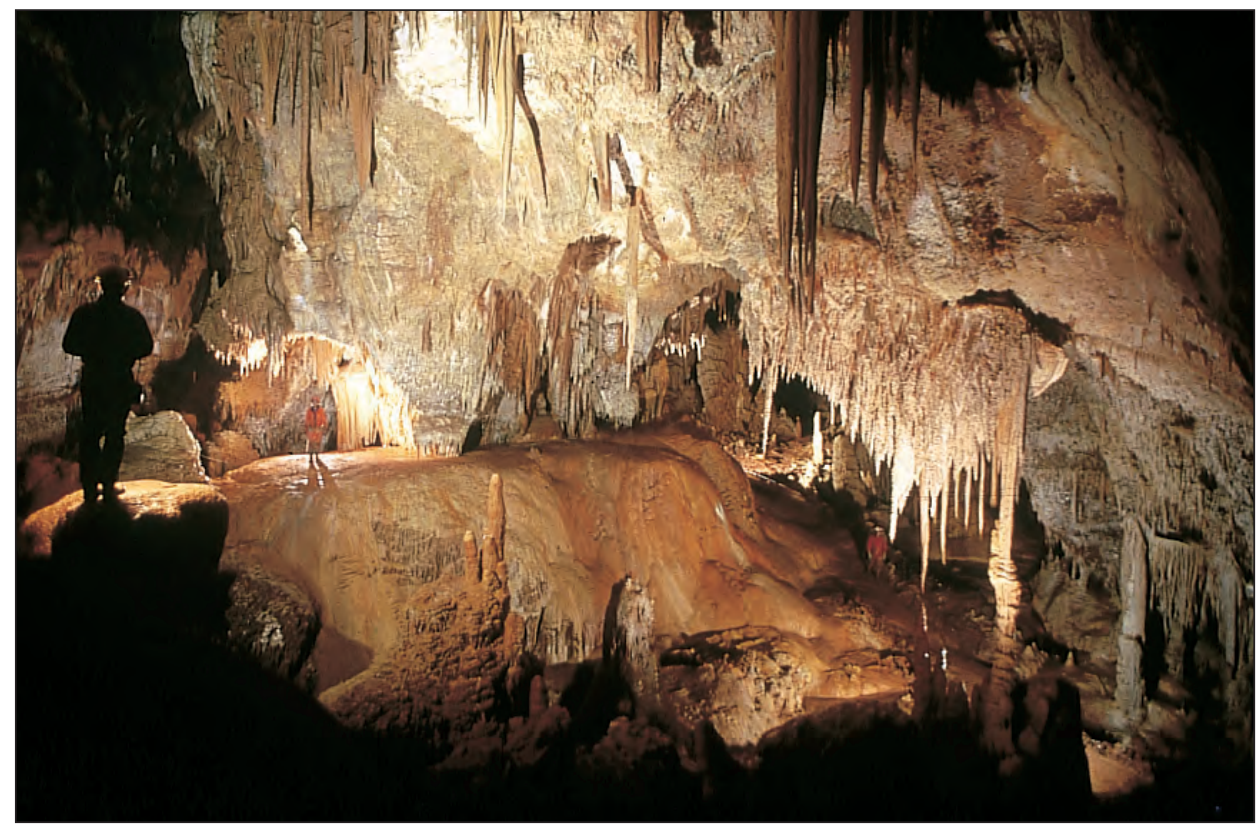


1968

Dépliant mettant en avant les qualités esthétiques du concrétionnement de l'Aven

... L'aménagement de cette caverne qui appartient à la commune d'ORGNAC-L'AVEN

(Ardèche) a été dirigé par l'inventeur qui a

exploré et visité plus de mille grottes dans le

Monde. La visite qui a été rendue très facile pour les touristes leur réserve une succession de coups de théâtre surprenants. La variété dans la

forme, la taille et les couleurs des stalagmites est unique au Monde. Les grandes coulées en forme de buffet d'orgue rappellent l'art Khmer. Le grand chaos au proche ogival de 50 mètres

de hauteur, les deux pilliers blanc et ocre

dépassant 20 mètres dans l'immense «Salle Rouge», sont prodigieux. L'AVEN D'ORGNAC ne ressemble à aucune autre cavité.»

1989 - 1990

Inscription de l'Aven dans son contexte local et régional : présentation du village, de ses infrastructures touristiques et des produits locaux, localisation par rapport au Pont d'Arc :

"Situé au Sud des Gorges de l'Ardèche, Orgnac village rassemble toutes les qualités d'un petit paradis où le visiteur ne peut rester insensible aux charmes de la vie ardéchoise. Sa végétation méditerranéenne, dans un univers de roches calcaires, son ensoleillement exceptionnel, son atmosphère transparente permettent de jouir au

maximum des loisirs de plein air : baignade,

canoë-kayak dans les Gorges de l'Ardèche, circuits pédestres, camping, piscine, boulodrome à Orgnac village. Vous découvrirez la gastronomie locale et dégusterez le cru réputé des vins d'Orgnac, au bouquet savoureux, nectar d'un été plein de soleil.»
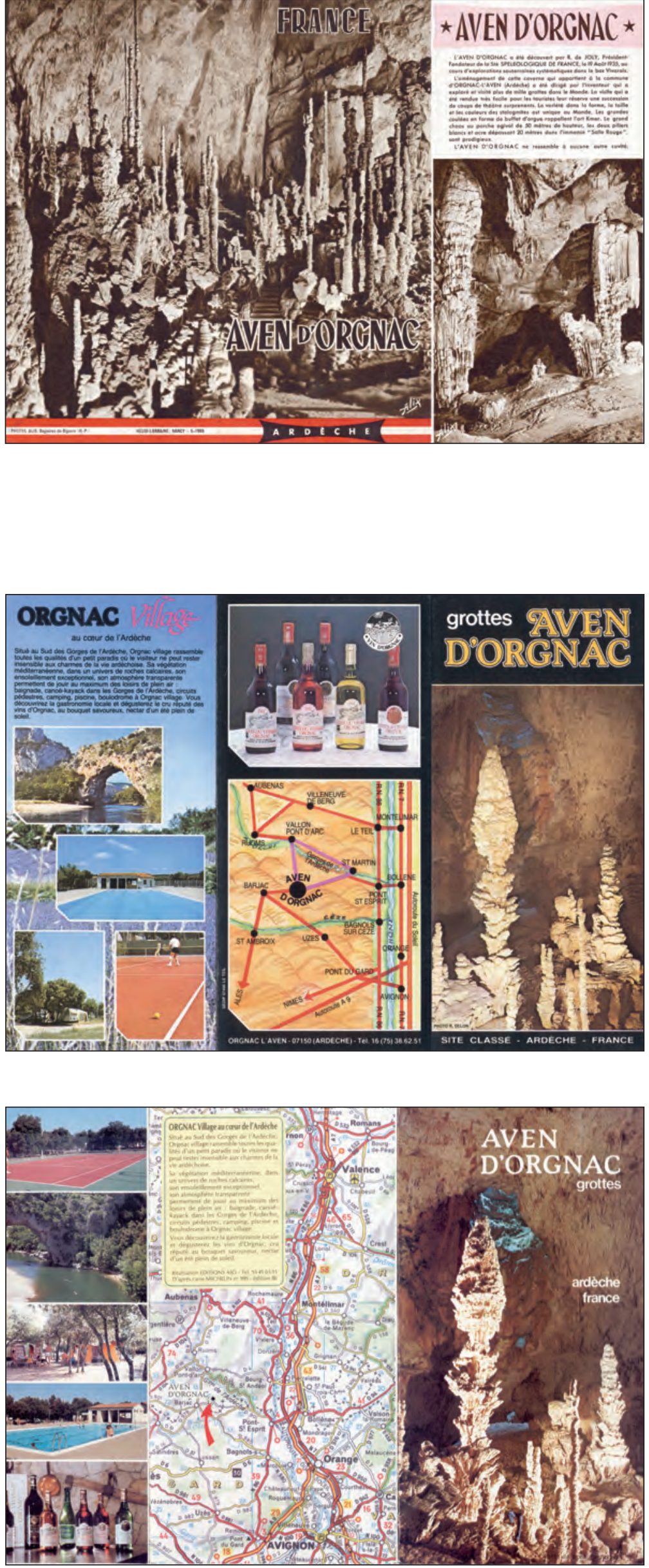

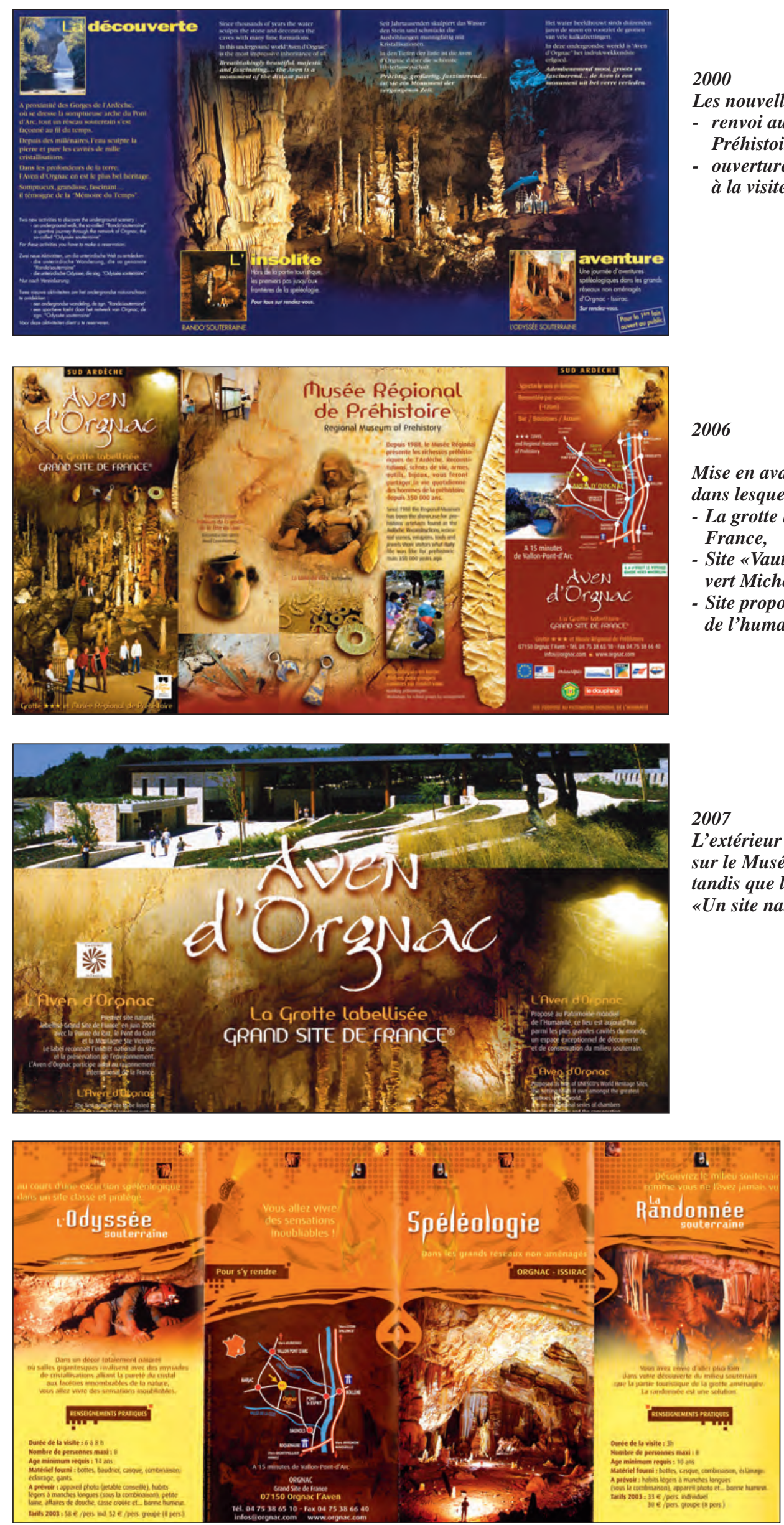

2000

Les nouvelles orientations du site :

- renvoi au Musée régional de Préhistoire,

- ouverture des nouveaux réseaux à la visite touristique.

\section{6}

Mise en avant des différents labels dans lesquels s'inscrit l'aven :

- La grotte labellisée Grand Site de France,

- Site «Vaut le détour» dans le Guide vert Michelin,

- Site proposé au patrimoine mondial de l'humanité.

2007

L'extérieur du dépliant met l'accent sur le Musée régional de Préhistoire tandis que l'intérieur insiste sur «Un site naturel grandiose».
Édition de brochures supplémentaires pour présenter les nouveaux produits : Randonnée et Odyssée souterraine, mise en avant de leur caractère «spéléologique». 
Figure 5

La région touristique sud Ardèche

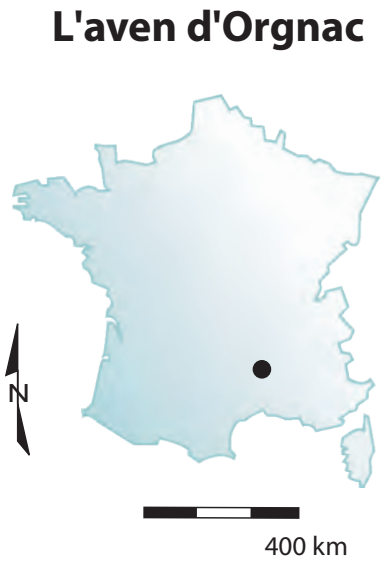

Échelle nationale

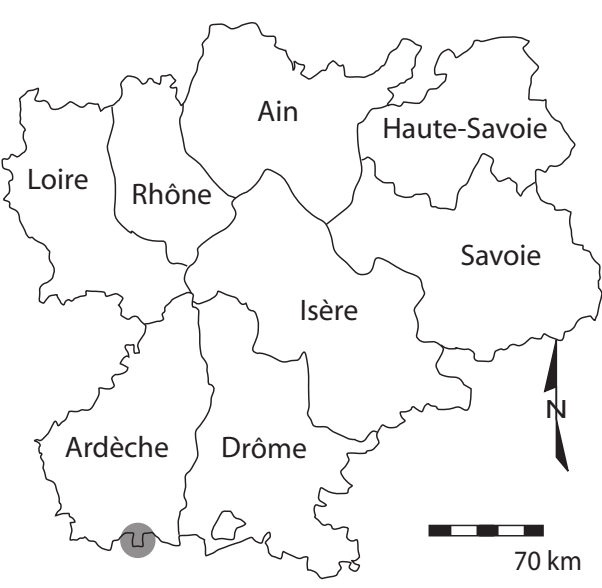

Échelle régionale et départementale

\section{Positionnement relatif des grottes touristiques par rapport aux gorges de l'Ardèche}

Éléments de localisation

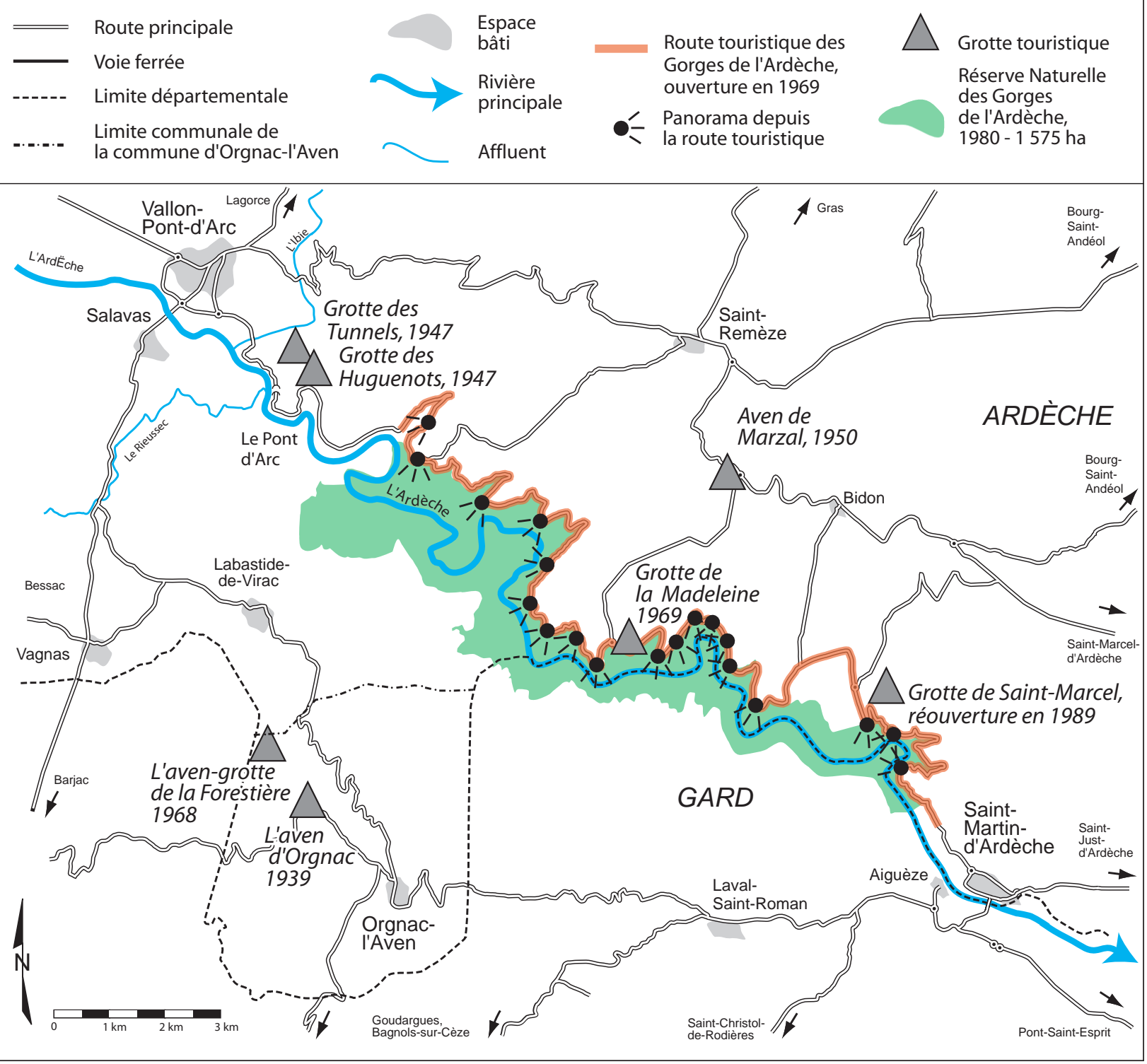




\section{III - L'AVEN D'ORGNAC DANS L'ÉCONOMIE TOURISTIQUE ET DANS LA STRUCTURATION DU TERRITOIRE}

\section{a - L'implication de la communauté hôte : aspects socio-économiques}

La volonté de la commune de lier son destin au nouvel aven se traduisit presque aussitôt sur le plan toponymique. Pendant l'hiver 1939, alors que les travaux d'aménagement battent leur plein et quatre mois avant l'inauguration du site, le conseil municipal d'Orgnac demande que la commune puisse changer de nom, au motif qu'il existe quatre communes d'Orgnac en France et que l'adjonction du suffixe « l'Aven » permettrait d' « éviter toute méprise dans la distribution du courrier postal et [de] faciliter la publicité pour son aven » (séance du 18 février 1939). On devine que, des deux arguments, l'un devait peser plus que l'autre! Un an plus tard, la commune obtient gain de cause et devient officiellement Orgnac-l'Aven, ce changement toponymique signant bien la symbiose qui s'établissait entre la commune et son nouveau sitephare et qui n'a fait que prospérer depuis 70 ans.

Car les habitants d'Orgnac ont eu le mérite de choisir des édiles capables de comprendre, sur la durée, l'importance de ce patrimoine et de sa valorisation, ce qui n'est pas partout le cas. En 1972, la mairie demandait un classement en commune touristique pour faire face aux charges spécifiques liées à l'activité. Le lien entre la commune et l'aven s'est donc renforcé au fil du temps, le succès rencontré par l'activité touristique s'est traduit par des investissements et des améliorations sur place, contrairement à d'autres grottes touristiques dont les gérants, moins liés à un territoire spécifique, ont préféré essaimer sur d'autres sites. Ces implications territoriales du tourisme se retrouveraient sur d'autres types d'espaces touristiques, et apparenteraient Orgnac au modèle communautaire (type community) plutôt qu'au modèle intégré (type corporate, A. Flagestad, 2003). Le cas n'est pas unique dans la région car les grottes de Saint-Marcel et de la Madeleine sont également gérées par les communes de Saint-Marcel-d'Ardèche et de Saint-Remèze, mais les liens n’ont jamais été aussi resserrés qu'à Orgnac.

Robert de Joly avait toujours fait miroiter que « le village d'Orgnac trouverait la prospérité » grâce à l'aménagement de l'aven (lettre du 19 août 1935). Le maire saisit la balle au bond, on l'a vu, et depuis l'origine, l'aven d’Orgnac est donc géré en régie directe par la commune qui est à la fois propriétaire et gestionnaire du site, même si elle n'est pas le seul acteur présent sur place (restaurant privé, boutiques en gérance libre...). Et de fait, l'aven est bel et bien devenu, avec la viticulture, le support de la principale activité économique sur la commune. En 2005, les recettes d'exploitation de l'aven se sont élevées à
$985577 €$, la régie put ainsi dégager un excédent sur cet exercice de $100106 €$. Pour avoir une idée plus précise de ce que cette somme peut représenter dans une commune rurale de 341 habitants (recensement de 1999), on peut la rapprocher de la dotation forfaitaire versée par l'État, d'un montant de $67122 €$ pour la même année 2005.

Aujourd'hui, l'aven d'Orgnac emploie 16 personnes, soit l'équivalent de 11,5 emplois à temps plein. Si l'on y ajoute les employés du Musée régional de Préhistoire et des activités annexes, on arrive à un total de 22 emplois permanents sur le site, dont 12 occupés par des habitants d'Orgnac-l'Aven. Cette implication très concrète des habitants de la commune contribue également à l'appropriation de l'aven par la population d'Orgnac. Le poids socio-économique de l'aven induit une grande complémentarité et une solidarité devenues quasi-obligatoires entre la collectivité locale, ses habitants et son principal site touristique. De surcroît, l'activité touristique sur Orgnac ne se limite pas à l'aven mais se traduit aussi par la présence au village de deux hôtels-restaurants (hôtel de l'Aven et hôtel des Stalagmites) et d'un camping, d'une piscine municipale, et par le maintien et la modernisation récente de plusieurs commerces au village (quatre commerces de proximité et une agence postale), établissements dont la fréquentation tient à la fois à l'aven lui-même et au contexte touristique régional. Une synergie se renforce aussi avec l'activité viticole qui trouve auprès des visiteurs de l'aven une clientèle non négligeable. Dans les années 1980-1990, la cave coopérative d'Orgnac engage ainsi de grands efforts pour l'amélioration de la production, jusqu'à l'obtention en 1999 d'une A.O.C. «Côtes du Vivarais-Orgnac-l'Aven ».

\section{b - Orgnac à l'échelle de la région touristique sud-Ardèche (figure 5)}

Si dès les premiers instants de la mise en tourisme, l'échelon communal est toujours apparu très en pointe, un tel aménagement touristique ne pouvait pas se concevoir à cette seule échelle. On a vu que, dans la recherche de financement, la commune s'appuie à plusieurs reprises sur l'intérêt national du site nouvellement découvert. Mais c'est surtout entre l'échelle communale et l'échelle du sud-Ardèche que s'est tissé tout un faisceau de liens très dense et très utile pour la compréhension de l'ancrage territorial de l'aven d'Orgnac. Cette relation, É.-A. Martel l'avait très rapidement pressentie puisqu'il écrivait en 1936 : « cette heureuse découverte [de l'aven d'Orgnac] va déclencher, souhaitons-le, l'équipement touristique (jusqu'à présent incomplet) du Bas-Vivarais et notamment du splendide cañon de l'Ardèche, trop peu visité » (Causses Majeurs, p. 24).

Mais c'est encore dans les archives du conseil municipal que nous trouvons la formulation la 
plus précise de cette implication territoriale. Lors de la séance du $1^{\mathrm{er}}$ novembre 1936, l'idée forte est mise en avant selon laquelle «l'aménagement de l'aven d'Orgnac est susceptible d'attirer un nombre considérable de touristes dans la pittoresque région du sud de l'Ardèche, à cause de la beauté naturelle des diverses salles ». Le 28 du même mois, toujours pour démontrer l'intérêt qu'il y a à décider de cet aménagement, un autre argument est invoqué, à savoir « la situation à proximité d'une région touristique du Pont d'Arc et des gorges de l'Ardèche en particulier, [qui] permet d'escompter un nombre considérable de visiteurs lorsque l’aven serait aménagé ».

Ainsi, à moins d'un mois d'intervalle, cette double argumentation est utilisée, contradictoire en apparence mais révélatrice des interactions qui allaient s’établir entre le site et la région dans laquelle il s'inscrit. Alors que l'on en est encore aux études préalables et à la discussion des premiers crédits, et que les conseillers municipaux ont sans doute besoin de se rassurer euxmêmes sur l'issue de l'aventure dans laquelle ils s'apprêtent à lancer la commune, on entrevoit que l'aven va jouer un rôle moteur dans la région en faisant venir de nouveaux touristes EN MÊME TEMPS qu'il pourra profiter de la notoriété déjà établie des autres curiosités naturelles environnantes. Ce que Robert de Joly résumait ainsi lors de l'inauguration de l'aven d’Orgnac : «Souhaitons que (...) vous puissiez retirer les fruits des efforts déployés en vue de faire mieux connaître votre belle Ardèche », efforts parmi lesquels il comptait l'aménagement d'Orgnac lui-même. Cette relation ambivalente est rendue possible par le fait que le tourisme est lui-même dans une phase de développement dans les gorges de l'Ardèche qui ne connaissent encore qu'une fréquentation modeste.

Il en est allé autrement dans la mise en tourisme d'autres cavernes comme Padirac ou Bétharram qui ont bénéficié respectivement du très grand rayonnement de Rocamadour et de Lourdes, qui ont été pourvoyeurs nets de clientèle et qui le sont restés : en l'absence de statistiques précises, on peut supposer que les grottes de Bétharram ont apporté peu de pèlerins supplémentaires à Lourdes... À Padirac, il est possible que l'aménagement du gouffre ait aussi profité à Rocamadour en procurant au pèlerinage un regain d'attractivité (Biot, 2006, p. 114). À l'inverse, Orgnac s'est affirmé sans site touristique majeur à proximité qui puisse lui servir de réservoir de clientèle plus ou moins captive (curistes, pèlerins...), mais dans une relation de complémentarité avec une région touristique elle-même émergente depuis la fin du XIXème siècle et dont l'essor allait être spectaculaire dans les 50 ans qui suivraient.

Or, il faut prendre en compte la situation particulière d'Orgnac : le village et l'aven se trouvent sur la rive droite de l'Ardèche, largement en retrait des gorges et sans accès direct à celles-ci. Alors que l'activité touristique se déploie pour l'essentiel entre VallonPont-d'Arc et Saint-Martin-d'Ardèche et que les autres villages occupent les plateaux de rive gauche, Orgnac vit dans un isolement relatif que la géographie administrative souligne encore davantage : en effet, les arbitrages consécutifs au découpage des départements par la Constituante ont rattaché la commune d'Orgnac au canton de Vallon et au département de l'Ardèche, en dépit de la plus grande proximité de Barjac et des anciens liens avec le diocèse d'Uzès.

Si Orgnac se retrouve ainsi impliqué dans le système touristique du Bas-Vivarais, il ne put guère y participer jusqu'à la mise en tourisme de l'aven. La découverte de 1935 prend alors un tout autre sens en offrant à Orgnac la possibilité de trouver sa place dans la région touristique en voie de constitution, jusqu'à y jouer un rôle moteur. Dans les années 1950, alors que l'activité touristique autour des gorges reste modeste et que la route des gorges sur la rive gauche n'existe pas encore, l'aven d'Orgnac est en passe de devenir un pôle majeur à l'échelle de la région. Et lorsque les centres de gravité du tourisme glisseront davantage vers les gorges elles-mêmes, les élus d'Orgnac auront à cœur de ne pas se laisser marginaliser et de faire prospérer la fonction touristique du site. Par un effet miroir, cette position de borne territoriale, cette situation de «télistokome » en périphérie de l'Ardèche et de Rhône-Alpes (Laslaz, 2005, p. 230), loin de n'avoir toujours constitué qu'une somme de handicaps, peuvent aussi expliquer l'attention dont a bénéficié à certains moments la commune d'Orgnac de la part de ces collectivités territoriales. Dans ses différentes entreprises, la commune d'Orgnac a su tirer parti de cette position a priori peu confortable et trouver l'appui du département et de la région, peu soucieux, à leur tour, de voir se développer un angle mort sur leurs confins méridionaux : l'implantation du Musée régional de Préhistoire en 1988 ou la participation des conseils généraux et régionaux au financement de l'O.G.S. illustrent cette dynamique. Comme la carte administrative rend difficile la construction d'un développement cohérent et concerté du côté du Gard et de la région Languedoc-Roussillon, Orgnac continue à se tourner préférentiellement vers le nord et les gorges de l'Ardèche où battent à la fois le cœur touristique de la région et la mesure donnée par les tutelles départementales et régionales.

Car la fréquentation de l'aven d'Orgnac ne peut être déconnectée du contexte touristique du sudArdèche : la clientèle de l'aven se compose à $25 \%$ de visiteurs étrangers, au premier rang desquels viennent les Allemands, les Hollandais puis les Belges. Parmi les visiteurs français, $40 \%$ sont domiciliés dans la région Rhône-Alpes, malgré le relatif éloignement des bassins de clientèles d'excursionnistes. Lyon étant à deux heures trente d'Orgnac, la visite de l'aven ne peut constituer le seul motif du déplacement et doit 
s'articuler avec d'autres attractions touristiques ou de court séjour. La fréquentation de l'aven est donc très dépendante de l'activité touristique générale dans la région, et en suit les aléas. Ainsi, entre 2002 et 2004, le taux d'occupation des terrains de camping-caravaning classés du sud-Ardèche, gros pourvoyeurs de clientèles pour les sites, a baissé de $35 \%$ à $31,4 \%$, ce qui n'a pas manqué de se répercuter sur la fréquentation des lieux de visite : les 9 grottes et avens aménagés du département perdaient dans le même temps de plus de $11 \%$.

La visite de sites payants est une composante majeure du tourisme ardéchois, et la concurrence est rude : pas moins de 105 lieux de visites ouverts en 2004 qui tous ensemble ont accueilli 1372000 visiteurs ! Bien sûr, ces sites sont très hétéroclites et ne pèsent pas tous du même poids : $85 \%$ de la fréquentation se concentrent en effet sur les 19 lieux (dont 4 grottes et avens) qui accueillent plus de 10000 visiteurs, alors que des dizaines de petits musées ou sites naturels vivotent en pratiquant un tourisme de cueillette. Dans cette offre pléthorique démultipliée depuis le début des années 1990, l'aven d'Orgnac s'affirme comme le deuxième site à entrée payante, derrière le parc animalier de Peaugres situé dans la partie nord du département.

\section{c - La valorisation du label « Grand Site de France " et le Pôle d'excellence rurale}

À l'échelle d'Orgnac, le label « Grand Site de France » décerné en 2004 a été immédiatement mis en avant comme argument de promotion du site, participant à un souci de démarcation de l'aven par rapport aux grottes touristiques environnantes. Créateur de rareté, le label Grand Site concourt à l'élection de l'aven d'Orgnac comme site touristique majeur à l'échelle de la région, et bien au-delà des gorges de l'Ardèche puisqu'il forme le troisième sommet d'un triangle que complètent le pont du Gard et la montagne SainteVictoire, sites prestigieux s'il en est. Participant au

\section{Photo 7}

Allocution de la vice-présidente du Réseau des Grands Sites de France lors de la remise, en juillet 2006, de l'oeuvre de verre symbolisant le label (photo Françoise Prud'homme).

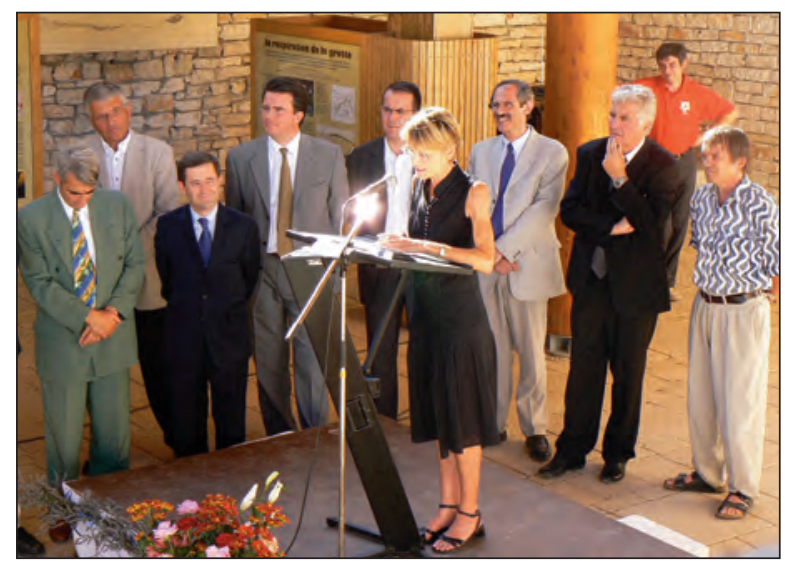

« rayonnement international de la France », il fait progressivement figure de « site vitrine » témoignant d'un mode de gestion durable d'un site touristique aux caractéristiques naturelles (cf. encadré sur les prospectus touristiques).

À l'échelle des gorges de l'Ardèche et des plateaux karstiques environnants, ce label fait l'objet d'une récupération/mobilisation d'une tout autre envergure à travers la démarche « pôle d'excellence rurale » (P.E.R.) lancée en 2006. Coordonné par la DIACT (Délégation interministérielle à l'aménagement et la compétitivité des territoires, anciennement DATAR), ce projet tend à encourager et à soutenir les dynamiques rurales, via : 1) la promotion des richesses naturelles, culturelles et touristiques, 2) la valorisation et gestion des bioressources, 3) le développement des offres de services et de l'accueil de nouvelles populations, 4) la recherche de l'excellence technologique pour des productions industrielles, artisanales et de services localisées.

Dans le cas de l'Ardèche, cette démarche de pôle d'excellence rurale est entendue comme « l'opportunité pour les gorges de l'Ardèche de réussir la transition d'un modèle de développement touristique de masse, basé sur l'utilisation des ressources et une forte saisonnalité, vers un modèle de développement visant l'excellence par la valorisation de son patrimoine et la création d'emplois pérennes » (source: Syndicat de gestion des gorges de l'Ardèche, 2006). Dans cette perspective d'asseoir la lisibilité d'un territoire dit « des gorges de l'Ardèche », ce projet s'appuie alors en partie sur les propriétés structurantes, réelles ou fantasmées, du site d'Orgnac.

Un premier volet vise à « conforter le label Grand Site de France de l'aven d'Orgnac ». Le pôle d'excellence rurale apparaît ni plus ni moins comme un moyen de terminer des actions projetées lors de l'O.G.S. qui n'avaient pu aboutir faute de financements: l'aménagement paysagé des abords du site, autrement dit, la suppression des parkings bitumés restants, la création d'un espace ludique afin de renforcer l'attrait auprès du jeune public, l'acquisition d'audio-guides afin de renforcer l'accueil du public étranger, la création d'un sentier d'interprétation sur le thème de la préhistoire avec un aménagement « raisonné » de la Baume de Ronze, site archéologique.

La nécessité de conforter ce label s'explique par le fait que l'aven d'Orgnac est présenté comme l'un des sites touristiques structurants de ce territoire. En effet, il fait figure de pivot sur lequel des politiques de diffusion et de structuration des flux touristiques peuvent s'appuyer. Dans l'objectif 5 de ce P.E.R. intitulé « fédérer les acteurs du tourisme autour d'un outil innovant de découverte du patrimoine », l'aven d'Orgnac s'inscrit comme un des sites porteurs de cette démarche, au même titre que la route touristique des gorges ou que la Maison de la réserve. 
Ce positionnement concourt à l'élection de l'aven d'Orgnac comme un site exceptionnel, en l'instituant comme un acteur touristique et territorial majeur de cet environnement, comme un interlocuteur de premier ordre. Peu à peu, un phénomène de récupération et d'extension spatiale de ce label Grand Site s'instaure. Initialement attribué à l'aven d'Orgnac, il est présenté comme le marqueur de l'excellence de ce territoire dans son ensemble.

Dans un second temps, la récupération du labelOpération Grand Site par les acteurs territoriaux environnants permet, par un effet rétroactif, de positionner l'aven d'Orgnac comme l'un des sites majeurs du paysage bas-vivarois, à la fois en terme de site touristique mais aussi en terme de site « territorialisant ». Une nouvelle fois, le site de l'aven d'Orgnac fait figure d'exception en ce sens où il est le seul site karstique souterrain en France à avoir fait l'objet d'un programme de réhabilitation d'une telle ampleur, porté conjointement par les services de l'État, par l'Union européenne et par les collectivités territoriales.

\section{Plan de financement O.G.S. :}

$\begin{array}{lr}\text { État } 3,750 \mathrm{MF}+5,780 \mathrm{MF}= & 9,530 \mathrm{MF} \\ \text { Union européenne } & 6,425 \mathrm{MF} \\ \text { Conseil régional Rhône-Alpes } & 3,750 \mathrm{MF} \\ \text { Conseil général de l'Ardèche } & 3,750 \mathrm{MF} \\ \text { Commune d'Orgnac } & 5,905 \mathrm{MF} \\ \text { Total } & 29,360 \mathrm{MF}\end{array}$

Chiffres issus de la convention Grand Site signée le 8 juin 2000

Cette articulation entre le local et le territoire des gorges de l'Ardèche fait l'objet d'une appropriation par la structure gestionnaire de l'aven. Dans une réflexion lancée en 2006 et intitulée "L'aven d'Orgnac - Grand Site de France. Positionnement et stratégie de développement à 10 ans », un comité de pilotage a été constitué et réfléchit à « la mise en place opérationnelle d'une double articulation monde souterrain/monde de surface et celle consistant à réinscrire le site d'Orgnac dans son territoire proche (Baume de Ronze, Orgnac III...) et son territoire plus lointain (les gorges de l'Ardèche) » (p.4). Orgnac, fort de son expertise touristique et environnementale, peut ainsi faire entendre sa voix dans les interminables discussions sur le futur de l'Espace de restitution de la grotte Chauvet et sur le choix de son lieu d'implantation. Cette convergence des intérêts locaux et des visées régionales alimente de fait cette synergie engagée sur le site d'Orgnac, lequel s'inscrit progressivement dans une dynamique de « haut-lieu », où l'on assiste à « l'élection d'un lieu singulier » et à sa promotion « au rang de modèle d'une action de changement social en train de se faire » (Micoud, 1991, p. 8).

\section{Conclusion}

On voit par là que les spécificités historiques et locales ont joué un grand rôle dans la trajectoire touristique de l'aven d'Orgnac, que de nombreux éléments se sont combinés ici de façon particulière, et rien n'indique que cette histoire soit reproductible ailleurs. La dynamique d'Orgnac se caractérise en effet, depuis le début, par une implication forte sur le territoire, auprès des collectivités territoriales (Département, Région) et des pouvoirs publics, et par une réactivité plus ou moins opérationnelle aux attentes du public : ajout d'un, puis de deux ascenseurs, amélioration de la structure d'accueil...

Cette évolution éclaire d'un jour fort instructif les rapports entre tourisme et patrimoine, souvent décrits sur un registre conflictuel, sinon antinomiques. Ici, et sur la longue durée, c'est l'exigence patrimoniale qui porte la réputation du site touristique, et c'est la réussite touristique qui permet une meilleure valorisation patrimoniale. Ce qui ne signifie pas que cette boucle vertueuse n'ait pas aussi ses limites, dues à des effets de situation ou à des problèmes d'inertie du système local. Mais de toute évidence il y a là un pari continu sur la qualité, ce qui n'est pas partout le cas, et surtout pas en matière de tourisme souterrain. Ce pari est assez ambitieux dans la mesure où il admet une part sans cesse croissante de contraintes que les acteurs commerciaux et territoriaux cherchent d'ordinaire plutôt à éviter (contraintes liées au classement, au cahier des charges du label Grand Site ou de l'UNESCO...) dans l'espoir que ces contraintes seront aussi pourvoyeuses d'une rareté, à travers les labels, et que cette rareté permettra à Orgnac de mieux se démarquer de la concurrence régionale.

Car le développement touristique de l'aven reste étroitement lié à la dynamique territoriale. L'aven n'est pas un motif de déplacement pour un séjour touristique ; en revanche, il fait partie des « incontournables » de l'Ardèche touristique et draine donc plus de 100000 visiteurs sur le plateau en rive droite de l'Ardèche, à l'écart de la Route touristique des Gorges. La reconnaissance actuelle de l'aven n'est ainsi pas un hasard mais l'héritage d'un dynamisme continu et d'une réelle prise de conscience de l'évolution du territoire touristique, de l'offre et de la pratique touristique. Le besoin de dépasser le simple cadre de l'aven et de travailler avec le territoire se traduit par l'implication de l'aven et de la commune dans différents dispositifs : O.G.S., P.E.R. mais aussi à l'échelon départemental avec l'association A.L.P. (Ardèche Loisir Patrimoine) pour la promotion de l'offre touristique ardéchoise; ou à l'échelon régional avec l'association des Sites de Découverte de la Nature en Rhône-Alpes dont l'aven d'Orgnac est un des membres créateurs, dont l'objet est d'accompagner la professionnalisation des acteurs du tourisme ; au niveau national enfin, la demande de classement par l'UNESCO (avec 17 autres cavités) est l'exemple de la cohérence de l'ensemble des actions passées et en cours. 


\section{BiBLIOGRAPHIE}

Barth Ph. et Prud'homme F. (2003) - Orgnac, Grand Site de France. Guide du site, $24 \mathrm{p}$.

Bıт V. (2006) - Le tourisme souterrain en France - thèse de Géographie Univ. Savoie. Karstologia-Mémoires, $\mathrm{n}^{\circ} 15,236 \mathrm{p}$.

Convention Opération Grand Site de l'Aven d'Orgnac, 8 juin 2000.

Duval M. (2006) - Ressource touristique et enjeux territoriaux, évolution et re-définition de la Route Touristique des Gorges de l'Ardèche. Actes du colloque Transports et Tourisme, Collection EDYTEM, Cahiers de Géographie, $\mathrm{n}^{\circ} 4,253-266$.

Duval M. et Gauchon Ch. (2007) - Analyse critique d'une politique d'aménagement du territoire, les Opérations Grands Sites. Annales de Géographie, n 654, 147-168.

De Joly R. (1946) - Guide de l'aven d'Orgnac (Ardèche). Uzès, Henri Peladan, 80 p (1ère édition).

Flagestad A. (2003) - Réussite stratégique et structure organisa-tionnelle des destinations de sports d'hiver. Actes des rencontres Cimes 2002, éd. Facim, 183-188.
LASLAz L. (2005) - Les zones centrales des Parcs nationaux alpins français (Vanoise, Écrins, Mercantour). Des conflits au consensus social ?. Thèse Géographie, Univ. Savoie, $539 \mathrm{p}$.

Micoud A. (1991) - La production symbolique des lieux exemplaires, in Des Hauts-Lieux, la construction sociale de l'exemplarité, éd. du CNRS, Paris, 7-15.

SyndicAt de GESTION DES GORGES DE L'ARDĖChe (mars 2006) Dossier de candidature au pôle d'excellence rurale, territoire des gorges de l'Ardèche, non paginé.

CABInet Oppidumsis (2006) - Comité de pilotage du 21/06/2006, l'aven d'Orgnac - Grand Site de France. Positionnement et stratégie de développement à 10 ans, 18 p.

Rieu G. (1983) - L’aven d'Orgnac. éd. AIO, 33 p.

Trébuchon J. (2000) - La saga de l'aven d'Orgnac-Issirac, l'épopée d'une fantastique découverte souterraine et ses ahurissantes conséquences. Auto-édition, 240 p.

Remerciements à la mairie d'Orgnac-l'Aven pour la mise à disposition des archives municipales et de celles de Robert de Joly, ainsi qu'à la famille Rieu pour le prêt de documents.

Photo 8

Vue aérienne du site d'Orgnac après l'Opération Grand Site (photo Serge Doumens).

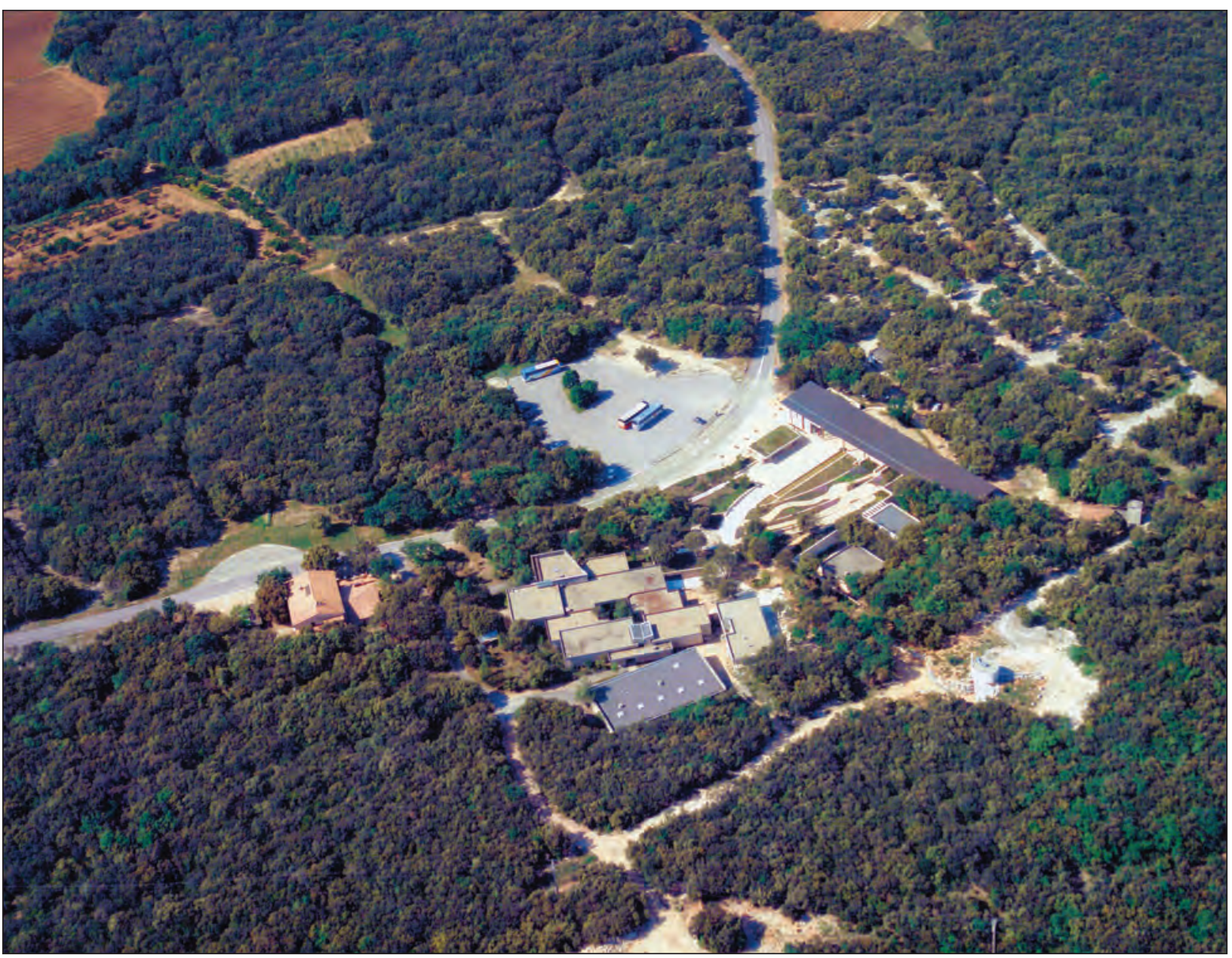




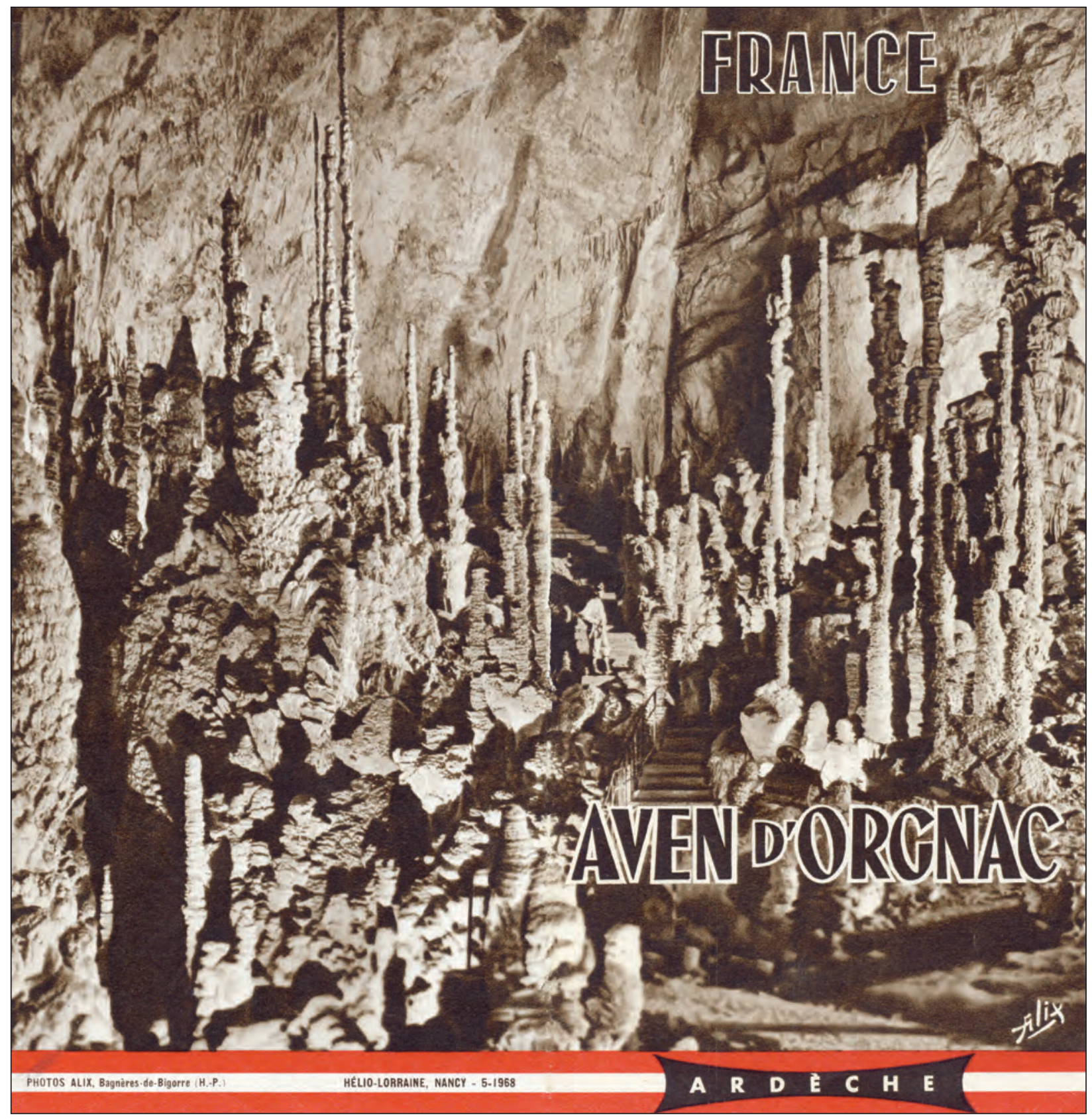




\section{ENCADRÉ TOPONYMIQUE}

L'aven s'appelle d'abord aven du Bertras. Cette appellation semble n'apparaître ni au cadastre ni sur les cartes mais c'est sous ce nom que « les gens du village » l'indiquèrent à Robert de Joly lorsqu'il y descendit le 19 août 1935.

Dans le Spelunca VI, p. 76, « compte-rendu sommaire... », De Joly parle encore de « BertrasOrgnac », mais la fortune de cette appellation sera bien courte. Quelques pages plus loin, dans le premier long article qu'il consacre à l'aven (p. 78-92), De Joly consacre le changement toponymique au détour d'une phrase : «l'aven de Bertras à l'avenir portera le nom d'Orgnac pour mieux le situer géographiquement » (p. 84). Dans un guide touristique de l'après-guerre (non daté), Robert de Joly ajoute qu'il a « tenu à lui donner le nom même de la commune (...) pour mieux le fixer dans les mémoires » ( $p .9)$, même s'il l'appelle encore indifféremment le Bertras (p. 21, 24 ou 31) ou l'aven d'Orgnac (p. 28), y compris dans deux phrases à la suite $(p .29)$.

Mais dès 1936, dans sa dernière grande œuvre consacrée aux "Causses Majeurs", Édouard-Alfred Martel décrétait que le gouffre «sera appelé désormais Aven de Joly: digne récompense de longs et persévérants efforts » (p. 24, efforts dont il regrette aussitôt le côté tapageur et brouillon). Or chacun sait que les relations entre les deux hommes sont souvent orageuses et De Joly n'honora pas cette proposition. Lors de la cérémonie d'inauguration de l'aven en 1939, De Joly explique pourquoi il a préféré décliner cette offre : « Ne valait-il pas mieux sacrifier cette satisfaction d'amourpropre à l'intérêt collectif qui veut que le nom d'Orgnac rayonne pleinement ?».

Les seuls noms qui apparaissaient sur la première topographie de l'aven étaient ceux de ces collaborateurs lors de l'exploration : Salle Latour, Salle Petit et Salle Glory mais aucun toponyme ne rappelait alors le nom de l'inventeur de la cavité. C'est encore le cas sur la topographie que publie Jean Balazuc en 1956. Il semble que c'est donc Jean Trébuchon, sur la topographie générale des réseaux parue en
1966, qui le premier donna le nom de De Joly à la grande salle que les visiteurs admirent au bas du puits d'entrée, et dans laquelle reposent ses cendres depuis 1969.

Les explorations des années 1960 et les conflits qui allaient s'ensuivre eurent aussi des répercussions toponymiques. L'ouvrage de J. Trébuchon recèle ainsi de multiples appellations pour désigner les nouveaux réseaux: Robert de Joly parla lui-même du «nouvel Orgnac »; puis, dans un document de 1969, la préfecture du Gard employa l'expression « aven d'Issirac » ( $p .112)$, puis de plus en plus, dans les documents liés aux projets d'aménagement, on parla du " gouffre géant d'Issirac (ex nouveaux réseaux de l'aven d'Orgnac) », ce qui serait devenu l'appellation commerciale si ces projets avaient abouti. Quant à la grande topographie publiée par Jean Trébuchon et le Centre de Spéléologie de Vallon-Pont-d'Arc après les explorations de 1965-1966, elle propose le nouveau nom d'« aven d'Orgnac-Issirac ». Or ces évolutions et ce flottement toponymiques ne sont pas seulement le fait des découvreurs des nouveaux réseaux ou de la mairie d'Issirac. Il apparaît en effet que du côté de la mairie d'Orgnac on entendait garder le monopole de la raison sociale « aven d'Orgnac », ce qui aurait obligé d'éventuels concurrents à employer une autre dénomination (conseil municipal du 11 janvier 1970).

Mais les textes de 1996 (convention entre les deux communes), de 1998 (création du SIVU) et de 1999 (arrêté préfectoral sur les conditions de fréquentation) ne parlent plus que des « réseaux de l'aven d'Orgnac » qui reste ainsi l'appellation " officielle ». Toutefois, il est devenu fréquent de distinguer un «aven d’Orgnac » désignant le circuit aménagé et des « réseaux d’OrgnacIssirac » parcourus par les visites sportives. Les documents émanant de la Diren Rhône-Alpes emploient indifféremment les appellations d'aven d'Orgnac et d'aven d'Orgnac-Issirac, y compris sur le même document. Un certain flou toponymique subsiste donc, qui reflète la complexité des jeux d'acteurs autour de cette caverne hors du commun! 


\section{CHRONOLOGIE}

19 août 1935 : Découverte et exploration de l'aven (Orgnac I) ; décision immédiate de l'aménagement touristique.

18 février 1939 : Délibération du conseil municipal : demande de changement du nom de la commune.

10 juin 1939 : $\quad$ Inauguration de l'aven d'Orgnac.

14 avril 1940 : $\quad$ Décret modifiant le nom de la commune d'Orgnac qui devient officiellement Orgnac-l'Aven (publication au J. O. le 26 avril 1940).

1946 : $\quad$ Classement de l'aven au titre des sites.

1948 : $\quad$ Construction d'un bâtiment de réception.

1955 : $\quad$ Prolongement de la visite touristique jusqu'aux Salles Rouges.

1965 : $\quad$ Mise en service de l'ascenseur d'accès à la Salle de Joly.

1965-1966 : $\quad$ Explorations des réseaux d'Orgnac II, III et IV par l'équipe Trébuchon.

1969 : $\quad$ Ouverture de la Route touristique des Gorges de l'Ardèche.

1972: Délibération du conseil municipal : demande de classement de la commune au titre des « communes touristiques ».

1974: $\quad$ Extension du périmètre de classement à l'ensemble de l'aven (tréfonds), inscription de la surface.

1975 :

Forage de reconnaissance entre la surface et la Salle des Treize.

26 mars 1976 : $\quad$ Délibération de la commission des sites, rejet des projets d'aménagement des nouveaux réseaux d'Orgnac en vue de leur exploitation touristique.

19 décembre 1978 : Première convention entre les communes d'Orgnac-l'Aven et d'Issirac : " mise en place d'un programme d'action commun en vue de favoriser une meilleure publicité et une meilleure exploitation des grottes d'Orgnac et de la Forestière et des réseaux souterrains ».
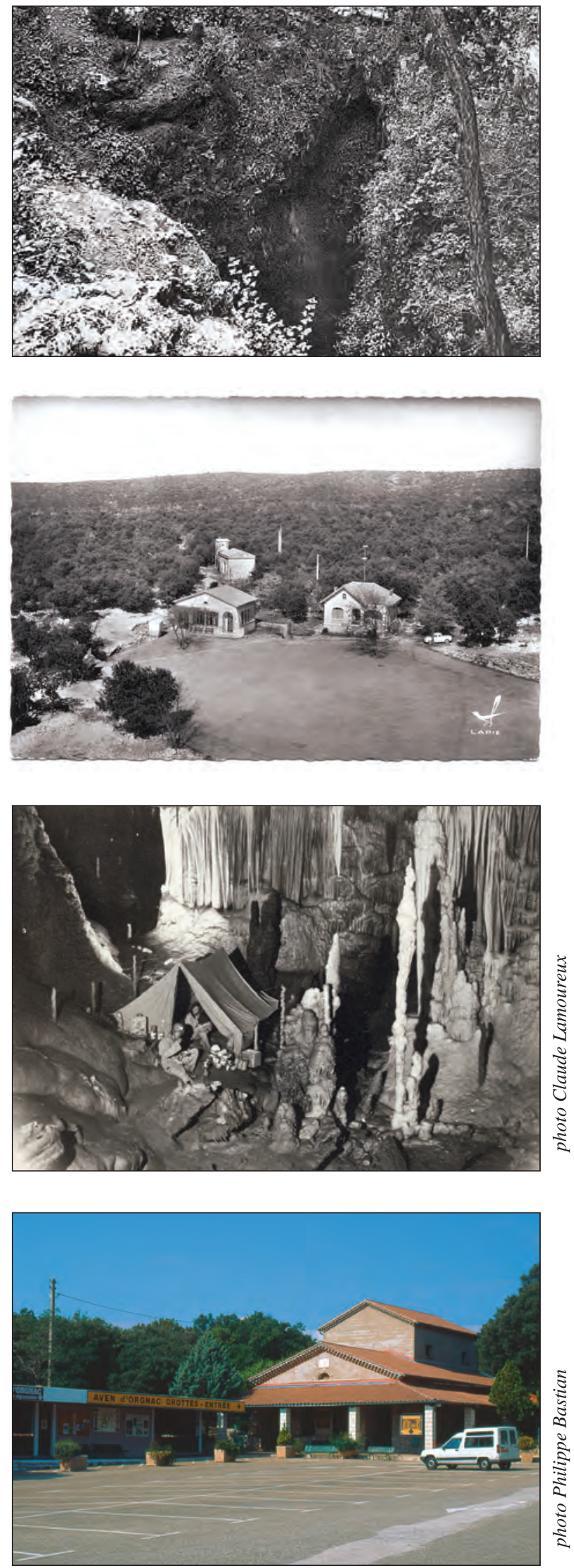


\section{CHRONOLOGIE}

21 janvier 1983 : $\quad$ Projet de ré-aménagement du circuit de visite de l'aven d’Orgnac : créer un circuit dans la grotte de manière à distinguer les escaliers de descente et de remontée, création d'un belvédère au-dessus des Salles Rouges. Sans suite.

1988 :

Ouverture du Musée régional de Préhistoire sur le site de l'aven d'Orgnac.

28 février 1996 : Renouvellement de la convention entre Orgnac-l'Aven et Issirac.

15 juin 1998 : $\quad$ Demande portée par la DIREN Rhône-Alpes (F. Gauquelin) devant la commission des sites pour l'aménagement et l'accès aux galeries jusqu'ici non ouvertes au public : «mieux vaut un gardien surveillant le réseau, lequel ne sera pas ouvert à un grand public, que de risquer un tourisme clandestin ».

4 août 1998 : $\quad$ Création du SIVU Orgnac-Issirac par arrêté interpréfectoral.

12 avril puis

12 juillet 1999 :

2000 :

2003 :

$2004:$

2005-2006 :
Arrêté préfectoral fixant les modalités de fréquentation

Signature de la convention O.G.S.

Inauguration des

Obtention du label O.G.S.

Extension du périmètre de classement. nouveaux aménagements.
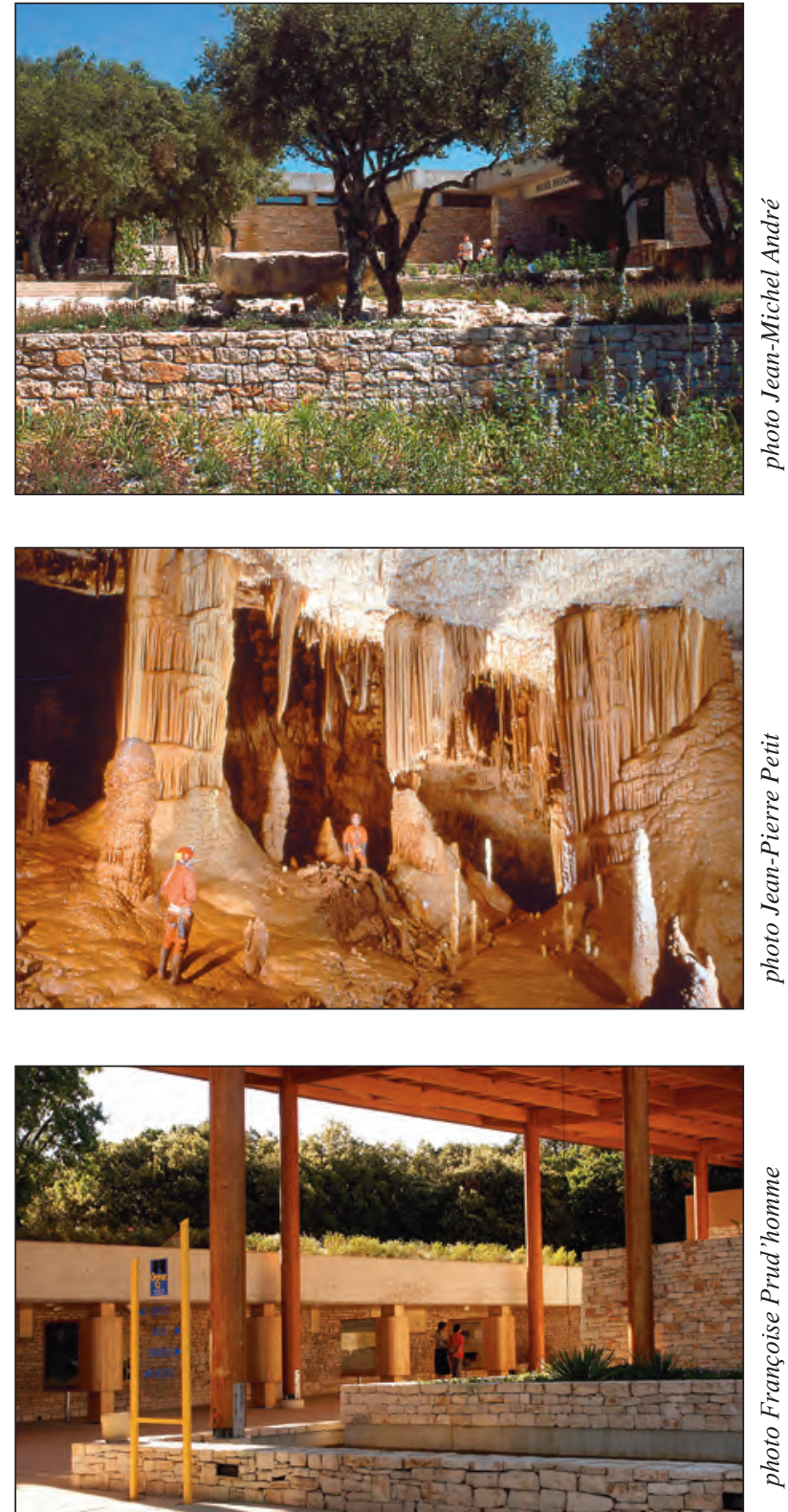

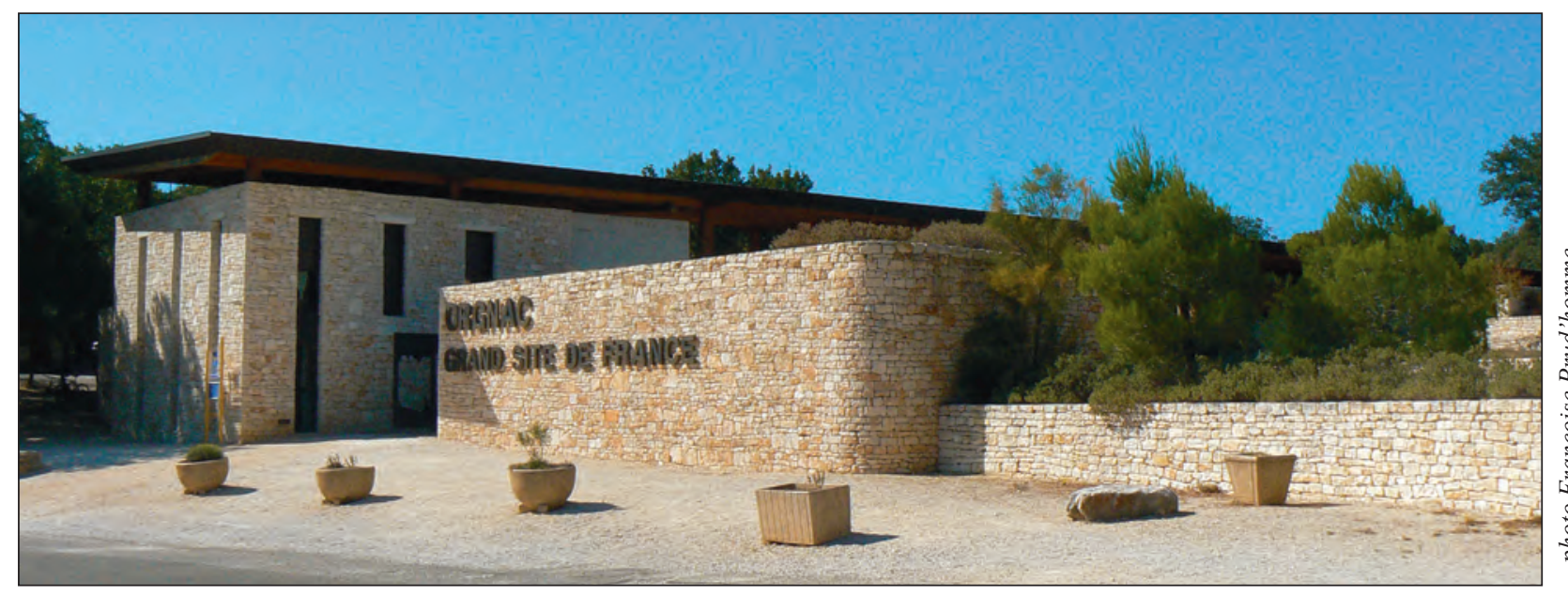




\title{
LA GESTION DES RÉSEAUX D’ORGNAC-ISSIRAC : UN EXEMPLE ORIGINAL DE VALORISATION DE RÉSEAUX SOUTERRAINS FRAGILES ET À HAUTE VALEUR PATRIMONIALE
}

\author{
par Stéphane TOCINO
}

En 1996, les conseils municipaux des communes d'Orgnac-l'Aven et d'Issirac se rencontrent afin de définir ensemble les moyens de protéger les réseaux spéléologiques de l'aven d'Orgnac tout en valorisant leur valeur minéralogique et karstique. Un des moyens évoqués a été d'ouvrir une partie des réseaux non aménagés à des visites spéléologiques encadrées. Après avoir pris l'avis des services de l'État (préfecture, DIREN, DDJS) partenaires dans l'élaboration de ce projet, un Syndicat intercommunal à vocation unique a été créé, regroupant Orgnac-l'Aven et Issirac.

La cavité est découpée en trois secteurs parmi lesquels (i) la partie aménagée d'Orgnac I bénéficiant des équipements permettant un accès des réseaux au grand public, (ii) une partie ouverte à des visites spéléologiques réglementées (Orgnac II et III partiellement), (iii) une partie qui demeure inaccessible: zone de protection intégrale (Orgnac IV).

Dès la mise en place du SIVU, il est apparu nécessaire de créer un emploi de "guide-gardien » des réseaux d'Orgnac-Issirac, ce poste étant jugé indispensable pour assurer un encadrement strict des visites, une vigilance des réseaux et un retour d'expérience sur les impacts des visites sur le milieu.
Un des premiers travaux a été de faire disparaître au mieux les traces des anciennes fréquentations spéléologiques, qu'elles soient libres dans les premières années de la découverte, autorisées, ou même parfois clandestines. Il est à noter que quelques années avant la création du SIVU, un premier balisage, sommaire mais efficace, avait été installé et que les visites étaient déjà accompagnées.

Ce travail de "réhabilitation » des réseaux a donc consisté à faire en premier lieu du nettoyage : (i) évacuation de plusieurs centaines de kilos de déchets..., (ii) nettoyage des concrétions et des coulées de calcite souillées d'argile ou de traces de passage (photo 1), (iii) effacement des traces de charbonnage liées à la combustion des lampes à acétylène, (iv) recollage de quelques concrétions, visiblement cassées par la fréquentation spéléologique.

Un nouveau balisage a été réalisé (photo 2) afin de limiter l'impact et l'empreinte spatiale des futures visites à un seul cheminement spéléologique. Un travail d'aménagement sommaire a été réalisé pour sécuriser certains passages et pour installer dans le réseau: (i) une ligne électrique servant à éclairer ponctuellement les volumes remarquables du réseau, (ii) une ligne téléphonique pour prévenir les secours

Photo 1

Nettoyage au jet d'une concrétion (photo Nicolas Legrand).
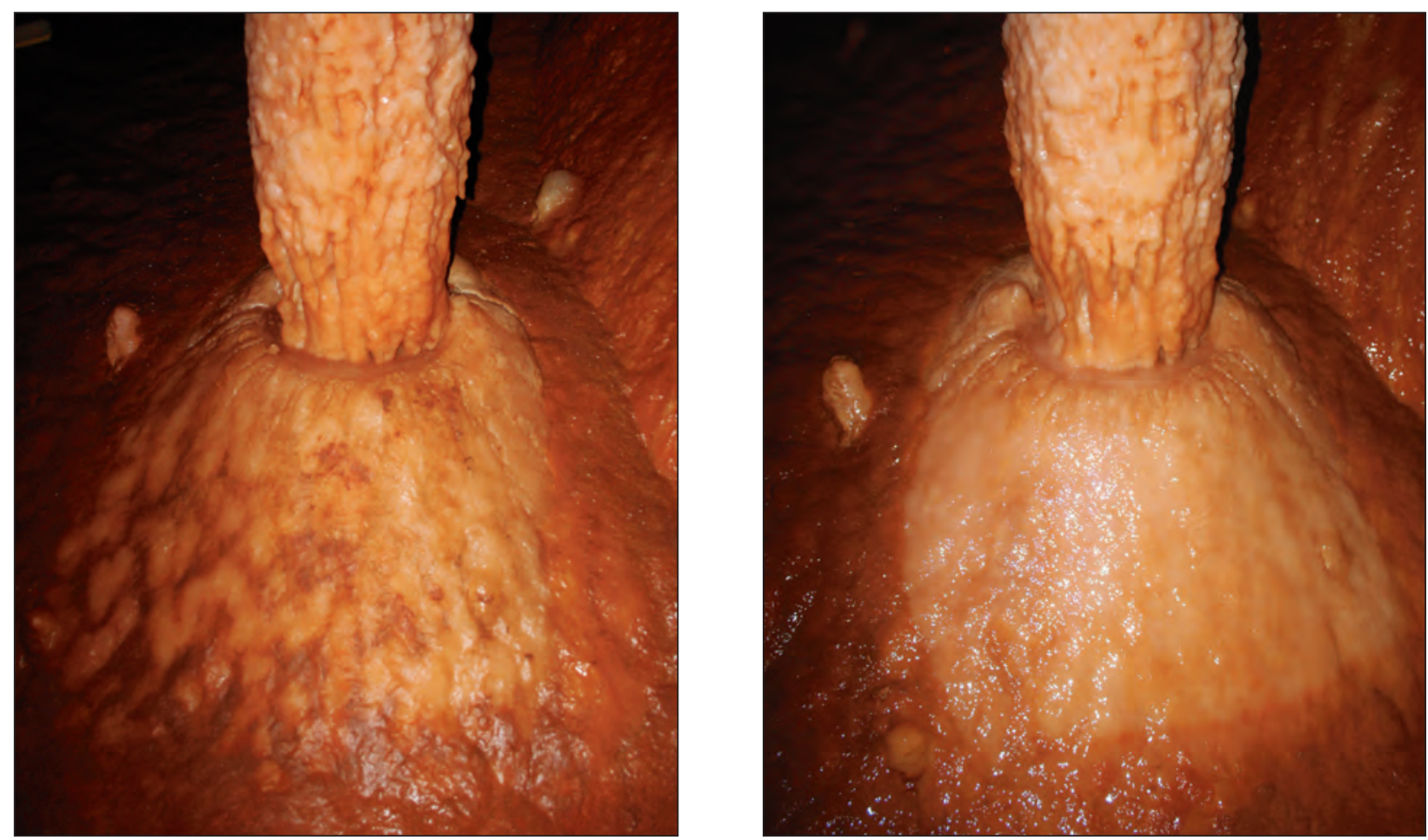


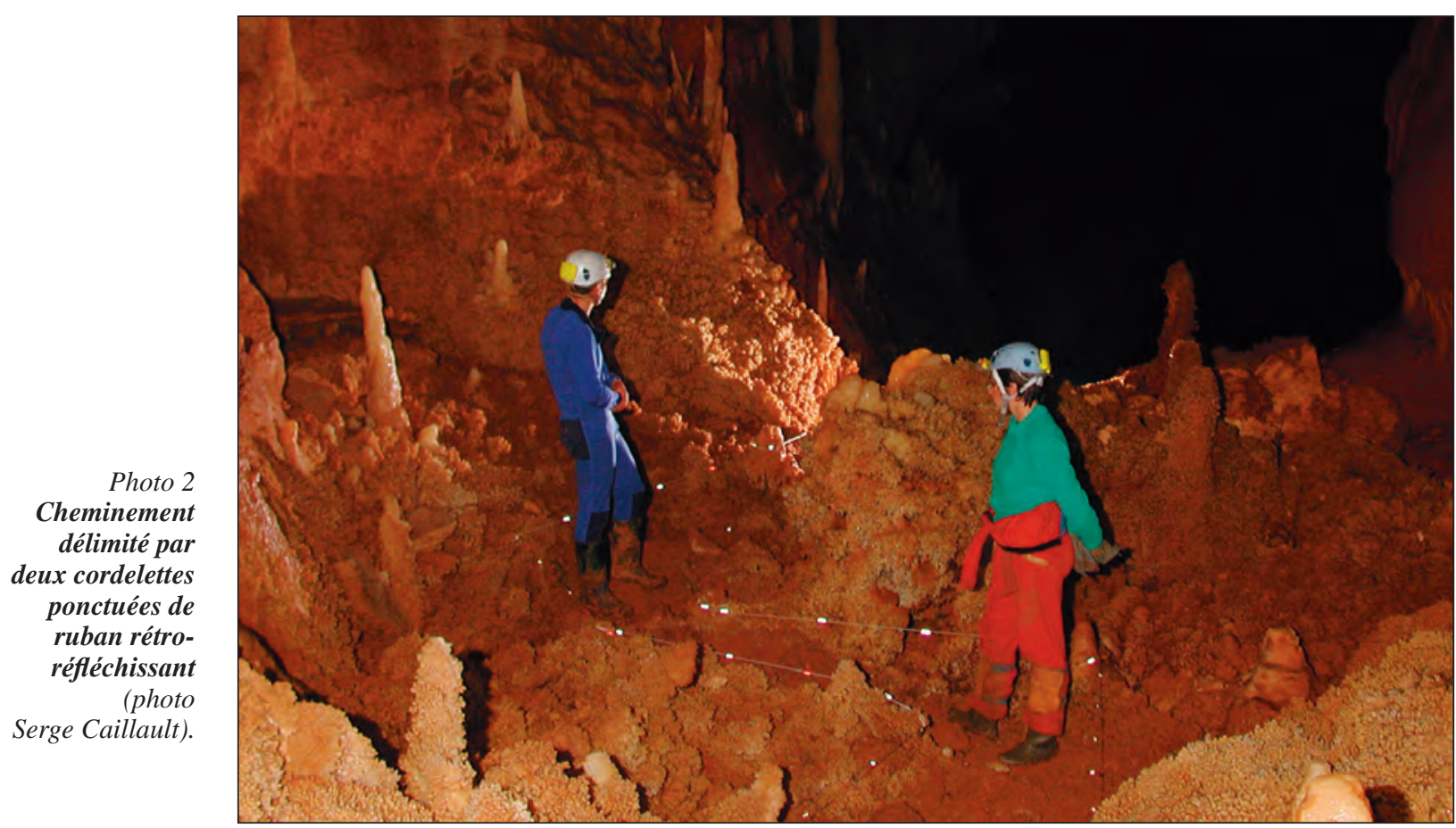

en cas d'accident, (iii) une ligne reliant à la partie touristique un capteur $\mathrm{CO}_{2}$ installé à la Chatière des Sables, afin d'en connaître la concentration dans les réseaux avant de partir avec un groupe.

En dernier lieu, un exercice secours testant l'évacuation d'une personne blessée depuis la Salle de l'Orfèvrerie a permis la signature de l'arrêté préfectoral du 12 avril 1999 qui autorise et réglemente l'accès aux réseaux d'Orgnac-Issirac.

Le nettoyage, l'organisation des visites et la mise en conformité des réseaux ayant été réalisés, les premières visites guidées ont débuté en juin 1999. Dès lors, une fréquentation relativement importante se met en place avec un public très divers. Si certains visiteurs sont des spéléos, pour $80 \%$ des visiteurs il s'agit de leur toute première approche du milieu souterrain. Il est de ce fait intéressant, à travers le discours de l'accompagnateur, de les sensibiliser aux fragilités particulières de ce milieu.

Entre le $1^{\text {er }}$ avril 1998 et le 15 septembre 2007, 1309 sorties ont été organisées permettant à 8587 personnes de pénétrer dans les réseaux.

Dans le cadre du suivi du syndicat, une réunion annuelle du comité scientifique ${ }^{1}$ a lieu sous la présidence de $\mathrm{M}$. le sous-préfet de Largentière. C'est l'occasion de dresser un bilan des activités du SIVU et de la fréquentation des

1 Le comité scientifique est composé notamment de représentants : de la Direction régionale de l'environnement Rhône-Alpes, de la Direction départementale de la jeunesse et des sports, du Laboratoire souterrain de Moulis, de Géologie Environnement Conseil, du Syndicat départemental d'incendie et de secours 07, du Comité départemental de spéléologie 07. réseaux. Une visite préalable par ces partenaires permet d'évaluer la qualité esthétique mais aussi la bonne conservation du site et l'impact des visites sur le milieu. Ce comité a le pouvoir, en fonction des constatations faites sur place, de faire des recommandations voire de réajuster le mode de fonctionnement du SIVU .

Le mode de gestion mis en place dans les réseaux d'Orgnac-Issirac par le SIVU est un des exemples possibles pour assurer la protection d'un réseau sur le long terme.

La partie d'accompagnement professionnel subvient aux besoins du poste de "guide-gardien » nécessaire au bon fonctionnement du SIVU et implique de fait les municipalités propriétaires quant à la valorisation de leur patrimoine. Il offre aussi l'énorme avantage de faire connaître à un plus grand nombre un milieu spécifique malheureusement peu ou mal connu du grand public. L'enthousiasme et la satisfaction des visiteurs sont autant d'encouragements pour persévérer dans cette voie.

Cette ouverture relative des réseaux n'a pu se faire qu'en s'appuyant sur l'expérience acquise au cours de dizaines d'années de pratique par des spéléos dans ce milieu fragile (comportement - techniques de balisage, de nettoyage, etc.). Elle a aussi contribué à dynamiser la recherche concernant le milieu souterrain.

Espérons qu'à l'avenir la recherche spéléologique et scientifique se développe encore car la preuve est faite dans cet ouvrage que ces connaissances acquises sous terre nous permettent de mieux comprendre l'environnement dans lequel nous vivons au quotidien. 


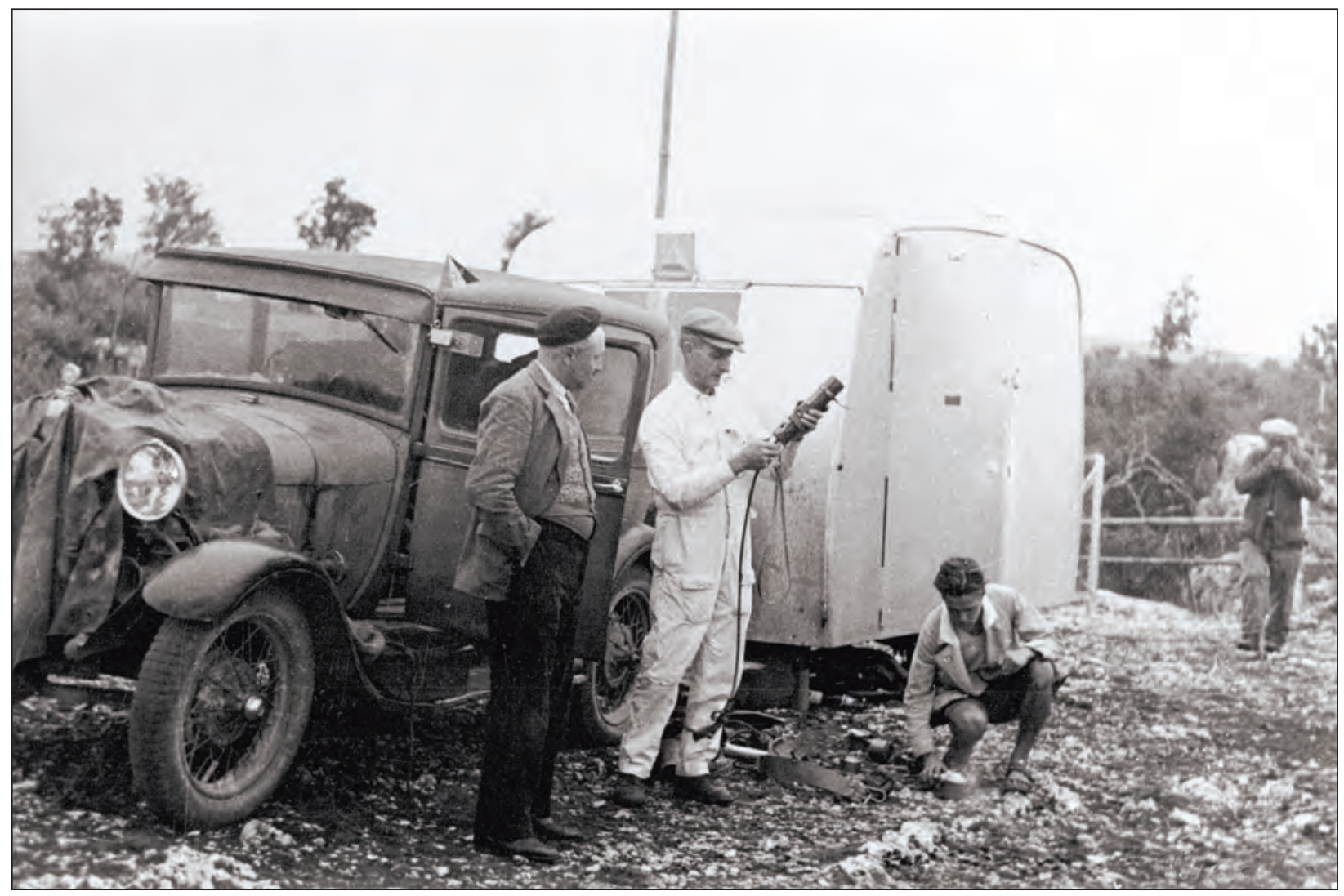

Photo 2

Robert de Joly avec sa voiture et sa caravane devant l'orifice de l'aven d'Orgnac (Archives Mairie d'Orgnac). 


\title{
L'AVEN D'ORGNAC
}

\section{UNE CAVERNE PRIVILÉGIÉE POUR L'ÉLABORATION DES CONNAISSANCES KARSTOLOGIQUES}

\author{
par Christophe GAUCHON ${ }^{1}$ et Françoise PRUD'HOMME ${ }^{2}$ \\ 1 Laboratoire EDYTEM - Université de Savoie \\ 2 Musée régional de Préhistoire - Orgnac-Grand Site de France - Orgnac-l'Aven
}

Dès la première exploration en 1935, Robert de Joly prit conscience et souligna le caractère tout à fait exceptionnel de l'aven d'Orgnac: sur le plan spéléologique, il s'agissait sans conteste de sa plus belle découverte. Sur le plan touristique, il entrevit aussitôt tout le parti que l'on devait en tirer. Et rapidement, il saisit également qu'il allait pouvoir multiplier les observations à caractère scientifique et peut-être progresser dans la compréhension du monde souterrain. En effet, les explorations spéléologiques qu'il menait depuis une dizaine d'années l'avaient amené à visiter de très nombreuses cavités, mais le plus souvent il faisait, dans les gouffres et les grottes qu'il explorait, des passages furtifs (photo 1) ; puis son automobile le conduisait aussitôt vers d'autres causses, vers d'autres canyons, vers d'autres cavernes où l'attendaient d'autres explorations...

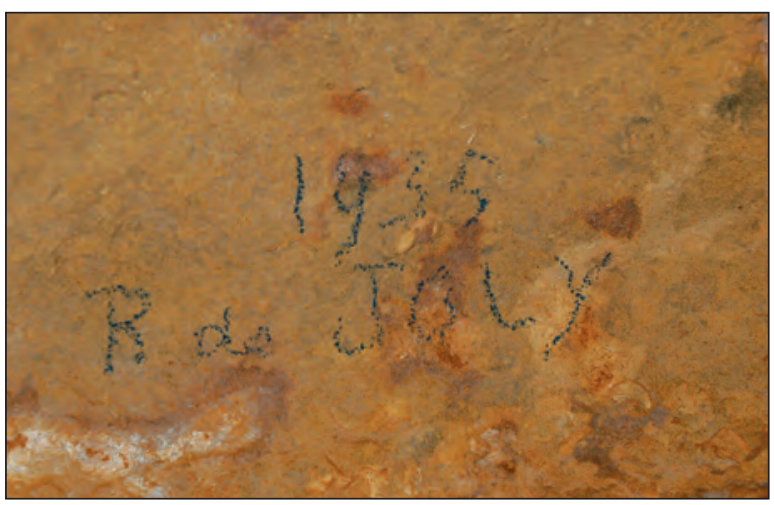

Photo 1

Griffe de Robert de Joly sur la paroi de l'une des cavités explorées en 1935.

L'aménagement touristique de l'aven d’Orgnac, la grande sollicitude dont il entourait « son » gouffre, la surveillance constante des travaux allaient amener De Joly à multiplier les descentes dans l'aven d'Orgnac, d'abord par l'orifice naturel, puis par le tunnel d'accès, et à acquérir une connaissance très fine de la cavité (photo 2). Plusieurs notes et articles témoignent de cet intérêt, de cette recherche qu'il mène, et qu'il anime aussi, dans les réseaux d'entrée et dans les Salles
Rouges. À partir du moment où l'aven est équipé, il devient beaucoup plus facile d'y travailler sur le plan pratique: l'éclairage électrique, les cheminements, la présence de personnel sont autant de commodités propres aux grottes touristiques qui simplifient le travail scientifique (Jaillet et Perrette, 2006), surtout lorsque l'on est à la fois l'inventeur de la cavité et le grand ordonnateur de l'aménagement! Les concrétions furent certainement le premier moteur de la curiosité et l'on verra que dès le début elles suscitèrent de nombreuses interrogations. Mais c'est aussi le gigantisme des salles et des galeries qui retinrent l'attention de De Joly et de ses compagnons d'exploration : si des cavités aussi richement ornées sont déjà très rares, de tels volumes sont inconnus dans les autres cavernes explorées à l'époque en Ardèche! Cette première phase du questionnement et de la recherche culmine avec le grand article que De Joly publie dans La Nature en 1947 (cf. infra).

Cependant, en 1965, la découverte des nouveaux réseaux par Jean Trébuchon et ses coéquipiers allait complètement renouveler cet intérêt : le développement de l'aven était multiplié par cinq ! De nouvelles salles, encore plus vastes et encore plus concrétionnées, reliées entre elles par d'imposantes galeries, succédaient aux réseaux reconnusen 1935 !Lesproblèmeskarstologiques posés par cette cavité hors-normes s'en trouvaient démultipliés, et la singularité de l'aven d'Orgnac dans les karsts ardéchois s'affirmait plus encore que par le passé. Si d'un côté l'accès à ces réseaux profonds devenait plus difficile pour les chercheurs, d'un autre ils ouvraient de nouvelles perspectives et de nouvelles opportunités ! Même lors des conflits qui opposèrent l'équipe Trébuchon et la mairie d'Orgnac, le volet scientifique ne fut pas oublié, et fut parfois invoqué au profit de telle ou telle partie : dans les annexes de La saga de l'aven d'Orgnac-Issirac (p. 203-211), on trouve deux rapports, malheureusement anonymes, datés de 1972 et 1973, qui tendent à prouver que l'argument scientifique pouvait aussi être utilisé à bon escient dans la grande polémique sur l'aménagement des «nouveaux réseaux ». Si le premier de ces deux rapports fait la liste des centres d'intérêt des réseaux 
et reste assez général, le second dresse les grandes lignes de ce qui pourrait être un programme d'études puis conclut à l'intérêt de l'ouverture d'un nouvel accès aux réseaux profonds. Parmi les avantages escomptés sont ainsi énumérées la «facilité d'accès permettant de plus amples études et explorations », ou la « facilité de transport de l'instrumentation de mesures ». Certes, à lire Jean Trébuchon, on n'a pas l'impression que la recherche scientifique ait toujours tenu le premier rang parmi les motivations de l'équipe qui découvrit les nouveaux réseaux d'Orgnac. Mais il est intéressant de constater que l'émulation entre les explorateurs se jouait aussi sur le terrain scientifique.

C'est cette histoire des recherches scientifiques que nous voulons retracer ici à grands traits, en essayant de montrer comment cette cavité phare de la spéléologie et du tourisme ardéchois fut aussi le lieu d'élaboration de nombreuses idées karstologiques, et parfois le théâtre d'innovations scientifiques majeures qui ont leur place dans la grande histoire de la karstologie. Trois thèmes émergent de la multitude des observations et constituent, aujourd'hui encore, la trame de l'interrogation scientifique sur l'aven d'Orgnac. À ce titre, les autres chapitres du présent recueil peuvent aussi être lus en les replaçant dans cette perspective d'histoire des sciences.

\section{I - LES CONCRÉTIONS D'ORGNAC}

Photographiées sous tous les angles, reproduites sur de multiples supports promotionnels, les grandes stalagmites d'Orgnac ont d'emblée marqué les explorateurs, puis les visiteurs privilégiés qui purent les admirer avant même l'ouverture de l'aven au public. Mais il ne s'agissait pas seulement d'une admiration béate, car Robert de Joly n'eut dès lors plus de cesse d'étudier et de comprendre ces concrétions exceptionnelles tant par leurs tailles que par leurs formes. Comment s'étaient-elles formées ? À quel rythme? Dans quelle mesure une connaissance plus précise des concrétions pouvait-elle contribuer à mieux comprendre la cavité elle-même ?

Bien sûr, les premières interrogations ne valaient que pour Orgnac I ; puis les nouveaux réseaux dévoilèrent des richesses inespérées, des formes plus variées encore et de nouveaux édifices aussi volumineux, sinon plus ! L'abondance du concrétionnement devint aux yeux des spéléologues la caractéristique la plus marquante de l'aven d'Orgnac. De multiples approches seront tentées, plus ou moins rigoureuses, plus ou moins techniques, et dès lors cet intérêt pour les concrétions d'Orgnac ne faiblira plus.

Dès les premières publications qu'il consacre à l'aven, Robert de Joly s'attacha à décrire les concrétions de la façon la plus précise qui soit, et ce souci du détail venait aussi étayer l'argumentaire sur les qualités esthétiques de l'aven: dès 1935, il livre ainsi de minutieuses descriptions des perles des cavernes, il en distingue plusieurs catégories selon que leur noyau est constitué d'un grain de quartz, d'une boulette d'argile ou d'un fragment d'os de chauve-souris. L'attention se porte également sur les impuretés ou les irrégularités visibles à la surface des grandes stalagmites, ainsi que sur les colorations de la calcite. L'année suivante, il mesure la hauteur de quelques édifices stalagmitiques et des voûtes, à l'aide de ballons-sonde à hydrogène (1936, p. 151). Bien sûr, il ne néglige pas non plus les excentriques dont il connaît la valeur esthétique, mais c'est surtout aux grandes stalagmites qu'il va se consacrer : il en sélectionne cinq en particulier, qui lui semblent porteuses du plus d'informations, à savoir « 3 dans la salle supérieure et 2 dans la salle basse », auxquelles il ajoute le Vaisseau fantôme, qu'il n'appelle pas encore ainsi (photo 3).

Mais il serait réducteur de s'en tenir aux seuls aspects descriptifs, et De Joly cherche aussi à préciser les modalités de formation des concrétions. Dès 1937, il rapproche la distribution des concrétions et la morphologie des voûtes, s'interrogeant sur la présence de stalactites en l'absence de fissures au plafond (1937, p. 30). Plus tard, dans le « Guide de l'aven d'Orgnac (Ardèche) », il pose le problème des conditions propices au concrétionnement ( $p .53)$, puis de l'alimentation des stalactites par le réseau fissural ( $p .55)$.

Dans le même temps, De Joly s'intéresse aussi aux concrétions parce qu'il pressent qu'elles peuvent l'aider à dater le réseau. Cette intuition est méritoire, car sur ce point, Martel avait été péremptoire : «il faut absolument renoncer à considérer [stalactites et stalagmites] comme pouvant le moins du monde fournir un argument chronologique en matière de préhistoire

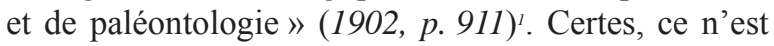
pas le seul point sur lequel De Joly s'est affranchi de l'enseignement du vieux maître mais, bien que dépourvu d'outils adaptés, il va prudemment chercher à explorer cette voie : "Quoique ne pouvant servir à lui donner un âge précis, par leur taille, on peut avoir un ordre de grandeur » (1935, p. 86-87).

L'idée est ici de se servir des stalagmites pour apprécier l'ancienneté de l'éboulis sur lequel elles reposent. Bien qu'il sache fort bien que « ces calculs n'ont aucune base sérieuse », De Joly part du volume approximatif des concrétions, leur applique une « loi de croissance » établie par les Américains donnant $16 \mathrm{~cm}^{3} / 100$ ans, et arrive à des âges compris entre 122000 et 300000 ans. Ces âges le confortent toutefois dans l'idée que la caverne est forcément très ancienne. L'ouverture de l'aven remonterait «au début du quaternaire » et peut-être même à des périodes plus reculées encore : " il semble bien que ce creusement [?] qui lui-même dura fort longtemps pour arriver à des salles de telles dimensions, doit être du Pliocène. » (idem).

$1 /$ Édouard-Alfred Martel (1902) - «Inaptitude des stalagmites à servir d'éléments chronologiques pour la préhistoire dans les cavernes ", Actes du congrès annuel de l'A.F.A.S., p. 908-911. 
Manifestement, ces approximations sur la base de modèles théoriques ne le satisfont pas et dès mars 1936, il rédige une « note pour la presse » (il y en aura plusieurs au fil des années) dans laquelle il explique que « des témoins de croissance de diverses concrétions furent posés. Quant à ceux installés trois mois avant, ils révélèrent, même sur de minuscules stalactites tubulaires extrêmement jeunes, que l'accroissement de longueur était nulle (sic). On reste donc confondu par le nombre de siècles qui fut nécessaire à l'édification de «monuments» de la grandeur de ceux dont il est question ci-dessus. Ces observations reculent singulièrement le Pliocène, que nos ancêtres virent probablement et partant l'humanité remonte encore dans la nuit des temps. " Cette conclusion est étonnante, d'abord parce qu'elle s'appuie sur une mesure qui n'a rien donné, ensuite parce que l'on y détecte une contorsion intellectuelle qui aboutit bizarrement à en tirer un enseignement sur l'âge de l'humanité, sans que l'on comprenne bien le lien entre les deux !

Il est toutefois assez difficile d' imaginer à quoi pouvaient exactement ressembler ces témoins de croissance que $\mathrm{R}$. de Joly continua à relever jusqu'à la fin de sa vie. Dans une lettre à Jean-Claude Duplessy, en date du 9 mars 1966, il peut avancer une première estimation : "Je vous montrerai mes "témoins de croissance" sur des stalagmites. Pour le moment je n'en ai retiré qu'un. Il a donné, pour la croissance en épaisseur d'une stalagmite de petite taille, $1 \mathrm{~mm}$ en 140 ans ! ». Cette approche expérimentale ne s'arrête d'ailleurs pas là :

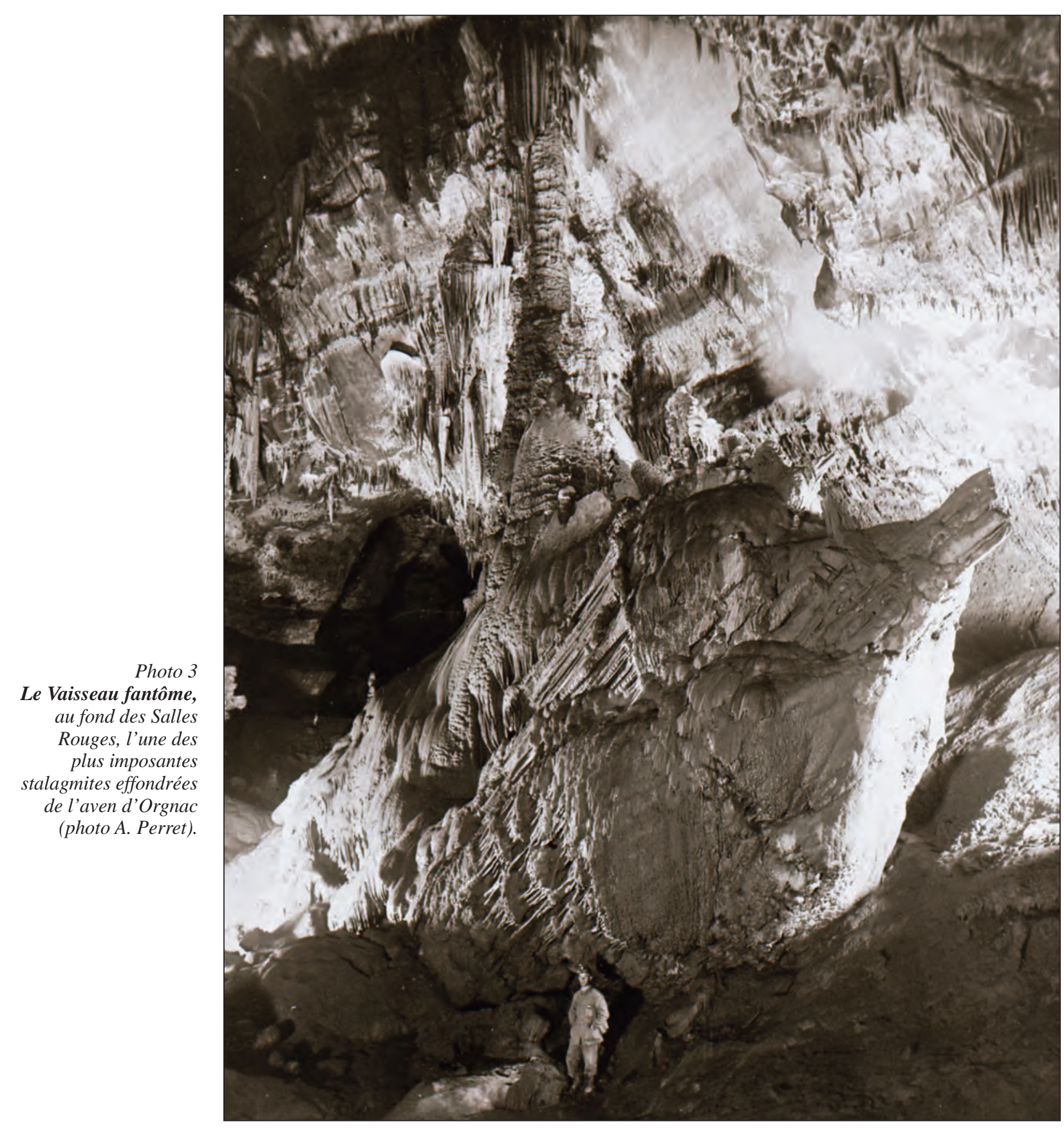




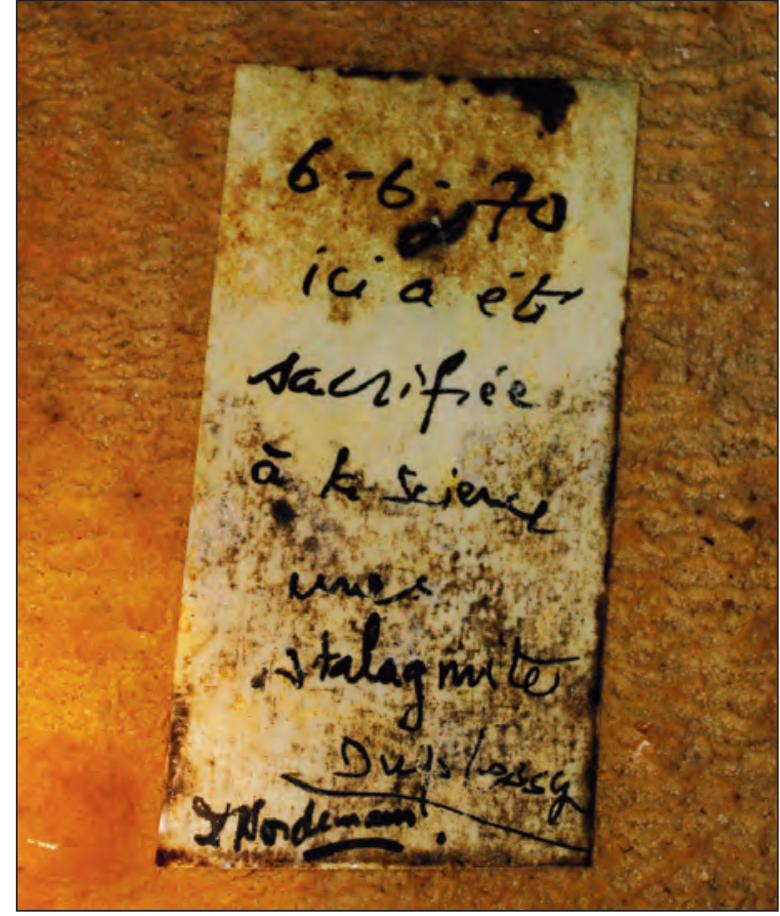

Photo 4

Étiquette retrouvée dans la Salle des Merveilles témoignant des premiers prélèvements de concrétions par Jean-Claude Duplessy et J. Nordemann (photo Stéphane Jaillet).

De Joly confie à Maurice Déribéré des échantillons de calcite venant de plusieurs grottes du midi languedocien, dont Orgnac. Après avoir observé les cassures sous microscope et réduit la calcite en poudre, M. Déribéré effectue des mesures de $\mathrm{pH}$, de fluorescence ou de thermoluminescence, sans que l'on sache réellement la finalité de ces manipulations. Mais M. Déribéré publie quand même ces «premiers résultats trouvés pour le cas, souhaitable, où d'autres chercheurs désireraient suivre cette voie qui peut être féconde » $(1937$, p. 16). Certaines mesures seront d'ailleurs complétées et publiées à nouveau dans le Guide de l'aven d'Orgnac (Ardèche), avec une nouvelle batterie de tests physicochimiques ( $p$. 63-67).

Si les travaux menés sous la houlette de De Joly n'avaient pas réellement fait progresser la connaissance des spéléothèmes, au moins avaient-ils réussi à attirer l'attention sur les stalagmites géantes d'Orgnac, et les nouvelles découvertes de 1965 confortent l'aven dans sa réputation. C'est peut-être sur la base de cette grande notoriété qu'une nouvelle phase dans l'étude des concrétions va débuter en 1966. Un jeune chercheur, Jean-Claude Duplessy, va en effet mener à bien une recherche doctorale presque entièrement fondée sur les stalagmites d'Orgnac. Le titre de sa thèse mérite déjà que l'on s'y arrête : Étude isotopique du concrétionnement de l'Aven d'Orgnac : application à la paléoclimatologie de la région Sud-Ardéchoise. En quelques mots se trouvent en effet rassemblés l'énoncé d'une méthode dont l'application au monde souterrain est alors tout à fait nouvelle (" étude isotopique ») ; l'hypothèse d'une relation entre les spéléothèmes, la cavité où ils se développent et le contexte régional; et enfin la proposition d'un objectif ambitieux mais appelé à une certaine fortune, l'application de ces travaux à la compréhension des climats anciens !

C'est sans doute la première fois qu'un programme aussi complet est affiché et que de tels moyens sont mis au service de l'étude des concrétions souterraines : les recherches de J.-Cl. Duplessy s'effectuent en effet au Centre des faibles radioactivités de Gif-sur-Yvette (CNRS) et au Service d'électronique physique du C.E.A. à Saclay.

À l'époque, les études isotopiques sont déjà entrées dans la panoplie utilisée par les physiciens, et elles ont déjà été mises au service des études paléo-climatologiques, mais surtout dans des contextes océaniques. L'idée est de trouver, en milieu continental, un support qui soit l'équivalent des coquillages ou des coraux : il faut alors montrer que les concrétions calcaires ont pu aussi fonctionner comme des enregistreurs pertinents pour «aborder la paléo-climatologie continentale » (p. 25). Car trois isotopes différents vont être dosés : le ${ }^{14} \mathrm{C}$ doit permettre de dater la formation des concrétions et de caler les variations de températures révélées par $1{ }^{18} \mathrm{O}$, tandis que le ${ }^{13} \mathrm{C}$ doit donner des indications sur «l'épaisseur d'humus au-dessus de la caverne (...) et l'ampleur du recou-vrement végétal aux différentes époques » (p.4). Comme ces dosages dépendent étroitement des conditions atmosphériques dans lesquelles la calcite s'est formée, J.-Cl. Duplessy délaisse les réseaux d'entrée dont la fréquentation touristique aura perturbé «les conditions physiques et biologiques » et effectue ses prélèvements dans «les salles nouvelles, de découverte récente » (p.13). Il attache aussi beaucoup d'importance au choix de la concrétion qu'il va prélever et jette son dévolu sur une stalagmite active de plus de deux mètres de haut et d'un diamètre régulier d'environ 10 centimètres (plus tard appelée stalagmite D) qu'il trouve dans Orgnac II : la datation par ${ }^{14} \mathrm{C}$ lui attribua un âge de 6480 ans \pm 200 , soit à peine plus qu'une autre stalagmite de 36 centimètres de haut prélevée dans la même salle (1967, p. 30). Pour la première fois, de véritables rythmes de croissance étaient donc proposés et montraient la vanité des «vitesses moyennes » dont il avait fallu se contenter jusque là.

Le dosage de $\mathrm{l}^{18} \mathrm{O}$ met en évidence, sur cette durée de 6000 ans, "une succession de périodes froides et chaudes » qui vérifie assez bien les données alors disponibles issues des observations liées à l'eustatisme et/ou à la croissance des coraux. Le dosage du ${ }^{13} \mathrm{C}$ apparaît plus complexe car les interactions entre évolution climatique, dynamique de la végétation, pédogenèse et fonctionnement propre de la stalagmite brouillent l'interprétation de la courbe obtenue. Malgré ces limites, J.-Cl. Duplessy conclut toutefois que la 
méthode peut être considérée comme riche de promesses et qu'elle pourra à l'avenir apporter des précisions fort utiles aux préhistoriens.

Contrairement à tant d'autres, la thèse de Jean-Claude Duplessy ne reste pas confidentielle et ses conclusions furent diffusées tant dans les milieux de la recherche fondamentale qu'auprès des spéléo-karstologues. Plusieurs articles parurent en effet entre 1969 et 1972 dans les Comptes rendus de l'Académie des Sciences, dans La Nature ou dans les Annales de Spéléologie afin de faire connaître les résultats obtenus sur la base des stalagmites prélevées dans Orgnac (photo 4). Au total, cinq grandes stalagmites de 163 à 370 centimètres de longueur furent prélevées en différents points des réseaux (1972, p. 458-459) : dans Orgnac II, dans Orgnac III, et même pour l'une d'entre elles au fin fond d'Orgnac IV! Les datations furent affinées et, dès 1969, l'utilisation de la méthode Uranium/Thorium permit d'obtenir sur la stalagmite Z, venue d'Orgnac IV, des âges jusqu'à 130000 ans BP (alors que les quatre autres échantillons ne remontaient pas au-delà de 10000 ans). Il est très significatif que l'aven d'Orgnac ait ainsi été le lieu où de telles recherches auront été initiées. Même si plus d'une vingtaine d'années s'écouleront avant que les chercheurs (D. Genty, Y. Perrette) ne se consacrent à nouveau à l'étude fine des concrétions, c'est bien à Orgnac que la voie avait été dressée, et c’est sans doute là que réside le principal apport de l'aven d'Orgnac à la karstologie physique.

\section{II - LA SPÉLÉOGENÈSE}

On a vu que, pour Robert de Joly, les concrétions étaient susceptibles de donner un certain nombre d'indications sur les conditions dans lesquelles l'aven d'Orgnac avait pu être creusé et sur la façon dont les formes s'étaient agencées. L'observation des parois avait en effet montré l'absence complète de traces d'érosion liée au passage de l'eau, les formes avaient été puissamment remaniées par les éboulements, par les remplissages argileux et par le concrétionnement. Ce premier constat permet déjà de penser que la cavité est fort ancienne et que «pendant des dizaines de millénaires » elle a évolué par colmatage argileux, par éboulement des voûtes et « report» du volume vers la surface. Seules les Salles Rouges (qu'il ne nomme pas ainsi) seraient originelles : on remarque « dans le plafond et les parois de la dernière salle des baumes de corrosion » (1935, p. 85).

De Joly ajoute que le creusement s'est probablement fait vers le sud, compte tenu du pendage, mais il remarque aussi qu' "à l'époque où l'eau passait par l'aven, le canyon [de la Cèze] n'existait pas, ou n'était obligatoirement pas si profond qu'à l'heure actuelle. Où allaient ces eaux ? Nous ne saurions le dire, car un problème hydrologique délicat est soulevé par Orgnac » (idem, p. 86). Le problème qui vaut pour la genèse de l'aven vaut aussi pour son fonctionnement actuel, nous y reviendrons.

Mais plus de dix ans passeront encore avant que Robert de Joly produise sur le sujet une véritable synthèse, dans un assez long article intitulé : "Hypothèse sur la formation de l'aven d'Orgnac (Ardèche) » (1947). Peutêtre avait-il fallu toutes ces années pour comprendre que la spéléogenèse de l'aven d'Orgnac était sans doute le sujet le plus important, peut-être plus que les concrétions.

D'emblée, De Joly dit très clairement que le creusement de l'aven d'Orgnac a mis en œuvre plusieurs processus qui se sont succédé sur le temps long: «Orgnac a pour origine l'érosion, et ce n'est que par la suite que certaines modifications accidentelles lui donnèrent son aspect actuel » (p. 209). L'érosion, la corrosion, le comblement et l'effondrement ont chacun joué leur rôle, ne s'appliquant pas en tous lieux au même moment. Cette histoire complexe fait alterner toute une série de temps longs et de phases d'évolution soudaine, illustrées par une série de sept croquis explicatifs (figure 1).

De Joly fait donc remonter le début du creusement de l'aven d'Orgnac au Pliocène, soit $3 \mathrm{Ma}$, « et peutêtre même avant la transgression de la mer Miocène » (idem). Mais le schéma qui accompagne cette hypothèse hardie est plus prudent et illustre plutôt un début de creusement au Pliocène sous couverture miocène avant qu'elle ne soit décapée. À ce stade, il s'agit du creusement par des eaux d'infiltration depuis la surface qui aurait été 50 à 100 mètres plus élevée qu'aujourd'hui. Cette surface s'est ensuite abaissée au fur et à mesure du déblaiement de la couverture, d'où inversion du relief: «ce qui est vallon maintenant était probablement colline » (p. 210). Sur ces phases anciennes de la première karstification, de Joly ne donne guère d'arguments, et procède plutôt par reconstitution à partir de l'actuel.

Il suppose qu'ensuite l'eau, rassemblée dans les fissures, « forait progressivement un chenal de plus en plus vaste sous terre » (idem), ce qui pose logiquement la question du bassin d'alimentation; mais il ne revient pas sur cette dimension du problème et avance simplement que la Baume de Ronze devait en faire partie et constituer « un regard sur le réseau d'Orgnac » mais sans trancher sur le sens de circulation, même s'il note en incise que « la rivière d'Orgnac n'était qu'un affluent de la Cèze (d'après nos observations) » (p. 210-212)...

À partir du Pliocène se succèdent donc plusieurs phases d'éboulements liés à des épisodes sismiques, de remblaiement, de décolmatage, de concrétionnement qui finiront par donner au réseau l'aspect que nous lui connaissons. Le principal problème que rencontre De Joly, c'est que, mis à part le volcanisme du Vivarais avec lequel il met en relation l'activité sismique supposée, lui font complètement défaut les éléments paléogéographiques qui permettraient d'expliquer ces différents épisodes... Il procède donc en rétablissant une chronologie relative fondée sur des observations 
Figure 1

Les sept phases de l'évolution de l'aven d'Orgnac selon Robert de Joly, 1947 (dessin Émile Dujardin-Weber).
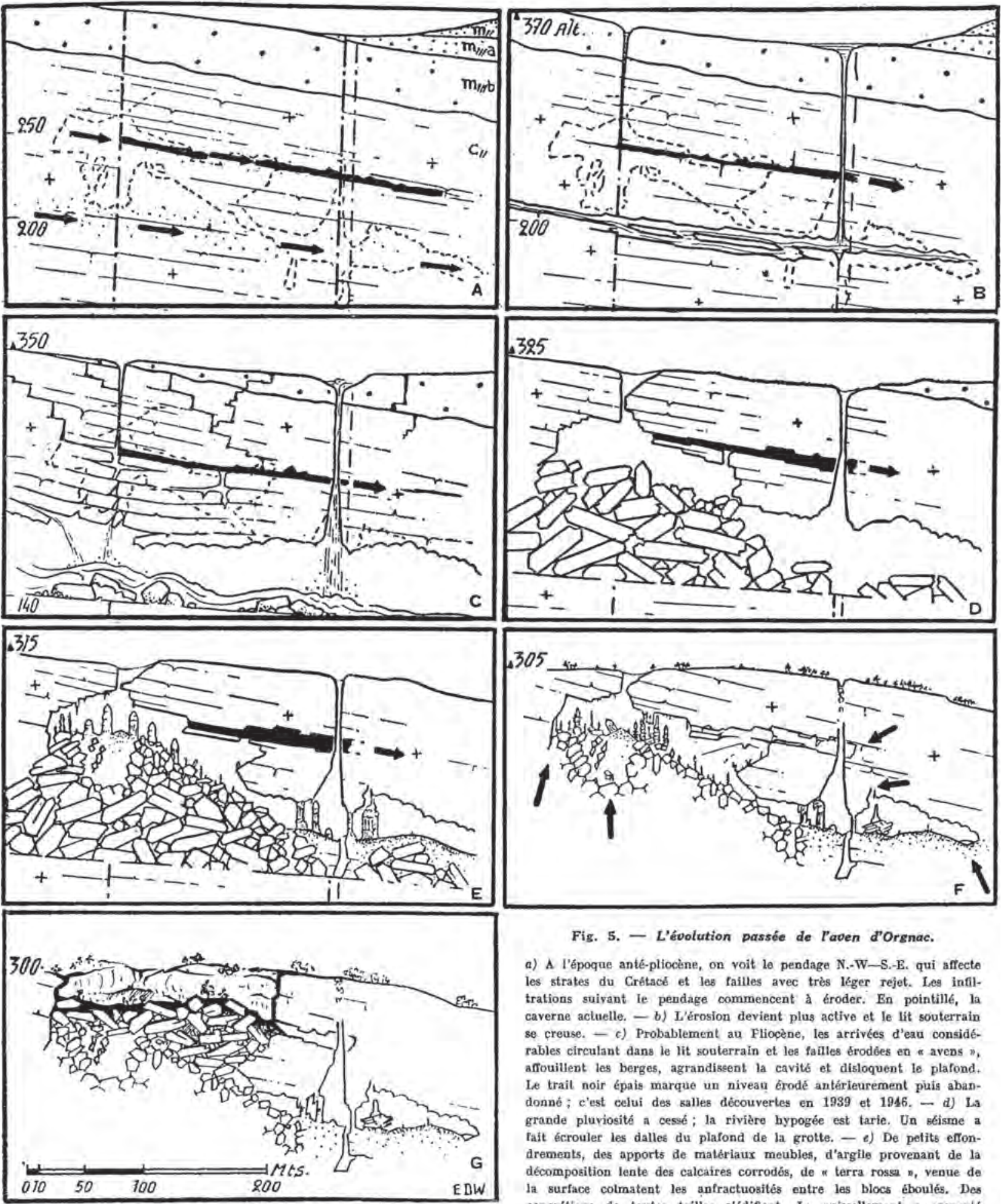

Fig. 5. - L'évolution passée de Paven d'Orgnac.

a) A l'époque anté-pliocène, on voit le pendage N.-W-S.-E. qui affecte les strates du Crátacé et les failles avec très léger rejet. Les infiltrations suivant ie pendage commencent à éroder. En pointillé, la caverne actuelle. - b) L'érosion devient plus active et le lit souterrain se creuse. - c) Probablement au Fliocène, les arrivées d'eau considérables circulant dans le lit souterrain et les failles érodóes en o avens ", affouillent les berges, agrandiseent la cavité et disloquent le plafond. Le trail noir épais marqque un niveau érodé antérieurement puis abasdonné ; c'est celui des salles découvertes en 1939 et $1916 .-$ d) Ls grande pluviosité a cessé ; la rivière hypogée est tarie. Un séisme a falt écrouler les dalles du plafond de la grotte. - e) De petits eflondrements, des apports de matériaux meubles, d'argile provenant de la décomposition lente des calcaires corrodés, de "terra rossa n, venue de la surface colmatent les anfractuosités entre les blocs éboulés. Des concrétions de toutes tailles s'édifient. Le ruissellement a emportí is manteau miocène superficiel. - $f$ ) Un' nouveau séisme a abattu les concrétions, sauf celles soudées au plafond. Les stalagmites actuelles s'ealtient, dont les plus grosses sont penchées, brisées ou renversées; là plus grosse (a droite en e et $f$ a été renversée et supporte une nouvelle conerétion, surmontée par une chape stalagmitique débordant sur les oôtés, C'est l'état actuel. - g) Plus tard, le plafond de la salle supérieure s'effondrera; une a doline a naftra, puis la terre et l'humus s'y formeront, la végétation $\mathrm{y}$ apparaitra et seules resteront les salles basses $(-140 \mathrm{~m})$ protégées par leur épais plafosd. 
précises associant le concrétionnement et les éboulis, il intègre dans sa réflexion des arguments paléontologiques qui nous surprennent parfois et étaye ainsi sa conclusion : " du même coup, les conditions d'établissement de cette cavité reculent dans le temps, nous venons d'en voir les différentes phases qui, toutes, nécessitaient de longues périodes, c'est-à-dire que le nombre de millions d'années dont il a été question au début de cet exposé n'a rien d'improbable » ( $p$. 213).

À une époque où beaucoup croient encore à l'exclusivité de la karstification quaternaire, c'est certainement cette chronologie longue qu'il a su percevoir, qui fait à ses yeux toute la valeur scientifique de l'aven d'Orgnac : «Le fait de pouvoir surprendre la succession des phénomènes est tellement rare qu'il méritait qu'on y attirât l'attention » (p. 214). D'autant plus que De Joly prolonge son scénario d'évolution sur l'avenir d'Orgnac. À la question: «Que deviendra l'aven d'Orgnac ?», il revient sur la Baume de Ronze (photo 5) dont il comprend qu'elle préfigure le futur aven d'Orgnac... Et quand il évoque ses «espérances », le spéléologue d'exploration rejoint l'observateur scientifique: les découvertes ultérieures qu'il escompte bien réaliser lui livreront, il en est sûr, l'accès à « des salles encore inconnues, à des couloirs qui nous permettront de parfaire notre étude » (p. 214).

Près de vingt ans plus tard, Philippe Renault soutient sa thèse de géologie sur les mécanismes de la spéléogenèse. Si De Joly avait surtout montré la complexité et le caractère polygénique de la mise en place des réseaux, $\mathrm{Ph}$. Renault va proposer un schéma général capable de rendre compte de cette complexité et intégrant la découverte des nouveaux réseaux. Sans doute la très grande majorité des exemples qu'il traite sont-ils choisis plutôt dans les Causses du Quercy, et les grottes d'Ardèche ne jouent qu'un rôle assez ténu dans la construction de sa pensée. Dès 1958, alors qu'il ne connaissait pas encore Orgnac et que les nouveaux réseaux n'avaient pas encore été découverts, $\mathrm{Ph}$. Renault avait proposé, dans un article modestement intitulé Éléments de spéléomorphologie karstique, le mécanisme de «creusement par le haut», qu'il appellera plus tard «paragénétisme». En 1967, la dernière partie de sa thèse est consacrée au rôle des «facteurs sédimentologiques" dans le creusement des cavernes et c'est alors qu'il se saisit de l'exemple d'Orgnac, présenté comme la caverne qui illustre de la façon la plus spectaculaire le bien fondé de cette approche. Même s'il semble qu'à ce moment-là, il n'ait fait qu'une seule excursion dans l'aven, sous la conduite de J.-Ch. Trébuchon qu'il remercie, et même s'il ne consacre que quelques lignes à la description des réseaux ( $p$. 581-582), la grande dimension des conduits et l'accumulation d'argile révélée par les soutirages correspondaient exactement au modèle proposé dix ans plus tôt et dont il avait pressenti toute la complexité lorsqu’il écrivait : « la question de ces larges galeries à remplissage épais est encore très mal connue »

Baume de Ronze, carte postale du début du XXe siècle (collection Philippe Mathon).

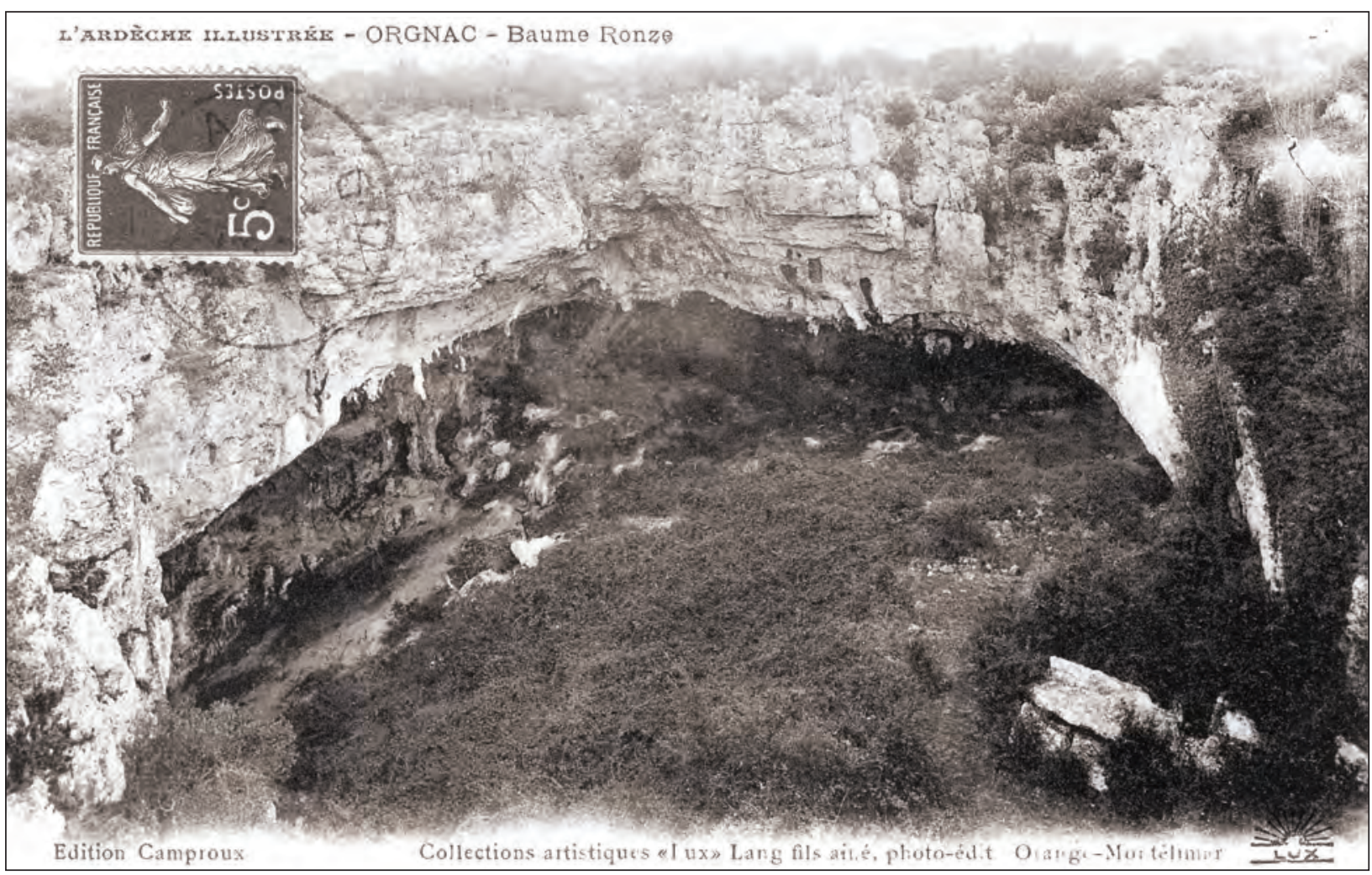


(1958, p. 39)2. Si l'exemple est fameux, il faut croire qu'il n'est pas indispensable à la démonstration : dans le « Que Sais-Je ? » qu'il consacre deux ans plus tard à « La formation des cavernes $»^{3}$, Ph. Renault ne revient pas une seule fois sur le cas de l'aven d'Orgnac. Il sera pourtant dès lors admis que les galeries d'Orgnac constituent le parangon du creusement paragénétique.

Ce n'est d'ailleurs pas sur ce point que Bernard Gèze revient lorsque, quelques années plus tard, il écrit à son tour sur la genèse du réseau d'Orgnac. Dans les années 1930, il avait fait partie des compagnons

2 / Philippe Renault (1958) - "Éléments de spéléomorphologie karstique », Annales de Spéléologie, $t$. XIII, $n^{\circ}$ 1-4, p. 23-48.

3 / Philippe Renault (1970) - La formation des cavernes, PUF, Que Sais-Je? n' 1400, 128 p. d'exploration de Robert de Joly, et il avait acquis une bonne connaissance de l'aven. Au début des années 1970 , le voilà qui s'intéresse plus précisément aux relations entre les formes de surface et le karst profond. Un premier article est publié en 1971 dans lequel il repose le problème « de l'inversion de relief pour les vallées karstiques », mais sans développer l'exemple d'Orgnac. On se souvient que De Joly avait déjà exprimé une réflexion analogue, et peut-être étaitelle liée à une discussion avec Bernard Gèze. Quoi qu'il en soit, ce dernier revient bientôt sur le sujet et précise ses vues (1975, p. 201-202) : il relève d'abord que l'aven d'Orgnac se développe juste sous «la ligne de crête », ce qui est interpelle légitimement sa curiosité. Un schéma de belle facture, consistant en

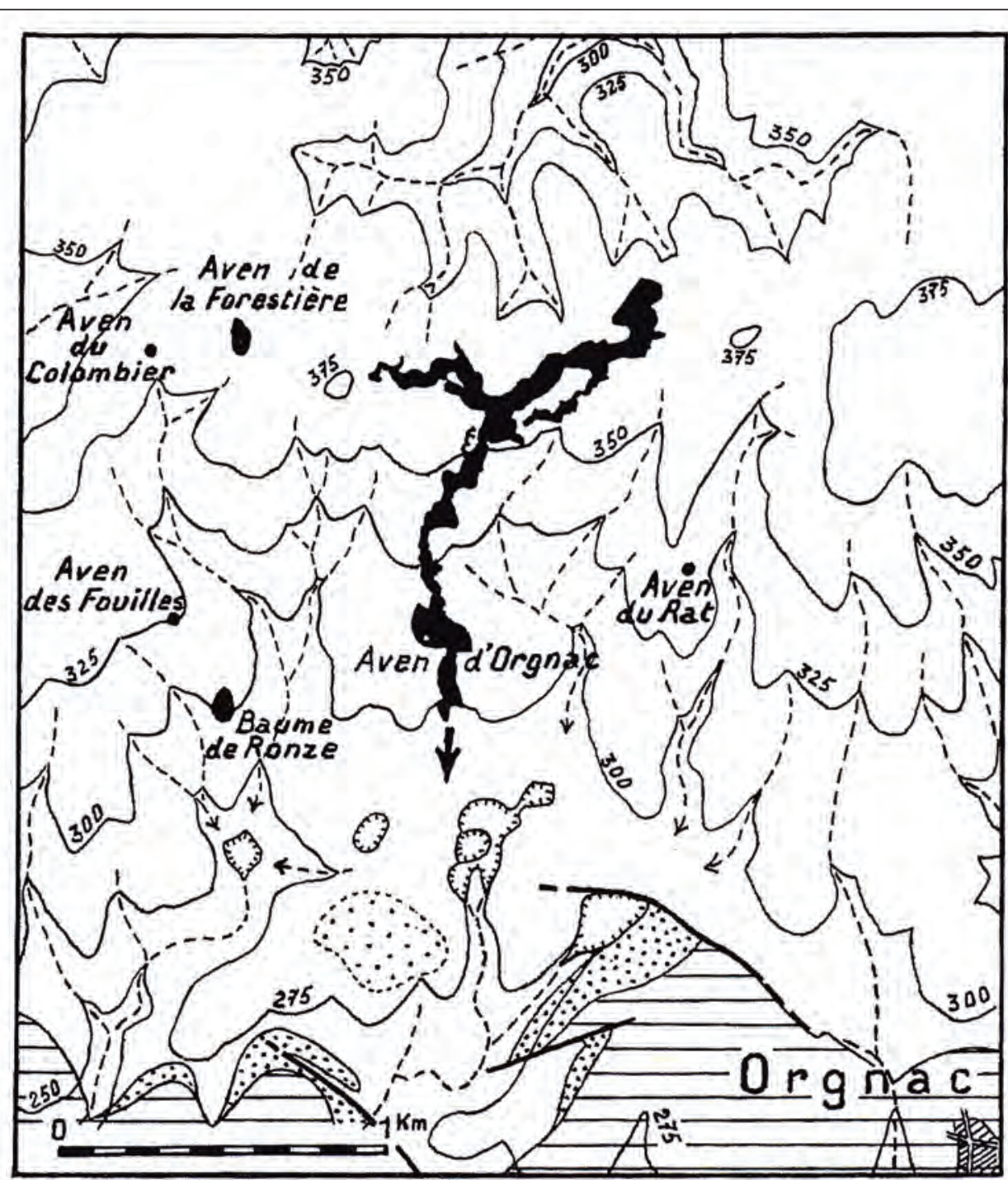

FIG. 5. - Le réseau de l'aven d'Orgnac et son cadre géographique. Equidistance des courbes de niveau : 25 mètres. Vallées sèches en traits discontinus. En blanc: calcaires urgoniens; en pointillé : sables et argiles continentaux éocènes (?) - le pointillé lâche, à contour peu défini, correspond à cette formation sous forme résiduelle empâtant irrégulièrement l'Urgonien; en tireté : calcaires lacustres oligocènes. Plan de l'aven d'Orgnac d'après J. Trébuchon (1967), géologie d'après levés originaux de B. Gèze (1968).
Figure 2

L'aven d'Orgnac

rapporté à la topographie de surface

(shéma Bernard Gèze). 
un report de surface du plan d'Orgnac sur une carte topographique et géologique, étaye d'ailleurs cette observation (figure 2). Une flèche épaisse dirigée vers le sud, qui n'est pas expliquée en légende, suggère un sens d'écoulement qui semble ne faire aucun doute pour B. Gèze.

Pour lui, l'inversion du relief est postérieure au creusement des grands réseaux dans la mesure où les écoulements souterrains limitent l'érosion en surface alors que les reliefs encadrants sont ravinés par les torrents et se retrouvent bientôt en position basse. Dans le cas d’Orgnac, les réseaux ont été ensuite désertés par les écoulements descendus plus en profondeur, et $B$. Gèze rejoint ici R. de Joly dans l'hypothèse d'une karstification ancienne qui remonte probablement au Tertiaire.

On voit que cette hypothèse, qui découle de la notion ancienne d'immunité karstique, présente surtout l'avantage de rendre compte de la présence en ces lieux d'un réseau que l'on serait bien en peine d'expliquer dans les conditions actuelles. Yann Callot prit d'ailleurs ses distances avec ce schéma d'évolution, « difficilement réalisable en l'absence de toute structure permettant cette inversion » $(1979, p$. 322). Il suggère plutôt que des avens type Orgnac ont pu s'ouvrir dans d'autres positions, mais que seuls ceux qui s'ouvraient sur les crêtes se sont maintenus ouverts, à l'abri des phénomènes péri-glaciaires.

Dans tous les cas, on voit aussi combien cette question de la spéléogenèse est liée à celle de l'organisation des écoulements. Tel est le troisième grand problème qu'Orgnac pose aux chercheurs, et peut-être le plus épineux.

\section{III - LES CIRCULATIONS, L'HYDROGÉOLOGIE DE L'AVEN D'ORGNAC}

La difficulté de cette question tient avant tout à la quasi-absence des circulations d'eau dans Orgnac, sauf épisodes exceptionnels. Le problème se pose sur deux plans : les circulations qui ont creusé la cavité - et l'on revient alors la question de la spéléogenèse ; et le fonctionnement actuel, qui est d'autant plus difficile à apprécier que l'aven s'ouvre sur la charnière du grand anticlinal Ardèche-Cèze et que les indications de la structure peuvent être interprétées de façon très divergente... ou avec beaucoup de prudence. Ainsi, lorsque R. de Joly annonçait des développements sur l'«hydrologie de l'aven d'Orgnac» (1936, p. 85), il s'intéressait surtout aux courants qui ont creusé la cavité...

Dans la «note pour la presse» de 1936, De Joly explique qu'il est retourné dans l'aven voir si les «pluies exceptionnelles » de l'hiver avaient commis des dommages ; tel n'est pas le cas, et De Joly conclut que c'est assez logique, sans quoi, au fil du temps, il n'y aurait plus la moindre concrétion dans Orgnac, et que c'est plutôt rassurant pour les futures visites touristiques.

Par des détours inattendus, cette indécision qui pèse sur l'hydrogéologie d'Orgnac s'est d'abord présentée par l'intermédiaire de la biospéléologie: lors des premières explorations, R.de Joly et B. Gèze avaient en effet effectué quelques observations éthologiques (par exemple De Joly, 1936, p. 150-151) et ils avaient posé des pièges et capturé de nombreux insectes. Confiés à René Jeannel pour détermination, ces Diaprysius allaient poser à leur façon le problème de l'interfluve Cèze-Ardèche. Plus tard, Jeannel devait expliquer que les Diaprysius étaient propres aux Cévennes car, au Plaisancien, les Cévennes avaient été isolées à la fois des Alpes et des Pyrénées par de grands golfes marins (1943, p. 213)4. À une échelle plus fine, il ajoutait que « les Diaprysius, comme la plupart des Bathysciinae, sont distribués par vallées » $(1936, p$. 65). C'est dire que la répartition des insectes troglobies peut donner de précieuses informations sur l'organisation des systèmes karstiques, et éventuellement sur leur cloisonnement. Or, les Diaprysius récoltés dans Orgnac, s’ils constituent deux nouvelles sous-espèces, sont rattachés l'un au Diaprysius serullazi peyerimhoffi identifié dans les cavités qui bordent la rive droite de l'Ardèche, l'autre au Diaprysius mazaurici caractéristique de la vallée de la Cèze. Et Jeannel est fort surpris car « de toutes les grottes actuellement connues des Cévennes où vivent des Diaprysius, l'aven d'Orgnac est la seule où deux espèces distinctes cohabitent » (figure 3). Malgré tous les problèmes biologiques que pose cette cohabitation, ce «double peuplement de l'aven d'Orgnac» lui paraît «facilement explicable » : « il est naturel que les deux lignées aient pu se rencontrer dans le massif $\mathrm{du}$ bois de Ronze, dont le drainage souterrain se fait

$4 /$ René Jeannel, 1943 - Les fossiles vivants des cavernes, Gallimard, $321 \mathrm{p}$.

Figure 3

Les deux espèces de Diaprysius détectées dans l'aven d'Orgnac (dessin Jean Balazuc).

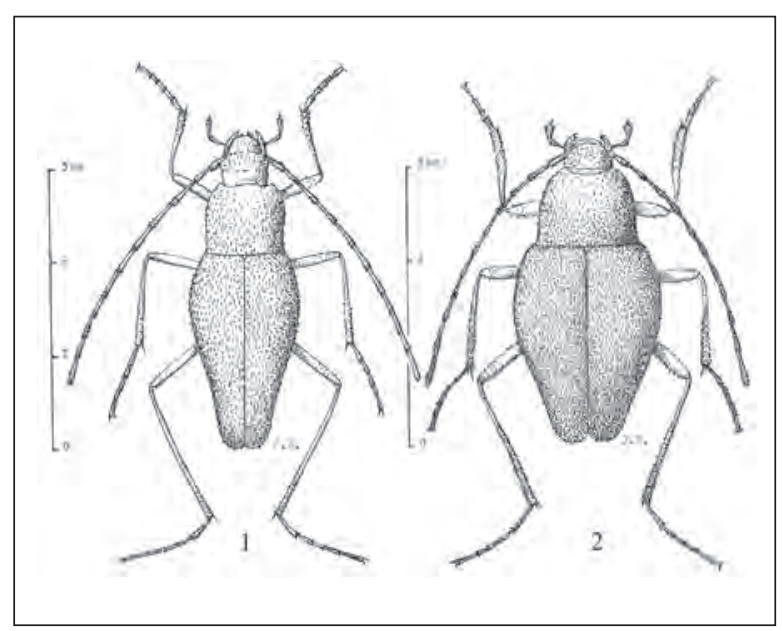


certainement des deux côtés » (idem). L'argument est logique, mais il ne s'appuie malheureusement que sur une position de principe... Ajoutons qu'en 1982, le Groupe de Recherches en Biospéléologie se saisira à nouveau de la question des Diaprysius, cherchant à vérifier les déterminations jadis opérées par Jeannel ; leurs conclusions seront plus prudentes, estimant que « le nombre de critères observé est trop différent pour définir deux espèces distinctes, le mélange est trop intime » (Slama, p. 3).

Dans sa thèse d'hydrogéologie soutenue en 1985, Luc Belleville fait le point sur les opérations de traçage et de délimitation des bassins versants (Première partie, chapitre 4), mais il bute alors sur ce qu'il appelle le «problème méridional » : entre les bassins d'alimentation dûment identifiés de l'Ardèche au nord et de la Cèze au sud demeure une zone incertaine de $27 \mathrm{~km}^{2}$ dont Belleville ne parvient pas à déterminer si elle est drainée dans une direction ou dans l'autre. L'absence de circulation dans l'aven d'Orgnac rend toute opération de traçage fort difficile à mener.

Il faudra finalement attendre les toutes dernières années pour préciser les conditions de drainage des réseaux d'Orgnac. On touche ici aux limites de l'observation in situ et des méthodes de terrain mises en œuvre par les spéléo-karstologues : lorsque des crues exceptionnelles remplirent le fond des Salles Rouges (par exemple en septembre 2002), l'occasion de procéder à un traçage fut manquée. C'est alors que le laboratoire de Moulis va instrumenter les différents forages du plateau, et établir de façon très nette que la nappe, qui affleure à faible profondeur sous le fond des réseaux, s'écoule en direction du sud, c'est-à-dire en direction des sources de Monteil.

\section{Conclusion \\ UNE RECHERCHE MARQUÉE PAR DES PHASES CONTRASTÉES}

Certainement l'évocation de ces trois grandes questions que sont le concrétionnement, la spéléogenèse et l'hydrogéologie de l'aven d'Orgnac n'épuisent-elles pas le sujet. Même en y ajoutant les observations biospéléologiques ou paléontologiques, il s'en faut encore de beaucoup avant d'atteindre l'exhaustivité. Les études en matière de climatologie souterraine que l'on trouvera dans le présent volume complètent d'ailleurs ce large spectre, sans pour autant l'épuiser. Il faudrait aussi évoquer, dans le domaine de la «parakarstologie », les expériences de radiesthésie menées par Bernard Gèze : armé de deux baguettes métalliques coudées, celui-ci s'efforça de suivre en surface le tracé

Figure 4

L'aven d'Orgnac se trouve au centre de la zone de $27 \mathrm{~km} 2$ dont le drainage n'est pas encore établi vers l'Ardèche ou vers la Cèze (Belleville 1985).

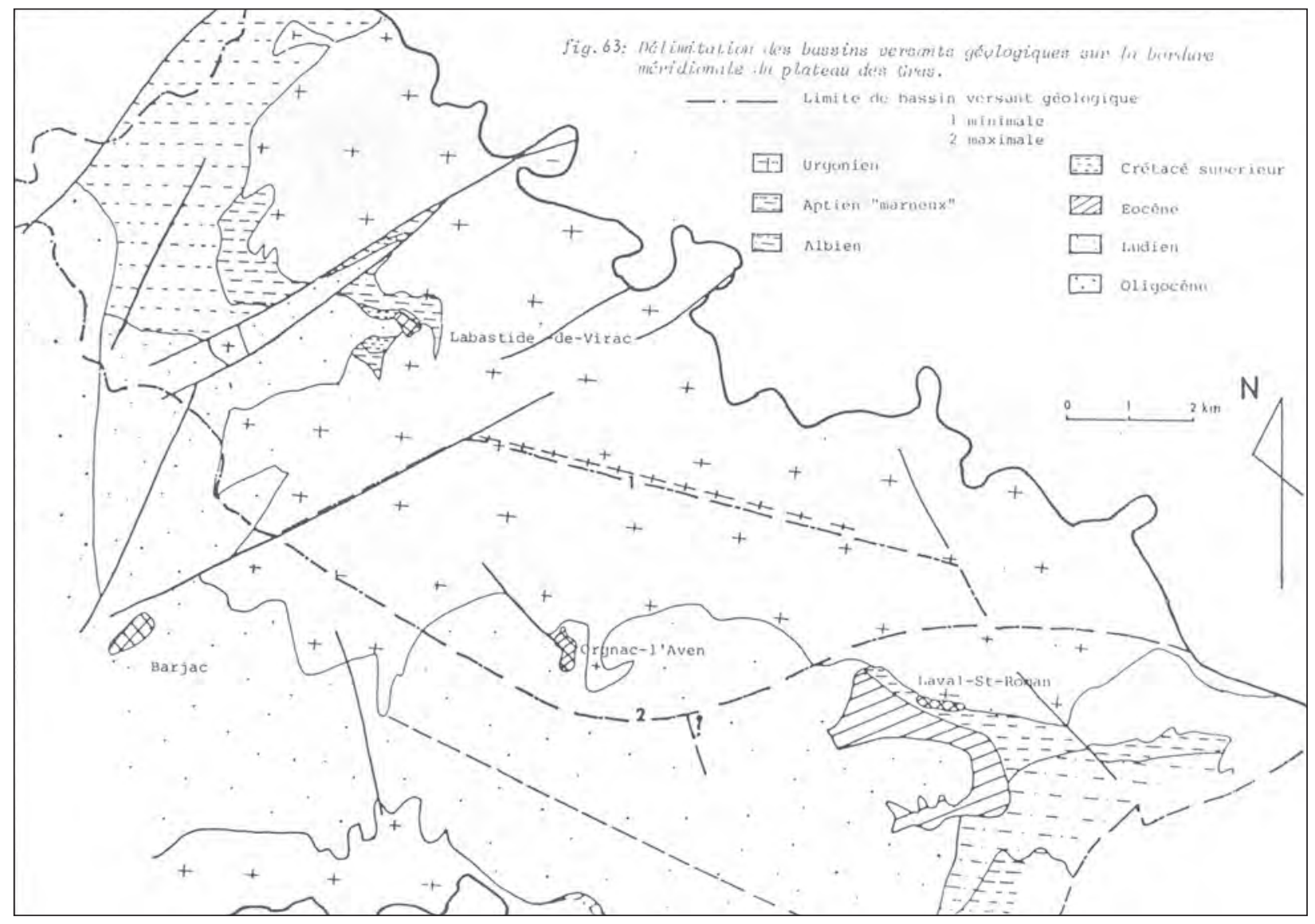


des galeries et des salles et, selon ses dires, y réussit pas mal (1990, p. 25-28). Certes l'expérience ne satisfaisaitelle guère aux règles de la zététique (ou science du doute) : B. Gèze n'était-il pas à la fois explorateur et fin connaisseur du réseau, concepteur de l'expérience, opérateur, démonstrateur et rédacteur du compte rendu, sans que s'exerce aucun contrôle extérieur? Mais les grands volumes d’Orgnac, associés ici à ceux de Padirac et de l'aven Armand, avaient encore une fois exercé leur pouvoir d'attraction et s'étaient imposés comme des lieux d'expérimentation inégalables.

L'approche thématique que nous avons choisie ne doit pas non plus nous faire croire que l'aven d'Orgnac a fait l'objet d'investigations scientifiques ininterrompues tout au long des soixante-dix années qui se sont écoulées depuis sa découverte... Là aussi, des temps forts et des pauses se sont succédé, selon une chronologie propre à l'histoire mouvementée de l'aven. Ils nous faut donc distinguer au moins trois périodes assez tranchées :

1 - Jusqu'à la fin des années 1960, beaucoup de recherches auront pu être menées dans l'aven d'Orgnac. Cette période est dominée par la figure de Robert de Joly : s'il n'est pas réellement un scientifique, il multiplie les observations dans l'aven et tente de les synthétiser, ce qui l'amène à publier sur Orgnac plus que sur aucune autre cavité. Certainement, Robert de Joly a-t-il noué avec Orgnac un lien tout à fait particulier, mais peut-être aussi a-t-il caressé l'idée que l'investigation scientifique viendrait renforcer la notoriété de l'aven et concourir à sa valorisation touristique. Ainsi accueille-t-il avec d'autant plus de satisfaction la découverte entomologique authentifiée par René Jeannel que l'un des deux Diaprysius identifiés a été baptisé du doux nom de Diaprysius serullazi jolyi - l'autre recevant en partage le nom de Diaprysius gezei (De Joly, 1935, p. 92).

Son activité se déploie dans de multiples directions : à plusieurs reprises, il collecte des vestiges paléontologiques de faune froide dans la salle d'entrée ou dans les interstices de l'éboulis (par ex. 1937, p. 30). En 1937, il entreprend aussi de baguer des rhinolophes (idem). Dans une note non datée, il prépare un argumentaire à l'attention des guides pour qu'ils soient en mesure de répondre aux questions des visiteurs, ce qui montre bien le lien entre les observations qu'il effectuait dans l'aven et ses préoccupations touristiques. On y lit par exemple, rédigé à la manière d'un catéchisme :

« - Pourquoi certaines stalagmites ont-elles l'extrémité coudée?

- À cause du déplacement régulier dans une direction donnée du trou d'alimentation du plafond ».

Sans doute une lecture attentive des nombreux écrits que De Joly a consacrés à Orgnac révèle les énormes difficultés qu'il eut à mettre en cohérence ses multiples observations, à les replacer dans un schéma d'évolution des karsts du sud de l'Ardèche, car il manquait à la fois de cadre épistémologique, d'outils et de repères. Mais De Joly a certainement eu à cour de faire de l'aven d'Orgnac sinon un véritable laboratoire, du moins un lieu de production scientifique (photo 6): il prélève ainsi différents échantillons de calcite ou d'argile qu'il confie à des chimistes ou à des pédologues (Guide de l'aven d'Orgnac, p. 64-69), il sollicite de nombreux spécialistes qui ne sont pas forcément liés au monde de la spéléologie.

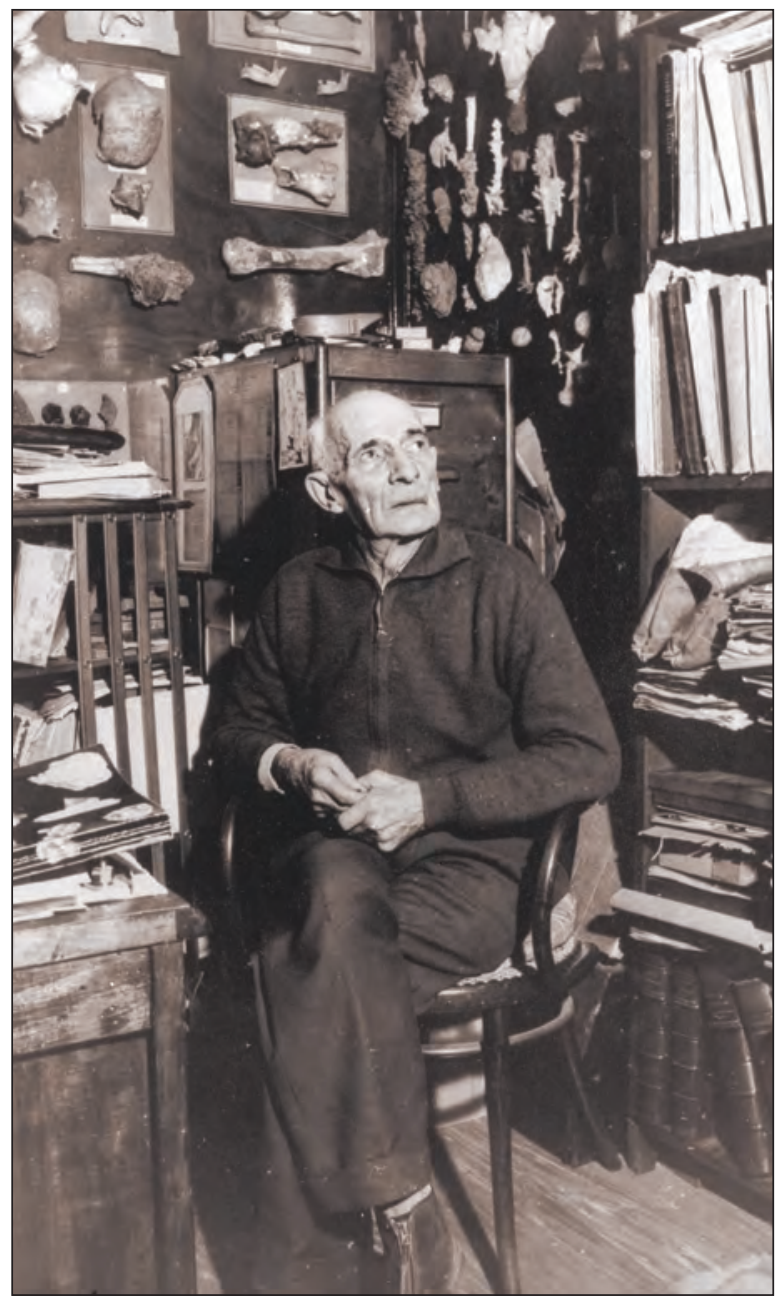

Photo 6

Le bureau de Robert de Joly dans sa maison d'Orgnac-l'Aven.

On trouve ainsi dans les archives de la commune d'Orgnac-l'Aven un intéressant échange de lettres entre J.-Cl. Duplessy et R. de Joly : le 4 mars 1966, le premier choisissait de s'adresser au vieux spéléologue pour lui demander l'autorisation de prélever des concrétions dans l'aven. Paraissant tout ravi de la demande et de pouvoir y satisfaire, Robert de Joly lui réservait cinq jours plus tard une réponse favorable, lui promettant une concrétion «au moins dix fois » plus vieille que celle que cherchait J.-Cl. Duplessy ! Comme ce dernier travaillait sous la direction de J. Labeyrie qui avait aussi été un spéléologue actif 
dans les années 1950, R. de Joly entrevoyait que la production scientifique qui découlerait de ce prélèvement vaudrait à l'aven une nouvelle notoriété dans le monde de la recherche... De même, Philippe Renault, oint de la double onction scientifique et spéléologique, eut accès aux réseaux où il conduisit des études de géomorphologie et de climatologie souterraine. Ainsi, jusqu'à la fin de sa vie, Robert de Joly continua-t-il à encourager les recherches qui souhaitaient se dérouler dans Orgnac.

2 - À l'opposé de la période précédente, les années 1970-1980 et le début des années 1990 se caractérisent par un blocage, sinon complet, du moins très net des recherches dans l'aven. La disparition de Robert de Joly en 1968 et les conflits qui se nouent autour de l'aven d'Orgnac à partir de la découverte des nouveaux réseaux se conjuguent en effet pour rendre beaucoup plus compliquée la poursuite des recherches scientifiques. Les querelles entre la municipalité de l'époque et «l'équipe Trébuchon » aboutissent à la fermeture sélective des réseaux, et plusieurs chercheurs sont dès lors empêchés de mener des investigations in situ. Certes, $\mathrm{Ph}$. Renault continue à fréquenter les réseaux et, les 13 et 14 juin 1972, il conduit une expertise pour le compte de la mairie qui l'a mandaté pour contrer les projets d'aménagement d'Orgnac IV (rapport inédit, 1972). Il s'agit là probablement de la première étude d'impact, fût-elle sommaire et orientée, préalable à l'aménagement touristique d'une cavité !

Mais il n'en va pas de même des autres chercheurs qui ne peuvent pénétrer dans les réseaux, et c'est sans doute la thèse de Yann Callot (1979) qui en porte le plus la marque : alors que ce travail sur les karsts des plateaux ardéchois est très fouillé et envisage autant les formes de surface que les phénomènes souterrains, l'auteur avoue ses lacunes sur l'aven d'Orgnac dont il n'a pu visiter que la partie touristique qui «n'est pas significative du reste du réseau » : c'est pourquoi « la description [de l'aven] sera sommaire, car il ne nous a jamais été permis de visiter cette cavité dont l'accès était rigoureusement interdit par la municipalité » ( $p .195)$. Dans une thèse de 384 pages, il n'y a donc que trois pages consacrées à Orgnac, et Y. Callot est obligé de s'appuyer sur les travaux antérieurs de $\mathrm{Ph}$. Renault, de J.-Cl. Duplessy ou de B. Gèze, sans pouvoir apporter la moindre observation nouvelle. On ne peut d'ailleurs que le regretter car cela aurait pu éclairer d'un jour nouveau la compréhension de la spéléogenèse.

Quelques années plus tard, Éric Gilli est confronté aux mêmes difficultés lorsqu'il effectue sa recherche sur les grands volumes souterrains : s'il lui est loisible de travailler dans la Salle de Joly et d'en proposer de nouvelles topographies $(1984$, t. 1, p. 77-80 et t. 2, p. 62-65), il ne peut travailler ni dans la Salle Plane ni dans la Salle des Treize, ce qui le prive de toute possibilité de comparaison intéressante au sein d'une même cavité.
À la même époque, mais dans un autre domaine, Pierre Slama explique qu'il lui a fallu un an et demi de discussions pour obtenir l'aval des « autorités » municipales (le maire d'Orgnac) et scientifiques (René Ginet, professeur de biospéléologie à Lyon) et pour aller échantillonner en 1982 des Diaprysius dans Orgnac II. Les scientifiques ont alors autant de peine à rentrer dans Orgnac que les autres spéléologues. Le prestige d'Orgnac se double d'un mystère qu'alimente la frustration du monde spéléo.

3 - Depuis le milieu des années 1990, le contexte qui entoure la préparation puis la réalisation et le suivi de l'Opération Grand Site a complètement changé la donne. La collaboration entre la mairie d'Orgnac, propriétaire exploitant du site, et les autorités de tutelle, à savoir la Direction régionale de l'environnement, s'est traduite, entre autres, par le lancement et la poursuite d'un programme de recherches multi-disciplinaires dont le présent volume constitue l'un des fruits. Sans doute cette décrispation salutaire doit-elle beaucoup au temps qui, en passant, avait permis à quelques blessures vives de se refermer peu à peu : le changement de génération chez tous les acteurs de cette petite scène permettait de repartir sur de nouvelles bases. D'un point de vue plus factuel, les projets de réaménagement de l'aven qui émergent à ce moment nécessitent l'acquisition de connaissances plus précises sur la climatologie souterraine et sur les facteurs qui commandent le renouvellement de l'atmosphère. De fil en aiguille, la DIREN et la mairie d'Orgnac conviennent que c'est aussi le rôle d'un Grand Site de France, protégé au titre de la loi et candidat à l'inscription sur la liste du Patrimoine de l'humanité, que de concourir à une meilleure connaissance du milieu karstique. Ainsi, et contrairement à ce que l'on constate parfois ailleurs, la protection réglementaire et la valorisation scientifique du site vont ici de pair : le classement fonctionne alors comme un moteur de la recherche, et celle-ci en retour met en lumière et précise les caractéristiques qui ont valu à l'aven d'être classé.

L'histoire des investigations scientifiques dans l'aven d'Orgnac illustre, après une trajectoire accidentée, une synergie finalement vertueuse, mais assez rare, entre tourisme, protection des paysages karstiques et recherche scientifique. Puisse cette synergie faire encore sentir longtemps ses effets !
Remerciements à Jean-Claude Duplessy et à Henri-Pierre Aberlenc pour les informations qu'ils nous ont transmises au cours de cette étude, à la commune d'Orgnac-l'Aven pour la mise à disposition des archives municipales et de celles de Robert de Joly, à Claude Lamoureux, Christian Bayle et Louis Berger pour les photos d'exploration des réseaux ainsi qu'à Philippe Mathon pour le prêt de cartes postales anciennes. 


\title{
BIBLIOGRAPHIE SCIENTIFIQUE SUR L'AVEN D'ORGNAC
}

\section{par ordre chronologique}

\author{
par Françoise PRUD’HOMME
}

Joly R. DE (1935) - Notes préliminaires sur l'aven d'Orgnac. Spelunca $\mathrm{n}^{\circ} 4,1935,78-91$.

Joly R. DE (1935) - Compte-rendu des explorations. 19 août : aven de Bertras. Spelunca nº, 1935, 76.

JoLy R. DE (1935) - Comment fut découverte une des plus belles cavernes d'Europe : l'aven d'Orgnac. La Nature, Paris, n²967, 1935, 529-533.

Joly R. DE (1935) - Un nouvel attrait pour l'Ardèche: l'exploration du plus bel aven du monde à Orgnac. Revue du Vivarais, t.42, n¹1-12, 1935, 226-228.

Jeannel R. (1936) - Deux nouveaux Diaprysius de l'Ardèche et remarques sur l'isolement des Bathysciinae des cavernes. Revue française d'entomologie, n³, 62-66.

Joly R. DE (1936) - Compte-rendu des explorations. 26 août : aven d'Orgnac. Spelunca n $7,1936,150-151$.

DÉRIBÉRÉ M. (1937) - Sur quelques perles des cavernes. Spelunca ${ }^{\circ} 8,1937,16-19$.

DÉRIBÉRÉ M. (1937) - Contrôle du pH des eaux et argiles à l'aven d'Orgnac. Spelunca nº, 1937, 24-25.

Joly R. DE (1937) - Compte-rendu des explorations.1937 : 31 mars au 4 avril, 27 juillet et 13 au 16 août : aven d'Orgnac. Spelunca n $8,1937,30$.

GLORY A. (1937) - Au pays du grand silence noir. Explorations souterraines. Éditions alsacia, 1937, 272 p.

Joly R. DE (1939) - Notes et observations d'un spéléologue, Bulletin de la Société Préhistorique Française, $\mathrm{n}^{\circ} 5$, 1939, 9-10
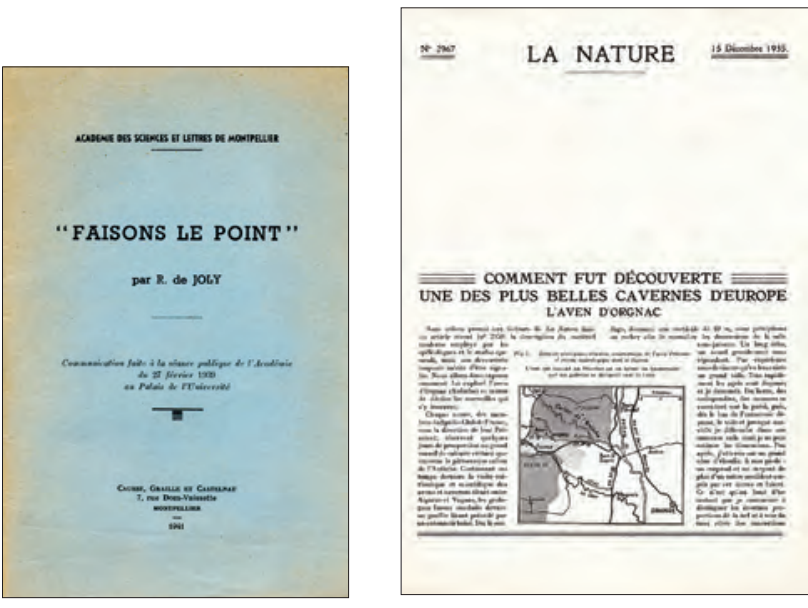

Joly R. DE (1941) - Faisons le point, communication scéance publique de l'académie du 27 février 1939. Académie des Sciences et Lettres de Montpellier, 1941.

JoLy R. DE (1946) - Guide de l'aven d'Orgnac. Édition Atelier Henri Péladan., Uzès, 1946, 72 p.

Joly R. DE (1946) - Ma découverte de l'aven d'Orgnac. Tourisme et travail, $\mathrm{n}^{\circ} 10$, Paris, 1946, 8-9.

Joly R. DE (1947) - Hypothèse sur la formation de l'aven d'Orgnac. La Nature, n³139, 1947, 209-214.

JoLY R. DE (1947) - Spéléologie : résultats récents obtenus à l'aven d'Orgnac. Le Monde Souterrain, n44, 1947.

Mire P. DE (1947) - À propos de la cohabitation de deux espèces du genre Diaprysius (Col. Sylphidae) dans l'aven d'Orgnac (Ardèche). D. Gezzi Jeannel et D. Serrulazi, s. sp. Jolyi Jeannel. Misc. entomol. $\mathrm{n}^{\circ} 44,62 / 63$

Balsan L. (1948) - L'aven d'Orgnac. Causses et Cévennes, revue du Club Cévenol, t.7, 1948, 291-293.

Joly R. DE (1948) - Les merveilles de l'aven d'Orgnac. Grottes et Gouffres. Bulletin du Spéléo-Club de Paris, $\mathrm{n}^{\circ} 2,1948,10-11$.

Joly R. DE (1948) - Nos belles régions ; l'aven d'Orgnac. Le Glacier français, ${ }^{\circ}{ }^{\circ}$, Paris, 1948, 30-33.

DÉribÉRÉ M. (1949) - La science de la spéléologie et la course aux abîmes. Le Monde Souterrain, n51, 1949, 159-160.

Joly R. DE (1949) - Travaux dans l'Ardèche et le Gard : Aven d'Orgnac. Annales de Spéléologie, T.4, fasc.3, 1949, 12-13. 
JoLY R. DE (1949) - Une belle grotte française. Scienza e lavoro, ${ }^{\circ} 12$, 1949, 8 fig., 5 ph., 228-232.

JoLy R. DE (1950) - L'aven d'Orgnac. Rassegna Speleologica Italiana Como, 2, fasc.1-2, 1950, 63-75.

BALAzuC J. (1956) - Spéléologie du département de l'Ardèche. Rassegna Speleologica Italiana Como, Mem. II, 1956,

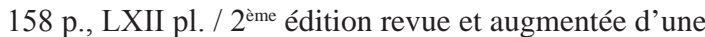
bibliographie additive par P. Drouin et A.-C. Gros, Éd. de la Bouquinerie ardéchoise, 1985, 189 p., LXII pl.

Joly R. De, Muxart R.et Lavancher L. (1962) - Prospections dans l'aven d'Orgnac (Ardèche). Spelunca n4, 1962, $10-11$

Blanc, J.-J. (1964) - Recherches sur les sédiments argileux des grottes dans le Sud-Est de la France. Bulletin du Musée d'Anthropologie préhistorique de Monaco, $n^{\circ} 11,5-36$.

TRÉBUCHON J.-C. (1965) - Du nouveau à l'aven d'Orgnac (Ardèche). Spelunca n4, 1965, 25-26.

TRÉBuChON J.-C. (1966) - L'aven d'Orgnac, 30 ans après. Spéléos, Valence, n52, 1966, 37-39.

Duplessy J.-C. (1967) - Étude isotopique du concrétionnement de l'aven d'Orgnac. Application à la paléoclimatologie de la région sud-ardéchoise, Thèse $3^{\text {ème }}$ cycle, Paris, $1967,45 \mathrm{p}$.

Labeyrie J., Duplessy J.-C. Delibrias G. et Letolle R. (1967) Étude des températures des climats anciens par la mesure de l'oxygène- 18 , du carbone- 13 et du carbone 14 dans les concrétions des cavernes. In Radioactive dating and methods of low-level counting (Intern. Atomic Energy Agency, Vienne), 153-160, 1967.

Gèze B., Moinereau J. (1967) - Sur l'évolution des sédiments argileux dans les cavernes en fonction de la profondeur. Actes du VII ${ }^{\circ}$ Congrès National Spéléologie, Bordeaux, 1966, Spelunca Mémoire n5, 1967, 58-62.
TréBuchon J.-C. (1967) - Le nouvel Orgnac. Spéléos, Valence, $\mathrm{n}^{\circ} 56,1967,26-27$.

TréBuchon J.-C. (1967) - Le nouveau réseau de l'aven d'Orgnac (Ardèche). Spelunca n¹, 1967, 7-18.

Joly R. DE (1968) - Une grotte extraordinaire: l'aven d’Orgnac. L'électron, Bruxelles, n²2, 1968, 37-44.

Joly R. de, Parrot R. (1968) - Le nouvel Orgnac. Causses et Cévennes, revue du Club cévenol, Paris, t.11, n³, 1968, 208-211.

LINGER G. (1968) - Impression d'Orgnac. Lapiaz, bulletin du CDS de l'Aisne, St-Quentin, n², 1968, n.p.

TRÉBUChON J.-C. (1968) - Orgnac (réseau III). c. r. d'activité du CSGA de Vallon, Spelunca n², 1968, p. 54

Pittard J.-J. (1968) - Une stalagmite peut être un remarquable enregistreur thermique. Les Bоиeux, bull. section de Genève de la Société suisse de spéléologie, 1968, 17-18.

Duplessy J.-C et al. (1969) - Étude des conditions de concrétionnement dans les grottes au moyen des isotopes stables de l'oxygène et du carbone. C.R. de l'Académie des Sciences de Paris, t.268, 2327/2330 -12 mai 1969.

Renault P. (1969) - Contribution à l'étude des actions mécaniques et sédimentologiques dans la spéléogénèse, Thèse, Annales de Spéléologie 22/1, 1967, 5-21 ; 22/2, 1967, 209-267 ; 23/1, 1968, 259-307 ; 23/3, 1968, $529-596$ et $581-582 ; 24 / 2,1969,317-337$.

Duplessy J.-C et al. (1970) - Continental climatic variations between 130.000 and 90.000 years B.P. Nature, vol.226, may 1970 .

Mazelier R. (1971) - Contribution à l'étude géologique et hydrogéologique des terrains crétacés du Bas-Vivarais. Le karst de la région d'Orgnac. Thèse Doct. Spéc. Univ. Montpellier,1971, 86 p.
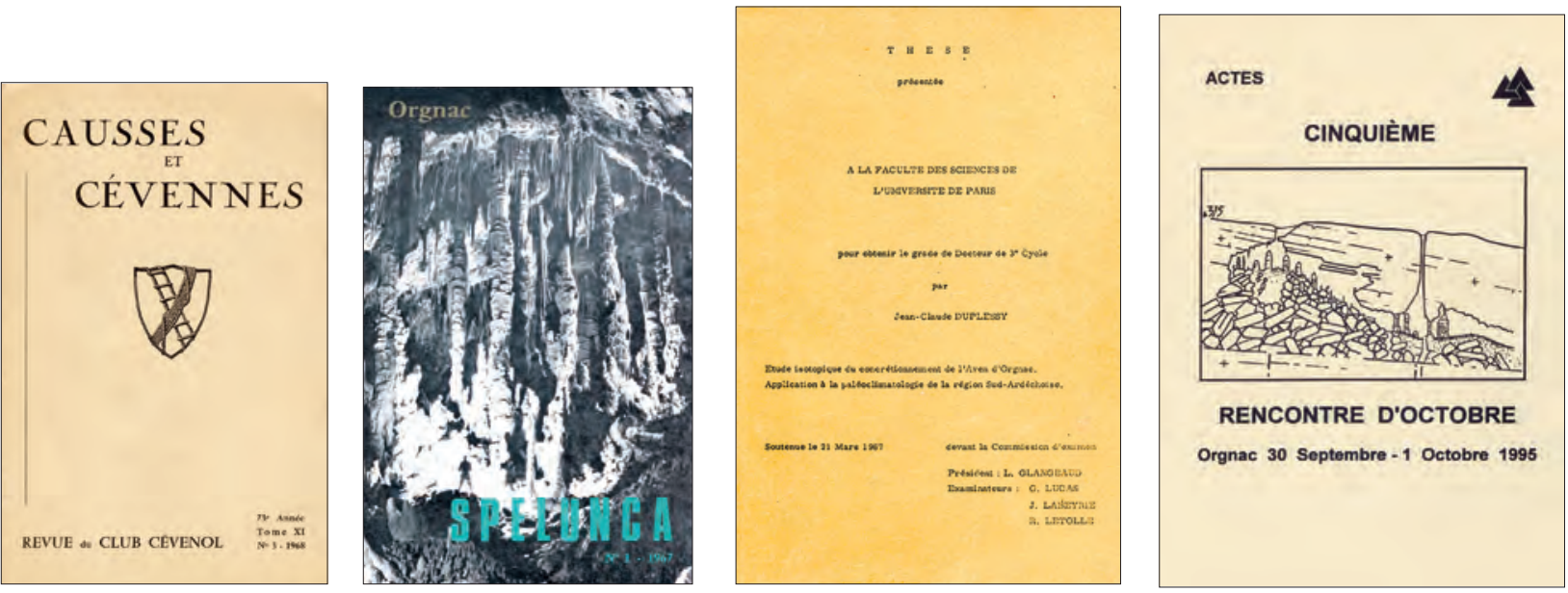
Duplessy J.-C., Labeyrie J., Lalou C. et Nguyen H.V. (1971) - La mesure des variations climatiques continentales. Application à la période comprise entre 130000 et 90000 ans BP. Quaternary Research, 1, 1971, 162174.

BlanC J.-J. (1972) - Recherches préliminaires sur la sédimentation argileuse dans les cavités du S.E. de la France. Annales de Spéléologie, n²7/2, 1972, 317-328

Duplessy J.-C et al. (1972) - Datations et études isotopiques des stalagmites. Application aux paléotempératures. Annales de Spéléologie, n²4/3, 1967, 445-464.

GUÉRIN R. (1973) - Liaisons entre karst et tectonique dans le bas-Vivarais calcaire. C.R. de l'Académie des Sciences de Paris, t.277, Série D, n¹6, 1617-1620.

GuÉRIN R. (1973) - Un exemple du rôle de la tectonique dans la géométrie des écoulements karstiques fossiles et actuels : le Bas-Vivarais calcaire. Thèse 3ème cycle Univ. Sciences et Techniques Montpellier, $112 \mathrm{p}$.

GĖze B. (1974) - Relation entre les phénomènes karstiques de surface et de profondeur. Phénomènes karstiques II, Mém. et Docum. Serv. Doc. et Cartogr. Géogr. 15, 195-207.

GUÉRIN R. (1974) - L'analyse tectonique et microtectonique dans l'étude de la karstification : exemple des karsts du Bas-Vivarais calcaire. Phénomènes karstiques II, Mém. et Docum., vol.15, t.2, 110 p.

GUÉRIN R. (1975) - L'analyse tectonique et microtectonique dans l'étude de la karstification. Exemple des karsts du Bas-Vivarais (étude préliminaire). Phénomènes karstiques II, Mém. et Docum., CNRS, 81-94.

CAllot Y. (1979) - À propos des plateaux ardéchois : karst, rapport fond/surface et évolution des paysages calcaires. Thèse $3^{\text {ème }}$ cycle, Univ.Reims, 384 p.
Cotillon P. et al. (1979) - Synthèse stratigraphique et paléogéographique sur les faciès urgoniens du sud de l'Ardèche et du nord du Gard. Géobios, Lyon, Mémoire spécial, ${ }^{\circ} 3,121-139$.

FABRE G. (1981)-Languedoc oriental et Bas-Vivarais calcaire : Aven d'Orgnac. Excursion du 13.09.1979. Actes du symposium international sur l'érosion karstique, Aixen-Provence. Mémoires de l'Association française de karstologie, Nîmes, 1981, 263-265.

Renault P., Marti A. (1982) - Intérêt des grottes aménagées pour la recherche scientifique. Études en France de la pCO2 atmosphérique. Atti Convegno internazionale sulle grotte turistische; Le grotte d'Italia (4) X, 61-72.

Slama P. (1982) - Synthèse biologique sur les Diaprysius du Bois de Ronze. Dossiers Techniques G.R.B., n² (1982). Équipe de recherches biospéléologiques (Argenteuil), $40 \mathrm{p}$.

FABRE G. (1984) - Hydrologie karstique des gorges de l'Ardèche et de leurs marges. Méditerranée n³, 71-77.

GiLli É. (1984) - Recherches sur le creusement et la stabilité des grands volumes karstiques souterrains. Thèse $3^{\text {ème }}$ cycle, Univ. Provence Aix-Marseille, t.1 et 2, 77-80 et 62-65.

Belleville L. (1985) - Hydrologie karstique : géométrie, fonctionnement et karstogénèse des systèmes karstiques des grottes de l'Ardèche. Thèse Univ. Sciences et Médecine, Grenoble, 228 p.

Champanet J.-M. (1986) - Un point commun entre l'aven d'Orgnac et l'aven des Neuf Gorges. Bulletin du CDS, Privas 1984/85, 26-28.

Champanhet J.-M. (1987) - Nouvelle présence de Diaprysius gezei Jeannel (Coleoptera, Bathysciinae) dans le soussol ardéchois. L'Entomologiste, t.43, fasc.6, 309/312.

Champanhet J.-M. (1987) - Propos sur Diaprysius fagei (Jeannel) de l'Ardèche (Coleoptera, Bathysciinae). L'Entomologiste, t.43, fasc.4, 199-200
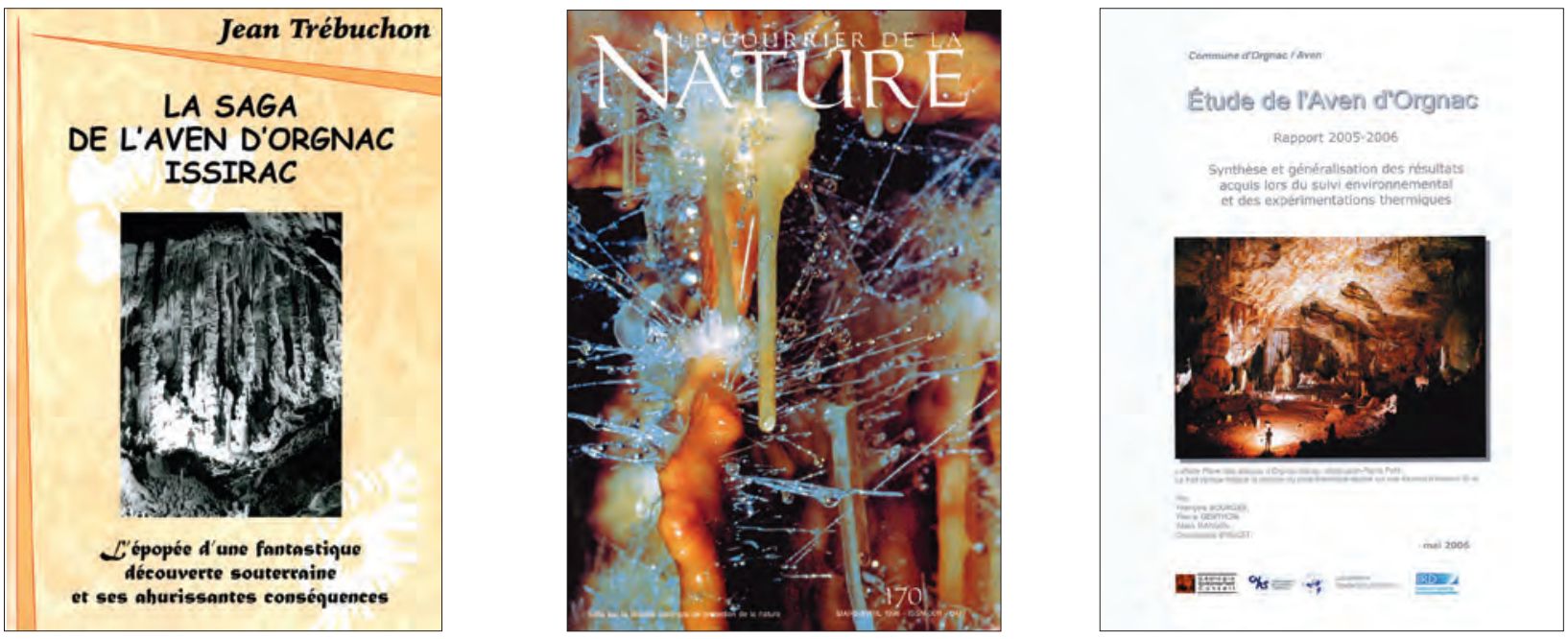
Champanhet J.-M. (1987) - Variabilité de l'édéage chez Diaprysius gezei Jeannel (Coleoptera, Bathysciinae) et cohabitation avec Diaprysius serullazi subsp. jolyi Jeannel. Bulletin de la Société Linnéenne de Lyon, t.56, fasc.10 (décembre 1987), 350-357.

Gombert P. (1988) - Hydrologie et karstogénèse du BasVivarais calcaire. Thèse Université Sciences et Techniques Montpellier, $483 \mathrm{p}$.

GÉze B. (1990) - Mea culpa d'un sceptique : prospection du réseau de l'aven d'Orgnac. Spelunca nº40, 1990, 28.

Blanc J.-J. (1995) - Étapes et facteurs de la spéléogénèse dans le sud-est de la France. Karstologia, n²6, 13-26.

Choppy J. (1995) - Visite du nouvel Orgnac. Actes des Rencontres d'octobre, n5, Orgnac, 1995, 129-130.

Renault P. (1995) - Note technique sur l'aménagement de l'aven d'Orgnac (Orgnac-l'Aven, Ardèche). Actes des Rencontres d'octobre, n5, Orgnac, 1995, 120-125.

Renault P. (1996) - Crues souterraines dans le Saut de la Pucelle (Lot), la grotte aménagée de la Cocalière (Gard) et l'aven touristique d'Orgnac. Actes des Rencontres d'octobre, ${ }^{\circ}$ 6, Osselle 1996, 1996, 83-85.

Dannenmuller J.-P. et Barth P. (1998) - L'aven d'Orgnac. Le Courrier de la Nature, n¹70, mars-avril 1998, 32-35.

TRÉBuCHON J. (2000) - La saga de l'aven d'Orgnac-Issirac, l'épopée d'une fantastique découverte souterraine et ses ahurissantes conséquences. Auto-édition, 240 p.

Bourges F., Mangin A. et D’Hulst D. (2001) - Le gaz carbonique dans la dynamique de l'atmosphère des cavités karstiques, l'exemple de l'aven d'Orgnac (Ardèche). C.R. Acad. des Sc. Paris, Science de la Terre et des planètes, 333, 2001, 685-692.

Bourges F., Mangin A. et D'Hulst D. (2002) - Étude de l'aven d'Orgnac. Suivi environnemental de l'aven d'Orgnac et expérimentations dans les réseaux d'Orgnac-Issirac. Opération Grand Site de France phase II 2001-2002. Rapport interne DIREN Rhône-Alpes.
Tocino S. (2002) - Échange d'expériences en matière de protection : expérience de l'aven d'Orgnac. Actes du colloque de St-Marcel-d'Ardèche, nov. 2002, Association de recherches spéléologiques et de protection de l'Aven de Noël, 2002, 143-149.

Bourges F., Mangin A. et D'Hulst D.(2003) - Pour en finir avec le $\mathrm{CO}_{2}$. Tubes $\mathrm{n}^{\circ} 23$, bulletin du Comité départemental de Spéléologie de l'Ardèche, 2003, 4751.

Bourges F., Mangin A. et D’Hulst D.(2003) - Radon and $\mathrm{CO}_{2}$ as markers of cave atmosphere dynamics: evidence and pitfalls in underground confinement; application to cave conservation». Communication au colloque "Climate Changes : the Karst Record III", Montpellier (France) 11th-14th May 2003.

Bourges F., Mangin A. et D'Hulst D.(2004) - Étude de l'aven d'Orgnac. Suivi environnemental du site souterrain et mesures dans l'aquifère karstique, année 2003-2004. Rapport interne DIREN Rhône-Alpes, Commune d'Orgnac-l'Aven.

Delannoy J.-J., Jaillet S. et al. (2004) - Aven d'Orgnac. Étude spéléogénique et karstogénique, étude des mémoires paléogéographiques et paléo environnementales du Bas-Vivarais. Rapport d'étape $\mathrm{n}^{\circ} 1$, Rapport interne DIREN Rhône-Alpes, Commune d'Orgnac-l'Aven, 2005, 193 p.

Lacelle D., Lauriol B. et Clark I. D. (2004) - Seasonal isotopic imprint in moonmilk from Caverne de l'Ours (Quebec, Canada) : implications for climatic reconstruction. Canadian Journal of Earth Science, $\mathrm{n}^{\circ} 41,1411-1423$.

Sadier B., Jaillet S., Delannoy J.-J., Perroux A.-S., et Perrette Y. (2004) - Mise en évidence d'un soutirage dans des remplissages endokarstiques par l'étude des formes et de la répartition des stalagmites (réseau d'Orgnac-Issirac, Ardèche, France). Poster colloque Han-sur-Lesse 2004 «Les séries sédimentaires endokarstiques: mémoires de l'environnement», poster, résumé $1 \mathrm{p}$.
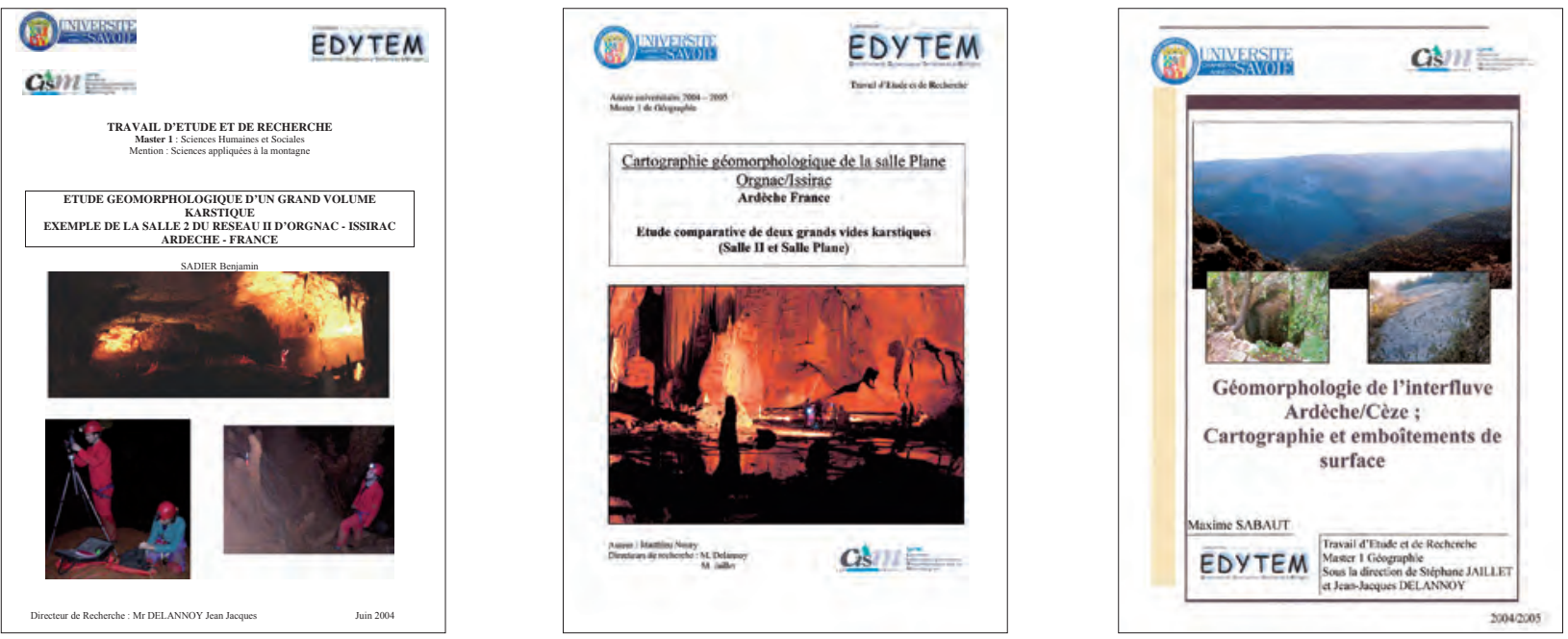
SAdier B. (2004) - Étude géomorphologique d'un grand volume karstique. Exemple de la Salle 2 du réseau II d'Orgnac-Issirac, Ardèche, France. TER Master 1, Géographie, Université de Savoie, EDYTEM, 2004, $81 \mathrm{p}$.

Bourges F., Genthon P., Mangin A. et D’Hulst D. (2005) Regime switch in karstic caves atmosphere; possible consequence on annual speleothem growth. American Geophysical Union, Fall Meeting 2005, abstract \#PP31A-1497

Delannoy J.-J., Jaillet S. et al. (2005) -Aven d'Orgnac. Étude spéléogénique et karstogénique, étude des mémoires paléogéographiques et paléoenvironnementales du Bas-Vivarais. Rapport d'étape $\mathrm{n}^{\circ} 2$, Rapport interne DIREN Rhône-Alpes, Commune d'Orgnac-l'Aven, 2005, 68 p.

Delannoy J.-J., Jaillet S. et al. (2005) - Aven d'Orgnac. Étude spéléogénique et karstogénique, étude des mémoires paléogéographiques et paléo environnementales du Bas-Vivarais. Rapport final $\mathrm{n}^{\circ} 3$, Rapport interne DIREN Rhône-Alpes, Commune d'Orgnac-l'Aven, 2005, 200 p.

Noury M. (2005) - Cartographie géomorphologique de la Salle Plane Orgnac-Issirac - Ardèche, France : étude comparative de deux grands vides karstiques (Salle 2 et Salle Plane). Master 1, Géographie, Université de Savoie, EDYTEM, 2005, 86 p.

Perroux A.-S. (2005) - Les remplissages détritiques endokarstiques - Contribution méthodologique à la lecture des mémoires paléogéographiques et environnementales. Application aux systèmes karstiques de Choranche (Vercors) et d'Orgnac (Bas-Vivarais). Thèse de doctorat de Géographie, Université de Savoie, EDYTEM, $418 \mathrm{p}$.

Sabaud M. (2005) - Géomorphologie de l'interfluve Ardèche/ Cèze : cartographie et emboîtements de surface, Master 1, Géographie, Université de Savoie, EDYTEM, 2005,85 p.
BERSIHAND J.-L. (2006) - Étude géomorphologique des Salles Rouges. Réseau d'Orgnac-Issirac (Ardèche-France). Contribution à l'étude spéléogénique et karstogénique de l'aven d'Orgnac, TER Master 1 de Géographie, Université de Savoie, EDYTEM, 2006, 85 p.

Jaillet S., Bersihand J.-L., Delannoy J.-J., Sadier B. et Tocino S. (2006) - Apport de l'analyse 3D par laser scanning (Lidar) à la connaissance des banquetteslimites de l'aven d'Orgnac (Ardèche, France). Poster Réunion des Sciences de la Terre, Dijon, déc. 2006.

Jaillet S., Bersihand J.-L., Delannoy J.-J., SAdier B. et Tocino S. (2006) - Les banquettes-limites de l'aven d'Orgnac : témoins d'une phase paragénétique majeure du réseau. Apport de l'analyse 3D par laserscanning. Actes des Rencontres d'octobre, $\mathrm{n}^{\circ} 16$. Publication en cours.

Jaillet S. et Perrette Y. (2006) - La grotte touristique, objet de recherche et lieu de médiation. Espaces, tourisme \& loisirs, $\mathrm{n}^{\circ} 236$, avril, 2006, 33-35.

Perroux A.-S., Delannoy J.-J., Perrette Y. et Desmet M. (2006) - Les sediments détritiques de grotte : un processus d'archivage original. In L'érosion, entre société, climat et paléoenvironnement. Actes de la table ronde de Clermond-Ferrand, 2004, Presses universitaires Blaise Pascal, 2006, 145-150.

Sadier B., Jaillet S. et Perrette Y. (2006) - La topographie $3 \mathrm{D}$ haute résolution : un outil pour l'étude des structures karstiques. Poster et Actes Colloque Hydrogéologie Karstique - Neuchâtel, Sept. 2006, 235-236.

Noury M. (2007) - L'ouverture au milieu extérieur des volumes karstiques. Détritisme, construction de cône et reconstitution paléo-environnementale. Mémoire Master 2, Géographie, Université de Savoie, EDYTEM, $65 \mathrm{p}$.

Barth P., Bigot J.-Y., Clauzon G., Delannoy J.-J., Jaillet S., Martini J. et Mocochain L. (2007) - Partie Géomorphologie. Ouvrage «De la Dent du Rez aux Gorges de l'Ardèche ». Publication en cours.
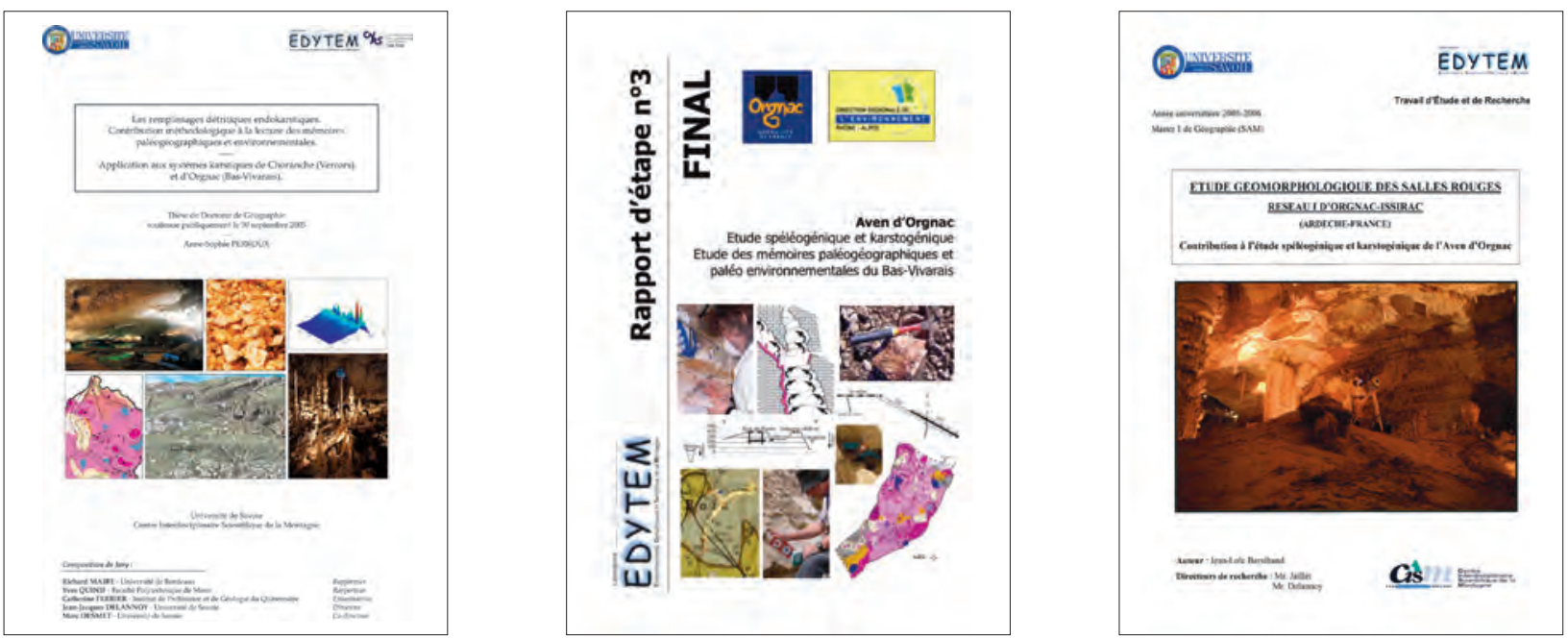


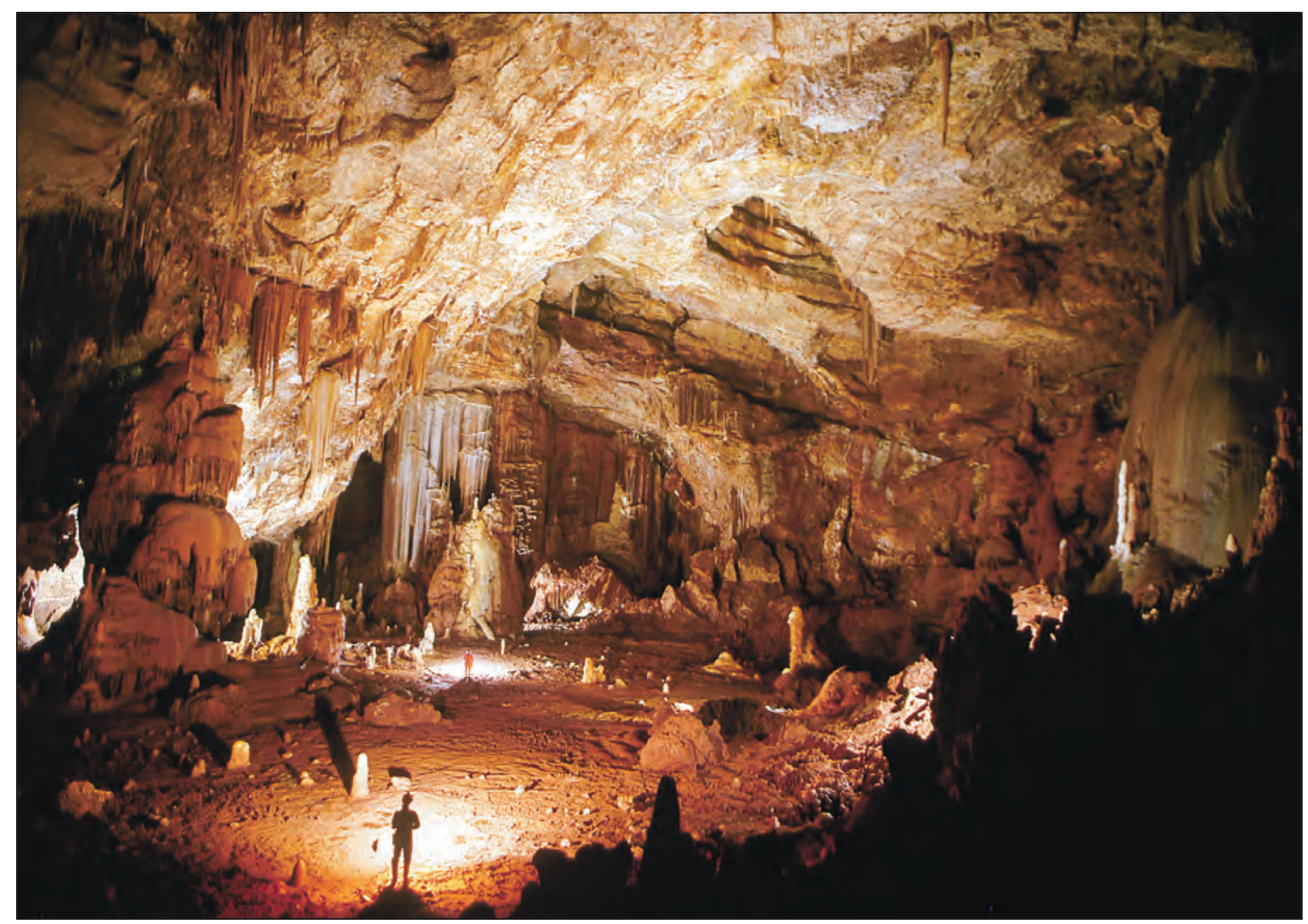

Photo 1

La Salle Plane

Sur cette photo qui permet de saisir le caractère grandiose de cette salle, on relève trois éléments importants : à la relative planéité du plafond (lié à l'effondrement de pans de voûte) répond la planéité du plancher, témoin d'ancienne phase de sédimentation. L'absence de blocs d'effondrement au sol de la salle permet de bâtir une première chronologie : l'essentiel des écroulements est antérieur à la sédimentation des dépôts argileux qui a nappé et/ou recouvert les blocs. La présence de cheminées recoupées par le plafond de la salle rapporte leur genèse à un épisode antérieur aux phénomènes de réajustements mécaniques (écroulements).

L'observation des formes permet de distinguer plusieurs phases spéléogéniques auxquelles il faut ajouter le concrétionnement, plus récent, qui scelle la morphologie de la salle (photo Jean-Pierre Petit). 


\title{
L'AVEN D'ORGNAC
}

\section{UN GRAND RÉSEAU PARAGÉNÉTIQUE, ÉTUDE SPÉLÉOGÉNÉTIQUE DES GRANDS VOLUMES KARSTIFIÉS}

\author{
par Stéphane JAILLET ${ }^{\prime}$, Jean-Jacques DELANNOY ${ }^{1}$, \\ Jean-Loïc BERSIHAND ${ }^{l}$, Matthieu NOURY' ${ }^{1}$, Benjamin SADIER ${ }^{l}$ et Stéphane TOCINO $^{2}$ \\ 1 Laboratoire EDYTEM - Université de Savoie - Chambéry \\ 2 Aven d'Orgnac-Orgnac-Grand Site de France-Orgnac-l'Aven
}

L’aven d’Orgnac et les réseaux non aménagés d’OrgnacIssirac constituent un ensemble spéléologique de l'ordre de 5 kilomètres de développement. S'il ne s'agit pas du réseau le plus important des plateaux des gorges de l'Ardèche ${ }^{l}$, Orgnac véhicule l'image d'un réseau de grandes dimensions offrant des volumes importants et un concrétionnement riche et varié. Cet article est plus particulièrement centré sur les volumes de cette cavité et les salles souterraines dont l'importance interroge tant les visiteurs que les spécialistes du monde souterrain. Hormis la salle d'entrée (Salle de Joly), le « gigantisme » des galeries et des salles d'Orgnac est le plus souvent associé à d'imposantes accumulations argileuses dont l'origine soulève de nombreuses interrogations. Y-at-il une relation entre ces accumulations et le volume des réseaux d'Orgnac ? Quels sont les processus et les dynamiques responsables de tels volumes souterrains ? Quelle dynamique spéléogénique peut aboutir à de tels volumes souterrains ? Cet article a pour objet de répondre à ces interrogations en se basant sur les relevés et les travaux menés ces dernières années dans cette cavité.

\section{I - UN GIGANTISME QUI INTERROGE}

La topographie de l'aven d'Orgnac (figure 1) met en avant l'organisation d'ensemble de la cavité : l'axe général des réseaux souterrains est subméridien et la plupart des gros volumes se développent dans une tranche altitudinale comprise entre $260 \mathrm{~m}$ (sol de la Salle des Treize) et $180 \mathrm{~m}$ (dans les Salles Rouges). La Salle des Treize, le Défilé des Géants, la Salle du Dôme, la Salle Plane (photo 1), les Salles 3, 2, et 1, ainsi que les Salles de Joly et Rouges constituent, du nord au sud, les gros volumes souterrains d'Orgnac. Séparés topographiquement par des rétrécissements parfois « sévères », encombrés de blocs et de dépôts argileux, voire masqués par un abondant concrétionnement, il est difficile au premier abord d'identifier l'organisation

\footnotetext{
1 Saint Marcel d'Ardèche (48 km), Foussoubie (23 km), RochasMidrö̈ $(7,7 \mathrm{~km})$ et Orgnac $(5 \mathrm{~km})$ sont les cavités majeures des plateaux des gorges de l'Ardèche en termes de développements spéléologiques.
}

d'Orgnac, de retrouver les témoins du (des) conduit(s) originel(s). Outre l'alternance de salles géantes et de rétrécissements, c'est la diversité morphologique des volumes qui interroge : plafond préservé et sol plan dans la Salle Plane, plafond effondré et sol argileux dans la Salle 2, écroulement généralisé dans la Salle de Joly, etc. Rien ne permet à première vue de donner « une » unité morphogénique pour ces volumes souterrains que tout sépare $a$ priori. Cette difficulté de lecture spéléogénique est accentuée par la diversité de processus qui ont altéré les morphologies et les dépôts susceptibles de nous renseigner sur les dynamiques à l'origine de la physionomie d'ensemble d'Orgnac et de la genèse des grands volumes souterrains : écroulements de plafond et/ou de paroi, soutirages, glissement des formations argileuses, puits trépanants, etc., sont autant d'éléments qui perturbent les premières lectures de la cavité.

Afin de retrouver les différentes étapes-clés spéléogéniques majeures, un premier choix a été fait : ne pas travailler sur l'ensemble de la cavité mais se centrer sur quelques secteurs jugés clés du réseau. Le choix de ces secteurs a été fait sur le principe de la complémentarité morphologique : travailler sur des salles et conduits présentant des caractères morphologiques différents pouvant ainsi renseigner sur la plus large gamme possible de processus et dynamiques à l'origine de l'organisation de la cavité et du gigantisme des salles. Les secteurs qui ont retenus notre attention, sont la Salle Plane (photo 1), la Salle 2 (photo 2) et les Salles Rouges. Ces différentes salles ont fait l'objet de relevés cartographiques détaillées. Parallèlement, des investigations ponctuelles (sondages ponctuels et électriques, coupes stratigraphiques, analyses sédimentologiques) ont été menées en divers points de la cavité pour reconnaitre les différents processus et les formes permettant de caractériser les différentes phases spéléogéniques. Dans cet article, l'accent a été mis sur les éléments permettant de caractériser la phase la plus précoce de la karstification, c'est-à-dire l'élaboration des conduits supposés originels du karst ; les processus ultérieurs (soutirage, concrétionnement, etc.) sont traités dans les articles suivants de cet ouvrage. 
Figure 1

Carte de localisation des secteurs étudiés dans l'aven d'Orgnac et dans les réseaux d'Orgnac-Issirac, d'après J.-C. Trébuchon.
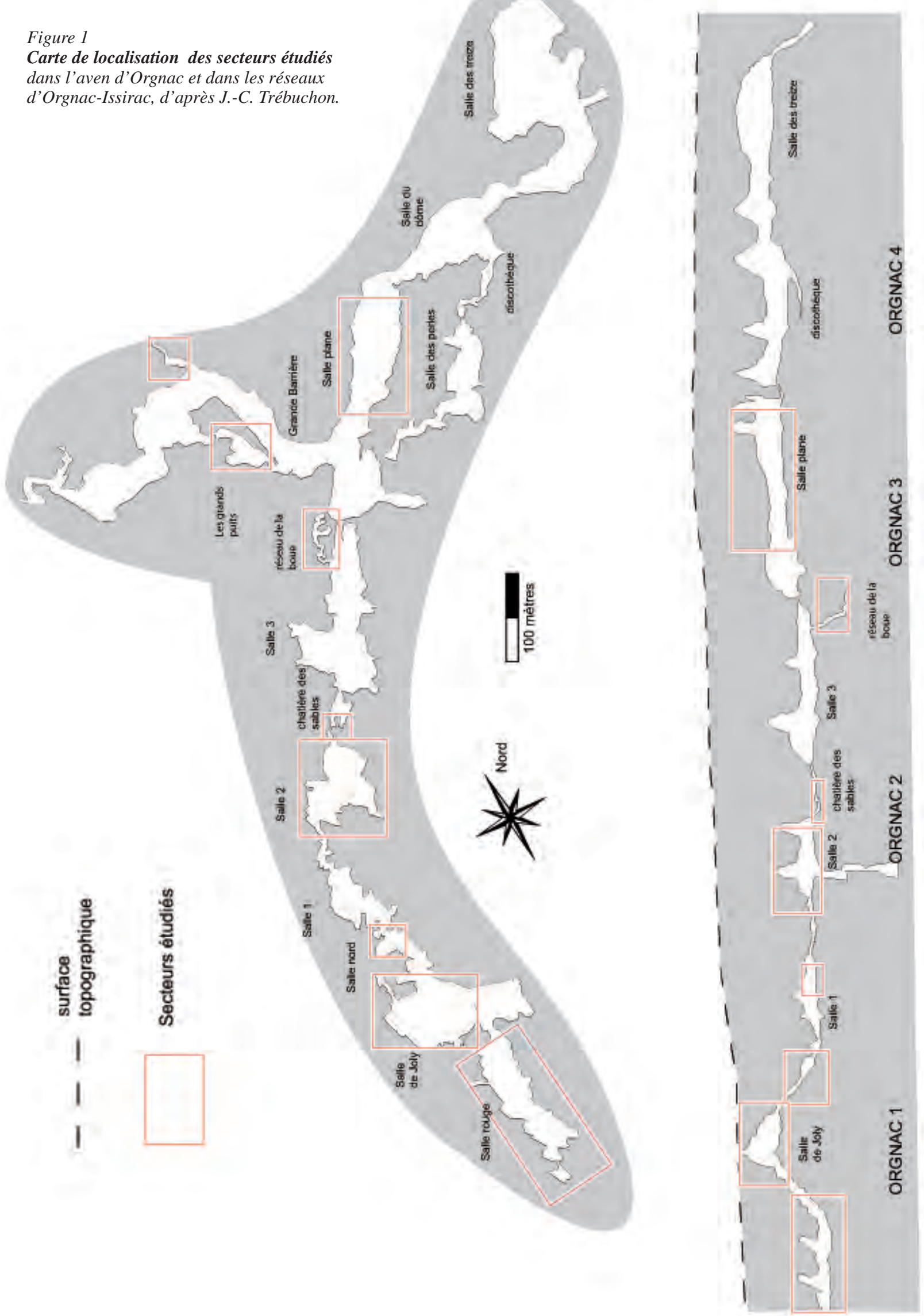
Le gigantisme des volumes, la reconnaissance de morphologies pariétales caractéristiques (banquetteslimites, «flutes »...) et le relevé d'importants dépôts argileux nous invitent à appréhender la primo-genèse d'Orgnac à partir du concept du «paragénétisme», formalisé par Ph. Renault (1968) suite à ces travaux à Orgnac. Les relevés cartographiques et morphologiques dans la cavité permettent de mettre en avant l'intérêt de ce concept dans la spéléogenèse d'Orgnac.

\section{II - LE PARAGÉNÉTISME : UN MODE DE CREUSEMENT AGGRADANT}

Les observations spéléologiques de Ph. Renault, l'ont conduit à formaliser le concept de "paragénétisme » qui associe la genèse de certains conduits à une sédimentation synchrone de sédiments très fins (argiles, argilo-limoneux) : le travail de la corrosion s'exerçant dans la partie supérieure du conduit (Ph. Renault, 1967) : «Un remplissage protégeant la partie inférieure d'un conduit spéléologique, l'action des eaux courantes se limitera au périmètre rocheux sus-jacent à ce remplissage. (...) Lorsque le dépôt est important, la partie inférieure du conduit est noyée sous la couverture imperméable, et le creusement limité à la partie supérieur du conduit, voire uniquement à la voûte. Nous avons baptisé ce processus creusement remontant ${ }^{2} »$. Plus loin l'auteur poursuit à propos d’Orgnac: "Le réseau de l'aven d'Orgnac pourrait être cité comme exemple spectaculaire d'une galerie paragénétique de dimensions exceptionnelles. (...) La Salle Rouge, vers le S, de grande dimension, dont la partie inférieure est colmatée par une masse argileuse, d'épaisseur inconnue, est trop courte pour qu'il soit possible d'étendre ses caractères paragénétiques à l'ensemble du réseau ». Ce concept de paragénétisme a été par la suite développé dans un «Que sais-je ? 》 du même auteur : «La formation des cavernes ». Bien que cette idée originale ait été reprise dans de nombreux ouvrages, l'application à des cas concrets de réseaux est restée relativement indigente et peu de travaux sont revenus sur ce concept.

Pour Philippe Renault (1967), le paragénétisme s'effectue en présence d'écoulements en régime noyé qui du fait de leur faible vitesse engendre le dépôt des sédiments les plus fins transportés jusque-là. Dans le cas d'une alimentation allochtone, les éléments les plus grossiers (sables, graviers...) sont soit stockés en amont des conduits affectés par le paragénétisme, soit piégés dès l'entrée de la zone noyée, sous forme de « delta gilbert » tels ceux observés dans les pièges

2 L'auteur parle aussi de creusement per ascensum.

Photo 2

Une des caractéristiques des réseaux d'Orgnac est leur abondant concrétionnement. Résultat des épisodes spéléogéniques les plus récents, le concrétionnement a pour effet de masquer les formes et formations issues des phases plus anciennes. Les relevés topographique et morphologique permettent néanmoins de révéler des formes liées à d'anciennes phases de fonctionnement de la cavité, notamment les phénomènes de soutirage.Une lecture attentive de la grotte indique que le «vernis stalagmitique» scelle, voire protège, des formes fort anciennes (photo Jean-Pierre Petit).

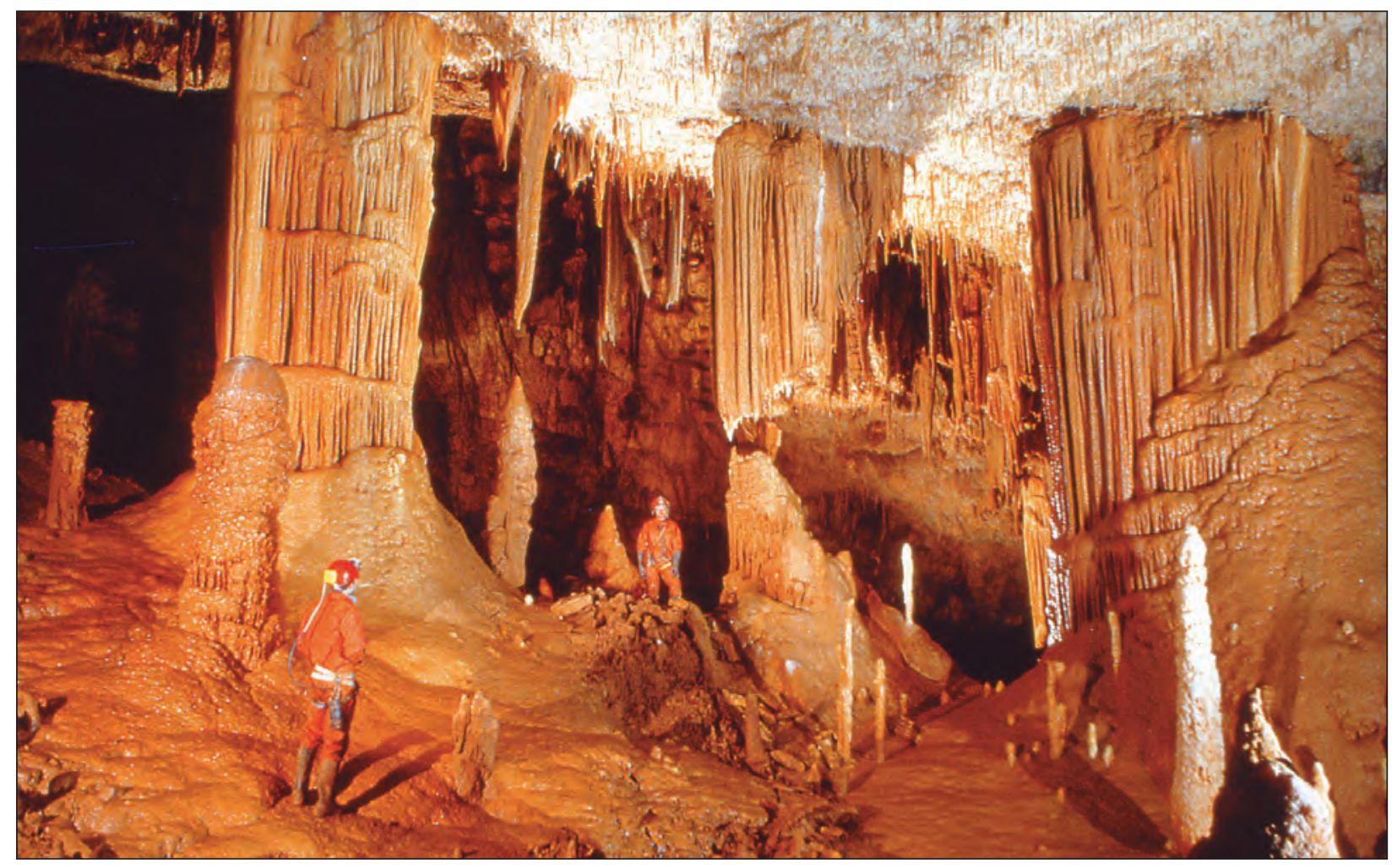




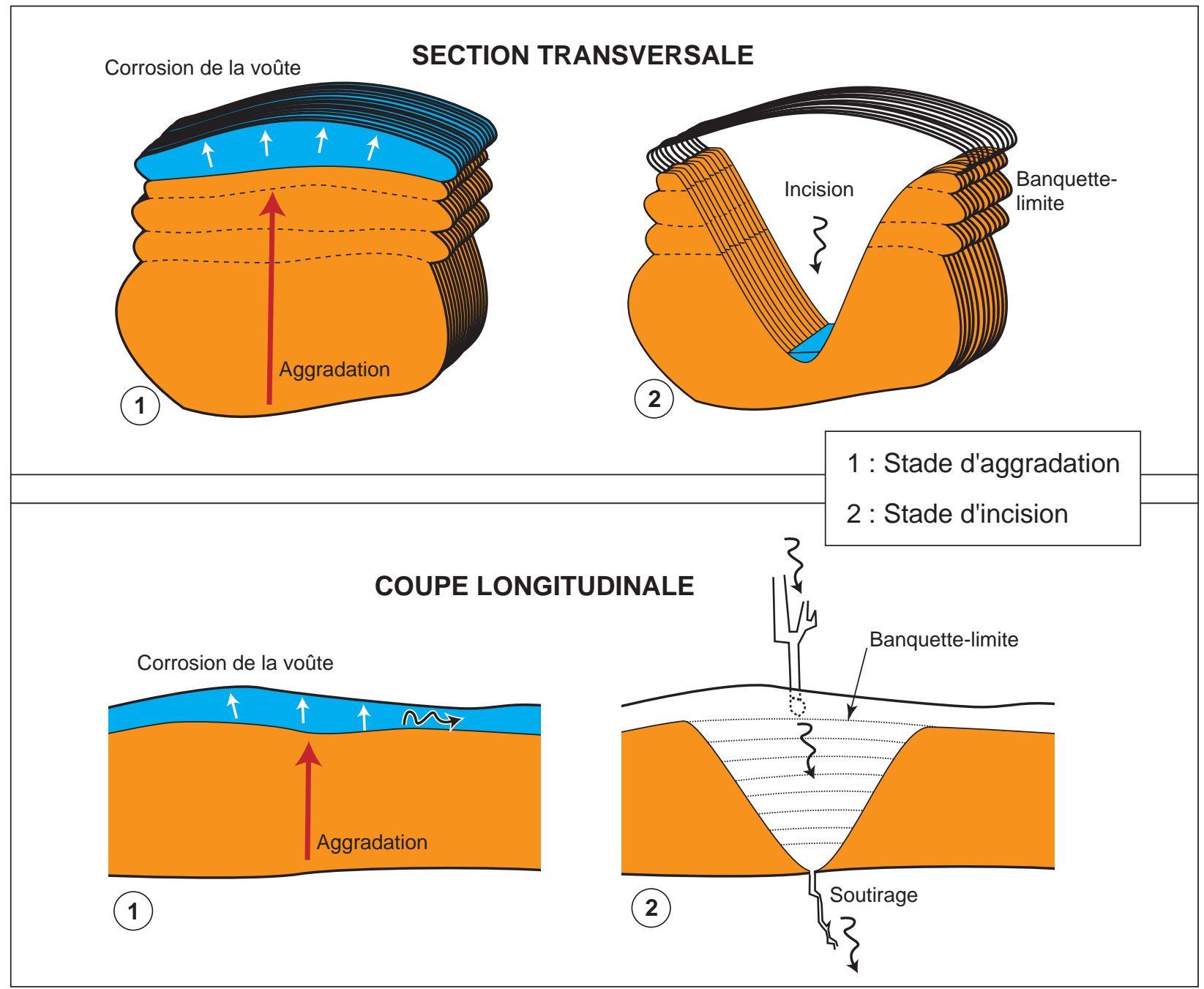

Figure 2

Présentation schématique de la genèse des réseaux d'Orgnac.

Ont été ici représentées les deux phases spéléogéniques majeures :

(1) le creusement des réseaux en régime paragénétique et (2) l'évacuation des argiles «paragénétiques». La combinaison de ces deux phases est à l'origine des grands volumes souterrains d'Orgnac.

lacustres et/ou marins. Une des caractéristiques des conduits «paragénétiques » est que la sédimentation argileuse ne conduit pas au comblement total de la galerie du fait de la corrosion synchrone de la galerie à la « voûte ». Il est intéressant de relever qu'au contact du remplissage et de la paroi calcaire se développent des formes pariétales originales dénommées «banquetteslimites » par Ph. Renault (1967). Ce sont des formes en creux, orientés longitudinalement dans l'axe de la galerie, souvent parallèles entre elles.

L'aggradation du remplissage sédimentaire se traduit par le scellement des banquettes-limites. La corrosion reprend alors à la voûte et génère la mise en place d'un nouveau plafond quelques centimètres à quelques décimètres au-dessus du précédent, et de nouvelles banquettes-limites se mettent en place (figure 2).

Peu d’observations ont été réellement menées en site actif pour appréhender ce type de creusement. Ces observations sont d'autant plus délicates qu'elles concernent des zones noyées «boueuses» où la visibilité des plongeurs est généralement des plus réduite. Néanmoins, il serait intéressant d'étudier les dépôts sédimentaires fins de fond de galerie noyée qui protègent le « bedrock » et concentre la corrosion sur le reste de la galerie.

L'intérêt de relier banquettes-limites et paragénétisme et de les associer à la partie supérieure du remplissage argileux est qu'il permet de renseigner sur le caractère aggradant du remplissage et de resituer géométriquement les différents niveaux ascendants du dépôt. En effet, une des caractéristiques de ces formes particulières est leur lisibilité dans le paysage souterrain, dès lors que le remplissage contemporain du paragénétisme a été évacué. Elles se caractérisent sous forme de reliefs pariétaux de quelques centimètres à quelques décimètres de profondeur, longiformes, se développant dans l'axe de la galerie. Parfois horizontales, souvent inclinées, elles offrent fréquemment un profil en montagnes russes qui indique que le toit de la série argileuse n'est pas aussi plan qu'on l'imagine; le 


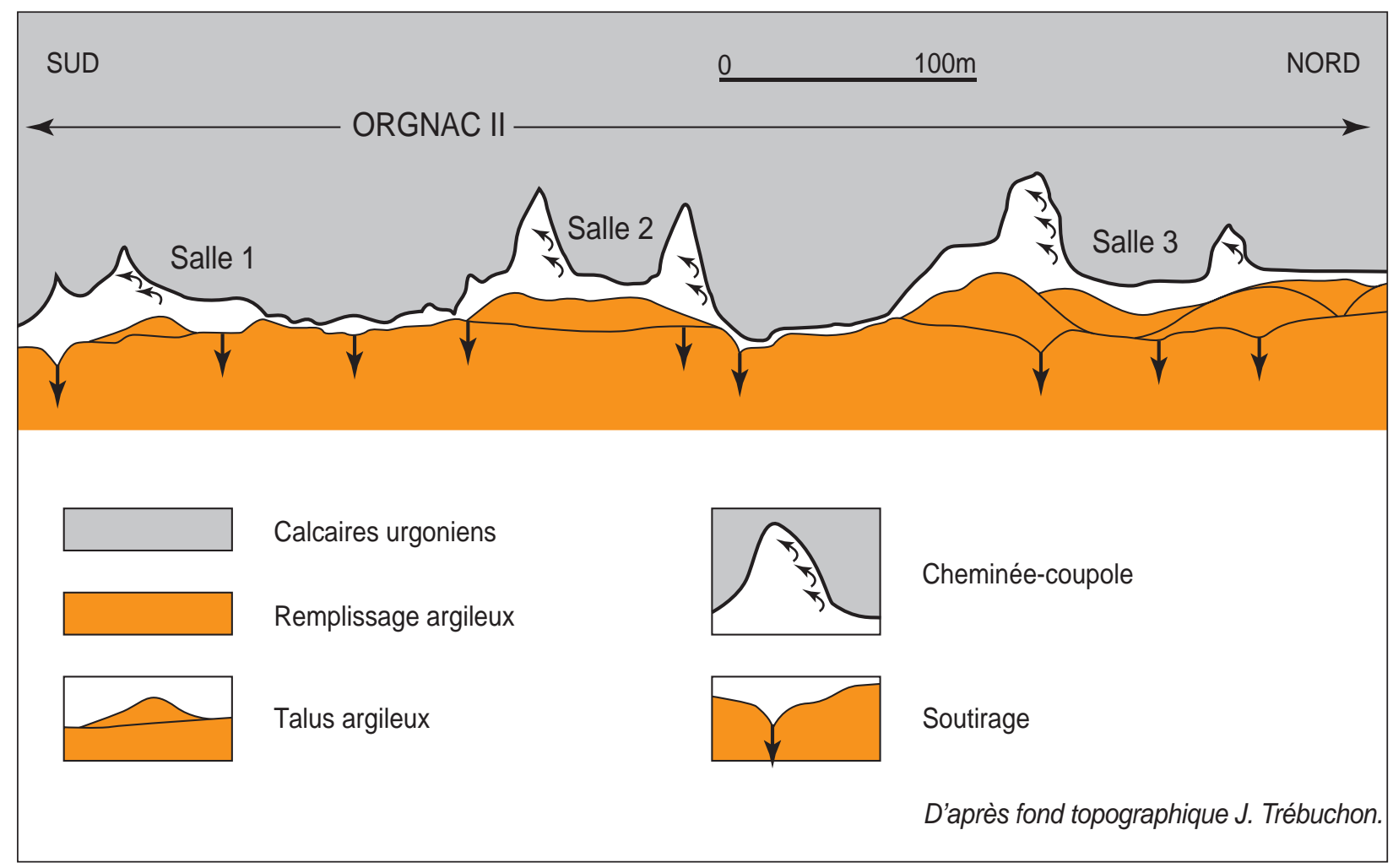

Figure 3

Profil longitudinal simplifié d'Orgnac II (Salles 1, 2 et 3). L'épaisseur du remplissage argileux n'est pas connue. Cette figure a pour objectif de mettre en avant le profil en «montagne russe» des dépôts argileux et leur adéquation avec la morphologie du plafond de la galerie (cloches, cheminées aveugles...). Cette relation «sol/plafond» est caractéristique d'une phase de creusement paragénétique.

toit argileux s'apparente ici plutôt à une succession de talus dont les pentes peuvent atteindre parfois les $45^{\circ}$. Il est intéressant de relever que, durant la phase paragénétique, la topographie du plafond de la galerie suit plus ou moins celle du toit du remplissage. Cela est particulièrement visible dans Orgnac II, où la succession des Salles 1, 2 et 3 présente une succession de cheminées-coupoles et de talus argileux (figure 3 ) : les sommets des talus se situent plus ou moins au droit des cheminées-coupoles. Ces dernières constituent des «excroissances» altitudinales du plafond de la galerie qui se sont agencées aux dépens de points faibles du substrat (fractures, joints de strates...) (figure 4). Du fait de remaniements ultérieurs (chutes de pan de plafond, soutirage et/ou glissement des formations argileuses, etc.), l'association «dunes argileuses /cheminées-coupoles » n'est plus aujourd'hui systématique ; il existe, néanmoins, d'autres indices morphogéniques permettant de resituer les anciennes «dunes argileuses » et leur corollaire (cheminéescoupoles). L'étude morphogénique d'Orgnac a permis de distinguer plusieurs processus responsables de l'évacuation du remplissage argileux et, par incidence, du dégagement des formes pariétales contemporaines $\mathrm{du}$ fonctionnement paragénétique (figure 5): les processus les plus fréquents sont (i) le recoupement

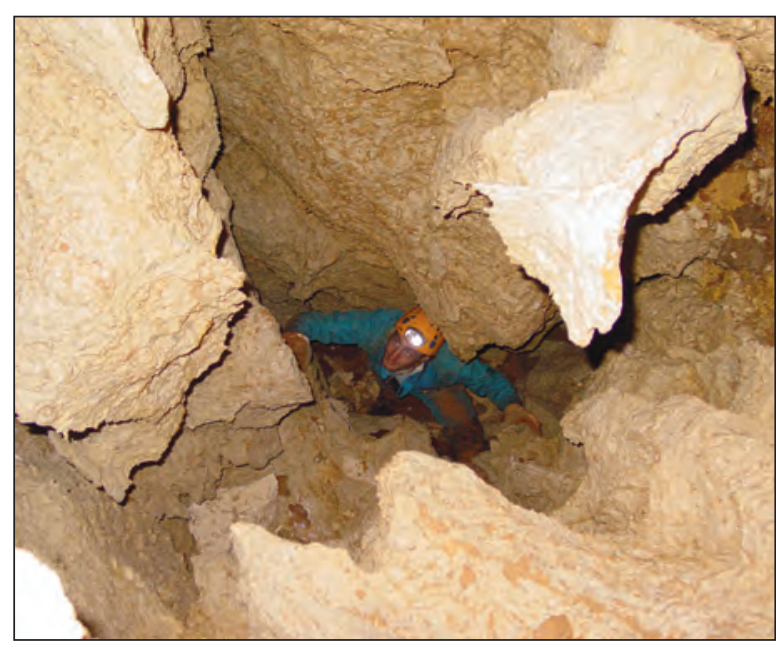

Photo 3

Exemple de puits de recoupement sur le rebord de la galerie d'Orgnac III. Ces puits appartiennent à une autre logique de creusement que les galeries principales d'Orgnac. Ces puits sont révélateurs d'une migration de la zone noyée du karst et d'une phase de verticalisation du karst.

du conduit « originel » par des réseaux plus récents (photo 3), (ii) l'infiltration des écoulements au contact du remplissage et de la paroi calcaire, (iii) les soutirages liés à un réseau sous-jacent... 
Ces différentes formes d'évacuation du remplissage permettent de reconnaître les formes caractéristiques du paragénétisme : les banquettes-limites, les chenaux de voûte et les chenaux anastomosés de plafond dit aussi «lapiaz de voûte ». Une identification de ces processus particuliers de creusement passe donc par le relevé de ces formes caractéristiques à macro et micro échelle, mais aussi par l'observation des témoins argileux qui tapissent parfois les parois et les voûtes du conduit.

Ce travail de relevé a été entrepris en plusieurs endroits $\mathrm{du}$ réseau, là où des galeries latérales permettent de descendre plus bas que le niveau du remplissage argileux, mais aussi dans le conduit principal. Dans cet article seront présentées les observations réalisées dans des réseaux recoupant le drain (réseaux de la Boue et des Grands Puits) et dans le «paléodrain » (les Salles Rouges).

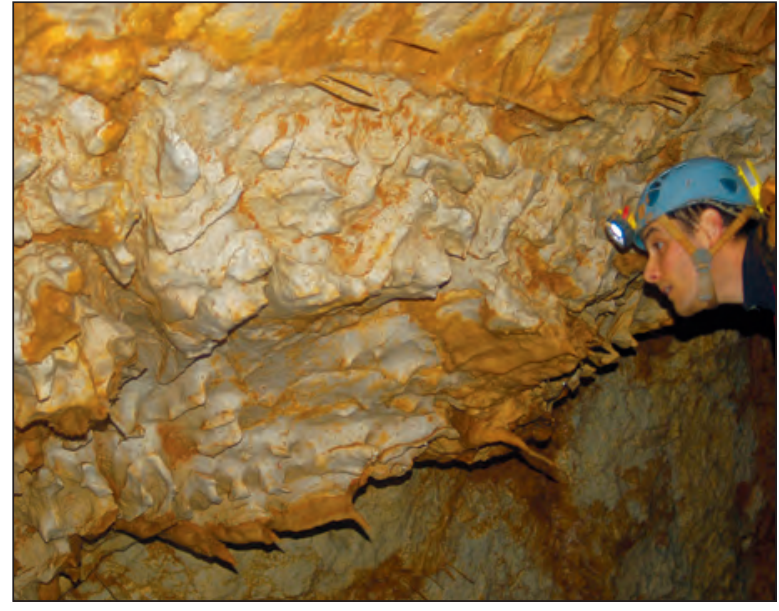

Photo 4

Le lapiaz de voûte au fond du réseau de la Boue. Les «lapiés» sont l'expression visible d'anciennes circulations d'eau qui naviguaient entre le toit de la série argileuse et la voûte calcaire. Le caractère anastomosé des chenaux suggère des conditions contraignantes de circulation des eaux.

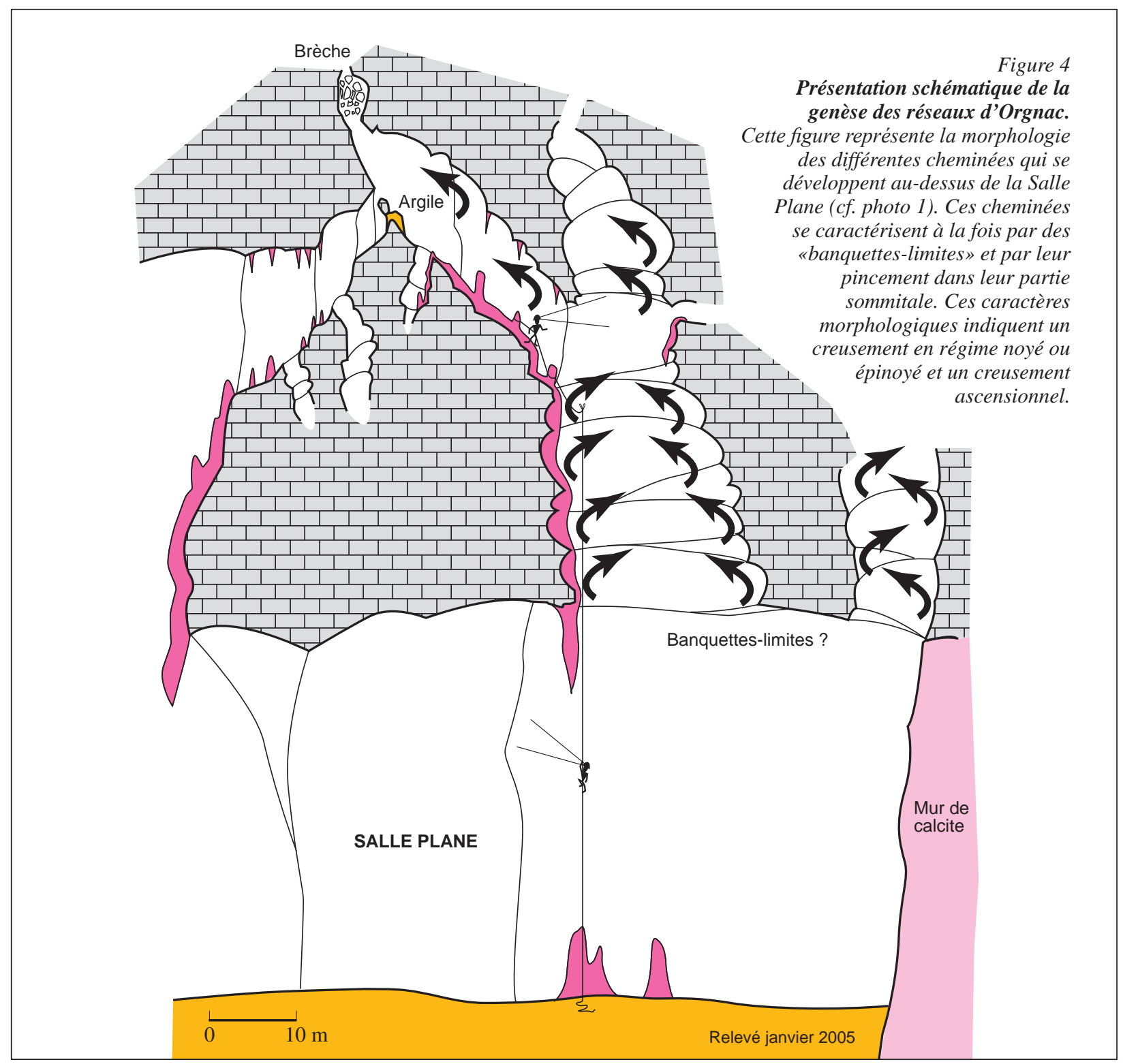


Figure 5

Coupe schématique de la zone d'accès

à la zone des puits « -200 » et ses relations avec le soutirage principal de la Salle 2.

Il s'agit d'un puits recoupant le bord de la Salle 2. Son fonctionnement est probablement associé au soutirage qui affecte la Salle 2 elle-même.

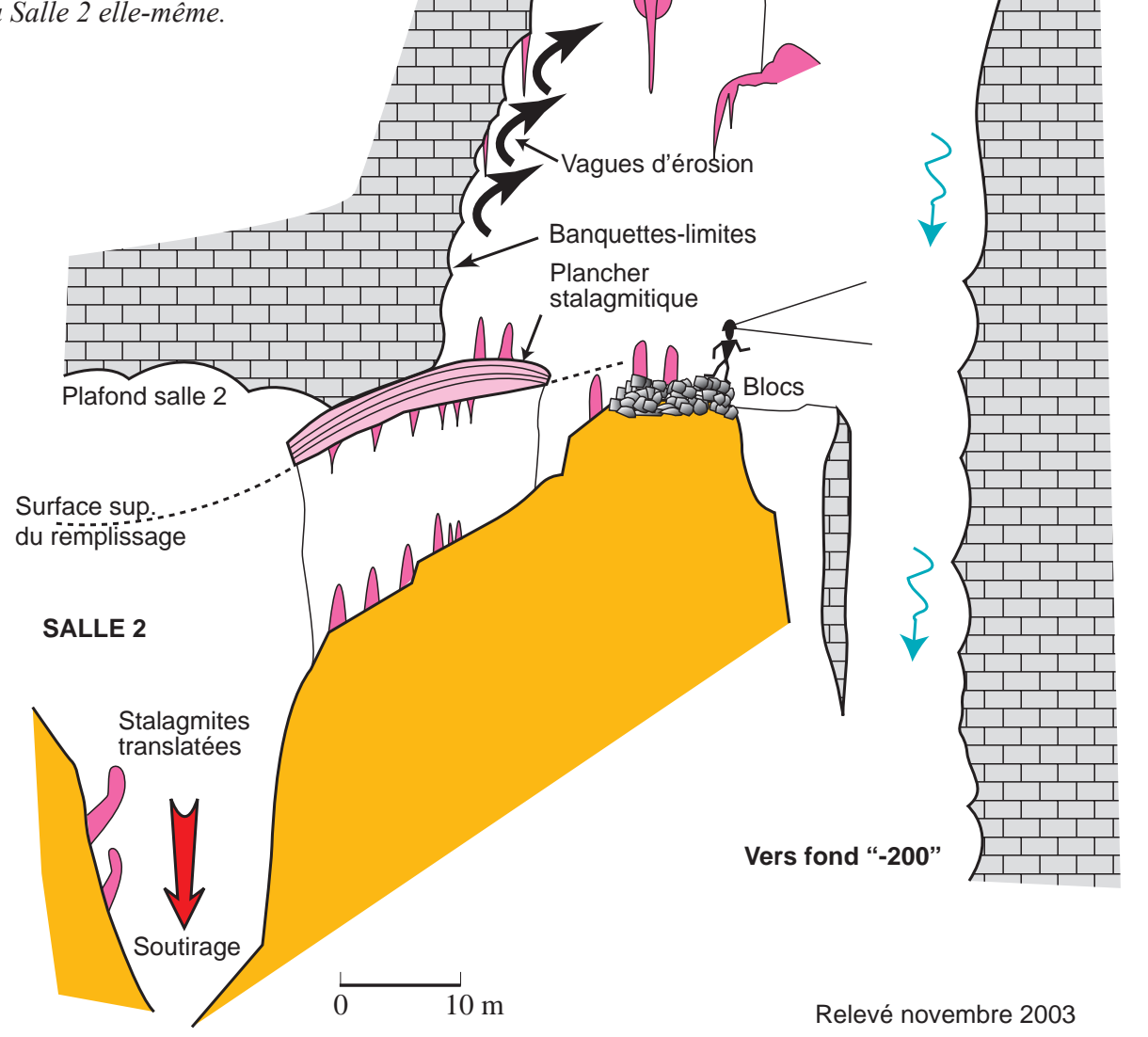

\section{III - ObSERVATIONS Dans des RÉSEAUX RECOUPANT LA GALERIE PRINCIPALE D'ORGNAC}

Deux réseaux ont fait tout particulièrement l'objet d'investigation : le réseau de la Boue et le réseau des Grands Puits. Ces deux réseaux se développent en rive occidentale du conduit principal et s'enfoncent de quelques dizaines de mètres sous ce dernier.

On accède au réseau de la Boue (figure 1) par une lucarne dans la Salle 3, à peu près au droit du site des Sabres. Une série de puits mène à un réseau labyrinthique où se mêlent puits, cheminées et conduits anastomosés. Vers le fond, le conduit est entièrement obstrué par le remplissage argileux. Au plafond, on relève la présence d'un lapiaz de voûte (photo 4) assez bien conservé, atteignant plus d'un mètre de commandement. À mesure que l'on remonte vers le haut, on relève que l'incision du lapiés de voûte est de plus en plus marquée pour se raccorder avec le puits cheminée
Photo 5

Série de banquettes-limites étagées.

Ces différentes banquettes mettent bien en avant leur "profil en montagnes russes» et permettent de reconstituer la géométrie des anciens stades de remplissage argileux.L'évacuation de ce remplissage permet d'observer ces morphologies pariétales particulières rapportées à un ancien fonctionnement paragénétique des réseaux d'Orgnac.

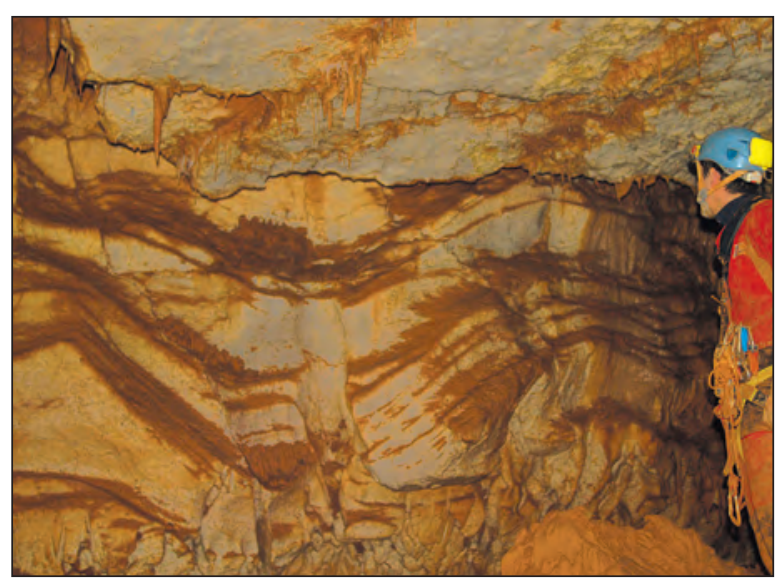


sus-jacent (figure 6). Ce raccordement suggère une alimentation remontante, transitant par les chenaux anastomosés du lapiés de voûte puis le chenal de voûte pour rejoindre le conduit «principal ». Cette paléocirculation a conduit à la mise en place au sein de ce conduit d'une série de banquettes-limites au profil longitudinal en montagnes russes (photo 5). C'est une forme parfaite très bien conservée dans laquelle il est possible de reconstituer la totalité de la genèse, bien que le remplissage argileux ait été entièrement soutiré.

Plus haut, on note encore le chenal de voûte (figure 6 et photo 6) parfaitement conservé mais plutôt discontinu dans sa distribution spatiale. Lorsqu'il est bien conservé, sa pente n'est jamais horizontale mais plutôt en montagnes russes. Le raccordement aux

Figure 6

Section de galerie au fond du réseau de la Boue.

Dans ce secteur d'Orgnac, le raccordement du lapiés de voûte au chenal de voûte est particulièrement démonstratif d'une même phase de creusement à laquelle on peut également associer la genèse des banquettes-limites.

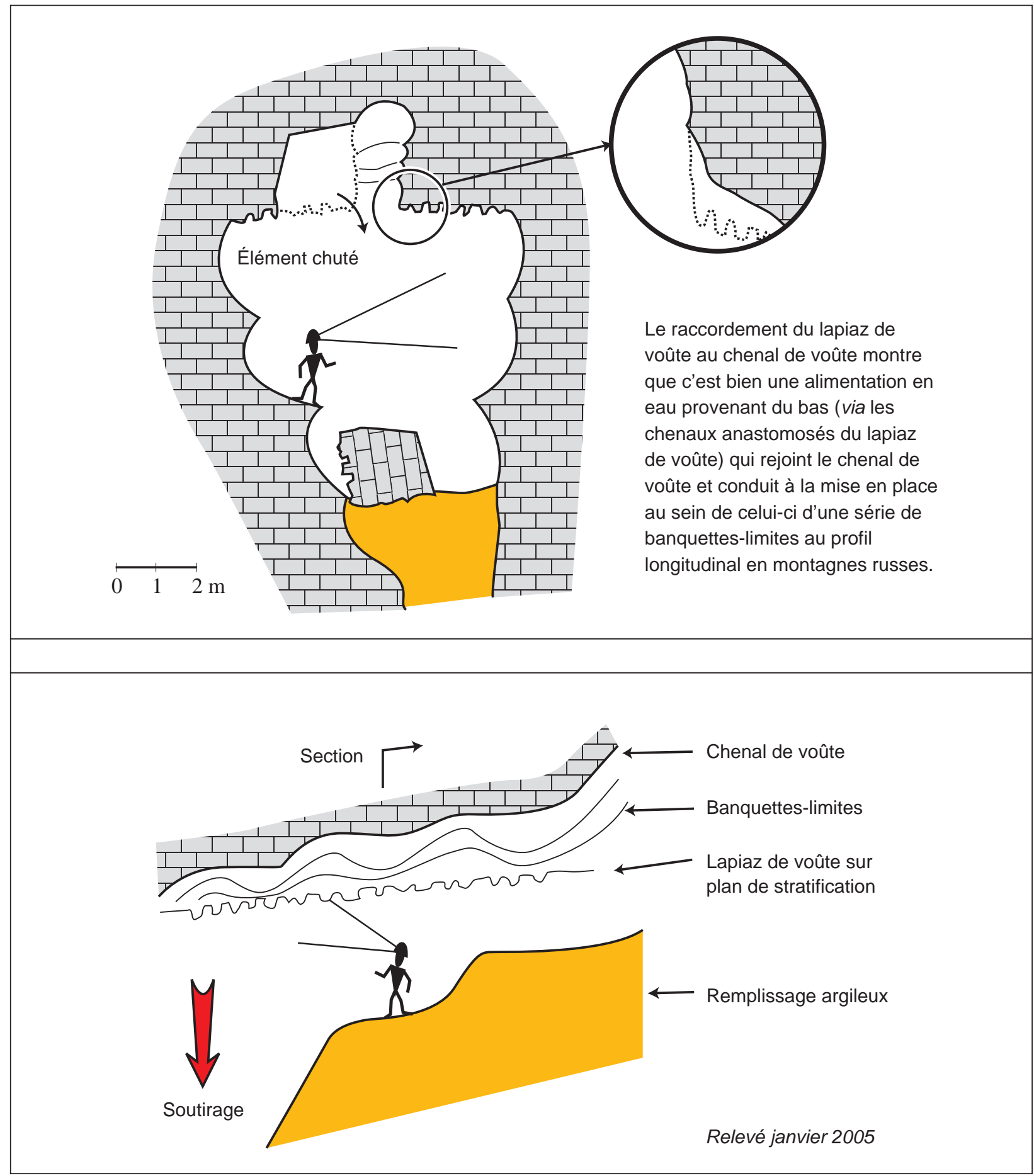




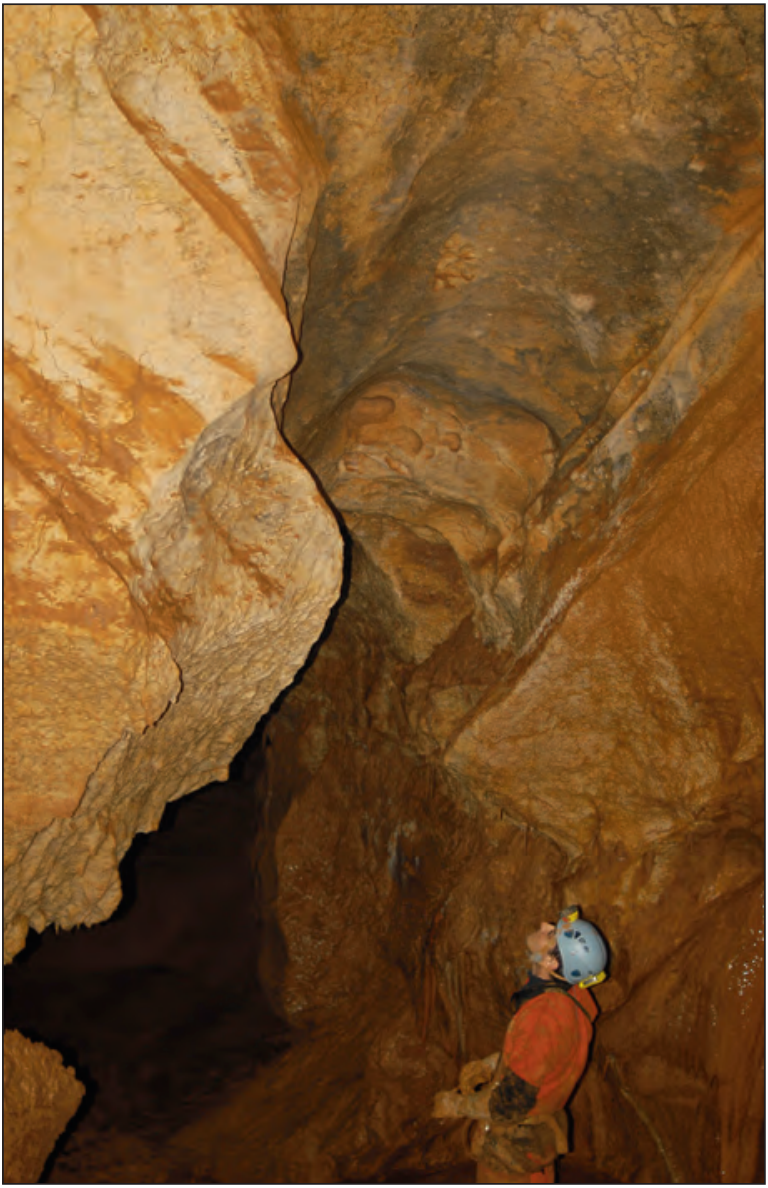

Photo 6

La partie supérieure de la galerie de la Boue.

La genèse de cette galerie en «trou de serrure» n'est pas celle à laquelle on s'attend. Le tube sommital est ici l'expression de la «fin» du creusement de la galerie. Les banquettes-limites présentes de part et d'autre du personnage indiquent que ce réseau a été creusé de bas en haut (fonctionnement paragénétique) ; le tube s'étant creusé en régime noyé au terme du fonctionnement paragénétique.

banquettes-limites, dont il n'est qu'une forme aboutie, montre bien le caractère noyé permanent de sa genèse. Plus spectaculaires, bien que plus localisées, sont les flûtes pariétales (photo 7) se développant au détriment de la masse calcaire au contact du remplissage argileux aujourd'hui surbaissé. Elles témoignent, ici encore, d'une circulation hydrologique de bas en haut et de la faiblesse des vitesses ayant conduit à la mise en place de telles formes, faiblesse avérée par la granulométrie fine des dépôts.

Le réseau des Grands Puits (figure 7) est une suite de deux puits d'une vingtaine de mètres de hauteur séparés par un tronçon de galerie pentue. Les parois et les plafonds présentent une succession de coupoles et de vagues indiquant de nouveau une genèse en régime noyé. Le sol est entièrement feutré d'argile plus ou moins compacte selon les secteurs. En plusieurs points de ce réseau il est possible de reconnaître la structuration initiale du dépôt argileux : on relève de

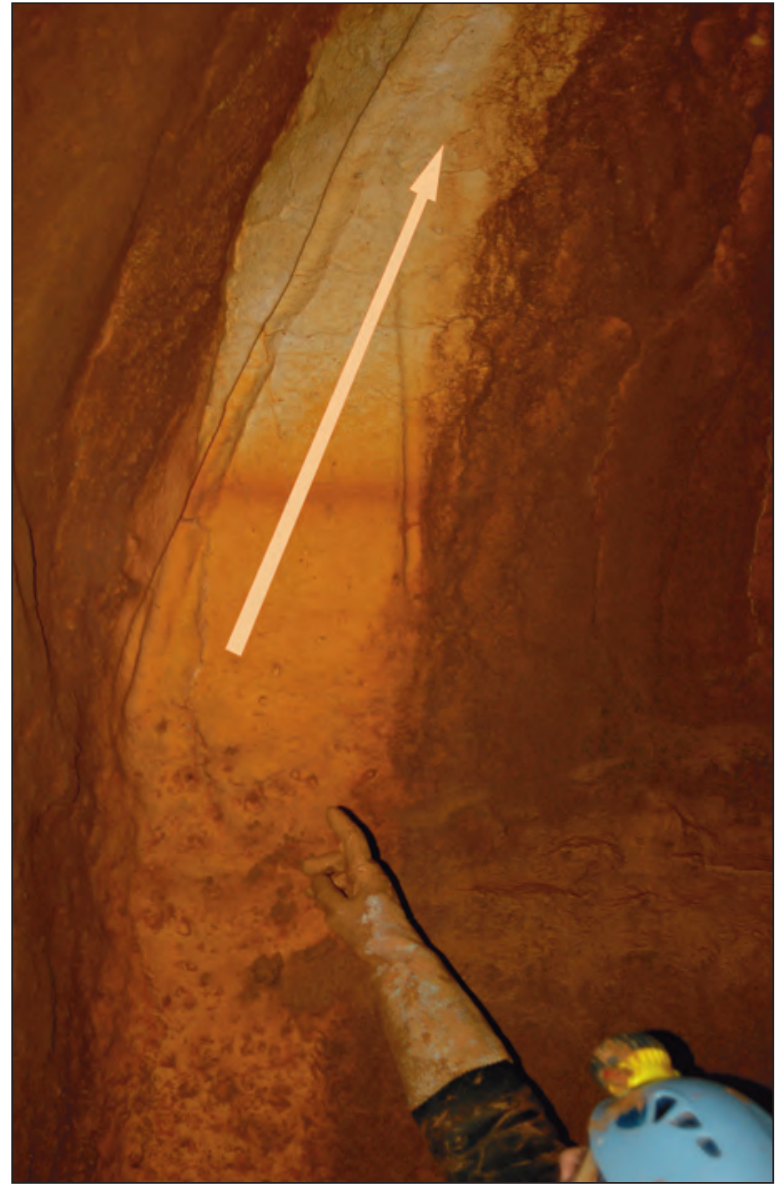

Photo 7

Flûte pariétale se développant dans les calcaires au contact du remplissage argileux et témoignant d'une phase paragénétique nette avec des circulations hydrologiques limitées, réseau de la Воиe.

nouveau que, dès que le dépôt se structure en dunes ou en talus pentus, la topographie du plafond s'élève et est affectée de coupoles plus ou moins accentuées. Cette étroite relation entre les variations du sommet du remplissage argileux et la topographie du plafond suggère une évolution paragénétique du réseau pendant une phase importante.

Dans ces mêmes secteurs ont également été relevés des témoins de très vieilles concrétions de grandes dimensions (métriques à plurimétriques) qui ont été entièrement corrodées. Certaines sont en paroi (salle ovoïde du fond), d'autres sont effondrées (jonction du réseau des Grands Puits et d'Orgnac III). Au stade actuel de nos travaux, il est délicat de rapporter cette phase érosive noyée à la «phase paragénétique». Vers le sud, l'étude des Salles Rouges a permis de poser un argumentaire plus développé sur l'ancien fonctionnement paragénétique d'Orgnac et d'en préciser les étapes spéléogéniques. 
Figure 7

Coupe synthétique du réseau des " Grands Puits". Le secteur des Grands Puits permet de mettre clairement en avant l'adéquation entre la géométrie du remplissage argileux («dunes») et la présence de cheminées ourlées de «banquettes-limites» et de morphologies de creusement en régime noyé.
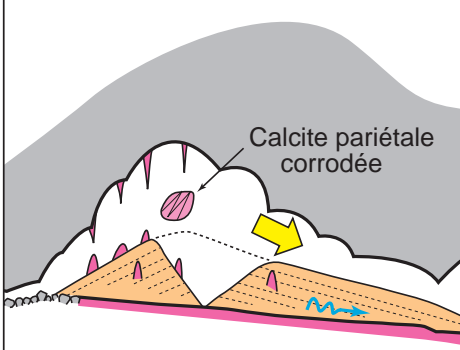

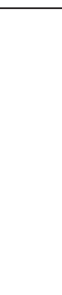
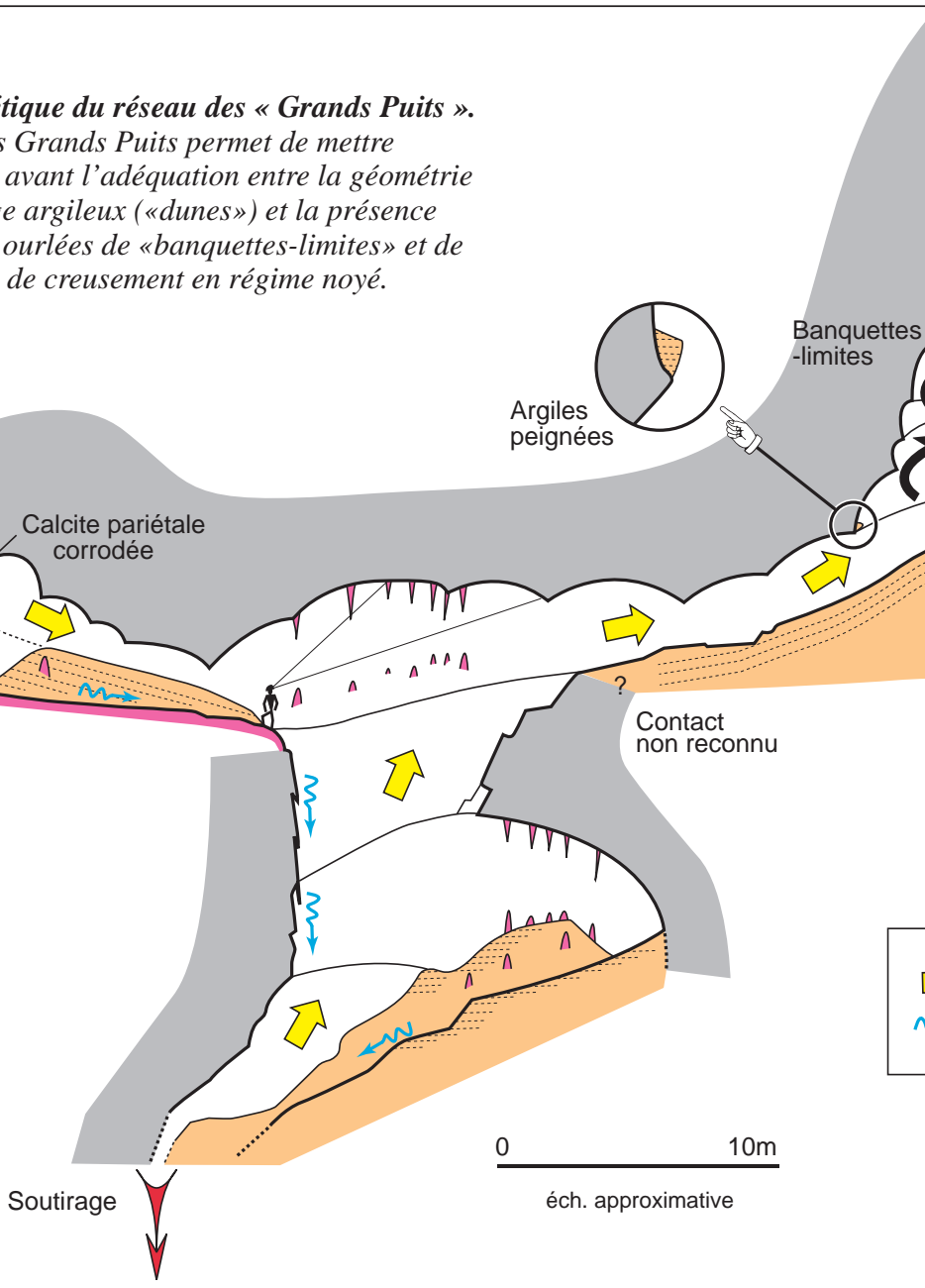

\section{IV - Les Salles Rouges : L'ÉLOQUENCE DU PARAGÉNÉTISME}

Les Salles Rouges se développent à $180 \mathrm{~m}$ NGF et constituent le terme de la partie touristique. Le gigantisme de ces salles associé à leurs morphologies pariétales et de plafond ainsi qu'à la puissance du remplissage argileux (dunes et soutirages) scellé par un concrétionnement démesuré en font un site de choix pour étudier la spéléogenèse d'Orgnac. De plus, il s'agit d'un des rares secteurs où il est possible d'observer les formes quasi «initiales »; en dehors de quelques édifices stalagmitiques basculés, tout est en place. Pour étudier cette immense «salle» et réaliser une étude détaillée de sa morphogenèse, un levé complet a été réalisé par laserscanning (Lidar Ilris Optech) (photo 8); ce type de relevé permet de travailler sur un nuage de plusieurs millions de points avec une maille de l'ordre de $30 \mathrm{~mm}$ et de restituer cet objet souterrain en 3D. L'objet étudié fait plus $130 \mathrm{~m}$ de longueur, $30 \mathrm{~m}$ de hauteur et $40 \mathrm{~m}$ de largeur. Pour réaliser un tel levé, plus de 60 scènes ont été nécessaires sous terre, puis assemblées sur un logiciel dédié (Polywork). Le traitement des données a permis de générer un modèle triangulaire irrégulier (TIN) à partir du nuage de points (figure 8).

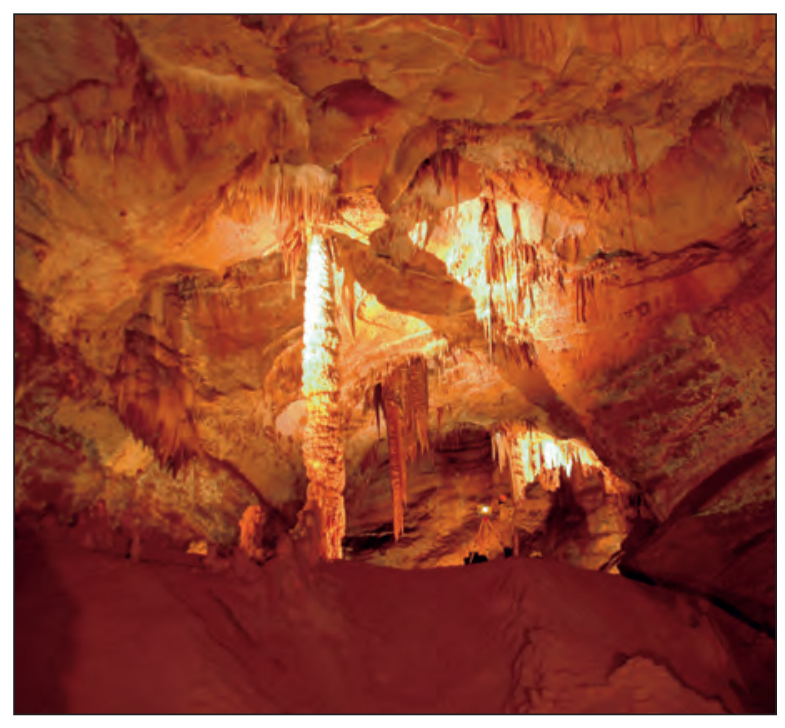

Photo 8

Mise en ouvre du lidar Ilris Optech dans les Salles Rouges de l'aven d'Orgnac.

Chaque scène permet de couvrir une fenêtre de $40^{\circ} \times 40^{\circ}$ avec une résolution de l'ordre de $30 \mathrm{~mm}$. On relève de part et d'autre les banquettes-limites témoignant de la mise en place de la galerie par aggradation de remplissage sédimentaire et corrosion associée de la voûte de la galerie. 
On identifie clairement, sur la restitution 3D (figure 9), les banquettes-limites de parois de plusieurs décimètres de large. D'une rare éloquence, les banquettes tranchent nettement avec la stratification (orientée SE). Toujours sur ce modèle, il est possible de mesurer finement les longueurs, largeurs, rayons de courbure et autres paramètres caractérisant ces formes pariétales majeures. L'outil utilisé permet de multiplier les mesures en plusieurs points de l'objet, de les resituer spatialement et de comparer leur géométrie avec d'autres indices morphogéniques présents dans la galerie. C'est donc une étude détaillée et complète de ces formes qu'il est possible de faire. Ces banquettes marquent chacune des stades d'arrêt de l'aggradation sédimentaire avec une corrosion importante de la voûte et des parois. Leur profil longitudinal est en " montagnes russes », constituant une des caractéristiques paragénétiques des réseaux anciennement noyés parcourus par des écoulements lents et favorables à la sédimentation des éléments les plus fins; sédimentation qui n'est pas homogène spatialement (structure en dunes). La fin de l'aggradation sédimentaire se traduit par une dernière banquette et un plafond généralement plan. Il est donc possible de reconnaitre la paléo-limite supérieure de cette aggradation à partir de la ligne de l'ultime banquette supérieure.

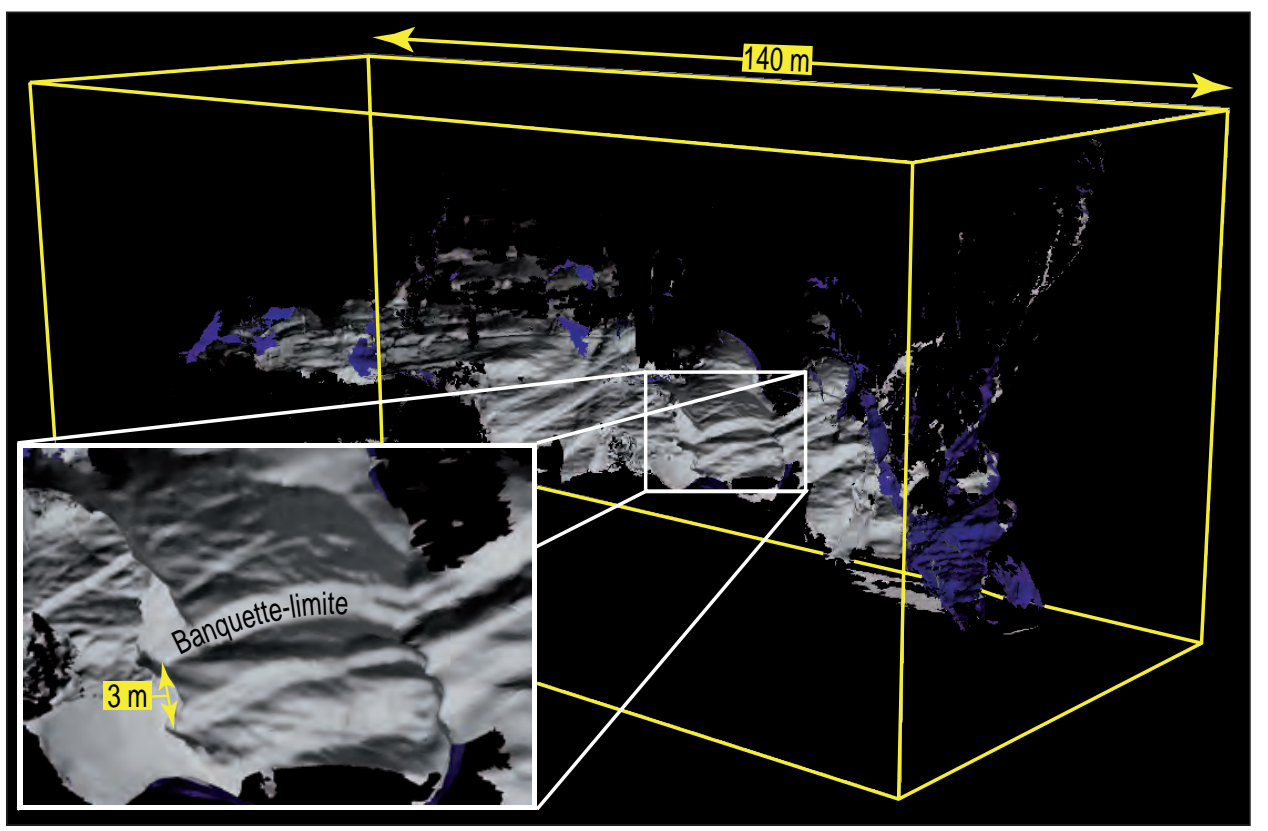

Figure 8

Le modèle 3D des

Salles Rouges est

réalisé avec une maille fine de l'ordre de $30 \mathrm{~mm}$. Il permet d'étudier les formes (élargissement ou rétrécissement du conduit, banquettes-limites, etc.) et de quantifier finement l'évolution de ces formes dans l'espace du volume karstique investigué.

Figure 9

Extrait du modèle 3D mettant en évidence la stratification et une série de banquettes-

limites (fond des Salles Rouges).

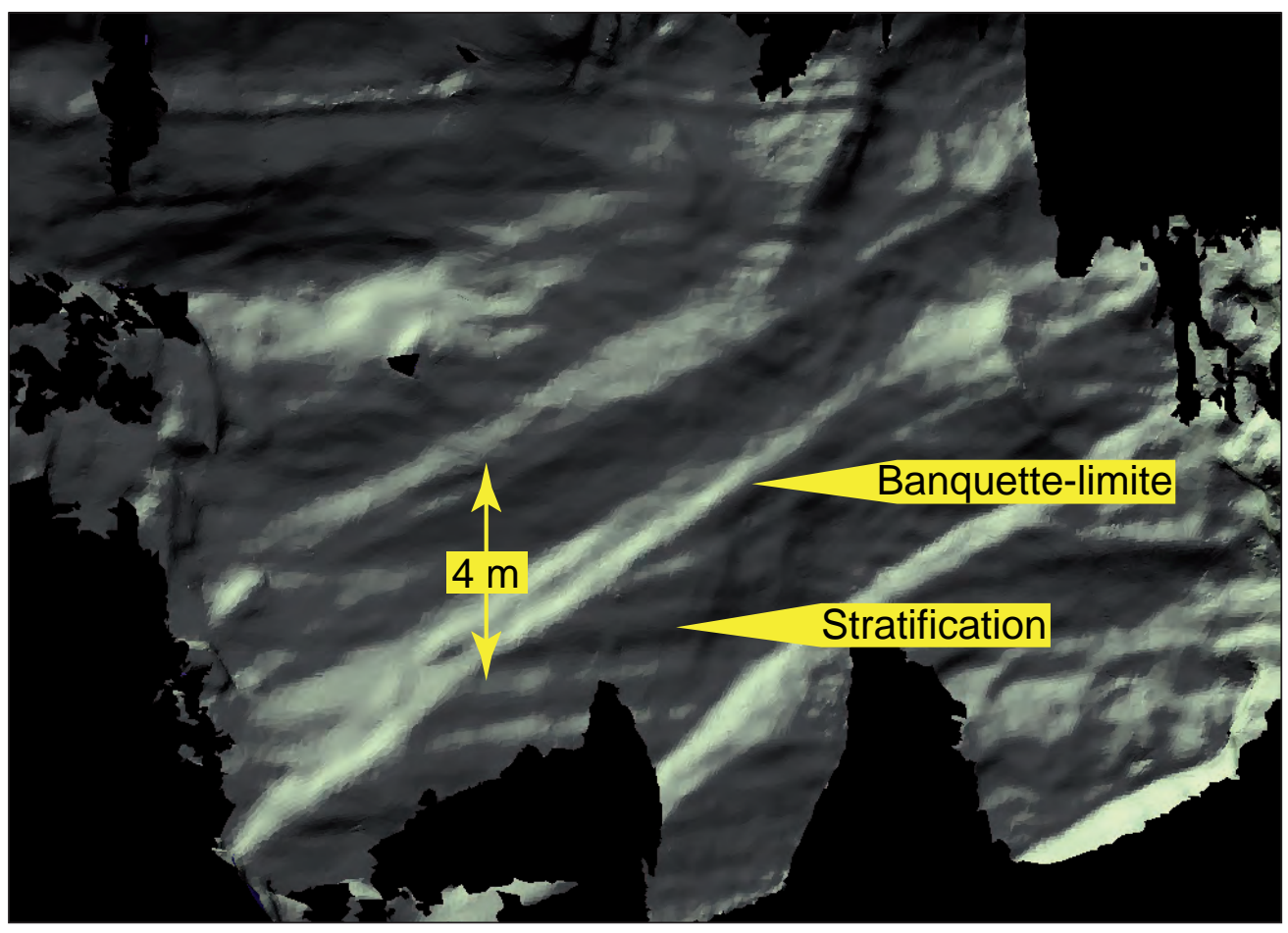


L'étude fine et quantifiée des banquettes des Salles Rouges permet de proposer la reconstitution morphogénique suivante de l'aggradation du remplissage endokarstique.

Une douzaine de coupes transversales (figure 8) permet de suivre spatialement sur un profil vertical, la construction des banquettes de bas en haut : chacune de ces banquettes permet de reconstituer la limite supérieure $\mathrm{du}$ remplissage argileux (figure 10). Peu d'observations sur site fossile permettent de reconstituer avec précision la ligne supérieure d'un ancien remplissage dans un profil en travers de galerie. Généralement admise plutôt bombée, parfois envisagée incisée, il ne nous est guère possible en l'état de dessiner cette ligne avec précision. Par souci de simplification, on pose ici comme hypothèse que cette ligne était plus ou moins proche de l'horizontale. On peut alors rejoindre (virtuellement) en vis-à-vis les banquettes et, à terme, notre objectif sera de reconstituer la section noyée et de pouvoir, à partir de vitesses limites, conditionnées par le dépôt argileux, proposer des débits bornés. La vérification devra être faite que l'évolution de la section mouillée en profil longitudinal reste constante; le modèle 3D nous permettra ici de contrôler ce paramètre. Dans cette perspective, la superposition des banquettes-limites des Salles Rouges de l'aven d'Orgnac constitue un nouveau type de mémoire morphologique pour suivre la remontée du niveau du remplissage. Cette évolution spéléogénique est bien entendu conditionnée par des causes externes qui seront analysées ultérieurement (chapitre 6).

Au cours des relevés et travaux dans les Salles Rouges, il est rapidement apparu nécessaire d'appréhender au mieux la structure « interne » du remplissage argileux des Salles Rouges afin de relever ou non la présence de stratification pouvant être rattachée aux différentes phases d'aggradation et d'évaluer l'épaisseur de la pile sédimentaire. Pour mener à bien cette étude, un forage a été réalisé dans cette partie du réseau.

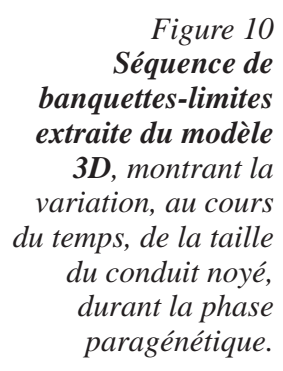

Figure 10 nquettes-limites extraite du modèle 3D, montrant la variation, au cours durant la phase paragénétique.

\section{V - UN DÉPÔT SÉDIMENTAIRE CONTEMPORAIN DU CREUSEMENT}

Afin de reconnaitre la nature et l'épaisseur de la série argileuse subsistant dans les Salles Rouges et en d'autres secteurs d'Orgnac, plusieurs séries de forages ont été réalisées. Une première expérience menée dans la Salle 2 d'Orgnac II a permis de «descendre » sur plus de $7 \mathrm{~m}$ sans rencontrer d'obstacle majeur. Dans les Salles Rouges, la même expérience a pu être conduite grâce à l'installation d'une poulie de renvoi au plafond permettant ainsi de soutenir le train de tige. Il a été ainsi possible d'atteindre la côte de $12,5 \mathrm{~m}$ où le sondage a buté sur un niveau caillouteux.

Le sondage des Salles Rouges (figure 11) a livré une série d'informations de premier intérêt sur la nature des dépôts qui tapissent le fond de ces salles.

La partie supérieure du remplissage est composée par 3,5 m d'argile rouge sans stratification apparente surmontant un fin plancher stalagmitique, témoin d'une phase d'émersion (désennoyement). Sous cefin plancher, des niveaux plus grossiers (sables fins) témoignent d'une autre dynamique des écoulements souterrains (énergie plus importante). À partir de ce point jusqu'au fond du sondage, soit sur près de dix mètres, la série se compose de nouveau d'argiles, ici jaunes à vertes, dans lesquelles s'intercalent des niveaux limoneux. Le fond de l'actuel sondage bute sur un ensemble sableux d'environ un mètre d'épaisseur qui répond à une autre logique de circulation. Il est tentant de rapporter celui-ci à un stade antérieur à l'aggradation argileuse contemporaine du « paragénetisme ». Cette éventuelle piste n'est au stade actuel des connaissances qu'hypothétique.

À la lumière de ces sondages, en particulier celui des Salles Rouges, on peut distinguer deux niveaux argileux superposés (argiles vertes à jaunâtres et argiles rougeâtres) ; ce dispositif a été, par ailleurs, relevé dans une des galeries « latérales » d'Orgnac III (figures 1 et 12). Dans ce conduit de dimension modeste au regard du reste du réseau (7 à $8 \mathrm{~m}$ de section) se développent des morphologies typiques d'une genèse en régime noyé (coupoles de plafond, coupoles pariétales noyées...). Un remplissage argileux brun clair (1) est reconnu en place. Il est rendu visible (à la faveur de soutirage) dans des niches pariétales où il a pu être conservé (figure 12). Un plancher stalagmitique occupant la totalité du conduit scelle ce dépôt argileux. Une analyse sommaire de ce plancher montre la succession suivante :

Figure 11 Sondage des Salles Rouges. Cette figure a pour objet de mettre en avant deux éléments majeurs des réseaux d'Orgnac: (i) l'importante épaisseur du remplissage des galeries (ici, arrêt sur «rien») et (ii) l'importance initiale de ce remplissage qui montait auparavant pratiquement jusqu'au plafond (cf. position des plus hautes banquettes-limites). 


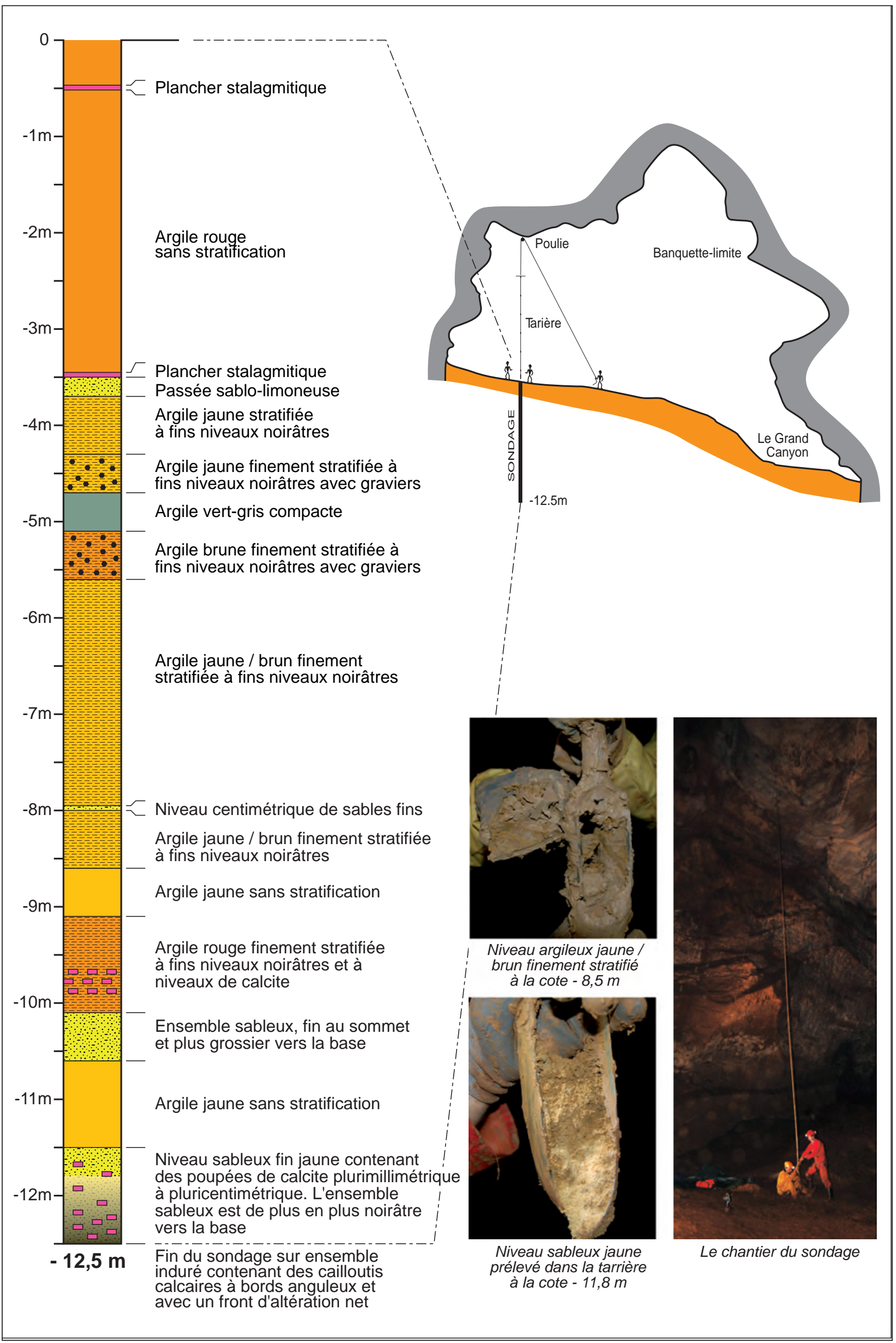




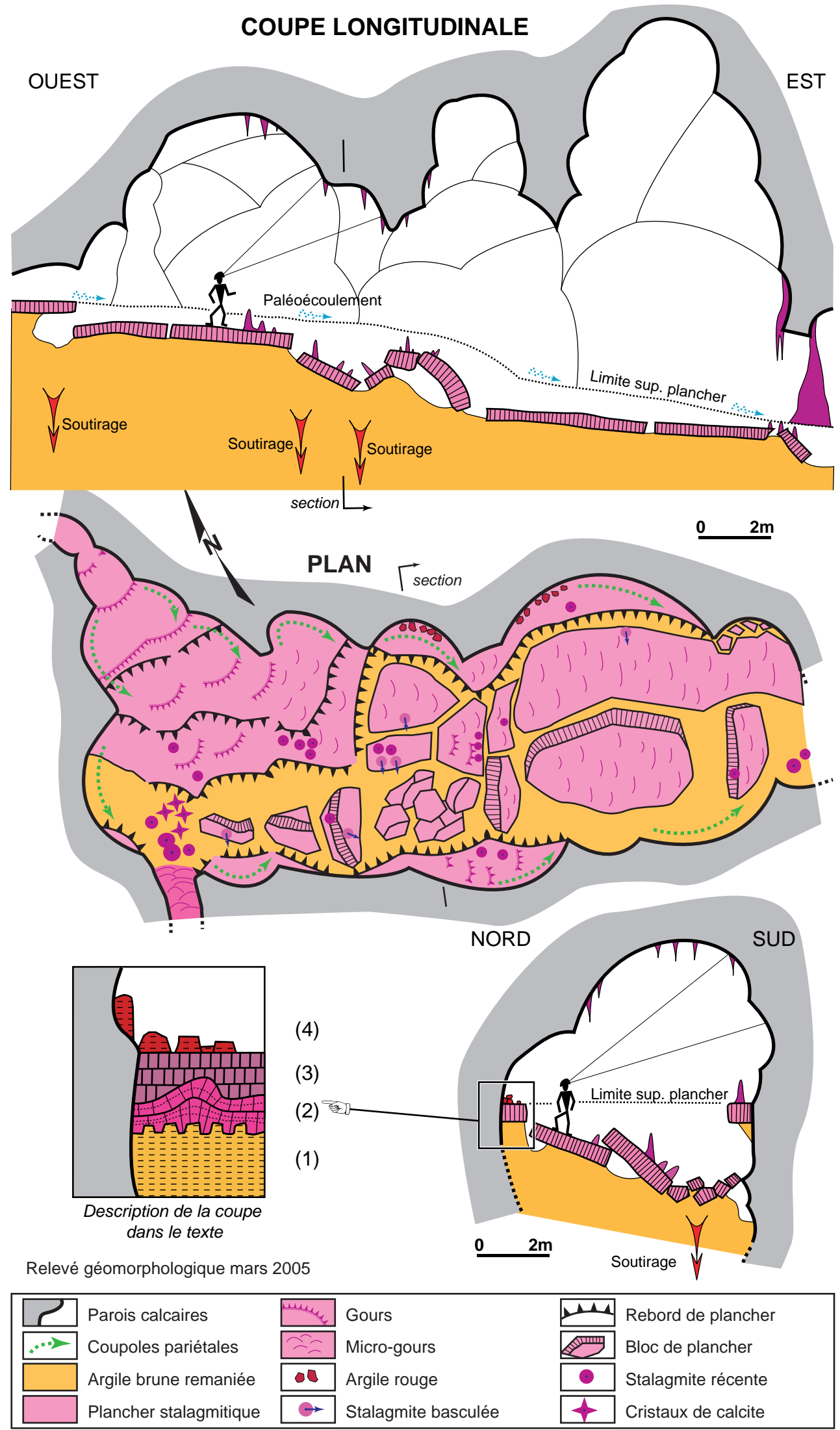

Figure 12

Relevé géomorphologique simplifié du site des "planchers basculés " dans les Salles Rouges. Plan (a), coupes longitudinale, transversale et de détail (b) et légende. Notez l'existence de deux séries argileuses distinctes (1) et (4) séparées par l'imposant plancher stalagmitique. 
- (2) À la base, une calcite rouge, laminée, à débit en plaquettes, à l'aspect pulvérulent et dont l'épaisseur varie de quelques centimètres à plusieurs décimètres.

- (3) Une calcite grise à gros cristaux la surmonte en scellant la surface terminale du plancher rouge. Il n'a pas été possible d'identifier de surface de ravinement entre les ensembles stalagmitiques (2) et (3).

Un dépôt argileux rouge (4) feutrant la série sédimentaire est également visible dans des niches latérales où il subsiste sous forme de boulettes craquelées. Ce dépôt argileux semble antérieur à la dynamique de soutirage qui affecte le plancher dans la galerie, mais ceci sans certitude.

\section{VI - Paragénétisme et soutirage : LES CLÉS DE COMPRÉHENSION DES GRANDS VOLUMES SOUTERRAINS D'ORGNAC}

L'observation, les levés et la cartographie morphologique (classique et 3D) ont permis de relever la fréquence de certaines formes et d'associations morphologiques. Les banquettes-limites constituent une des formes pariétales caractéristiques d'Orgnac ; aux variations géométriques de celles-ci répondent le plus souvent en écho les variations topographiques du plafond du conduit. Ces formes et la présence d'une puissante série argileuse invitent à poser l'existence « d'une » phase paragénétique majeure. "Cette » phase serait à l'origine d'une corrosion s'exerçant préférentiellement à la voûte des conduits ; chaque aggradation argileuse se traduisant par une phase corrosive ascendante (se faisant aux dépens des morphologies antérieures de plafond). Dans le cas des Salles Rouges, cette aggradation, associée à la corrosion de la voûte, a pu s'établir sur une hauteur de plusieurs dizaines de mètres, voire d'une centaine de mètres si l'on rattache les cheminées-coupoles à cette évolution originelle.

Tant que le phénomène se maintient, la galerie maintient sa section noyée. Sur la base des observations réalisées et des reconstitutions, celle-ci ne devait pas dépasser un à deux mètres de hauteur pour une largeur d'environ dix à vingt mètres.

Condition nécessaire au gigantisme des réseaux d'Orgnac, le fonctionnement paragénétique ne suffit pas à lui seul à expliquer l'importance des salles et des galeries de cette cavité. L'importance des volumes souterrains d'Orgnac est liée à l'évacuation du remplissage argileux. Cette évacuation résulte d'une évolution courant sur du temps long et issue d'un ensemble de processus différents : soutirages, lessivages, glissements progressifs des talus argileux (voir article suivant). C'est l'ensemble de ces processus qui, en évacuant progressivement le remplissage argileux, est responsable de l'importance des volumes souterrains. Là où l'évacuation du remplissage est indigente, le réseau reste de dimensions modestes (rétrécissements, par exemple, entre les Salles 1 et 2, ou entre les Salles 2 et 3 ). Là où l'évacuation a été importante, se développent de grands volumes souterrains (Salle 2, Salles Rouges...). Un des principaux «moteurs» d'évacuation du remplissage argileux paragénétique d'Orgnac est le soutirage. La géographie des soutirages obéit à une loi de répartition totalement indépendante de l'axe général subméridional du réseau originel. Si le premier est sous la commande d'un apport hydrique et détritique et d'un niveau de base précis, la phase de soutirage est associée à une verticalisation généralisée des écoulements souterrains que l'on ne peut que rattacher à un abaissement du niveau de base.

L'association «d'une longue » phase d'aggradation détritique et de corrosion associée de la voûte, et «d'une longue» phase d'évacuation du matériel argileux permet de répondre à la genèse des importants volumes souterrains de l'aven d'Orgnac et ceci sans invoquer des écoulements souterrains énormes. C'est plus l'importance de la «dimension temps » qui est ici à prendre en compte et à mettre en exergue.

Exceptionnellement, le réseau connait des mises en charge épisodiques qui réennoyent temporairement le réseau. La mise en charge la plus récente date de septembre 2002 qui a affecté 1'ensemble des Cévennes et le Sud Ardèche. Durant cet épisode pluviométrique exceptionnel, les Salles Rouges se sont ennoyées jusqu'à la côte de 188 m NGF (photos 9, 11 et 12). L'occurrence de ce phénomène n'a pu être à ce jour évaluée car jusqu'alors on n'imaginait pas qu'un tel réennoyement des galeries d'Orgnac était possible. Avec le recul et la connaissance de la géométrie de l'actuelle zone noyée d'Orgnac (toit de la zone noyée en connexion avec la Cèze d'après les relevés piézométriques de F. Bourges et d'A. Mangin), on peut raisonnablement imaginer que ce phénomène d'ennoyement est synchrone des

Photo 9

En septembre 2002, la lente montée de l'eau dans les Salles Rouges a submergé la plateforme, dernière station de la visite touristique (photo Stéphane Tocino).

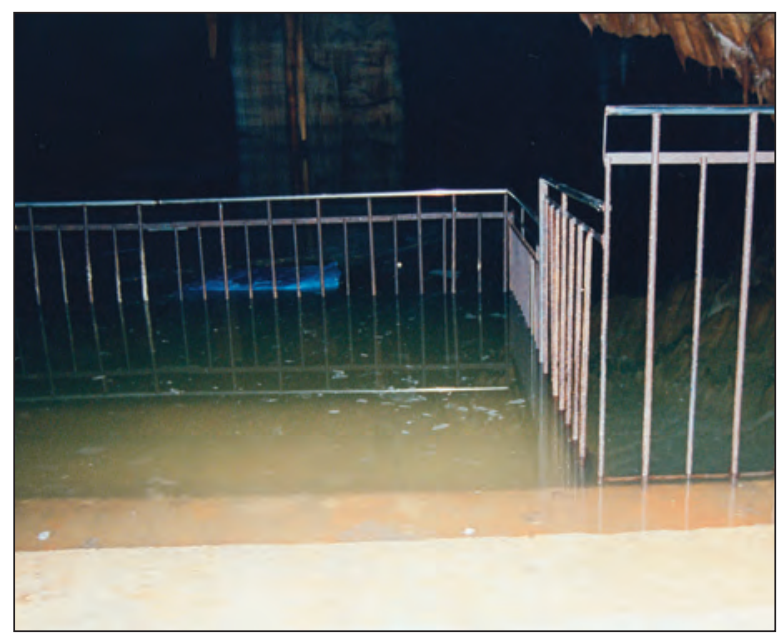




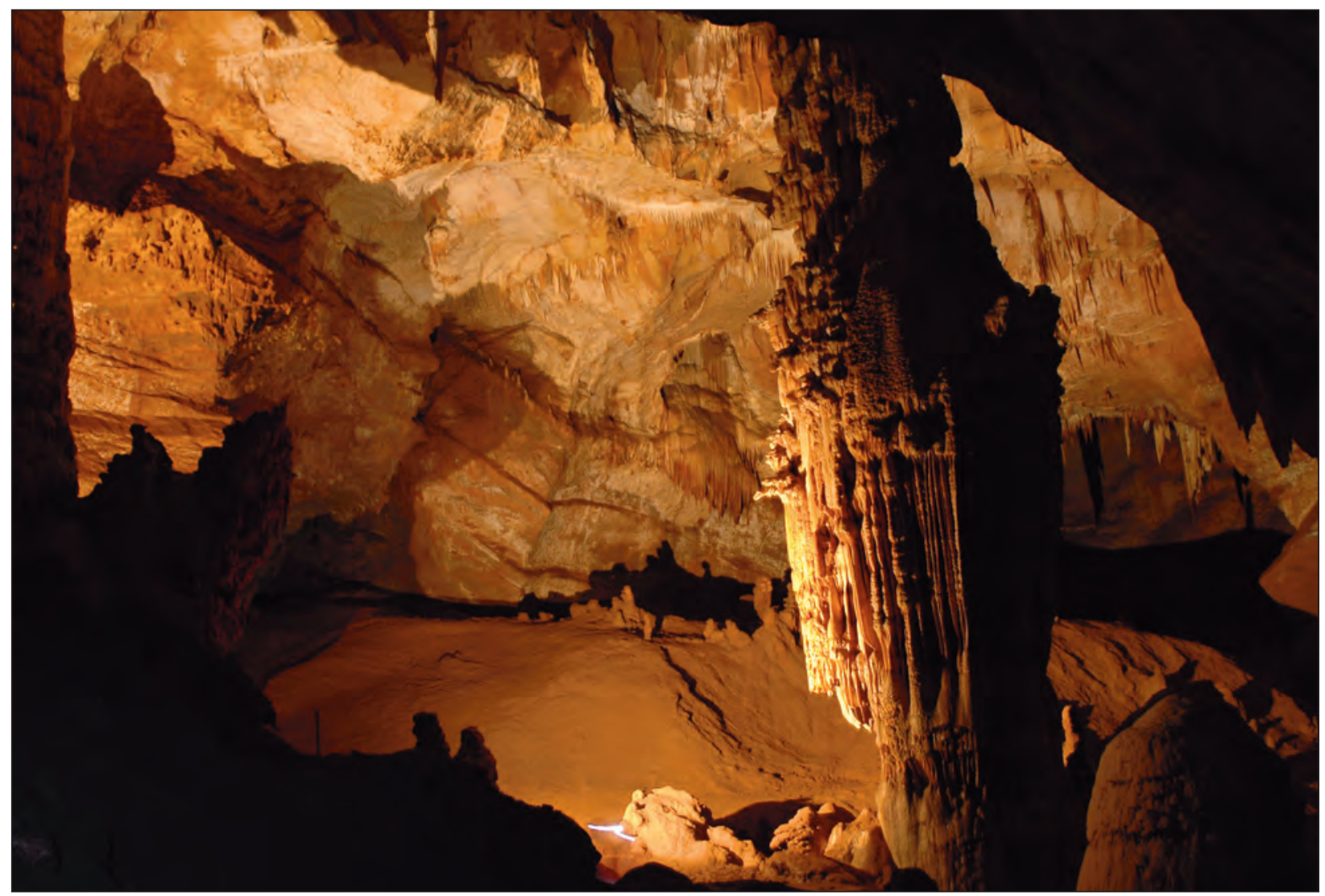

Photo 10

Étagement des banquettes-limites dans les Salles Rouges. Chacune témoigne d'une phase d'aggradation du remplissage sédimentaire argileux. Notez le profil longitudinal en montagnes russes (la hauteur entre les deux grosses banquettes est de l'ordre de deux mètres).

crues centennales voire millénales affectant la Cèze. Nous attribuons à ces événements exceptionnels mais répétés sur une longue échelle temporelle, les dépôts secondaires d'argiles rouges brunâtres, observés dans le réseau d'Orgnac ; les épaisses argiles jaunes à vertes étant, quant à elles, rattachées à la phase paragénétique du réseau.

Les différentes phases d'évolution du réseau (figure 13) mises ici en avant suggèrent que le moteur de cette évolution soit commandé par les des conditions géomorphologiques externes. La phase paragénétique (phase 1) milite en faveur d'un niveau de base remontant et d'un niveau d'alimentation stable. La phase de soutirage (phase 2) marque une réorganisation complète des écoulements souterrains traduisant un abaissement généralisé du niveau de base et d'un changement des modes d'alimentation. Enfin, la phase des mises en charge (phase 3) montre que l'état stationnaire du système n'est pas encore atteint et que la structuration du karst durant la phase 2 ne permet pas de drainer la totalité des écoulements notamment lors des situations hydrologiques exceptionnelles.

Le recoupement de ces différentes phases avec les données morphogéniques présentes en surface (chapitre 6) permet de proposer un premier scénario karstogénique qui reste à préciser et à caler dans le temps ainsi que spatialement :
-1- La phase paragénétique, dite « $1 »$ car elle correspond aux témoins les plus anciens recensés dans la cavité, pourrait trouver une limite supérieure vers $250 \mathrm{~m}$ d'altitude. En effet, aucune accumulation argileuse conséquente n’a été observée au-delà de cette côte. La platitude de la Salle Plane (à 250 m NGF) milite de même en ce sens. Des éléments (développés dans le chapitre 6) suggèrent qu'un réseau hydrographique aurait pu participer à l'alimentation du karst d'Orgnac vers $260 \mathrm{~m}$ NGF. La limite inférieure de cette phase, c'est-à-dire la base de la série argileuse, n'a pu être déterminée. Le sondage dans les Salles Rouges montre qu'elle se situe au plus haut vers 170 à $180 \mathrm{~m}$ NGF.

La plupart des banquettes-limites qui témoignent d'une évolution paragénétique ont été identifiées au plus haut vers les côtes altitudinales de 250 à $260 \mathrm{~m}$. Dans le puits d'entrée de l'aven d'Orgnac, certaines ont pu être reconnues jusqu'à $280 \mathrm{~m}$. Des morphologies caractérisant un régime noyé ou épinoyé ont été également identifiées dans la Salle Plane à des cotes supérieures.

-2- La phase 2, phase d'abaissement du niveau de base, n'a pas de limite inférieure reconnue. On rattache les formes associées à cette phase à l'altitude du réseau hydrographique actuel : la Cèze et le Rhône, c'est-àdire aux environs de $50 \mathrm{~m} \mathrm{NGF}$. 


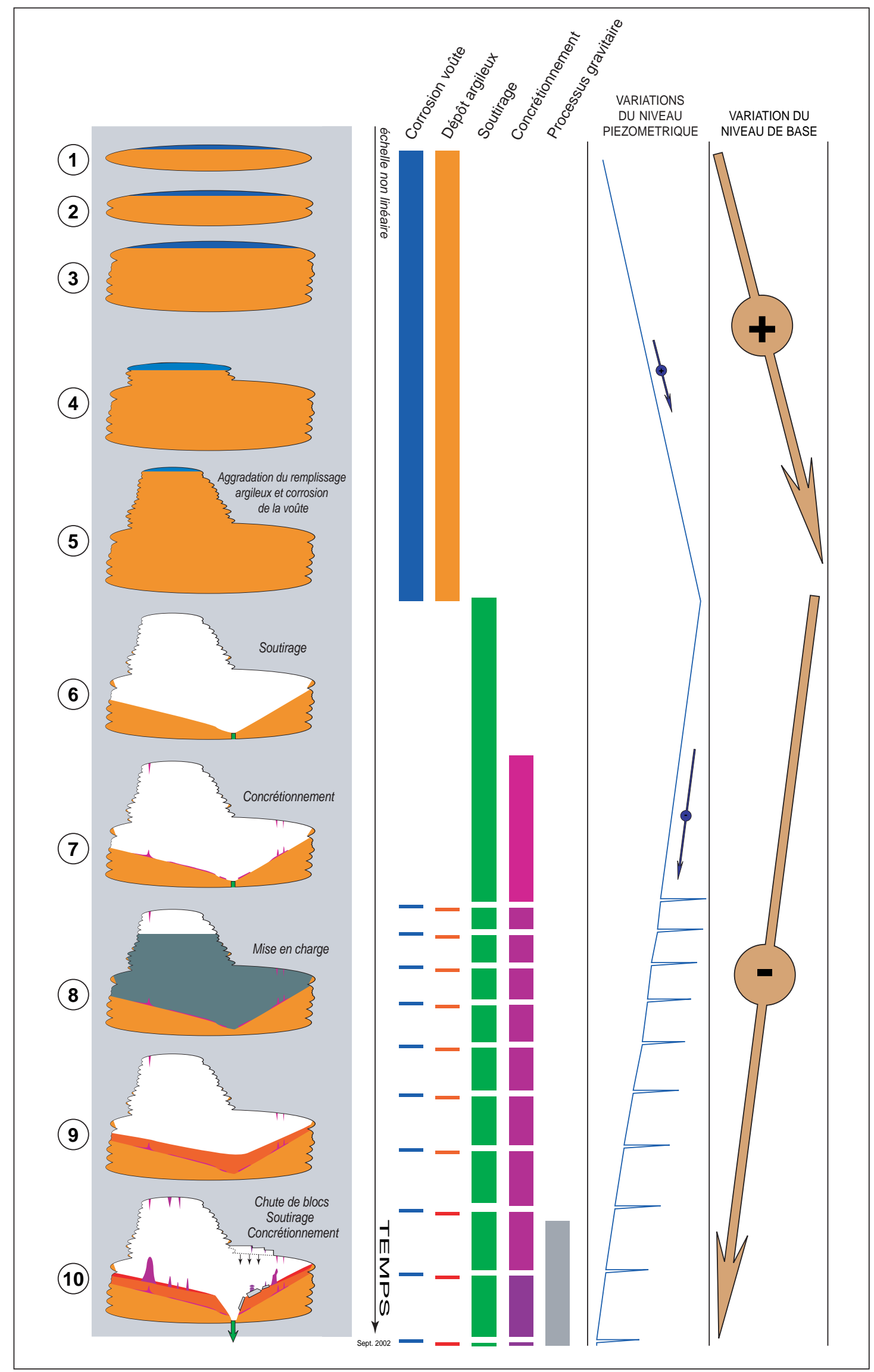

Figure 13

Reconstitution en 10 étapes de la mise en place d'un volume karstifié d'Orgnac

à partir de l'exemple des Salles Rouges. 


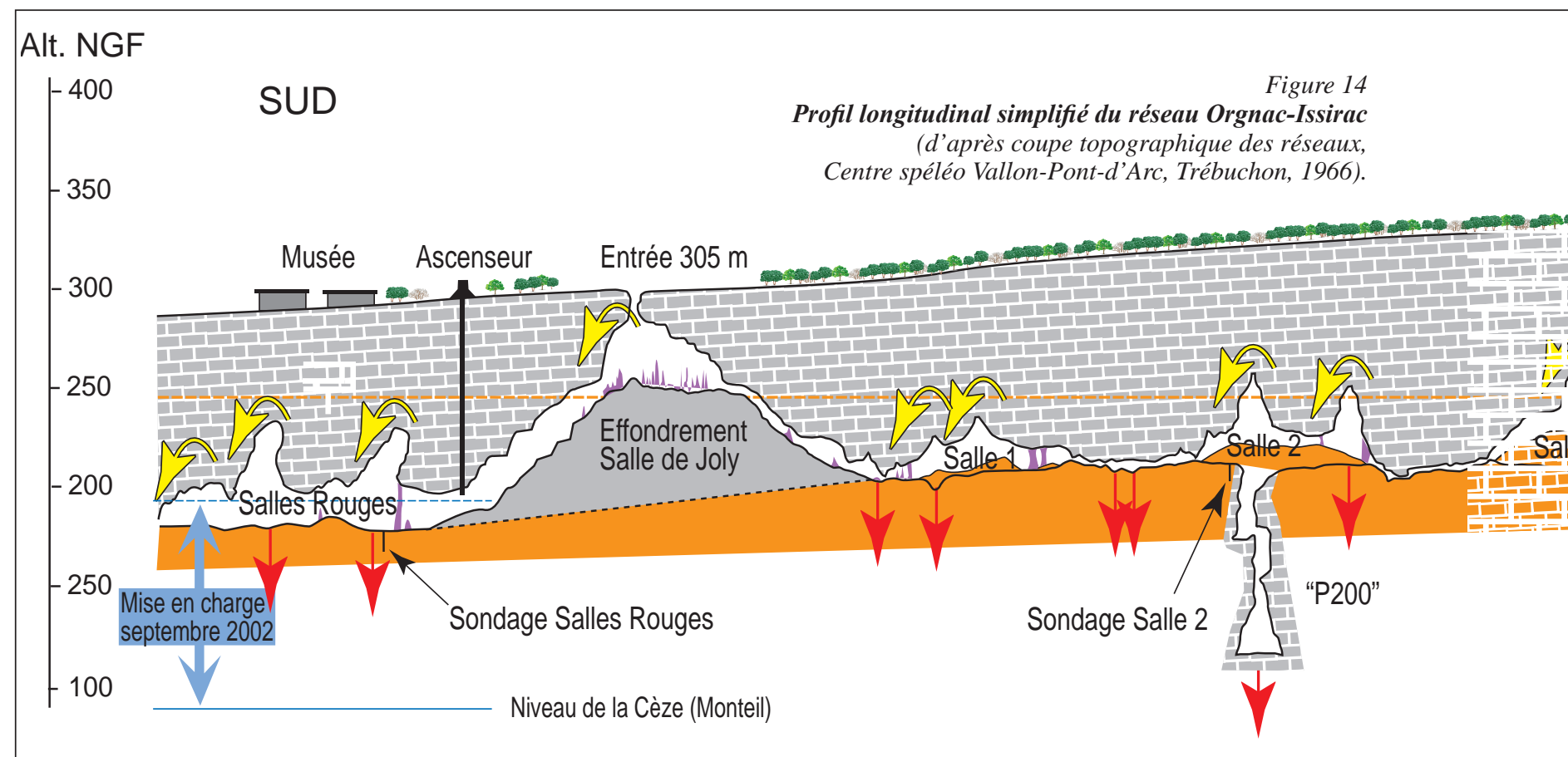

Dans les articles suivants, on s'attachera à utiliser ces cotes et cette évolution du réseau d'Orgnac pour expliquer ou compléter l'évolution paléogéographique de la Basse-Ardèche, dans le cadre notamment du cycle messino-pliocène et de l'évolution quaternaire.

\section{Conclusion}

Le gigantisme des salles d'Orgnac, s'il a pu interroger au départ les explorateurs, peut trouver des premiers éléments d'explication par l'observation des formes et des dépôts présents dans le réseau et la reconnaissance de différentes phases spéléogéniques. Le paragénétisme s'exprime avec éloquence dans l'aven d'Orgnac et son étude, en particulier par l'utilisation de visualisations et d'analyses 3D, a permis de reconnaitre qu'il s'agit « d'une » phase majeure de genèse du réseau.

Si le paragénétisme est à l'origine d'une sédimentation argileuse et du maintien du « réseau» souterrain (par dissolution concomitante de la partie supérieure du réseau), il ne permet pas d'expliquer à lui seul le gigan-
Photo 11

Vue des Salles Rouges depuis la plateforme touristique. Cette photo des Salles Rouges permet de mieux visualiser l'importance de la crue de septembre 2002 (largeur de la colonne au premier plan : $4 \mathrm{~m}$ ).

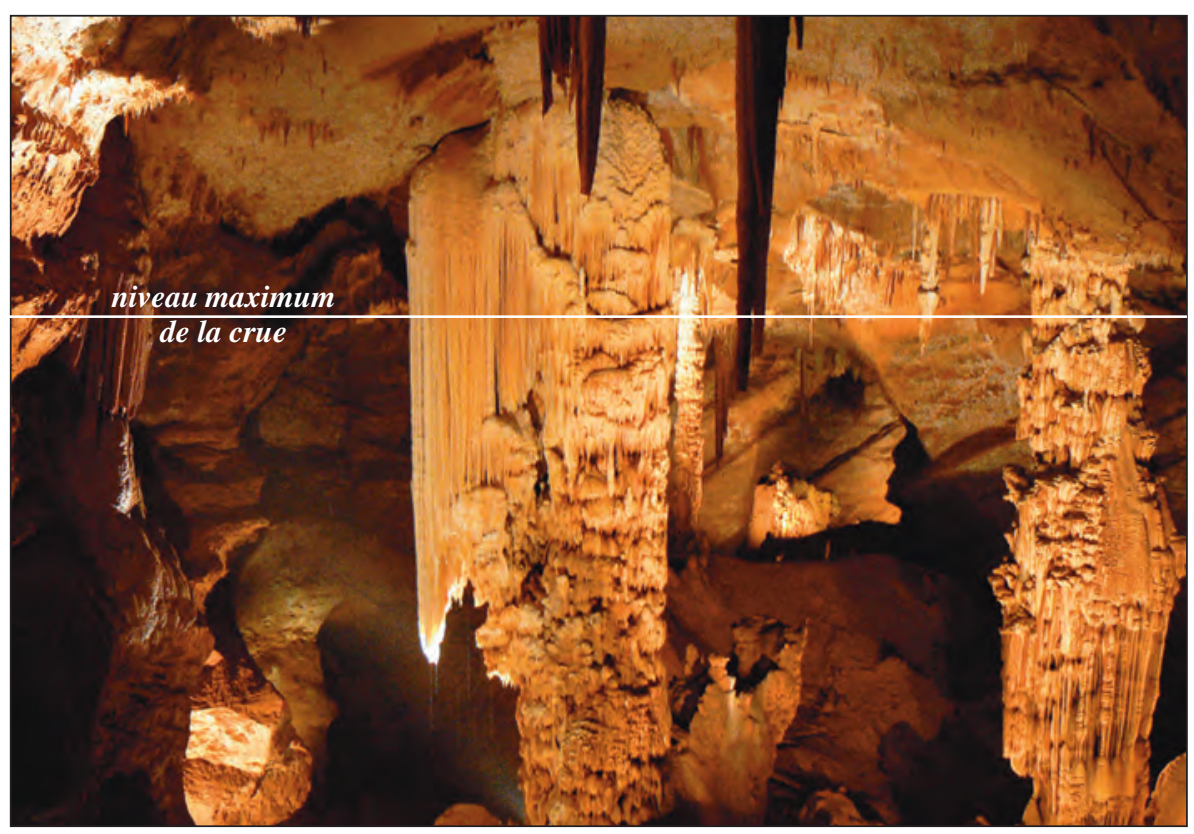


Flanc sud de l'anticlinal de Ronze

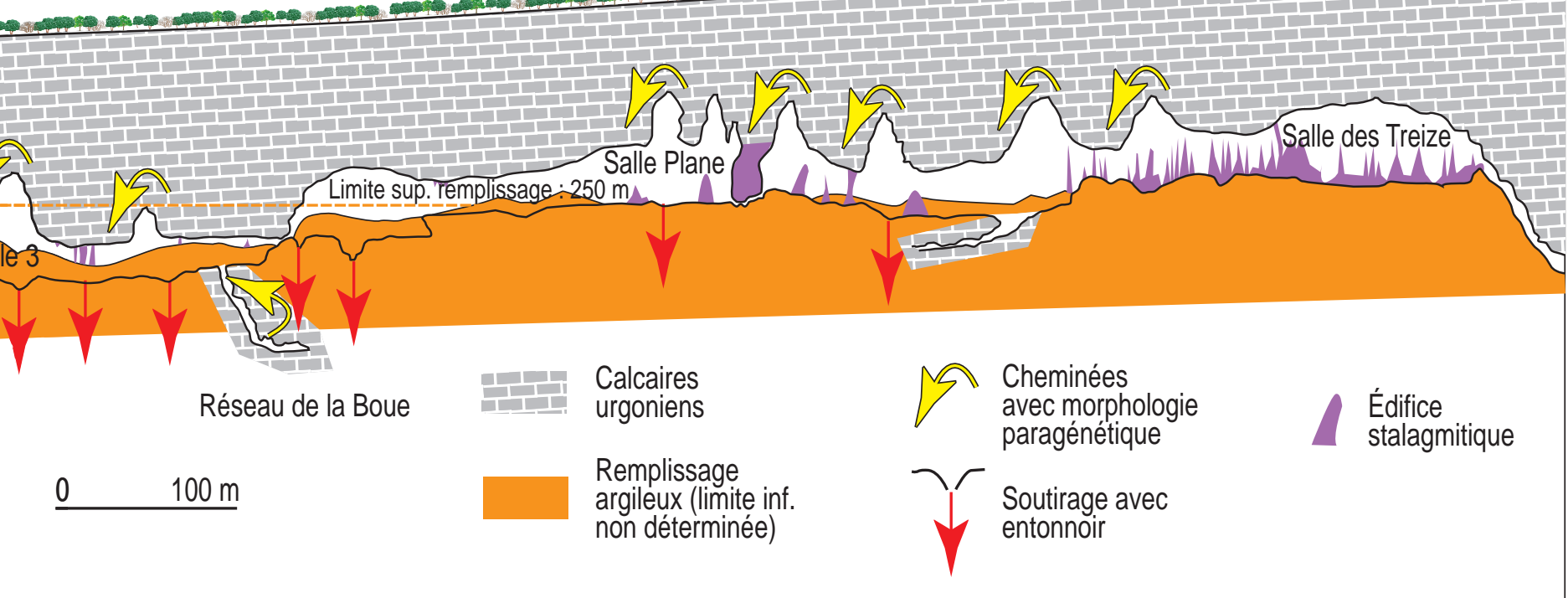

tisme des réseaux d’Orgnac : celui-ci est liéà l’évacuation progressive mais durable sur une vaste échelle de temps des argiles « paragéniques ». Cette phase dite « 2 »'est initiée dès l'arrêt du paragénétisme engendré par un abaissement généralisé du niveau de base ; les raisons de cet abaissement (relatif) sont à préciser : soulèvement du massif, abaissement du niveau de base régional...

La nouvelle structuration endokarstique ne semble pas totalement aboutie si l'on se réfère aux mises en charge, certes exceptionnelles, qui peuvent réennoyer en partie le réseau.
L'ensemble de cette spéléogenèse permet d'expliquer avec des débits raisonnables, la mise en place des plus grands volumes d'Orgnac. C'est dans cette ultime phase que se mettent en place les édifices stalagmitiques dont certains comptent parmi les plus imposants connus en France. Certains sont recouverts en partie par des dépôts argileux (associés aux phases de mises en charge précédemment présentées).

L'étude de ces dépôts dans le chapitre suivant permet de saisir les derniers moments de la longue histoire du réseau d'Orgnac.

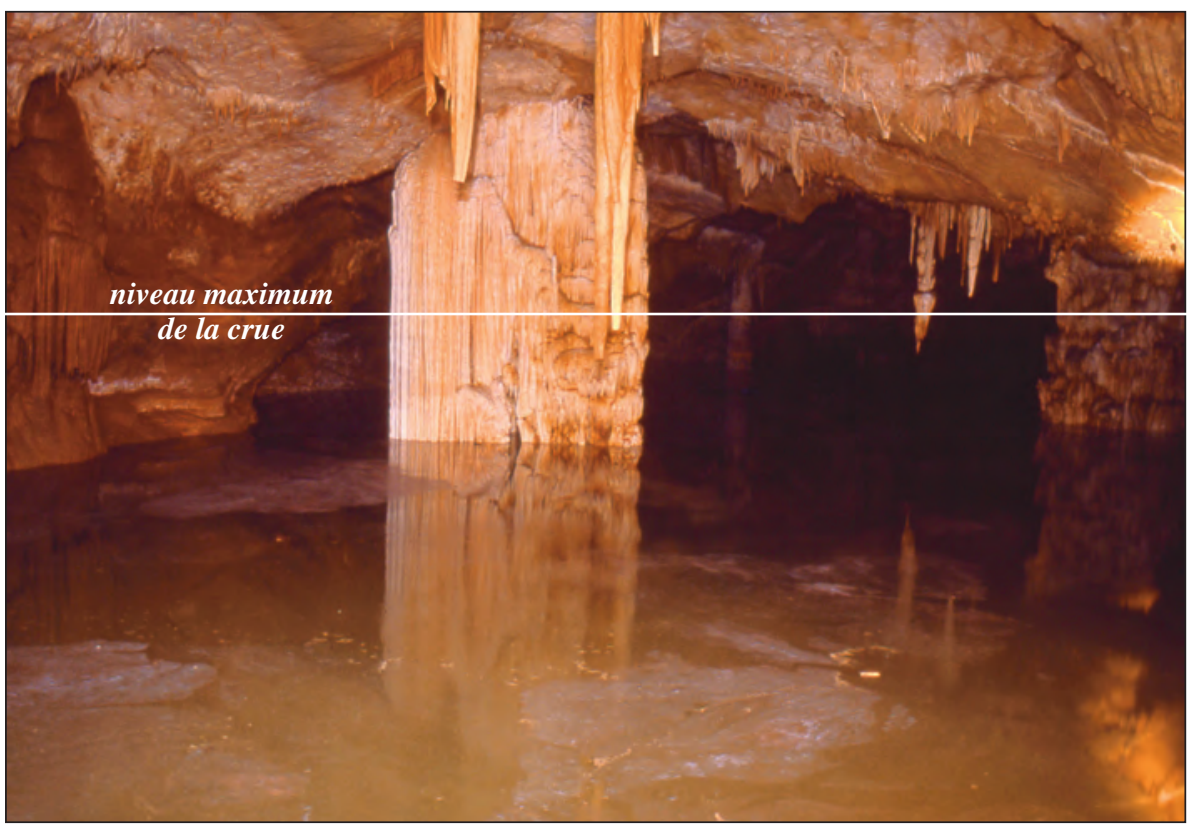

Photo 12

La crue de septembre 2002 a provoqué une mise en charge très importante des réseaux avec un ennoiement quasiment complet des Salles Rouges jusqu'à la plateforme touristique. Ce phénomène, bien qu'exceptionnel, indique la relative «proximité» du toit de l'actuelle zone noyée du karst et l'incapacité de la structure de drainage actuel à évacuer la totalité des eaux d'infiltration lors d'événements météorologiques majeurs (photo Françoise Prud'homme). 


\section{BiBLIOGRAPHIE}

Bersihand J.-L. (2006) - Étude géomorphologique des Salles Rouges, réseau I d'Orgnac-Issirac (Ardèche, France). Contribution à l'étude spéléogénique et karstogénique de l'aven d'Orgnac. TER Master 1 Géographie, Université de Savoie, EDYTEM, 85 p

Jaillet S., Bersihand J.-L., Delannoy J.-J., Sadier B. et Tocino S. (2006) - Apport de l'analyse 3D par laser scanning (Lidar) à la connaissance des banquettes-limites de l'aven d'Orgnac (Ardèche, France). Poster 21ème Réunion des Sciences de la Terre, Dijon, déc. 2006, résumé, 179-180.

Jaillet S., Bersihand J.-L., Delannoy J.-J., Sadier B. et Tocino S. (2007) - Les banquettes-limites de l'aven d'Orgnac : témoins d'une phase paragénetique majeure du réseau. Apport de l'analyse 3D par laserscanning. Actes de la $16^{\text {ème }}$ Rencontre d'octobre, 2006, Méaudre, 64-70.
Renault Ph. (1967) - Contribution à l'étude des actions mécaniques dans la spéléogenèse. Thèse d'État. Annales de Spéléologie, t. 22 (1967) et t. 23 (1968), 600 p.

Renault Ph. (1970) - La formation des cavernes. Que sais-je ?, $\mathrm{n}^{\circ} 1400$. Presses universitaires de France. Paris.

SADIER B. (2004) - Étude géomorphologique d'un grand volume karstique, exemple de la Salle 2 du réseau II d'Orgnac-Issirac, Ardèche, France. TER Master 1 Géographie, Université de Savoie, EDYTEM, 81 p.

TréBuchon J. (2000) - La saga de l'aven d'Orgnac-Issirac, l'épopée d'une fantastique découverte souterraine et ses ahurissantes conséquences, auto-édition, $240 \mathrm{p}$.

Magnifique banquette-limite en montagne russe dans le réseau de la Boue. Notez la pente $\left(45^{\circ}\right)$ des banquettes de part et d'autre du sommet du paléo-talus ainsi que la dissymétrie dans l'intervalle inter-banquette.

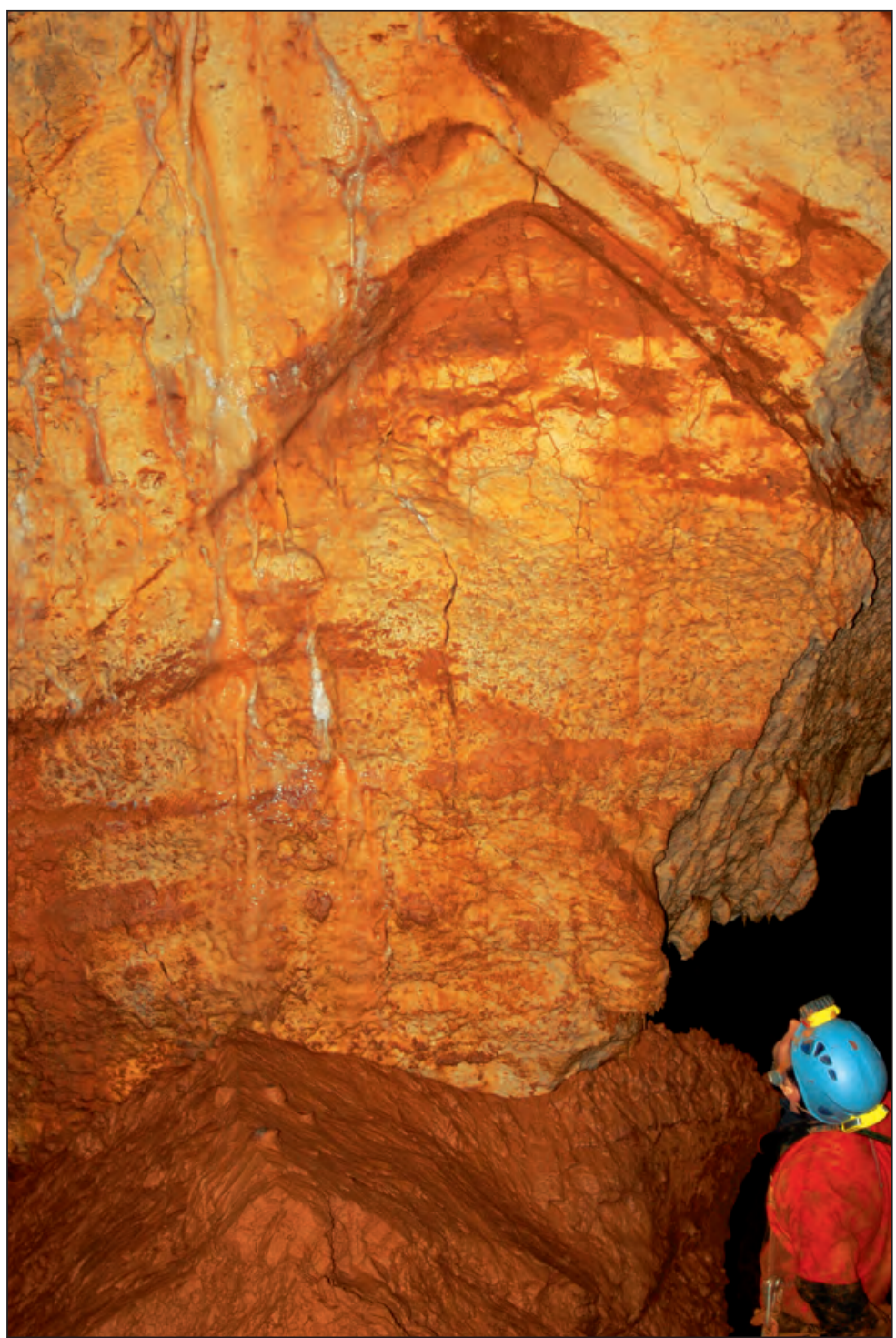




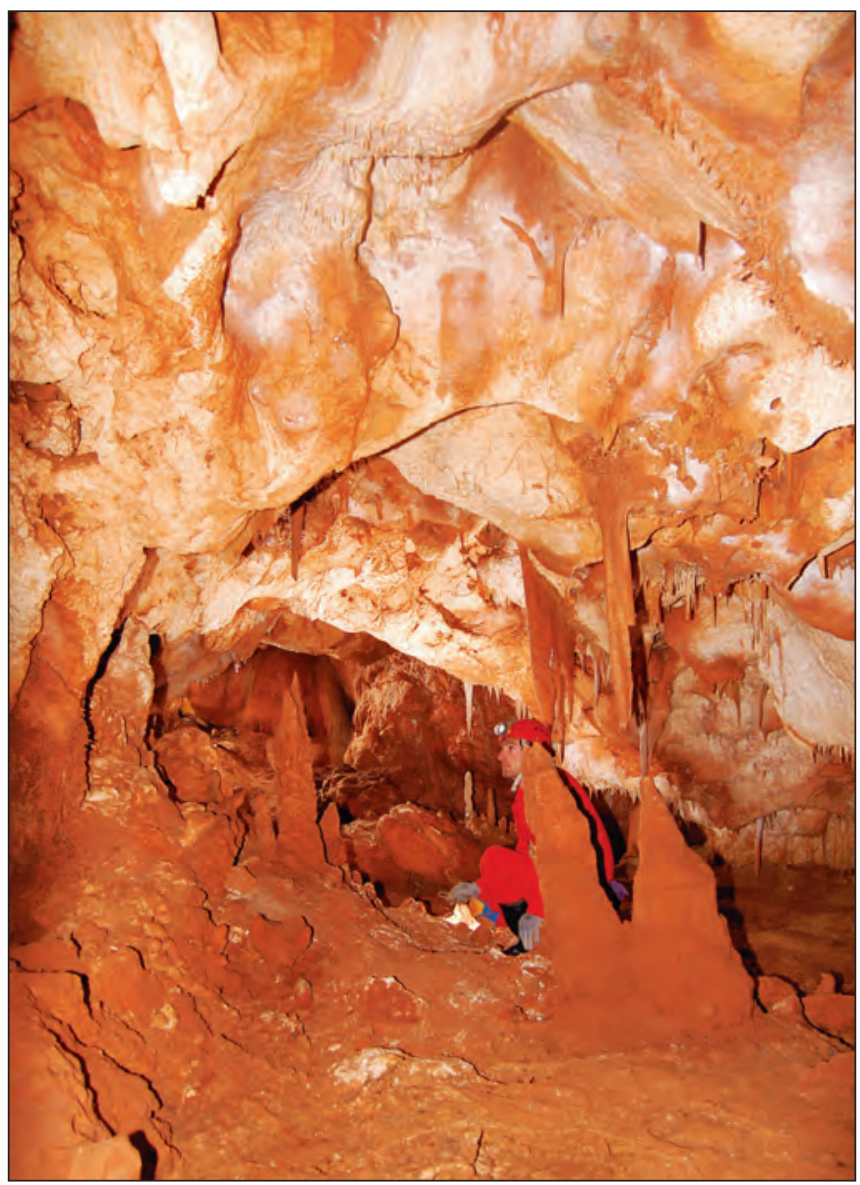

Dans les Salles Hautes du réseau I de l'aven d'Orgnac, les morphologies de plafond témoignent d'une genèse noyée (pendeloques, chenaux anastomosés...).

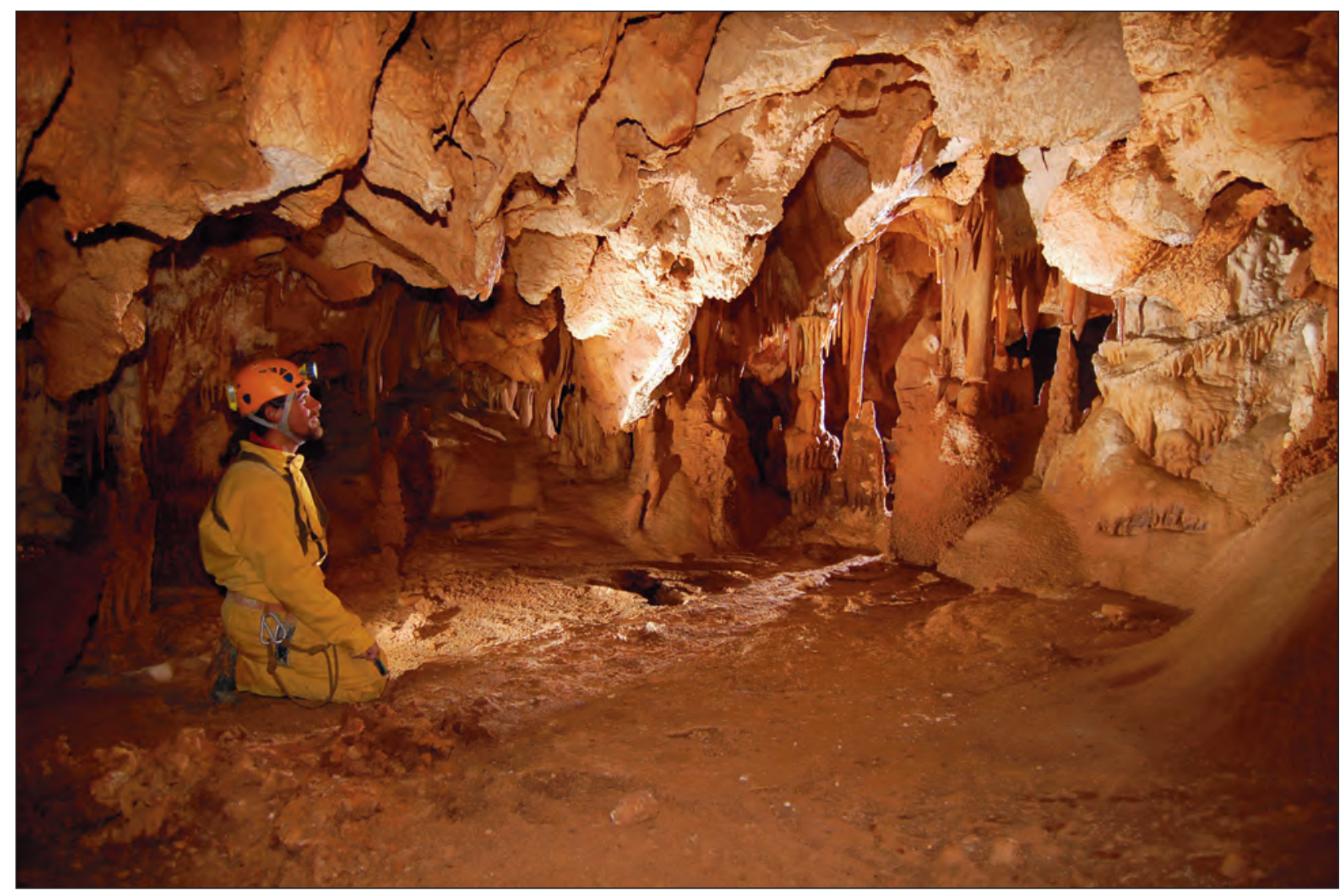




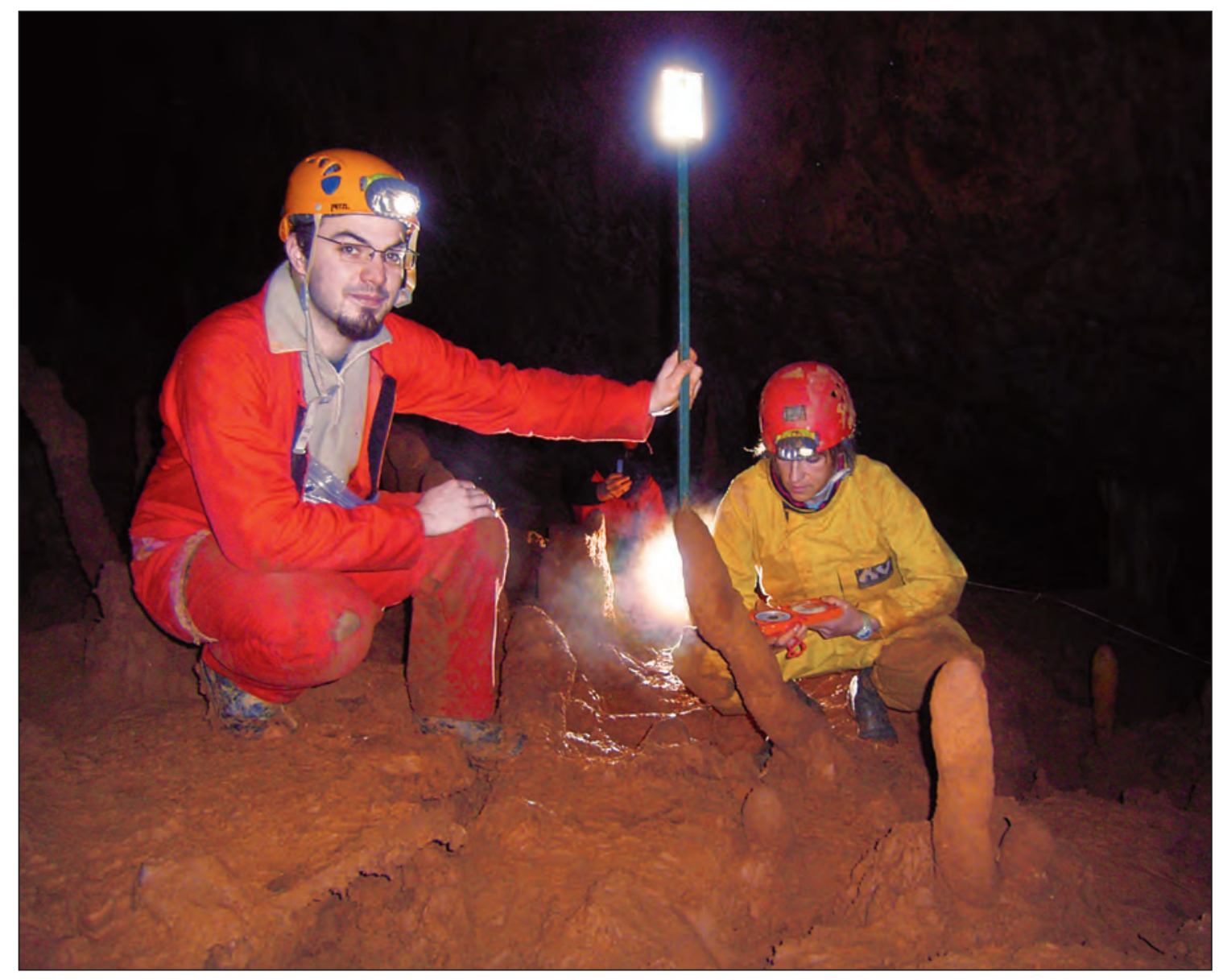

Cartographie et mesures de directions sur les stalagmites translatées de l'aven d'Orgnac (réseau I) (photo Stéphane Jaillet). 


\title{
L'AVEN D'ORGNAC
}

\section{ÉTUDE DES REMPLISSAGES, MÉMOIRES DES DYNAMIQUES SPÉLÉOGÉNIQUES POST-PARAGÉNÉTIQUES}

\author{
par Benjamin SADIER ${ }^{1}$, Anne-Sophie PERROUX ${ }^{1}$, Yves PERRETTE ${ }^{1}$, Jean-Jacques DELANNOY ${ }^{1}$, \\ Yves QUINIF² et Olivier KAUFFMAN². \\ 1 Laboratoire EDYTEM - Université de Savoie \\ 2 Faculté polytechnique de Mons - Belgique
}

\section{INTRODUCTION}

Ce chapitre a pour objet l'étude des remplissages des réseaux d'Orgnac ; aux côtés des remplissages argileux abordés dans le précédent chapitre, l'aven d'Orgnac se caractérise par deux autres grandes familles de dépôts : les sédiments clastiques et les spéléothèmes. Si ces trois familles sont présentes dans l'ensemble de la cavité, ce sont assurément les spéléothèmes qui sont les plus visibles dans le paysage souterrain d'Orgnac. Cette visibilité est liée à la fois à leur place dans la spéléogenèse (phases les plus récentes de l'évolution de la grotte), à l'importance, et à la diversité du concrétionnement. Cette importance et cette diversité constituent une des principales caractéristiques d'Orgnac, aux cotés des grands volumes souterrains.

Dans ce chapitre seront tout d'abord présentés les différents remplissages visibles dans la cavité ainsi que leur emboîtement chronologique et spatial. Les observations et analyses réalisées sur ces dépôts et plus particulièrement sur les spéléothèmes scellant les talus argileux permettront d'appréhender certains des processus d'évacuation des remplissages argileux contemporains $\mathrm{du}$ fonctionnement paragénétique d'Orgnac (chapitre 3), notamment ceux liés aux phénomènes de soutirage.

\section{I - LES SÉDIMENTS D’ORGNAC : NATURES, ORIGINES ET IMBRICATIONS SPATIO-TEMPORELLES}

Afin de cerner les caractéristiques des différents remplissages contemporains des paléofonctionnements du système d'Orgnac, l'attention sera tout d'abord portée sur une description des sédiments présents dans la cavité puis sur leur relation avec la géométrie des réseaux. L'approche méthodologique mise en place pour ce travail est développée en fin d'ouvrage (annexe 4 : Sédimentologie endokarstique).
Comme cela a été présenté dans les chapitres précédents, les réseaux d'Orgnac-Issirac se développent sur plus de $4 \mathrm{~km}$ et se caractérisent par une succession de salles et de galeries séparées par des passages plus étroits (chapitre 3, figure 1). Un des dénominateurs communs des différents réseaux d'Orgnac est l'omniprésence d'importantes accumulations argileuses scellées soit par des dépôts clastiques, soit plus fréquemment par de puissants dépôts stalagmitiques. Afin de pouvoir cerner les relations spéléogéniques entre ces différentes familles de remplissages et d'en extraire les informations morphogéniques pertinentes pour poser les différentes étapes d'évolution de la grotte, plusieurs approches méthodologiques ont été nécessaires pour aller au-delà de la simple observation surfacique. Trois approches ont été plus particulièrement développées :

- la cartographie morphologique : cette méthode permet de distinguer les différents types de dépôts et morphologies en fonction des processus responsables de leur mise en place et de leur «âge »; ce dernier étant abordé selon une chronologie relative. L'intérêt de cette démarche est de poser cartographiquement l'ensemble des phénomènes endokarstiques, d'en rechercher l'origine (processus et dynamiques responsables de leur mise en place) et de s'interroger sur leurs relations avec les formes des réseaux. Une des limites de cette approche est qu'elle ne prend en compte que les phénomènes visibles à la surface des remplissages (Delannoy et al., 2001). Plusieurs secteurs clés de la grotte ont été cartographiés selon ce principe ;

- les sondages à la tarière complètent les informations issues de la cartographie morphologique en fournissant une dimension stratigraphique. Plusieurs sondages ont été effectués dans les réseaux d'Orgnac ; en dehors de celui déjà présenté des Salles Rouges (chapitre 3), des sondages ont été réalisés dans la Salle Plane et dans la Salle 2. Des prélèvements ont été réalisés au cours de ces sondages et analysés (Delannoy et al., 2005b) ; 
- le relevé par tomographie électrique ; cette méthode de prospection géophysique complète les approches ponctuelles par sondage et permet de travailler sur la géométrie interne du remplissage. Cette méthode a été réalisée dans la Salle Plane (Kaufmann, 2002).

Pour illustrer l'intérêt de ces différentes approches méthodologiques et leur complémentarité informationnelle, nous présentons ici les travaux réalisés dans la Salle 2. Cette salle permet de poser la plupart des phénomènes morphogéniques qui se sont développés dans Orgnac depuis la fin de la phase paragénétique. Les travaux réalisés dans les Salles de Joly, Nord et Plane seront ensuite développés afin de confirmer et compléter les informations issues de l'étude de la Salle 2.

\section{I.1 - Étude spéléogénique de la Salle 2}

\section{a. Apports de la cartographie morphologique}

La cartographie morphologique de la Salle 2 permet de mettre en avant les différents remplissages et morphologies présents au sol de cette salle (figure 2) : quoique bien représentés, les dépôts clastiques couvrent une bien moindre surface que les dépôts argileux et les formations carbonatées disposées soit ponctuellement (stalagmites), soit sous forme d'encroûtements progradants. Concernant la morphologie du plancher de la salle, on relève les topographies relativement pentues qui affectent les argiles et la présence d'un important soutirage dans sa partie sud-est; on observe que ce soutirage affecte dans la réalité une grande partie de la salle, comme l'indiquent les fentes de décollement qui parcourent les argiles et les encroûtements carbonatés ainsi que le nombre de concrétions cassées et basculées.

Cette relation entre spéléothèmes (plus ou moins en place) et dynamique du soutirage sera développée dans la seconde partie de ce chapitre. Plusieurs générations de concrétions ont pu être distinguées à partir de l'observation géomorphologique; cette distinction reste d'ordre relative étant donné que la plupart des concrétions se situent hors de la méthode de datation isotopique (>450000 ans) et/ou présentent des systèmes géochimiques ouverts, rendant les résultats isotopiques peu fiables. Les plus anciennes générations de concrétions relevées dans cette salle correspondent à de puissants édifices stalagmitiques non fonctionnels partiellement nappés d'argiles et pour certains effondrés. Une autre génération d'anciens édifices stalagmitiques a été distinguée : celle-ci se caractérise par des ensembles stalagmitiques cette fois en place. Certaines concrétions contemporaines de cette génération se sont développées sur les édifices stalagmitiques basculés des premières générations. Les générations les plus récentes regroupent les concrétions de taille plus modestes, dont certaines sont toujours actives.
L'observation des blocs d'effondrement, dont certains de très grande taille, a également permis de distinguer plusieurs générations d'effondrement; les plus anciens, qui correspondent aux blocs les plus massifs, sont nappés d'argile du même type que celle recouvrant les premières générations de concrétions; des blocs « plus récents » sont pour leur part exempts d'argiles et reposent sur les blocs précédents, sur les argiles voire sur les générations plus récentes de concrétions.

La cartographie morphologique met également en évidence la présence de dépôts sableux à proximité de l'étroiture qui relie cette salle à la Salle 3 (extrémité nord de la salle : Chatière des Sables)

Les différentes observations et interprétations morphogéniques rassemblées sur cette carte permettent de poser la chronogenèse des dépôts affleurant au sol de la Salle 2. Cette chronogenèse sera ensuite enrichie par les informations issues des sondages et de l'étude des sables.

Dans un premier temps, l'évolution suivante peut être posée : postérieurement aux dépôts des argiles dont une part est vraisemblablement liée au fonctionnement paragénétique, deux phénomènes caractérisent la genèse de cette salle : les phénomènes de détente mécanique et d'effondrement de pans de voûte et de paroi, et le concrétionnement; phénomènes qui affectent cette salle depuis relativement longtemps comme en témoignent les différentes générations de concrétionnement et d'effondrement. Parallèlement à ces phénomènes, un autre processus majeur a affecté la physionomie de la salle : le puissant soutirage ; bien qu'un certain nombre d'indices semblent indiquer une relative activité de ce soutirage (fentes de décollement, concrétions basculées...), ce processus est relativement ancien comme le suggèrent les encroûtements stalagmitiques anciens qui scellent les talus se raccordant au soutirage ainsi que les «talus» de blocs qui descendent en direction du soutirage.

Les observations effectuées à partir des sondages à la tarière et les analyses sédimentologiques des sédiments présents dans la Chatière des Sables permettent de compléter cette primo-chronogenèse de la Salle 2.

\section{b. Apports des sondages de la Salle 2}

Afin de compléter les données issues de la cartographie morphologique, six sondages ont été réalisés dans le secteur ouest de la Salle 2 où le remplissage argileux est le plus accessible ; cette série de sondages alignés le long d'un profil nord-sud recoupe le talus argileux qui descend vers la paroi sud et le soutirage. L'objectif de ce profil était de relever la stratigraphie (figure 3 ) de ce remplissage et les déformations potentielles engendrées par le soutirage. Tous ces sondages ont été réalisés à la tarière; le plus profond a permis de recouper plus de $6 \mathrm{~m}$ de dépôt. Un des premiers enseignements est qu'aucun de ces sondages n'a atteint le bedrock, ce qui confirme l'importance des dépôts argileux relevée 


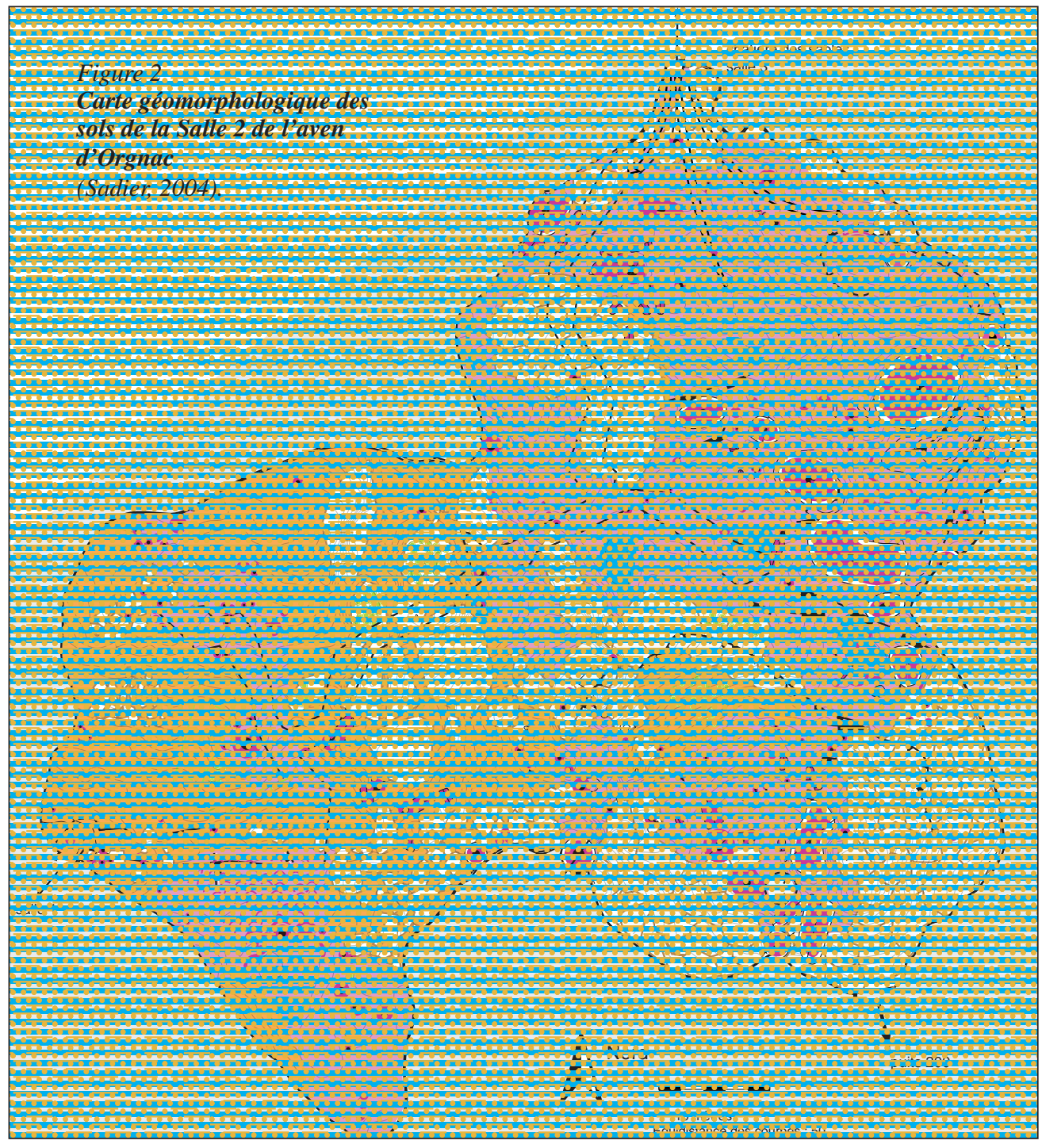

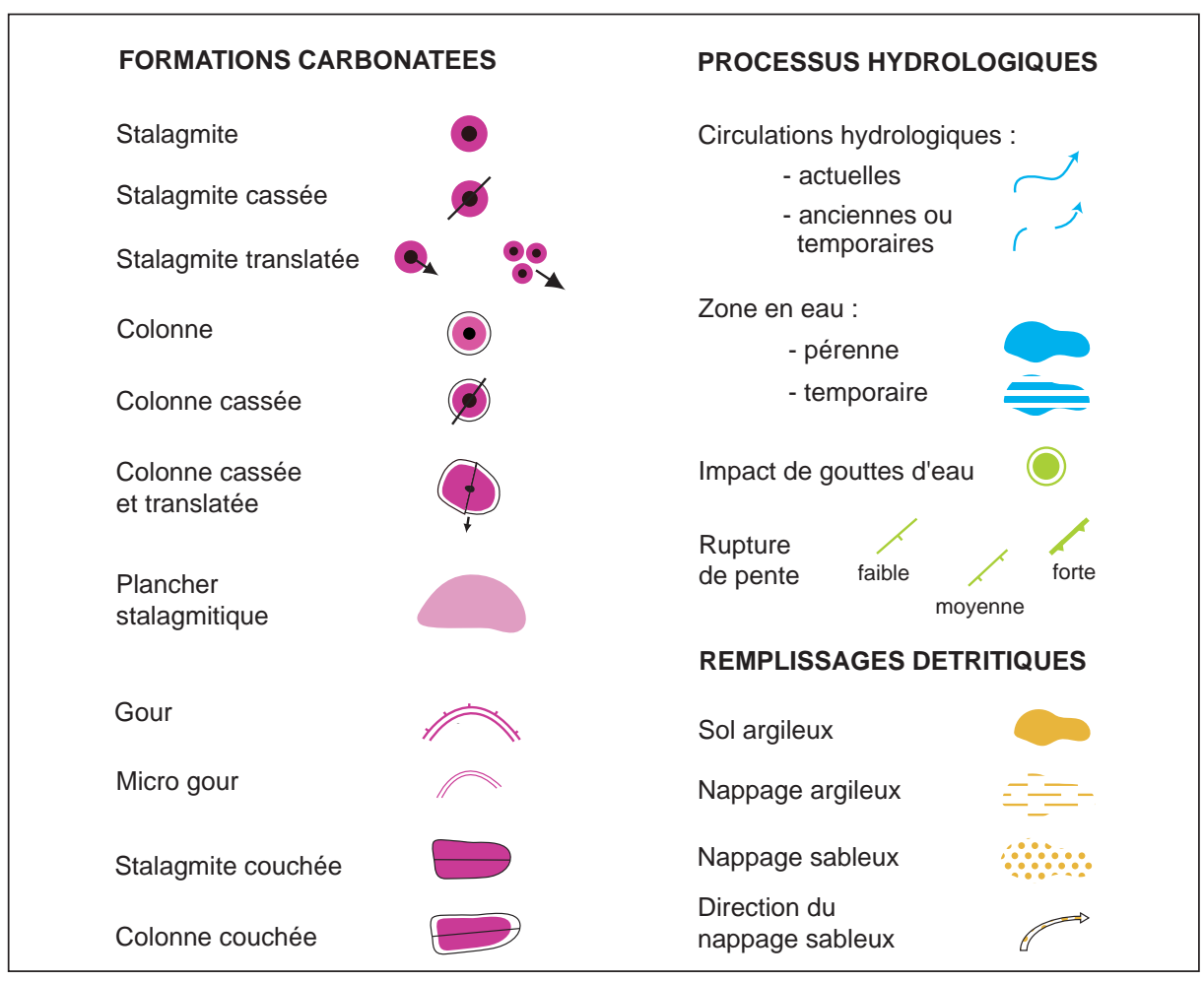


Figure 3

Localisation et profil des différents sondages à la tarière de la Salle 2 de l'aven d'Orgnac

(d'après Sadier, 2004, Delannoy et al., 2005a).
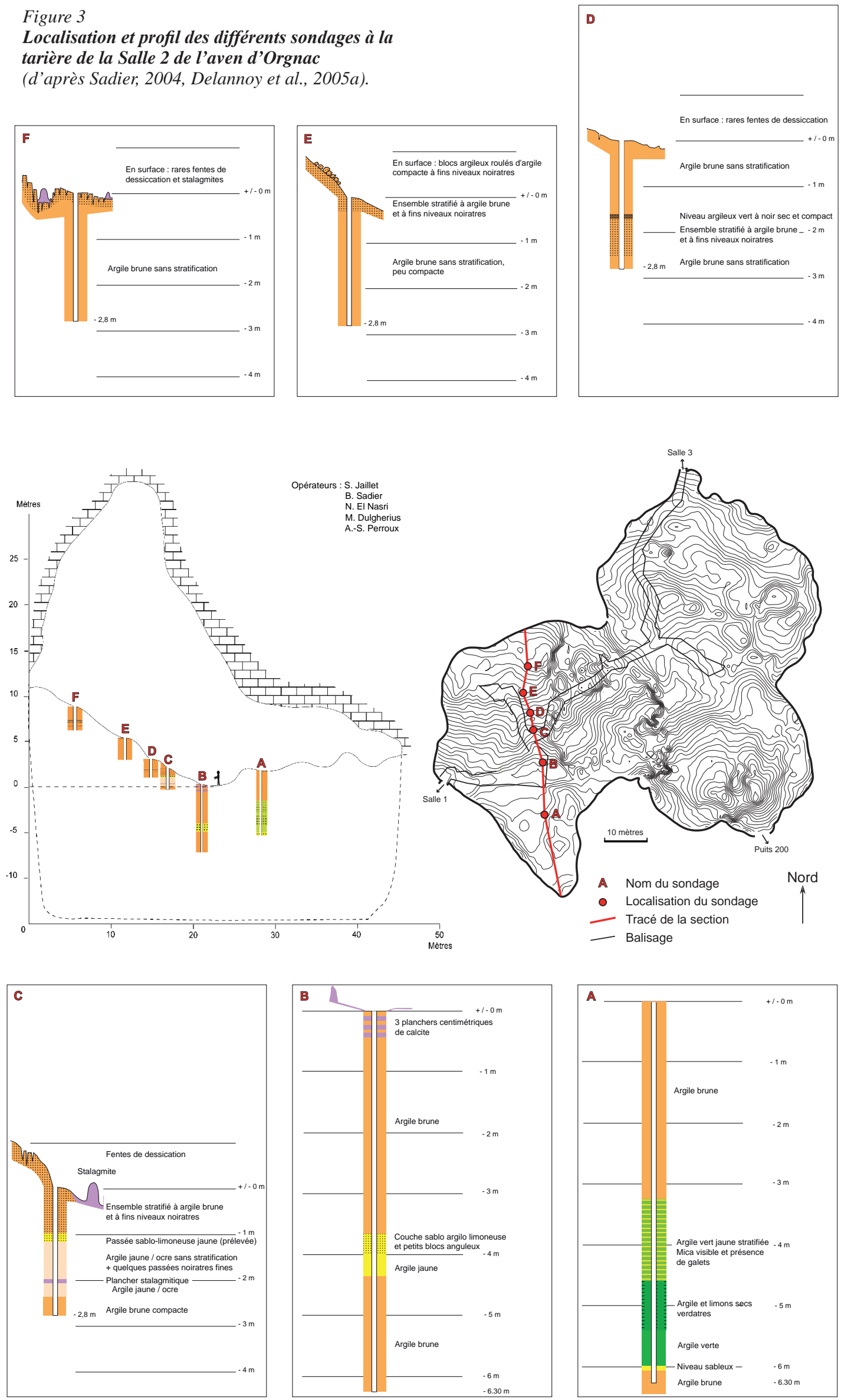
dans les Salles Rouges (chapitre 4). D’un point de vue stratigraphique, les dépôts sont majoritairement argileux (argiles rouges à brunâtres plus ou moins litées). Les argiles rouges caractérisent les 2 à 3 derniers mètres des sondages. Le sondage $\mathrm{A}$ est le seul à montrer une variante stratigraphique : les argiles rouges font place sur plusieurs mètres à des d'argiles vertes à jaunâtres. Enfin, il faut noter que dans la plupart des sondages, un, voire plusieurs planchers stalagmitiques ont été franchis, ce qui suppose des phases d'émersion entre les différentes périodes de sédimentation argileuse (Delannoy et al., 2004). Ces différents sondages ont également mis en avant le caractère lité des argiles ainsi que la présence de phénomènes de dessiccation et/ou de perturbation dans la partie supérieure des remplissages actuels. Le diamètre de la tarière n'a pas permis de mettre en avant d'éventuels fluages généralisés des argiles; la relative cohérence d'un sondage à un autre tend à confirmer que le matériel argileux n'a pas subi de déformations depuis sa sédimentation.

\section{c. Étude des sédiments sableux de la Salle 2 et de la Chatière des Sables}

À l'extrémité nord de cette Salle 2, à l'entrée du rétrécissement donnant accès à la Salle 3 , on relève la présence de dépôts sableux. Compte tenu de l'indigence de ces dépôts dans le reste du réseau, une attention particulière a été portée à ce secteur et à ces sédiments.
Un sondage a permis de reconnaître, sur une trentaine de centimètres, deux niveaux sableux non indurés entre lesquels s'intercalent des argiles et un plancher stalagmitique (figure 4). Ce dépôt sableux se prolonge dans l'étroiture qui mène à la Salle 3 . On le suit de façon discontinue jusqu'à un point bas qui se présente sous forme d'alcôve métrique au plafond de laquelle se développe un chenal de voûte. On suit ce chenal sur une grande partie de l'étroiture; celui-ci passe parfois à des coupoles de dissolution. À mi-chemin de cette descente, on note la présence d'un diverticule, qui contient également un remplissage de sables non consolidés. De place en place dans ce cheminement de quelques dizaines de mètres, on remarque des niveaux de sables, très localisés et ne dépassant pas quelques centimètres de haut. Dans la dernière partie de cette étroiture, avant son débouché dans la Salle 3, les sables disparaissent et laissent place aux argiles rouges.

L'analyse sédimentologique des sables prélevés au niveau de l'alcôve (figure 4) apporte des informations complémentaires quant à la granulométrie des sables, aux modes de transport et à l'origine de ces sédiments. La figure 5 synthétise les caractéristiques morphoscopiques des sables prélevés en différents endroits de la chatière. Ces sables ont également fait l'objet d'une étude réalisée par M. Wienin [non publiée]. Entre les différents sites de prélèvement, seule la granulométrie des sables semble légèrement varier; la composition est partout la même : présence dominante

Coupe schématique de la Chatière des Sables ; coupes descriptives du sondage et du prélèvement de sédiments (Perroux, 2005).

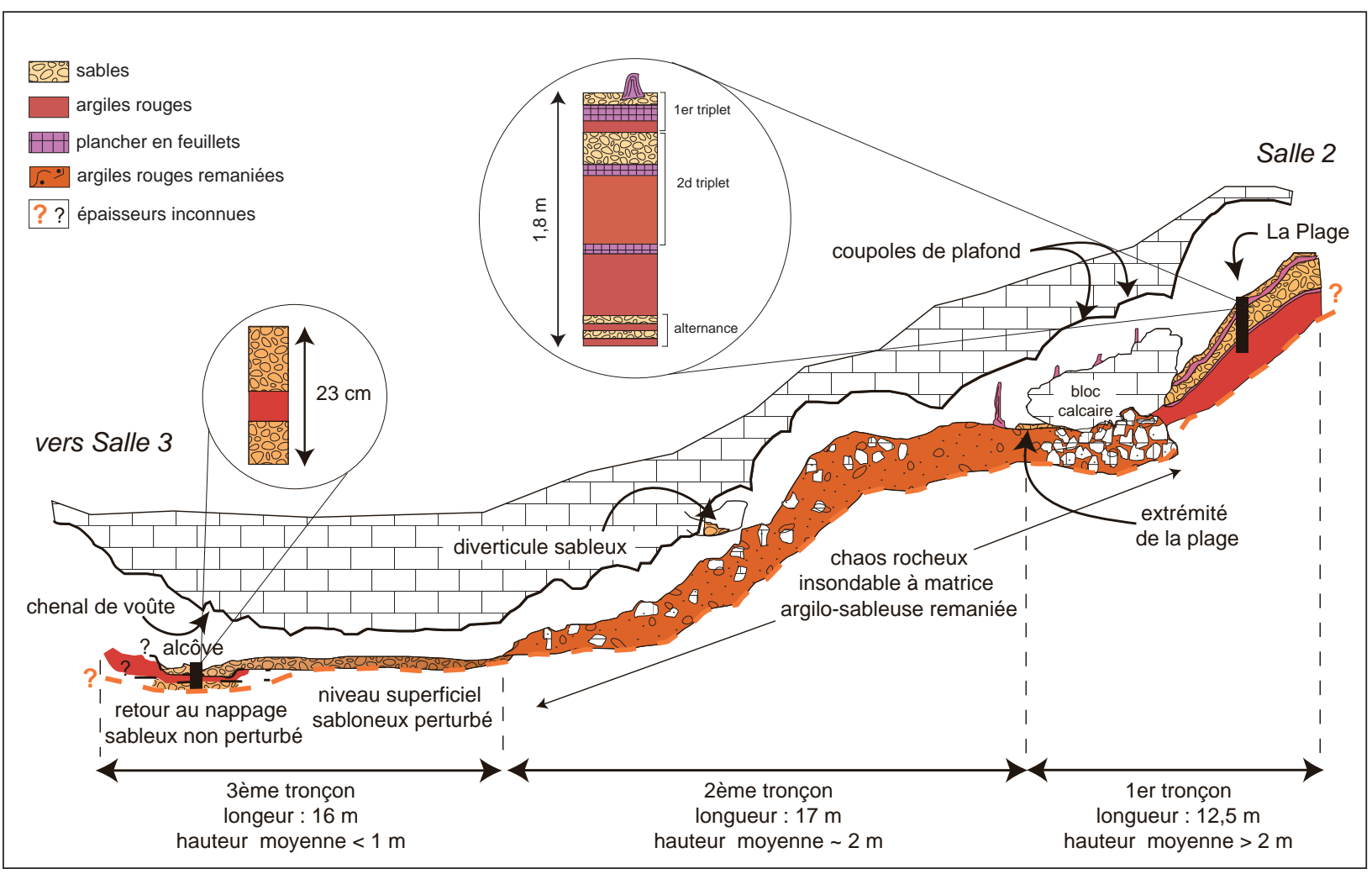




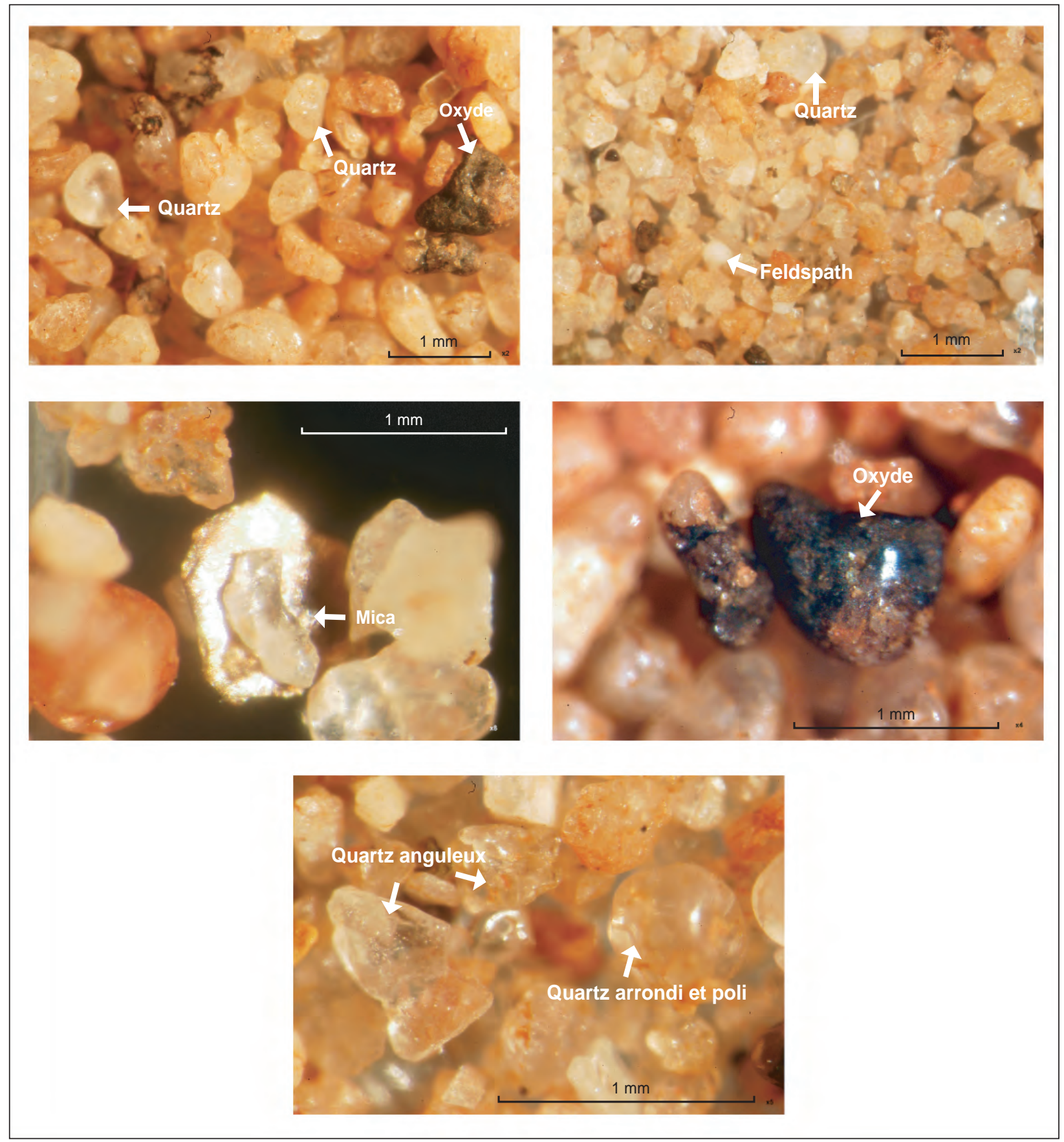

Figure 5

Quelques observations à la loupe binoculaire sur les sables de la chatière (Perroux, 2005).

de quartz. Outre les quartz dont la plupart présentent des traces d'oxydation (teinte rosée), on trouve quelques oxydes de fer (hématite et magnétite), des feldspaths et de très rares calcites. La présence de rares micas blancs et noirs a également été constatée, mais toujours dans des proportions extrêmement réduites. La morphoscopie des grains, observés à la loupe, met en évidence un mélange de grains très arrondis et de grains anguleux, qui témoignent de sources variées et de modalités de transport fluviatiles (figure 5). La composition minéralogique et la morphoscopie de ces sables renvoient à deux sources de matières. L'une, correspondant aux quartz les plus gros, aux feldspaths, aux oxydes de fer et aux micas, pourrait se rapprocher du cortège alluvial des ruisseaux d'origine cévenole, comme le Chassezac ou l'Ardèche, qui transportent du matériel issu du socle. La fraction sableuse émoussée, et notamment les quartz, pourrait avoir pour origine les dépôts paléocènes à éocènes (entre 65 et $45 \mathrm{MA}$ ) : ressemblance avec les sables cénozoïques affleurant au hameau de Pouzol, à Orgnac-l'Aven (Pascal et al., 1989). 
Compte tenu de la relative indigence des sédiments sableux dans le reste du réseau, l'hypothèse d'un dépôt localisé a été posée pour expliquer leur présence au niveau de la Chatière des Sables. La géométrie $\mathrm{du}$ remplissage sableux permet de placer celui-ci postérieurement au dépôt argileux et de l'associer à un écoulement empruntant l'étroit réseau entre les Salles 2 et 3, lié à un décolmatage partiel des argiles, dont on trouve encore quelques poches au creux des lapiés de voute. La répartition des sables tout au long de l'étroiture suggère un sens des écoulements nordsud, c'est-à-dire provenant de la Salle 3 et rejoignant la Salle 2 : l'accélération des écoulements à l'entrée de l'étroiture ayant pour effet une prise en charge des sables alors que le débouché des écoulements dans la vaste Salle 2 favorisait la sédimentation de ces mêmes sables (perte d'énergie; figure 6). Il est délicat d'aller au-delà de ces interprétations ; restent posées les questions de la durée de cet événement hydrologique ainsi que de la provenance du matériel sableux. Le fait que les sables soient scellés par un horizon argileux et un encroutement carbonaté indique l'existence d'ennoiements du réseau (favorables à la décantation des argiles) du même type que celui observé récemment dans les Salles Rouges (chapitre 3) et d'une phase de répit hydrologique (mise en place du plancher stalagmitique). Compte tenu des perturbations liées à la désobstruction de la Chatière des Sables par les premiers explorateurs, il est prudent de ne pas tenir compte des accumulations éparses de sables en différents endroits du rétrécissement (Delannoy et al., 2005a ; Perroux, 2005).

\section{d. Premiers éléments spéléogéniques de la Salle 2}

Les observations issues de la cartographie morphologique, des sondages et de la Chatière des Sables permettent de poser les premiers jalons spéléogéniques de la Salle 2 :

- suite au fonctionnement paragénétique, le réseau a connu une longue phase de décolmatage à l'origine de la topographie bosselée du remplissage argileux; il est probable, si on se réfère au fonctionnement paragénétique et à la géométrie des banquetteslimites, que cette topographie bosselée préexistait (chapitre 3);

- cette topographie bosselée a été «fossilisée» par deux types de dépôts : les dépôts clastiques issus de l'écroulement de pans de paroi et de voûte et les dépôts carbonatés (stalagmites, encroûtement...). Plusieurs générations d'effondrement et de spéléothèmes ont été relevées dont certains ayant été affectés par des phases d'ennoiement du réseau (nappage argileux); une de ces phases a également été identifiée dans la Chatière des Sables (niveau argileux scellant les sables) ;

- la présence de dépôts sableux limités à la zone de rétrécissement entre les Salles 3 et 2 a permis de relever l'existence d'écoulements ayant un hydrodynamisme suffisant pour transporter des sables; l'éventualité de tels écoulements avait également été suggérée dans l'étude du sondage des Salles Rouges. Reste posée l'origine de ces écoulements transportant un cortège pétrographique

Figure 6

Hypothèse de dynamique de mise en place pour le dépôt sableux entre la chatière et la Salle 2 des réseaux d'Orgnac-Issirac.

(1) Mise en place de l'écoulement

Des particules sont remobilisées de la Salle 3 et des secteurs avoisinants. La puissance hydrodynamique transporte les matières en suspension jusqu'à la chatière. La remontée vers la Salle 2 implique une perte d'énergie des écoulements, le dépôt peut se faire, les particules sableuses, étant les plus grosses, se déposent en premier.
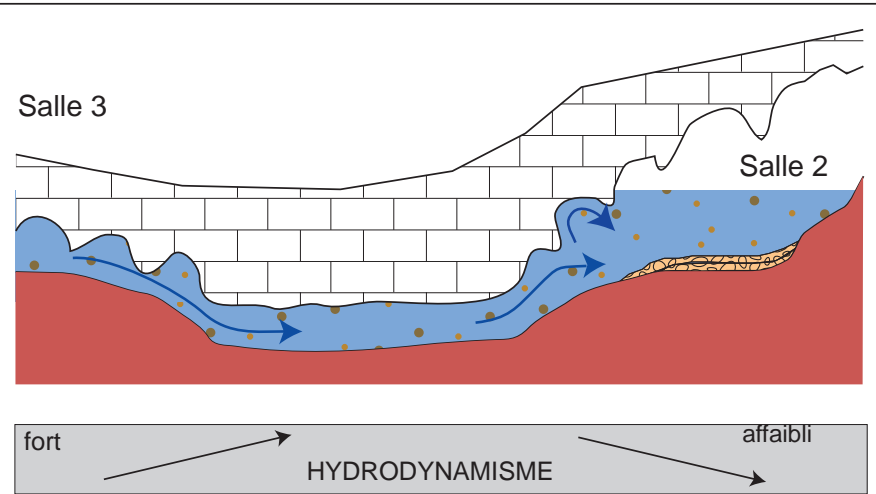

\section{(2) Retrait des écoulements}

Le dépôt sableux s'est constitué, nappant en remontant les argiles. Lors du retrait des eaux, la perte générale d'énergie hydrodynamique permet le dépôt des particules les plus fines qui avaient été remobilisées. Dans ce cas précis, ce phénomène se serait produit deux fois au moins. Le dernier épisode aurait été particulièrement rapide, puisque le nappage sableux superficiel n'est pas recouvert d'argiles.

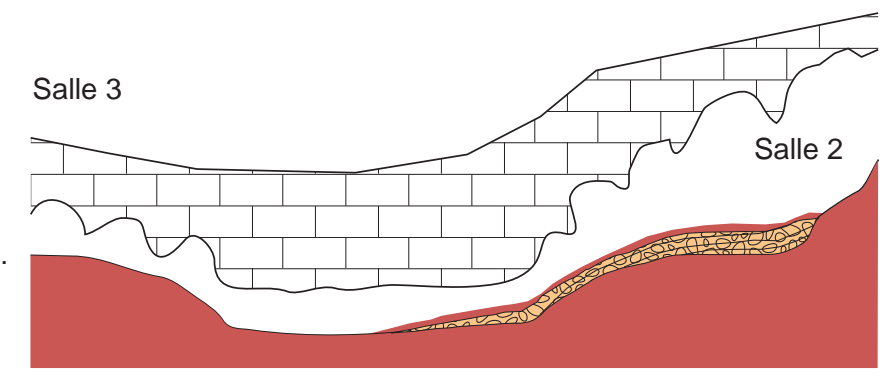


en grande partie allochtone ; deux hypothèses peuvent être ici posées : (i) ce matériel a été acheminé par des écoulements issus de circulations descendant des Cévennes; (ii) ce matériel a été transporté par des écoulements locaux prenant en charge des sédiments hérités « cévenols » ou « cénozoïques » présents à la surface du karst.

Cette reconstitution spéléogénique d'Orgnac, basée sur les travaux menés dans la Salle 2 est confirmée et complétée par des indices spéléogéniques présents dans les autres salles et réseaux d'Orgnac. Trois exemples sont ici développés : la Salle Plane, la Salle de Joly et le fond de la Salle Nord.

\section{I.2 - La Salle Plane : apports spéléogéniques de la tomographie électrique}

Afin de compléter les informations issues des sondages réalisés dans les Salles 2 et Rouges, une autre approche a été développée dans la Salle Plane : la tomographie électrique. Cette méthode se prêtant bien à cette salle qui, comme son nom l'indique, se caractérise sur l'ensemble de son développement par un sol plat qui contraste avec les morphologies présentes dans les autres salles d'Orgnac. La tomographie électrique a pour intérêt d'appréhender la nature interne des remplissages à partir de mesures de la résistivité électrique et ce de manière non destructrice. La qualité de la prospection tomographique est directement liée à la longueur du profil, à l'équidistance des sondes plantées à la surface du remplissage et, en milieu souterrain, aux effets de bords induits par les parois. Pour limiter ces effets de bords, le profil réalisé dans la Salle Plane a été réalisé en son centre selon un axe NNE-SSW allant de l'entrée de la salle (bas du talus d'éboulis) jusqu'à l'entrée de la chatière donnant accès à Orgnac IV.

Le profil tomographique se présente sous forme d'une image en 2D donnant pour chaque abscisse $\mathrm{X}$ des valeurs de résistivité pour les différentes profondeurs Y.
Ce profil rectiligne de $57 \mathrm{~m}$ a permis d'appréhender les caractéristiques du remplissage sur une profondeur supérieure à 7 m (figure 7) (Kaufmann, 2002).

Les variations de résistivité mettent en valeur les changements de nature du sol. Les résistivités élevées mesurées entre $41 \mathrm{~m}$ et $51 \mathrm{~m}$, à proximité de la surface (0 à $0,5 \mathrm{~m})$ correspondent à des gours et à un encroûtement carbonaté. Jusqu'à 5 ou $6 \mathrm{~m}$ de profondeur, le profil met en évidence un ensemble sédimentaire à faible résistivité électrique, caractéristique de sédiments argileux. Au sein de cet ensemble, plusieurs zones de résistivité intermédiaires à élevées ont été relevées :

- entre les abscisses de $40 \mathrm{~m}$ et $54 \mathrm{~m}$, trois zones de résistivité élevée situées entre $1,5 \mathrm{~m}$ et $3 \mathrm{~m}$ de profondeur révèlent la présence de blocs calcaires (d'effondrement) au sein du remplissage ;

- les zones à résistivités intermédiaires visibles vers 2 ou $3 \mathrm{~m}$ de profondeur (abscisse de $21 \mathrm{~m}$ et $33 \mathrm{~m}$ sur la coupe) pourraient également être associées à la présence de blocs de plus petites tailles ou de concrétions. Cette seconde possibilité est suggérée par la présence de massifs stalagmitiques présents à quelques mètres au nord du profil.

À la base du profil atteint par la tomographie (profondeur supérieure à 7,3 m), les résistivités apparaissent, à nouveau, plus élevées. Deux interprétations peuvent être proposées : soit ces résistivités élevées marquent le fond rocheux de la salle; soit elles sont liées à un rétrécissement en profondeur de la largeur de la salle. Dans les deux cas, ces interprétations semblent indiquer la relative proximité de la roche encaissante.

Les observations de la Salle Plane mettent en avant l'existence de phénomènes d'effondrement contemporains de la phase de sédimentation argileuse ainsi que de phases «d'émersion» favorables au développement de concrétions. On retrouve ici la prééminence des dépôts argileux relevés dans les Salles Rouges et 2 .

Tomographie électrique de la Salle Plane : localisation et profil des résistivités (Kaufmann, 2002).
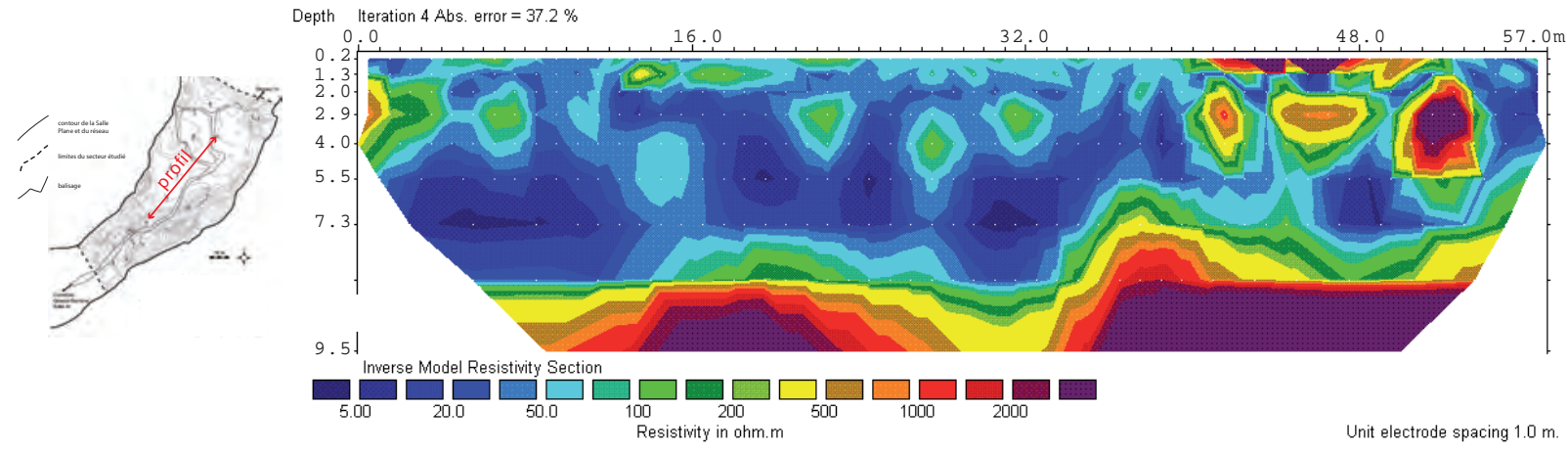


\section{I.3 - La Salle de Joly : les apports du carottage dans la concrétion basculée de la Tour de Pise}

L'étude de la Salle 2 a permis de distinguer trois grandes phases de concrétionnement. Ces trois phases ont également été identifiées dans la Salle de Joly qui se différencie fortement des autres salles d'Orgnac par sa morphologie chaotique liée à l'effondrement d'importants pans de voûte et de parois. L'attention a été portée sur une concrétion caractéristique de cette salle : la Tour de Pise (photo 1). Cette concrétion se présente sous forme d'un gros dôme stalagmitique basculé et sur lequel on relève plusieurs générations de repousses stalagmitiques. Trois échantillons correspondant aux «deuxième » et «troisième 》 générations ont été carottés (figure 8).

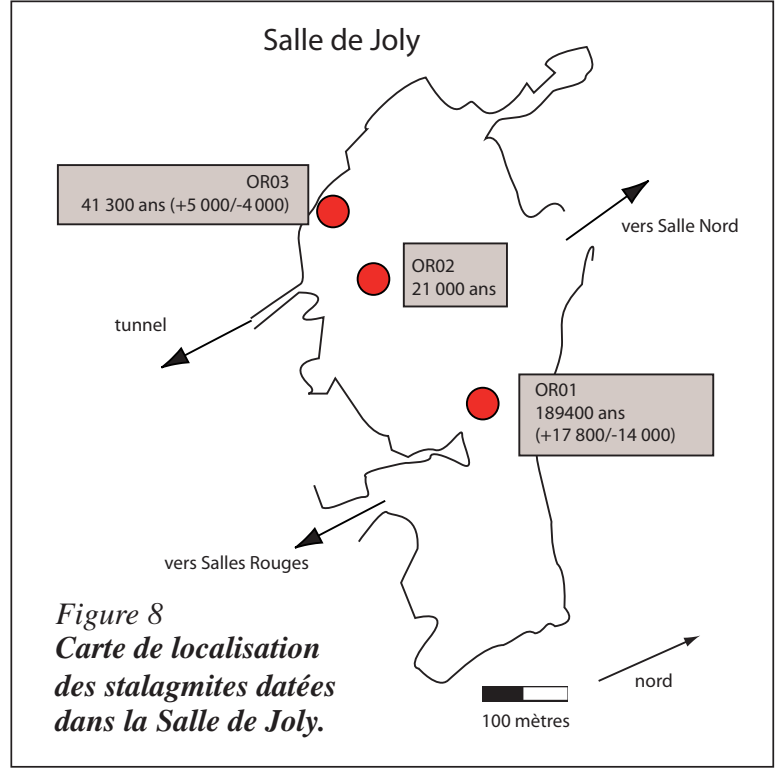

Photos 1

Extraction d'une carotte prélevée dans la Tour de Pise (photos Pierre Gotteland et Françoise Prud'homme).
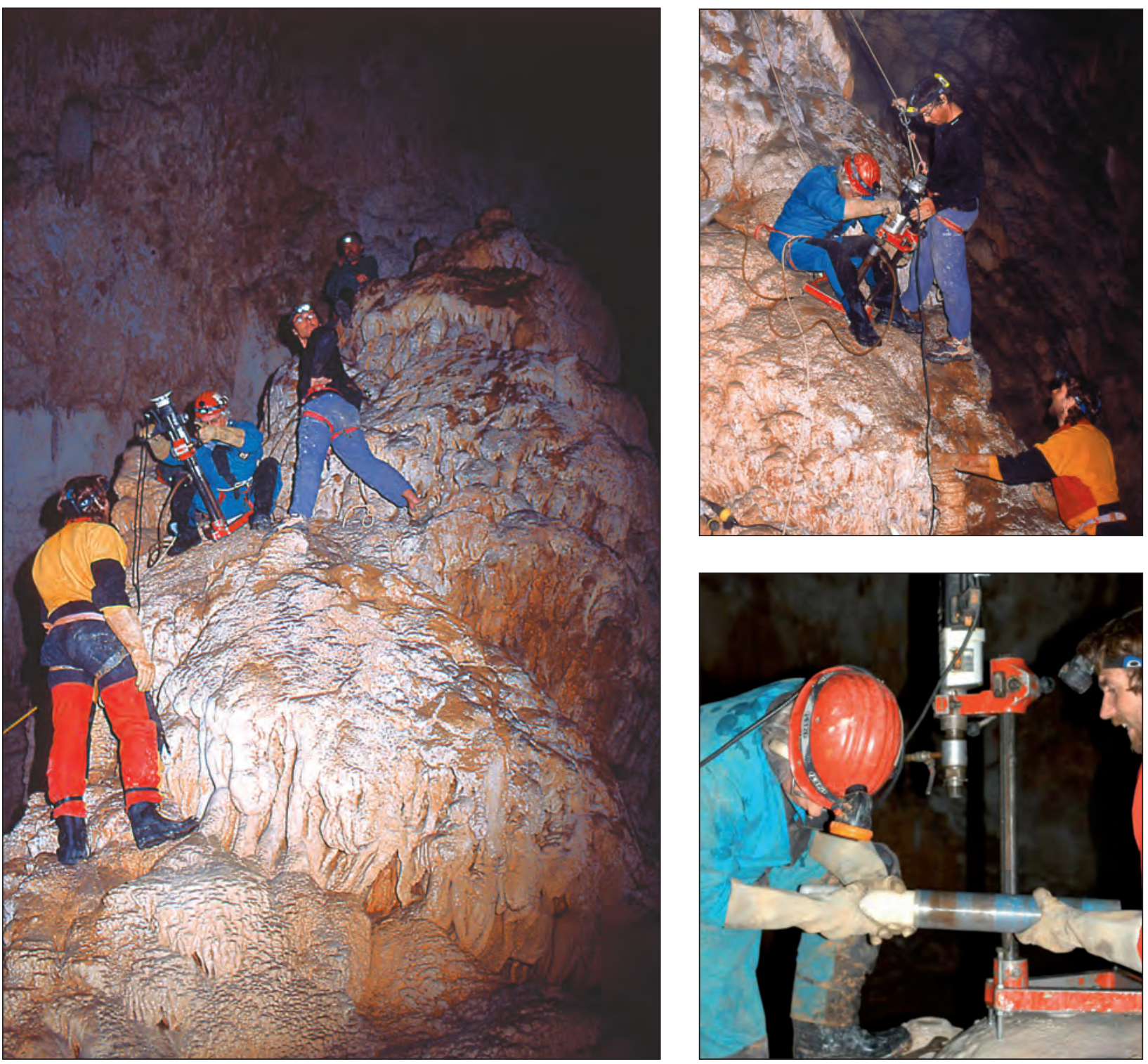


\begin{tabular}{|l|r|r|r|r|r|r|}
\hline Échantillon & [U]ppm & ${ }^{234} \mathbf{U} /{ }^{238} \mathbf{U}$ & ${ }^{230} \mathbf{T h} /{ }^{234} \mathbf{U}$ & ${ }^{230} \mathbf{T h} /{ }^{232} \mathbf{T h}$ & {$\left[{ }^{234} \mathbf{U} /{ }^{238} \mathbf{U}\right] \mathbf{t}=\mathbf{0}$} & Âge (en m.a.) \\
\hline $1 / 03-1$ & $0,068 \pm 0,001$ & $1,013 \pm 0,016$ & $0,829 \pm 0,023$ & $43 \pm 7$ & 1,022 & $189,9[+17,8 /-14,9]$ \\
\hline $1 / 03-1 b$ & $0,065 \pm 0,001$ & $1,031 \pm 0,012$ & $0,803 \pm 0,017$ & $92 \pm 25$ & 1,051 & $173,6[+10,7 /-94,9]$ \\
\hline $2 / 03-1$ & $0,097 \pm 0,001$ & $1,035 \pm 0,016$ & $0,069 \pm 0,010$ & $8,1 \pm 6,5$ & 1,035 & $7,8[+1,2 /-1,2]$ \\
\hline $2 / 03-2$ & $0,069 \pm 0,001$ & $1,00 \pm 40,013$ & $0,182 \pm 0,009$ & $7,0 \pm 1,1$ & 1,004 & $21,8[+1,2 /-1,2]$ \\
\hline $2 / 03-3$ & $0,104 \pm 0,001$ & $1,015 \pm 0,011$ & $0,053 \pm 0,006$ & $1,8 \pm 0,3$ & 1,015 & $5,9[+0,7 /-0,7]$ \\
\hline $2 / 03-4$ & $0,102 \pm 0,001$ & $1,043 \pm 0,020$ & $0,134 \pm 0,010$ & $3,5 \pm 6$ & 1,044 & $15,6[+1,3 /-1,2]$ \\
\hline $3 / 03-2$ & $0,067 \pm 0,001$ & $1,025 \pm 0,017$ & $2,027 \pm 0,074$ & $30 \pm 6$ & & \\
\hline $3 / 03-3$ & $0,081 \pm 0,001$ & $1,044 \pm 0,014$ & $10,88 \pm 022$ & $29 \pm 1$ & & \\
\hline
\end{tabular}

Tableau 1 : Résultats d'analyse U/Th sur la Tour de Pise (Cerak).

Des datations par déséquilibre U/Th en comptage alpha ont été réalisées par le CERAK (Mons, Belgique). Parmi les analyses (tableau 1), certains échantillons sont hors méthode, c'est à dire plus âgés que 450000 ans. D'autres présentent des âges non interprétables en raison d'une forte pollution du système géochimique par du thorium détritique. Ce résultat peut être lié à une pollution syn-cristallisation, ou à une altération postérieure au dépôt. Dans le cas des échantillons carottés dans la Tour de Pise, ces deux causes se combinent. La photo 2 présente un des échantillons carottés ainsi que le grossissement d'une zone vacuolée. L'observation de la cristallisation de cette stalagmite révèle une calcite dendritique contenant de nombreuses inclusions. Dans certains cas, comme au

Photo 2 Zoom sur une zone vacuolée de la carotte prélevée dans la Tour de Pise.

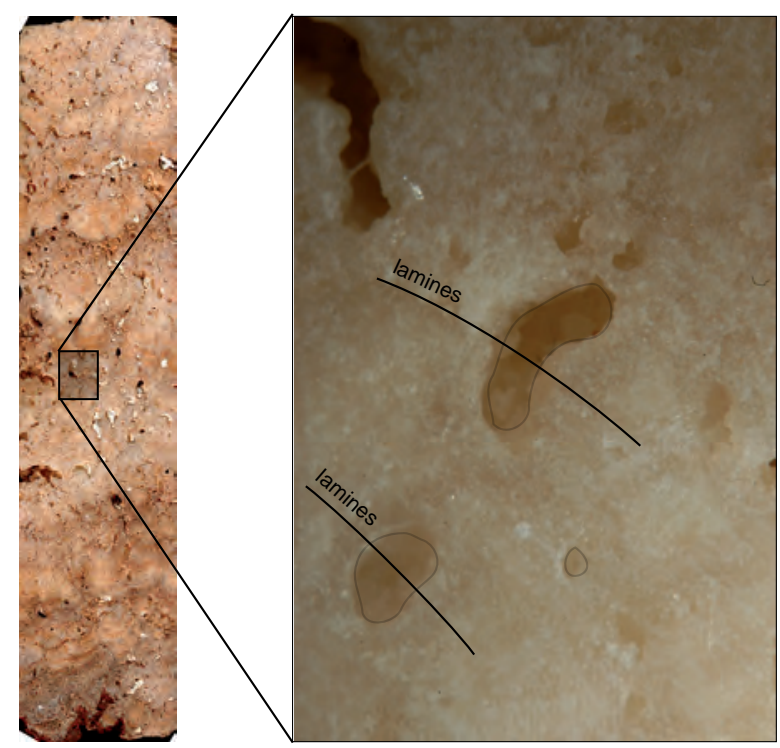

centre de cet échantillon, on observe un niveau d'argiles qui révèle des phases de sédimentation détritique contemporaines de la croissance de la stalagmite. Ces phases d'ennoiement de la Salle de Joly ont également été à l'origine d'une altération de la calcite, comme le montre la photo 2 . En effet, une vacuole tronque à l'emporte pièce les lamines de croissance.

Si les échantillons stalagmitiques prélevés dans la Salle de Joly n'ont pas fourni les calages chronologiques escomptés, ils montrent clairement que les phases anciennes de concrétionnement ont été entrecoupées d'épisodes d'ennoiement, confirmant ainsi les observations des Salles 2 et Plane. La Salle de Joly constituant un des points hauts du système permet d'étendre ce résultat à l'intégralité du réseau.

\section{I.4 - Le fond de la Salle Nord}

La Salle Nord, située en contrebas de la Salle de Joly, constitue le point d'accès à la Salle 1 . Cette salle se caractérise par une topographie très pentue liée aux blocs d'effondrement provenant de la Salle de Joly; ces blocs sont scellés par un dépôt stalagmitique « cascadant ». Au pied de cette descente, deux éléments morphologiques sont à relever :

(i) au plafond, on relève des formes de dissolution (coupoles...) contemporaines de la phase « initiale» de creusement du réseau (on retrouve les mêmes morphologies au bas de la Salle de Joly, juste avant son débouché dans les Salles Rouges) au creux desquelles subsistent des argiles;

(ii) au sol, on retrouve les sédiments argileux quasi exempts de la Salle de Joly. On relève également, au point bas de cette salle, un petit soutirage.

À l'est de ce soutirage, le talus argileux est relativement bien conservé, avec une hauteur maximum d'environ $3 \mathrm{~m}$, pour $8 \mathrm{~m}$ de longueur. Ce talus présente une 


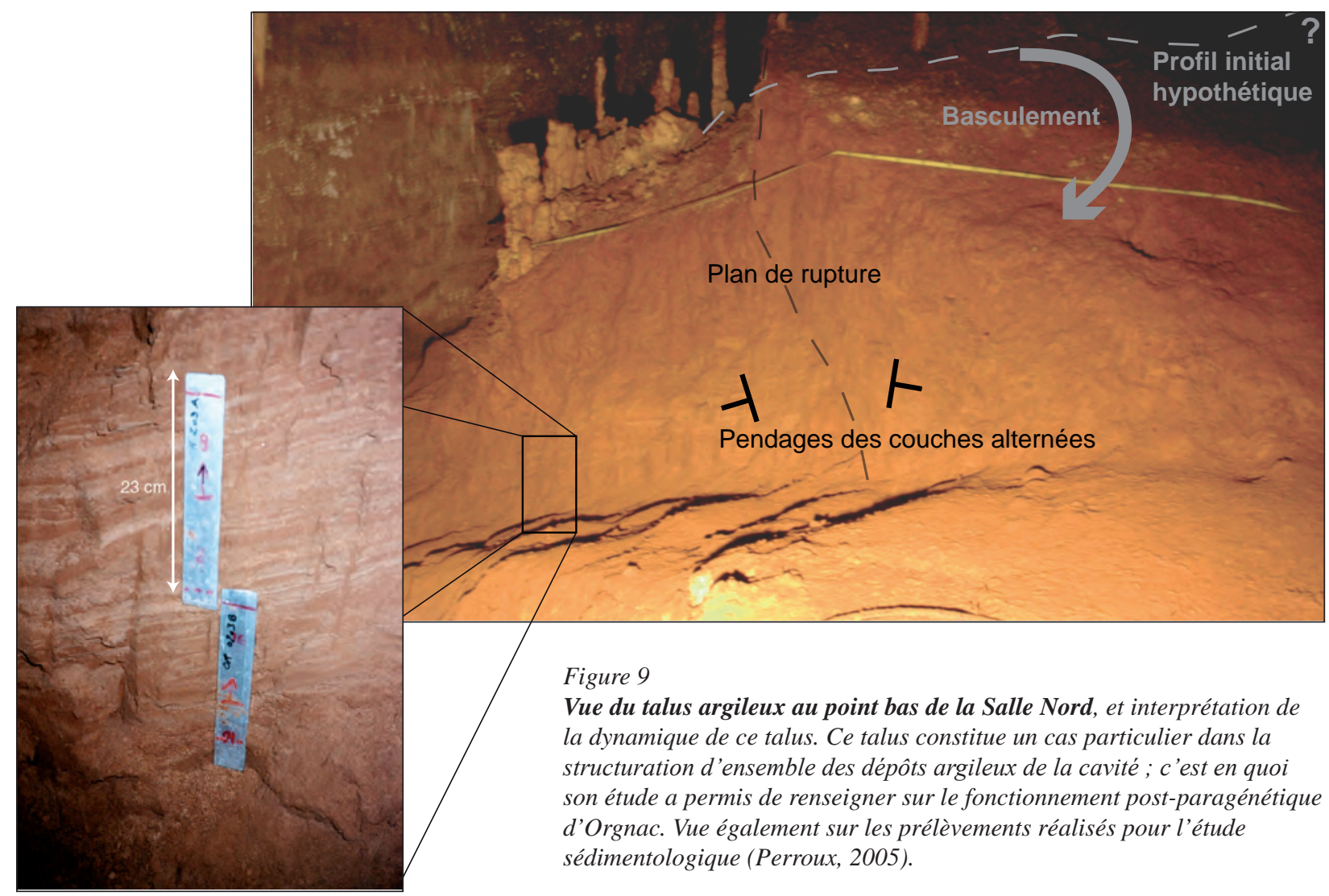

structure intéressante, complémentaire de ce qui a été jusqu'ici observé : le remplissage se caractérise par une alternance de fines couches sableuses et argileuses (quelques millimètres à quelques centimètres). On peut observer un pendage conforme à la pente générale de ce point bas, sauf à l'extrémité sud où, très localement, il présente une inversion (figure 9).

$\mathrm{Au}$ niveau de ce talus, des prélèvements ont été réalisés afin d'étudier l'hydrodynamisme responsable de cette formation sédimentaire et de sa disposition. Parmi les différentes analyses effectuées, l'analyse en composantes principales (ACP), appliquée sur les données granulométriques, a permis de mettre en avant une double dynamique sédimentaire engendrée par une alternance de courants forts (dépôts sableux) et faibles (lits argileux) (figure 10). Cette analyse a également permis d'identifier un troisième mode de sédimentation, déconnecté du phénomène d'alternance ; il correspond aux niveaux les plus grossiers qui apparaissent dans la stratigraphie sans produire la moindre perturbation sur les autres niveaux du remplissage. À partir de ces données, la mise en place proposée pour expliquer ce dépôt et sa géométrie est celle d'un écoulement issu de la zone vadose et rejoignant au niveau du point bas de la Salle Nord une zone partiellement ennoyée. En effet, l'homogénéité sédimentaire et l'alternance des lits argileux et sableux suggèrent un fonctionnement simple et répété des apports. Celui-ci présente un enchaînement de courants forts capables d'entraîner jusqu'à «l'entrée » de la zone noyée les sables, et de courants faibles apportant des éléments plus fins (lits argileux) (Perroux, 2005). À cette dynamique sédimentaire se surimposent des phénomènes plus « catastrophiques » acheminant jusqu'à ce piège des sédiments grossiers. Une telle géométrie sédimentaire rappelle celle présente à l'entrée des pièges lacustres, ce qui confirmerait l'hypothèse que le secteur étudié corresponde à une ancienne zone de contact entre la zone vadose et une zone ennoyée (voire noyée).

D'un point de vue chronologique, la mise en place de ce dépôt dans l'histoire de la cavité est probablement assez « récente » puisque la pente généralisée de ce secteur est le résultat de l'ouverture de l'aven et de l'effondrement de la voûte de la Salle de Joly. Il est intéressant de relever que ce caractère relativement « récent» confirme les phénomènes de mise en charge des réseaux d'Orgnac suite à des événements pluviométriques exceptionnels : la mise en charge du point bas de la Salle Nord a été vraisemblablement facilitée par l'obstruction clastique et carbonatée du conduit permettant d'accéder à la Salle 1 ; c'est la désobstruction de ce conduit qui a permis la découverte des réseaux d'Orgnac au-delà de la Salle de Joly et des Salles Rouges.

Il est également intéressant de relever que la présence de sédiments sableux est associée aux points bas et 


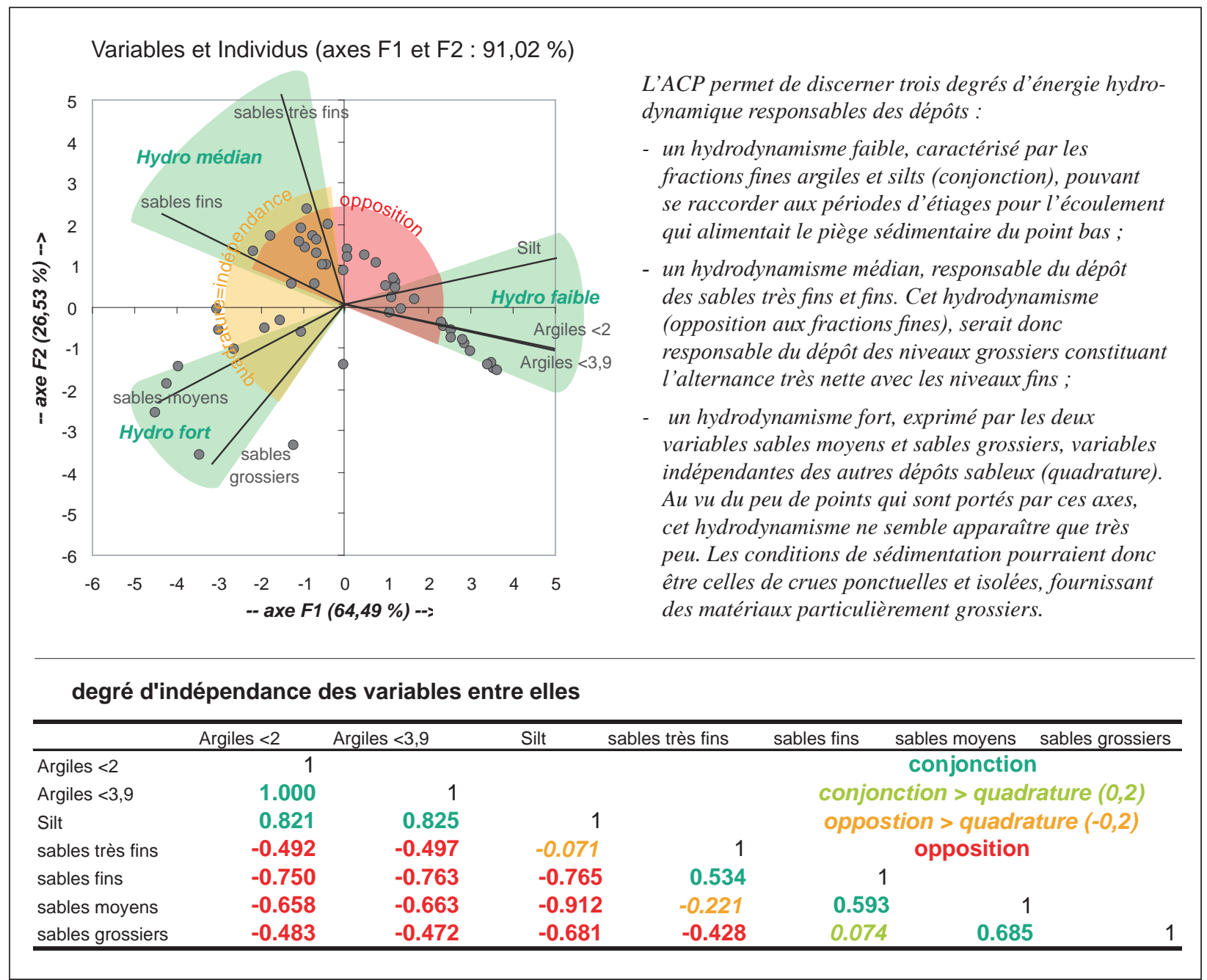

Figure 10

Analyse en Composantes Principales commentée sur la granulométrie des sédiments de la salle Nord (Perroux, 2005).

rétrécissements des réseaux d'Orgnac (Chatière de la Salle Nord, Chatière des Sables). Il est probable qu'un hydrodynamisme particulier devait affecter ces zones de rétrécissements lors des épisodes de mise en charge des réseaux et de fonctionnement hydrologique exceptionnel capable d'acheminer dans les réseaux d'Orgnac des sédiments sableux.

L'étude morphologique des Salles 2 et Plane ainsi que l'étude des secteurs de la Tour de Pise, de la Chatière des Sables et de la Salle Nord ont permis de fixer plusieurs étapes spéléogéniques des réseaux postérieurs au fonctionnement paragénétique de la cavité. La mise en charge "récurrente » des réseaux bien après l'épisode paragénétique peut être un des moteurs de la physionomie des paysages souterrains, notamment de la dynamique des soutirages. L'étude des spéléothèmes permet de préciser la dynamique des soutirages qui affectent les remplissages argileux d'Orgnac et responsables de la topographie en buttes, et creux des planchers des Salles Rouges, 1 et 2.

\section{II - LES APPORTS DES STALAGMITES TRANSLATÉES DANS LA CONNAISSANCE DE LA DYNAMIQUE D'UN SOUTIRAGE}

Le chapitre précédent, sur le paragénétisme, a souligné que le gigantisme des réseaux d’Orgnac était lié au dégagement partiel des remplissages argileux. Une des caractéristiques d’Orgnac est que l'évacuation des argiles n'est pas liée à des écoulements souterrains réincisant les remplissages antérieurs mais à une dynamique généralisée de soutirages (figure 11). On peut observer ces phénomènes dans de nombreux endroits du réseau; un des exemples les plus spectaculaires est celui qui accidente la Salle 2. Vaste dépression circulaire (figure 2) d'une vingtaine de mètres de diamètre et d'une dizaine de mètres de profondeur, ce soutirage donne sur un large orifice par lesquel ont été et sont évacués les sédiments ; cet orifice rejoint probablement le puits «-200» localisé à quelques mètres de là (connexion spéléologique non réalisé compte tenu de la dangerosité du site). 


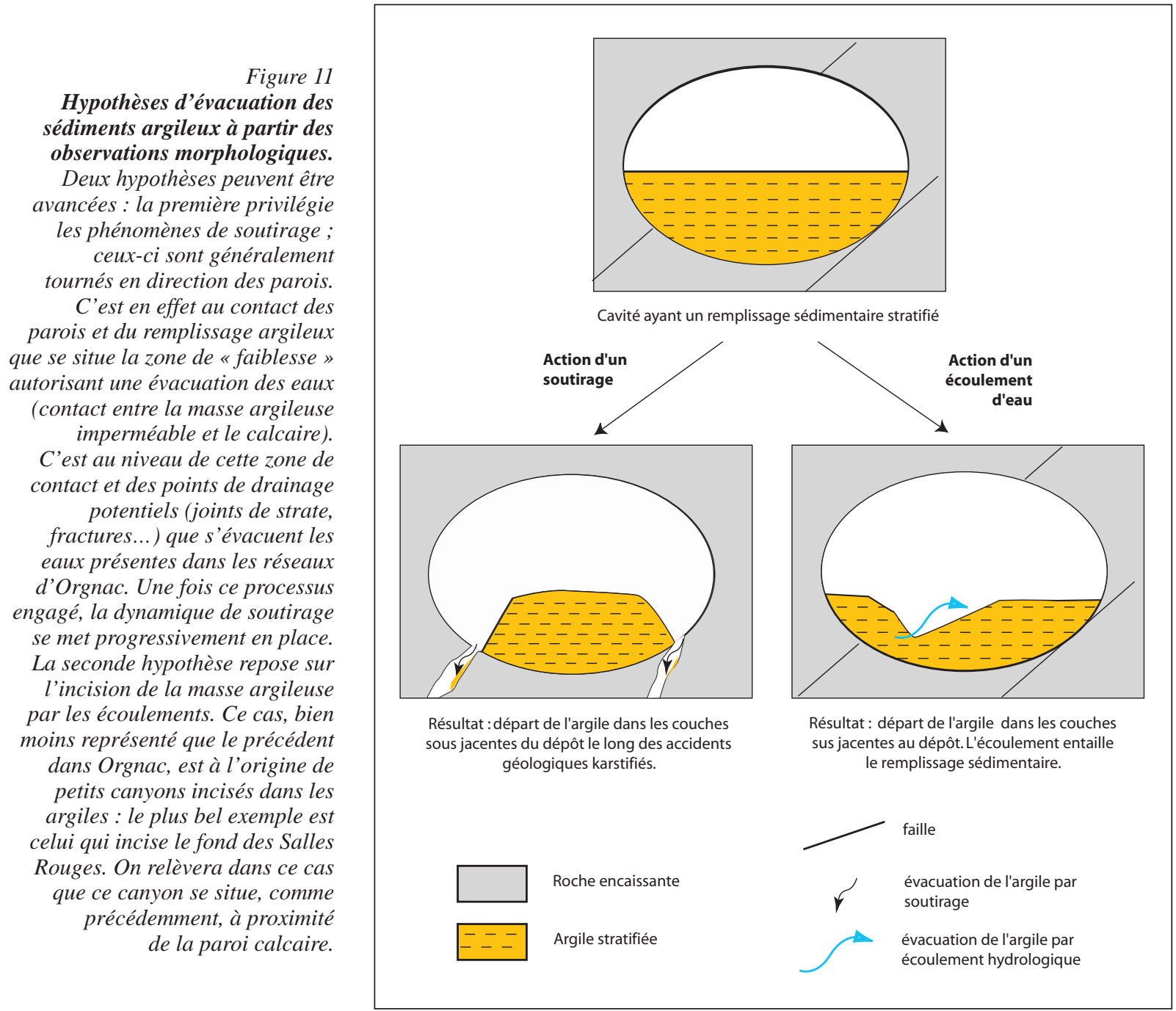

L'intérêt de ce soutirage est la présence de stalagmites ayant une morphologie coudée particulière dont l'origine a pu être reliée à la dynamique du soutirage : c'est à l'étude de ce soutirage et des stalagmites coudées que se consacre cette seconde partie de l'article.

\section{Photo 3}

Une concrétion translatée dans la Salle 2 (photo Stéphane Jaillet).

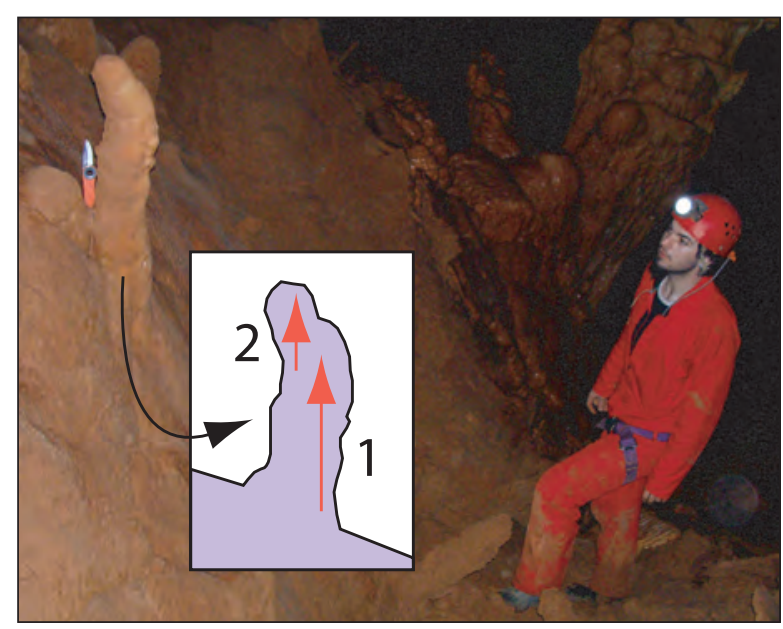

\section{II.1 - Enregistrement de la dynamique du soutirage par les stalagmites : exemple des concrétions translatées d'Orgnac}

À l'aven d'Orgnac, les concrétions ont depuis longtemps suscité l'intérêt scientifique (chapitre 2). Dans une note non datée, Robert de Joly prépare un argumentaire pour répondre aux questions des visiteurs à propos notamment de la forme coudée de certaines concrétions. Il propose alors comme élément de réponse à cette morphologie particulière, la migration du point d'alimentation au plafond (De Joly, inédit).

Effectivement, un très grand nombre de concrétions des Salles 1 et 2 ont une morphologie présentant un déplacement de l'axe de croissance. C'est ce que nous nommons «coude» dans la suite de ce paragraphe (photo 3 ). Après relevé topographique et géoréférencement de l'ensemble des stalagmites à proximité du soutirage de la Salle 2 (figure 12), il apparaît clairement que la direction des «coudes» des stalagmites peut être associée au soutirage. Contrairement à l'explication communément admise (déplacement de la zone d'alimentation), 
la forme coudée des stalagmites d’Orgnac est ici liée au déplacement de la stalagmite. Les coudes correspondent à un effet de translation de la base de la stalagmite en direction du soutirage (figure 13). Du fait de ce mouvement, la croissance postérieure n'est plus dans l'axe de croissance de la base de la concrétion, expliquant ainsi son allure coudée. Ces spéléothèmes particuliers ont été appelés « stalagmites translatées ».
Quatre stalagmites translatées réparties sur le rebord de soutirage ont été étudiées :

- sur place: étude statistique des directions des différentes translations identifiées à partir de la morphologie coudée des stalagmites. Lors des campagnes de prélèvements, des échantillons dont les axes de translations avaient été mesurés, ont été prélevés. Cet axe, gravé sur les échantillons

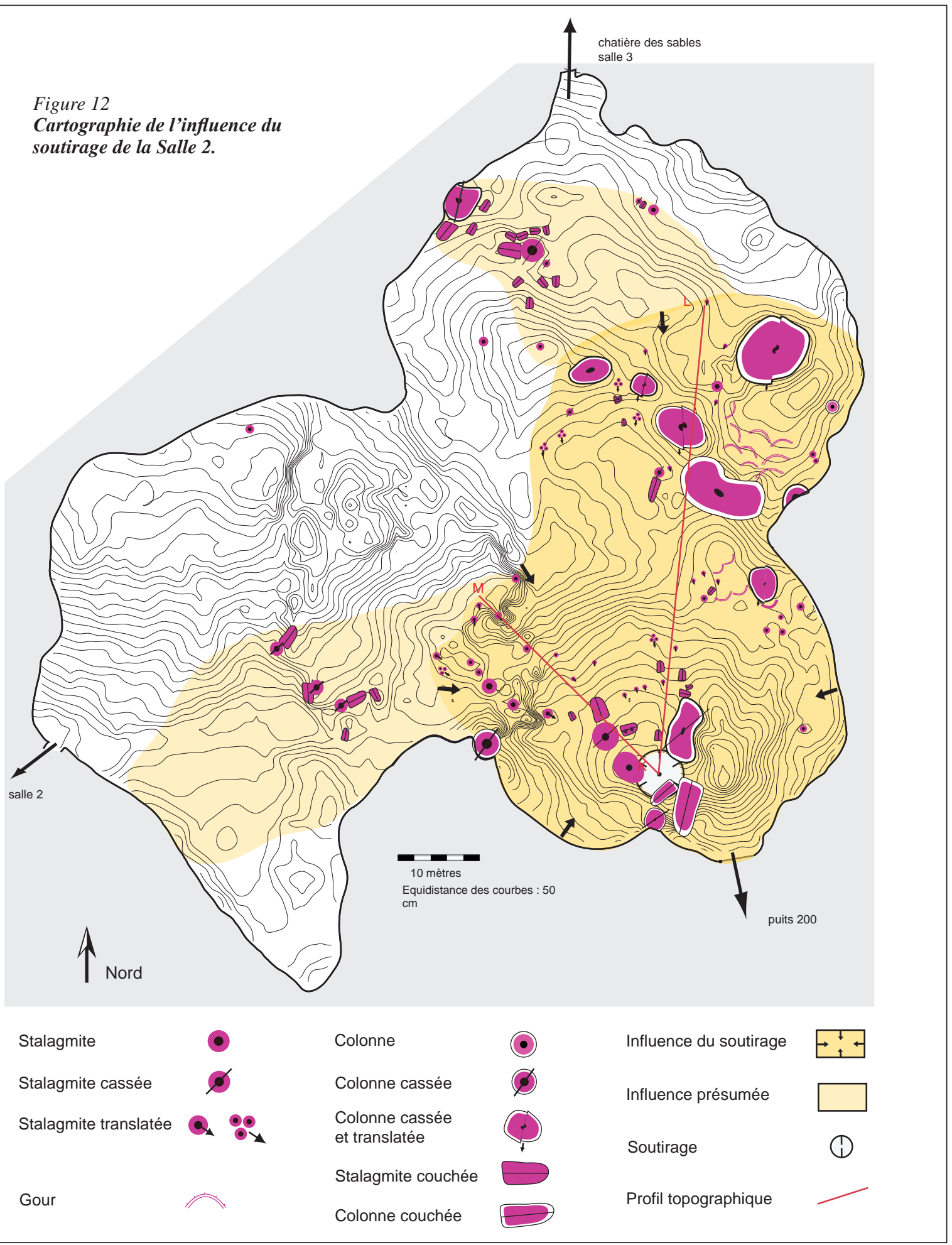



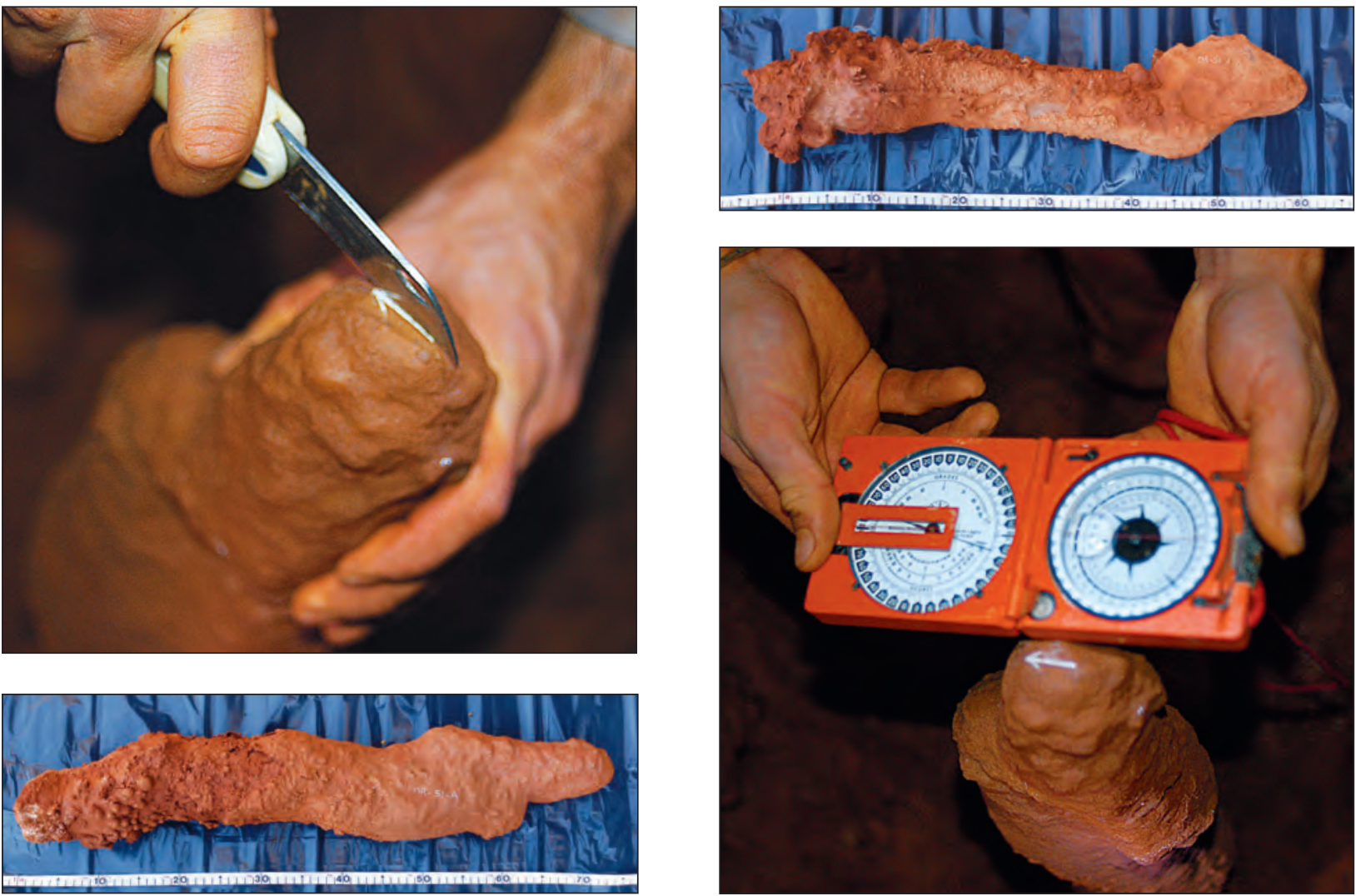

Photos 4

Prélèvement de stalagmites translatées (photo Stéphane Jaillet).

(photos 4), a été utilisé pour le sciage et leur étude en laboratoire. Le choix des prélèvements s'est porté sur des objets de dimension modeste sans intérêt esthétique particulier et avec le souci constant du respect de l'intégrité paysagère du site ;

- en laboratoire :

- étude micro morphologique sur section polie ou lame mince,

- datation des phases de pousse encadrant un mouvement de translation.
Sur les sections polies a été relevée la présence de film argileux précédant le départ du coude (figure 14). Ceci rappelle les phénomènes d'ennoiement synconcrétionnement relevés dans l'étude de la Tour de Pise (Salle de Joly) ainsi que le dépôt d'argiles sur les blocs d'effondrement de la Salle 2. La présence de ces films argileux suppose une phase d'ennoiement. Il est intéressant de relever que ces témoins d'anciens ennoiements ne sont pas systématiquement présents sur l'ensemble des stalagmites translatées, notamment

Figure 13

Reconstitution des dynamiques des talus argileux à partir de l'étude des stalagmites translatées.

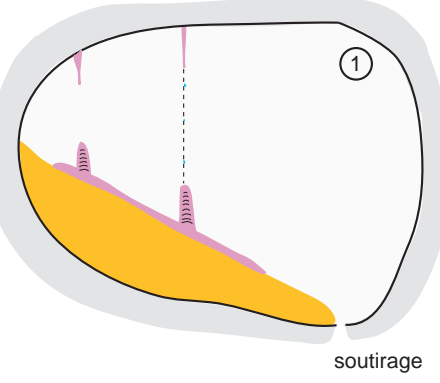

Temps 1 : Phase de concrétionnement

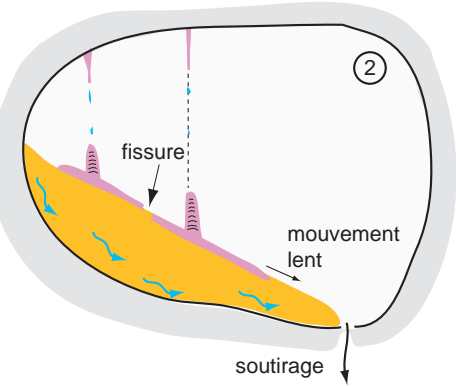

Temps 2 : Départ de matière entraînant un mouvement de terrain vers le soutirage. Ceci se marque par une fissure dans le plancher stalagmitique. La translation de la stalagmite vers le soutirage commence progressivement.

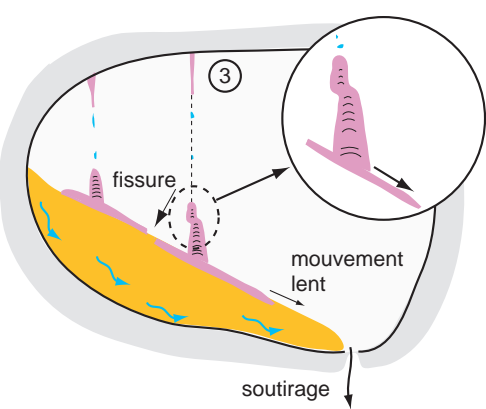

Temps 3: La stalagmite translatée continue d'être rattachée à son point d'alimentation et cela se marque par la formation d'un décrochement dans sa structure. On peut repérer ainsi plusieurs phases de ruptures. 


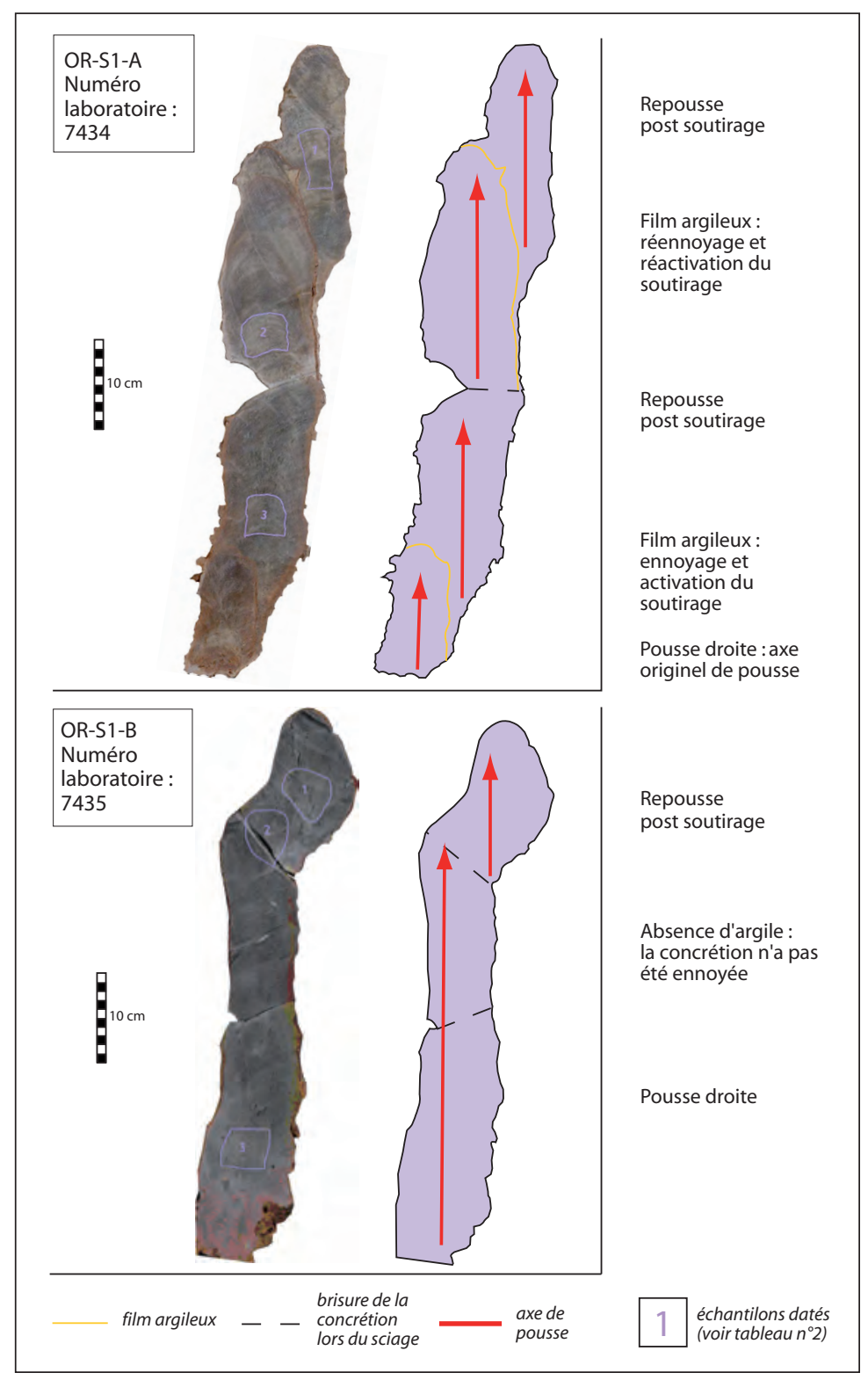

Figure 14

Identification des différentes phases de croissance d'une stalagmite sur section polie.

celles situées dans la partie supérieure de la salle : ce qui signifie que les ennoiements n'affectaient pas la totalité de la salle (figure 15). Quoi qu'il en soit, il est vraisemblable que ces mises en charge du réseau aient modifié les caractéristiques mécaniques du remplissage argileux, en les saturant en eau, et aient favorisé son fluage en direction du soutirage durant ou après ces épisodes hydrologiques particuliers. Le fait que la présence de ces films argileux se situe juste avant les mouvements de translation des stalagmites vont dans le sens d'une telle dynamique associant ennoiement et fluage de la masse argileuse en direction du point de soutirage. Sur la base des concrétions étudiées, il semble que ces phénomènes d'ennoiement / fluage correspondent à des événements exceptionnels dans la cavité ; suffisamment exceptionnels pour permettre une repousse relativement conséquente des concrétions entre deux mouvements de translation.

Des datations U/Th (comptage alpha) ont été réalisées sur deux des quatre concrétions prélevées de part et d'autre de «coudes» des stalagmites afin de pouvoir "caler» des mouvements de translation (tableau 2 et figure 14). Plusieurs phases de soutirage ont pu être ainsi «calées » dans le temps : une première entre 150000 et 100000 ans, une deuxième entre 78000 et 60000 ans et une troisième entre 60000 et 34000 ans.

Figure 15

Exemple de l'activation du soutirage après mise en charge du réseau.

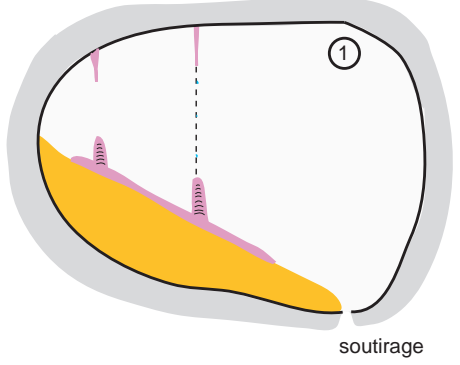

Temps 1

Phase de concrétionnement

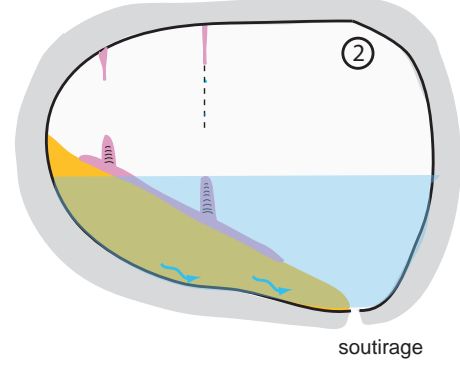

Temps 2

Phase d'ennoiement. Phase de sédimentation : des argiles se déposent sur les concrétions. Les dépots argiles se gorgent d'eau.

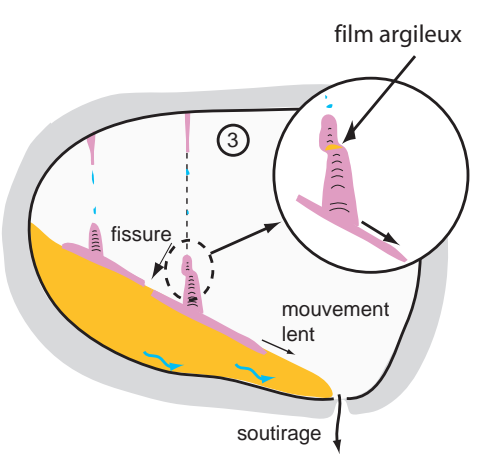

Temps 3

Phase de dénoyage.

Le concrétionnement reprend.

La vidange de la cavité entraine un départ de matière sédimentaire, devenue fluante, par soutirage. 


\begin{tabular}{|l|r|r|r|r|r|r|}
\hline Échantillon & [U]ppm & ${ }^{234} \mathbf{U} /{ }^{238} \mathbf{U}$ & ${ }^{230} \mathbf{T h} /{ }^{234} \mathbf{U}$ & ${ }^{230} \mathbf{T h} /{ }^{232} \mathbf{T h}$ & $\left.{ }^{234} \mathbf{U} /{ }^{238} \mathbf{U}\right] \mathbf{t}=\mathbf{0}$ & Âge (en m.a.) \\
\hline$[7434]-1$ & $0,110 \pm 0,001$ & $0,975 \pm 0,013$ & $0,271 \pm 0,028$ & $14 \pm 10$ & 0,972 & $34,3[+4,3 /-4,1]$ \\
\hline$[7434]-2$ & $0,073 \pm 0,001$ & $0,959 \pm 0,029$ & $0,426 \pm 0,029$ & ---- & 0,951 & $60,5[+5,9 /-5,6]$ \\
\hline$[7434]-3$ & $0,085 \pm 0,001$ & $0,940 \pm 0,012$ & $0,512 \pm 0,016$ & $24 \pm 4$ & 0,926 & $78,5[+3,8 /-3,6]$ \\
\hline$[7435]-1$ & $0,094 \pm 0,001$ & $0,969 \pm 0,026$ & $0,605 \pm 0,022$ & $52 \pm 15$ & 0,959 & $101,4[+7,1 /-6,4]$ \\
\hline$[7435]-2$ & $0,101 \pm 0,001$ & $0,972 \pm 0,013$ & $0,760 \pm 0,082$ & ---- & 0,956 & $156,9[+50 /-34]$ \\
\hline$[7435]-3$ & $0,105 \pm 0,001$ & $0,989 \pm 0,010$ & $0,733 \pm 0,016$ & $50 \pm 7$ & 0,983 & $143,7[+7,4 /-6,7]$ \\
\hline
\end{tabular}

Tableau 2 : Résultats d'analyse U/Th sur des concrétions translatées d'Orgnac (Cerak).

Plus que les âges eux-mêmes qui représentent deux concrétions parmi un grand nombre de stalagmites, ce qui est intéressant de relever est, d'une part, la confirmation que les phénomènes d'ennoiement des réseaux d'Orgnac-Issirac sont et restent exceptionnels et, d'autre part, que les soutirages résultent d'une évolution se réalisant sur une très longue durée mais de manière discontinue.

Un autre enseignement de l'analyse des concrétions translatées est que le fluage du remplissage argileux en direction des points de soutirage ne se limite pas aux seuls secteurs ayant été ennoyés mais est un phénomène qui affecte l'ensemble de la masse argileuse (figure 16) ; la preuve étant la présence de stalagmites translatées dans la partie supérieure des salles et ne présentant pas de film argileux avant la phase de « repousse » postcoudage. Ces observations permettent de mieux saisir la topographie bosselée et généralisée des remplissages argileux des grandes salles d'Orgnac (Salle Plane mise à part)

\section{II.2 - Le rôle des soutirages dans le façonnement des paysages souterrains d'Orgnac}

Sur la carte géomorphologique de la Salle 2, on a fait ressortir les concrétions translatées, la direction générale de leur translation, ainsi que les autres indicateurs de mouvements de la masse argileuse (figures 11 et 12). La reconnaissance de ces indicateurs ainsi que la compréhension des morphologies coudées des stalagmites permettent d'attester du fluage généralisé du remplissage argileux qui converge vers le même point : l'entonnoir de soutirage. On peut donc supposer que dans le cas d'un soutirage moins visible que dans la Salle 2, l'étude des stalagmites translatées devrait permettre de localiser plus précisément le point d'origine et l'ampleur du soutirage. L'ampleur de celui-ci peut être appréhendée de plusieurs façons : l'existence ou non de concrétions translatées, l'importance de leur translatation (celle-ci apparaît toujours plus marquée dans l'aire proche du point de soutirage que dans les

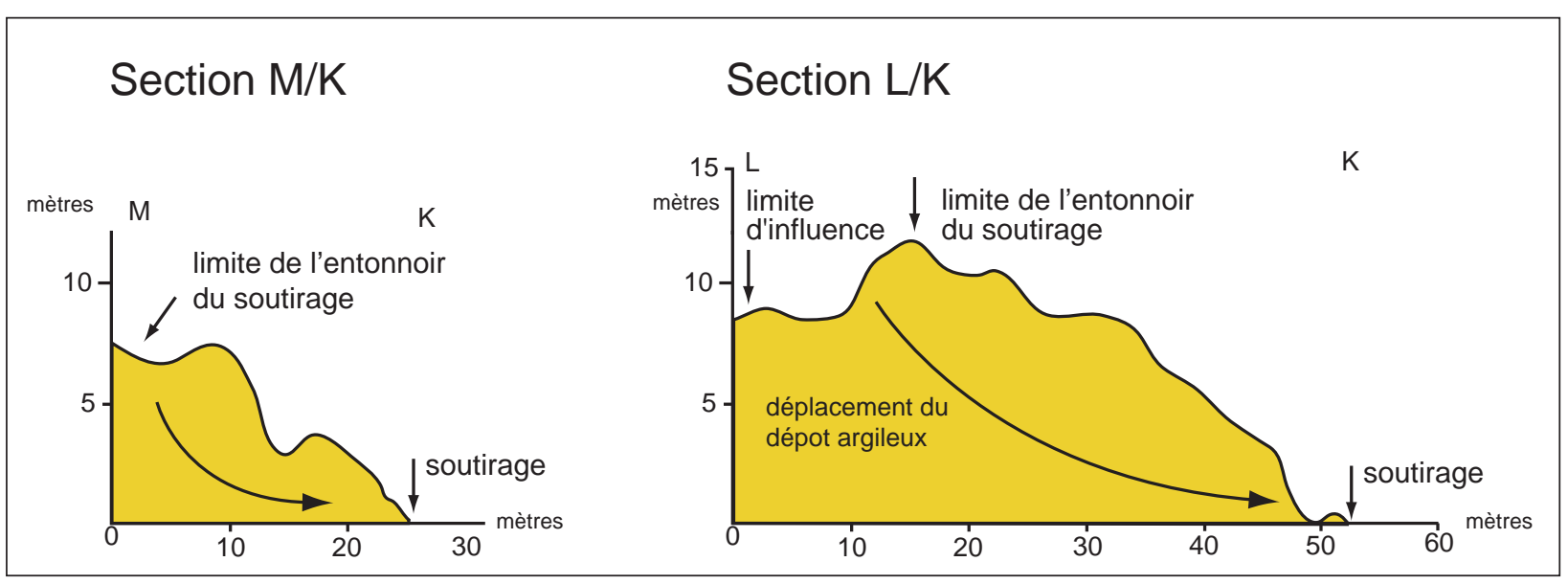


points hauts de la salle). La dynamique du soutirage peut être également appréhendée par l'étude des concrétions translatées : l'absence de translation sur les plus « récentes » repousses de stalagmites est synonyme d'une relative stabilité des talus argileux. La prise en compte des concrétions translatées dans la compréhension et la dynamique des phénomènes de soutirage d'Orgnac offre de nombreuses perspectives de recherche : géographie des soutirages « anciens » et « fonctionnels », définition des aires d'influence des différents soutirages, géographie des salles toujours affectées par les soutirages et des galeries « stabilisées »...

Les travaux à venir dans Orgnac porteront sur ces perspectives et sur la définition des causes expliquant les répartitions spatiales évoquées.

Quoi qu'il en soit, les soutirages constituent un phénomène marquant d'Orgnac ; plus que leur incidence dans la morphologie de la cavité, nous voulons mettre ici l'accent sur la dynamique d'évacuation des argiles via ces phénomènes sur une longue échelle temporelle ; c'est petit à petit, au cours d'événements exceptionnels d'ennoiement, que les argiles sont progressivement soutirées par des réseaux souterrains sous-jacents et que les volumes souterrains d'Orgnac ont pris de l'ampleur. La prise en compte de cette dimension temporelle permet de prendre conscience du facteur temps, nécessaire ici non pas à la création des vides souterrains mais à l'évacuation des remplissages argileux qui colmataient la quasi-totalité des vides karstiques (chapitre 3). Ce facteur temps souligne à nouveau l'ancienneté du creusement initial des réseaux d'Orgnac; ancienneté déjà relevée dans le façonnement paragénétique des conduits de cette cavité.

\section{Conclusion}

Ce chapitre portant sur les formations détritiques et carbonatées avait pour objet de mettre en avant leur fonction de mémoire spéléogénique. L'étude des remplissages détritiques et des spéléothèmes a permis de relever des phases d'évolution des réseaux d'Orgnac. Ces différentes phases complètent les étapes déjà mises en évidence (chapitre 3) et permettent de préciser l'évolution des réseaux depuis leur façonnement paragénétique.

La cartographie morphologique, les sondages réalisés à la tarière et la prospection tomographique ont permis de confirmer l'importance des remplissages argileux. Les différentes observations ont également mis en avant que le remplissage argileux n'est pas uniforme et que deux séquences argileuses peuvent être distinguées : la première (argiles rouges litées sans discontinuités apparentes) rapportée au fonctionnement paragénétique des réseaux d'Orgnac; la seconde (séquence supérieure: argiles rouges présentant des discontinuités stratigraphiques: lits sablo-limoneux; fins niveaux carbonatés...) rapportée à un ennoiement des réseaux entrecoupé par des phases d'émersion (encroutement stalagmitique) ou d'hydrodynamisme plus marqué (niveaux sableux). C'est à cette seconde phase que l'on rapporte la planéité de la Salle Plane; cette planéité ne pouvant être liée au fonctionnement paragénétique compte tenu de la présence de banquetteslimites relativement haut dans les plafonds de cette salle (chapitre 3, figure 4); position des banquettes qui suppose un niveau de remplissage beaucoup plus élevé que ce qui est aujourd'hui observable dans cette salle.

Le croisement des informations issues des formes pariétales et de galeries et de celles issues des formations permet ici de distinguer clairement deux phases de fonctionnement d'Orgnac ayant toutes les deux engendré une sédimentation argileuse : la première est contemporaine $\mathrm{du}$ fonctionnement paragénétique; la seconde est contemporaine d'ennoiements des réseaux. Il est probable que cet ennoiement des réseaux n'était pas total, ce qui pourrait expliquer le caractère plan du plancher de la Salle Plane ainsi que la moindre présence d'argile dans Orgnac IV et des réseaux se développant au NNE de la Grande Barrière, situés en contre-haut de la Salle Plane.

Les recherches à venir dans Orgnac devront permettre de confirmer ce scénario. Quoi qu'il en soit, entre ces deux phases de sédimentation argileuse, une étape spéléogénique doit être envisagée : phase de dégagement d'une part des argiles contemporaines du paragénétisme.

La cartographie morphologique a par ailleurs permis de mettre en avant des phénomènes de détente mécanique comme l'atteste la présence de blocs d'effondrement à la surface des talus argileux ; la tomographie électrique de la Salle Plane a permis de mettre en avant que ces phénomènes étaient déjà actifs durant la seconde phase de sédimentation argileuse (cf. ci-dessus). La cartographie de ces blocs d'effondrement a permis de relever que nombre d'entre eux étaient recouverts d'un film argileux rapporté à des ennoiements exceptionnels et temporaires des réseaux. L'existence de ces ennoiements est confirmée par la présence de films argileux recouvrant d'anciens édifices stalagmitiques. La mise en évidence de concrétions particulières (coudées) présentes sur les talus argileux et leur étude interne ont permis d'associer ennoiement temporaire et fluage des talus argileux en direction des points de soutirage.

C'est la première fois qu'une telle dynamique morphologique a été mise en évidence en milieu souterrain. Cet apport est fondamental car il permet de poser de nouveaux regards sur les phénomènes de soutirage, plus souvent traités comme phénomènes rapides et catastrophiques; dans le cas d'Orgnac, le soutirage des argiles a été commandé par la répétition de phénomènes d'ennoiement exceptionnels et temporaires. 
Le caractère exceptionnel a été clairement mis en évidence par la datation des stalagmites translatées : plusieurs dizaines de milliers d'années séparent les fluages responsables de la mise en mouvement des talus argileux en direction des soutirages. Le caractère temporaire est marqué par l'absence de séquences sédimentaires clairement reconnaissables. L’ensemble des observations réalisées dans Orgnac

\section{Bibliographie}

De Joly R. (non daté) - Lettre destinée aux guides de la grotte, inédit

Delannoy J.-J., Debard É., Ferrier C., Kervazo B. et Perrette Y. (2001) - La cartographie morphologique souterraine : Apports aux reconstitutions paléogéographiques et paléo-environnementales. Application à la Grotte Chauvet (Ardèche-France). Quaternaire, vol. $12, \mathrm{n}^{\circ} 4,2001,235-248$

Delannoy J.-J., Perrette Y., Debard É., Ferrier C., Kervazo B., Perroux A.-S., Jaillet S. et Quinif Y. (2004) - Intérêt de l'approche morphogénique pour la compréhension globale d'une grotte à haute valeur patrimoniale : la grotte Chauvet (Ardèche, France). Karstologia, $\mathrm{n}^{\circ}$ 44, 2004, 25-42.

Delannoy J.-J. et al., coordination Jaillet S. (2004) - Aven d’Orgnac - Étude spéléogénique et karstogénique, étude des mémoires paléogéographiques et paléoenvironnementales du Bas-Vivarais. Rapport d'étape n¹, Université de Savoie, EDYTEM, 192 p.

Delannoy J.-J. et al., coordination JAillet S. (2005a) - Aven d’Orgnac - Étude spéléogénique et karstogénique. étude des mémoires paléogéographiques et paléoenvironnementales du Bas-Vivarais. Rapport d'étape $\mathrm{n}^{\circ} 2$, Université de Savoie, EDYTEM, 68 p.

Delannoy J.-J. et al., coordination Jaillet S. (2005b) Aven d’Orgnac - Étude spéléogénique et karstogénique. étude des mémoires paléogéographiques et paléoenvironnementales du Bas-Vivarais. Rapport final, Université de Savoie, EDYTEM, 198 p.

Genty D., Ghaleb B, Plagnes V., Causse C., Valladas H., Blamart D., Massault M., Geneste J.-M., et Clottes J. (2004) - Datations U/Th (TIMS) et C14 (AMS) des stalagmites de la grotte Chauvet (Ardèche, France) : intérêt pour la chronologie des évènements naturels et anthropiques de la grotte. CR Palevol, 2004, 629-642.

Jaillet S., Pons-Branchu E., Maire R., Hamelin B. et BRULHET J. (2006) - Enregistrement de paléo-mises en charge holocènes dans deux stalagmites du réseau du Rupt-du-Puits (Barrois, France). Analyses morphologiques des lamines et datations U/TH en TIMS. Geologica Belgica, 2006, 297-307.

KaufManN O. (2002) - Rapport de synthèse de la prospection géophysique réalisée dans la Salle Plane de l'aven d'Orgnac. Rapport interne, Université de Savoie, EDYTEM, 12 p. met en avant l'ancienneté de ses réseaux, tant en ce qui concerne le creusement « originel» des conduits que l'évacuation progressive des remplissages argileux (séquences 1 et 2 ). L'ancienneté de cette évacuation peut être ici argumentée par le fait que les talus (issus de cette dynamique) portent plusieurs générations de concrétions dont la plupart se situent bien au-delà de la limite du chronomètre U/Th (>450 000 ans).

Noury M. (2005) - Cartographie géomorphologique de la Salle Plane Orgnac/Issirac - Ardèche, France. étude comparative de deux grands vides karstiques (Salle II et Salle Plane). Mémoire de Maîtrise, Université de Savoie, EDYTEM, 65 p.

Pascal M. dir. (1989) - Carte géologique de la France au $1 / 50000^{\circ}$, feuille Bourg-St-Andéol (889) et notice explicative. Éd. BRGM, 67 p.

Perrette Y. (2000) - Étude de la structure interne des stalagmites: contribution à la connaissance géographique des évolutions environnementales du Vercors (France). Développement et application d'une approche multi paramètres des archives stalagmitiques. Thèse, Université de Savoie, EDYTEM, 324 p.

Perroux A.-S. (2005) - Les remplissages détritiques endokarstiques. Contribution méthodologique à la lecture des mémoires paléogéographiques et environnementales. Application aux systèmes karstiques de Choranche (Vercors) et d'Orgnac (Bas-Vivarais). Thèse, Université de Savoie, EDYTEM, 418 p.

Perroux A.-S., Delannoy J.-J., Perrette Y. et Desmet M. (2004) - Les sédiments détritiques de grotte : un processus d'archivage original. In L'érosion entre société, climat et paléoenvironement, Table Ronde en l'honneur de R. Neboit-Guilhot, Clermont-Ferrand, 2004, 147-152.

QuINIF Y. (2005) - Rapport des datations de quatre stalagmites de l'aven d'Orgnac. Note de synthèse, inédit.

Renault P. (1969) - Contribution à l'étude des actions mécaniques et sédimentologiques dans la spéléogénèse, Thèse, Annales de Spéléologie 22/1, 1967, 5-21 ; 22/2, 1967, 209-267 ; 23/1, 1968, 259-307 ; 23/3, 1968, $529-596$ et $581-582 ; 24 / 2,1969,317-337$.

Renault P. (1996) - Crues souterraines dans le Saut de la Pucelle (Lot), la grotte aménagée de la Cocalière (Gard) et l'aven touristique d'Orgnac. Actes de la $6^{\text {ème }}$ Rencontre d'octobre, Osselle 1996, 1996, 83-85.

SADIER B. (2004) - Étude géomorphologique d'un grand volume karstique. Exemple de la Salle 2 du réseau II d'Orgnac-Issirac, Ardèche, France. TER Master 1, Géographie, Université de Savoie, EDYTEM, 2004, $81 \mathrm{p}$.

WIENIN M. (non daté) - Étude succincte des sables du siphon des sables d'Orgnac II. Note de synthèse, inédit. 


\title{
L'AVEN D'ORGNAC
}

\section{SUIVI ENVIRONNEMENTAL ET MODÈLE DE FONCTIONNEMENT ACTUEL DU MILIEU SOUTERRAIN KARSTIQUE AU SERVICE DU DÉVELOPPEMENT DURABLE}

\author{
par François BOURGES ${ }^{\imath}$, Alain MANGIN², \\ Pierre GENTHON², Dominique D’HULST² et Françoise GAUQUELIN ${ }^{4}$ \\ 1 Géologie-Environnement-Conseil, St-Girons \\ 2 Laboratoire de Moulis, CNRS, St-Girons \\ 3 IRD Hydrosciences, Maison des Sciences de l'Eau, Montpellier \\ 4 Ministère de l'Écologie, du développement et de l'aménagement durables, CERTU, Lyon.
}

\begin{abstract}
Exploré en 1935 par Robert de Joly accompagné de l'abbé A. Glory, de J. Latour, A. Petit et F. Chagnard, l'aven d'Orgnac est une grotte touristique qui fait partie d'un réseau de cavités karstiques classé initialement au titre des sites en 1946 puis en 1974 après les découvertes des nouveaux réseaux par les équipes de Guy Rieu et Jean-Charles Trébuchon.
\end{abstract}

Dans les années 1990, des installations d'accueil obsolètes et une gestion difficile font apparaître la nécessité d'une requalification du site touristique. Avant toute conception de projet apparaissait la nécessité de lancer une étude sur le milieu souterrain. Ce travail d'étude sur les problèmes d'aménagement et l'impact des travaux a été initialement commandé à l'initiative de la DIREN, en 1996, au bureau d'étude Géologie Environnement Conseil associé au Laboratoire souterrain de Moulis. Cette collaboration, augmentée récemment de l'IRD, se poursuit sur le site depuis cette époque, accompagnant successivement les phases d'étude initiale (rendu 1998) et complémentaire (rendu 1999), le contrôle des travaux (2000-2001), le suivi après modifications, une Opération Grand Site (2000-2004) à laquelle contribue également l'équipe du laboratoire EDYTEM de l'Université de Savoie, et un projet de classement de la surface (actuellement en cours).

Cet article présente les thèmes abordés par notre équipe dans le travail de suivi et d'étude sur l'aven d'Orgnac et les replace dans le contexte d'accompagnement de l'aménagement et de la valorisation d'un site souterrain exceptionnel.

Les études sur l'aven d'Orgnac ont été réalisées sur la base d'un objectif de compréhension du fonctionnement actuel du milieu naturel. La mesure des impacts et l'évaluation des risques, par l'identification des sensibilités particulières du milieu, est nécessaire à sa préservation et à la bonne gestion du site. La meilleure connaissance du système naturel karstique permet également de valoriser un patrimoine naturel et culturel en améliorant la qualité de sa présentation au public.

Les opérations consistent principalement en un suivi environnemental actif depuis maintenant un peu plus de dix ans sur le site de l'aven d'Orgnac. L'outil technique principal est un système de stations de mesures et de capteurs mesurant en continu les paramètres pertinents du milieu souterrain (températures dans l'air et en paroi en divers points du site, pression barométrique, concentrations en $\mathrm{CO}_{2}$, en radon 222, humidité relative, piézométrie dans un forage situé dans le secteur) et ceux de l'atmosphère de surface (température de l'air, pluviométrie, pression barométrique). Les mesures sont enregistrées au pas du quart d'heure. Les données acquises ont été complétées par des mesures ponctuelles pour acquérir de l'information spatiale (profils en $\mathrm{CO}_{2}$ et $\mathrm{O}_{2}$ le long de la cavité) et par des expérimentations complémentaires (mesures des concentrations en $\mathrm{CO}_{2}$ dans le sol pendant une année, expérimentations sur profils thermiques verticaux dans la Salle Plane et dans la Salle de Joly, jaugeage différentiel de la Cèze, mesures de débits d'air et de $\mathrm{CO}_{2}$ aux entrées naturelles et artificielles du site, expérience de ventilation forcée dans la zone confinée du Canyon). À ce jour, plus de 2 millions de données numériques ont été archivées.

L'interprétation des données acquises lors du suivi et des expérimentations ont permis de mettre au point et d'affiner au cours des années un modèle de fonctionnement de l'ensemble du système karstique d'Orgnac sur des bases qualitatives et quantitatives. $\mathrm{Ce}$ modèle permet d'évaluer les propositions d'aménagement en fonction des sensibilités du milieu. 
En septembre 2002, une pluie centennale de l'ordre de $400 \mathrm{~mm}$ a provoqué, le lendemain, une inondation des cavités profondes rappelant brutalement l'existence d'une composante hydraulique dans le fonctionnement actuel. La nouveauté de certains résultats a fourni matière à publications dans des revues scientifiques (Bourges et al., 2001, Bourges et al,. 2006) et a fait l'objet de communications en congrès (Bourges et al., 1998, 2003, 2005).

Dans cet article, après avoir rappelé les propriétés du milieu karstique et les approches adoptées, nous abordons le problème des transferts du $\mathrm{CO}_{2}$ dans le cadre de la faisabilité de l'opération de réaménagement du site. Un schéma de fonctionnement naturel des cavités de l'aven d'Orgnac est ensuite exposé, il donne une vision globale des phénomènes d'échanges et précise leur localisation, il est utilisé comme modèle pour le suivi et le contrôle des travaux en surface et de fonçage du puits d'ascenseur. La réalisation d'expérimentations complémentaires dans différentes parties du réseau dans le cadre d'une Opération Grand Site a complété un modèle thermique et permis de généraliser le modèle d'échange. Les observations après la pluie centennale de septembre 2002 ont ouvert un champ de réflexion nouveau avec l'instrumentation de la zone noyée permettant une description et une analyse du fonctionnement de toutes les parties du système karstique d'Orgnac.

\section{I - Propriétés et APPROCHE DU MILIEU SOUTERRAIN KARSTIQUE}

Le système naturel qui héberge l'essentiel du patrimoine souterrain est le karst. Il s'agit d'un ensemble de morphologies développées à l'échelle des temps géologiques dans des formations calcaires par les dissolutions et précipitations chimiques résultant d'un drainage essentiellement souterrain des eaux. Le fonctionnement d'un karst actuel peut être décrit en termes de transferts de matière et d'énergie depuis la surface, au travers d'une zone d'infiltration (qui héberge les cavités accessibles) puis dans une zone noyée vers un exutoire final.

À cause de discontinuités de la roche élargies par la dissolution, les grottes des systèmes karstiques échangent des gaz et de l'eau avec le milieu extérieur au travers des réseaux de vides de tailles variées. Ces vides de petite taille sont appelés réseau macrofissural et microfissural (Mangin, 1995). Les réseaux de macrofissures sont le résultat de dissolutions à partir de discontinuités initiales (fractures, fissures ou joints) et sont caractérisés par des ouvertures millimétriques à centimétriques. Ces réseaux sont soit colmatés par des sédiments, particulièrement dans des systèmes karstiques comprenant différents niveaux, soit ouverts, assurant alors le transfert rapide de gaz entre les grands vides souterrains des grottes et l'atmosphère extérieure ainsi que l'infiltration des eaux météoritiques durant les forts évènements pluvieux. Au contraire, le réseau microfissural est constitué par les fissures initiales de la roche avec des ouvertures inférieures à $1 \mathrm{~mm}$. À cause des tensions superficielles et de l'étroitesse des ouvertures, le réseau microfissural est soumis à des écoulements diphasiques permettant le transfert vers le bas de l'eau de pluie et de l'air du sol enrichi en $\mathrm{CO}_{2}$ vers les différentes grottes et vers l'aquifère. Ainsi, la taille du système naturel est largement plus importante que le volume de la grotte, tandis que les différents niveaux d'énergie et de flux dépendent des types de vides, de leurs positions dans le système karstique et aussi de la grande variabilité des conditions locales en surface. Ceci amena notre équipe à utiliser d'abord une approche systémique basée sur l'analyse des flux de matière et d'énergie (Mangin, 1984) sans s'interdire une approche physique plus classique s'agissant de processus actifs dans les microclimats souterrains.

\section{II - LES COMPOSITIONS DES ATMOSPHÈRES SOUTERRAINES}

Le confort et la sécurité des personnes dans un site souterrain touristique sont dépendants de la qualité de l'air qu'on y respire. Ainsi, la présence de gaz carbonique dans l'atmosphère de l'aven d'Orgnac et le questionnement sur son origine, sur l'évolution saisonnière ou à plus long terme des concentrations fut un thème majeur de l'étude d'impact initiale.

Le projet envisageait une extension de l'aménagement souterrain au bas des Salles Rouges. L'instrumentation initiale cibla donc les zones du Balcon des Salles Rouges et du Canyon qui sont les parties les plus profondes et facilement accessibles de cette zone.

Les résultats de la première année de suivi montrèrent un comportement singulier de la zone du Canyon des Salles Rouges avec des abaissements quasi instantanés de la concentration en $\mathrm{CO}_{2}$ et des remontées progressives des valeurs jusqu'à des niveaux de 3,5 à $4 \%$. Ce fonctionnement fut interprété par des vidanges aérodynamiques successives du Canyon en période d'hiver lorsque de l'air souterrain était remplacé par de l'air directement venu de l'extérieur (figure 1). La réalisation de profils le long de la cavité, la visualisation d'une interface aérodynamique par des fumigènes et un suivi ultérieur simultané en radon et $\mathrm{CO}_{2}$ (figure 2) confirmèrent que la zone du Canyon se comportait comme un compartiment confiné de la cavité qui s'ouvrait occasionnellement à l'influence extérieure.

La question de l'origine de ce gaz et des concentrations mesurées dans le Canyon restait problématique. Nous n'avions identifié aucune influence des visites touristique sur la teneur en $\mathrm{CO}_{2}$ de l'air souterrain dans l'aven; de plus, du $\mathrm{CO}_{2}$ en teneur comparable était 


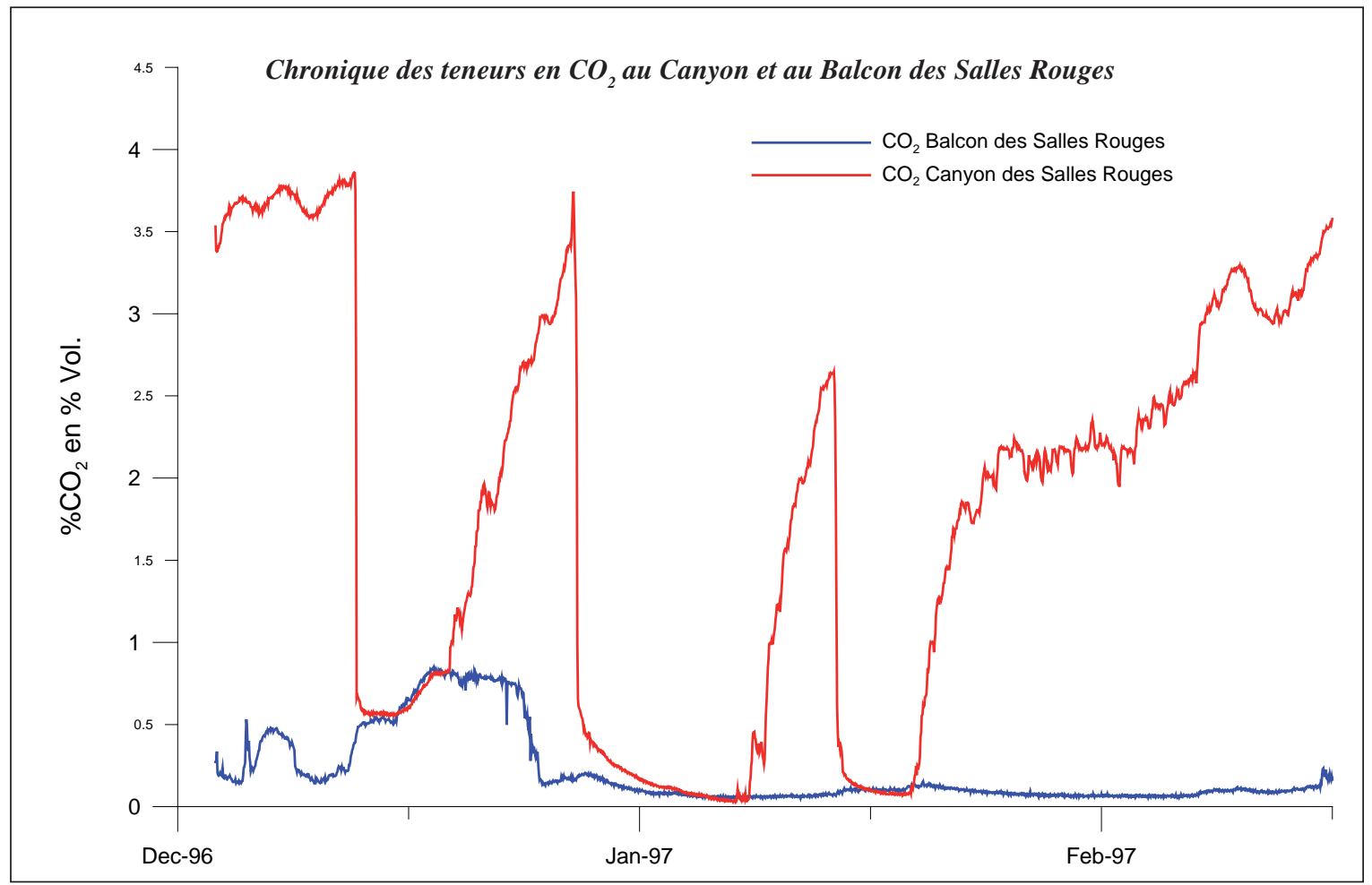

Figure 1

L'enregistrement de l'évolution des concentrations en $\mathrm{CO}_{2}$ dans le Canyon des Salles Rouges montre une succession de vidanges et de remplissages d'un compartiment confiné. Les vidanges sont le résultat d'un phénomène aérodynamique instantané d'ouverture, les remplissages se font à vitesse à peu près constante et permettent de calculer un flux moyen de $\mathrm{CO}_{2}$.

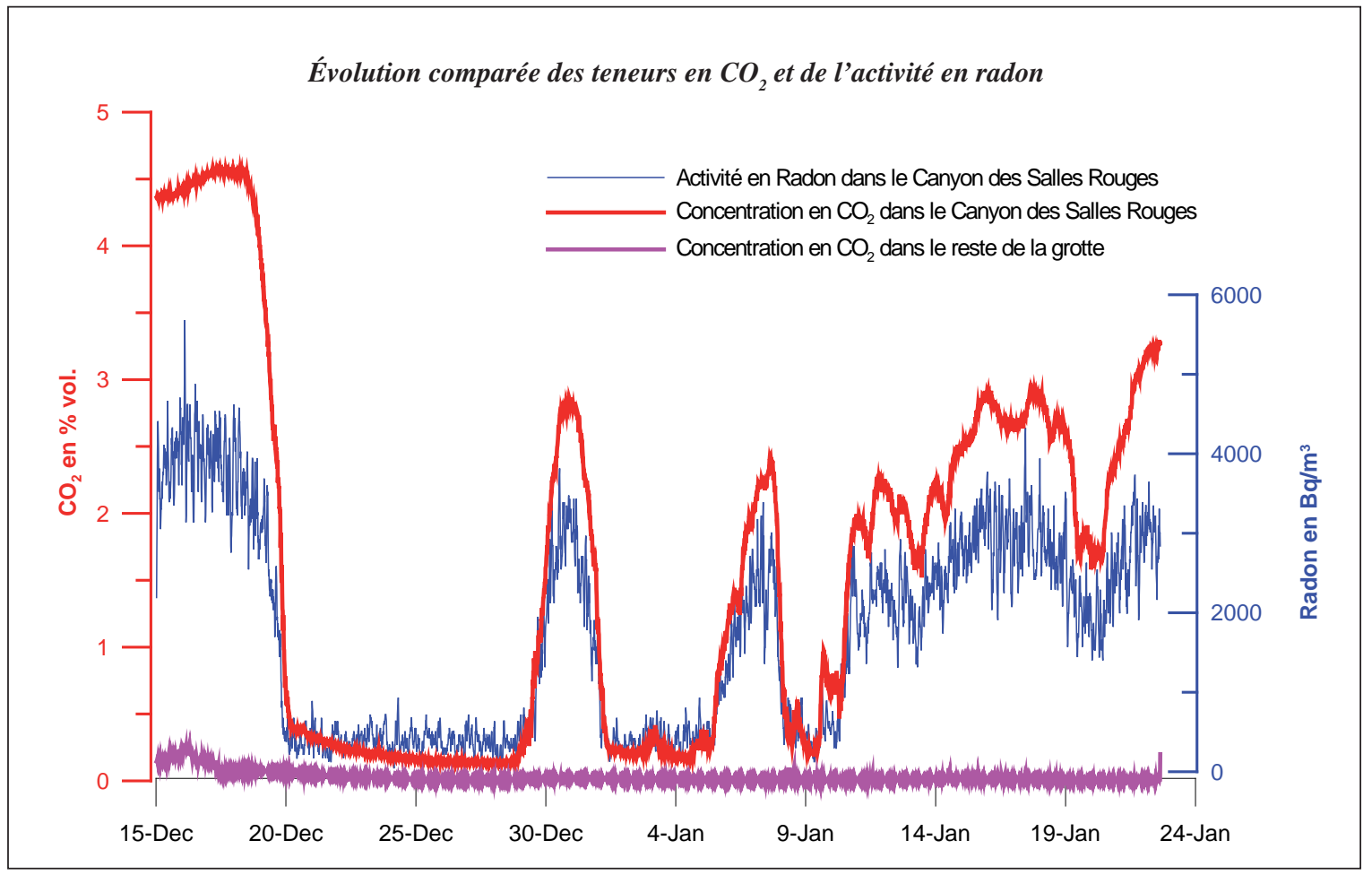

Figure 2

En 2004, les enregistrements du radon et du $\mathrm{CO}_{2}$ témoignent des successions de conditions de confinement et ouvertures de l'atmosphère du Canyon. Notons que cette année le caractère progressif de ces vidanges indique que des phénomènes comme la diffusion au travers d'une interface pourraient également être actifs dans l'évolution du compartimentage aérodynamique. 
également présent dans l'atmosphère des nouveaux réseaux et dans d'autres grottes voisines en l'absence de toute fréquentation humaine. L'analyse des isotopes de l'hélium $\left({ }^{3} \mathrm{He},{ }^{4} \mathrm{He}\right)$ permit d'éliminer une arrivée de gaz profond ; l'analyse des isotopes du carbone $\left(\delta^{13} \mathrm{C}\right)$ indiquait que le carbone du $\mathrm{CO}_{2}$ était essentiellement d'origine biogénique. La diminution de l'oxygène corrélativement à l'augmentation du $\mathrm{CO}_{2}$ dans l'air souterrain dans un rapport mole à mole identifiait un phénomène analogue à une combustion ou à une respiration.

L'hypothèse de l'origine de ce $\mathrm{CO}_{2}$ dans les sols en surface a donc été émise et testée. Nous avons tubé et équipé une zone de surface près de l'aven pour suivre sur une année les compositions de l'air du sol à différentes profondeurs. Des concentrations volumiques en $\mathrm{CO}_{2}$ similaires à celles des zones profondes des grottes ont été identifiées en base de ce sol (figure 3). Une estimation à $0,004 \mathrm{l} / \mathrm{s} / \mathrm{m}^{2}$ du flux de $\mathrm{CO}_{2}$ pur arrivant dans la grotte au travers de la roche a été réalisée à partir des données de vitesse de remplissages du canyon et des surfaces potentiellement productives. Un calcul permet d'extrapoler la production de $\mathrm{CO}_{2}$ pour l'ensemble de la cavité (1,9 tonnes/jour). La mesure des quantités de $\mathrm{CO}_{2}$ expulsé en été à l'ouverture naturelle a confirmé pour l'ensemble de la cavité les ordres de grandeur de la production (entre 0,5 et 4 tonnes de $\mathrm{CO}_{2}$ pur par jour). Ces valeurs sont importantes par rapport à celles potentiellement émises par les visiteurs même en haute saison touristique et expliquent que leur impact n'est pas visible dans la chronique du $\mathrm{CO}_{2}$ de l'air de la grotte.

Malgré une tendance à la hausse sur le long terme, les concentrations maximales atteintes dans l'aven (2,5\%) restaient inférieures à celles des parties confinées. Cette différence est attribuée à la présence de fissures ouvertes permettant des dilutions de l'air souterrain par l'arrivée d'air extérieur dans certaines parties du volume de la grotte. Les sections cumulées calculées pour ces fissures sont très faibles $\left(0,78 \mathrm{~m}^{2}\right.$ pour la ventilation des Salles Rouges hors Canyon) et peuvent facilement être colmatée par des aménagements impliquant une sensibilité de l'état de surface. L'analyse indiquait aussi qu'un confinement artificiel

Figure 3

En 2000 et 2001, un dispositif de tubes drainant de l'air souterrain à des profondeurs différentes du sol montrent une évolution des teneurs de plus en plus élevées avec la profondeur et une évolution saisonnière des concentrations.

Notons que les concentrations volumiques maxima en $\mathrm{CO}_{2}$ obtenues en base de sol correspondent à celles de l'atmosphère des cavités souterraines en situation de confinement souterrain.

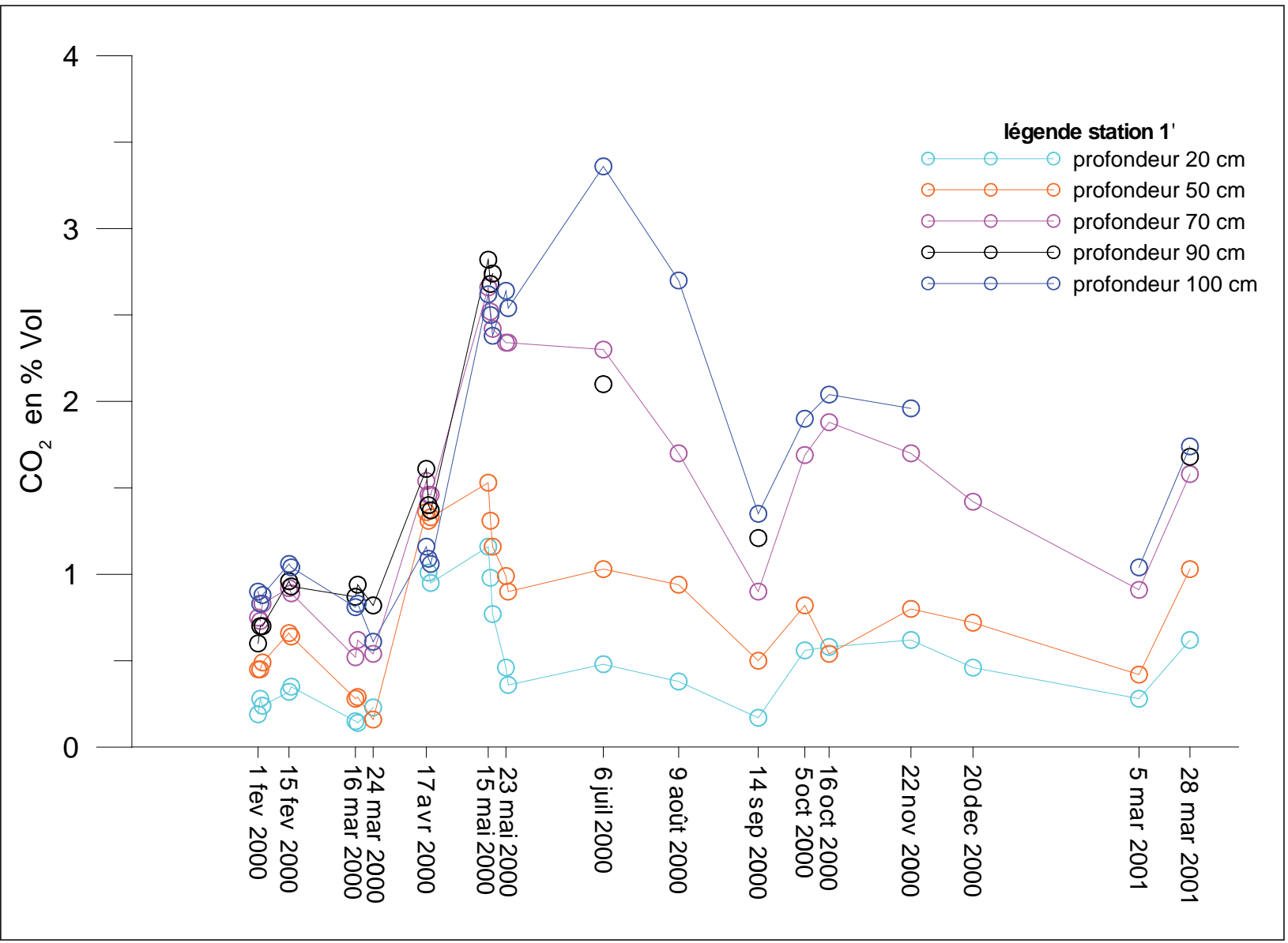




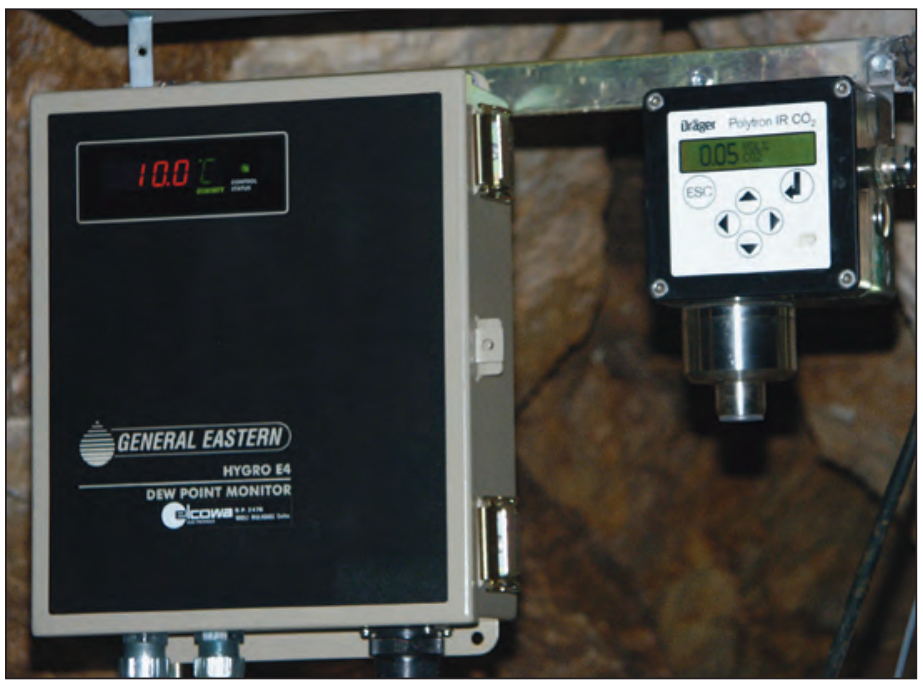

Photos 1

Station de mesures

(température, hygrométrie,

teneur en $\mathrm{CO}_{2}$ ) installée

dans la Salle de Joly

(photos Françoise Prud'homme).

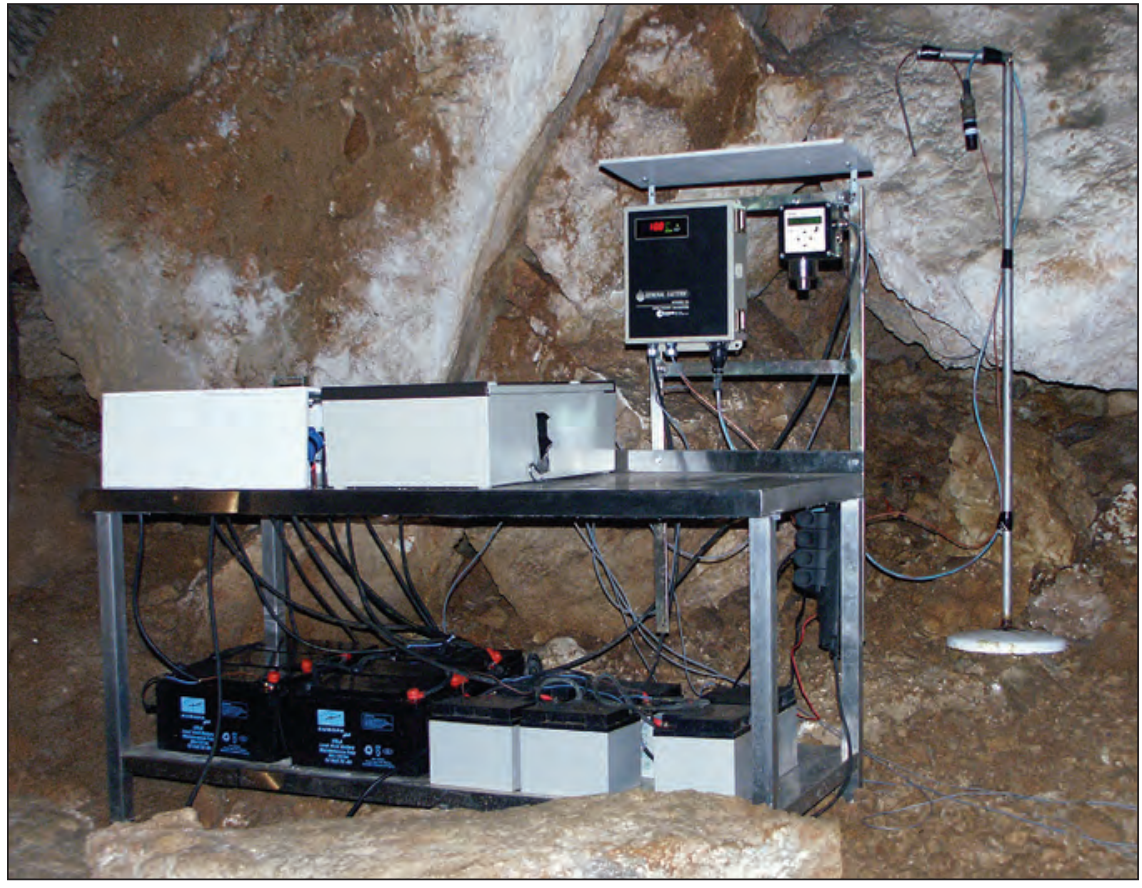

de la cavité responsable de teneurs croissantes en $\mathrm{CO}_{2}$ dans l'air souterrain pouvait avoir été provoqué par la diminution de la section de l'entrée naturelle par une plateforme et par l'extension progressive des zones étanches au-dessus des cavités (parkings, bâtiments nouveaux) qui a pour effet de diminuer les transferts hydriques et aérodynamiques. À cause du ralentissement du transit, la dégradation de la matière organique serait favorisée par un temps de séjour plus long dans le réseau fissural (Wood, 1985).

Un aménagement des parties les plus profondes (Salles Rouges) a ainsi été déconseillé en raison principalement du risque de concentrations élevées en $\mathrm{CO}_{2}$ naturellement persistantes. Les visites régulières en randonnées spéléologiques encadrées avaient été déclarées possibles mais pourraient être compromises certaines années (c'est le cas en été et automne 2007) où les concentrations dépasseraient naturellement les $3 \%$, valeur considérée comme critique pour la sécurité des personnes (cf. arrêté préfectoral).

Enfin, la description du fonctionnement naturel du site souterrain rejoint l'activité de recherche sur les paléoclimats fortement motivée par la perspective d'un changement climatique. En effet, les concrétions de grottes sont devenues des jalons fondamentaux dans ce travail de reconstitution car elles constituent les meilleures archives des conditions continentales passées. La mise en évidence dans le Canyon de l'aven d'Orgnac d'un contrôle aérodynamique très net des concentrations en $\mathrm{CO}_{2}$ de l'atmosphère souterraine identifie une contrainte physico-chimique forte dans le dépôt des lamines de calcite des spéléothèmes. 


\section{III - UN MODÈLE DYNAMIQUE DE TRANSFERT DES FLUIDES.}

Dans la perspective d'une requalification globale du site (incluant le réaménagement complet des installations de surface et le fonçage d'un puits vertical de 120 mètres rejoignant les Salles Rouges), la mise au point d'un modèle global de fonctionnement naturel prenant en compte la géométrie de l'aven était nécessaire pour identifier et présenter les recommandations en vue de la préservation du milieu souterrain. Un schéma de circulation des fluides (air et eau) a été mis au point

Figure $4 a$

Le régime d'échange de l'aven d'Orgnac se caractérise par l'infiltration d'eau et d'air à partir du sol. L'été, l'air souterrain en provenance du sol (flèches jaunes) est drainé par les cavités et expulsé vers l'extérieur, l'eau poursuit son trajet vers la profondeur, une ventilation peut cependant se produire par les macrofissures (flèches bleues). La présence de zones étanches ralentit la dynamique des infiltrations.

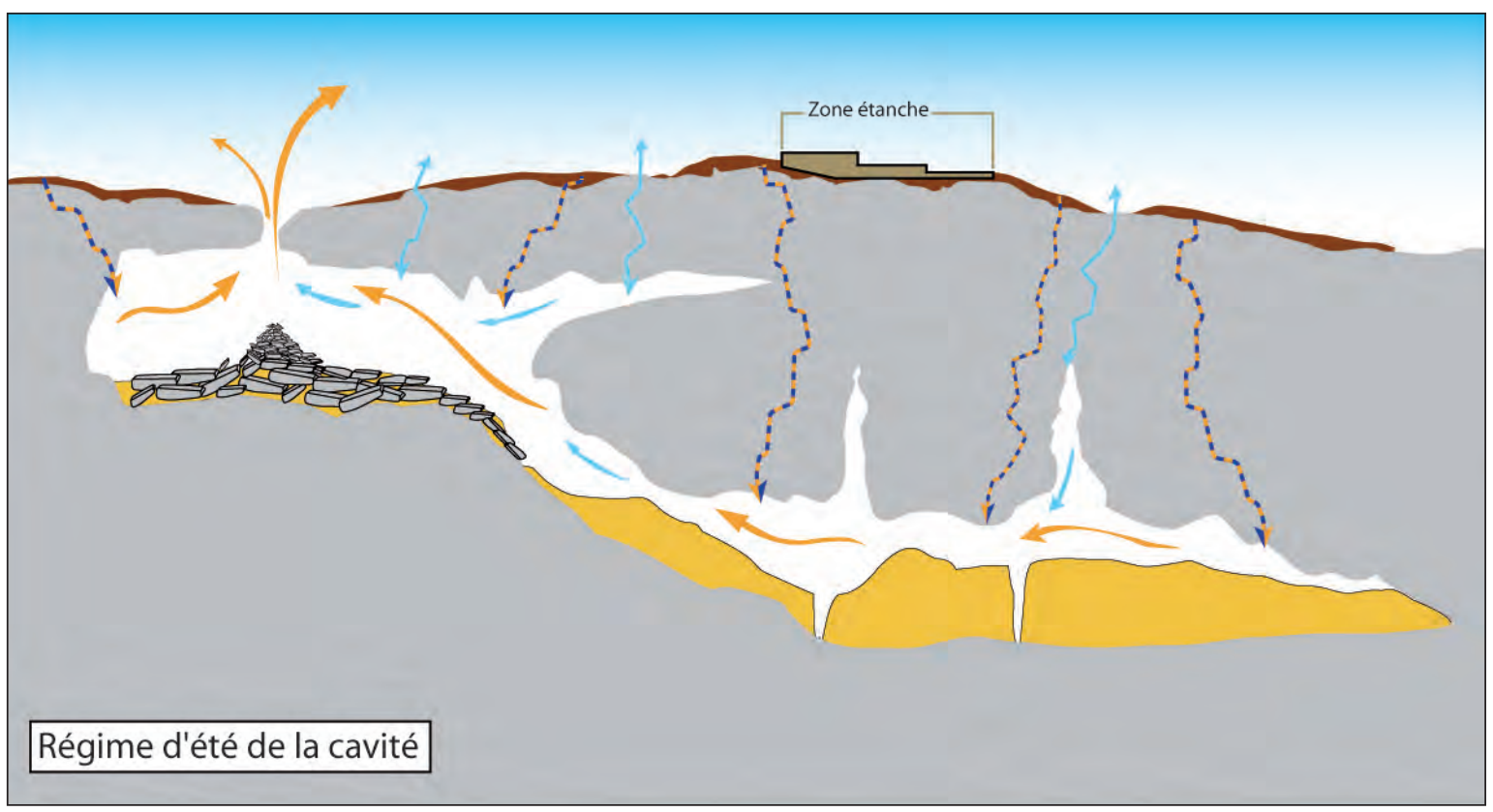

Figure $4 b$

Le régime aérodynamique d'hiver se caractérise par l'entrée d'air extérieur par les entrées naturelles. Ces arrivées (flèches bleues) viennent diluer l'air souterrain et ouvrent l'espace souterrain à l'influence de l'extérieur. Cet effet est tamponné par des rééquilibrages thermiques très actifs et limité par le compartimentage aérodynamique de la cavité qui n'ouvre que progressivement les segments de grotte à l'influence extérieure (les limites des compartiments $C 1$ à $C 4$ sont représentées en pointillés).

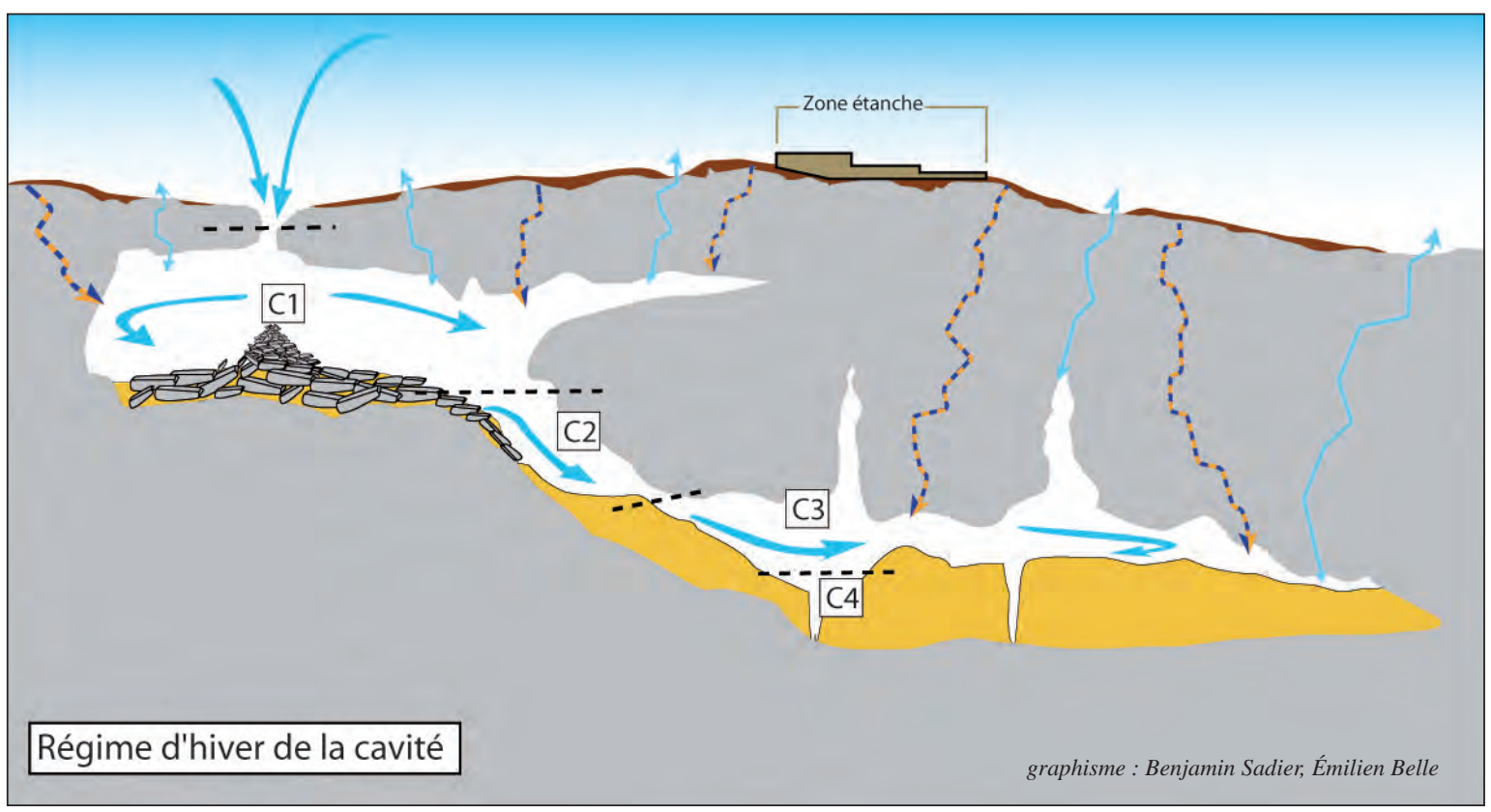


puis progressivement affiné pour aboutir à un modèle de transfert quantifié et cohérent intégrant l'ensemble des paramètres du milieu (figures $4 \mathrm{a}$ et $4 \mathrm{~b}$ ).

L'atmosphère souterraine de l'aven d'Orgnac est marquée par une forte saisonnalité avec un régime d'été où l'air souterrain (riche en $\mathrm{CO}_{2}$, en radon, appauvri en $\mathrm{O}_{2}$, quasiment saturé en humidité et stable thermiquement) occupe la totalité des grands vides. Cet air souterrain est produit au niveau de l'interface rocheuse après un transfert diphasique avec l'eau depuis le sol au travers des microfissures du karst puis drainé par les cavités et expulsé aux ouvertures naturelles. Le flux supposé constant est mesuré en sortie de l'aven : 60000 à $160000 \mathrm{~m}^{3}$ d'air enrichi en $\mathrm{CO}_{2}$ sont expulsés chaque jour de la cavité. Ce fonctionnement à flux constant détermine une grande homogénéité de la qualité de l'atmosphère, il est qualifié de confinement souterrain. En début d'hiver au contraire, lorsqu'un seuil de température $\left(\mathrm{T}^{\circ}\right.$ inférieure à $\left.10^{\circ} \mathrm{C}\right)$ est franchi pendant les premières nuits froides, le confinement de la première salle disparaît. Les dilutions du $\mathrm{CO}_{2}$ et du radon jusqu'à des valeurs proches de l'atmosphère extérieure, la baisse de l'humidité concomitante et le changement de régime thermique signent une arrivée d'air extérieur. Les profils thermiques verticaux montrent qu'un phénomène thermo-convectif se met en place après une brisure de l'interface entre les deux milieux lorsque la densité de l'air extérieur dépasse la densité de l'air intérieur. Les entrées d'air froid par l'aven ont été identifiées sur des profils thermiques dans la Salle de Joly et quantifiées par des mesures de débit d'air entrant (estimé de 100000 à $500000 \mathrm{~m}^{3}$ / jour). Le déconfinement du milieu se produit d'abord dans la Salle de Joly mais se poursuit par l'ouverture successive de compartiments plus profonds jusqu'au Canyon des Salles Rouges, les limites de compartiment s'installant sur des singularités géométriques du réseau. Notons que certains sites comme la grotte Chauvet (figure 4c) ou les parties lointaines du réseau peuvent ne jamais se déconfiner (figure 5).

Le projet d'ascenseur accédant directement au Balcon des Salles Rouges devait éviter, en fin de visite, la pénible remontée des 120 mètres de dénivelée par les touristes dans une atmosphère enrichie en $\mathrm{CO}_{2}$. Le fonçage du puits d'ascenseur de $123,5 \mathrm{~m}$ pour $8 \mathrm{~m}$ de diamètre, puis d'un tunnel horizontal pour accéder dans l'aven d’Orgnac au Balcon des Salles Rouges, était l'opération la plus importante mais aussi la plus risquée de l'aménagement du site. Le risque était d'abord de rencontrer un vide important (un sondage de reconnaissance avait été effectué antérieurement), c’était aussi la déstabilisation générale du microclimat souterrain.

Cette opération nous avait paru compatible avec la préservation du milieu à condition que l'aménagement laisse les Salles Rouges en l'état et que, lorsque le percement serait effectué, les échanges d'air soient immédiatement parfaitement contrôlables par des stable sépare la zone du fond où l'air est toujours plus riche en $\mathrm{CO}_{2}$ que dans le reste de la cavité.

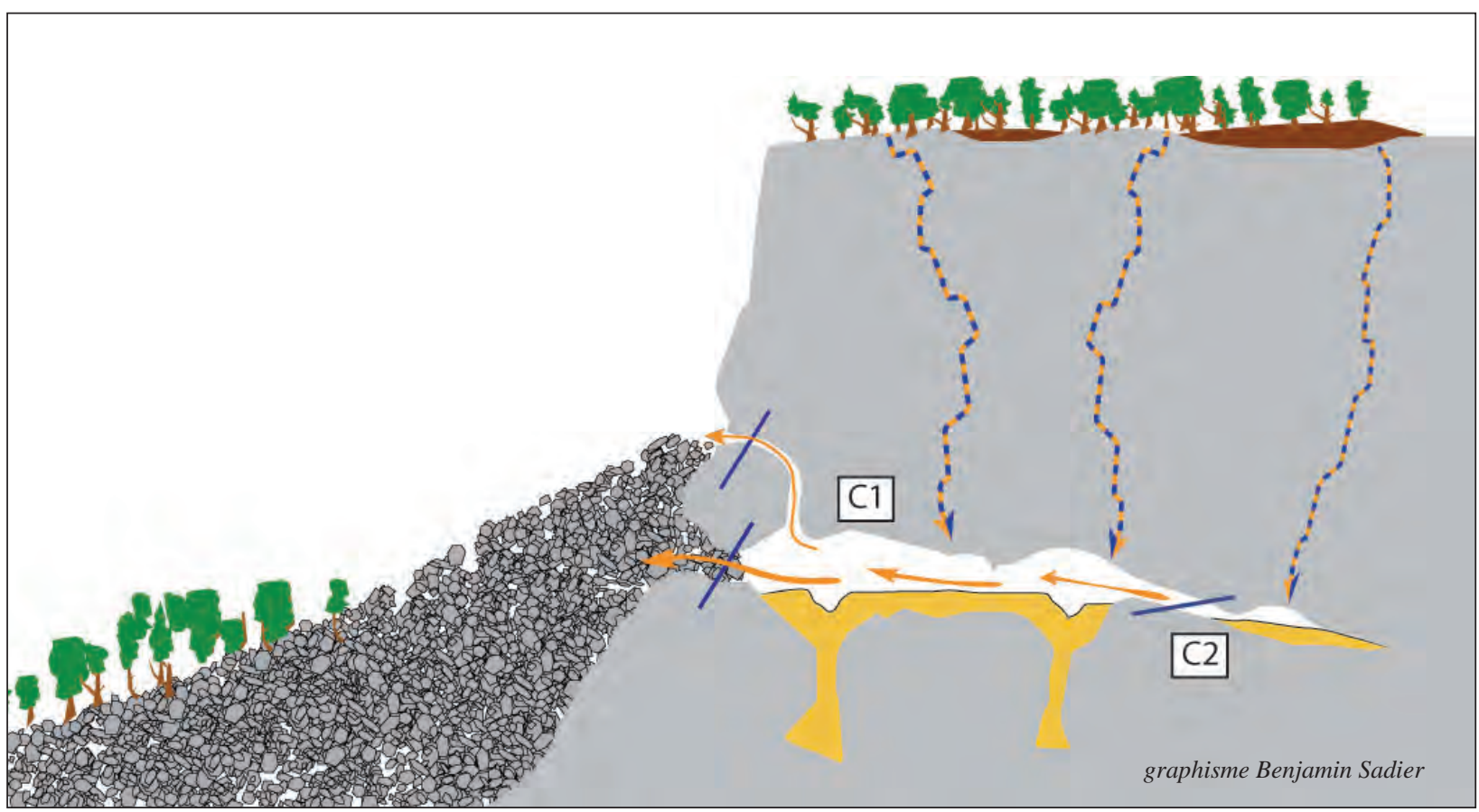



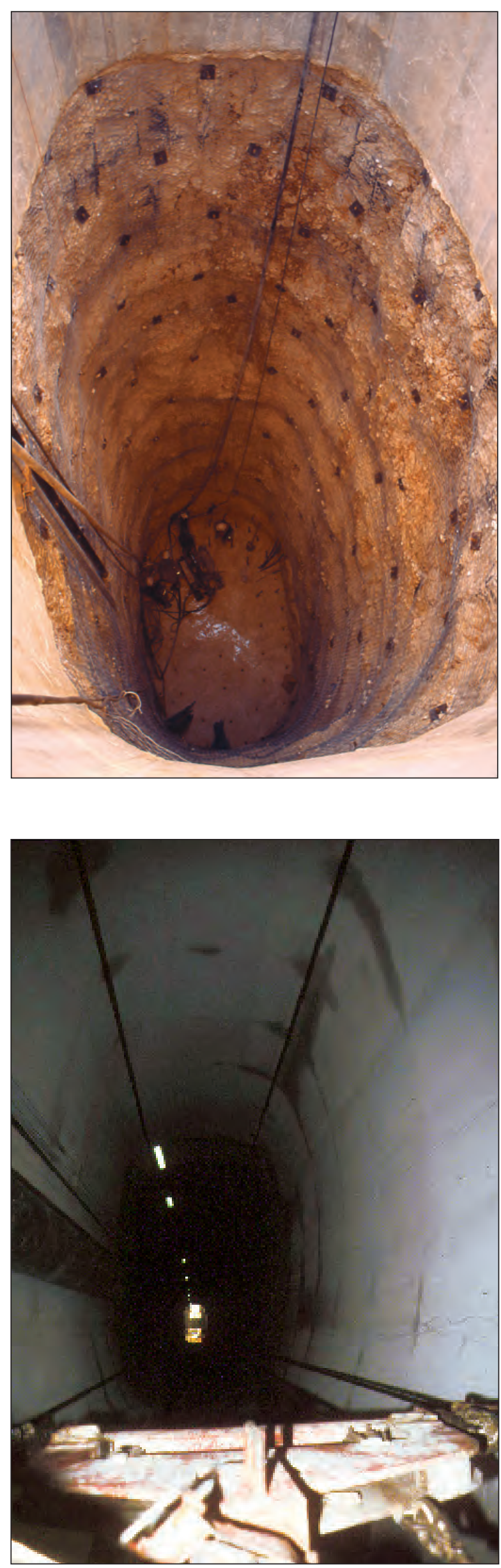

systèmes de sas. L'impact des travaux était suivi par les paramètres de composition et de température de notre installation de mesure. La société SOTRABAS contrôlant elle-même les vibrations lors des tirs dans le puits (photos 2).

L'activité de ces phénomènes d'interface avec le milieu souterrain et les volumes d'air impliqués dans la dynamique justifient les recommandations de contrôle des échanges par un sas et de réalisation du débouchage en situation de contraste thermique faible entre la grotte et l'extérieur. Le suivi en composition et en température a permis de vérifier que, lorsque le tunnel débouche dans la grotte le 31 mai à 20 heures et les jours suivants, aucun phénomène violent susceptible de modifier les conditions souterraines ne s'est produit dans les cavités souterraines (figures 6 et 7). Ainsi la connaissance de la dynamique de fonctionnement permettait de contrôler, grâce au suivi, l'impact réel de cet aménagement.

\section{Photos 2}

Le puits d'ascenseur en cours de percement.

Profond de $125 \mathrm{~m}$ et de $8 \mathrm{~m}$ de grand diamètre, ce puits a été équipé de deux cabines. Il rejoint les Salles Rouges par une galerie horizontale (ci-dessous). Les déblais extraits ont été réutilisés sur le Site pour l'aménagement de jardins en terrasses (photos $2 a$ et $2 c$ : Françoise Prud'homme).

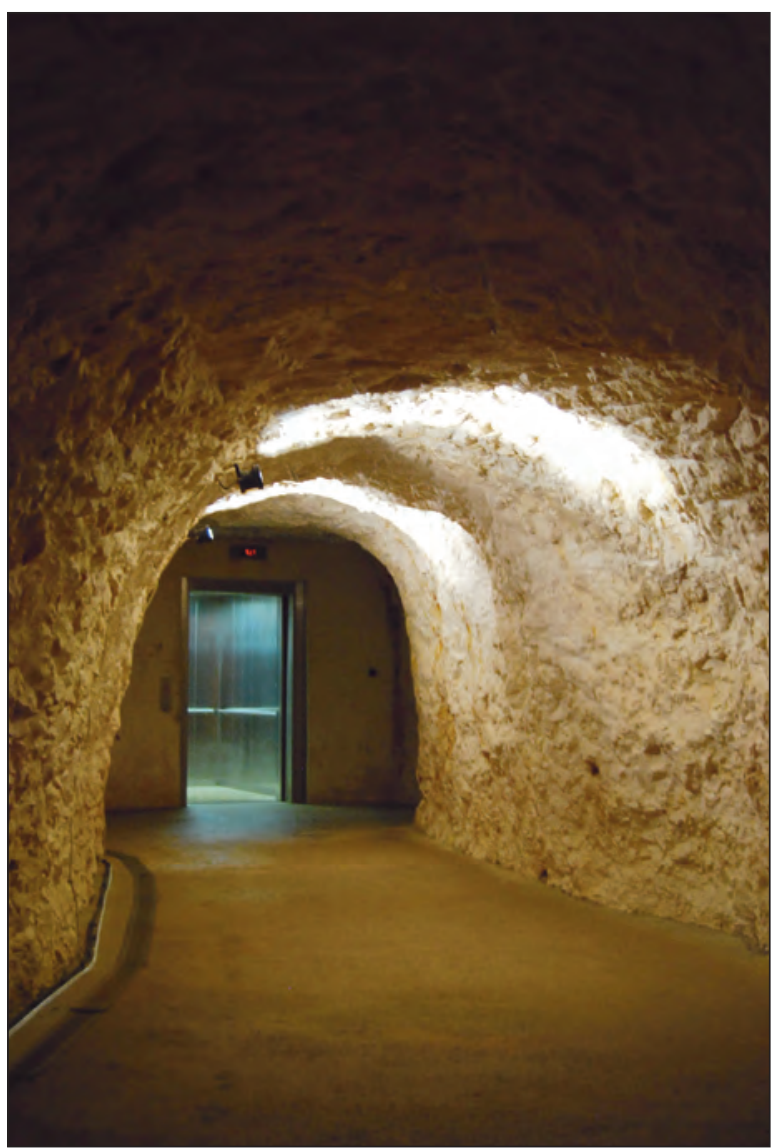


Figure 6

Suivi thermique dans la zone de percement.

Les capteurs qui étaient situés dans la zone même du débouché du tunnel ont été déplacés quelques jours avant le percement, ce déplacement a modifié la porteuse du capteur de paroi T3, et le régime pour le capteur T2 situé dans l'air. L'effet du percement ultérieur est nul pour les capteurs non déplacés et négligeable pour les capteurs déplacés qui se trouvent au plus près de l'entrée du nouveau tunnel.

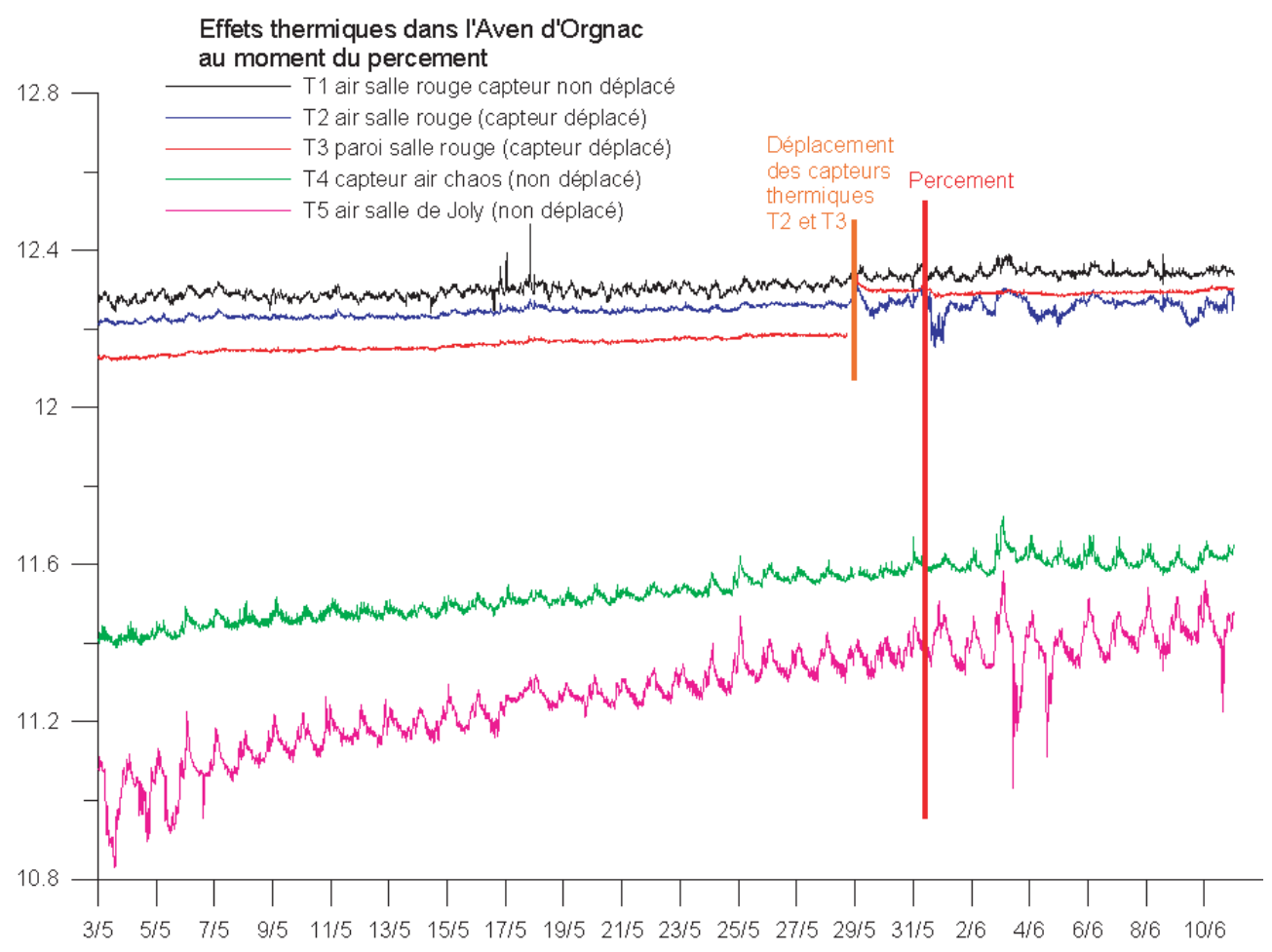

Figure 7

Suivi des concentrations en radon au Balcon des Salles Rouges.

La stabilité de la concentration en ${ }^{222} \mathrm{Rn}$ et du régime de ses variations indiquent que le percement du tunnel n'a produit aucun impact significatif sur le confinement ni sur le fonctionnement aérodynamique du site. Seule une modification sur quelques heures du régime des variations est observée au moment ou le tunnel débouche.

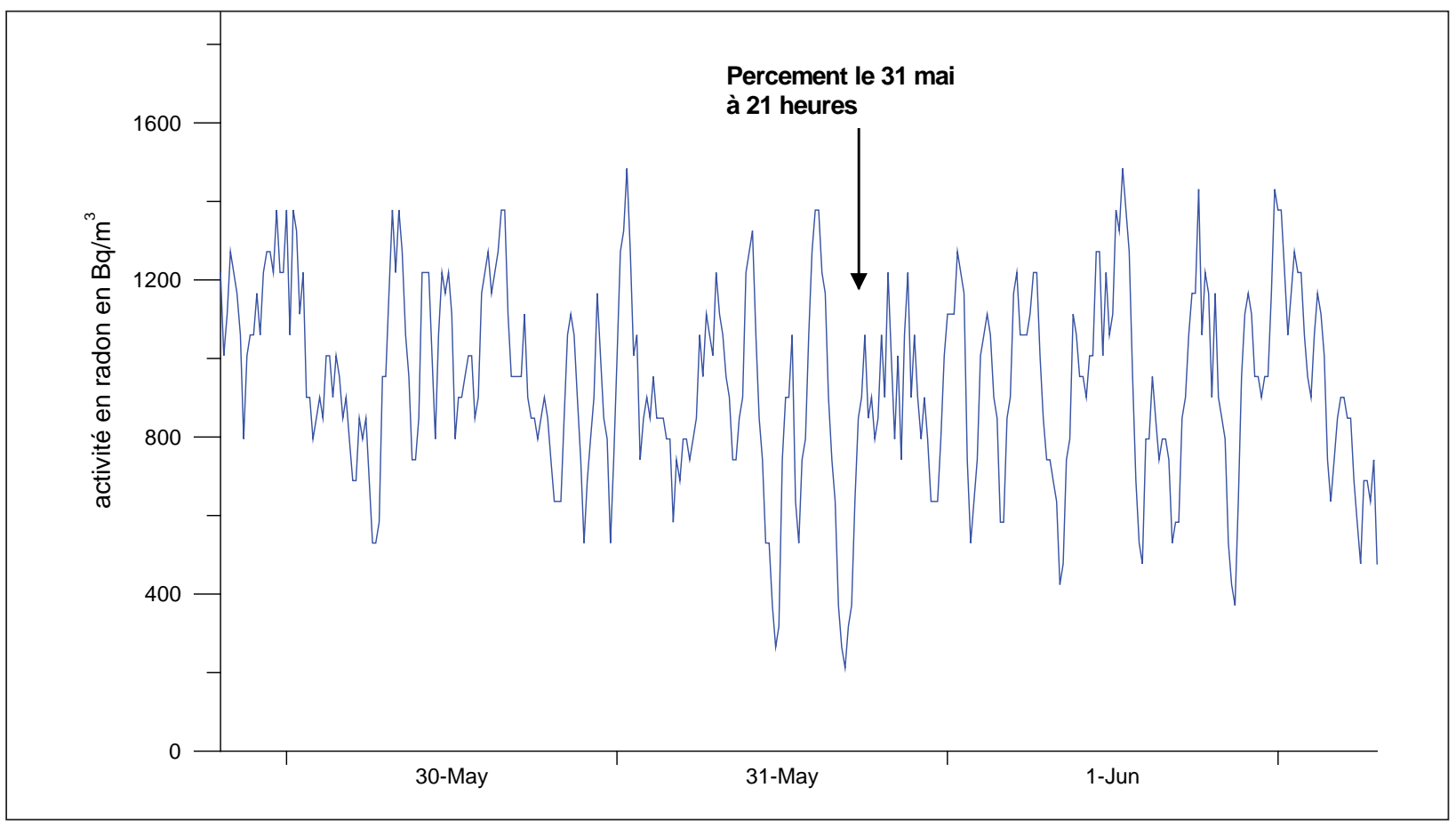




\section{IV - LES PHÉNOMÈNES DE RÉGULATION THERMIQUE, UNE CLÉ DE LA CONSERVATION.}

La recherche des phénomènes conservatoires du milieu souterrain impliquant la thermique fut un thème principal des travaux sur l'aven d'Orgnac dès l'origine, puis au cours de l'Opération Grand Site. Le problème de l'impact thermique des visites et des risques de déstabilisation du milieu fut abordé le premier ; ultérieurement, le travail s'est poursuivi par l'identification in situ des phénomènes de régulation thermique et l'analyse des signatures thermiques contrastées dans les différentes parties de la grotte.

Le première analyse consistait à vérifier l'impact de la fréquentation. La corrélation entre les visites et la température n'apparaît pas dans les zones visitées de la grotte au-delà de la Salle de Joly. Dans cette salle en revanche, la relation est très nette sur le très court terme, elle est interprétée comme l'effet direct du passage des visiteurs dans la zone du capteur et non comme un impact thermique affectant cette partie de la cavité. Le réalisation d'un profil thermique en été a confirmé que l'impact thermique journalier des visites, même en haute saison, était rapidement et complètement effacé dans les heures de fermeture et que de ce point de vue le site n'était pas surfréquenté.
La description fine du fonctionnement naturel complexe de la Salle de Joly et, plus largement, des phénomènes à l'interface entre le milieu souterrain et l'extérieur était l'objectif du redéploiement de l'instrumentation en 2003. En automne, lors des ouvertures aérodynamiques des compartiments supérieurs à l'influence extérieure, l'importance des volumes d'air entrés dans la grotte (mesurées entre 100000 et $500000 \mathrm{~m}^{3} /$ jour) explique les dilutions instantanées en $\mathrm{CO}_{2}$ et radon. Cependant, dans la Salle de Joly, malgré des températures extérieures très basses, la température de l'air intérieur diminue de seulement $2^{\circ} \mathrm{C}$ en hiver. Ainsi, une interprétation thermoconvective des échanges implique des mécanismes d'amortissement très actifs des variations thermiques par le milieu souterrain. La condensation partielle de l'eau présente dans l'air de la grotte peut expliquer ce phénomène. Avec une chaleur latente de vaporisation de l'eau de $2,5.10^{6} \mathrm{Jkg}^{-1}$, une chaleur spécifique de l'air extérieur de $10^{3} \mathrm{Jkg}^{-1} \mathrm{C}^{-1}$, une différence de température de $7^{\circ} \mathrm{C}$ entre l'air extérieur froid et l'air intérieur saturé en eau et une pression de vapeur saturante de $1400 \mathrm{~Pa}$ pour l'eau à $12^{\circ} \mathrm{C}, 100000 \mathrm{~m}^{3}$ d'air froid entrant dans la grotte sont capables de condenser $350 \mathrm{~kg}$ d'eau, ce qui est une valeur modeste en comparaison des $3300 \mathrm{~kg}$ d'eau contenue dans les $100000 \mathrm{~m}^{3}$ d'air humide quittant la grotte chaque jour. Ce mécanisme pourrait aussi présentent toutes une périodicité très nette à 12 heures, exceptée celle qui est prise dans le sol.

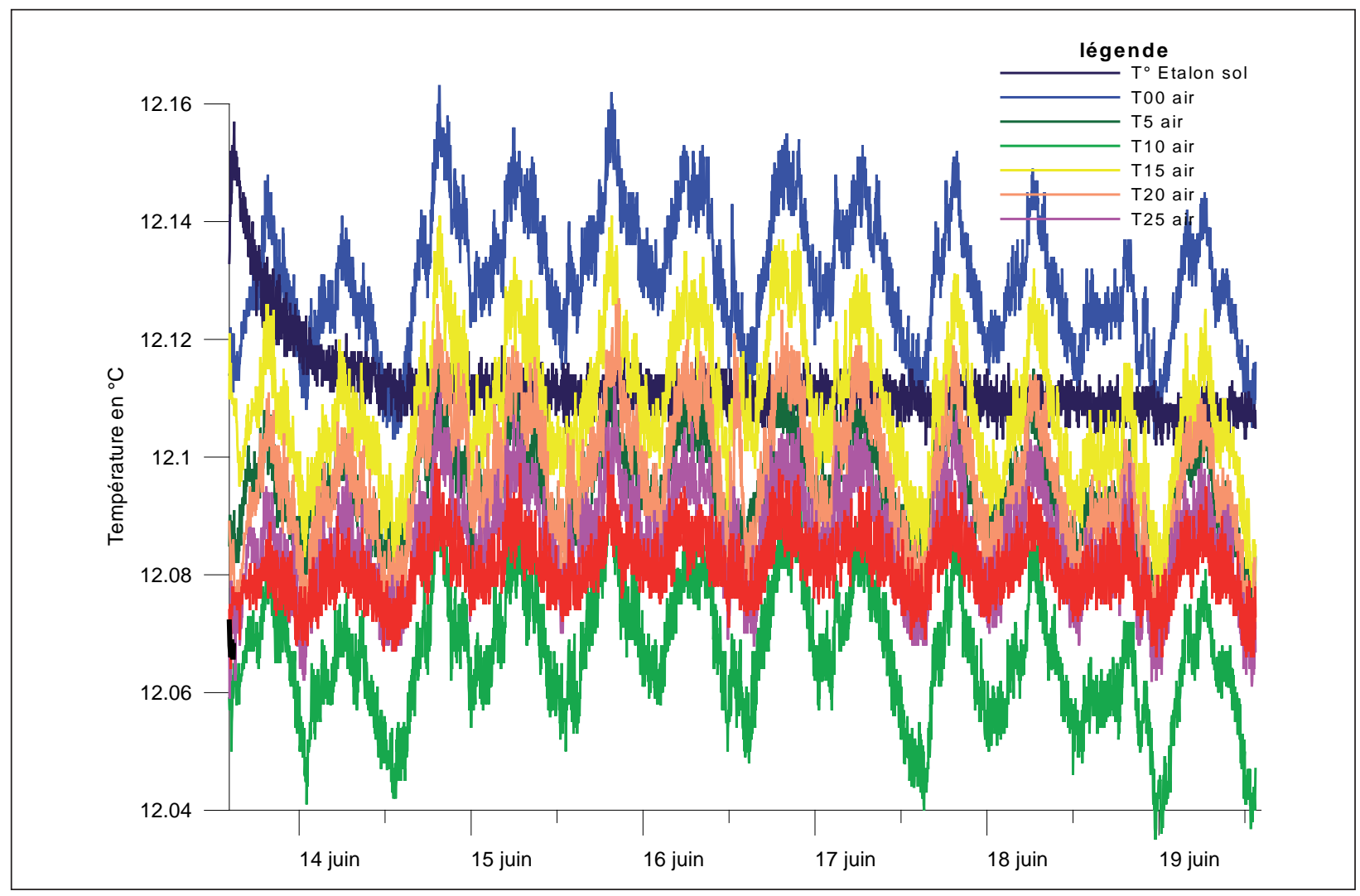


expliquer la grande quantité de brouillard observée en hiver dans la zone située au-dessous de l'entrée de la grotte. Cette eau condense sur le sol et sur les parois à l'aplomb de l'ouverture de l'aven. Comme cette eau est en déséquilibre chimique avec la roche (De Freitas et Schmekal, 2003), elle peut induire des dissolutions ou des précipitations en paroi. Ainsi, les secteurs placés à l'interface avec l'air extérieur pendant le régime d'hiver ne sont probablement pas compatibles avec la conservation à long terme d'éléments fragiles comme des peintures ou certains types de spéléothèmes. En revanche, la stabilité au-delà de la zone d'interface protège les parties aval des réseaux des chocs thermiques et diminue fortement les amplitudes saisonnières.

Les parties confinées des grottes contiennent souvent les objets naturels ou les vestiges archéologiques les plus fragiles : les mécanismes d'échange thermique détectés dans ces zones apparaissaient importants à décrire et à interpréter. Les amplitudes naturelles des variations y étaient de l'ordre du centième de degrés avec des évolutions saisonnières de l'ordre du dixième de degré. Nous avions également remarqué une grande similarité dans les enregistrements thermiques des parties confinées de grottes différentes (grotte Chauvet et aven d'Orgnac); en revanche, dans le même site de l'aven d'Orgnac, différentes parties peuvent avoir des comportements thermiques très dissemblables. Un certain nombre d'enregistrements thermiques de suivi et d'expérimentations réalisés dans ces zones confinées présentaient une bonne corrélation quasiinstantanée (à l'échelle de notre pas de mesure) avec la dérivée première par rapport au temps du signal de pression barométrique (figures 8 et 9). Cette relation permet de reconstituer très finement les chroniques de

Figure 9

Comparaison entre les chroniques de l'un des capteurs de l'air (T25) de l'expérimentation de la Salle Plane (figure 8) et la dérivée première de la pression barométrique par rapport au temps (chronique brute et moyenne mobile).

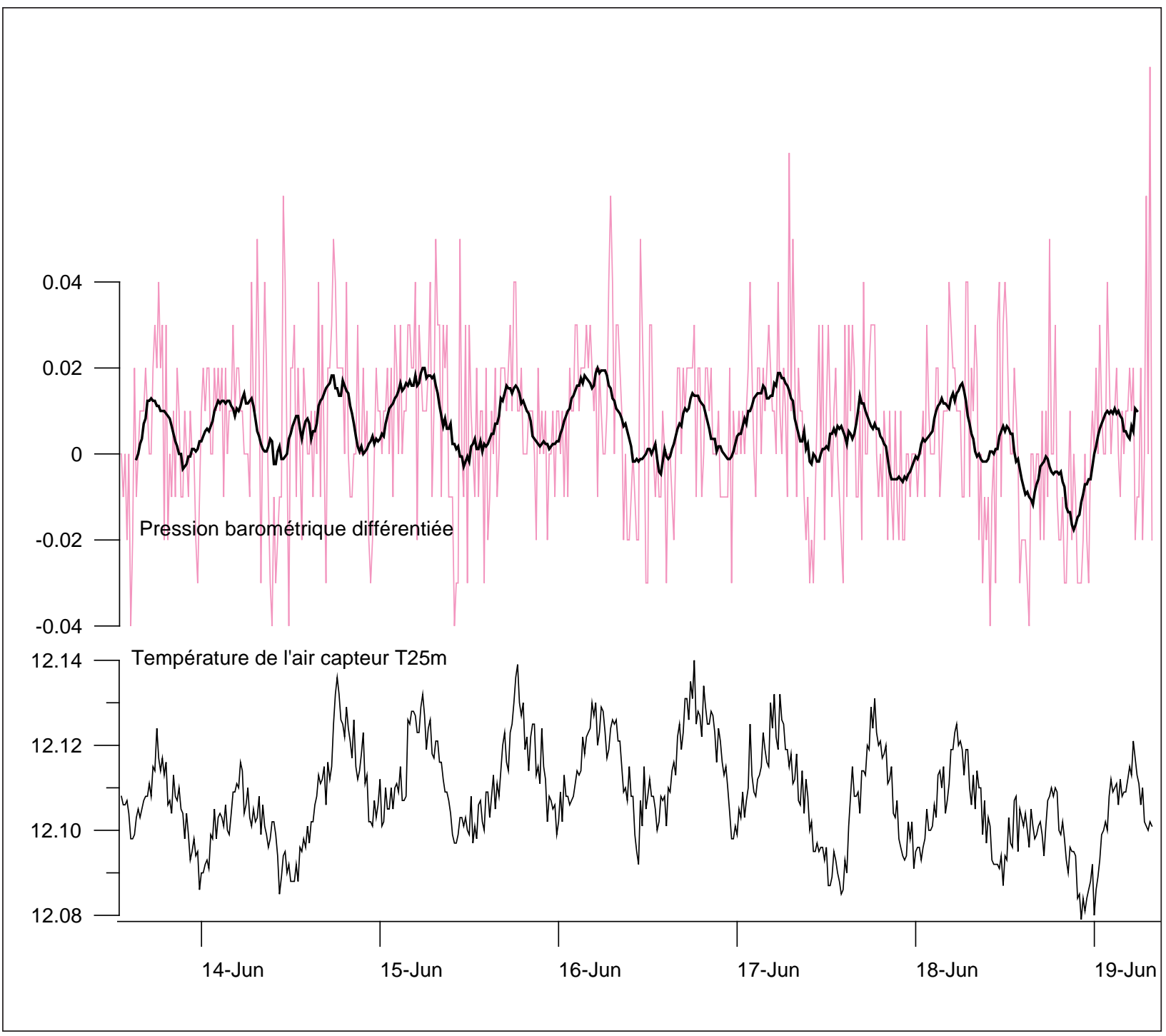


température à partir de celles de la pression (figure 10). L'élimination par filtrage de ces composantes de la dérivée de la pression affectées d'un coefficient ne laisse sur la chronique de température qu'un résidu bruité indiquant qu'aucun autre effet physique attaché à des fonctionnements périodiques n'intervient dans ces zones. La physique de ce phénomène décrite par l'un d'entre nous (Pierre Genthon) indique que la relation entre la température mesurée et la dérivée première de la pression par rapport au temps correspond à un transfert thermique conductif de la chaleur produite ou absorbée lors des changements de pression vers le milieu rocheux réservoir infini à température fixe. Les échanges identifiés aux échelles de temps accessibles par nos mesures signent un comportement isotherme du milieu souterrain.

Le phénomène est suffisamment clair et général à toutes les grottes confinées ou parties confinées de grottes de sorte qu'il est utilisable pour caractériser des conditions physiques considérées comme optimales pour la conservation en grotte.

Ce travail a permis de comparer le fonctionnement de l'aven, pris comme référence, avec celui de la grotte voisine de Chauvet et aux sites plus éloignés de Marsoulas (grotte ornée préhistorique), d'Esparros (site naturel, grotte à cristaux) ainsi qu'à des endroits plus exotiques du Pacifique sud-ouest comme la grotte de Thoubotr (Lifou, Iles Loyauté).

Figure 10

Amplitude de l'intercorrélation entre la dérivée de la pression et la température de l'air dans différentes parties de l'aven d'Orgnac montrant la persistance de la zone confinée dans les parties profondes (Salles Rouges) du site.

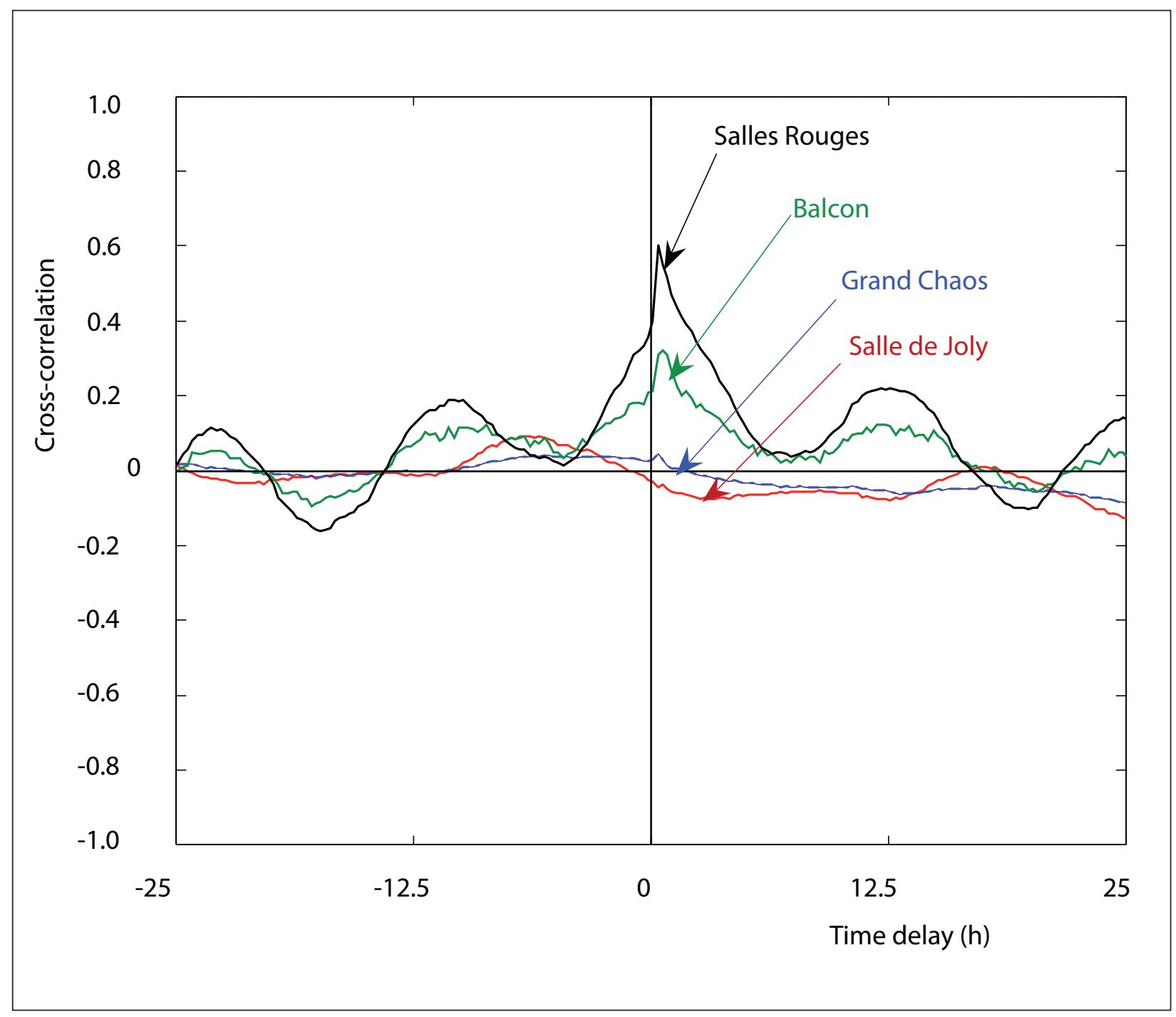


Figure 11

Comparaison entre les enregistrements des températures de l'air dans l'aven d'Orgnac et dans la grotte Chauvet avec la dérivée de la pression barométrique.

Les parties confinées des sites (Salles Rouges d'Orgnac et totalité de la grotte Chauvet) montrent des chroniques de températures similaires à la dérivée de la pression barométrique.
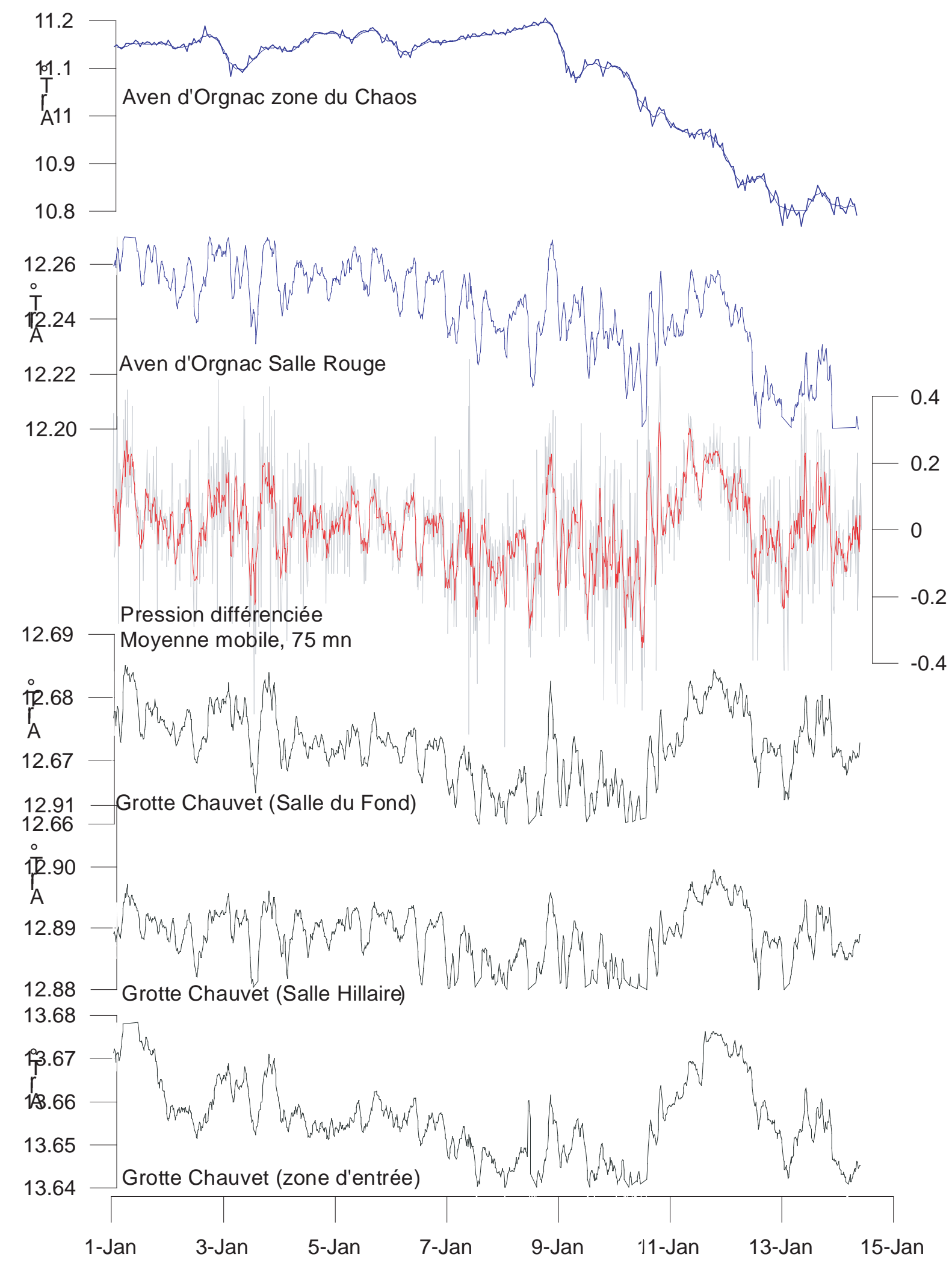


\section{V - LE FONCTIONNEMENT DE LA ZONE NOYÉE DU KARST D'ORGNAC ; IMPLICATIONS POUR LA COMPRÉHENSION DU SYSTÈME ACTUEL ET CONSÉQUENCES TECHNIQUES.}

Les réseaux de cavités d'Orgnac étaient interprétés comme un paléokarst dont les morphologies et les remplissages témoignaient de fonctionnements et d'événements très anciens. Cependant un événement d'inondation, analysé comme une remontée de la zone noyée du karst, a ouvert un champ d'investigation nouveau sur le fonctionnement actuel et passé du site. Une pluie centennale de $390 \mathrm{~mm}$ tombée les 8 et 9 septembre 2002 en moins de 48 h a causé l'ennoyage d'une partie des Salles Rouges sous 20 mètres d'eau (figure 12). Cette situation doit maintenant être aussi prise en compte dans l'aménagement et la gestion du site souterrain mais aussi dans la recherche d'information sur lazone noyée du karst. L'instrumentation d'un forage à 3,5 km au sud-est de l'aven, au lieu dit le Pavillon, de $106 \mathrm{~m}$ de profondeur et atteignant l'eau, permettait d'avoir des informations sur les eaux souterraines du secteur. L'analyse de la piézométrie du forage, équipé en septembre 2003 avec un capteur de pression et un enregistreur, confirmait le caractère karstique de l'aquifère. Une seule grande crue annuelle recharge un aquifère à grande capacité de stockage, comme le montre l'effet mémoire qui s'atténue complètement sur une période de 35 à 40 jours. La relation pluiedébit montre un temps de régulation de l'ordre de 30 jours signant un système inertiel. Le déphasage de la relation pluie-débit (1,5 jours), le même que celui observé lors de la crue, étaye l'hypothèse d'un aquifère unique qui forme la zone noyée du système d'Orgnac et dont l'exutoire serait les fontaines de Monteil, en bordure de Cèze.

L'évolution du niveau d'eau dans le forage permet, grâce à l'étude des périodes de tarissement (apports nuls dans le réservoir), d'estimer l'importance des réserves de cet aquifère. Le modèle de Maillet qui utilise comme loi de vidange une fonction exponentielle permet de travailler uniquement sur la variation d'un paramètre qui suit la même évolution que celle des débits (ici la piézométrie mesurée au forage). Il suffit ensuite d'avoir une valeur du débit pour caler les résultats et calculer les volumes des réserves.

Comme les Fontaines de Monteil sourdent à proximité et dans le cours de la Cèze, il était difficile d'en mesurer directement le débit. Nous avons donc réalisé un jaugeage différentiel de la Cèze, le 2 septembre 2004, qui donne un débit d'étiage des sources de l'ordre de 300 l/s. reconstitué d'après les observations et mesures du personnel du Site et du Musée d'Orgnac).

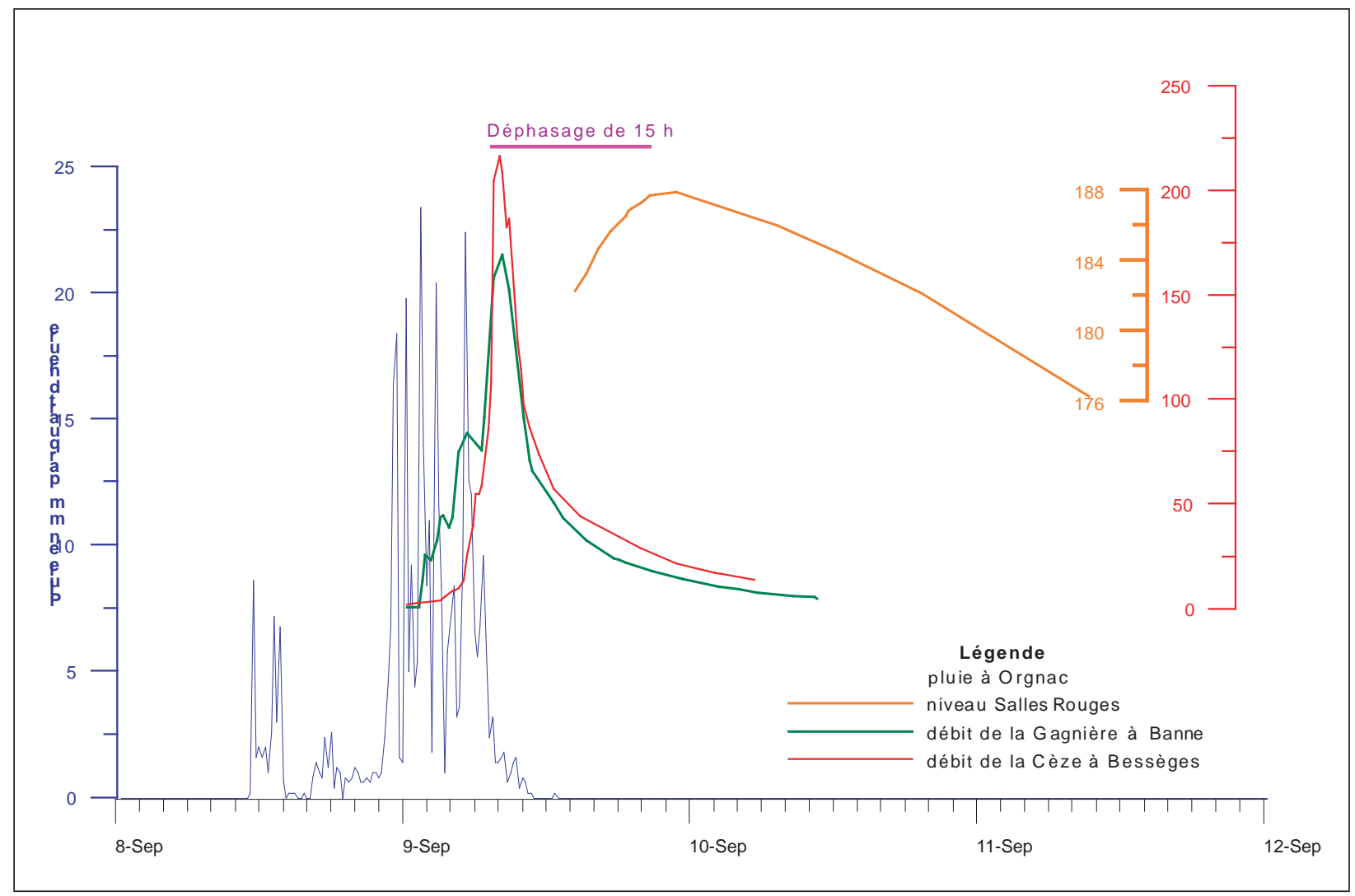




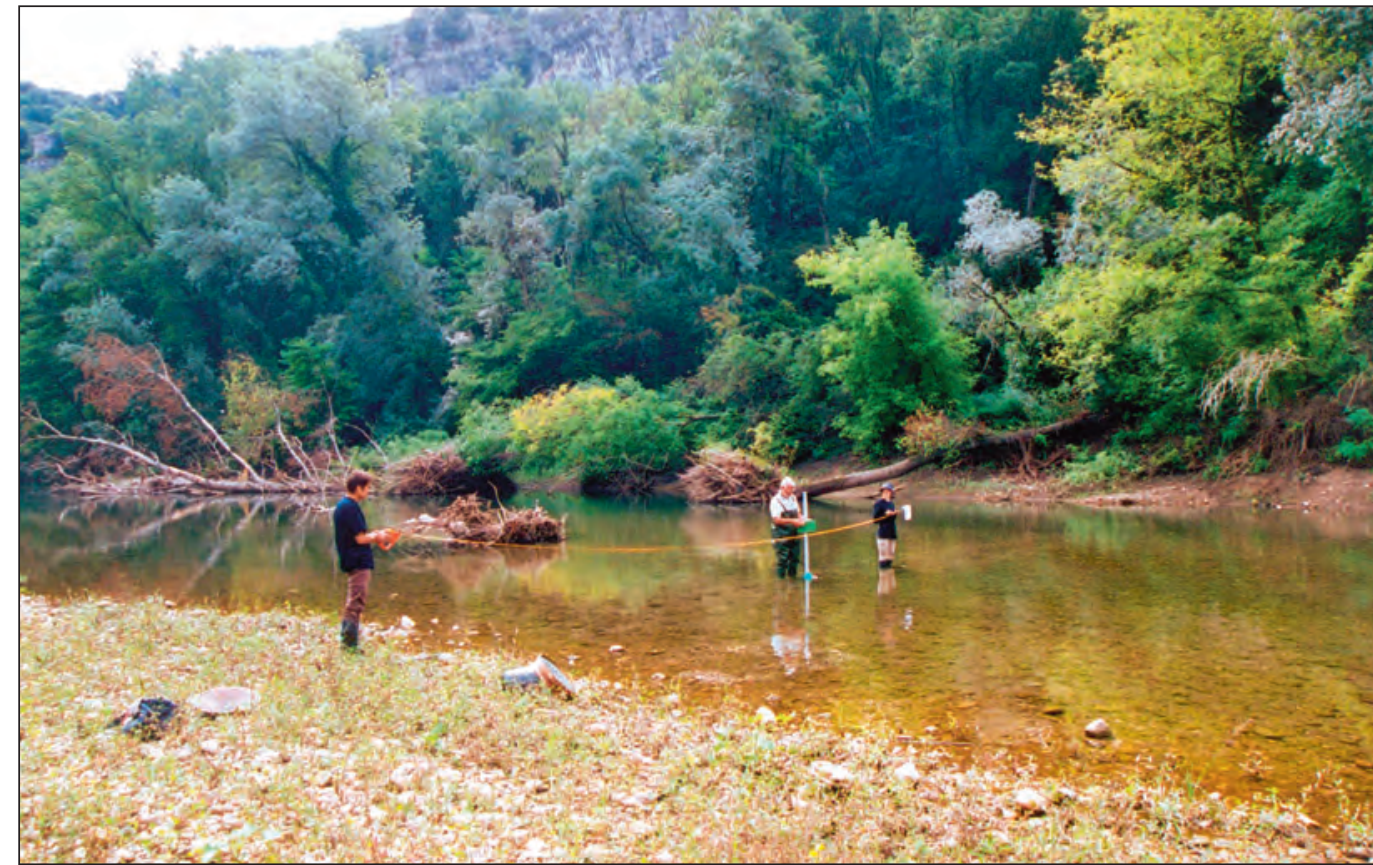

Photo1

Jaugeage de la

Cèze, en amont

et en aval des

sources de

Monteil.

L'ajustement d'une courbe de tarissement sur l'étiage de 2004 donne un coefficient $\alpha=0,0006 \mathrm{j}$-1 traduisant un aquifère qui se vidange lentement, ce qui implique des perméabilités faibles. Grâce au débit d'étiage mesuré des sources, il est possible de calculer un volume dynamique (volume de la zone noyée qui assure le débit d'étiage). Ce volume est égal à : $\mathrm{V}=\int_{0}^{\infty} \mathrm{Qdt}=\frac{\mathrm{Q}_{0}}{\alpha} 86400=\frac{0,3}{0.0006} \times 86400=43$ millions dem $^{3}$

Ce volume correspond à celui qui se vidangeait le 2 septembre 2004. En extrapolant la loi de vidange exponentielle au début de la décrue, c'est-à-dire en décembre 2003, on obtient un débit Qo de $0,350 \mathrm{~m}^{3} / \mathrm{s}$. Le volume serait alors de 50 millions de mètres cubes. L'importance de ce volume indique une zone noyée très étendue en amont des sources de Monteil, la zone d'Orgnac est forcément située sur cet aquifère. La zone noyée correspond à un calcaire fissuré peu karstifié, ou à un calcaire karstifié mais non fonctionnel car en partie colmaté. Le colmatage est corroboré par les remplissages importants du fond de l'aven d'Orgnac et le fort colmatage d'argile rencontré en fond de forage. La valeur régionale du module spécifique permet d'évaluer l'extension de l'aquifère entre 40 et $50 \mathrm{~km}^{2}$. La porosité efficace, en supposant une puissance moyenne de l'aquifère de l'ordre de $25 \mathrm{~m}$, indiquée par les données du forage, est de l'ordre de $4 \%$.

Les informations sur les sources de Monteil et sur la piézomètrie au Pavillon, montrent les caractéristiques d'un aquifère souterrain karstique qui constitue très probablement l'actif du réseau d'Orgnac-Issirac.

Les cavités des réseaux d’Orgnac sont des vestiges plus ou moins colmatés, soit par des argiles, soit par des concrétionnements, d'anciens systèmes de drainage actifs à une époque où les niveaux de base étaient nettement plus hauts. Par rapport aux karsts actifs actuels tels que nous les connaissons, l'ensemble des cavités accessibles d'Orgnac-Issirac peut être considéré comme des systèmes annexes au drainage. On sait, en effet, pour les karsts actuels, que les vides résultant des écoulements sont organisés avec des drains (les rivières souterraines) qui assurent les voies principales d'évacuation des eaux avec des vitesses rapides dans des vides de dimensions modestes, mais en continuité. Autour de ces drains, se développent des ensembles de grandes cavités où se stockent de grandes quantités d'eau en crue, qui alimentent ensuite les drains en basses eaux et en étiage, ce sont les systèmes annexes au drainage: les vitesses d'écoulement y sont réduites. La morphologie des cavités d'Orgnac, de grande dimension, avec des ensembles séparés par des passages étroits, la présence sur paroi de cupules de plusieurs mètres de diamètre, l'existence de dépôts de décantation organisés autour de soutirages actifs, sont autant de caractères qui montrent que le réseau d'Orgnac appartient à ce type de vide.

Les cavités de l'aven d’Orgnac sont un regard sur la zone noyée et correspondraient à un système annexe au drainage, vraisemblablement peu éloigné du drain comme le montrent les faibles déphasages observés entre les crues de la Cèze et la mise en eau des Salles Rouges.

Les travaux sur les formes et les dépôts, présentés dans les deux articles précédents ont d'ailleurs montré le rôle des remplissages argileux dans l'évolution karstique des cavités (processus paragénétique). Cette évolution est compliquée ensuite par la dynamique des soutirages et les mises en charge évoquées ici. 


\section{Conclusion}

Si le suivi environnemental du site a permis d'amasser une grande quantité d'information sur un site complexe, l'interprétation de ces données a révélé la richesse des processus actifs et les interactions entre toutes les parties du système naturel karstique. La zone noyée, dont le fonctionnement hydraulique est accessible, détermine, lors d'évènements exceptionnels à l'échelle humaine, une partie du fonctionnement et de la morphologie des réseaux souterrains. La zone d'infiltration du karst héberge les vides accessibles et constitue le lieu du transfert de matière et d'énergie déterminant les grandes constantes du milieu souterrain pénétrable. Dans certaines parties de ce réseau, un fonctionnement aérodynamique ajoute une complexité supplémentaire en terme de saisonnalité, de compartimentage géométrique et d'intensité des échanges. Enfin, en surface, la dynamique de l'infiltration et les processus pédologiques sont déterminants dans le fonctionnement des tréfonds. La caractérisation de ces phénomènes de surface et la présence de gisements archéologiques majeurs associés à différents états d'évolution des morphologies karstiques ont motivé l'extension proposée en surface du site classé de l'aven d'Orgnac.

Pour l'aven d'Orgnac comme pour tous les sites naturels fragiles, qu'ils soient souterrains ou de surface, la compréhension du fonctionnement du milieu naturel reste un préalable à la prise de bonnes décisions d'aménagement et de gestion. Les outils intellectuels et technologiques existent pour l'identification des régulations naturelles et des seuils de stabilité du milieu souterrain. Le respect de ces limites permet d'agir sans altérer de manière irréversible le système naturel et permet la mise en valeur du patrimoine naturel sans le détruire.

Des opérations d'aménagement ou d'amélioration d'un site nécessitent des investissements pour comprendre et suivre les évolutions du milieu naturel et supposent l'acceptation des conditions de gestion qui peuvent en résulter. Ces investissements ont un poids économique non négligeable mais les informations recueillies peuvent être utilisées pour faire progresser la connaissance scientifique. Localement, elles sont utilisées pour la mise en valeur, la sensibilisation du public et sont finalement un gain de qualité pour le site.

C'est plus largement le défi du développement durable qui se pose avec ses conditions d'intégrité environnementale et plus largement patrimoniale, de prospérité économique et sociale. L'aménagement de l'aven d'Orgnac apparaît comme un modèle de ce qu'il est possible de réaliser en partenariat étroit entre l'État, les élus, les scientifiques, les spéléologues et les différents partenaires locaux.

\section{Bibliographie}

Bourges F., Mangin A. et D’Hulst D. (1998) - Le $\mathrm{CO}_{2}$ dans l'atmosphère des grottes, sa place dans la dynamique des systèmes karstiques. Communication à la Réunion des Sciences de la Terre de Brest, 31 mars au 3 avril 1998.

Bourges F., Mangin A. et D’Hulst D. (2001) - Le gaz carbonique dans la dynamique de l'atmosphère des cavités karstiques, l'exemple de l'Aven d'Orgnac (Ardèche). C. R. Académie des Sciences, Paris, 333, 2001, 685-692.

Bourges F., Mangin A. et D'Hulst D. (2003) - Radon and $\mathrm{CO}_{2}$ as markers of cave atmosphere dynamics: evidence and pitfalls in underground confinement; application to cave conservation. Communication au colloque "Climate Changes : the Karst Record III", Montpellier (France), 11th-14th May 2003.

Bourges F., Genthon P., Mangin A. et D’Hulst D. (2005) Internal climate of some karstic caves, consequences on annual speleothem growth. Communication to the American Geophysical Union meeting, 5-9 dec., 2005, San Francisco (USA).

Bourges F., Genthon P., Mangin A. et D’Hulst D. (2006) Microclimates of l'Aven d'Orgnac and other French limestone caves (Chauvet, Esparros, Marsoulas). Intern. Journal of Climatology, 26 (12), 2006, 1651-1670.
De Freitas C.-R., Schmekal A. (2003) - Condensation as a microclimate process: measurement, numerical simulation and prediction in the Glowworm Cave, New Zealand. International Journal of Climatology, 23, 2003, 557-575.

Mangin A. (1976) - Contribution à l'étude hydrodynamique des aquifères karstiques, Thèse Université de Dijon, $124 \mathrm{p}$.

Mangin A. (1984) - Pour une meilleure connaissance des systèmes hydrologiques à partir d'analyses corrélatoires et spectrales. Journal of Hydrology, 67, 1984, 27-43.

Mangin A. (1995) - Karst hydrogeology, in : Groundwater Ecology, J. Gilbert, D.L. Danielopol, J. Stanford and J.H. ThORP, Editors. 1995, Academic Press. New York.

Perrier F., Morat P., et Le Mouel J.-L. (2001) - Pressure induced temperature variations in an underground quarry. Earth Planet. Sci. Lett., 191, 2001, 145-156.

Wood W.-W. (1985) - Origin of caves and other solution openings in the unsaturated (vadose) zone of carbonate rocks: a model for $\mathrm{CO}_{2}$ generation, Geology, 13, 1985, 822-824. 


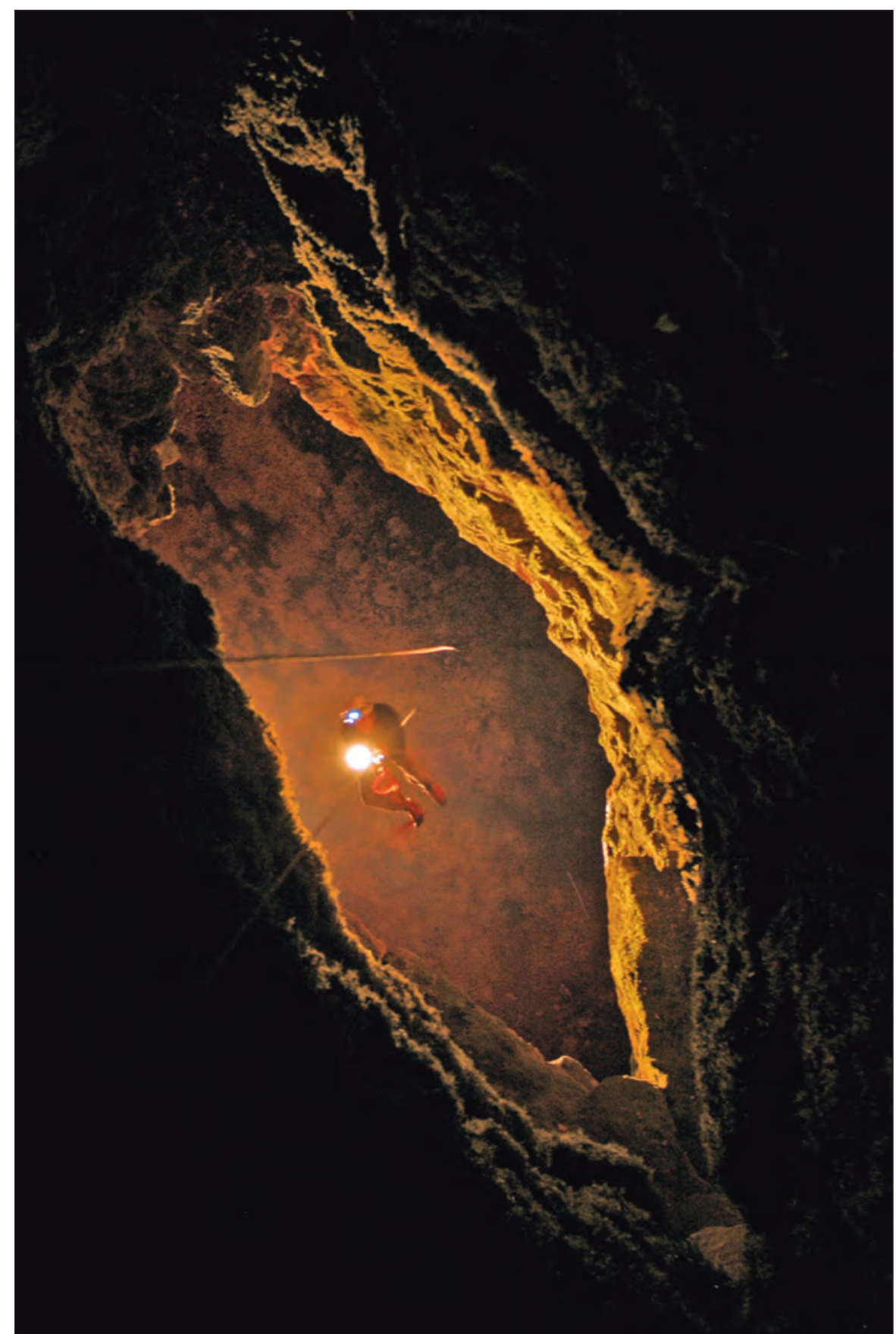

Le puits d'entrée de l'aven d'Orgnac : passage obligé des échanges aérodynamiques entre la cavité et l'exérieur. En régime d'été, le flux d'air souterrain provenant des grands réseaux est pour l'essentiel sortant. En régime d'hiver, le flux s'inverse, l'air extérieur plus dense entre en cascade dans la Salle de Joly (photo Stéphane Jaillet). 


\title{
L'AVEN D'ORGNAC
}

\section{UN JALON KARSTIQUE POUR \\ LA RECONSTITUTION PALÉOGÉOGRAPHIQUE DE L'INTERFLUVE ARDÈCHE/CÈZE}

\author{
par Jean-Jacques DELANNOY ${ }^{\prime}$, Stéphane JAILLET ${ }^{\prime}$, \\ Serge FUDRAL ${ }^{l}$, Dominique GASQUET ${ }^{l}$, Olivier KAUFMANN ${ }^{2}$, Maxime SABAUD ${ }^{i}$, Estelle PLOYON ${ }^{\imath}$.
}

\author{
1 Laboratoire EDYTEM - Université de Savoie \\ 2 Faculté polytechnique de Mons - Belgique
}

\begin{abstract}
Que ce soit à travers ses formes, comme à travers ses formations, l'étude de l'aven d'Orgnac a permis d'appréhender et de poser les principales étapes qui ont guidé sa mise en place et son évolution (cf. chapitres précédents). Cet article a pour objet de démontrer que l'étude spéléogénique d'Orgnac apporte des éléments clés dans la connaissance paléogéographique de l'interfluve Ardèche / Cèze.

L'étude de cette cavité dépasse amplement son emprise spatiale et renseigne sur des événements anciens dont il ne reste plus de témoins visibles en surface. Utiliser une cavité en tant que vecteur d'informations paléogéographiques et paléoenvironnementales suppose de la replacer dans son environnement géomorphologique et de prendre en compte l'ensemble des moteurs ayant influencé l'histoire géologique des plateaux calcaires du Bas-Vivarais, notamment l'évolution paléogéographique du bassin rhodanien.
\end{abstract}

Pour mener à bien cette démonstration, le cadre géologique et géographique sera ici présenté en insistant particulièrement sur le Néogène. L'analyse détaillée des morphologies de surface de l'interfluve Ardèche /Cèze permettra de retracer les principales étapes de l'évolution du relief. Au terme de cet article seront croisées les informations spéléogéniques, géologiques et géomorphologiques afin de proposer une reconstitution paléogéographique du Bas-Vivarais / Ardèche.

\section{I - Les Plateaux Calcaires du BaS-ViVARAIS DANS LEUR ENVIRONNEMENT GÉOLOGIQUE ET PALÉOGÉOGRAPHIQUE}

Entre les contreforts du Massif central et la vallée du Rhône, le plateau calcaire du Bas-Vivarais a connu une évolution géologique et géomorphologique liée autant aux influences amont (massifs cristallins pourvoyeurs en eau et en matériaux) qu'aux influences aval (variations eustatiques méditerranéennes en particulier) (figure 1).

Cette partie se veut une courte présentation de ces deux espaces encadrant ce plateau calcaire (amont cristallin et vallée du Rhône) où les vallées de l'Ardèche et de la Cèze, véritable traits d'union, ont creusé deux profond canyons qui ont fortement influencé la karstification des calcaires.

\section{I.1 - Les amonts du bassin versant de l'Ardèche}

Le bassin versant de l'Ardèche en amont des gorges est divisé en trois sous-bassins : le Chassezac, la Beaume et l'Ardèche elle-même. Ces trois bassins drainent des terrains géologiques allant du socle hercynien aux séries sédimentaires du Jurassique. Le volcanisme tertiaire et quaternaire complète ces terrains.

\section{Le socle hercynien et le Houiller}

Le socle hercynien est ici constitué de séries métamorphiques (de degré métamorphique variable) et de granites localement déformés (cataclasites et mylonites).

Les séries métamorphiques se décomposent en deux sous-ensembles :

- la série cévenole : elle se caractérise par des schistes parfois conglomératiques, des micaschistes-gneiss, \pm anatectiques (migmatites), des quartzites et autres roches à silicates calciques. On relève la présence d'amphibolites intercalées dans cette série : elles correspondent à d'anciens basaltes sous-marins épanchés dans le « bassin sédimentaire cévenol »;

- la série ardéchoise : elle est composée essentiellement par des gneiss (œillés, méta-leucogranites, gneiss quartzeux...) qui ont été soumis à un métamorphisme, rapporté à l'Hercynien. 
Figure 1

Carte géologique simplifiée du Bas-Vivarais.

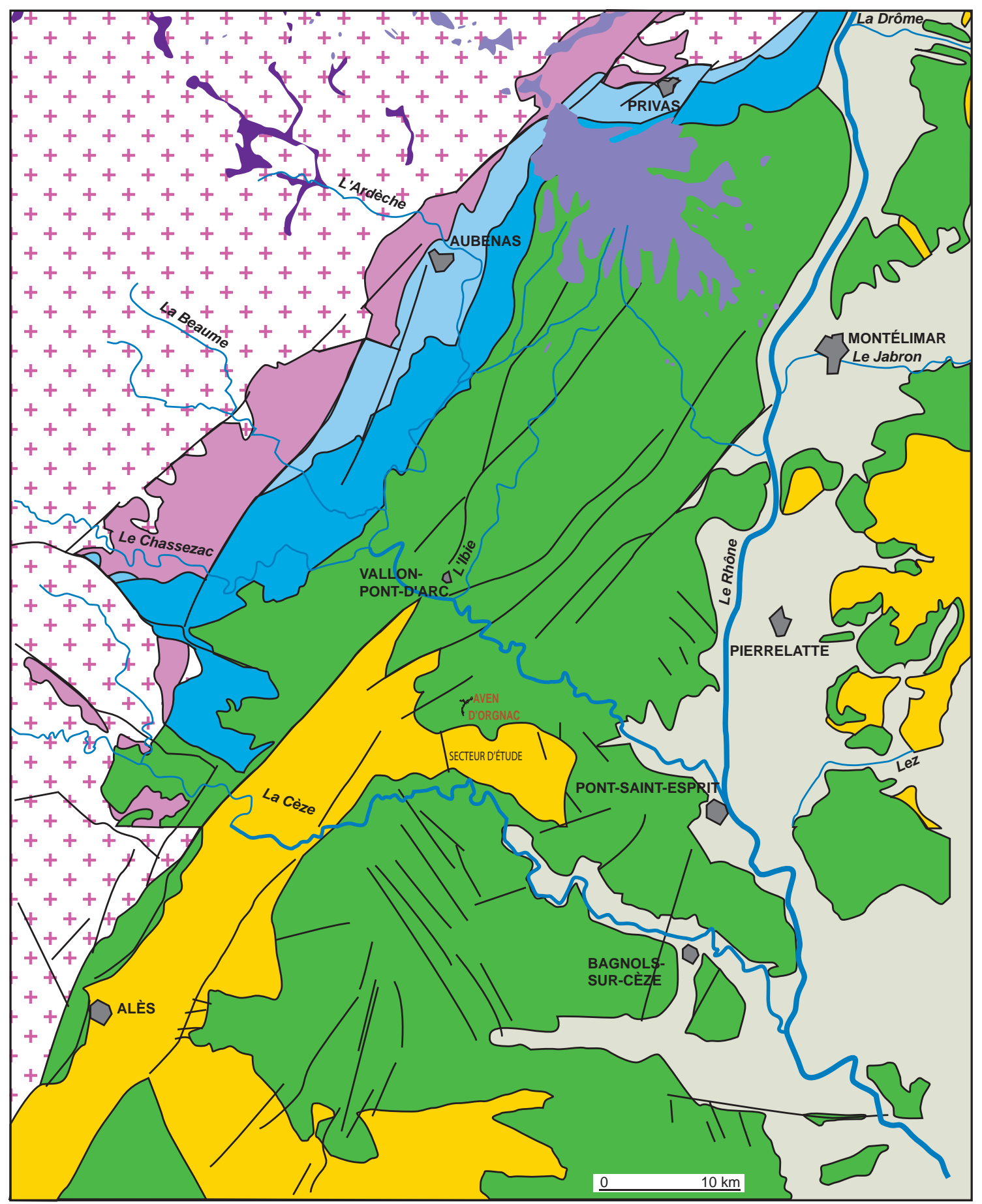

\begin{tabular}{|c|c|c|c|c|}
\hline 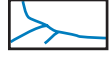 & Réseau hydrographique & & \multicolumn{2}{|c|}{ Crétacé } \\
\hline & Quaternaire & & \multicolumn{2}{|c|}{ J urassique supérieur } \\
\hline & Volcanisme des vallées & & \multicolumn{2}{|c|}{ J urassique moyen et inférieur } \\
\hline & Volcanisme des plateaux & & Trias & \\
\hline & Tertiaire moyen et inférieur & $+{ }_{+}^{+}$ & Socle & $\begin{array}{l}\text { D'après carte géologique } \\
1 / 250.000 \text { Valence }\end{array}$ \\
\hline
\end{tabular}


Deux « familles » de granites ont été distinguées, en fonction de leur origine :

- les granites dérivés de l'anatexie des séries métamorphiques (le faciès type étant le granite du Velay, $305 \mathrm{Ma}$ ) : ils sont généralement clairs, hétérogènes, et contiennent la plupart du temps des cordiérites en taches, cocardes ou arborescences pluri-centimétriques ;

- les granites intrusifs (dans les séries métamorphiques et le granite du Velay) sous forme de filons « tardimigmatitiques » ou de massifs homogènes hecto- à kilométriques plus ou moins porphyroïdes.

Le Houiller, visible dans le bassin de Prades, se caractérise par une série transgressive sur le socle cristallin et par les faciès sédimentaires suivants : conglomérats, grès plus ou moins grossiers et arkosiques, schistes et veines de houilles irrégulières et lenticulaires.

Les terrains du Houiller sont recouverts par les assises permiennes : celles-ci sont présentes dans le bassin de Largentière et sont formées de conglomérats, de grès lie-de-vin et de marnes schisteuses micacées.

Bien que présentant une forte diversité lithologique, les assises qui affleurent dans les hauts bassins de l'Ardèche et de la Cèze ont pour dénominateur commun une très faible perméabilité. Celle-ci a favorisé la mise en place de structures hiérarchisées efficaces de drainage des eaux de surface qui, vers l'aval, recoupent les terrains mésozoïques.

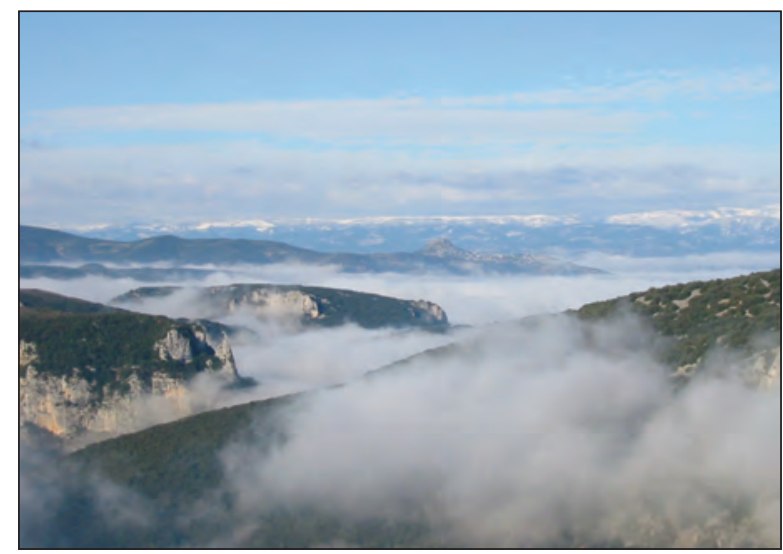

Photo 1

Le bassin versant de l'Ardèche et de ses affluents (Chassezac et Beaume) est développé dans les terrains imperméables du socle hercynien (massifs des Cévennes). Ce vaste impluvium imperméable a fourni le potentiel érosif nécessaire au recoupement en gorges des plateaux calcaires du Bas-Vivarais (photo Laudy Doumit).

\section{La couverture mésozoïque}

Si les terrains mésozoïques les plus emblématiques du secteur sont les calcaires massifs et clairs recoupés par les gorges de l'Ardèche et de la Cèze, il importe ici de présenter l'ensemble de ces assises. Du Trias au Crétacé, on relève les terrains suivants :
- grès, arkoses et sables argileux (Buntsandstein) ;

- argiles, marnes, calcaires dolomitiques et dolomies (Muschelkalk) ;

- argiles versicolores, grès fins, grès rouges et grès caverneux grossiers (Keuper et/ou Rhétien ?);

- grès dolomitiques puis marnes et calcaires marneux très fossilifères caractérisant le Lias inférieur qui évoluent vers des calcaires gréseux noirs ou rougeâtres (Lias moyen et inférieur) ;

- calcaires à chailles, schistes et calcaires noduleux caractérisant le Jurassique moyen ;

- calcaires clairs massifs en bancs souvent épais, typiques du Jurassique supérieur.

En dehors des calcaires du Jurassique, il est intéressant de relever que la couverture mésozoïque est composée essentiellement de terrains peu perméables favorisant les écoulements superficiels et la hiérarchisation du réseau hydrographique. C'est la conjonction de la nature peu perméable du socle et de la couverture mésozoïque qui offre à l'Ardèche comme à la Cèze un fort potentiel érosif dès lors qu'elles abordent les reliefs calcaires crétacés qu'elles recoupent en gorges. Ce potentiel érosif est de plus accentué par le matériel transporté abrasif (granite, gneiss, grès...).

\section{Le volcanisme}

Postérieurement à la sédimentation mésozoïque, cette région a été affectée par des manifestations volcaniques (Mergoil et al., 1993). On distingue « deux » grands épisodes :

- le volcanisme du Velay oriental, à l'origine de coulées de laves à faciès basaltique et de dykes (rhyolites). Ce volcanisme a été calé entre 10 et $6 \mathrm{Ma}$. On lui rattache le volcanisme des Coirons (haute vallée de l'Ibie) : coulées et pyroclastites interstratifiées, datés à $6.4 \pm$ $0,2 \mathrm{Ma}$.

- le volcanisme des «vallées» (haute vallée de l'Ardèche, vallées de la Volane, de la Bezorgue, de la Bourge, de la Fontaulière...) constitué essentiellement de basaltes riches en olivine, interstratifiés avec des sédiments et paléosols. Les âges radiométriques $\left({ }^{14} \mathrm{C}\right)$ de ces derniers sont répartis en deux groupes : 11000 ans BP et 30000 ans BP. Certains cônes et cratères sont encore bien conservés et visibles dans le paysage (volcans d'Aizac, Montpezat...). Ces épandages volcaniques renforcent si besoin est la faible perméabilité des bassins d'alimentation de la Cèze, de l'Ardèche et de leurs affluents. Ces événements volcaniques constituent par ailleurs des marqueurs de premier ordre en ce qui concerne le calage chronologique des anciens dépôts alluviaux de ces cours d'eau et plus particulièrement de l'Ardèche et de l'Ibie. L'étude pétrographique des galets et des minéraux lourds des sables transportés par l'Ardèche permet ainsi de caler chronologiquement la sédimentation de ces alluvions (anté- ou postmanifestations volcaniques) ainsi que leur position 
altitudinale (reconstitution de paléo-talwegs de ces cours d'eau). Ce travail est en cours de réalisation dans le cadre des recherches menées autour de la grotte Chauvet (Delannoy et al., 2004) et d'une recherche doctorale (B. Sadier).

Après ce rapide aperçu des conditions géologiques et paléogéographiques de l'environnement amont des plateaux calcaires du Bas-Vivarais, il est important d'appréhender les caractéristiques morphogéniques de la borne aval de la région étudiée : la vallée du Rhône. Cette vallée se caractérise par des événements paléogéographiques exceptionnels : la crise messienne et la transgression pliocène. Ces événements ont fortement marqué la karstogenèse des plateaux calcaires $\mathrm{du}$ Bas-Vivarais et ont pour effet de limiter l'influence morphogénique des bassins amont de la Cèze et de l'Ardèche. Cette influence ne doit pas être négligée car sans l'importance de l'impluvium imperméable situé à l'amont des gorges de la Cèze et de l'Ardèche et sans la nature pétrographique de cet impluvium, la morphogénèse des plateaux de l'Ardèche aurait été tout autre et aurait engendré d'autres phénomènes que le creusement des gorges : éléments majeurs dans le paysage et dans la karstogénèse de ces plateaux.

\section{I.2 - LA VALLÉE DU RHÔNE ET LE CYCLE MESSINO-PLIOCÈNE}

La confluence entre l'Ardèche et le Rhône se situe à l'aval de Saint-Martin-d'Ardèche à l'altitude de $50 \mathrm{~m}$. La Cèze, quant à elle, conflue avec le Rhône à $32 \mathrm{~m}$ NGF. D'une vallée taillée en gorges dans les assises crétacées, ces deux rivières quittent le domaine calcaire pour rejoindre la plaine alluviale du Rhône (figure 2).

Alors que tout au long de leur traversée du plateau calcaire crétacé ces deux cours d'eau coulent sur le bedrock calcaire, le Rhône s'écoule, quant à lui, sur un très important remblaiement sédimentaire dont la nature (marine, continentale) est directement liée aux influences eustatiques de la Méditerranée dont la plus importante est, sans conteste, la crise messinienne.

\section{La crise messinienne et ses conséquences}

Il y a 5,95 millions d'années, la mer Méditerranée a connu une crise exceptionnelle tant par son importance que par sa brièveté (Clauzon, 1982 ; Gautier et al., 1996 ; Beaudoin, 1997). Suite à sa déconnexion de l'océan Atlantique au droit du seuil de Gibraltar, elle s'est fortement asséchée faisant baisser le niveau eustatique de plusieurs milliers de mètres. Cherchant à rattraper le niveau de ces plaines abyssales (Clauzon, 1982), la plupart des fleuves méditerranéens surcreusèrent leurs vallées en canyon de plusieurs centaines de mètres au droit de leur ancienne embouchure. Cet événement dura quelques centaines de milliers d'années. Pour le Rhône, le surcreusement de la vague d'érosion régressive est identifié jusqu'à 40 km au nord de Lyon (Baumard, 2002). Les affluents du Rhône, rive droite (Ardèche, Cèze...) et gauche (Isère, Drôme, Durance) ont subi l'influence de cet abaissement considérable du niveau de base.

La Cèze et l'Ardèche ont réagi différemment à la crise messienne. La première s'est incisée de plusieurs centaines de mètres. Pour retrouver la Cèze coulant sur son fond rocheux, il faut remonter à l'amont de SaintAndré-de-Roquepertuis, à plus de vingt kilomètres en amont de sa confluence avec le Rhône (Ambert, 1997). À l'inverse, l'Ardèche coule sur son lit calcaire à la côte de $50 \mathrm{~m}$ environ à Saint-Martin-d'Ardèche, ce qui signifie que lors du surcreusement messinien, ce cours d'eau n'a pas pu s'inciser plus profondément (Mocochain, 2002). Cette différence de comportement est à relier à l'environnement géologique des roches recoupées par ces deux rivières. En effet, si l'Ardèche entaille les calcaires urgoniens jusque dans la vallée du Rhône, la Cèze, elle, quitte ces mêmes calcaires vers Goudargues pour s'écouler ensuite sur les assises du Crétacé supérieur plus tendres et donc plus à même d'être incisées. Bien que durant « seulement » 650000 ans, la crise messinienne entraîne dans la vallée de la Cèze le creusement d'une quantité très importante de matériaux. Ce décapage, associé à l'abaissement du niveau de base, entraîne une modification profonde de l'organisation des écoulements de surface mais aussi souterrains dont les karsts de l'interfluve Ardèche / Cèze ont pu être les témoins privilégiés.

\section{Le remblaiement pliocène}

Tout aussi exceptionnel est le remblaiement des vallées messiniennes. La reconnexion du seuil de Gibraltar provoque le déversement des eaux de l'océan Atlantique dans la Méditerranée. Celle-ci se remplit avec une vitesse vertigineuse et dépasse son niveau actuel pour atteindre +60 à $+90 \mathrm{~m}$ (Haq et al., 1987). La durée de ce remplissage est estimée de l'ordre de 1000 ans (Clauzon, 1996, 2002) voire serait inférieure à 50 ans (Blanc, 2002).

Les vallées messiniennes se transforment en de longues rias dans lesquelles sédimentent dépôts marins et continentaux. Au débouché des fleuves se mettent en place des structures sédimentaires originales : les gilbert-deltas qui, du fait de l'importance des apports continentaux, présentent une dynamique aggradante. Ces structures se caractérisent à la base par des matériaux fins, marins (bottom-set). Ces matériaux se raccordent au-dessus à des sédiments plus grossiers, progradants (fore-set); le toit des fore-set marque la transition marin/ continental. Ce toit est recouvert par des dépôts continentaux aggradants (top-set). La dynamique aggradante de ces structures conduit au colmatage sédimentaire des rias pliocènes (Gilbert, 1885 ; Clauzon, 1996)]. Concernant la ria du Rhône, le colmatage sédimentaire s'est fait en 3,3 millions d'années. 
Figure 2

Reconstitution de l'évolution du talweg du Rhône lors du cycle messino-pliocène aux confluences avec l'Ardèche et la Cèze.

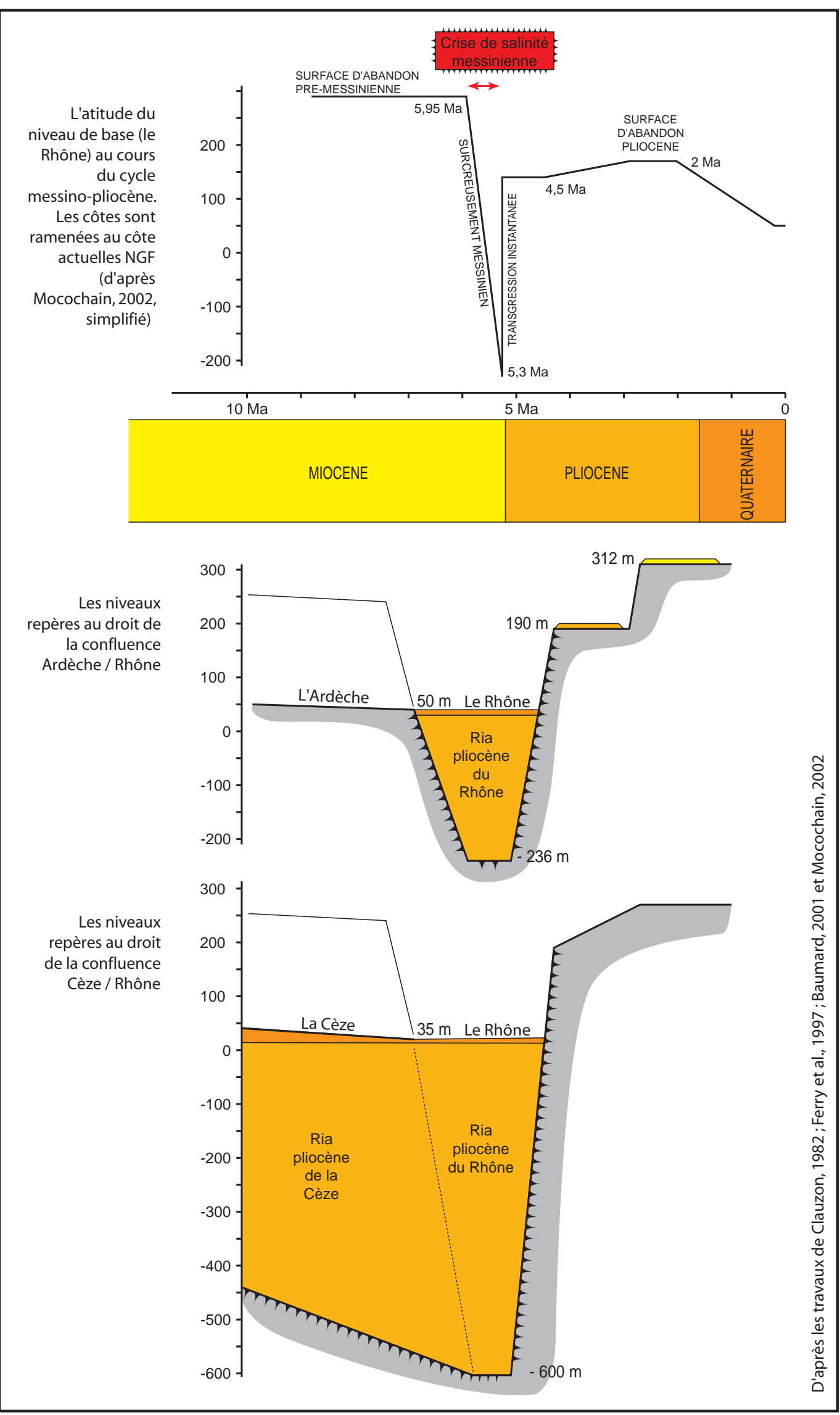




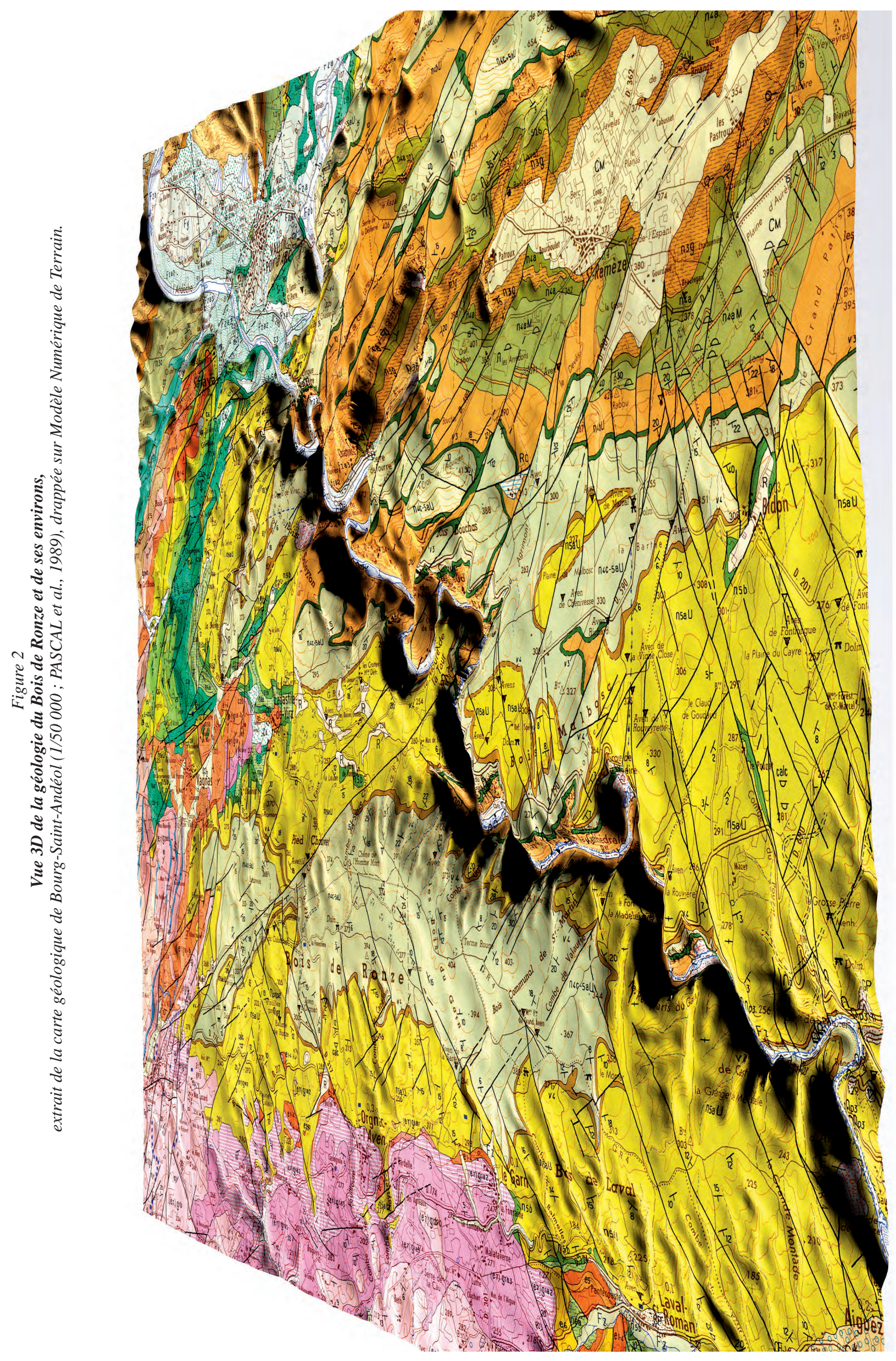


Au même titre que l'incision messinienne, la remise en eau, brutale, de la vallée du Rhône associée à un haut niveau marin $(+60$ à $+90 \mathrm{~m})$ a marqué la dynamique et l'organisation des écoulements de surface et souterrains. Le comblement de la Cèze a pu provoquer un réajustement complet des structures de drainage et le karst n'y échappe pas. En effet, on sait que le karst est susceptible de réajuster ses structures en fonction de ces variations de niveau de base (Delannoy, 1997). Les jalons exo- et endo-karstiques de l'interfluve Ardèche / Cèze ont été ici analysés dans cette perspective

\section{I.3 - L'interfluve Ardèche / Cèze et son karst}

Les plateaux calcaires urgoniens (Gras et anticlinal de Ronze) présentent un réel intérêt géomorphologique car ils sont, d'une part, en lien direct avec de vastes bassins hydrographiques hiérarchisés issus des assises imperméables du socle hercynien et de la couverture mésozoïque, et d'autre part, directement dépendants des variations mio-pliocènes du niveau de base régional (vallée du Rhône) (figure 3). Ce trait particulier est, de plus, accentué par le fait que ces plateaux se développent essentiellement dans les assises calcaires (Crétacé moyen) et que les réponses morphogéniques sont quasiment toutes d'ordre karstique. Au côté du trait karstique majeur que sont les gorges de l'Ardèche, ce secteur est connu de très longue date pour ses paysages calcaires et l'importance tant quantitative (plusieurs centaines de cavités connues) que qualitative des phénomènes souterrains. Les travaux de référence sur les cavités et le karst sont sans nul doute ceux de Balazuc (1965), Blanc et al. (1975), Callot (1976), Bellevile (1985), Gombert (1988), Debard (1988) et Drouin \& Marchand (1989). Ces travaux ont permis de fixer les caractéristiques du karst ardéchois et de poser des jalons karstogéniques.

Plus récemment, de nouveaux travaux ont permis de préciser voire de revisiter l'évolution de ce secteur en relation avec l'incision du réseau hydrographique (Blanc, 1999 ; Audra et al., 2001 ; Delannoy et al. ; 2001, 2004 ; Mocochain ; 2002 ; 2006 a et b, Martini, 2005). De ces travaux ressort également la richesse des enregistrements karstiques, tant de surface que de profondeur, pour reconstituer la morphogénèse des « Gras ». Ces travaux sont essentiels à la compréhension morphogénique de l'interfluve Ardèche / Cèze et à la mise en place de jalons paléogéographiques calés dans le temps ; ces jalons devant être croisés aux informations karstogéniques issus de l'étude du réseau d'OrgnacIssirac. Cet exercice de recoupement de données est au cœur de ce chapitre et du travail mené ces dernières années par le laboratoire EDYTEM.

La géologie du plateau des Gras se caractérise par une « omniprésence» des calcaires urgoniens ; ceux-ci se disposent en de lourdes déformations synclinales et anticlinales (orientées est-ouest) héritées de la tectonique pyrénéo-provençale et de la mise en place du fossé d'Alès (rifting oligocène). La dépression de Labastide-de-Virac et le Bois de Ronze constituent deux structures géomorphologiques orientées est-ouest liées à ce soubassement tectonique. Si le synclinal de Labastide est, aujourd'hui, en partie évidé des assises du Crétacé supérieur qui y étaient conservées, l'anticlinal du Bois de Ronze est globalement bien conservé du fait de l'armature urgonienne ; il est, néanmoins, tronqué dans sa partie sommitale par une surface d'aplanissement (vers $400 \mathrm{~m}$ d'altitude).

C'est dans ce contexte litho-structural que se positionne le réseau d'Orgnac-Issirac ; celui-ci se développe plus précisément sur le rebord sud de l'anticlinal du Bois de Ronze. L'extrémité nord des réseaux d'OrgnacIssirac (Salle des Treize) se situant à peu près au droit de l'axe de cet anticlinal. La cavité se développe selon une orientation subméridienne, c'est-à-dire perpendiculairement à l'axe du pli. Le pendage général des couches urgoniennes, en direction du sud pourrait constituer un élément d'explication de cette organisation des réseaux souterrains d'Orgnac ; cet élément devant être recoupé avec l'un des moteurs essentiels de la karstification : la position du niveau de base karstique contemporain de la genèse d'Orgnac (cf. infra).

L'étude du relief de l'anticlinal de Ronze va permettre de préciser la connaissance du secteur et de démontrer en quoi les formes et formations exokarstiques identifiées constituent autant de jalons complémentaires à l'analyse du réseau souterrain d'Orgnac-Issirac.

\section{II - GÉOMORPHOLOGIE DE L'ANTICLINAL DE RONZE}

Les recherches géomorphologiques menées sur le Bois de Ronze avaient pour objet de recenser les différents types de morphologies de surface et, à partir de cellesci, de poser à la fois un canevas chronologique et les différents processus à l'origine des reliefs actuels de ce secteur. Ce travail a été entrepris à partir de relevés de terrain et de l'analyse de photographies aériennes. L'ensemble des informations a été rassemblé dans une carte géomorphologique du Bois de Ronze et de la dépression de Labastide-de-Virac à l'échelle du 1/12 500, réduite ensuite pour l'édition. Cette carte a été représentée sur un fonds topographique réalisé à partir du MNT IGN $(50 \mathrm{~m})$. Les symboles correspondent aux « normes pour l'établissement de la carte géomorphologique détaillée de la France ».

Ce travail a permis d'identifier trois agencements morphologiques issus de contextes morphogéniques très différents

- des surfaces d'aplanissement: deux surfaces étagées (400 et $260 \mathrm{~m}$ ) ont pu être distinguées ; ces deux surfaces étant aujourd'hui nettement perchées au-dessus des talwegs de l'Ardèche et de la Cèze ; 


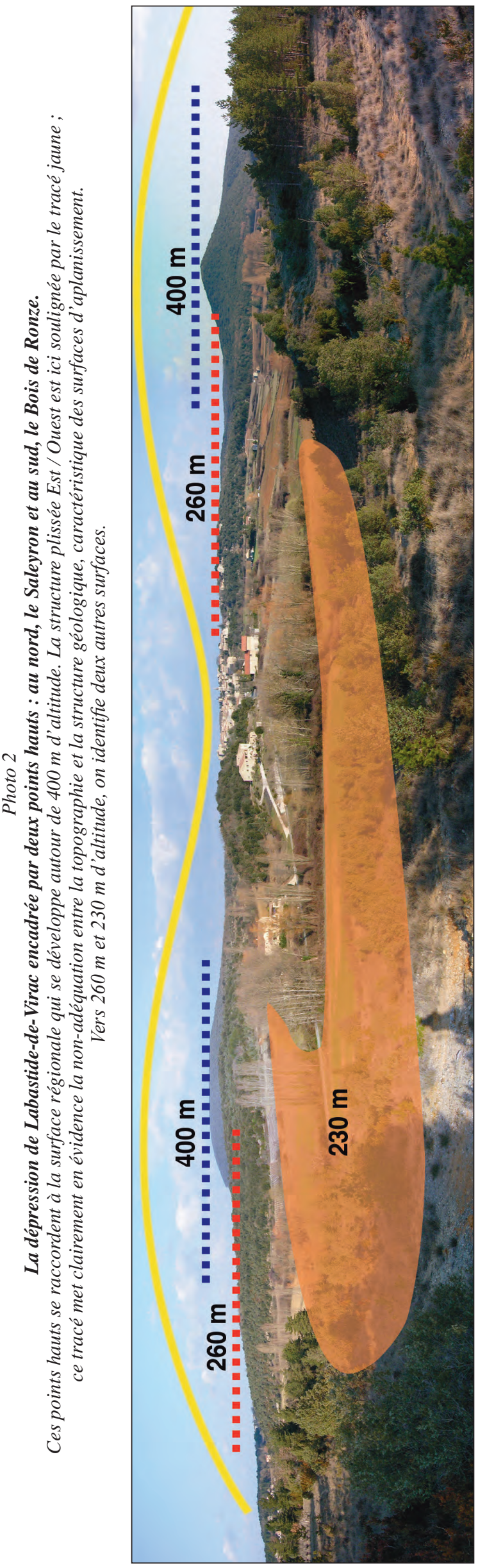

- des formes structurales: surfaces structurales, chevrons...

- des vallons incisés dans la masse calcaire ; ces vallons aujourd'hui secs sont perchés au dessus des talwegs de l'Ardèche et de la Cèze ;

- des phénomènes karstiques engendrés par l'existence d'un gradient hydraulique (avens, dolines...)

Chacune de ces familles est porteuse d'informations qui permettront de bâtir le canevas morphogénique de ce secteur; canevas qui sera ensuite confronté à l'évolution spéléogénique issue de l'étude des réseaux d'Orgnac-Issirac.

\section{1 Deux surfaces d'aplanissement perchées}

Deux surfaces d'aplanissement ont été identifiées : la première, qui se développe vers $400 \mathrm{~m}$, est particulièrement visible sur le faîte anticlinal du Bois de Ronze; la seconde, qui se situe autour de $260 \mathrm{~m}$ d'altitude, se confond avec le fond de la dépression de Labastide-de-Virac.

\section{La surface sommitale}

Cette surface affecte la voûte anticlinale du Bois de Ronze et passe par les points les plus hauts suivants : sommets du Saleyron (408 m) et du Bois du Garn (404 m) (photo 3). Comme toute surface d'aplanissement, celle-ci recoupe les assises géologiques quel que soit leur pendage. Étendu sur environ $9 \mathrm{~km}^{2}$ dans le secteur du Bois de Ronze, cet aplanissement appartient à une surface régionale : en rive gauche de l'Ardèche, elle correspond à la surface du plateau de SaintRemèze ; vers le sud, au-delà de la vallée de la Cèze, elle affecte le secteur de Méjannes-le-Clap. Décrite par Baulig (1928), cette surface fondamentale est citée par de nombreux auteurs (Clauzon, 1982 ; Belleville, 1985 ; Gombert, 1988 ; Debard, 2000 ; Delannoy et al., 2004 ; Martini, 2005 ; Mocochain et al., 2006).

Cette surface s'est mise en place dans un contexte paléogéographique différent de l'actuel; tout aplanissement calcaire se développe en effet dans un contexte de faible énergie gravitaire; cette faiblesse étant compensée par une machine érosive efficace reposant sur le travail de la dissolution et de l'altération des assises non carbonatées (Delannoy, 1997 ; 2001).

Cette surface qui s'est développée durant le Miocène (Aquitanien : 20 à $30 \mathrm{Ma}$ ) est un marqueur paléogéographique majeur du fait de son antériorité à la crise de salinité messinienne et à la morphogenèse engendrée par cette crise qui a plus favorisé le creusement de vallées que le façonnement de surfaces d'aplanissement; Clauzon (1982) identifie d'ailleurs cette surface comme la «surface d'abandon préévaporitique », c'est-à-dire précédant la crise de salinité messinienne. Cet auteur raccorde, par ailleurs, cette surface aux cailloutis de Saint-Restitut dans la vallée du Rhône, situé à 312 m (340 m corrigé de l'érosion). L'identification, vers 380 à $360 \mathrm{~m}$ sur le plateau de 

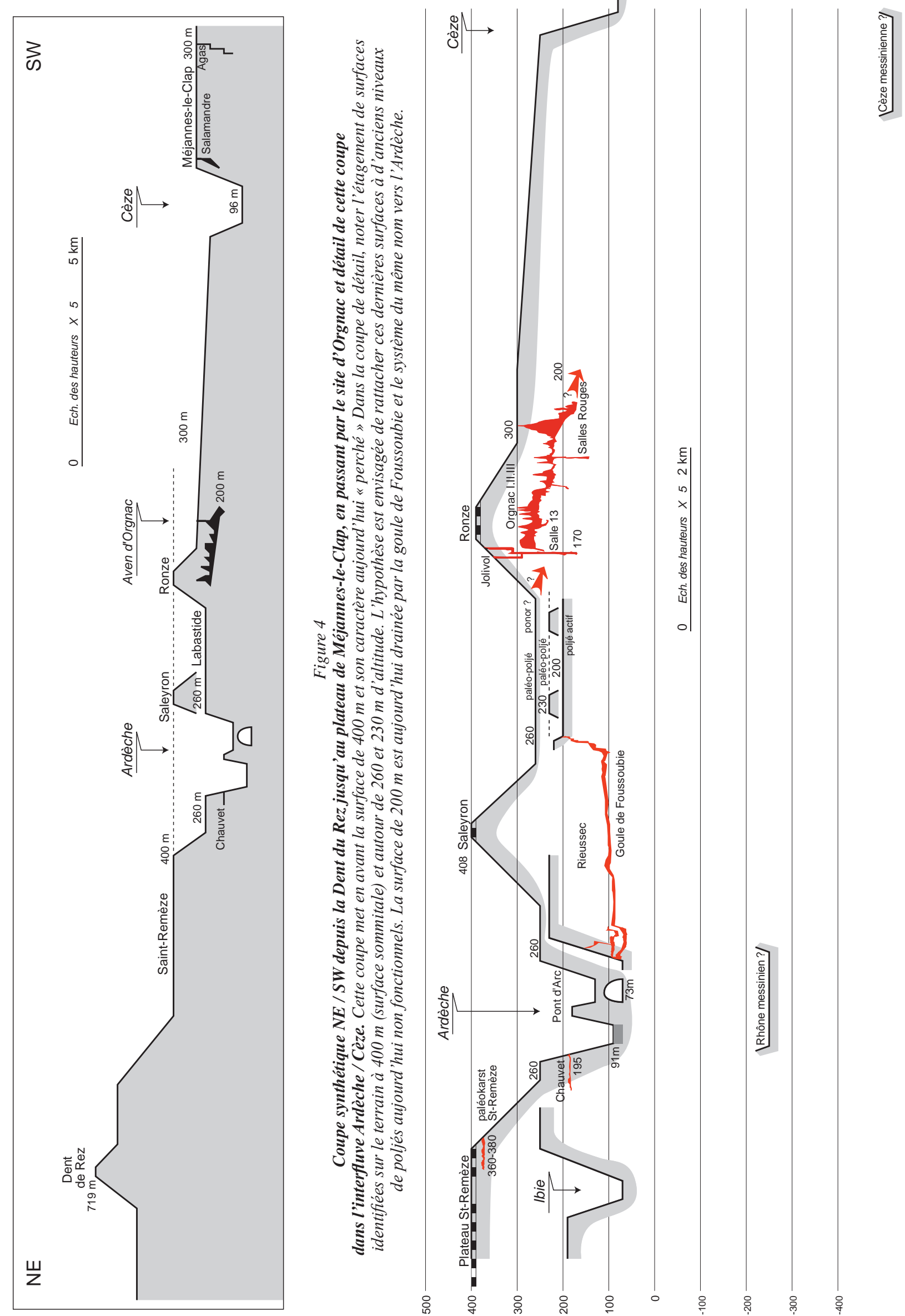

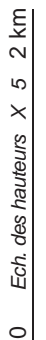

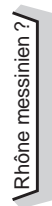




\section{ENCADRÉ 1}

\section{LeS STRUCTURES CASSANTES DE L'ANTICLINAL DE RONZE}

La structure générale des terrains carbonatés présente des plis à grand rayon de courbure. Du sud au nord, on rencontre les éléments suivants :

- un anticlinal assez faiblement prononcé avec des pendages plus importants sur son flanc nord que sur son flanc sud, c'est l'anticlinal de Ronze d'axe Est-Ouest ;

- un synclinal assez symétrique, au centre de la coupe ;

- un nouvel anticlinal immédiatement au nord avec des pendages plus prononcés au sud qu'au nord.

Les terrains sont affectés par des failles (décrochements dominants). Elles ne modifient pas fondamentalement la structure générale mais leur rejet atteint parfois plusieurs dizaines de mètres. À l'extrémité sud de la coupe affleurent des terrains de l'Éocène terminal se raccordant au bassin paléogène d'Issirac. Au nord affleure la série urgonienne au sein de laquelle se trouvent plusieurs vires marneuses dont les deux supérieures (v3 et v4) affleurent sur ce secteur. Des terrains tertiaires raccordés à la terminaison nord du fossé tectonique d'Alès sont présents sur le synclinal de Labastide. Entre ces terrains tertiaires et l'ensemble urgonien affleure une couche marneuse du Bédoulien supérieur. Plus au nord apparaît à nouveau l'ensemble urgonien.

Un schéma structural simplifié du secteur montre les failles majeures (cartographiques) de la zone d'étude et permet d'identifier clairement l'axe anticlinal du Bois de Ronze ainsi que les failles qui l'affectent. Pour certaines d'entre elles, il est possible de déterminer cartographiquement le jeu décrochant (dextre pour les directions NE / SW et senestre pour les directions $\mathrm{NW/SE).} \mathrm{Le} \mathrm{système} \mathrm{karstique} \mathrm{Orgnac-Issirac,}$ replacé dans ce schéma, se développe intégralement sur la bordure sud de l'anticlinal dans une direction plus ou moins proche du pendage.
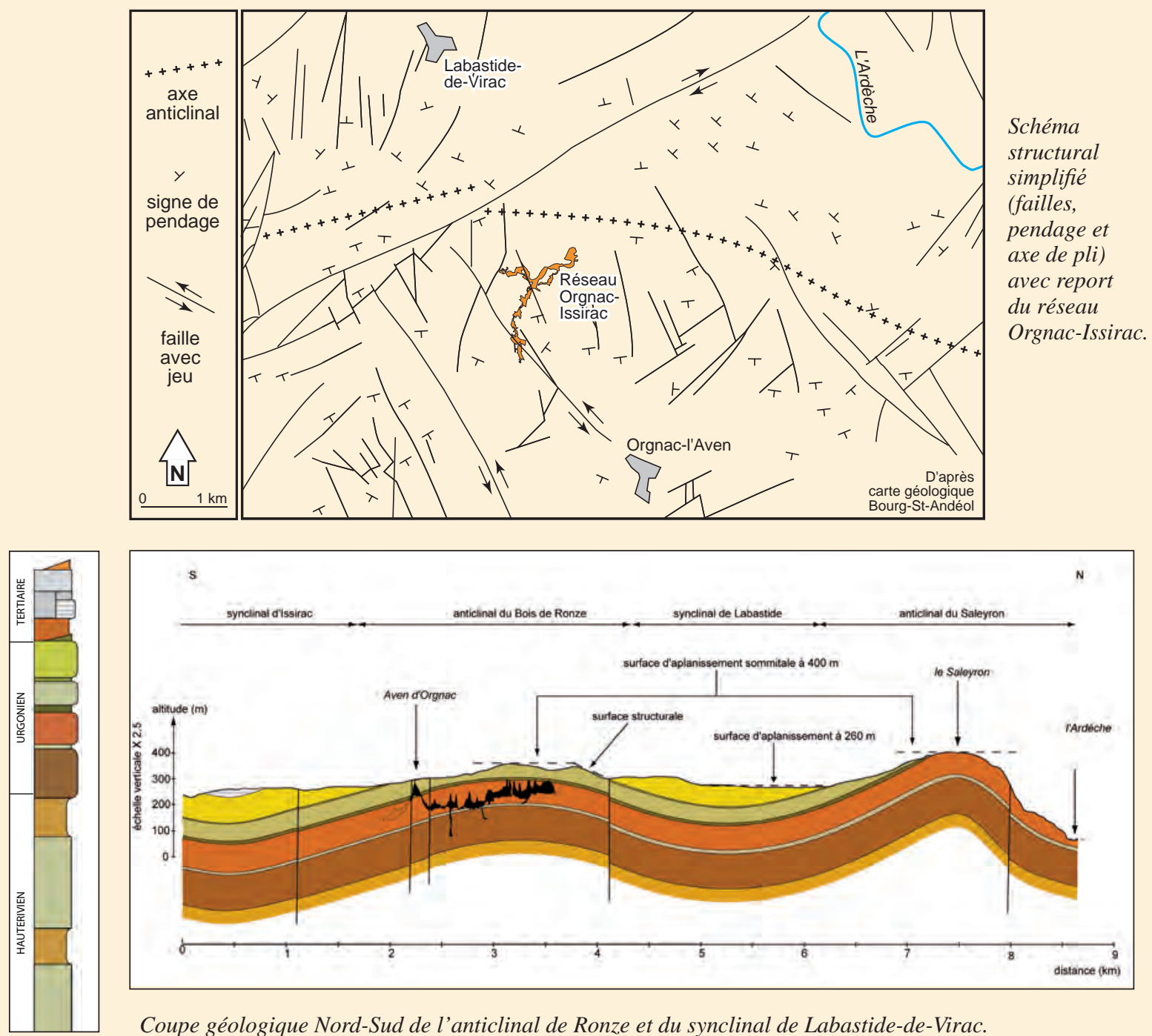

Coupe géologique Nord-Sud de l'anticlinal de Ronze et du synclinal de Labastide-de-Virac. 


\section{ENCADRÉ 1}

\section{Les STRUCTURES CASSANTES DE L'ANTICLINAL DE RonZE}

Les données structurales de fracturations relevées sur le terrain ont pu être traitées par le logiciel Angelier. On identifie ainsi les contraintes tectoniques à l'origine de ces plans. Les données encore trop parcellaires et l'absence de plans conjugués bien identifiés permettent cependant de ressortir les éléments suivants :

- une fréquence de direction comprise entre $N 0^{\circ}$ et $N 30^{\circ}$;

- une fréquence de direction de plongement essentiellement ouest ;

- une fréquence d'inclinaison généralement supérieure à $80^{\circ}$.

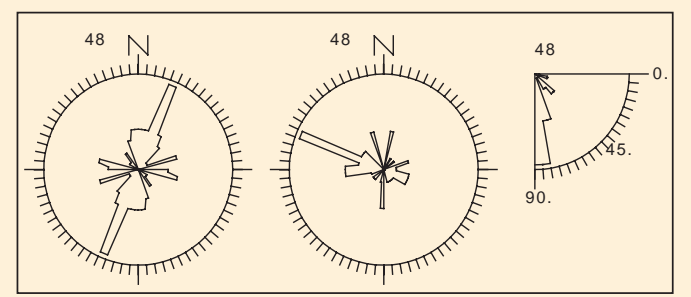

Diagramme des fracturations mesurées sur le terrain.

1 : Fréquence de directions

2 : Fréquence de directions de plongement

3 : Fréquences de valeurs de pendage.

Il apparaît clairement sur ces diagrammes que la famille de joints dominants dans la région d'Orgnac a pour orientation $N 20^{\circ} \mathrm{E}$ et un pendage fort vers l'Ouest. Des joints de moindre importance sont orientés $N 80, N 100, N 140^{\circ} \mathrm{E}$. Il s'avère que (i) ces familles ont également été identifiées à l'échelle cartographique, (ii) que ces directions sont celles que l'on est en droit d'attendre dans un anticlinal comme celui de Ronze, si l'on se réfère au schéma de répartition des joints dans un pli (Ramsay et Hubert, 1987). Toutefois leur importance relative devrait être différente. Il est donc très probable que les joints $\mathrm{N} 20^{\circ} \mathrm{E}$ soient postérieurs aux plis.

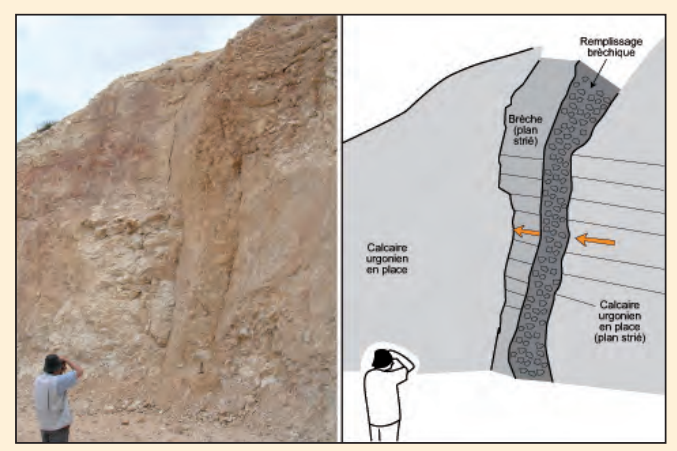

Décrochement sur brèche dans la carrière en activité entre Barjac et Orgnac-l'Aven. Notez les plans striés identifiés autant sur les calcaires urgoniens que sur le remplissage brèchique.
En effet, la bordure cévenole à laquelle appartient ce pli est affectée de plusieurs phases tectoniques postérieurement à l'orogenèse hercynienne. On distingue :

+ une phase compressive E-W du Stéphanien moyen au Trias se traduit par un charriage des unités sédimentaires et par une déformation du socle;

+ une phase distensive modérée pendant le Trias, plus importante pendant le Lias et qui se prolonge jusqu'au Crétacé, permet le développement de bassins sédimentaires NE-SW ;

+ une phase compressive dite pyrénéo-provençale se traduit, à l'Eocène supérieur, par une compression sub-méridienne et des plis $E-W$ à grand rayon de courbure comme l'anticlinal de Ronze ;

+ une phase distensive oligocène à l'origine de bassins sédimentaires délimités par des failles normales (dépression de Vagnas-Virac, fossé d'Alès) ;

+ une phase tectonique "alpine» fini-miocène correspond à une phase de compression globalement $E-W$; elle est à l'origine des décrochements NW-SE et ENE-WSW présents dans la région d'Orgnac ainsi que de la rotation des blocs calcaires délimités par ces failles.

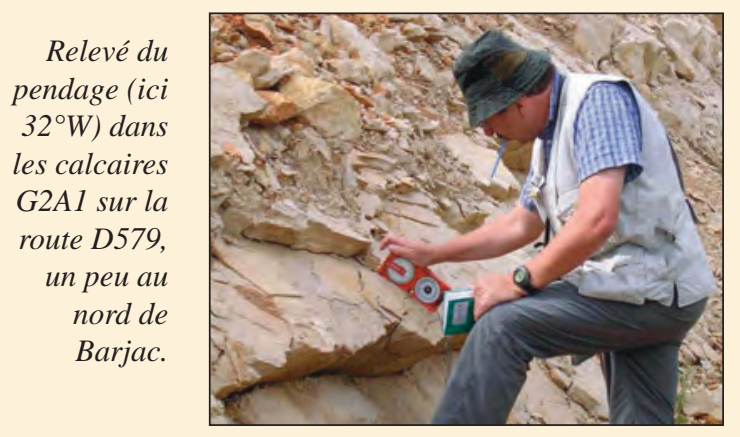

Enfin, une tectonique en distension post-miocène a été identifiée dans le couloir rhodanien et le long de la bordure cévenole. Il s'agit souvent d'un rejeu des accidents plus anciens.

L'anticlinal de Ronze illustre bien la phase compressive pyrénéo-provençale. Il est compliqué par une tectonique cassante syn- et post-plissement.

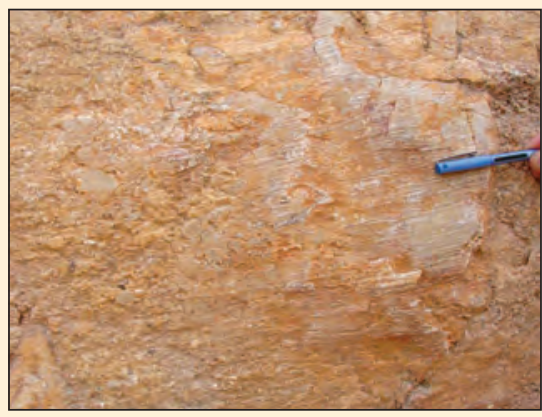

Détail des stries décrochantes (même carrière). 


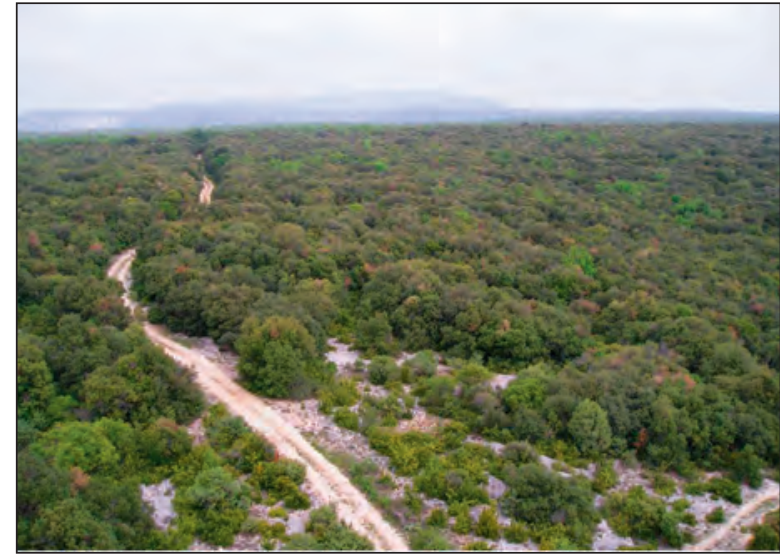

Photo 3

La surface d'aplanissement vers 380 à $\mathbf{4 0 0}$ m d'altitude

constitue ici le sommet du Bois de Ronze (vue vers le NE).

Saint-Remèze, d'un paléo-système karstique (alimenté par des eaux transportant du matériel haut-ardéchois) permet de confirmer l'existence d'un ancien niveau morphogénique (aujourd'hui perché) (Martini, 2005). Cette ancienne évolution qui s'est traduite en surface par la genèse d'aplanissement et en profondeur par des réseaux peu pentus recoupant la masse calcaire, permet de reconstituer une paléogéographie ayant un très faible gradient hydraulique; en l'absence de ce gradient, l'essentiel du travail de la dissolution se porte sur la partie supérieure de la masse calcaire et engendre la réalisation d'aplanissement recoupant indifféremment les différentes assises carbonatées. C'est pourquoi elle constitue un témoin paléogéographique majeur et une mémoire d'un contexte géographique bien différent de l'actuel. Les éléments allochtones présents sur les surfaces calcaires sont des témoins de cette ancienne géographie.

\section{La surface « inférieure » (260 m d’altitude)}

La seconde surface qui recoupe le dispositif géologique a été identifiée autour de $260 \mathrm{~m}$ d'altitude: elle est particulièrement visible dans la dépression de Labastide-de-Virac (synclinal d'orientation est-ouest). Cette surface s'étend sur environ $5 \mathrm{~km}^{2}$ : elle est limitée au nord par le versant sud du Saleyron et au sud par les versants du Bois de Ronze. À l'est, elle est recoupée par les gorges de l'Ardèche (photo 4).

On identifie sur cette surface les éléments suivants :

- quelques témoins de dépôts allochtones ;

- sur les bordures de la surface, se raccordant au versant nord du Bois de Ronze, un trottoir de dissolution marquant dans le paysage un talus discontinu ;

- la présence de dolines, toutes de petites dimensions, qui accidentent cette surface.

Cette surface se prolonge vers le nord au-delà du Saleyron. Elle forme même les rebords sommitaux de la partie amont des gorges de l'Ardèche. Il serait fécond de pouvoir définir précisément les conditions morphogénétiques qui ont prévalu à la mise en place de cette surface emboitée. Certains auteurs (Mottet, 1993) ont évoqué la possibilité d'un passage de l'Ardèche à l'ouest du Saleyron. En dehors de cette hypothèse, la présence de trottoirs de corrosion affectant les flancs des reliefs urgoniens permet de suggérer une autre cause possible à l'élaboration de cette seconde surface : le fonctionnement en poljé du secteur de Labastide. On sait que les poljés se logent généralement dans des dépressions structurales (grabens, synclinaux...) et qu'ils doivent leur existence à un dysfonctionnement du drainage karstique : incapacité d'absorber la totalité des écoulements durant les périodes de hautes eaux ; ce dysfonctionnement se traduisant par l'ennoiement de la dépression et par un travail latéral de la dissolution (trottoirs de corrosion) (Delannoy, 1997). La cartographie géomorphologique de la dépression de Labastide présente de nombreuses similitudes avec les traits morphologiques d'un poljé (aplanissement des assises carbonatées, altération des assises non calcaires encore présentes dans la dépression...). Il est intéressant de relever qu'à l'ouest de Labastide, on retrouve des témoins d'anciens aplanissements aux alentours de $230 \mathrm{~m}$ et de $200 \mathrm{~m}$; c'est dans ce même secteur que le ruisseau de la Planche se jette dans la Goule de Foussoubie dont l'engorgement chronique engendre une mise en eau.

Quelle que soit son origine, cette seconde surface se situe nettement en contrebas de la surface sommitale. Elle constitue un autre témoin paléogéographique important de ce secteur. Bien que régie par la même dynamique morphogénique (érosion chimique dans un contexte de faible énergie gravitaire), ces deux surfaces appartiennent à deux évolutions paléogéographiques différentes entre lesquelles un événement important a eu lieu : le dégagement de

Vue depuis la rive gauche de l'Ardèche des deux surfaces d'aplanissement : la surface sommitale $(400 \mathrm{~m})$ recoupe la structure anticlinale du Bois de Ronze (cf photo 3) ; la surface inférieure $(260 \mathrm{~m})$ est particulièrement bien représentée au niveau de la dépression de Labastide-de-Virac.

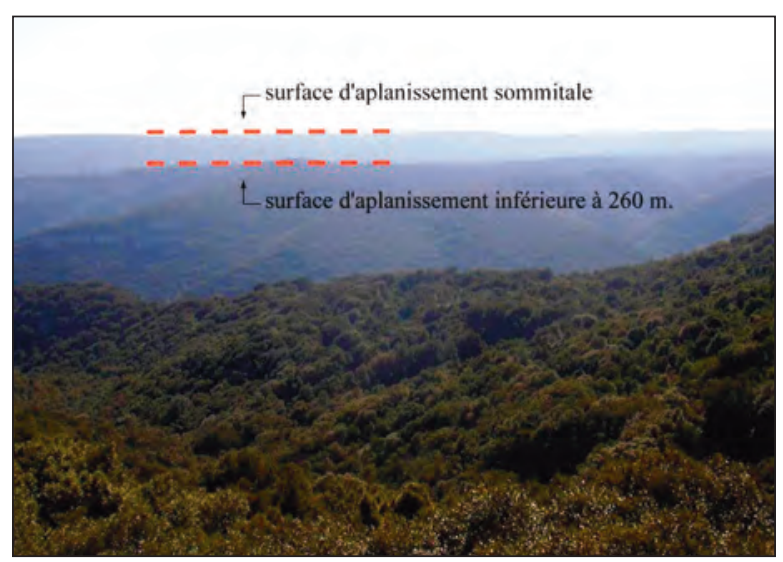


la couverture du Crétacé supérieur. Ce dégagement nécessite des agents morphologiques privilégiant l'érosion mécanique et la mise en place de structures de drainage superficiel efficaces.

La mise en avant de deux surfaces emboitées permet de poser trois étapes morphogéniques dont il reste à définir les moteurs :

- la première surface suppose l'existence d'un contexte de faible énergie gravitaire, rapportée au Miocène (anté-messinien);

- une phase érosive favorisant l'évacuation des assises tendres du Crétacé supérieur et perchant la surface sommitale (là où affleurent les assises urgoniennes) ;

- une troisième étape responsable d'aplanissements localisés dans les dépressions structurales et entrainés par, sinon un contexte à nouveau de faible énergie gravitaire, tout au moins par des dysfonctionnements karstiques.

Les observations sur les rebords de l'anticlinal de Ronze et dans la dépression de Labastide permettent d'appuyer et compléter ce canevas morphogénique.

\section{II.2 - LES APPORTS DES FORMES PRÉSENTES SUR LES REBORDS DE L'ANTICLINAL de RONZE}

Sur les flancs nord et sud de l'anticlinal de Ronze, on relève des formes issues de processus morphogéniques favorisant l'émergence de surfaces structurales, le creusement de vallons et la formation de cavités (figure 5). Ces processus répondent à une toute autre logique morphogénique que ceux ayant engendré les aplanissements karstiques (faible gradient hydraulique). Le dégagement de surfaces structurales, le creusement de vallons et de gouffres supposent un travail d'érosion différentielle et une énergie hydraulique liée, entre autres, à l'existence d'un gradient hydraulique.

L'observation de ces différentes formes permet de les rattacher pour l'essentiel à la phase glyptogénique décelée entre l'élaboration de la surface sommitale et la surface karstique de $260 \mathrm{~m}$. Nous avons précédemment rattaché à cette phase le dégagement des assises tendres du Crétacé supérieur. L'évacuation de ces assises a eu pour effet de dégager le toit des assises urgoniennes; l'érosion différentielle en butant sur les assises calcaires a favorisé l'agencement des surfaces structurales, toujours visibles sur les flancs de l'anticlinal de Ronze.

\section{Mise en place des surfaces structurales emboitées de Ronze}

Ces surfaces structurales qui occupent une partie importante des flancs de l'anticlinal de Ronze sont, dans le détail, un peu plus complexes que le simple affleurement du toit urgonien. On relève, en effet, la présence de surfaces « emboitées », de chevrons et de vallons qui les incisent sur quelques dizaines de mètres de profondeur (photo 5). Le travail de terrain a permis de distinguer deux types de surfaces structurales. La première (SS1) est armée par le mur de la couche supérieure d'Urgonien (n5aU). Cette couche est érodée en de nombreux endroits et la vire marneuse sousjacente (v4) dégagée forme le talus du chevron. Au pied de ce talus, une seconde surface structurale (SS2)

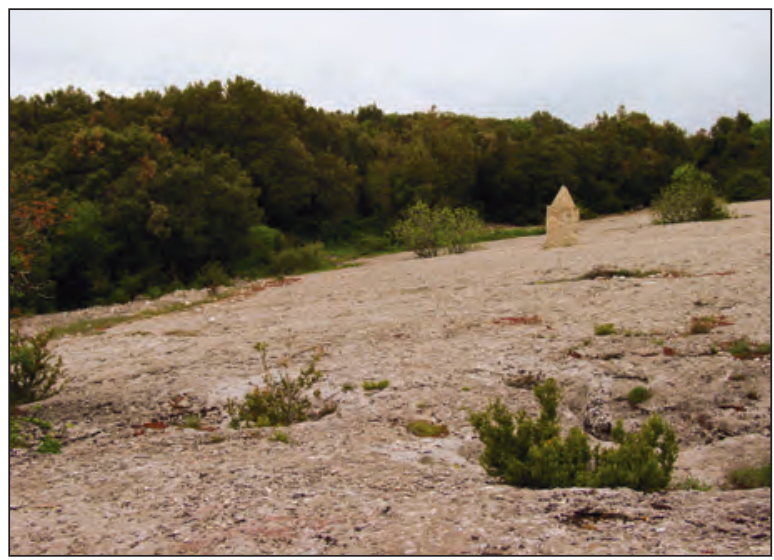

Photo 5

Vue d'une des surfaces structurales (ici SS2) qui se développent sur le flanc sud de l'anticlinal du Bois de Ronze (en direction de la dépression de Labastide-de-Virac). La mise en place de ces surfaces est contemporaine du dégagement de la couverture du Crétacé supérieur. Leur maintien dans le paysage est lié à une distribution de l'érosion karstique qui privilégie la dissolution profonde du fait de l'existence d'un gradient hydraulique.

est armée cette fois par le toit de la couche géologique n4c-5aU. Ce dédoublement des surfaces structurales est présenté figure 6. Celle-ci met bien en avant que la surface structurale inférieure (SS2) s'est agencée aux dépens de la surface supérieure (SS1) et de la vire marneuse (v4). L'agencement de la seconde génération de surface structurale suppose une morphogenèse active capable de démanteler la surface supérieure ; deux processus sont vraisemblablement responsables de cette morphogenèse : la dissolution superficielle et l'évacuation du matériel calcaire (non dissous); ce second processus suppose une prise en charge par des écoulements superficiels ce qui peut paraître $a$ priori étonnant en domaine karstique. La mise en place de tels écoulements karstiques est possible dans les conditions suivantes: karstification déficiente des calcaires, présence de niveaux contrariant un enfoncement des écoulements, faible gradient hydraulique. Or dans le contexte d'une dynamique associant ces surfaces au dégagement de la couverture crétacée supérieure, ces conditions sont réunies : la karstification de l'Urgonien (ouverture de vides karstiques par les eaux d'infiltration) ne débute qu'une fois qu'il est dégagé de sa couverture lithologique (Crétacé sup.) et celle-ci ne peut se réaliser que dès lors qu'il existe un gradient hydraulique ; or celui-ci dépend de la vitesse de dégagement de la couverture crétacée qui en contrebas jouelerôle de barrièrehydrogéologique. 
Figure 5

Carte géomorphologique du Bois de Ronze et de ses environs.

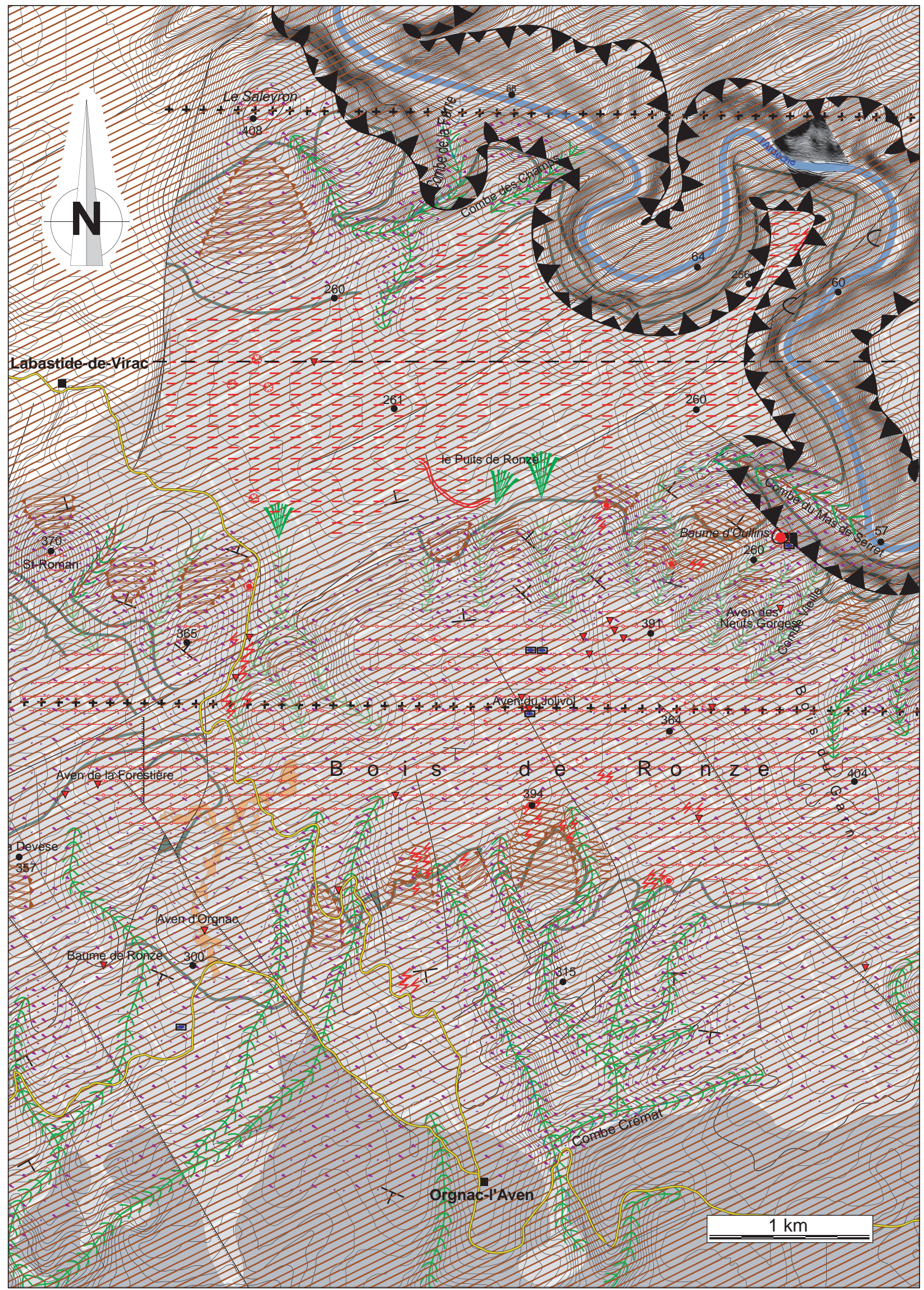




\section{Topographie :}

- $\quad$ point coté

courbes de niveau

(équidistance $5 \mathrm{~m}$ )

courbes de niveau maîtresses

(équidistance $100 \mathrm{~m}$ )

\section{Hydrographie :}

cours d'eau pérenne

- - - cours d'eau temporaire

\section{Lithologie:}

calcaires urgoniens

vires marneuses intra-urgoniennes

calcaires et marnes de l'É ocène

\section{Tectonique :}

\section{人 pendage}

- faille

++ axe anticlinal

- - - axe synclinal

\section{Formes structurales :}

Surfaces structurales (chevrons) :

surface structurale "SS1"

et talus associé

surface structurale "SS2"

et talus associé

\section{Formes et formations issues de} l'action des eaux courantes :

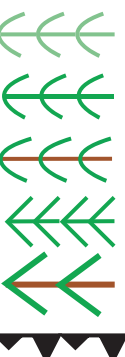

$\Lambda$

vallon en berceau déconnecté

vallon en berceau connecté

vallon en berceau guidé par une faille

vallon en $\mathrm{V}$

vallon en $\mathrm{V}$ guidé par une faille

gorges

cône de déjection

galets, trace d'une paléo-Ardêche?

\section{Formes et formations karstiques :}

タ४ lapiés

3 doline en baquet

doline dissymétrique

limites de trottoir de dissolution (rebord de poljé?)

surface d'aplanissement sommitale

surface d'aplanissement inférieure

réseaux karstiques d'Orgnac-Issirac

$\nabla \quad$ aven

- plancher stalagmitique

cavité souterraine ouverte au flanc d'un versant

\section{Formations d'origine périglaciaire :}

$\therefore \therefore$

gélifracts (couverture importante)

gélifracts (couverture mince) 
Figure 6

Cette figure présente schématiquement les deux types de surface présentes sur le relief du Bois de Ronze et qui répondent à deux logiques morphogéniques différentes : la surface sommitale (400 m) qui recoupe le dispositif géologique et les surfaces structurales (SS1 et SS2) qui mettent en avant le dispositif géologique (ici pendage des assises urgoniennes sur le versant nord du Bois de Ronze).

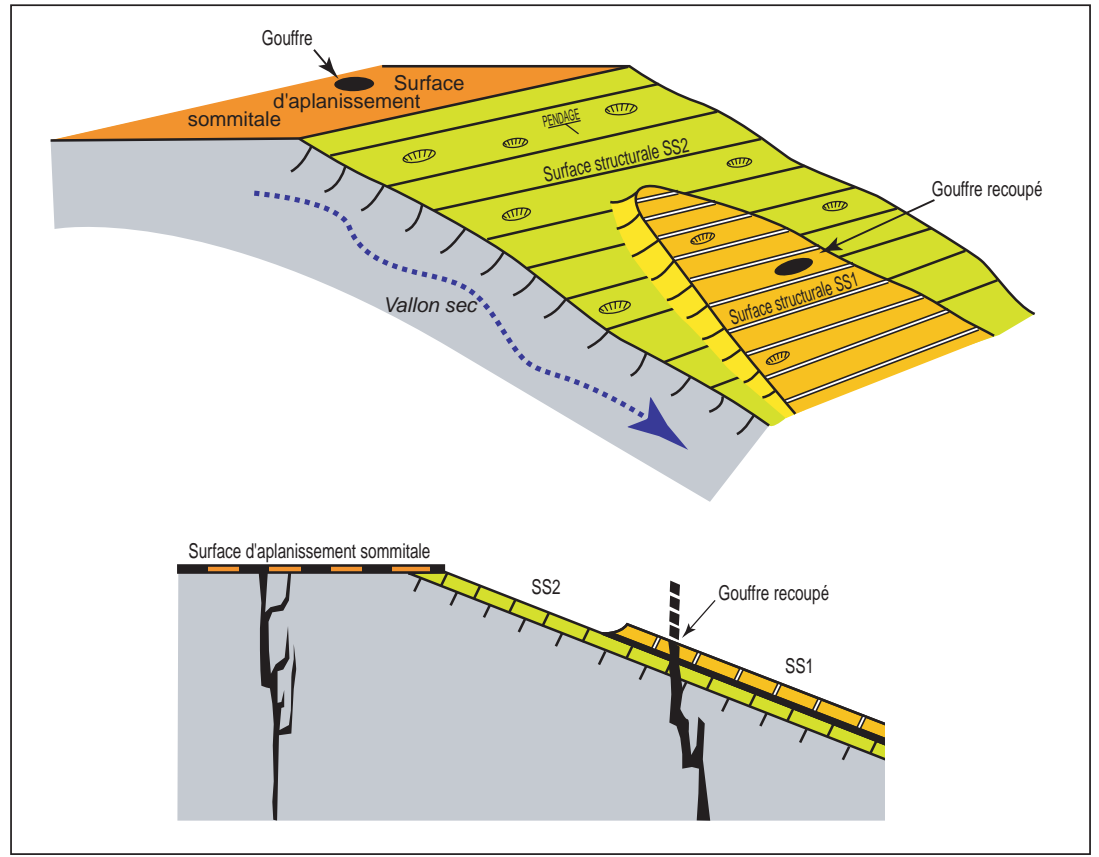

La karstification a de plus été freinée par la présence de la vire marneuse v4 (photo 6). Cet effet de retard dans le déclenchement de la karstification malgré la mise au jour des affleurements urgoniens n'est pas antinomique d'un travail actif de la dissolution superficielle, au même titre que les aplanissements calcaires supposent un travail de la dissolution en l'absence de gradient hydraulique. C'est à cette combinaison d'interactions limitant la karstogenèse que nous rapportons la mise en place des vallons et l'agencement de la surface structurale 2 (SS2). Il est vraisemblable que la mise à l'affleurement de la vire marneuse (v4) a favorisé une dynamique d'écoulement superficiel et la structuration des vallons qui accidentent les flancs de l'anticlinal.

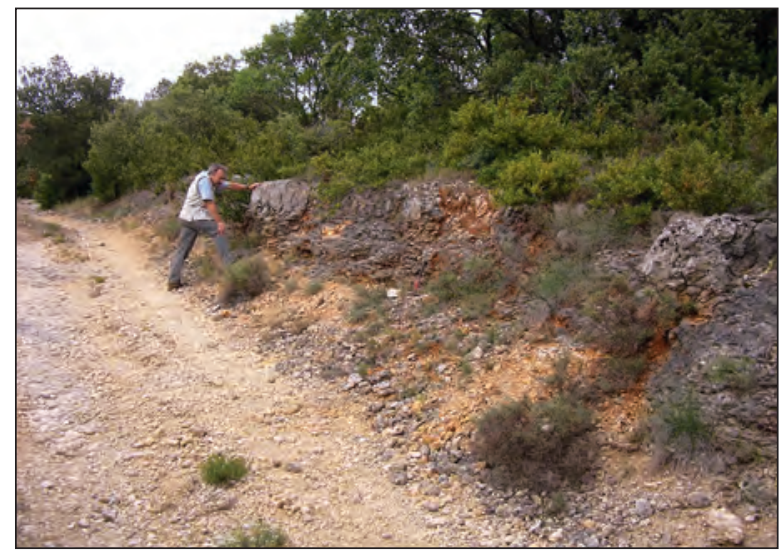

Photo 6

Rôle des vires marneuses intra-urgoniennes dans la morphologie des versants. Au premier plan se dessine la surface structurale inférieure SS2. Le talus correspond à la vire marneuse (v4), sur laquelle se développe la surface structurale SS1. Ces vires marneuses ont vraisemblablement favorisé la mise en place des vallons qui entaillent les surfaces structurales du Bois de Ronze pour se raccorder à la surface $260 \mathrm{~m}$.

\section{Les vallons secs du Bois de Ronze}

Les vallons qui entaillent les flancs de l'anticlinal de Ronze présentent une organisation hydrographique différente selon qu'on se situe sur le flanc nord ou sur le rebord sud.

Sur le rebord nord, les vallons se développent parallèlement selon une direction subméridienne (photos 7 et 8 ) ; leur faible développement longitudinal (environ $800 \mathrm{~m}$ ) ne permet pas de déceler une organisation hydrographique : ils s'apparentent aujourd'hui à des vallons évasés (profil en berceau) dénués de traces d'écoulements superficiels. Aucune perte n'a pu y être repérée. Le fond de ces vallons est occupé par un tablier

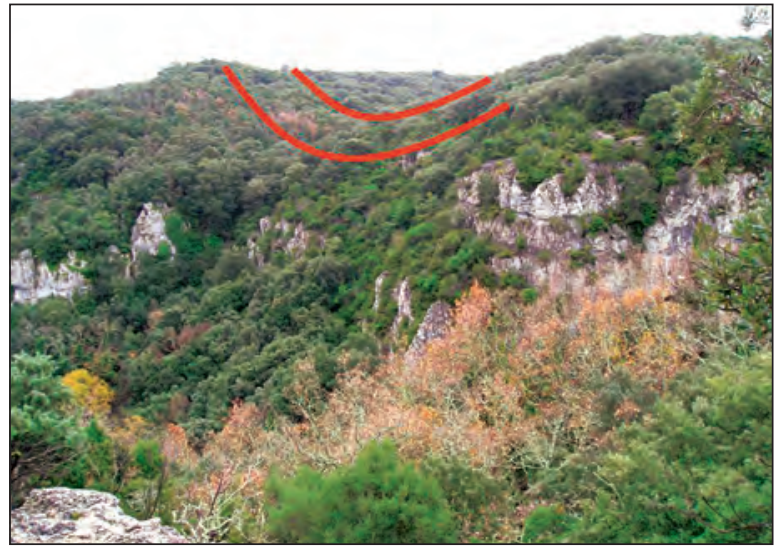

Photo 7

Exemple de vallons secs perchés sur le flanc nord du Bois de Ronze (secteur de la Baume d'Oullins). Trépanés par l'incision de l'Ardèche, la plupart de ces vallons sont restés perchés au-dessus des gorges. Il est intéressant de relever que la base de la plupart de ces vallons se situe vers $260 \mathrm{~m}$ d'altitude, c'est-à-dire au niveau de la surface inférieure à laquelle ils devaient se raccorder. 


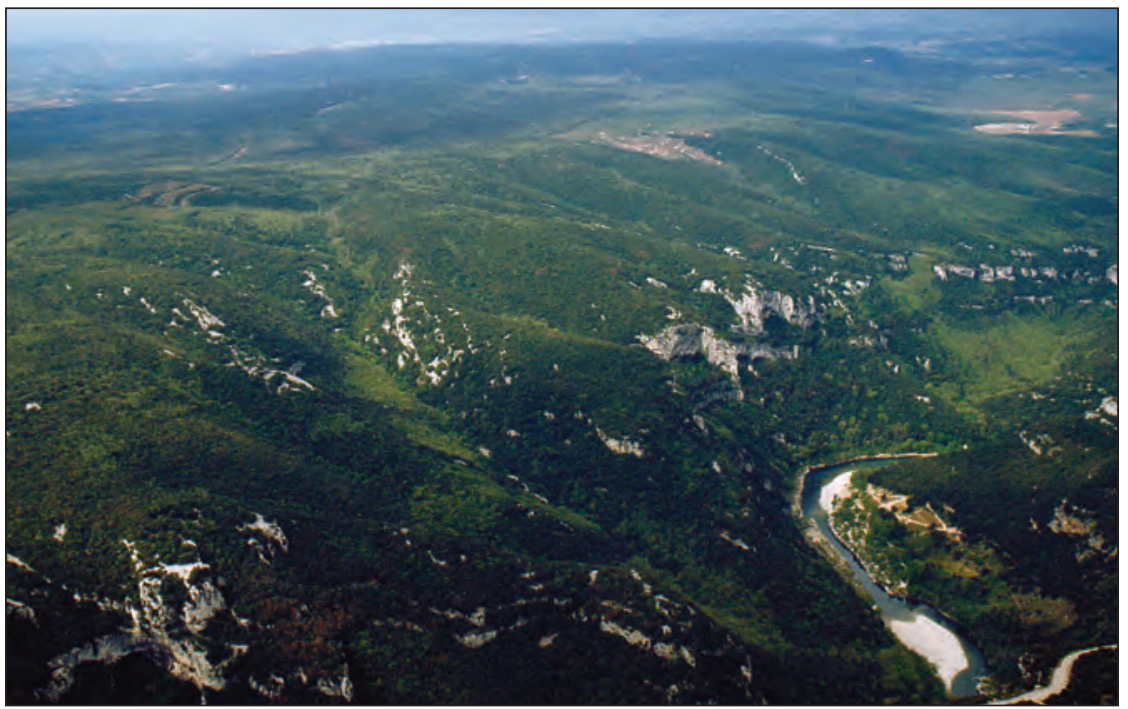

\section{Photo 8}

Bois de Ronze : vallons perchés dans le secteur de la Combe Vieille, vue vers le sud (photo Françoise Prud'homme).

de gélifracts d'épaisseur parfois plurimétrique. Par endroits, ces matériaux cryoclastiques sont cimentés en brèches, mettant ainsi en avant plusieurs générations de gélifracts. Formes héritées, ils se raccordent vers l'aval à la surface de Labastide (surface $260 \mathrm{~m}$ ) ou sont tronqués par les rebords des gorges de l'Ardèche ou par des vallons situés en contrebas.

Les vallons du flanc sud de l'anticlinal de Ronze se raccordent au bassin hydrographique de la Cèze. Différents des précédents, ils sont bien organisés et hiérarchisés et sont encore empruntés temporairement par des écoulements superficiels lors de périodes de fortes précipitations. Secs la plus grande partie $\mathrm{du}$ temps, ces vallons présentent un fonctionnement intermittent, bien que peu de traces d'écoulement y ont été repérées. Ces vallons présentent comme ceux $\mathrm{du}$ flanc nord un profil en travers en berceau. Dans leur partie aval, une épaisse couverture de matériaux cryoclastiques occupe le fond du talweg.

Témoins d'une évolution morphologique précédant la généralisation de la karstification des calcaires urgoniens, les vallons du Bois de Ronze peuvent être associés à la phase glyptogénique post-surface sommitale et anté-surface de Labastide et à l'évacuation de la couverture du Crétacé supérieur.

La présence de gélifracts à la base des versants et dans le talweg de ces vallons permet de souligner que leur morphologie aujourd'hui visible n'est pas celle contemporaine de leur mise en place et de leur fonctionnement.

\section{Des gouffres tronqués par les versants des vallons}

En dehors des lapiés qui entaillent les surfaces structurales, les seules formes karstiques visibles sur les rebords urgoniens de Ronze correspondent à des dolines peu profondes et à des avens. Si certains gouffres s'ouvrent au niveau de la surface sommitale (aven Jolivol : - $198 \mathrm{~m}$; Passe-Muraille) les autres s'ouvrent sur les flancs de l'anticlinal (ex. de l'aven

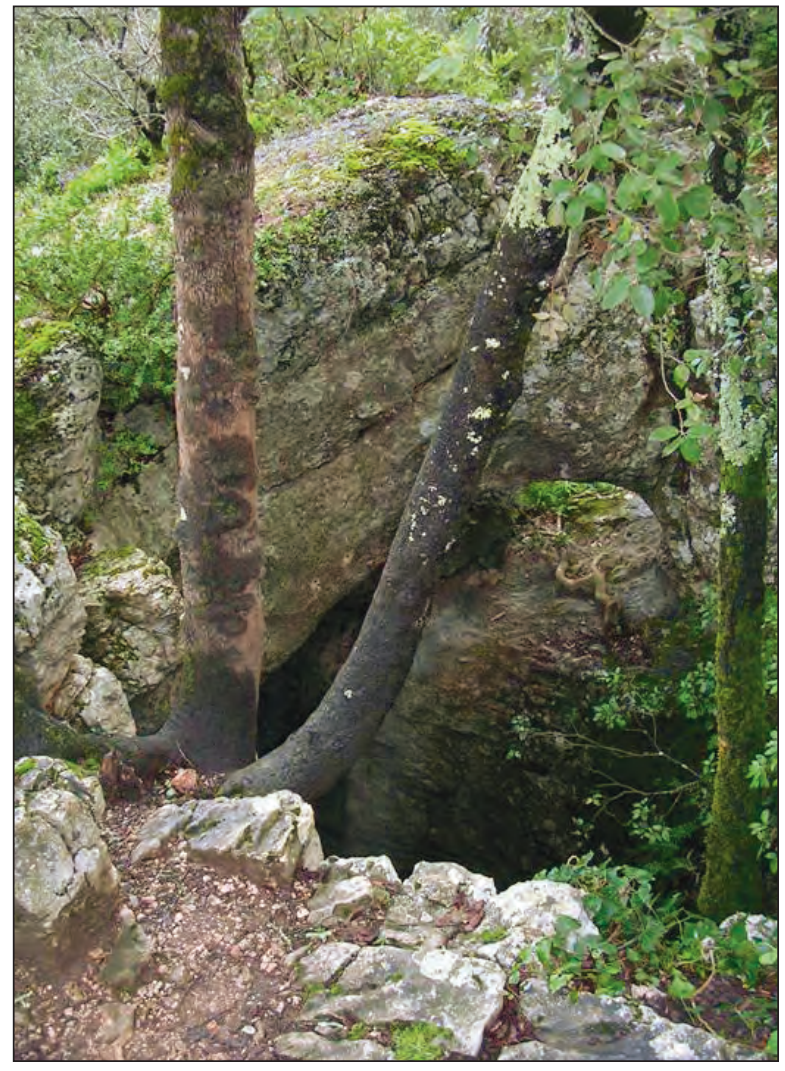




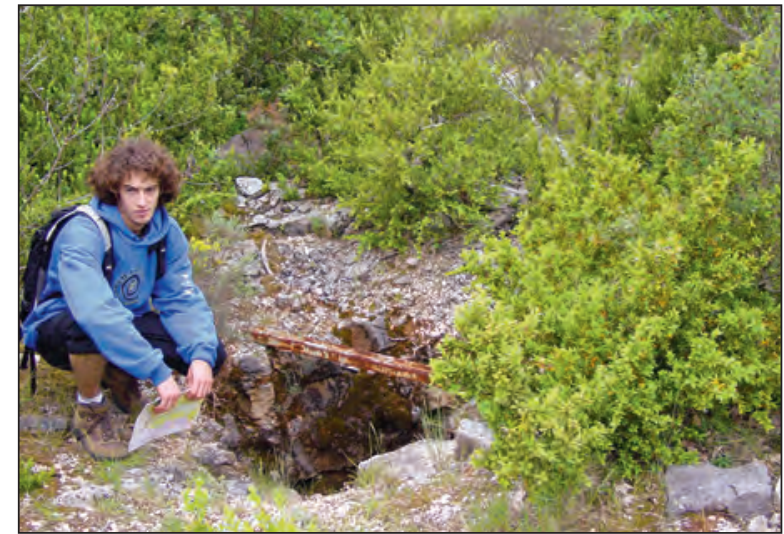

Photo 10

Entrée de puits karstique sur le sommet du Bois de Ronze (ouest de la Forestière).

des Neufs-Gorges : - $170 \mathrm{~m}$ ) (photos 9 et 10). Il est intéressant de relever qu'aucun des avens identifiés sur les flancs de l'anticlinal ne s'ouvre au fond des vallons. Cette absence peut être interprétée de deux manières : soit ces cavités sont contemporaines d'une karstification antérieure à la mise en place des vallons (dans ce cas le creusement des vallons a recoupé les cavités pré-existantes: avens); soit ces cavités sont postérieures au creusement des vallons et ont été recoupées par le recul des versants sous l'effet de la morphogénèse, dont la cryoclastie quaternaire (photo 11). La seconde hypothèse est la plus probable dans le sens où il est délicat d'envisager le creusement de vallons en présence de vides déjà ouverts par la karstification (cavités) : en présence de tels vides les eaux météoriques auraient emprunté plutôt les vides pré-existants que des vallons qu'elles devaient de plus contribuer à creuser. Dans le schéma précédent associant dégagement de la couverture crétacée, mise en place des surfaces structurales et mise en place des

\section{Photo 11}

Exemple de plancher stalagmitique trouvé en "pierre volante " au droit de la surface sommitale. Un tel dépôt à cette altitude montre que l'abaissement de la surface topographique recoupe des cavités karstiques préexistantes.

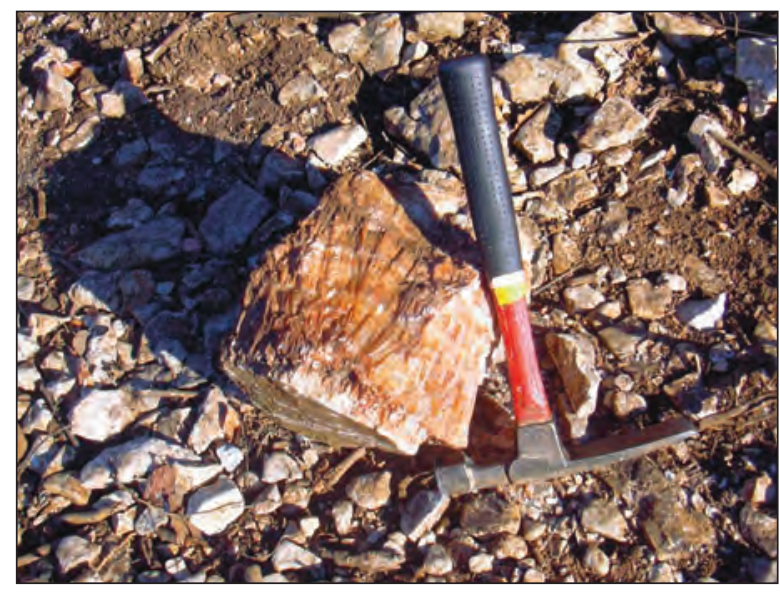

vallons, il est difficile d'envisager une karstification engendrant des cavités verticales (verticalisation) alors que le karst est encore tamponné par la couverture du Crétacé supérieur. Par contre, dès l'ouverture de «fenêtres hydrogéologiques ", la mise en place de gradient hydraulique va engendrer un basculement du drainage vers le karst.

Quelle que soit l'hypothèse retenue quant à la genèse de ces cavités (anté ou post-vallons), leur développement traduit une karstification ancienne étant donné que leur ouverture résulte de leur recoupement par la surface topographique. Ce recoupement est particulièrement visible aux abords des avens de la Vache, Jolivol, des Deux-Gorges, des Neufs-Gorges.

Vis-à-vis de cette ancienne génération de cavités, une génération plus récente d'avens a pu être relevée à proximité de la surface d'aplanissement inférieure (260 m d'altitude). Celles-ci sont vraisemblablement en lien avec l'Ardèche actuelle.

$\mathrm{Au}$ niveau du Bois de Ronze, les phénomènes exokarstiques restent discrets et ne retouchent que faiblement la surface sommitale et les surfaces structurales. Il s'agit essentiellement de formes "mineures» tant d'un point de vue morphologique que karstogénique : ce sont des lapiés et des dolines qui n'affectent pas l'allure générale du relief. Il en est de même pour les formations liées à la gélifraction contemporaine des épisodes froids quaternaires: la mince couverture de gélifracts s'apparente plus à une dégradation de tables de lapiés (clapiers). La présence de ceux-ci sur la surface du massif de Ronze met en avant l'indigence de leur prise en charge par des ruissellements superficiels même localisés.

L'ensemble des formes exokarstiques et périglaciaires n'a pu être porté sur la carte du fait du caractère extrêmement fermé de végétation rendant difficile l'accès à certains secteurs.

Les différents avens s'ouvrant au niveau de cette surface ont été, quant à eux, tous portés sur la carte.

\section{II.3 - L'aplanissement karstique de Labastide}

La dépression de Labastide se caractérise par une relative planéité qui n'est pas d'ordre structural : la surface qui se développe vers $260 \mathrm{~m}$ d'altitude recoupe les assises géologiques du Crétacésupérieur et del'Urgonien déformées en gouttière synclinale. Il est intéressant de relever que ce niveau d'aplanissement karstique coïncide avec l'altitude de la Salle Plane et une grande partie d'Orgnac IV ainsi qu'avec le développement de la Baume d'Oullins, cavité horizontale de faible développement. Il paraissait donc judicieux de s'intéresser à ce secteur et plus particulièrement à ces coïncidences altimétriques. Le secteur viticole du «Puits de Ronze » a retenu plus particulièrement notre attention du fait de sa " proximité » géographique avec les réseaux d'Orgnac. Ce secteur se caractérise par : 


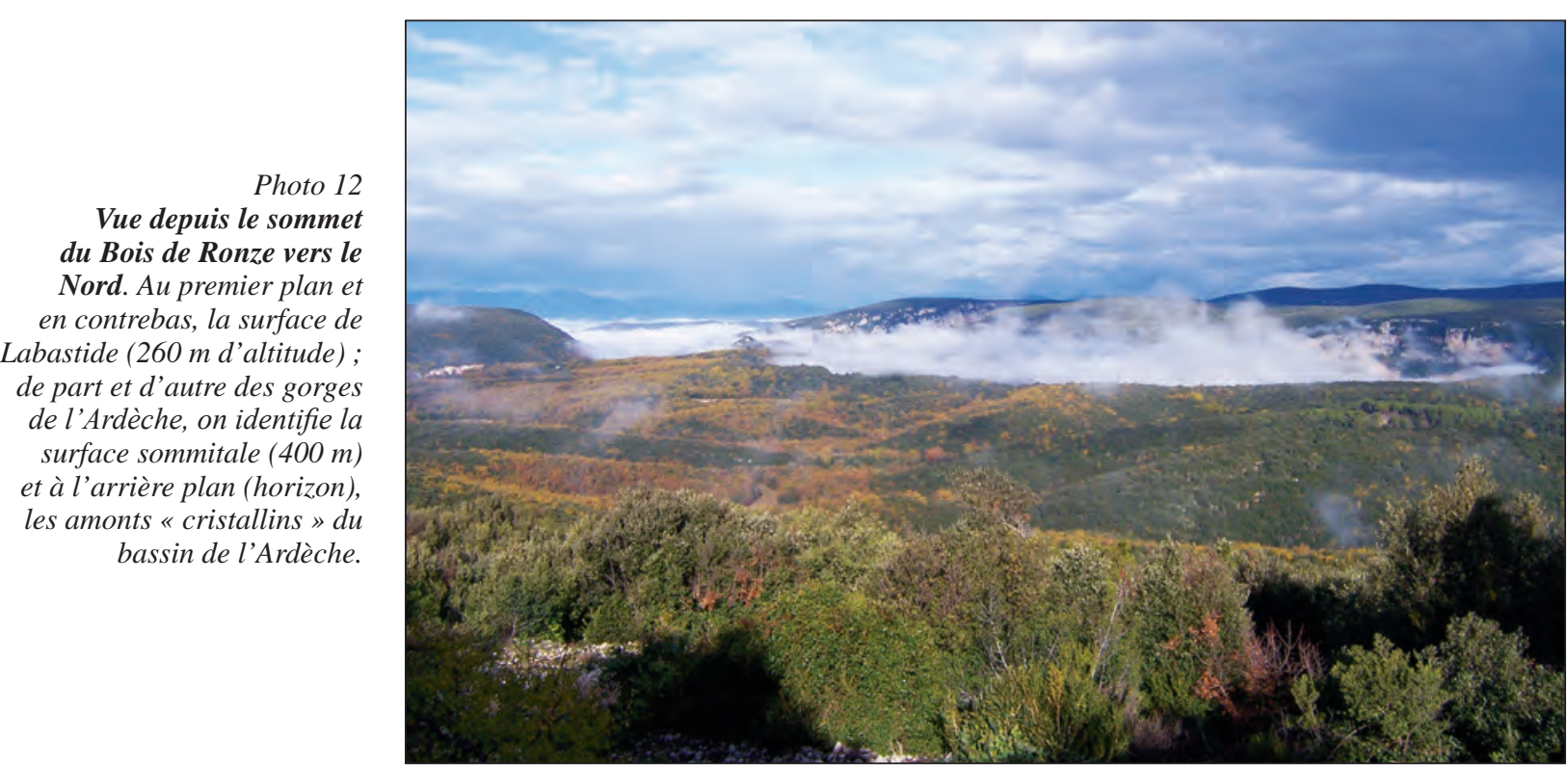

- sa localisation au pied du rebord nord de l'anticlinal du Bois de Ronze ;

- la planéité de sa surface autour de la cote $260 \mathrm{~m}$;

- son alignement (en plan) avec le réseau karstique d'Orgnac-Issirac (figure 8).

Pour appréhender les morphologies sous-jacentes, nous avons utilisé la méthode de prospection géophysique (tomographie électrique). Quatre profils parallèles ont été réalisés au cours de deux missions. Les résultats de ce travail sont présentés dans l'encadré 2 . L'objectif était de caractériser l'agencement du substrat (remplissages, roche en place, failles...) sur 10 à $20 \mathrm{~m}$ de profondeur. Cette prospection a mis en évidence des structures de faible résistivité d'orientation subméridienne, d'une largeur moyenne de 50 à $100 \mathrm{~m}$ et d'une profondeur d'une quinzaine de mètres. Vers le sud, ces structures semblent s'approfondir et les flancs qui les limitent semblent de plus en plus raides. Séparant ces deux structures allongées se développe un secteur de plus forte résistivité qui serait lié aux calcaires urgoniens (50 à $100 \mathrm{~m}$ de large), comme le suggère l'affleurement de ces calcaires vers le nord (profil 1). Sur l'ensemble des relevés, on note un dépôt d'ordre métrique de résistivité moyenne, discontinue, qui a été rattaché à des accumulations clastiques (gélifracts remaniés).

À partir de l'identification de ces quelques éléments, plusieurs interprétations géologiques et/ou géomorphologiques de ces profils peuvent être proposées (encadré 2).

Quelle que soit l'interprétation, l'hypothèse d'un fonctionnement en poljé de la dépression de Labastide est en grande partie confirmée par cette prospection géophysique qui met en avant l'existence d'un aplanissement karstique, également perceptible au contact de la dépression et des rebords urgoniens de l'anticlinal de Ronze où on relève la présence de trottoirs de corrosion latérale. De futures prospections géophysiques seront à nouveau menées dans ce secteur

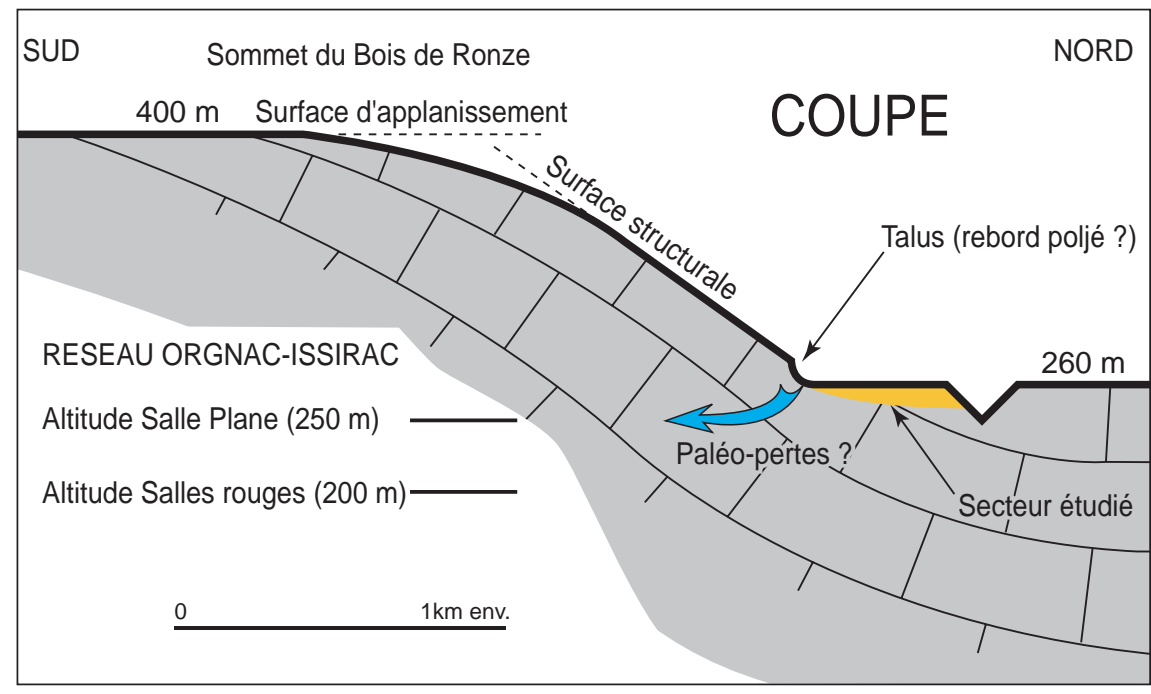

Figure 7

Coupe schématique du versant nord du Bois de Ronze et son raccordement à la surface de Labastide. Une zone de paléopertes (partielles ou totales) reste envisagée. Elle constituerait une paléo-alimentation pour le karst d'Orgnac à une époque où le réseau hydrographique se situait à une cote altitudinale de l'ordre de 250 à $260 \mathrm{~m}$. 


\section{ENCADRÉ 2}

\section{Reconnaissance du secteur du Puits de Ronze par tomographie électrique}

Quatre profils de mesure rectilignes ont été implantés, perpendiculairement aux structures recherchées avec des électrodes disposées régulièrement et espacées de 2,5 mètres. Le relief le long de ces profils a été pris en compte. La résolution a été choisie de sorte à atteindre une profondeur de l'ordre de 20 à $25 \mathrm{~m}$ sous la surface du sol tout en assurant une couverture spatiale et une résolution maximale sur l'ensemble de la section.

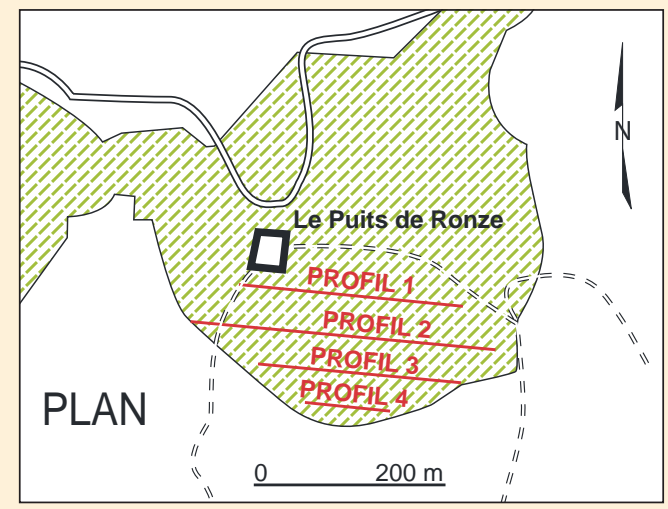

Afin de faciliter la lecture des tomographies, on distingue trois gammes de résistivités :

- les faibles résistivités (<50 $\Omega . m$ ), représentées par des teintes bleues; les terrains argileux et les terrains meubles gorgés d'eau présentent des résistivités de cet ordre ;

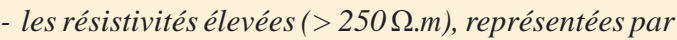
des teintes brunes, rouges ou mauves ; les calcaires compacts présentent des résistivités qui entrent dans cette catégorie ;

- Les résistivités intermédiaires, comprises entre 50 et $250 \Omega . m$, représentées par des teintes vertes à jaunes.

\section{Profil 1}

Trois tronçons sont identifiés le long du profil. Entre le début du profil et l'abscisse cumulée $55 \mathrm{~m}$, la section se caractérise par une couche de faibles résistivités (qui s'amincit vers les abscisses croissantes). Sous cette couche, on observe une seconde couche d'une quinzaine de mètres d'épaisseur où les résistivités sont plus élevées. Entre $55 \mathrm{~m}$ et $95 \mathrm{~m}$, on observe une zone où les résistivités des zones proches de la surface sont en moyenne plus élevées que sur le reste du profil. Ce second tronçon est également caractérisé par des résistivités très élevées en profondeur.

Dans la partie supérieure du troisième tronçon, soit au-delà de la cumulée $95 \mathrm{~m}$, on observe nettement une forme en lentille ou en chenal de faible résistivité dont l'épaisseur au centre atteint une dizaine de mètres. En surface, les résistivités sont plus élevées, ce qui peut être attribué à des terrains plus secs et probablement moins argileux que sur la partie supérieure du premier tronçon.

En profondeur, le tronçon débute par une zone de faibles résistivités qui contraste nettement avec le tronçon précédent. Ensuite, on retrouve des résistivités élevées comme auparavant.

La tomographie fait apparaître un décalage vertical de l'ordre de 8 à $10 \mathrm{~m}$ entre la cote du sommet de la zone à résistivité élevée du second et du troisième tronçon. La transition entre le second et le troisième tronçon pourrait être liée à la présence d'un accident (faille ?) situé vers la cumulée $100 \mathrm{~m}$. Le décalage vertical n'est pas nécessairement lié à un rejet mais pourrait aussi être associé à une fracturation et une karstification plus intense des calcaires dans le troisième tronçon.

Mise en place du dispositif (ligne et piquets) entre deux rangs de vignes, installation des électrodes et mise en place du dispositif d'enregistrement.
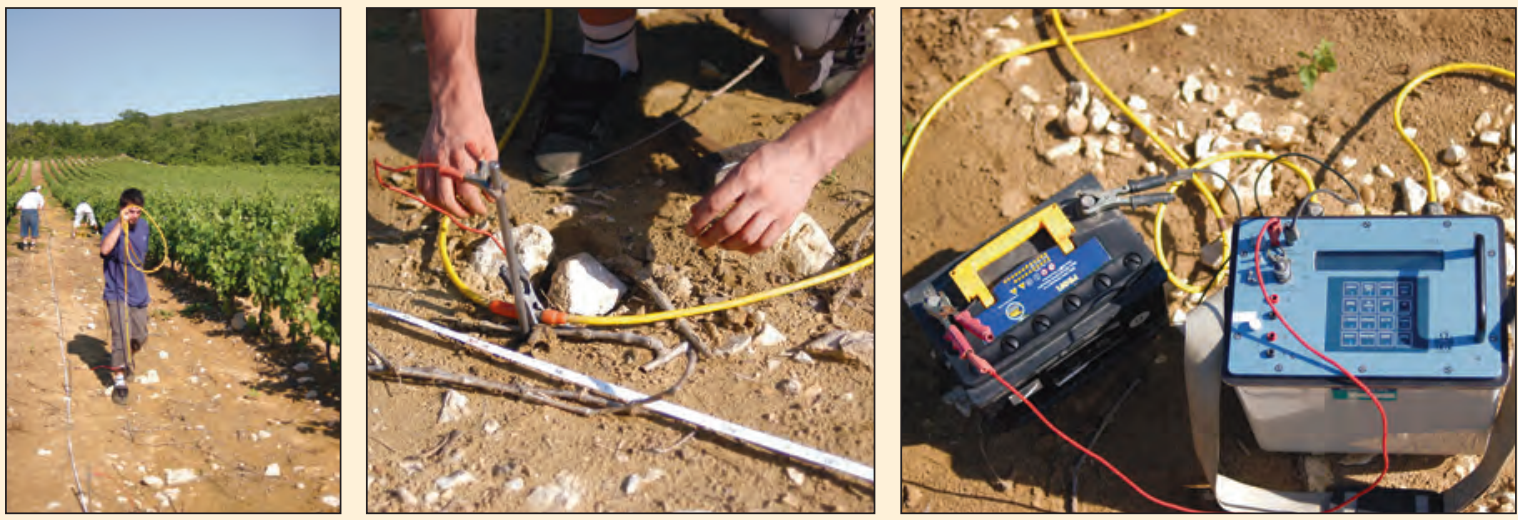


\section{ENCADRÉ 2}

\section{Reconnaissance du secteur du Puits de Ronze par tomographie électrique}

\section{Profil 2}

On retrouve sur cette section des éléments déjà visibles sur la première tomographie. On constate que comme sur la section précédente, les terrains superficiels du début du profil (cumulées de 0 à $45 \mathrm{~m}$ ) montrent des résistivités plus faibles que dans la suite du profil. On note également la présence entre les cumulées $82,5 \mathrm{~m}$ et 122,5 $\mathrm{m}$ d'une zone dont la géométrie (taille et forme) est très proche de celle observée sur le second tronçon du profil 1, même si les résistivités de la zone sont inférieures à celles observées sur la tomographie précédente. Cette tendance à la diminution des résistivités s'observe d'ailleurs dans le reste de la partie inférieure de la section à l'exception de ses deux extrémités (les résistivités très élevées qui y sont obtenues doivent être interprétées avec prudence car elles pourraient être renforcées par les effets latéraux de zones non couvertes par la section).

Au-delà de la cumulée 122,5 m, on remarque sous la couche superficielle des résistivités intermédiaires et ce sur une longueur de 80 m environ. Le sommet de cette zone se situe en moyenne vers la cote $245 \mathrm{~m}$.

Plus loin, une zone de faible résistivité d'allure verticale descend jusqu'à la base de la tomographie vers la cumulée $240 \mathrm{~m}$. Il est possible que cette zone corresponde avec la légère baisse de résistivité observable en bout de profil sur la tomographie précédente. En revanche, la correspondance avec la zone de faible résistivité en forme de lentille ou de chenal du profil 1 (ronze 0), ne semble pas aisée. En se basant sur la géométrie et les valeurs de résistivités, on pourrait la rapprocher de l'ensemble faiblement résistif qui débute vers la cumulée $160 \mathrm{~m}$ et que l'on rencontre jusqu'au bout du profil. Il faut toutefois noter qu'en bout de profil, les épaisseurs atteignent une quinzaine de mètres.

\begin{abstract}
Profil 3
Sur le profil 3, on identifie entre les abscisses 35 et 120 une vaste structure d'environ $80 \mathrm{~m}$ de large et d'une quinzaine de mètres d'épaisseur où la résistivité est faible. Les bordures de cette structure sont raides. Elle semble être le prolongement d'une structure identique identifiée sur le profil 2. Au-delà de la cote 120 et jusqu'à la cote 190, on note une zone de résistivités plus fortes. Les contacts sont assez francs et il semble raisonnable de penser qu'il s'agit là des calcaires urgoniens. Il n'est pas possible pour l'heure, de connaître la nature de ce contact (faille ?). Entre les cotes 200 et 320, on retrouve une vaste structure lenticulaire plus ou moins évasée de plus de $100 \mathrm{~m}$ de largeur et d'au moins $15 \mathrm{~m}$ de profondeur dans sa partie la plus épaisse. Là encore, cette structure constitue le prolongement logique de celle identifiée plus au nord à la faveur du profil 2 . À la cote 280 , on note une zone de forte résistivité à la base du profil. Ces résistivités très élevées doivent être interprétées avec prudence car elles pourraient être renforcées par les effets latéraux de zones non couvertes par la section.
\end{abstract}

\section{Profil 4}

Avec une longueur de $200 \mathrm{~m}$, le profil 4 est plus court. À part une zone de résistivités moyennes identifiables à la surface, on note un profil épais de résistivités très faibles sur une épaisseur d'une quinzaine de mètres minimum. Au droit de la cote 60, cette épaisseur dépasse $20 \mathrm{~m}$ au moins. Il n'y a que sur les bords du profil et entre les cotes 80 et 120 que l'on peut identifier un léger bombement de résistivités plus fortes. Ce bombement semble pouvoir être rattaché à la structure centrale à fortes résistivités identifiée dans les profils 1, 2 et 3. Cette fois, les contacts bien que francs, ne sont plus verticaux. Il convient de préciser enfin que les calcaires urgoniens affleurent en surface à peine $50 \mathrm{~m}$ plus au sud de ce profil 4 en formant un léger talus marqué dans la topographie.

\section{Sondage à la tarière sur 2 mètres pour vérifier la nature des premiers terrains traversés (ici sur profil 2).}
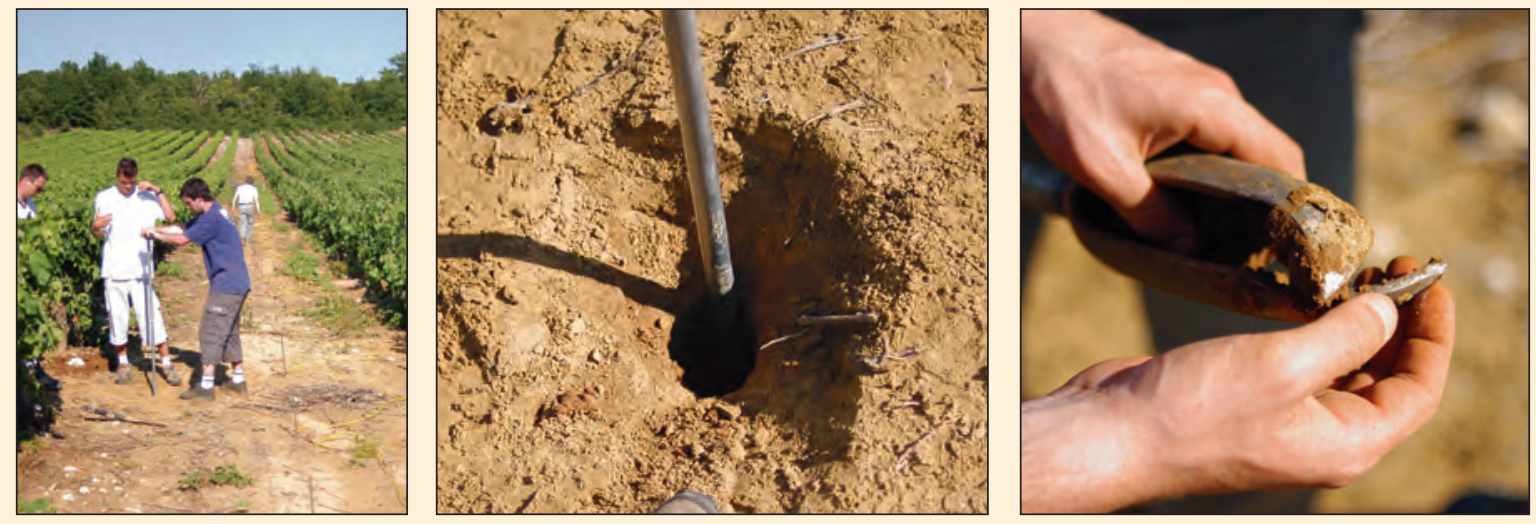


\section{ENCADRÉ 2}

\section{Reconnaissance du secteur du Puits de Ronze par tomographie électrique : interprétation}

À partir de ces éléments, il est possible d'identifier 4 types de structures géologiques et / ou géomorphologiques. Cependant en l'absence de sondages de reconnaissance, il apparait difficile pour l'heure de trancher.

(1) mise en évidence d'une structure faillée déterminant de petits grabens dans lesquels subsistent des éléments de la couverture du Crétacé supérieur (marnes et argiles). La présence de glauconie et l'affleurement $n 5 b$ militent en faveur de cette hypothèse.

(2) mise en avant d'une évolution cryptokarstique à l'origine de l'aplanissement recoupant à l'emporte pièce les petits grabens et le horst médian caractérisé par les calcaires de l'Urgonien. Il reste à définir les causes de cette nouvelle phase d'aplanissement karstique postérieure au dégagement de la couverture du Crétacé supérieur et des surfaces structurales du rebord de l'anticlinal de Ronze. La couverture de clastes rapportée à la remobilisation des gélifracts contemporains des épisodes froids quaternaires permet de rapporter cette phase d'aplanissement à un fonctionnement karstique ancien de la dépression de Labastide.

(3) Un paléoméandre comblé de dépôts alluviaux. Il s'agirait dans ce cas d'une structure unique qui épouserait l'intégralité du site du Puits de Ronze en formant une large boucle (méandre de rivière). Les éléments qui militent en faveur de cette hypothèse sont les dimensions similaires des deux structures à faibles résistivités identifiées et l'absence de "chicot central " dans le profil 4. Dans cette occurrence, cette structure centrale, calcaire, identifiée par des résistivités plus fortes constituerait le pédoncule du méandre.

(4) Une série de ponors qui drainerait un vaste poljé dont l'extension correspond aux limites de la dépression de Labastide-de-Virac à la cote $260 \mathrm{~m}$ environ. Cette fois les deux structures parallèles à faibles résistivités seraient interprétées comme des écoulements de surface se perdant plus au sud dans les calcaires urgoniens au droit de pertes (ponors). L'élément qui milite en faveur de cette hypothèse est l'approfondissement progressif du fond de ces deux structures vers le sud. Les deux structures peuvent être synchrones ou diachrones. Notons que les interprétations 3 et 4 ne sont pas antinomiques quant à l'alimentation d'un karst dans les calcaires urgoniens. En effet, l'hypothèse qui avait guidé ces travaux de prospection géoélectrique sur le site du Puits de Ronze était basée sur la recherche d'une paléo-alimentation potentiel du karst d'Orgnac-Issirac depuis la dépression de Labastide-de-Virac à 260 m NGF avec une origine des eaux pouvant être des pertes latérales à une paléoArdèche qu'au drainage d'un poljé. Les résultats issus de cette prospection géophysique militent en faveur d'une telle hypothèse sans pour autant la démontrer.
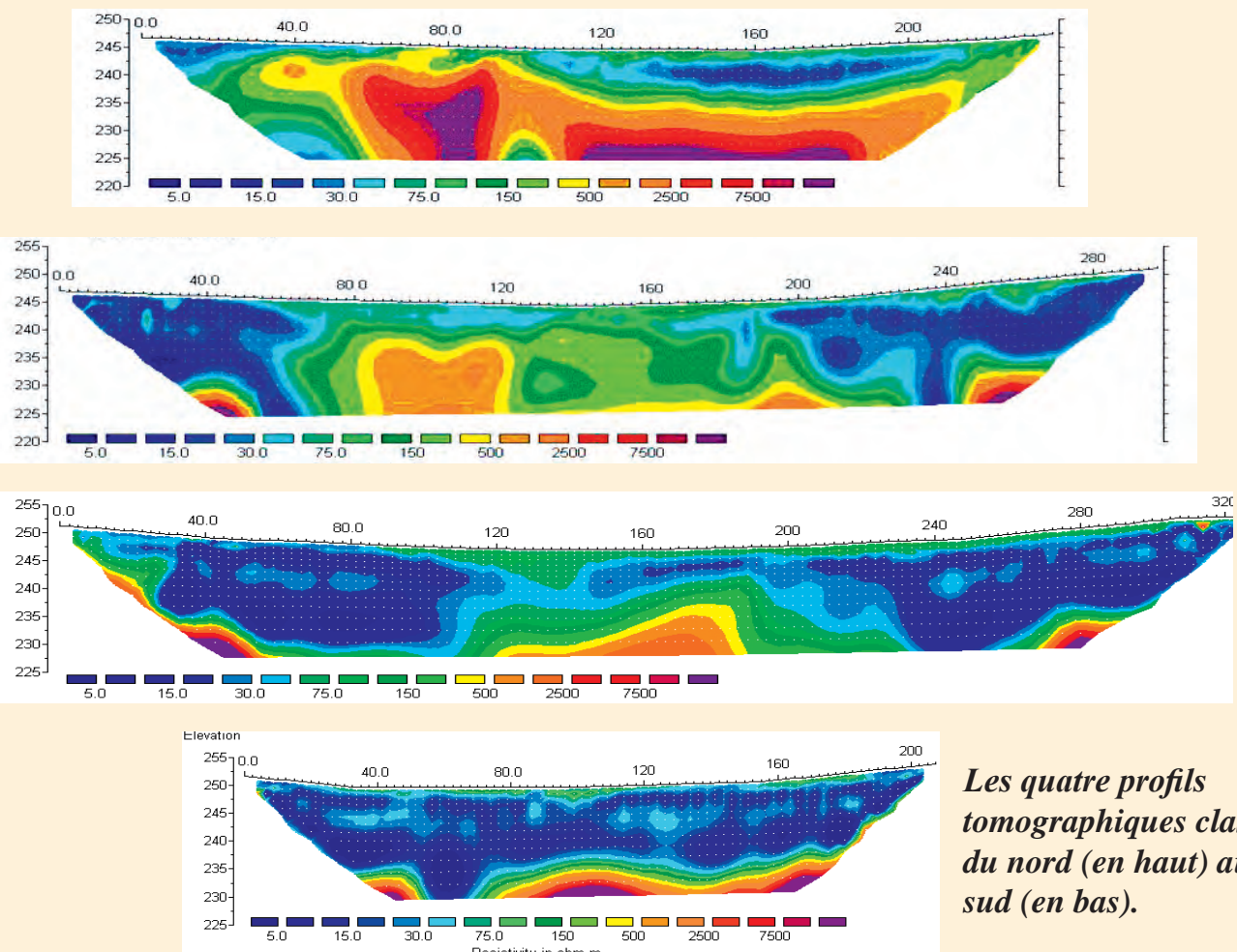

Les quatre profils tomographiques classés du nord (en haut) au sud (en bas). 
afin de mettre en évidence la présence de paléoponors ; paléo-ponors qui auraient pu contribuer à la paléo-alimentation du karst d'Orgnac-Issirac depuis la dépression de Labastide-de-Virac. Seule une série de travaux complémentaires (sondages des structures à faibles résistivités, compléments cartographiques, analyse d'échantillons) permettra d'infirmer ou de confirmer telle ou telle piste.

\section{La Baume d'Oullins : un paléo-ponor?}

À la même altitude et plus à l'est se développe la Baume d'Oullins. Cette cavité ouverte sur le flanc d'un versant de la Combe du Mas de Serret est surtout connue pour son intérêt archéologique.

Le site d'entrée est un porche majestueux. Vers le nord, il a été possible d'identifier des restes de dépôts stalagmitiques (planchers, concrétions...) en place et témoignant de l'ancienne extension de la cavité plus au nord. Celle-ci est en fait tronquée par le recul des versants, recul lié à l'incision de la Combe du Mas de Serret, associée à l'incision de l'Ardèche. D'ailleurs, depuis la surface à $260 \mathrm{~m}$, on relève l'existence de plusieurs vallons (Combe de la Farre, Combe des Champs, Combe de Régord...) qui se connectent à l'Ardèche (65 m NGF). Ils présentent des profils en travers en V. En fond de talweg, des marques d'écoulement sont présentes et bien prononcées. Ces formes témoignent d'une adaptation du réseau de drainage au niveau du canyon de l'Ardèche.

Concernant l'incision de la Combe du Mas de Serret, celle-ci a contribué au recoupement, à la fois des vallons du flanc nord de l'anticlinal de Ronze, de la baume d'Oullins et de la surface de $260 \mathrm{~m}$. Compte tenu de l'antériorité de la surface et de la Baume d'Oullins, il est tentant de rattacher cette cavité à une paléo-perte contemporaine de la mise en place de la surface d'aplanissement de $260 \mathrm{~m}$. Dans cette perspective, des recherches ont donc été conduites sur le site pour retrouver des dépôts pouvant témoigner de ce fonctionnement en perte. Plusieurs galets allochtones (parfois décimétriques) ont pu être retrouvés, mais jamais en place ; compte tenu de l'occupation de ce site, ces matériaux allochtones ont pu être amenés par les hommes de la préhistoire. Les fouilles réalisées dans la cavité à l'occasion des recherches préhistoriques n'ont livré que des gélifracts calcaires sur des épaisseurs importantes (supérieures à $2 \mathrm{~m}$ ) témoignant de l'évolution sous conditions périglaciaires du porche. Seules des investigations complémentaires (sondages ?) permettraient d'identifier de tels restes et de montrer la possibilité d'un tel fonctionnement paléo-karstique.

La carte géomorphologique du Bois de Ronze et l'analyse associée du secteur a permis de distinguer plusieurs étapes morphogéniques (figure 7) : (i) surface sommitale $(400 \mathrm{~m})$, (ii) érosion de la couverture crétacée et dégagement des surfaces structurales (rebords anticlinal de Ronze), (iii) nouvelle phase d'aplanissement karstique (surface $260 \mathrm{~m}$ ) liée au fonctionnement en poljé de la dépression de Labastide, (iv) arrêt du fonctionnement en poljé dû au creusement de vallons rejoignant une Ardèche située en contrebas du niveau $260 \mathrm{~m}$, (v) encombrement des vallons et de la dépression de Labastide par du matériel clastique lié à la gélifraction des calcaires et dégradation des lapiés. Il est intéressant de croiser ces différentes phases morphogéniques avec le canevas spéléogénique d'Orgnac élaboré à partir des formes de galeries et pariétales ainsi que des remplissages endokarstiques.

\section{III - L'AVEN D'ORGNAC : UN MARQUEUR DE LA TRANSGRESSION PLIOCÈNE ET DE L'ÉVOLUTION QUATERNAIRE}

Les reliefs, tant de surface que de profondeur, ont permis de mettre en avant plusieurs grandes étapes d'évolution dont il reste à définir les liens notamment entre le canevas spéléogénique d'Orgnac et les phases morphogéniques et événements paléogéographiques. Il s'agit à présent de confronter ces éléments afin de proposer une reconstitution paléogéographique du secteur d'Orgnac à partir des données issues des différents vecteurs d'information morphogénique dégagés dans les différents articles de ce volume. Après avoir rappelé dans un premier temps les éléments repères, un schéma d'évolution sera proposé et confronté aux données spéléogéniques.

\section{III.1 - Les surfaces repères du cycle messino-pliocène}

Dans la première partie de cet article a été posée l'influence des variations eustatiques méditerranéennes à la fin du Miocène et au Pliocène sur le réseau hydrographique rhodanien et ses principaux affluents. Le cycle messino-pliocène a laissé dans le paysage de la moyenne vallée du Rhône quatre surfaces repères qu'il convient de retrouver dans le paysage et le karst de l'interfluve Ardèche / Cèze.

Les travaux de référence de Clauzon (1982; 1996), complétés par les études récentes de Mocochain (2002, 2006 a. et b., 2007) sur le cycle messino-pliocène ont permis d'identifier quatre niveaux altitudinaux repères de ce cycle, basés sur des marqueurs chronostratigraphiques; ces niveaux sont donnés en altitude NGF actuel, c'est-à-dire tenant compte des mouvements de surrection fini- et post-pliocène.

- (1) La surface d'abandon pré-évaporitique : les cailloutis fini-miocènes de Saint-Restitut, à $312 \mathrm{~m}$ NGF (340 m reconstitués pour le toit de la nappe), constituent le niveau du Rhône avant la crise eustatique messinienne. Ce niveau repère est aujourd'hui calé à 5,95 M.a. La surface sommitale d'aplanissement de $400 \mathrm{~m}$, bien développée de part et 
d'autre des gorges de l'Ardèche, est rattachée à cette étape paléo-géographique. Les travaux de Martini (2005) ont montré l'existence d'un paléo-niveau de karstification horizontal inscrit dans cette surface. Cette surface est incisée vers $330 \mathrm{~m}$ par une surface intermédiaire, précédant la crise messinienne. Elle n'a pas été identifiée sur l'interfluve Ardèche / Cèze.

- (2) La surface d'érosion messinienne : le sondage de Pierrelatte a atteint le substratum mésozoïque à -236 m NGF. Il témoigne d'une incision de $580 \mathrm{~m}$ du Rhône par rapport à la situation précédente au droit de sa confluence avec l'Ardèche. Vers le sud, le Rhône messinien se situe vers -600 m NGF comme l'indiquent les profils sismiques réalisés dans le secteur de Bagnols-sur-Cèze. La surface de régression messinienne est aboutie à 5,3 M.a.

\section{- (3) La surface de transition marin / continental} (fore sets / top sets) marque la limite supérieure de la transgression pliocène (Clauzon et al., 1997 ; Blanc, 2002) ; celle-ci se situe vers 130 m NGF (Mocochain, 2002, 2006). Cette cote marque la limite altitudinale des dépôts marins progradants et des dépôts continentaux agradants. C'est le niveau du rivage pliocène, compliqué aujourd'hui par la surrection plio-quaternaire qui n'est pas homogène sur l'ensemble de la région étudiée. D'un point de vue temporel, la limite des dépôts marins et des dépôts continentaux est diachrone.

- (4) La surface d'abandon fini-pliocène correspond à la fin de l'aggradation continentale pliocène, il y a 2 M.a. C'est le toit de la formation continentale (top-sets) des dépôts alluviaux du Rhône et de ses affluents. On la rencontre vers 190 / 200 m NGF dans la moyenne vallée du Rhône (Mocochain, 2006). Cette surface remonte dès lors qu'on se dirige vers les amonts des affluents du Rhône : ici de la Cèze et de l'Ardèche.

- La topographie actuelle résulte de cette évolution et de la morphogenèse fini-pliocène et quaternaire ; celle-ci se traduit principalement par l'incision du réseau hydrographique liée à l'effet combiné de l'abaissement eustatique et du relèvement tectonique du secteur d'étude. Pour repère, l'actuelle plaine du Rhône se situe à $50 \mathrm{~m}$ NGF à Saint-Martin-d'Ardèche et à $32 \mathrm{~m} \mathrm{NGF}$ à Bagnols-sur-Cèze, soit plus de $150 \mathrm{~m}$ en contrebas de la surface d'abandon fini-pliocène.

Ces quatre "surfaces-repères » sont calées chronologiquement depuis le Tortonien. Elles sont toutes individuellement synchrones sauf la transition marin / continental qui est diachrone et se développe dans la vallée du Rhône entre 5.3 et 2 M.a.

À partir de ces niveaux repères ont été calées les différentes étapes morphogéniques mises en évidence par l'étude spéléogénique de l'aven d'Orgnac et par l'analyse géomorphologique de l'anticlinal de
Ronze. Ce calage est dans l'état actuel d'ordre relatif en l'absence de datations chronologiques; ce calage est essentiellement basé sur l'évolution du niveau de base régional (Rhône) qui a favorisé ou contrarié la glyptogenèse régionale selon ses abaissements (Messinien ; Plio-quaternaire) ou relèvement (Pliocène).

\section{III.2 - Reconstitution paléogéographique}

Nous proposons ici une reconstitution simplifiée en quatre grandes étapes. Chacune de ces étapes constitue le terme d'une évolution du relief et trouve son expression dans le paysage par la mise en place d'une « surface-repère ». L'objectif est donc ici de raccorder chacun de ces «niveaux de référence » à l'évolution du Bois de Ronze et du réseau souterrain d'Orgnac dont le niveau de lecture peut, sur certaines périodes, être beaucoup plus fin.

-1- Comme cela a déjà été précisé dans l'item précédent, c'est au cours du Miocène que se développe la vaste surface d'aplanissement qu'on rencontre dans le paysage du Bas-Vivarais vers $400 \mathrm{~m}$ d'altitude. La mise en place de cette surface est rattachée dans la littérature à l'Aquitanien (20 à 23 M.a). Cette surface se raccorde à la surface d'abandon pré-évaporitique (Clauzon, 1982). Cette surface d'aplanissement s'est agencée dans un contexte de faible énergie gravitaire favorable à la dissolution et l'altération des roches affleurantes, voire leur fantômisation (Delannoy, 1997 ; 2003 ; Quinif, 2000) ; la présence de galets allochtones au sommet du Bois de Ronze et du Saleyron témoigne de la présence de cours d'eau descendant des Cévennes et rejoignant le fossé rhodanien. Ils sont les témoins du passage d'une paléoArdèche / Chassezac dans le secteur, à cette altitude.

Dans ces conditions, la karstification se réalise essentiellement à proximité de la surface et en lien avec les faibles incisions hydrographiques traversant les plateaux urgoniens et avec le fossé rhodanien; le faible gradient hydraulique ainsi que la présence de la couverture du Crétacé supérieur ont contrarié toute karstification profonde des assises urgoniennes. En rive gauche des gorges de l'Ardèche, les travaux de Martini (2005) et Mocochain (2006) ont montré qu'une seconde surface (vers $330 \mathrm{~m}$ ) est emboitée dans cette surface sommitale. L'ensemble précède la crise de salinité messinienne.

-2- Au Messinien, l'important abaissement du niveau de la Méditerranée entraîne le surcreusement des grands fleuves et de leurs principaux affluents. Le Rhône et la Cèze vont ainsi atteindre la côte de $-600 \mathrm{~m}$ NGF au droit de Bagnols-sur-Cèze ce qui correspond à un abaissement du réseau hydrographique de plus de $900 \mathrm{~m}$ en quelque 650000 ans.

Les travaux de prospections géologiques, en particulier les profils sismiques, réalisés par l'ANDRA sur les 


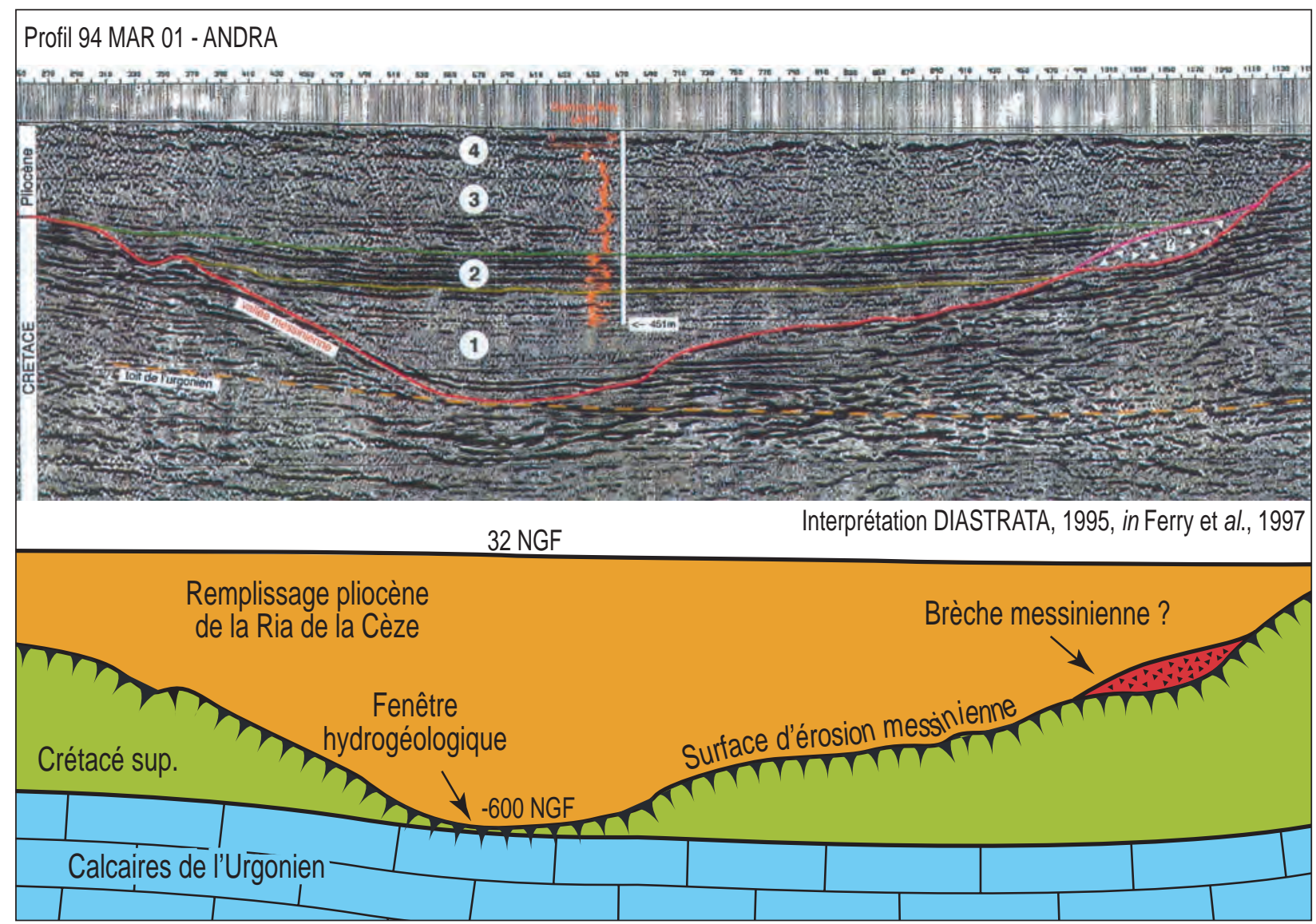

Figure 8

Profil sismique 94 MAR 01 de la vallée pliocène de la Cèze à la confluence avec le Rhône (extrait Ferry et al., 1997) et coupe géologique simplifiée associée. Notez la surface d'érosion messinienne et l'incision de la Cèze juqu'aux calcaires urgoniens à -600 m NGF. Cela signifie qu'à ce moment-là, il existe une possibilité de vidange (et donc de karstification) de l'aquifère des calcaires urgoniens grâce à l'ouverture de cette fenêtre hydrogéologique. Cette fenêtre a été ensuite refermée (tout au moins dans la partie profonde) par la sédimentation des argiles marines pliocènes.

argiles pliocènes de la vallée de la Cèze ont permis de reconstituer avec précision la topographie de cette vallée au droit de sa confluence avec le Rhône (Ferry et al., 1997) (figure 8). On constate que l'importante incision messinienne de la Cèze s'est effectuée dans les assises du Crétacé supérieur composées de matériaux tendres aisément évacuables. L'incision atteint le toit urgonien et ouvre ainsi une "fenêtre hydrogéologique ». Une telle ouverture dans des matériaux de couverture libère l'aquifère jusqu'alors captif des calcaires (Jaillet, 2004, 2005). Ces données sont essentielles à la morphogenèse du secteur d'Orgnac; ; en effet, l'existence d'un important gradient hydraulique combinée à l'ouverture d'une fenêtre hydrologique favorise le développement de structures de drainage karstique profond. Ces structures de drainage karstique entrainent une verticalisation du karst dont le terme aval se situe vers la côte de $-600 \mathrm{~m}$ NGF dans la vallée aval de la Cèze. La région étudiée se situant sur l'interfluve entre l'Ardèche et la Cèze a pu être affectée par une telle dynamique karstique. Dans cette hypothèse, les points d'entrée dans le karst s'ouvrent vers $400 \mathrm{~m}$ (NGF) au sommet de l'anticlinal de Ronze et le (ou les) point(s) de sortie se situe(nt) dans le talweg messinien de la Cèze (-600 m NGF) : c'est un gradient de l'ordre de $1000 \mathrm{~m}$ de dénivelé pour une distance de $25 \mathrm{~km}$ qui marque alors la karstogenèse. Un tel gradient hydraulique est compatible avec la mise en place d'un karst important, verticalisé, vadose à transit hydrologique rapide (figure 9).

C'est également durant cet épisode messinien favorable à une importante glyptogenèse que nous rattachons le dégagement progressif de la couverture du Crétacé supérieur conservée dans les dépressions structurales (ex. du synclinal de Labastide; dépression de St-Remèze...). Ce dégagement a pour effet de mettre au jour le toit urgonien jusque-là préservé de l'érosion (aplanissement): la surface structurale supérieure identifiée sur les flancs de l'anticlinal de Ronze relève de cette dynamique. Il peut en être de même de certaines cavités verticales aujourd'hui recoupées par les vallons et/ou les surfaces structurales emboîtées.

-3- Le karst mis en place durant l'épisode messinien n'a pu être identifié avec certitude du fait notamment de la transgression pliocène qui a obturé nombre de conduits profonds. En effet, la remontée eustatique 
Figure 9

Répartition de la genèse des principaux ensembles morphologiques de l'interfluve Ardèche / Cèze au cours du Néogène.

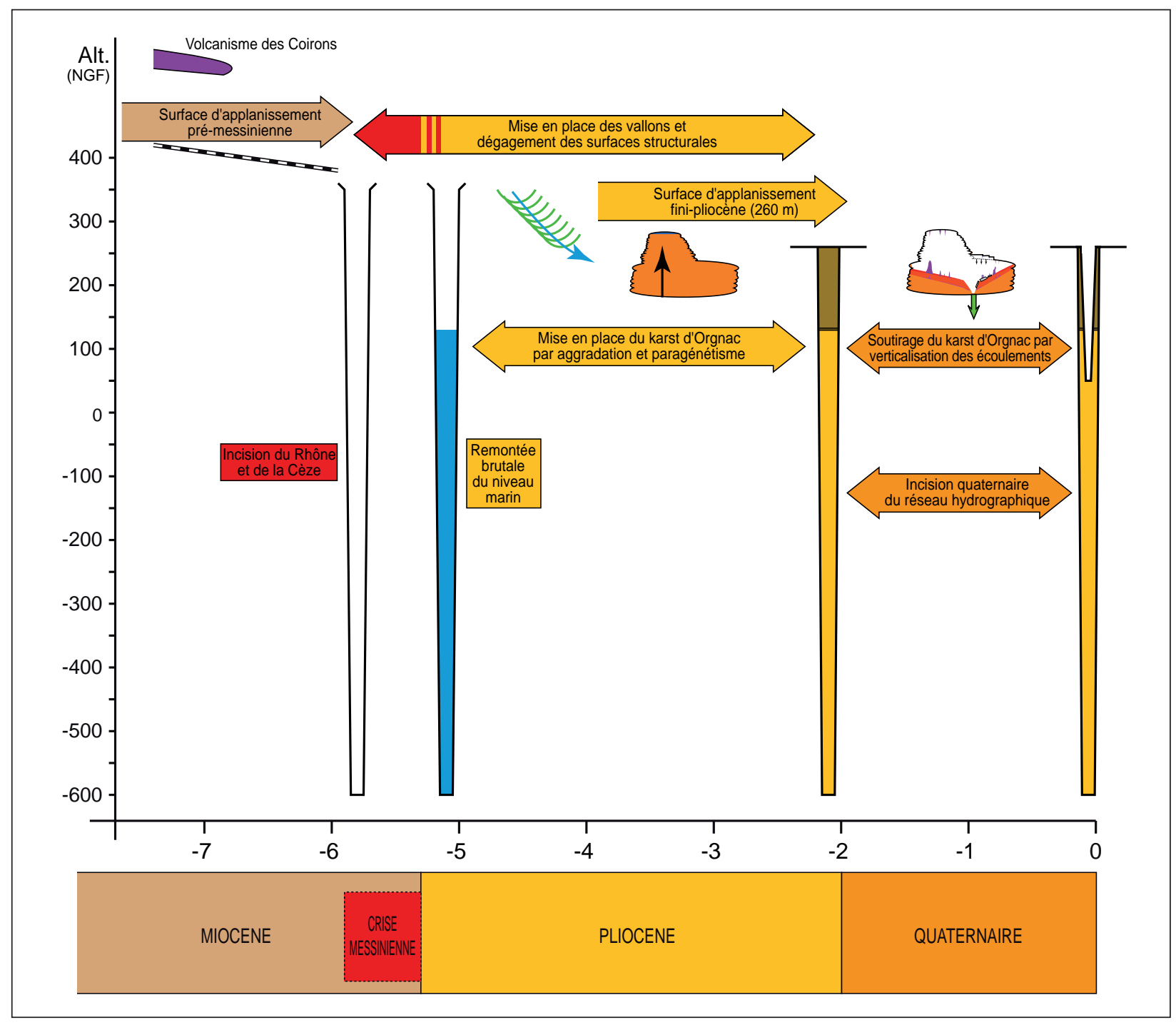

pliocène, en transformant en rias les fleuves méditerranéens et ses affluents directs, a favorisé une importante sédimentation marine et continentale à l'origine de leur comblement. L'ennoiement des drains profonds du karst et le colmatage des rias (fermeture des « fenêtres hydrogéologiques ») va conduire à une restructuration du drainage karstique qui va se caler sur la position du nouveau niveau de base : $130 \mathrm{~m}$ NGF. La paléo-structure karstique (contemporaine de l'épisode messinien) est abandonnée du moins dans sa partie profonde $(<130 \mathrm{~m})$ et soumise à un colmatage progressif par décantation des particules fines. En ce qui concerne la nouvelle structuration karstique adaptée à la remontée du niveau de base pliocène, il est vraisemblable qu'elle ait repris des conduits préexistants ; certains de ceux-ci creusés en régime vadose durant la phase de karstification messinienne ont pu localement évoluer en drain noyé de la structuration karstique pliocène (Delannoy et al., 2004).
Le comblement des rias par aggradation continentale provoque une élévation continue de ce niveau de base jusqu'à la cote de $200 \mathrm{~m}$ dans la vallée du Rhône et $260 \mathrm{~m}$ dans les parties amonts des vallées de rive droite. C'est à cette phase d'aggradation continentale que nous rattachons les morphogenèses suivantes :

- la réalisation de l'aplanissement qui caractérise le fond de la dépression de Labastide (260 m). L'atténuation du gradient hydraulique liée à la remontée eustatique et au comblement continental des rias est favorable à la réalisation d'aplanissement karstique et au fonctionnement en poljé des dépressions structurales en grande partie évidée de la couverture du Crétacé supérieur. L'aplanissement de la structure faillée mise en avant par la prospection géophysique du secteur viticole du «Puits de Ronze» (encadré 2) et la mise en évidence de trottoirs de dissolution tronquant la base des flancs urgoniens de l'anticlinal de Ronze mettent en avant le fonctionnement en 
poljé de cette dépression. Ce même site ainsi que le développement sub-horizontal de la Baume d'Oullins tendent à suggérer la présence de paléo-ponors dans ce secteur de la dépression de Labastide ; ces paléoponors se raccordant à la structure de drainage endokarstique «pliocène ». La remontée du niveau de base engendrée par l'aggradation continentale a sans aucun doute engendré des dysfonctionnements du drainage karstique: l'engorgement des ponors, l'inondation du poljé de Labastide et la réalisation de l'aplanissement karstique répondent à cette même logique de dysfonctionnement endokarstique ;

- ce dysfonctionnement endokarstique peut être également responsable de l'évolution paragénétique des réseaux d'Orgnac (chapitre 3) sur laquelle nous reviendrons ensuite. La remontée eustatique ainsi que l'élévation progressive du niveau de base consécutive de l'aggradation continentale ont entrainé une évolution en régime noyé des conduits karstiques pré-existants et contemporains de la réorganisation endokarstique pliocène. La mise en évidence de formes pariétales caractéristiques d'un fonctionnement paragénétique ainsi que d'un important remplissage argileux ont conduit à distinguer une longue évolution en régime noyé des réseaux d'Orgnac ; cette longue évolution est cohérente avec la durée de la morphogénèse pliocène.

Cette situation est aboutie à la fin du Pliocène, c'està-dire il y a 2 M.a. Alors que 650000 ans auront suffi à inciser profondément le Rhône et ses affluents et à mettre en place une karstification profonde, 3,3 millions d'années sont nécessaires au comblement des rias, au réajustement des niveaux karstiques, à la mise en place de nouvelles structures de drainage endokarstique contrariées par l'élévation du niveau de base hydrographique (aggradation continentale) et la fermeture des «fenêtres hydrogéologiques » ainsi qu'au façonnement de l'aplanissement de Labastide (260 m) (figure 10).

-4- La fin du Pliocène et le Quaternaire se caractérisent par un nouvel abaissement du niveau de base. La surrection alpine et l'abaissement du niveau marin vont conduire à une réincision des réseaux hydrographiques. Le Rhône atteint aujourd'hui les côtes respectives de $50 \mathrm{~m}$ et $32 \mathrm{~m} \mathrm{NGF}$ au droit de ses confluences avec l'Ardèche et la Cèze et c'est en fonction de ce nouveau niveau de base que les formes vont se réajuster. En surface, les aplanissements réalisés durant la morphogenèse «pliocène » prennent fin du fait de l'accroissement du gradient hydraulique; celui-ci va favoriser la mise en place de nouvelles structures de drainage endokarstique (pouvant localement reprendre les paléo-conduits messiniens) et une nouvelle étape de verticalisation karstique. Cette verticalisation marque l'arrêt du fonctionnement en poljé des dépressions structurales. Celles-ci sont progressivement perchées et recoupées par des vallons se raccordant au nouveau talweg des vallées quaternaires de la Cèze et de l'Ardèche.

C'est à cette phase de restructuration du drainage endokarstique et de verticalisation karstique que nous rattachons l'arrêt du fonctionnement paragénétique des réseaux d'Orgnac ainsi que la mise en place progressive des soutirages. Ces soutirages constituent les « moteurs 》 de l'évacuation du matériel accumulé dans l'endokarst au cours du Pliocène et du dégagement des gros volumes souterrains d'Orgnac. Certains de ces volumes (comme la Salle de Joly) ont connu des réajustements mécaniques (effondrements de pans de parois) à l'origine de sa morphologie chaotique en partie masquée par le concrétionnement. La datation et l'étude fine de certains édifices stalagmitiques de cette salle ont permis de préciser deux événements: (i) l'effondrement du plafond est ancien (antérieur à plusieurs générations de concrétions >450000 BP); (ii) cette salle a été ennoyée à plusieurs reprises (piégeage d'argiles dans les concrétions ; chapitre 4). Cet ennoiement peut être lié à deux causes ayant pu, durant une certain moment, combiner leurs effets : (i) phase d'expectance hydrogéologique contemporaine des prémices de la nouvelle structure de drainage endokarstique; (ii) événements météorologiques exceptionnels. L'étude morphologique des salles d'Orgnac et de leurs remplissages a mis en évidence qu'elles sont toujours le siège d'ennoiements temporaires engendrés par des conditions météorologiques particulières ; cet ennoiement est également lié à la relative proximité du toit de la surface noyée du karst (cf. travaux de Mangin et de Bourges).

Cette histoire plus récente d'Orgnac (soutirage, effondrements, concrétionnement, ennoiement temporaire...) est à l'origine de la richesse et de la variété des paysages souterrains de cette cavité. Cette évolution a également pour effet de rendre plus difficile la lecture des formes « originelles » du système karstique d'Orgnac. C'est pourquoi nous avons insisté dans ce volume sur les formes pariétales des conduits d'Orgnac, témoins de leur fonctionnement paragénétique.

\section{III.3 - Le paragénétisme à Orgnac : un fonctionnement lié à l'aggradation pliocène}

$\mathrm{Au}$ terme de cet article, nous souhaitons insister à nouveau sur le fonctionnement paragénétique des réseaux d'Orgnac, révélé par la présence de morphologies pariétales caractéristiques (banquetteslimites) et d'un important remplissage argileux (chapitre 3).

Cette évolution paragénétique est à présent replacée dans son contexte paléogéographique régional et il a été possible de montrer que c'est au cours du Pliocène, pendant 3,3 millions d'années, pendant 
Figure 10

Reconstitution paléogéographique simplifiée (quatre étapes) de la mise en place du karst de l'interfluve Ardèche / Cèze associée aux variations eustatiques de la Cèze au cours du Néogène.

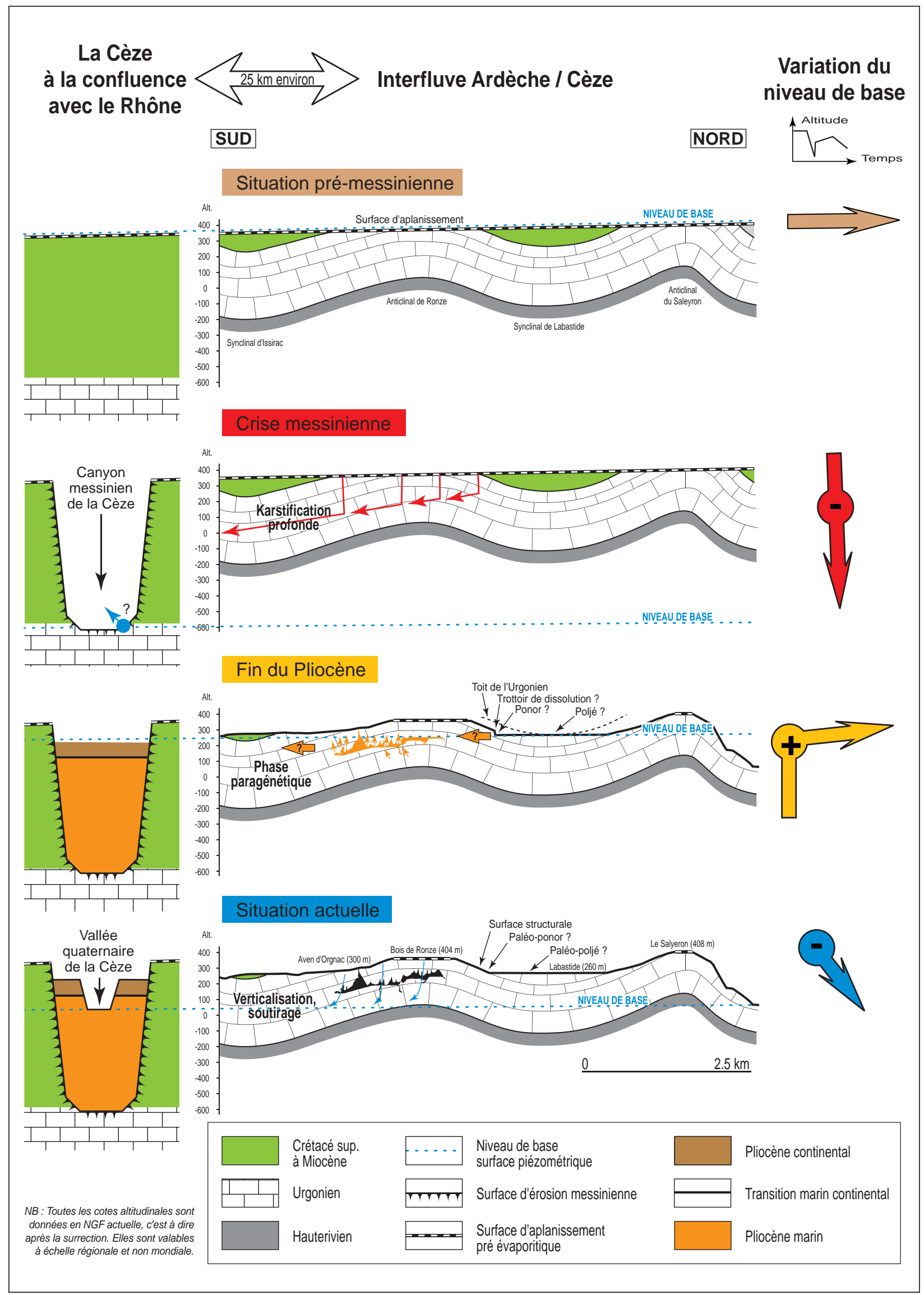


l'alluvionnement des affluents du Rhône (en particulier la Cèze), que les conditions favorables à ce fonctionnement ont été réunies : relèvement du niveau de base karstique; dysfonctionnement du drainage lié au comblement des rias et vallées affluentes et à l'aggradation continentale...

Cette évolution endokarstique a été mise en évidence grâce à la reconnaissance de formes pariétales particulièrement éloquentes à Orgnac : notamment les banquettes-limites de remplissage. On a vu combien ces formes étaient bien représentées dans l'ensemble des réseaux soit sous forme de micro-banquettes dans les réseaux mineurs profonds (réseau de la Boue...), soit sous forme de méga-banquettes (Salles Rouges...). Point commun à toutes ces formes, leur étagement continu du bas vers le haut. Il serait intéressant de voir si on peut utiliser cet étagement aggradant sous forme de « séquences sédimentaires » et rapporter ces différentes « séquences » aux variations de conditions

\section{Bibliographie}

Audra P., Mocochain L., Camus H, Gilli É., Clauzon G., Bigot J.-Y. (2004) - The effect of the Messinian Deep Stage on karst development around the Mediterranean Sea. Examples from Southern France. Geodinamica Acta 17/6, 2004, 27-38.

BALAZUC J. (1986) - Spéléologie du département de l'Ardèche. Éd. de la Bouquinerie ardéchoise, 1985, 189 p.

Baudoin B., Accarie H., Berger E., Brulhet J., Cojan I., Haccard D., Mercier D., Mouroux B. et Clauzon G. (1997) - Caractérisation de la crise messinienne et de la réinondation pliocène. Poster GG10. Atlas des Posters Bagnols-sur-Cèze, 20-21.

Baumard B. (2001) - Valorisation de données pour l'étude de la crise messinenne dans le Gard rhodanien et la moitié Est de la France. Thèse École des Mines de Paris, $269 \mathrm{p}$.

Belleville L. (1985) - Hydrologie karstique : géométrie, fonction-nement et karstogenèse des systèmes karstiques des gorges de l'Ardèche. Thèse doctorat, Institut Dolomieu, Grenoble, 1985, 228 p.

Blanc P.-L. (2002) - The opening of the Plio-Quaternary Gibraltar Strait: assessing the size of a cataclysm. Geodinamica Acta n¹5, 2002, 303-317.

Bois J.-J., Damiani L., Vogt J., Masse J.-P., Triat J.-M., Truc G., Humbert S., Philip J. et Tronchetti G. (1980) - Carte géologique de la France, feuille Pont-Saint-Esprit, 913, Orléans, BRGM.

Bois J.-J., Damiani L., Vogt J., Masse J.-P., Triat J.-M., Truc G., Humbert S., Philip J. et Tronchetti G. (1980) - Notice de la carte géologique de la France, feuille PontSaint-Esprit, 913, Orléans, BRGM, 36 p. environnementales au cours du Pliocène. Compte tenu des modalités de mise en place des banquetteslimites de remplissage (contrôle amont par les eaux d'infiltration et contrôle aval par l'altitude de l'exutoire du système karstique), ces variations pourraient être ici de deux ordres :

- soit des variations du niveau de base, ici de la Cèze et donc du réseau hydrographique rhodanien (aggradation continentale);

- soit des variations climatiques influençant les quantités d'eau entrant dans le système.

Calées dans le Pliocène rhodanien, ces banquetteslimites de remplissage constitueraient dans cette occurrence une paléo-chronique de l'évolution régionale et leur lecture fine renseignerait en détail sur ces évolutions. Il resterait à combler la part d'incertitude qui subsiste dans la fenêtre temporelle car une grande partie de la chronique, enfouie sous les sédiments, fait encore défaut.

Bourges F. et Jacquin F. (non daté) - Détermination des plans de drainage principaux du réseau karstique de la région d'Orgnac et des gorges de l'Ardèche à partir de l'analyse microtectonique. Rapport, $15 \mathrm{p}$.

Clauzon G. (1982) - Le canyon messinnien du Rhône : une preuve décisive du "Dessiccated deep-basin model» [Hsu, Cita, Ryan, 1973]. Bull. de la Soc. Géol. de France, t. $24, \mathrm{n}^{\circ} 3,1982,597-610$.

Clauzon G. (1996) - Limites de séquences et évolution géodynamique. Géomorphologie, n¹, 1996, 3-22.

Debard É. (1988) - Le Quaternaire du Bas-Vivarais d'après l'étude des remplissages d'avens, de porches de grottes et d'abris sous-roche. Thèse, Documents du Laboratoire de géologie de Lyon, ${ }^{\circ} 103,1988,317$ p.

Delannoy J.-J. (1997) - Recherches géomorphologiques sur les massifs karstiques du Vercors et de la Transversale de Ronda (Andalousie). Les apports morphogéniques du karst. Thèse d'État, Grenoble, Septentrion, 678 p.

Delannoy J.-J., Perrette Y., Debard É., Ferrier C., Kervazo B., Perroux A.-S., Jaillet S. et Quinif Y. (2004) - Interêt de l'approche morphogénique pour la compréhension globale d'une grotte à haute valeur patrimoniale; La grotte Chauvet (Ardèche-France). Karstologia, ${ }^{\circ} 44,2004,25-42$.

Drouin Ph. et Marchand T. (1989) - Spéléo sportive en Ardèche. Édisud, 108 p.

Ferry S., Ballesio R. et Monier P. (1997) - Modalités du remplissage sédimentaire de la ria pliocène du Rhône. Problèmes en suspens après les premiers travaux ANDRA. Poster GG11. Atlas des Posters Bagnols-surCèze, 22-23. 
Gautier F., Clauzon G., Suc J.-P., Cravatte J., Violanti D. (1996) - Âge et durée de la crise de salinité messinienne. C.R. Academie des Sciences, Paris, II, t.318, 1996, 1103-1109.

Gombert Ph. (1988) - Hydrogéologie et karstogenèse du BasVivarais calcaire (Ardèche, France). Thèse, Université des sciences et techniques du Languedoc, Montpellier, $1988,483 \mathrm{p}$.

Haq B.-U., Hardenbol J. et Vail P. (1987) - Chronology of fluctuating sea levels since the Triassic (250 million years ago to present). Science 235, 1987, 1156-1167.

Labrousse (1977) - Altération des terrasses anciennes de l'Ardèche. Thèse Géologie, Marseille, 134 p.

Mangin A. (1975) - Contribution à l'étude hydrodynamique des aquifères karstiques. Thèse, Annales de Spéléologie, 1975 , t.29, fasc. 3 et 4 , t.30, fasc. 1 .

Mergoil J., Boivin P., avec la collaboration de Blès J.-L., Cantagrel J.-M. et Turland T. (1993) - Le Velay. Son volcanisme et les formations associées. Notice de la carte à 1/100 000. Géologie de la France, 3, 1993, 3-96.

Mocochain L. (2002) - Utilisation de marqueurs chronostratigraphiques miocènes et pliocènes pour l'étude karstologique et hydrogéologique du Bas-Vivarais (Ardèche, France). Mémoire de DEA, Université de Provence, $42 \mathrm{p}$.

Mocochain L., Clauzon G. et Bigot J.-Y (2006a) - Réponse de l'endokarst ardéchois aux variations eustatiques générées par la crise messinienne. Bull. Soc. Géol. France, 1, t.177, 2006, 27-36.

Mocochain L., Bigot J.-Y., Clauzon G., Faverjon M. et BRunEt P. (2006b) - La grotte de Saint Marcel (Ardèche) : un réferentiel pour l'évolution des endokarsts méditerranéens depuis 6 Ma. Karstologia, 48, 2006, FFS et AFK, 33-50 + carte HT.
Mocochain L. (2007) - Les manifestations géodynamiques - externes et internes - de la crise de salinité sur une plate forme carbonatée péri-méditerranéenne : le karst de la Basse-Ardèche calcaire (moyenne vallée du Rhône, France). Thèse CEREGE, Univ. Provence, Aix Marseille I.

Montel J.-M., Bouloton J., Veschambre M., Pellier C. et CEREt K. (2002) - Âges stéphaniens des microgranites du Velay (Massif central français). Géologie de la France, $1,2002,15-20$.

Pascal M., Elmi S., Busnardo R., Lafarge D., Truc G., Valleron M.-M., Chedhomme J. et Combier J. (1989) Carte géologique de la France (1/50 000), feuille BourgSaint-Andéol (889), Orléans, BRGM.

Pascal M., Lafarge D., Chedhomme J. et Glintzboeckel C. (1989) - Notive explicative de la carte géologique de la France, feuille Bourg-Saint-Andéol, Orléans, BRGM, $67 \mathrm{p}$.

Ramsay J. et Huber M. (1987) - The techniques of modern structural Geology. Vol. 2 : Folds and Fractures. 309-700.

TRÉBuchon J. (2000) - La saga de l'aven d'Orgnac-Issirac, l'épopée d'une fantastique découverte souterraine et ses ahurissantes conséquences. Auto-édition, 240 p.

Vail P.-R., Colin J.-P., Chene R.-J. du, Kuchly J., Mediavilla F. et TrifiliefF V. (1987) - La stratigraphie séquentielle et son application aux corrélations chronostratigraphiques dans le Jurassique du bassin de Paris. Bull. de la Soc. Géol. de France, t.III, n 7, 1987, 1301-1321.

Weisbrod A. (1967) - Explication sommaire de la carte géologique des Cévennes médianes. (Massif central français). Sciences de la Terre, Nancy, 4, 301-344. 


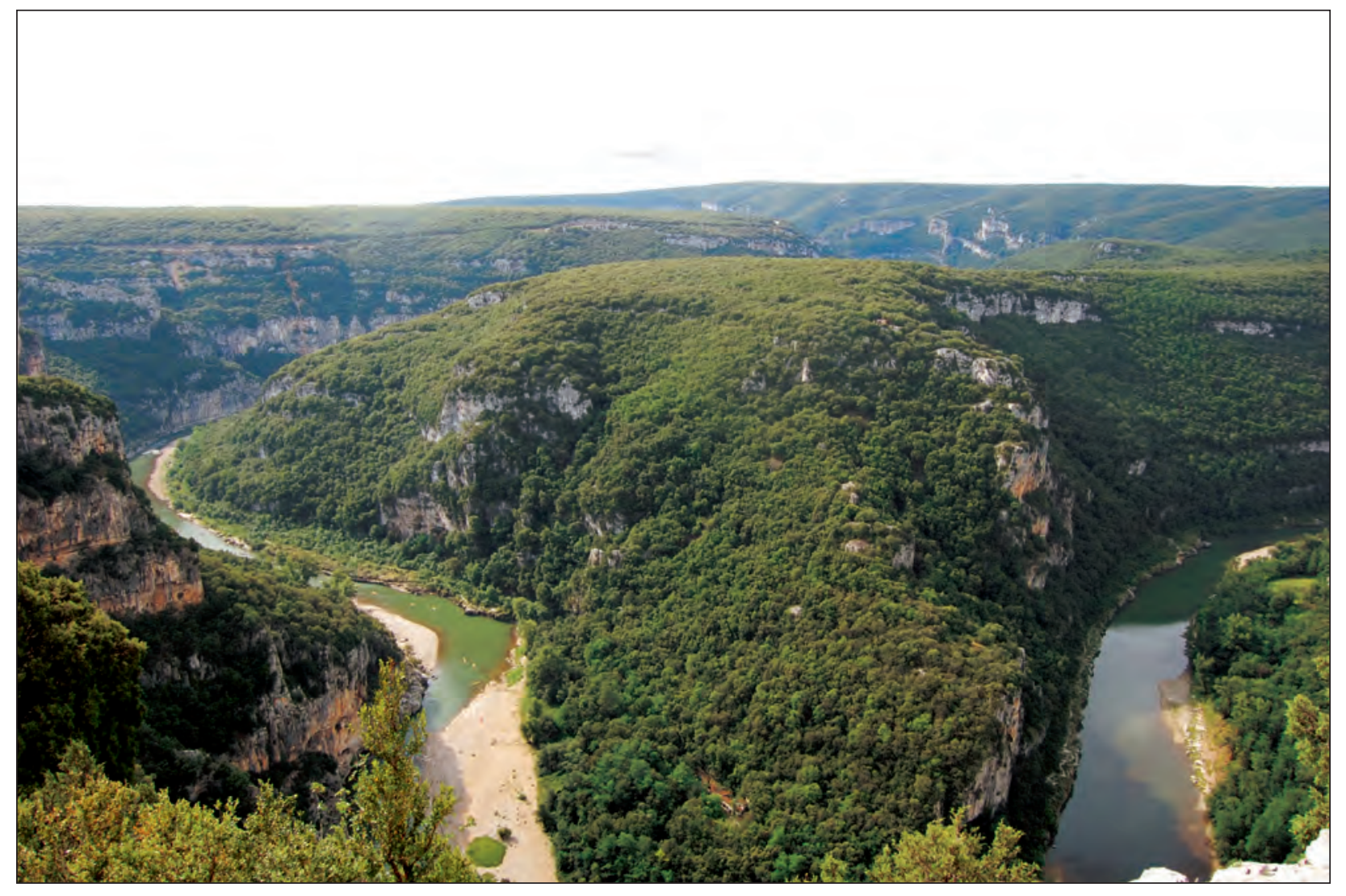

Les gorges de l'Ardèche dans le secteur du cirque de Gaud, vue depuis la rive gauche. En face, le Moure de la Toure constitue un tronçon de la surface de $260 \mathrm{~m}$. Au fond, à droite, la ligne de crête souligne l'axe de l'anticlinal de Ronze et la surface de $400 \mathrm{~m}$. 


\title{
L’AVEN D’ORGNAC
}

\section{VALORISATION TOURISTIQUE, APPORTS SCIENTIFIQUES}

\section{CONCLUSION}

\author{
par Jean-Jacques DELANNOY ${ }^{l}$ \\ 1 Laboratoire EDYTEM - Université de Savoie
}

Les recherches initiées depuis une dizaine d'années dans le cadre de l'Opération Grand Site ont permis de renouveler l'intérêt et la place de l'aven d'Orgnac dans l'étude géographique, morphogénique et karstogénique des plateaux calcaires du BasVivarais.

La réussite de l'Opération Grand Site est due à une forte volonté locale de repenser et de renouveler l'offre touristique en combinant avec intelligence la valorisation, la protection et l'exploitation des fortes valeurs patrimoniales du karst souterrain ; cette réussite repose également sur le soutien appuyé de la DIREN Rhône-Alpes qui a dégagé l'ensemble des moyens nécessaires pour définir les conditions conciliant la protection du patrimoine endokarstique et une gestion touristique raisonnée des réseaux non aménagés. Cette définition s'est faite en relation étroite avec les chercheurs impliqués dans l'étude de la cavité. Cette synergie entre acteurs locaux, services de l'État et chercheurs mérite d'être soulignée et portée en exemple au regard de ce qui se passe dans d'autres sites karstiques de haute valeur patrimoniale où le spectre de la protection est souvent brandi comme inhibiteur de développement socio-économique. L'exemple d'Orgnac met clairement en avant que toute capacité d'écoute est synonyme d'avancées et de recherches de solutions adaptées aux différents modes d'utilisation et de valorisation du site concerné. La dynamique issue de la labellisation de l'aven d'Orgnac en tant que Grand Site de France (2004) fait de ce site (cavité et Musée régional de Préhistoire) un élément majeur dans la réflexion actuelle sur la "réorganisation » de l'offre touristique du Sud-Ardèche, en lien avec l'Espace de Restitution de la grotte Chauvet.
La découverte de la grotte Chauvet et l'opération Grand Site sur Orgnac ont sans nul doute replacé cette région au cœur des recherches sur les différentes valeurs patrimoniales du monde souterrain. Il est d'ailleurs intéressant de relever que l'intérêt scientifique de ces deux sites a d'emblée été mis en avant et que les recherches qui y ont été développées se déclinent sous le sceau de l'interdisciplinarité. Cette dimension interdisciplinaire ouvre assurément de nouvelles perspectives dans le développement des recherches en karstologie et plus largement sur le karst souterrain. Il est ici également intéressant de relever que les deux laboratoires impliqués dans l'étude de ces deux sites : le laboratoire souterrain de Moulis et le laboratoire EDYTEM appartiennent tous deux au nouveau Département scientifique du CNRS « Environnement et Développement Durable » qui mise sur l'interdisciplinarité pour répondre aux questions actuelles de gestion environnementale et de développement. La démarche entreprise sur Orgnac répond pleinement à cette logique de gestion intégrée et de développement durable. Le travail réalisé par les membres et doctorants du laboratoire EDYTEM entre également dans cette dynamique ; le croisement des différents regards de la géographie et des géosciences a permis de poser les différentes valeurs patrimoniales du karst et leurs enjeux en termes de protection, de valorisation et de modes de gestion intégrée.

Les recherches menées en géographie du tourisme ont souligné que la diversité et la magnificence des paysages karstiques présents dans le Sud Ardèche constitue un véritable support de développement et de diversification touristique. Dans la réflexion 
actuelle sur les «Géoparcs » et les Géotopes (patrimoines géologiques et géomorphologiques), le secteur d'Orgnac - gorges de l'Ardèche - Chauvet compose assurément un site sans pareil sur les patrimoines karstiques. Les recherches en cours au sein d'EDYTEM sur les dimensions patrimoniales du karst et ses enjeux en termes de développement seront l'objet de nouvelles publications (thèses de M. Duval et de N. Cayla ; mémoires d'HDR de Ch. Gauchon et F. Hobléa). Si ces recherches portent sur différents sites karstiques rhônalpins et européens, le Bas-Vivarais calcaire constitue un des sites-ateliers majeurs du laboratoire EDYTEM.

Les recherches menées sur le karst de surface et souterrain d'Orgnac ont également permis de poser de nouveaux regards sur l'évolution morphogénique et karstogénique de cette région calcaire. Ici également, le travail mené parallèlement sur les sites d'Orgnac, de Chauvet et de l'entrée des gorges de l'Ardèche a mis en avant leur forte complémentarité et leur cohérence dans le canevas paléogéographique régional. Si les études à Chauvet ont permis de souligner l'inscription dans le karst souterrain des événements géologiques néogènes (cycle messino-pliocène) et quaternaires (Delannoy et al., 2001 ; 2004), les recherches menées dans Orgnac ont mis en exergue les incidences karstogéniques de la transgression pliocène et ce tant dans le façonnement des reliefs de surface que du karst souterrain. En effet, si les incidences de la crise messinienne sont maintenant relativement bien appréhendées dans la dynamique des karsts dépendant du niveau de base méditerranéen (cf. travaux de G. Clauzon ; P. Ambert ; J.-J. Delannoy ; H. Camus ; L. Mocochain), les implications karstogéniques du relèvement eustatique pliocène avaient été jusque-là relativement peu abordées. Les recherches menées à Orgnac ont permis de rapporter à cet important événement paléogéographique le fonctionnement paragénétique des grands réseaux de cet aven. Cet apport est majeur car s'il est relativement «aisé » de reconstituer l'évolution spéléogénique (et/ou karstogénique) engendrée par l'abaissement du niveau de base (lié à des causes tectoniques et/ou eustatiques) et de décrypter leurs empreintes dans l'organisation des conduits karstiques, il a toujours été plus délicat de distinguer et de caractériser les témoins morphologiques contemporains des épisodes de remontée du niveau de base karstique.
L'étude géomorphologique menée dans les réseaux souterrains d'Orgnac a permis d'appuyer la thèse de $\mathrm{Ph}$. Renault sur le fonctionnement paragénétique des réseaux d'Orgnac. La cartographie morphologique des différentes salles d'Orgnac, le laserscanning de grands volumes souterrains (Salles Rouges, Salle de Joly...), les sondages (manuels et tomographiques) ont permis de rapporter à une même dynamique la mise en place des banquettes-limites et des remplissages argileux : la reconstitution 3D des volumes souterrains a permis de raisonner sur l'ensemble du réseau souterrain et ainsi de mieux saisir l'importance du fonctionnement paragénétique pliocène dans la genèse endokarstique. Ce fonctionnement peut être considéré comme une des réponses morphogéniques de l'endokarst aux dysfonctionnements du drainage souterrain entrainés par le relèvement eustatique et l'aggradation continentale pliocène. Cette réponse est cohérente, tant d'un point de vue fonctionnel que spatial, avec les autres formes karstiques engendrées par le dysfonctionnement du drainage karstique durant le Pliocène : l'évolution en poljé de la dépression de Labastide en est un bel exemple. Le dernier article de cet ouvrage a permis de souligner la portée du recoupement des canevas morphogéniques issus de l'étude des formes superficielles et souterraines et de démontrer à nouveau la richesse des données paléogéographiques inscrites dans l'endokarst.

C'est autour de cette même idée de recoupement d'informations morphogéniques qu'ont été menées les recherches dans les grandes salles d'Orgnac. Le recoupement des données issues de la cartographie, du laserscanning, des sondages et de l'étude de la morphologie interne des concrétions a permis de souligner l'importance des soutirages dans la physionomie actuelle des paysages souterrains d'Orgnac, notamment des Salles Rouges et des Salles 1, 2 et 3. La physionomie et l'ampleur de ces salles ont pu être associées aux soutirages qui accidentent leur plancher. Situés le plus souvent au droit d'accidents géologiques et à proximité des parois calcaires, ces soutirages ont contribué et continuent à concourir à l'évacuation des argiles paragénétiques. L'étude des différentes générations de stalagmites qui scellent les flancs des soutirages a permis de révéler (i) que la courbure qui caractérise ces spéléothèmes est liée au fluage du remplissage argileux vers les points de soutirage, (ii) que ces fluages sont liés à des épisodes 
d'ennoiement temporaire des réseaux souterrains et (iii) que ces ennoiements sont provoqués par des épisodes climatiques exceptionnels. Si l'un de ces ennoiements a pu être, pour la première fois, observé en septembre 2002, l'étude de la morphologie interne des concrétions d'Orgnac a révélé la récurrence de ce phénomène et permis d'en appréhender les incidences sur l'évacuation des argiles paragénétiques et l'agrandissement synchrone des volumes souterrains d'Orgnac. La dynamique des soutirages mise au jour dans Orgnac constitue un apport important dans la compréhension de la spéléogenèse des réseaux apparemment isolés des structures de drainage. Dans le cas d'Orgnac, les soutirages ne résultent pas d'un phénomène catastrophique mais constituent l'expression d'une morphogenèse courant sur une très large fenêtre temporelle. La relative permanence spatiale des points d'évacuation des argiles constitue un indicateur d'une connexion avec les structures actuelles de drainage. Reste à définir si l'indigence de ces connexions est l'expression (i) du colmatage des conduits sous-jacents dû à l'apport régulier de matériel argileux et/ou des fluages post-ennoiements ou (ii) d'une karstogenèse bridée par la situation particulière du réseau (en position d'interfluve), par la proximité du toit de la zone noyée ou par un fonctionnement annexe du système d'Orgnac.

Un des intérêts majeurs des recherches d'Orgnac est que, tout en posant de nouveaux jalons dans la connaissance spéléogénique et karstogénique des plateaux calcaires du Bas-Vivarais, elles ouvrent de nouveaux champs de recherche et de nouvelles perspectives méthodologiques. L'utilisation des nouveaux vecteurs d'information spéléogénique comme les banquettes-limites, les stalagmites translatées, etc. d'une part, et le développement des relevés tomographiques, du laserscanning et des représentations 3D d'autre part, apporteront assurément de nouvelles données majeures sur la genèse du karst ardéchois. C'est à cette tâche que nous allons désormais nous atteler dans le cadre des programmes de recherche en cours, de recherches doctorales (B. Sadier), et des collaborations scientifiques développées durant ces dernières années. Ces recherches continueront à être déclinées sous l'angle de l'interdisciplinarité qui, comme l'ont mis en avant les différents chapitres de cet ouvrage, permet de dépasser les limites analytiques et méthodologiques des différents champs disciplinaires impliqués dans l'étude du karst et surtout de renouveler les questionnements sur les phénomènes karstiques en les abordant via leurs relations avec leurs environnements qu'ils soient géologique, bio-climatique, géomorphologique et anthropique.

Bien que cela puisse passer inaperçu pour les nonspécialistes, le fait de recouper sur un même réseau et au sein d'un même programme les analyses géologique, paléogéographique, géomorphologique, spéléogénique, sédimentologique (dépôt détritique et concrétion) et climatologique n'est pas commun en cette période d'hyperspécialisation, de compétition scientifique et de chasse-gardée. À ce titre, la démarche entreprise sur Orgnac est exemplaire de la façon dont nous souhaitons poursuivre l'étude des systèmes karstiques. Le développement de recherches en relation avec la Préhistoire (zone d'entrée) et avec l'actuel fonctionnement hydrogéologique (cf. travaux en cours d'A. Mangin et F. Bourges) permettra de compléter la portée interdisciplinaire des travaux scientifiques engagés sur le site d'Orgnac.

La mise en place d'un axe de recherche transversal sur les "systèmes et milieux karstiques " au sein d'EDYTEM va également dans ce sens, en croisant sur de mêmes objets karstiques les regards et apports de la géologie, géomorphologie, hydrogéologie et géographie du tourisme. Nous sommes convaincus que cette démarche allant du diagnostic des ressources et valeurs patrimoniales du karst jusqu'à la définition des modes de valorisation et de gestion (via la compréhension des dynamiques actuelles et l'appréhension de leurs vulnérabilités) est la plus à même de répondre aux questionnements actuels de la société sur les différents types de développement et/ou de valorisation des espaces et phénomènes karstiques. Reste à convaincre l'ensemble des acteurs travaillant sur le karst. Ce volume n'a pas la prétention de couvrir l'ensemble de cette démarche mais d'en poser les premiers jalons. 


\title{
Annexe 1
}

\section{OBJECTIFS ET MÉTHODOLOGIE DE CARTOGRAPHIE 2D ET 2.5D}

\author{
par Benjamin SADIER
}

Pour mener a bien l'étude de la spéléogenèse de l'aven d'Orgnac et ensuite remettre ses principales étapes dans son cadre paléogéographique, nous avons dû comprendre comment s'emboîtent les différents objets endokarstiques et exokarstiques. La difficulté de cette réflexion est, d'une part, de connecter ces objets entre eux pour les placer dans un ordre chronologique relatif, et d'autre part, de mesurer leur emprise dans l'espace afin d'en tirer des informations sur leur contexte de mise en place. L'avantage de réfléchir à partir d'un support cartographique est qu'il permet les deux en même temps en spatialisant les phénomènes mais aussi en représentant leurs emboîtements.

Cette annexe est consacrée à la méthodologie utilisée pour la réalisation des cartes topographiques ayant servi de support aux relevés géomorphologiques de l'aven d'Orgnac.

Leur réalisation passe par plusieurs étapes : (i) le relevé de terrain, (ii) le traitement informatique des données, (iii) la construction d'un MNT (modèle numérique de terrain) puis la production de cartes en 2D avec courbes de niveau ou de cartes en $2,5 \mathrm{D}$ qui serviront à mieux percevoir des phénomènes particuliers.

Les levés de terrain sont effectués au télémètre laser, avec un compas électronique et une mire.

Figure 1

Principes de topographie au théodolite.
Les principes de la topographie au théodolite sont expliqués dans la figure 1. Étant donné le caractère accidenté des terrains d'études et leurs surfaces importantes, nous les avons partagés en plusieurs secteurs en prenant le soin de disposer de points communs de secteur en secteur.

Ensuite, nous calculons les coordonnées $\mathrm{x} / \mathrm{y} / \mathrm{z}$ de chaque secteur de levé et nous les replaçons dans un même repère orthonormé par triangulation des points communs à chaque secteur. L'ensemble des calculs de coordonnées est fait avec le tableur « Excel», ce qui permet de les automatiser (figure 2).

À partir du semis de points obtenu, nous pouvons dès lors créer un modèle numérique de terrain à partir duquel nous élaborerons des cartes des sols en 2D ou en 2,5D. Le logiciel Surfer (Golden software editor) est utilisé pour mailler le nuage de points. Ce dernier propose plusieurs méthodes de production de MNT. Nous avons choisi celle lissant le moins l'information : la triangulation par interpolation linéaire (triangulation de Delaunay). Les documents obtenus peuvent alors servir de support à la cartographie géomorphologique. Une fois les relevés géomorphologiques effectués, nous pouvons remettre ces informations en relief sur un maillage en 2,5D. Pour la Salle 2, ce rendu a permis de mieux percevoir le rôle du soutirage dans le remaniement des remplissages sédimentaires.
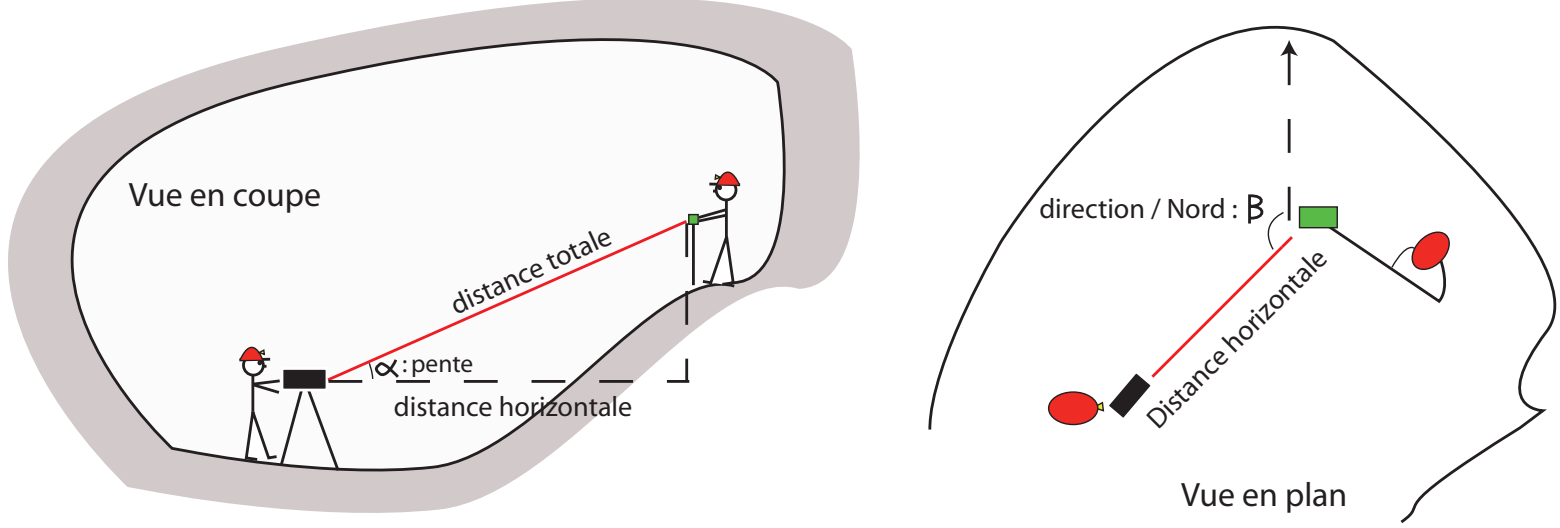
Figure 2

Étapes de construction d'un modèle numérique de terrain $2 \mathrm{D}$ et $2.5 \mathrm{D}$.

Calcul de coordonnées de chaque secteur et triangulation de bases communes pour placer chaque secteur dans un même système de coordonnées
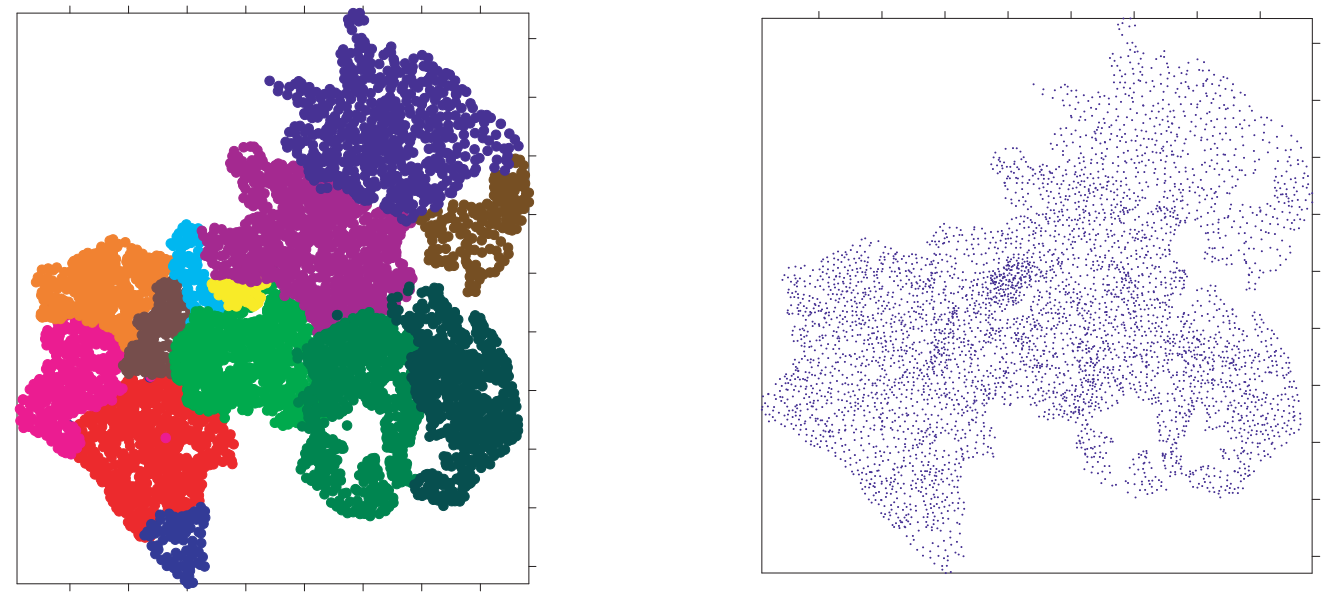

Maillage du nuage de points pour production de cartes avec courbes de niveau ou MNT 2,5D
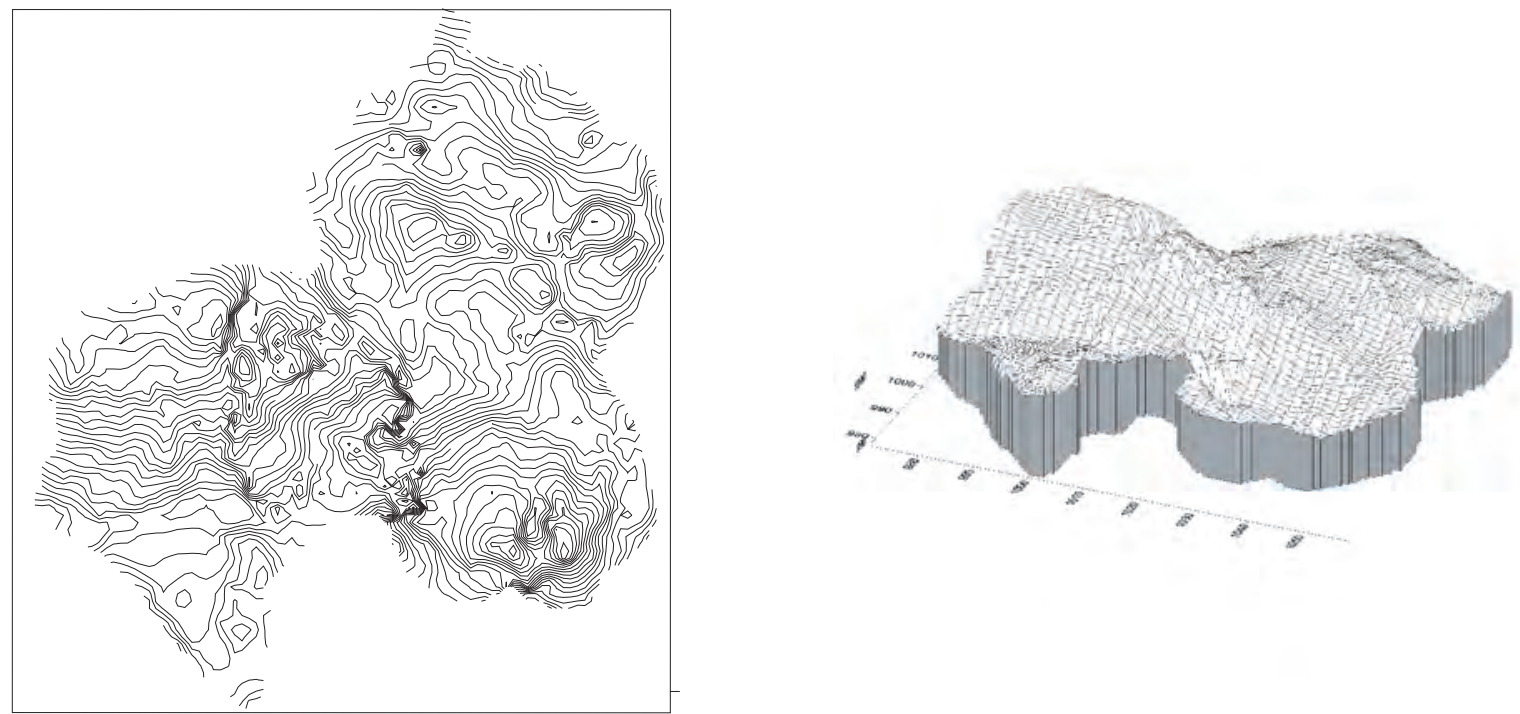

Drappage de la carte géomorphologique de la Salle 2 de l'aven d'Orgnac sur la carte en 2,5D
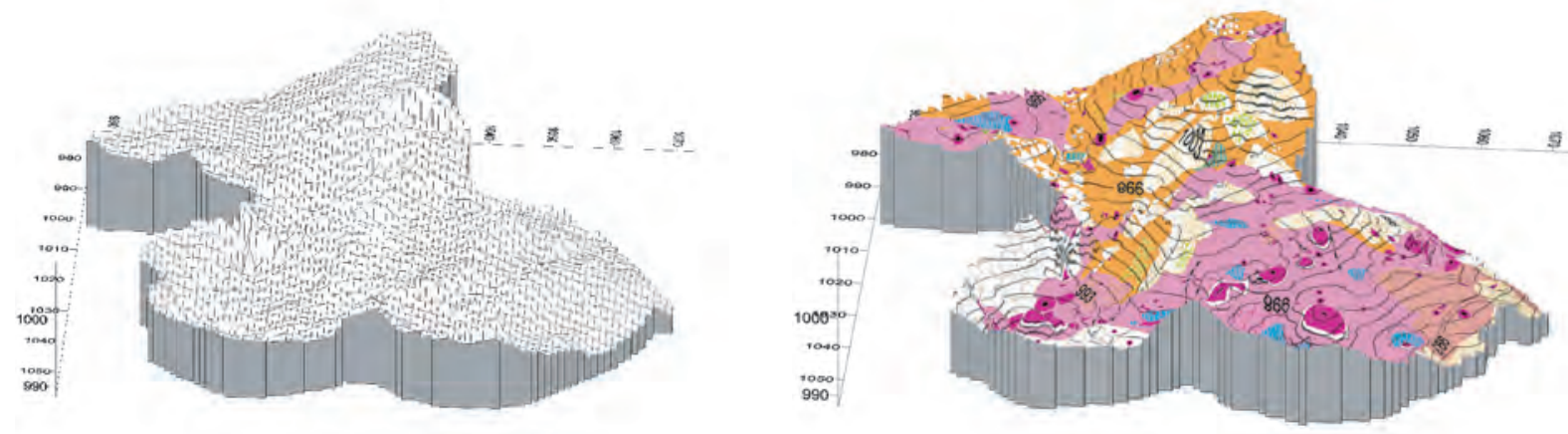


\title{
Annexe 2
}

\section{VOLUME SOUTERRAIN 3D ET LASERSCANNING}

\author{
par Stéphane JAILLET
}

L'analyse géomorphologique des volumes souterrains à échelle moyenne passe par la reconnaissance fine des morphologies pariétales. Sur le site d'Orgnac, les Salles Rouges et une partie du puits d'entrée ont ainsi été scannées en 3D.

\section{OBJeCtiF}

Il s'agit de reconstituer numériquement un volume 3D (une galerie, une salle, une paroi...) avec un niveau de détail permettant l'analyse détaillée des formes. Ce peut être la reconnaissance de banquettes-limites dont on veut étudier l'étagement, l'évaluation volumétrique de concrétions massives ou l'analyse détaillée de plans de fracturation (orientation, répartition...). Pour chacune de ces problématiques, la mise en œuvre du lidar terrestre permet d'analyser et de quantifier les formes sur logiciel dédié en travaillant sur le clone numérique de l'objet étudié. C'est particulièrement intéressant pour un grand nombre de configurations : accessibilité délicate (plafond), fragilité du milieu (empreintes, peintures pariétales) ou simplement pour la multiplication des mesures sur des objets de grandes tailles.

\section{Mise en GUURe}

Nous utilisons, au sein du laboratoire EDYTEM, un lidar terrestre Ilris3D produit par la société Optech. C'est un scanner transportable alimenté sur batteries et piloté par un PC directement sur le terrain et pouvant scanner sur des distances de $3 \mathrm{~m}$ à $800 \mathrm{~m}$. Les fenêtres de scan sont de $40^{\circ}$ par $40^{\circ}$ ce qui impose pour des objets fortement repliés (c'est le cas de cavités karstiques) de multiplier les scènes et par recouvrements successifs d'obtenir un modèle 3D de l'ensemble de la forme étudiée. La résolution du scanner est angulaire $\left(0,00115^{\circ}\right)$ et la taille du spot dépend de l'éloignement. À $100 \mathrm{~m}$, la résolution et la précision du positionnement est de l'ordre de 7 à $8 \mathrm{~mm}$. La vitesse d'acquisition (2 500 points par seconde) permet un travail relativement rapide sur le terrain.

Les conditions de scan sous terre ne permettent pas d'utiliser les photos prises par le scanner pour coloriser le nuage de points. Aussi, dans un premier temps, utilisons-nous uniquement la reflectance en plus de l'information de positionnement de chaque point. Les fichiers obtenus sont des nuages de plusieurs millions de points traités sous logiciel dédié Polyworks (InnovMétric, se déclinant en une suite logiciel) sur une station de travail bi-processeur. La chaine opératoire de traitement des données comprend quatre étapes : (i) l'exportation des données dans un format utilisable sur le logiciel choisi, (ii) l'importation des scènes et leur assemblage par recouvrement et reconnaissance de forme (ImAlign), (iii) l'amélioration du calage et la suppression des recouvrements et enfin (iv) l'exportation du nuage de points pour son exploitation.
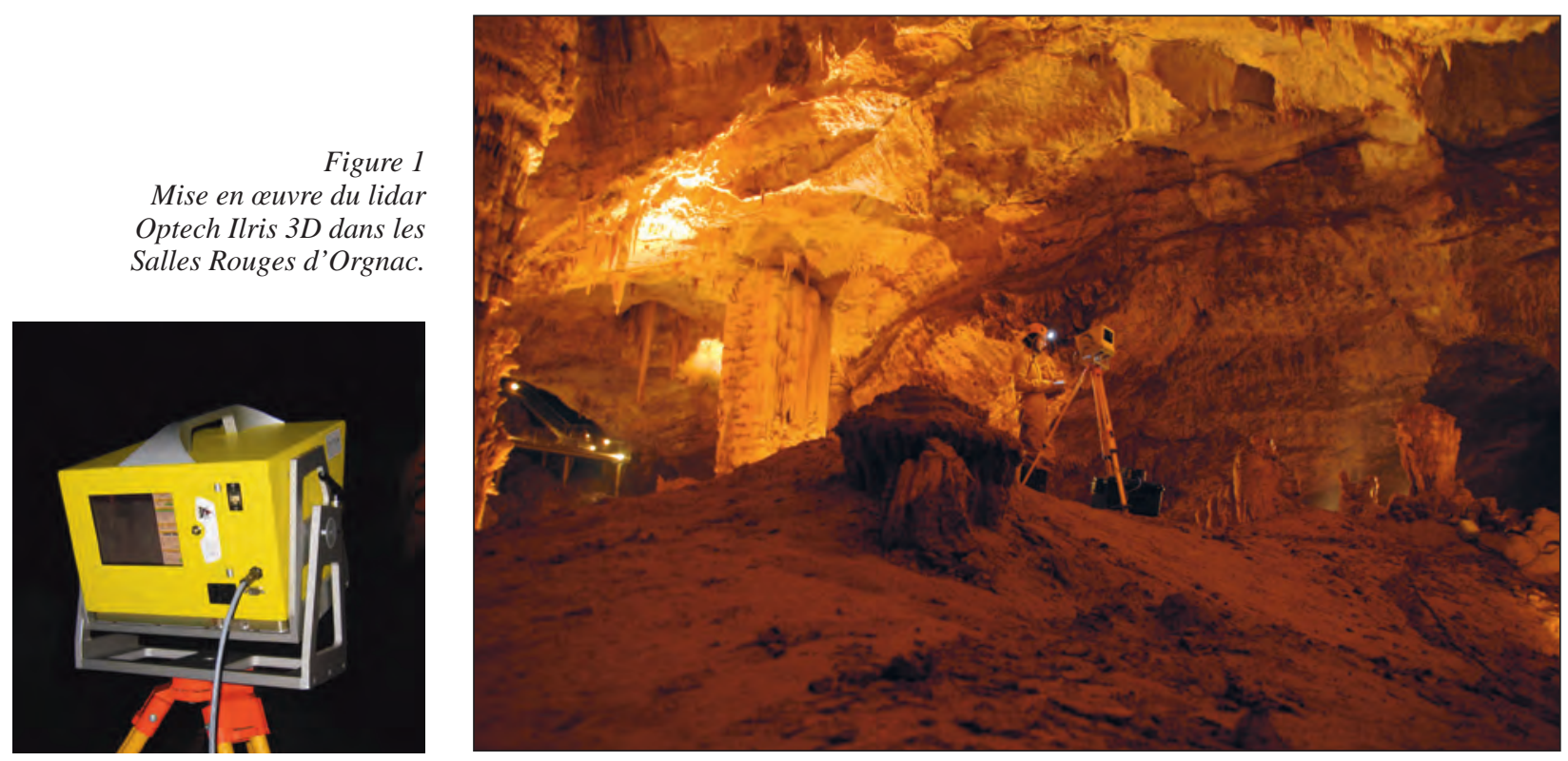


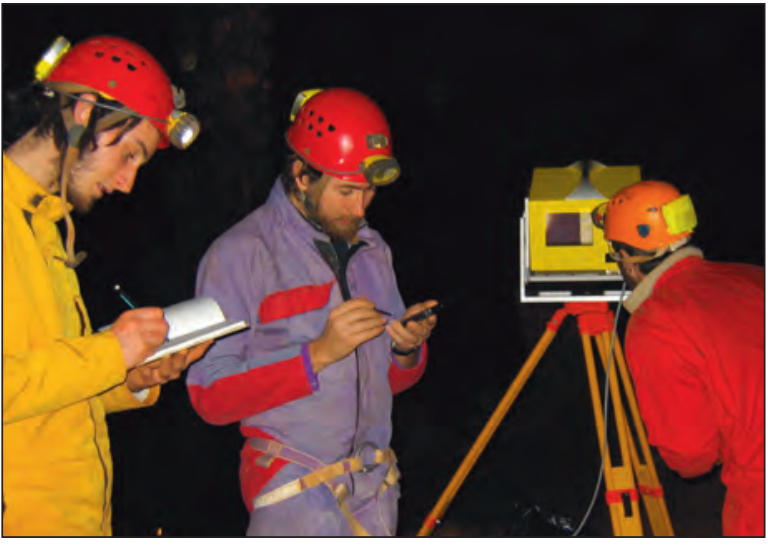

\section{RÉSULTATS ATTENDUS}

Il est possible de travailler directement sur le nuage de points 3D ou de générer un réseau (modèle) haute résolution de triangles irréguliers (ImMerge). On parle de HRTINM ${ }^{1}$. Des procédures d'amélioration du modèle sont possible (ImEdit). Elles permettent de simplifier le modèle là où l'information est peu importante et de la conserver là où la rugosité des formes l'impose. Elles permettent d'interpoler des secteurs particuliers et même de boucher des trous (masque du modèle).

L'exploitation du HRTINM commence alors véritablement avec les mesures (distances, rayons de courbures, orientations...), l'ajustement de formes simples (plan, cylindre, cône...) ou la comparaison diachronique de scènes (étude des écroulements rocheux). Si des points géoréférencés ont été identifiés dans la scène, il est possible de recaler le modèle soit dans un repère local, soit dans un système de projection plus vaste.

Les possibilités offertes par ce type d'analyse sur des objets naturels n'en est encore qu'à ses débuts et les perspectives sont prometteuses pour ce qui pourrait être une refonte importante de la reconnaissance, de l'analyse et de l'exploitation scientifique des formes endokarstiques.

1 High Resolution Triangular Irregulated Network Model
Figure 2

Le clone numérique du puits d'entrée et du cône d'éboulis de l'aven d'Orgnac

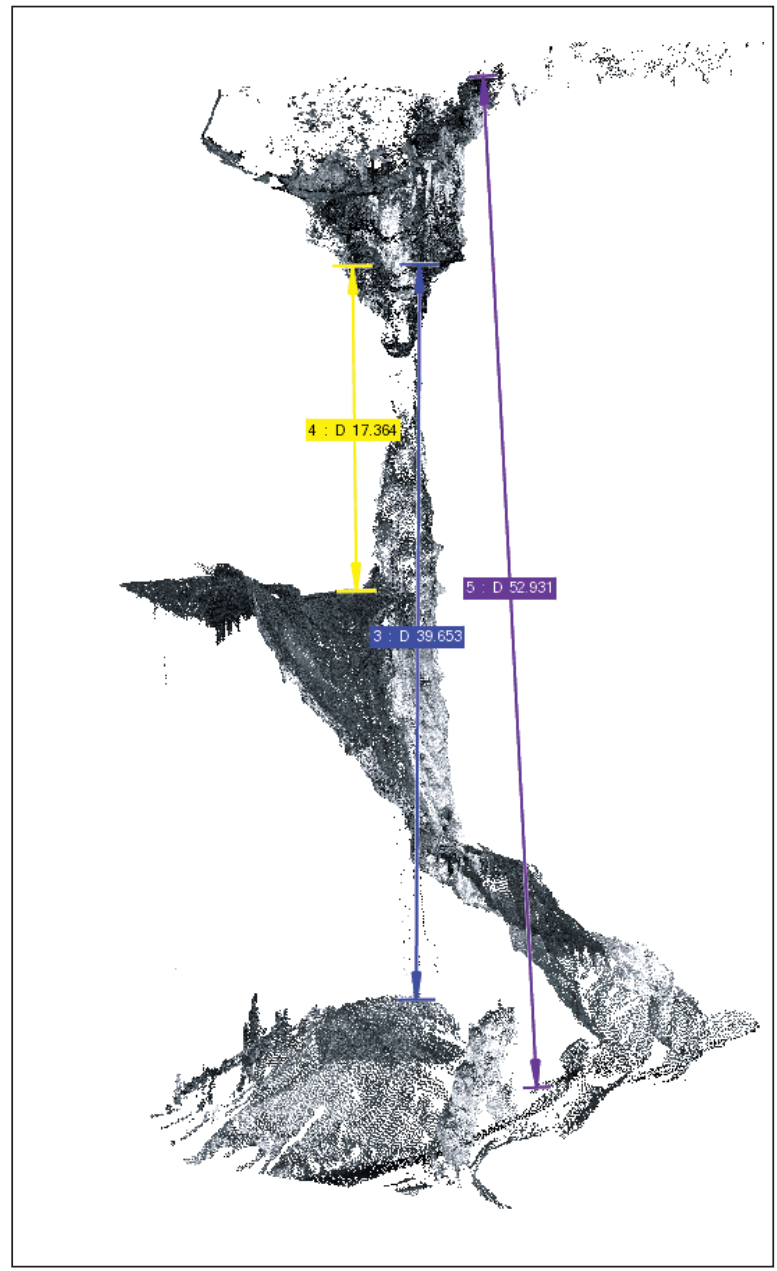

Figure 3

Exemple de scène $3 D$ assemblée : la paroi de gauche des Salles Rouges d'Orgnac. Notez les formes aisement identifiables et mesurables sur le modèle. Notez aussi les masques liés à la difficulté de scanning sur ce type d'objet fortement replié.

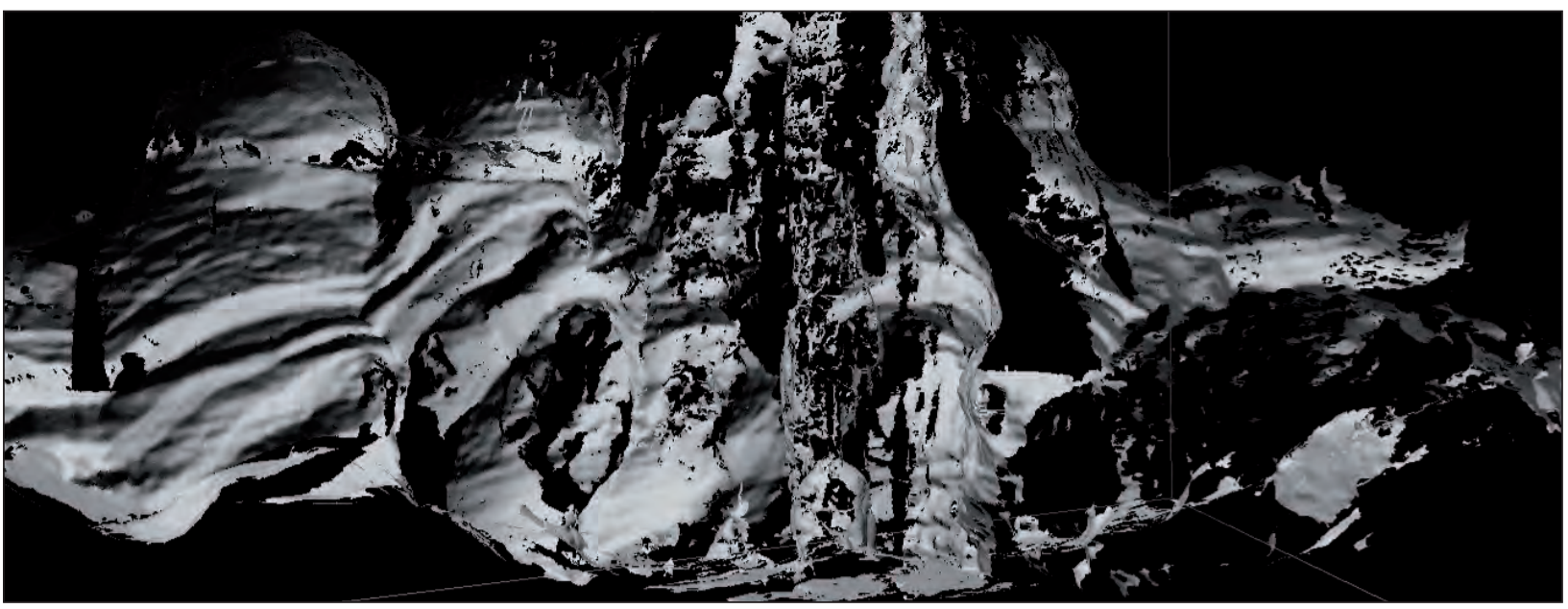


Annexe 3

\title{
CARTOGRAPHIE GÉOMORPHOLOGIQUE DES SOLS
}

\author{
par Jean-Jacques DELANNOY
}

\section{OBJECTIFS}

La cartographie géomorphologique est un outil performant pour (i) distinguer les différents processus qui sont intervenus dans la morphogénèse d'une cavité, (ii) travailler sur l'emboitement des différents dépôts et formes présentes sous terre et (iii) mettre en place une chronologie relative des différents événements qui ont marqué la genèse endokarstique (J.-J. Delannoy 1997).

Un des intérêts de la cartographie géomorphologique est de relever tout ce qui est visible en parois et sur les sols des cavités étudiées. Cette volonté de prendre en compte l'ensemble (i) des formes pariétales, (ii) des différents sédiments présents au sol et (iii) l'ensemble des morphologies inscrites dans les sédiments tout en distinguant (iv) les processus qui en sont responsables et (v) la chronologie des événements peut être critiquable notamment envers la lecture du document cartographique final. La lecture des cartes géomorphologiques n'est effectivement pas aisée mais est-elle plus difficile qu'une carte géologique ou une carte de la végétation lors de leur toute première lecture? La lecture d'une carte géomorphologique nécessite de fait deux préalables : avoir les bonnes clés de décodage (c'est le rôle de la légende qui accompagne la carte ou la figure) et avoir une idée précise des informations qu'on recherche dans le document cartographique. Sans ces préalables, il est clair que la carte géomorphologique est un document difficile d'accès. Cet écueil peut être, aujourd'hui, contourné par la possibilité d'extraire telle ou telle couche d'informations selon la problématique de recherche, via les outils des SIG ; cette possibilité permet ainsi d'extraire les informations souhaitées à partir de la base de données qu'est la carte géomorphologique. Sans occulter la question de la lisibilité des cartes géomorphologiques, il importe ici de souligner que la réalisation d'une telle cartographie s'apparente à une « opération vérité » tant (i) dans la reconnaissance des différentes formes et dépôts présents dans la cavité, (ii) sur les causes de leur présence (iii) que sur la chronologie des événements morphogéniques. Entre un regard tout aussi aiguisé soit-il et le fait de cartographier les différents éléments morphologiques, il y a une importante différence de perception de la grotte et des événements morphogéniques qui se sont succédé tant d'un point de vue temporel que spatial.
Celles et ceux qui ont pratiqué cet exercice connaissent ces moments magiques où l'histoire de la grotte se déroule au bout de leurs crayons.

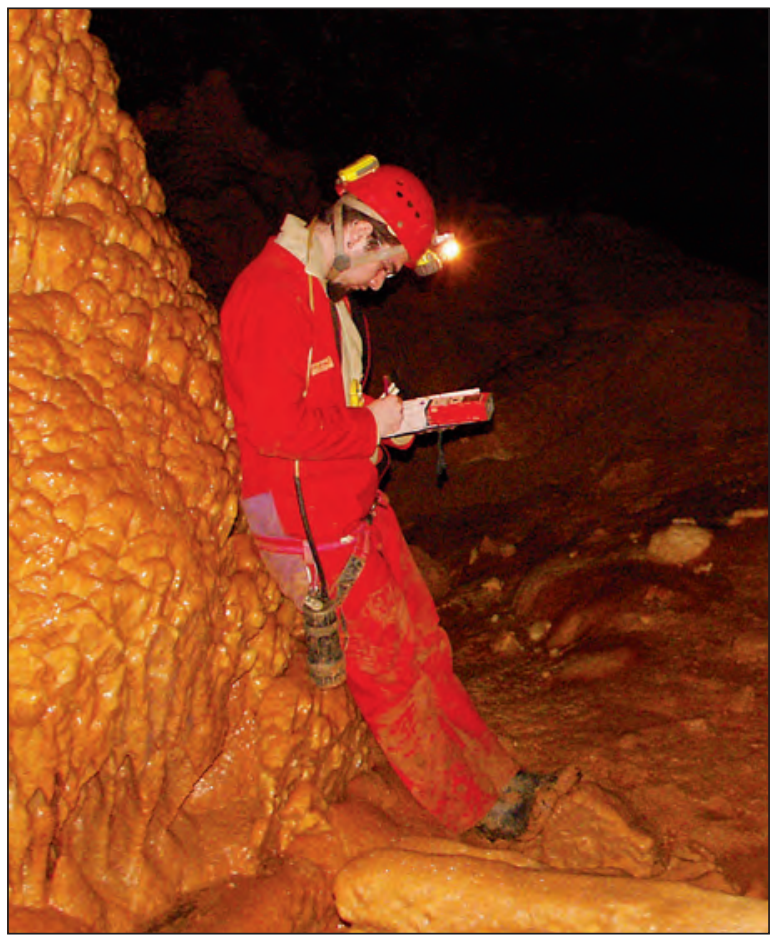

La cartographie géomorphologique de sols s'inscrit dans la même démarche en se concentrant sur les différents dépôts souterrains présents au plancher de la cavité, sur les processus responsables de leur mise en place et sur les dynamiques post-sédimentaires à l'origine de leur physionomie et disposition actuelles. Cette démarche initialement mise en œuvre pour l'étude spéléogénique a été développée et adaptée à l'étude des sols archéologiques. L'étude des sols de la grotte Chauvet a été une école particulièrement instructive (J.-J. Delannoy et al., 2001 et 2004). Le croisement des regards des spéléologues, karstologues, géologues, préhistoriens, paléontologues et ichnologues a permis de relever le large spectre d'indicateurs permettant de distinguer les différents événements qui ont marqué la cavité liés aux processus naturels, occupations animales et incursions humaines. 
C'est sur la base de ce développement méthodologique que la cartographie des grandes salles d'OrgnacIssirac a été réalisée. Cette cartographie a été adaptée aux problématiques de recherche visant ici à définir les processus et dynamiques morphogéniques à l'origine des grands volumes souterrains, de l'importance spatiale des formations argileuses ainsi que de leurs relations avec les dépôts gravitaires (effondrements...) et les concrétions (en place ou non). La cartographie morphologique des sols a permis de bâtir une chronologie relative de chacune des salles étudiées, de les croiser, et de proposer un canevas chronologique cohérent pour l'ensemble de la cavité.

\section{Mise en GUVRE}

Un des supports indispensables à la cartographie morphologique est un fonds topographique de qualité. Ce fonds est nécessaire, à la fois, pour le relevé sous terre et pour la restitution cartographique. Il importe avant de se lancer dans un tel travail de se poser la question de l'échelle à laquelle on va faire le relevé et à laquelle on va publier la carte. Les éléments de réponse dépendent avant tout de la finesse des informations recherchées et aussi de la cavité cartographiée. L'engagement en temps et en énergie n'est pas le même pour une cavité de quelques centaines de

Extrait de la carte géomorphologique de la Salle 2.

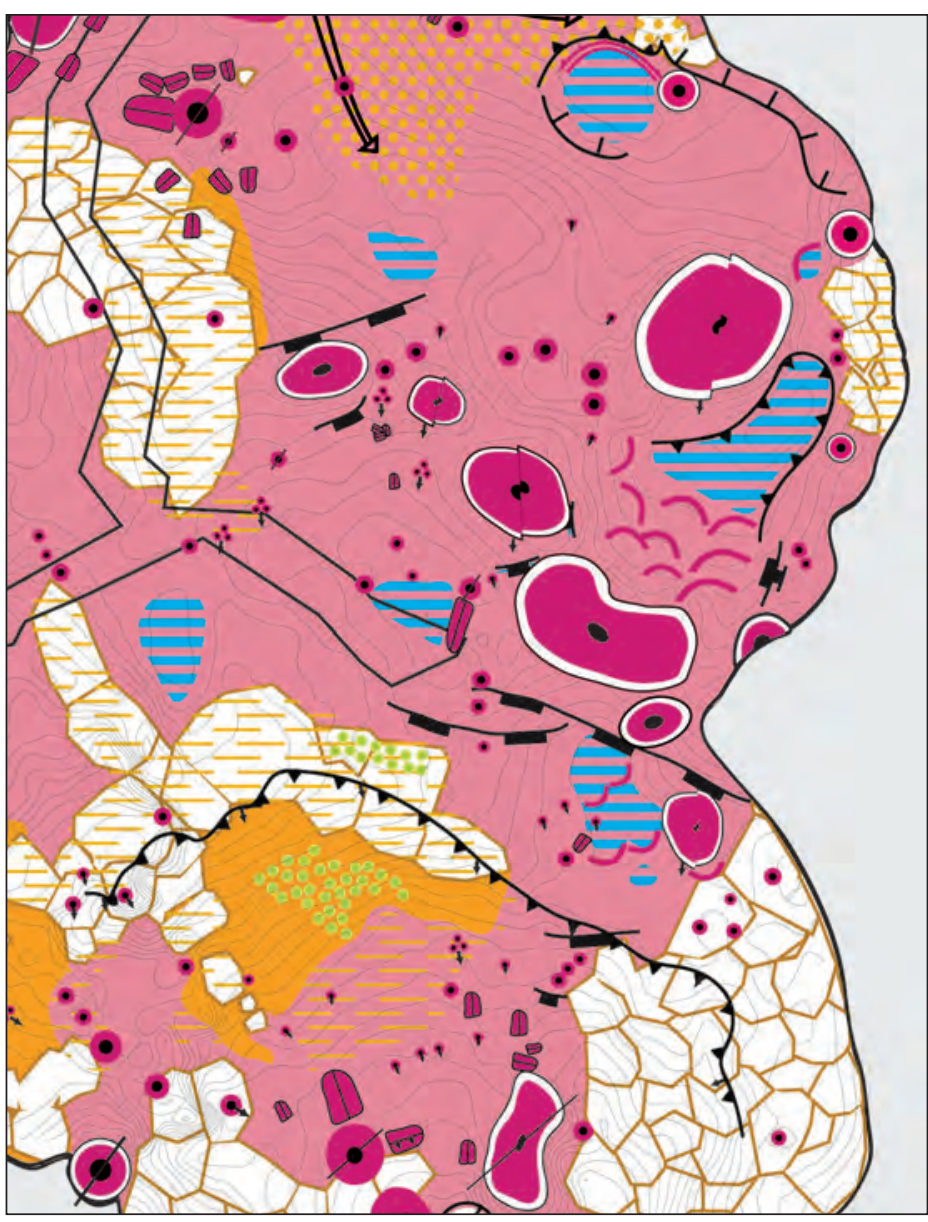

mètres ou pour un réseau de plusieurs kilomètres. Après avoir travaillé à l'échelle du 1/50 dans la grotte Chauvet compte tenu de l'importance des indices morphologiques, paléontologiques et archéologiques présents au sol, nous avons été confrontés au gigantisme des réseaux d'Orgnac et à leur développement sur plus de $5 \mathrm{~km}$. Le choix a été ici de ne pas réaliser in extenso la cartographie des réseaux souterrains mais de se focaliser sur différentes salles présentant une complémentarité morphologique (Salle Plane, Salle 2, Salles Rouges). Pour Orgnac, le relevé cartographique a été réalisé à l'échelle du 1/250 (cf. cartes présentes dans cet ouvrage). Ces échelles sont apparues les plus pertinentes compte tenu du nombre de phénomènes à cartographier.

L'accent a été mis à Orgnac sur les différents types de remplissages, leurs emboitements, leur «âge » (chronologie relative) et les processus morphogéniques postérieurs à leur mise en place (p.e. : ruissellement, glissement, soutirage...). Ces différents éléments sont portés dans la légende ci-jointe. Les différents types de remplissage et les processus morphogéniques sont représentés par des symboles graphiques et par des couleurs selon un code faisant aujourd'hui une relative unanimité. La chronologie (relative) des événements est représentée par l'intensité des couleurs selon le principe que plus un phénomène est récent, plus il sera visible dans le paysage souterrain, d'où le choix de le représenter par une couleur soutenue; à l'inverse un phénomène ancien sera cartographié dans une couleur claire. Cette nuance d'intensité de couleur (foncée/ claire) joue pour une même gamme de phénomène (p. e. concrétionnement), c'est là une des limites de la cartographie. En effet, un phénomène récent (couleur foncée) pour un type de processus donné peut être plus ancien qu'un autre type de phénomènes considéré comme très ancien (couleur claire). Il faut être conscient de ce biais dans la lecture de la carte géomorphologique souterraine. C'est pourquoi toute cartographie géomorphologique se doit d'être accompagnée de (i) coupes permettant d'appréhender au mieux les emboitements morphogéniques et (ii) d'une notice guidant le lecteur dans la visite de la grotte via la carte. Les nouveaux traitements et supports visuels offerts par les SIG et la restitution 3D permettront dans un bref avenir de gommer ces différents biais engendrés par la représentation 2D des phénomènes souterrains auxquels on confère une dimension temporelle. C'est à ce nouveau type de représentations que nous travaillons en ce moment: notre objectif étant d'offrir les meilleurs supports visuels possibles pour appréhender la genèse et l'évolution des cavités. C'est là l'apport du géomorphologue. 
Contexte topographique et litho-structural

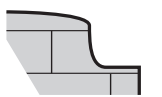

Paroi calcaire

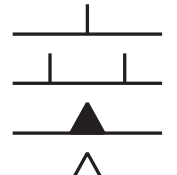

Rupture de pente

(commandement

de + en + fort $)$

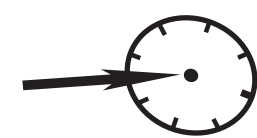

Soutirage

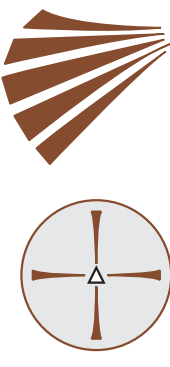

Cône d'éboulis

$\leq$ Détente lithostatique

\section{Hydrologie}

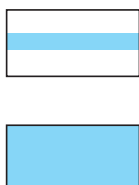

Zone en eau temporaire

Zone en eau pérenne

Circulation

hydrologique pérenne

Circulation

hydrologique temporaire
Sédiments déposés par des ruissellements

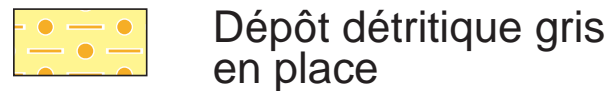

[-- Dépôt détritique rouge en place

Dépôt détritique gris remanié

Dépôt détritique rouge remanié
Sédiments d'origine gravitaire
Poudre de calcaire ou stalagmitique

Clastes de desquamation

Blocs d'effondrement 
Sédiments

\section{carbonatées}
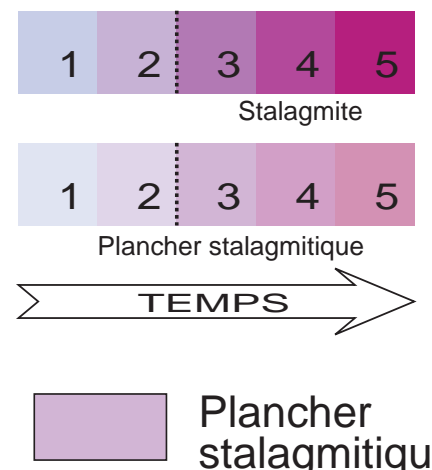

Plancher

stalagmitique

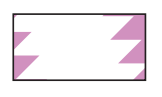

Encroûtement

stalagmitique

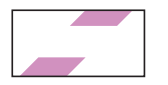

Nappage

stalagmitique (fin)

Micro-gours étagés

$\curvearrowright$ Micro-gours

- Stalagmite

- Colonne

$\because \quad$ Stalagmite corrodée

Stalactite cassée

Stalagmite cassée

- Stalagmite basculée

Stalagmite avec picots

Concrétionnement

lié à l'évaporation

Fleur de

calcite

\section{Formes et micro-formes} d'érosion

$\int$ Coupole de paroi

- Coupole de voûte

$\int$ Marmite d'érosion

๑ Impact de goutte

M Cône lié à des

1 écoulements laminaires

Incision (ruissellement)

\section{Éléments anthropiques et préhistoriques}

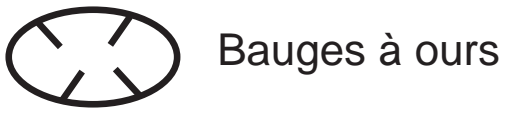

Traces et/ou empreintes

$\bigcirc$ Ossement

Ossement altéré

Indice anthropique

Bloc déplacé 


\title{
Annexe 4
}

\section{ÉTUDE SÉDIMENTOLOGIQUE DES DÉPÔTS FINS ENDOKARSTIQUES - SYNTHÈSE MÉTHODOLOGIQUE}

\author{
par Anne-Sophie PERROUX
}

La collecte de données et d'informations sur les sédiments détritiques souterrains s'articule en trois grands temps. La plupart des méthodes mises en œuvre découlent logiquement des protocoles classiquement utilisés en sédimentologie « de surface ». L'application de ces outils et savoir-faire à l'endokarst peut impliquer des ajustements, le plus souvent d'ordre pratique.

\section{Méthodes de TerRaiN}

Le travail de terrain s'initie le plus souvent par la topographie et la cartographie morphologique des sols (figure 1). Ce relevé exhaustif des dépôts et de leur répartition spatiale améliore la connaissance de la cavité. Il permet aussi de déterminer les zones à étudier plus en détails, avec d'autres techniques :

- Les sondages profonds à la tarière (figure 2) sont un moyen d'observer la stratigraphie des dépôts et de dresser des profils, sur plusieurs mètres de profondeurs. Les sédiments sont par contre déstructurés et ne peuvent pas être récupérés.

- Les prélèvements de sédiments, par carottage ou profilés (figure 3) permettent de garder les dépôts intacts (organisation, nature) pour les analyses de laboratoire.

À ces méthodes vient s'ajouter la tomographie électrique, moyen de prospection non destructif des dépôts en profondeur (cf. annexe 6).

\section{MÉTHOdes DE LABORATOIRE}

Sur les sédiments ramenés au laboratoire, plusieurs outils analytiques peuvent être mis en œuvre :

- La granulométrie laser donne la composition précise des sédiments, avec les tailles de grains (des argiles aux sables) et leurs proportions relatives. En pratique, le sédiment peut être analysé de façon quasi-continue (1 mesure/3 mm), ce qui fournit des courbes de l'évolution granulométrique du dépôt en fonction de la profondeur (figure 4).

- L’imagerie en niveaux de gris, la colorimétrie et la susceptibilité magnétique sont d'autres techniques qui permettent d'analyser la composition du sédiment (niveaux grossiers, ferro-magnétiques) et son évolution, à haute résolution spatiale (figure 5).

- L'étude exoscopique des niveaux grossiers à la loupe binoculaire (figure 6) ou au microscope est importante pour préciser la composition minéralogique (sources de matières) et les conditions de transport des sédiments (degré d'usure).

\section{MéTHOdes de TRAITEMENTS DES DONNÉES}

Le traitement des données acquises se fait autant par des outils sédimentologiques, comme les images de Passega (figure 7), que par des méthodes statistiques telles que l'analyse en composantes principales (figure 8) ou de traitement du signal par ondelettes (figure 9).

Ces différents outils, souvent à résolution graphique, apportent des informations sur l'identification des contextes hydrodynamiques de transport et de dépôt des sédiments, sur le degré d'information restitué par chaque signal, et les corrélations qui peuvent s'observer pour certains d'entre eux.

L'ensemble de cette démarche permet de proposer des interprétations et des hypothèses sur les conditions environnementales lors de la mise en place des dépôts, sur les types de pièges sédimentaires et les sources de matière, sur la qualité de l'archivage sédimentaire en tant que mémoire environnementale. Elle contribue également à la compréhension des grandes phases karstogénétiques d'un réseau tel que celui d'Orgnac, des événements plus particuliers qui ont jalonné son histoire, et de sa place dans le contexte paléogéographique régional. 
Du terrain au laboratoire : des prélèvements aux traitements des données.

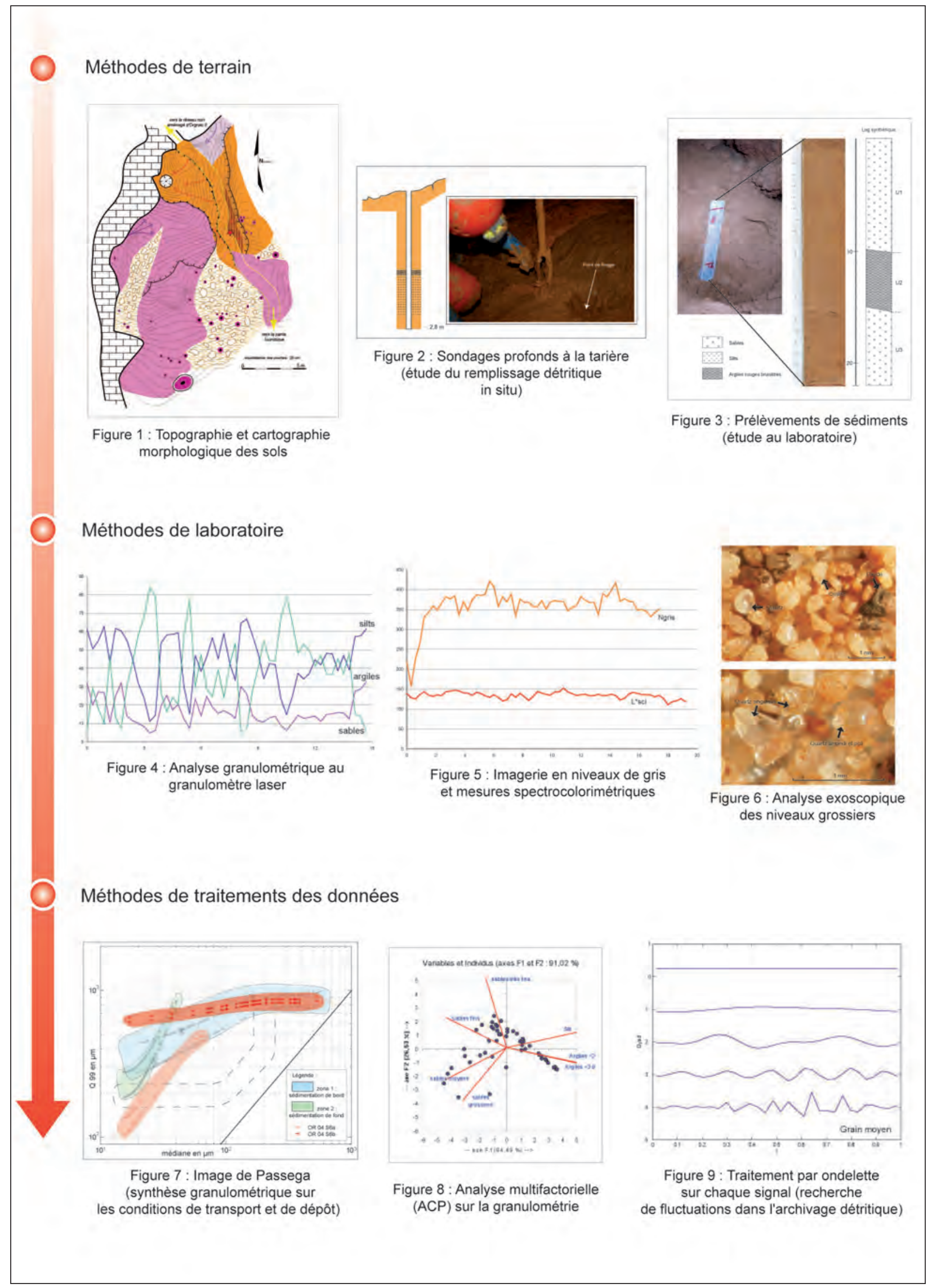




\title{
Annexe 5
}

\section{DATATIONS U /Th DES STALAGMITES}

\author{
par Yves QUINIF
}

La radioactivité est un phénomène physique par lequel un élément "père" donne naissance à un élément "fils" par perte d'un noyau d'hélium (rayonnement $\alpha$ ), d'électron (rayonnement $\beta$ ) et de photon $\gamma$ (énergie). La radioactivité est un phénomène dépendant du temps selon une loi bien connue. On peut ainsi dater la fermeture d'un système géochimique (la cristallisation d'une stalagmite par exemple) par la mesure de l'activité entre une espèce père et une de ses espèces fils. On parle donc de chronologie absolue. Différents couples isotopiques sont utilisés comme géochronomètres dans les spéléothèmes. Le couple U/Th est fréquemment utilisé dans l'étude des stalagmites. Différents auteurs ont décrit les fondements de cette méthode (Schwarcz 1986 ; Quinif 1990 ; Gascoyne 1992 ; Ford in Hill et Forti 1997).

La figure ci-dessous (Quinif, 1990) présente les fondements de cette méthode. Lorsque l'eau de pluie

\section{Cheminement géochimique de l'uranium et du thorium} dans la zone non saturée du karst.

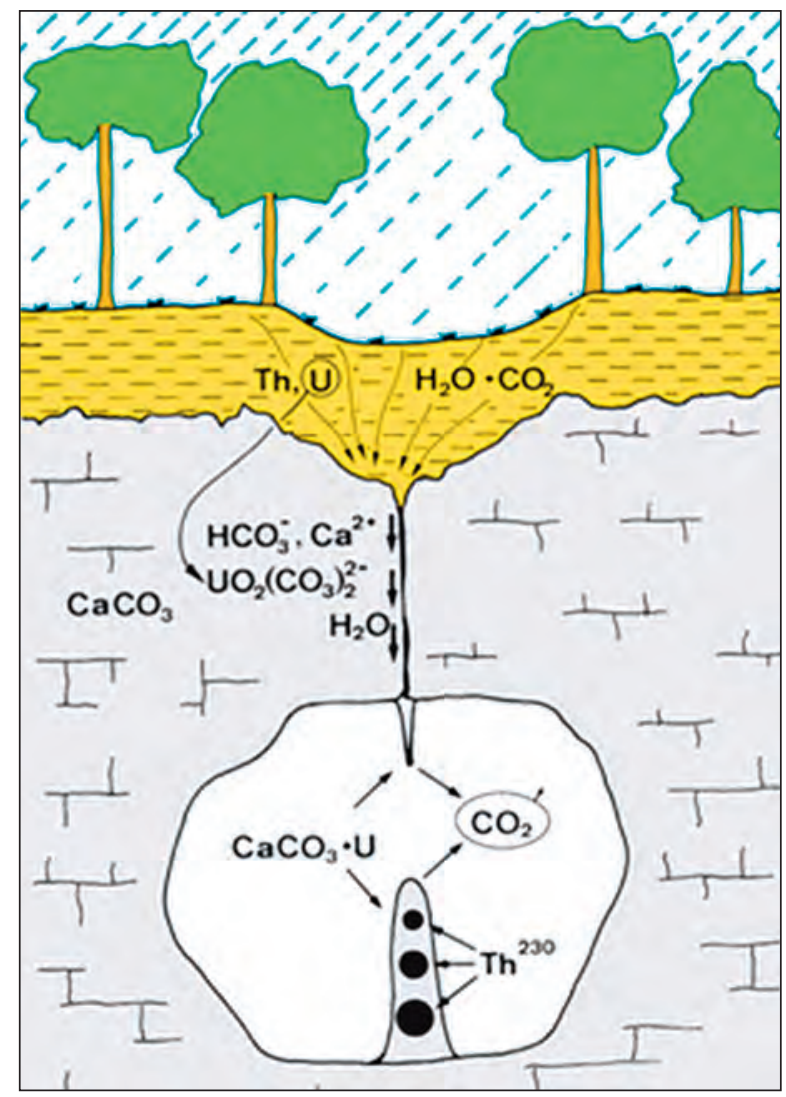

transite dans le sol, elle dissout de l'uranium soluble sous sa forme oxydée mais non le thorium. Cette dissolution mobilise deux isotopes de l'uranium $\left({ }^{234} \mathrm{U}\right.$ et ${ }^{238} \mathrm{U}$ ) mais n'entraîne pas de ${ }^{230} \mathrm{Th}$, descendant insoluble de $\mathrm{l}^{, 234} \mathrm{U}$. Lorsque l'eau précipite la calcite stalagmitique dans une cavité, seuls les deux isotopes de l'uranium se fixent dans le cristal ainsi formé. Au cours

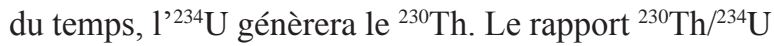
constitue l'horloge radioactive proprement dite ; il tend vers 1 vers $6.10^{5}$ ans, la méthode est considérée fiable jusque environ $3,5.10^{5}$ ans. La fiabilité de cette horloge naturelle dépend d'une part de l'absence initiale de thorium dans la calcite, or cette absence théorique est liée à son insolubilité, d'autre part de la fermeture du système.

Lors de leur croissance, les stalagmites peuvent piéger des particules, voire des molécules insolubles transportées par accrétion ou floculation au sein de la calcite. Dans ce contexte, on comprend bien que cette absence initiale de thorium est problématique et théorique. Un marqueur permet de tester cette absence théorique, il s'agit de l'isotope ${ }^{232} \mathrm{Th}$. Celui-ci n'appartient pas à la famille radioactive de l'uranium. Il peut être transporté par accrétion sur les collö̈des d'argiles ou complexion avec les molécules organiques, et se retrouver ainsi piégé dans la calcite lors de la fermeture géochimique du système. Pour cette raison, $\mathrm{ce}^{232} \mathrm{Th}$ est appelé thorium détritique. Ainsi, en mesurant le rapport d'activité du ${ }^{230} \mathrm{Th} /{ }^{232} \mathrm{Th}$ on doit, théoriquement, trouver une valeur élevée si la concrétion ne contenait pas de thorium détritique lors de la fermeture du système chimique. En pratique, on considère que ce rapport doit être supérieur à 20 pour que l'âge soit fiable. Un rapport faible vieillit l'âge obtenu, ce qui est néanmoins une information, certes non absolue.

L'altération d'une concrétion, en ouvrant son système géochimique, peut enlever ou apporter de l'uranium, et ainsi perturber l'état initial du système. L'horloge radiologique n'est donc plus à 0 et conduit à un âge incorrect. Apparaît ici une limite des datations dans le domaine des études environnementales. Les concrétions intéressantes du point de vue de l'environnement humain et biopédologique sont bien souvent connectées à la surface. Elles contiennent donc des inclusions et des molécules organiques rendant leur datation isotopique difficile. 

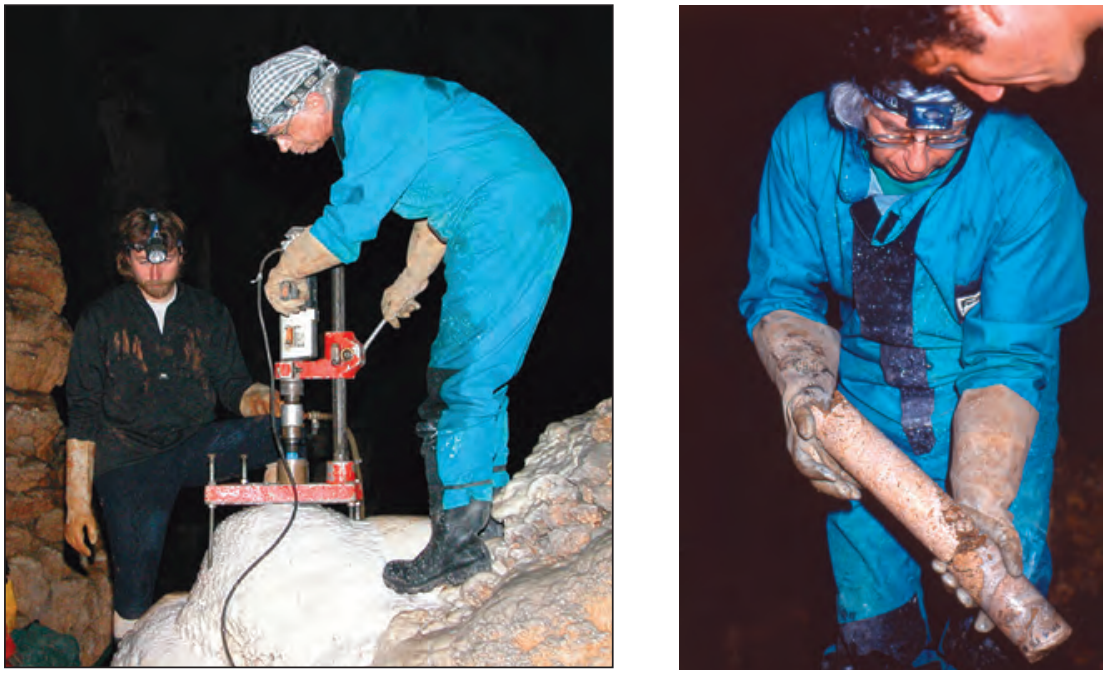

Carottage d'un édifice stalagmitique sur le cône d'éboulis, au bas du puits d'entrée, Salle de Joly (11-12 juin 2003) (photos Pierre Gotteland et Françoise Prud'homme).

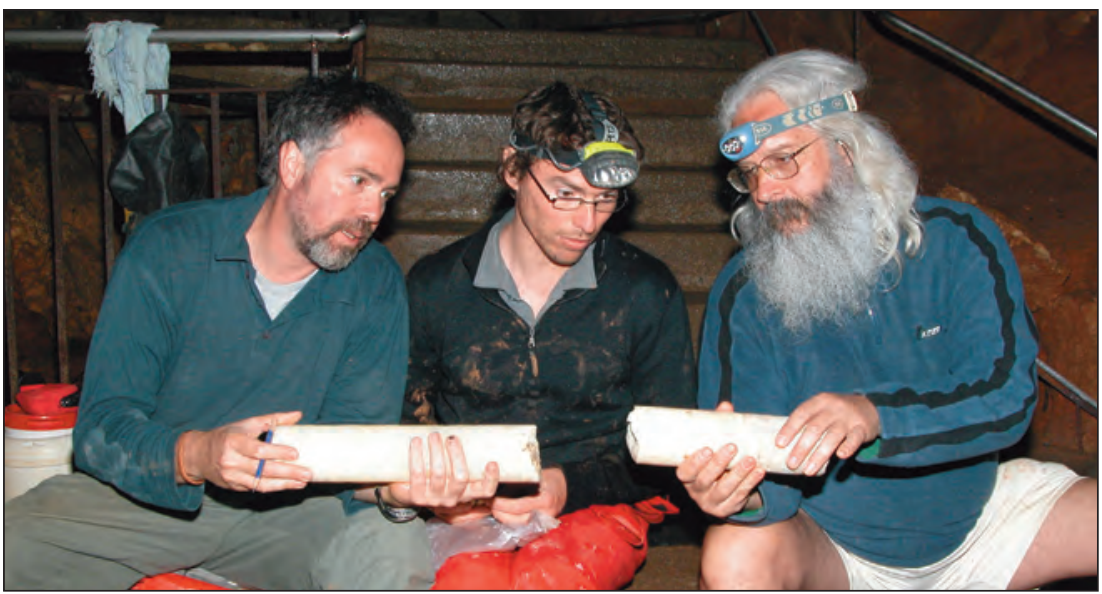

\section{Exemples d’analyses SuR Un ÉChantillon de la Salle de Joly}

La première colonne comprend le nom de l'échantillon, la deuxième colonne donne la teneur en uranium exprimée en ppm (parties par millions, soit le nombre de milligrammes d'uranium par kilogramme de stalagmite), la troisième le rapport isotopique entre $l^{2234} U$ et $l^{1238} U$, la quatrième le rapport isotopique entre le ${ }^{230} \mathrm{Th}$ et $l^{234} U$, la cinquième le rapport isotopique entre le ${ }^{230} \mathrm{Th}$ et $l^{232} \mathrm{Th}$, la sixième le rapport isotopique entre l $l^{234} \mathrm{U}$ et l'238 $\mathrm{U}$ à l'instant initial et, enfin, la septième, l'âge de l'échantillon. Le rapport isotopique entre l ${ }^{234} U$ et l l'238 $U$ intervient dans le calcul de l'âge parce que ces deux isotopes, bien que possédant les mêmes propriétés chimiques (ce sont tous les deux de l'uranium), ont la plupart du temps un rapport isotopique différent de 1 dans les eaux d'infiltration et, par là-même, dans les spéléothèmes. Le rapport isotopique entre le ${ }^{230} \mathrm{Th}$ et l l'234 $U$ constitue l'horloge proprement dite. Le rapport isotopique entre le ${ }^{230} \mathrm{Th}$ et le ${ }^{232} \mathrm{Th}$ est un indice qu'il pourrait y avoir $d u^{230} \mathrm{Th}$ en provenance d'une source autre que son «père» direct, $l^{2234} U$. On estime que, pour qu'un âge soit fiable, il faut que ce rapport isotopique soit supérieur à 20. En dessous, il existe une probabilité non négligeable que l'âge soit faux, généralement plus vieux que l'âge réel à cause de la présence de ce ${ }^{230} \mathrm{Th}$ "étranger». Le rapport isotopique entre l ${ }^{2344} U$ et l l'238 $U$ à l'instant initial est calculé à partir des autres paramètres. C'est une variable qui n'intervient pas dans l'âge mais qui apporte des informations précieuses sur la géochimie de la concrétion étudiée. Enfin, les erreurs indiquées entre crochets proviennent de la nature statistique des mesures. Il faut les lire de la manière suivante :10[+-2] signifie qu'il y a 67\% de chances pour que la valeur se situe entre 8 et 12, 10 étant la valeur la plus probable.

\begin{tabular}{|c|c|c|c|c|c|c|}
\hline Échantillon & [U]ppm & $234 \mathrm{U} / 238 \mathrm{U}$ & $230 T h / 234 \mathrm{U}$ & $230 T h / 232 T h$ & {$[234 \mathrm{U} / 238 \mathrm{U}] \mathrm{t}=0$} & Âge (en m.a.) \\
\hline $1 / 03-1$ & $0,068 \pm 0,001$ & $1,013 \pm 0,016$ & $0,829 \pm 0,023$ & $43 \pm 7$ & 1,022 & $189,9[+17,8 /-14,9]$ \\
\hline $1 / 03-1 \mathrm{~b}$ & $0,065 \pm 0,001$ & $1,031 \pm 0,012$ & $0,803 \pm 0,017$ & $92 \pm 25$ & 1,051 & $173,6[+10,71-94,9]$ \\
\hline
\end{tabular}




\title{
Annexe 6
}

\section{TOMOGRAPHIE ÉLECTRIQUE}

\author{
par Olivier KAUFMANN
}

\section{Principe}

La méthode choisie est une méthode géophysique d'imagerie géoélectrique aussi appelée tomographie en résistivité électrique. La méthode comporte deux étapes :

\section{Le panneau électrique}

Il s'agit de la réalisation d'une série de mesures de résistivités électriques apparentes à l'aide d'électrodes réparties à la surface du sol le long d'un profil (panneau électrique);

\section{La tomographie}

Il s'agit du calcul d'une coupe verticale (section) montrant les résistivités des matériaux qui constituent le sous-sol le long du profil. Cette coupe résulte d'un traitement mathématique (inversion) des mesures effectuées dans la première étape.

Le choix de cette méthode se justifie, d'une part, parce que le contraste de résistivité entre la roche calcaire massive et les sédiments meubles qui les surmontent est, en règle générale, élevé et, d'autre part, du fait de la possibilité d'une reconstruction géométrique.

\section{Panneau électrique}

Cette technique d'investigation indirecte du sous-sol consiste généralement à déplacer un quadripôle (soit 4 électrodes) le long d'un parcours linéaire appelé profil. Ce quadripôle est constitué de deux électrodes dites d'émission (A et B sur la figure ci-dessous) et de deux électrodes dites de réception ( $\mathrm{M}$ et $\mathrm{N})$.
Les investigations sur le terrain consistent en la mesure de deux paramètres:

- l'intensité du courant injecté via le circuit d'émission (I) ;

- la différence de potentiel générée entre les électrodes de réception $(\mathrm{V})$.

Dans un milieu constitué d'un demi-espace homogène, il est possible de déduire de ces deux grandeurs, en tenant compte d'un facteur géométrique associé à la configuration du quadripôle, la résistivité électrique des terrains (application de la loi d'Ohm). Cette résistivité électrique, caractéristique du matériau est nommée résistivité effective.

Lorsque le milieu n'est pas homogène, la résistivité mesurée de cette manière est une résistivité apparente. Cette résistivité résulte en effet de la contribution de l'ensemble des résistivités des différentes formations occupant le volume de terrain dans lequel s'écoulent les courants.

En pratique, les mesures de résistivité électrique réalisées sont donc des mesures de la résistivité apparente du sous-sol. La valeur de la résistivité apparente mesurée dépend bien entendu de la valeur et de la distribution spatiale des résistivités effectives en sous-sol mais aussi de la position et de la géométrie du quadripôle avec lequel cette mesure est réalisée.

Dans le cadre de la présente étude, nous avons retenu deux types de dispositifs de mesure: les dispositifs dipôle-dipôle et les dispositifs Wenner-Schlumberger.
Lignes de courants et équipotentielles associées à un quadripôle Wennerdans un milieu homogène.

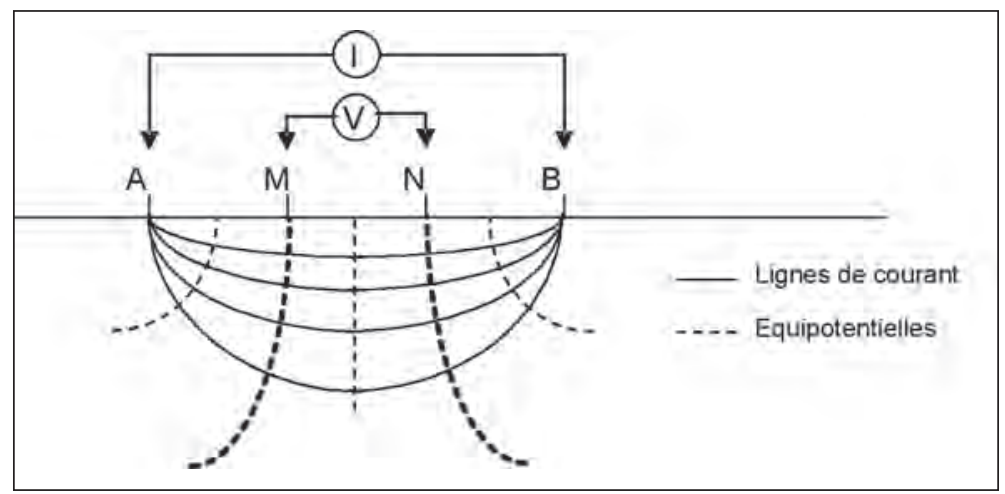

Dispositifs dipôle-dipôle et Wenner-Schlumberger $C$ : électrodes d'injection de courant, $P$ : électrode de mesure de potentiel.

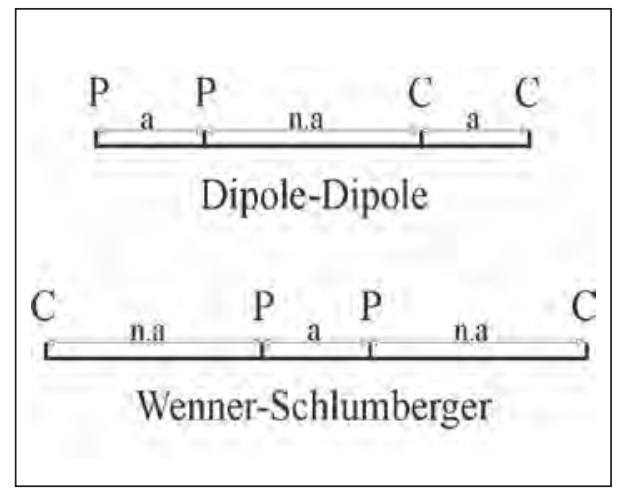




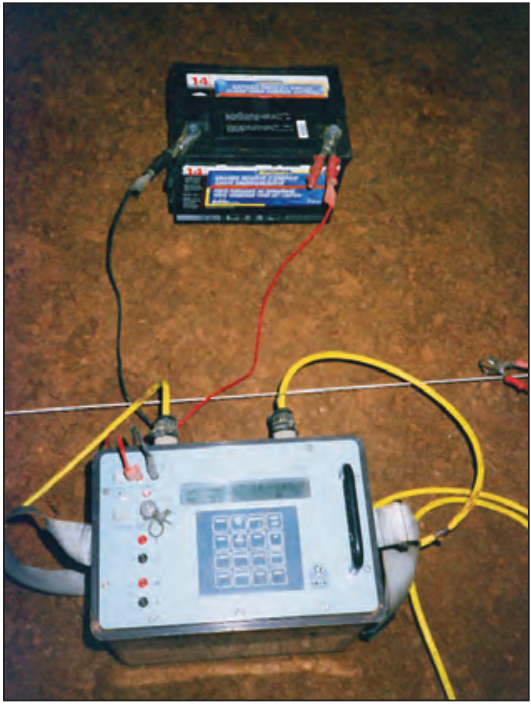

Mise en ouvre du matériel tomographique dans la Salle Plane en 2002 (photo Anne-Sophie Perroux).

Ces configurations ont des réponses différentes à la présence de discontinuités dans le sous-sol, ce qui justifie l'utilisation de plusieurs configurations lors d'une même prospection.

Par ailleurs, pour une même configuration, des tailles de dispositif croissantes permettent d'intégrer, dans la résistivité apparente mesurée, la contribution de terrains situés plus profondément.

Une série de séquences de mesures adaptées au cas étudié a été élaborée. Les mesures ont été réalisées en plusieurs implantations, chaque implantation comportant au maximum 48 électrodes. À la fin de chaque implantation et avant chaque série de mesures, les résistances de prise de chacune des électrodes ont été contrôlées.

Afin d'assurer une fiabilité maximale des résultats, chaque mesure de résistivité a été réalisée au moins à trois reprises, plus si nécessaire. La valeur moyenne et la dispersion de chaque mesure ont été enregistrées. Enfin, les quelques mesures qui présentaient une dispersion jugée trop importante ont été écartées de la suite du traitement.

\section{TOMOGRAPHIE ÉLECTRIQUE}

La tomographie électrique consiste à construire une section en résistivités effectives en accord avec les résistivités apparentes mesurées le long du profil. La reconstruction de la répartition spatiale des résistivités effectives en sous-sol permet en effet d'inférer la nature et la géométrie des ensembles géologiques. Ceci est bien entendu conditionné par un contraste de résistivité suffisant entre les ensembles que l'on souhaite distinguer. Remarquons d'ailleurs que la teneur en eau des sédiments a une influence importante sur la résistivité de la formation. En règle générale, cette dernière diminue sensiblement lorsque la teneur en eau et en matériaux argileux du sédiment augmente.

La reconstruction d'une section en résistivités effectives à partir des résistivités apparentes mesurées est un problème d'inversion dont la solution n'est pas unique. Il convient de contraindre la solution à ce problème en fonction du contexte géologique afin d'approcher au mieux la réalité.

Dans le cadre de ces travaux, les différentes tomographies sont calculées en combinant les résistivités mesurées avec les deux dispositifs. Le reliefdu sol le long des profils est aussi pris en compte lors de l'inversion. La section obtenue au terme de l'inversion est un modèle bidimensionnel de répartition des résistivités effectives construit de telle sorte que les résistivités apparentes que l'on mesurerait sur un terrain présentant cette configuration soient aussi proches que possibles de celles réellement mesurées. Un indicateur (RMS error) permet d'apprécier la qualité de l'ajustement. Notons que le modèle repose sur un découpage de la section en petites blocs supposés homogènes du point de vie de leur résistivité. Dans le cas d'un milieu fortement hétérogène tel que des petits blocs de calcaire emballés dans des sédiments argileux ou des calcaires très fracturés et dont les fractures sont remplies d'argile, la résistivité de l'ensemble dépendra bien entendu des proportions relatives et des résistivités des différentes composantes du milieu.

Tomographie électrique de la Salle Plane : localisation et profil des résistivités (Kaufmann, 2002).

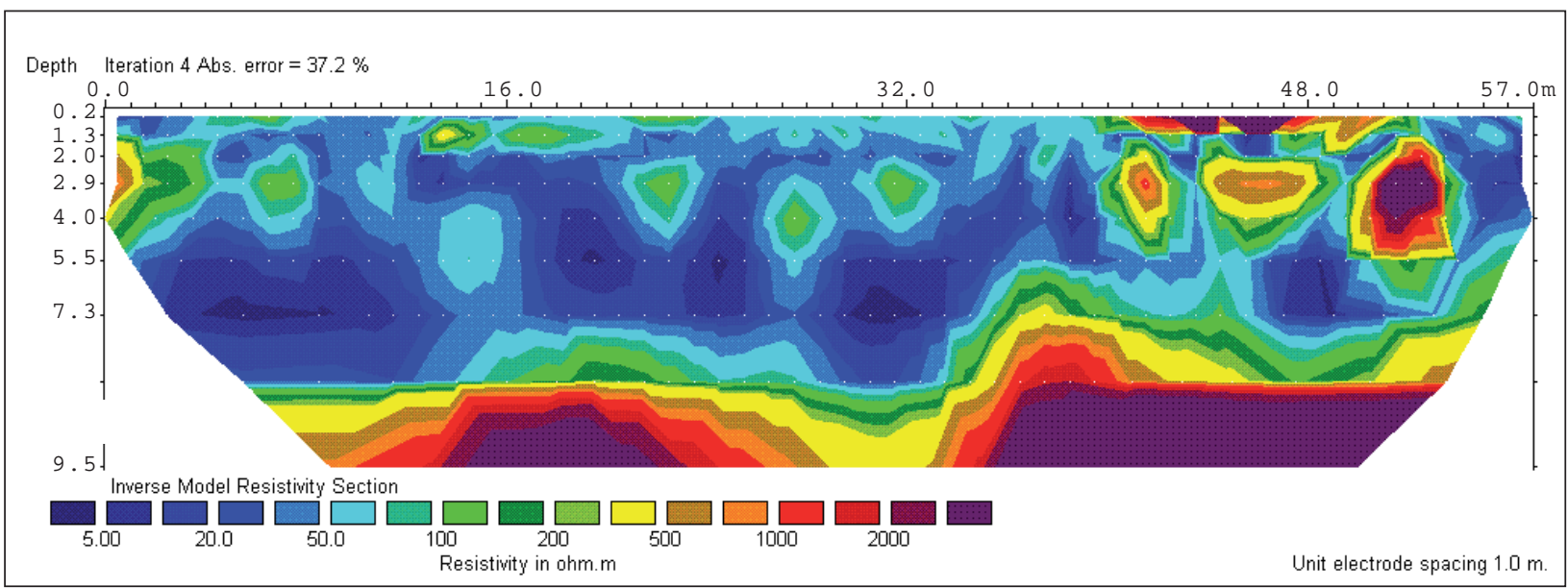




\title{
Annexe 7
}

\section{CLIMATOLOGIE SOUTERRAINE}

\author{
par François BOURGES, Alain MANGIN, Dominique D’HULST, Pierre GENDON et Françoise GAUQUELIN
}

Le dispositif d'acquisition des températures à l'Aven d'Orgnac est constitué par une centrale AOIP SA32 connectée à des capteurs de type résistances de platine Pt100 répartis dans cinq zones le long de la cavité (de $-45 \mathrm{~m}$ à $-135 \mathrm{~m}$ sous la surface). Ce type de dispositif a déjà largement été utilisé par notre équipe dans d'autres sites souterrains. La précision absolue des capteurs de température est de $0,3^{\circ} \mathrm{C}$, mais elle a été largement améliorée, premièrement par un calibrage absolu de la centrale par une référence Pt100 étalon, ensuite par un calibrage de l'ensemble de la chaîne de mesure dans la grotte. De plus, une résistance de $100 \Omega$ a été incluse dans la chaîne de mesure pour contrôler une éventuelle dérive ou des dysfonctionnements de la centrale. La précision absolue des mesures peut être évaluée à presque $0,05^{\circ} \mathrm{C}$, avec une précision relative de $0,01^{\circ} \mathrm{C}$ et une sensibilité de $0,001^{\circ} \mathrm{C}$. Un hygromètre à miroir refroidi (Général Electric, type M4 avec capteur de haute précision) mesure l'humidité relative avec une précision de $1 \%$ et une résolution de $0,01 \%$. La radioactivité alpha du radon est obtenue à partir d'une sonde Barasol de la société Algade, un détecteur en silicium passivé détecte et permet le comptage par spectrométrie des atomes de ${ }^{222} \mathrm{Rn}$ et de ses descendants créés dans le volume de détection (fenêtre de comptage réglée entre $1.5 \mathrm{MeV}$ et $6 \mathrm{MeV}$ ). L'étalonnage de la sonde permet de calculer l'activité volumique $\mathrm{du}^{222} \mathrm{Rn}$. Sensibilité : 0,02 impulsion. $\mathrm{h}^{-1}$ pour $1 \mathrm{~Bq} / \mathrm{m}^{3}$. $\left(1 \mathrm{~Bq} / \mathrm{m}^{3}\right.$ est équivalent à une concentration en radon de $1,77 \times 10^{-20}$ ). Deux capteurs de $\mathrm{CO}_{2}$ (Dreager Polytron IR $\mathrm{CO}_{2}$ à capteur infrarouge) et un baromètre complètent le réseau de mesure. Toutes les données sont enregistrées chaque 15 minutes. En surface, une station climatique comprenant un pluviomètre, une mesure de la température de l'air et un capteur de pression enregistre au même pas de 15 minutes. Nous avons complété le suivi par des expérimentations thermiques et des profils dans différentes salles.

Coupe de l'aven d'Orgnac et localisation des points de mesure thermique.

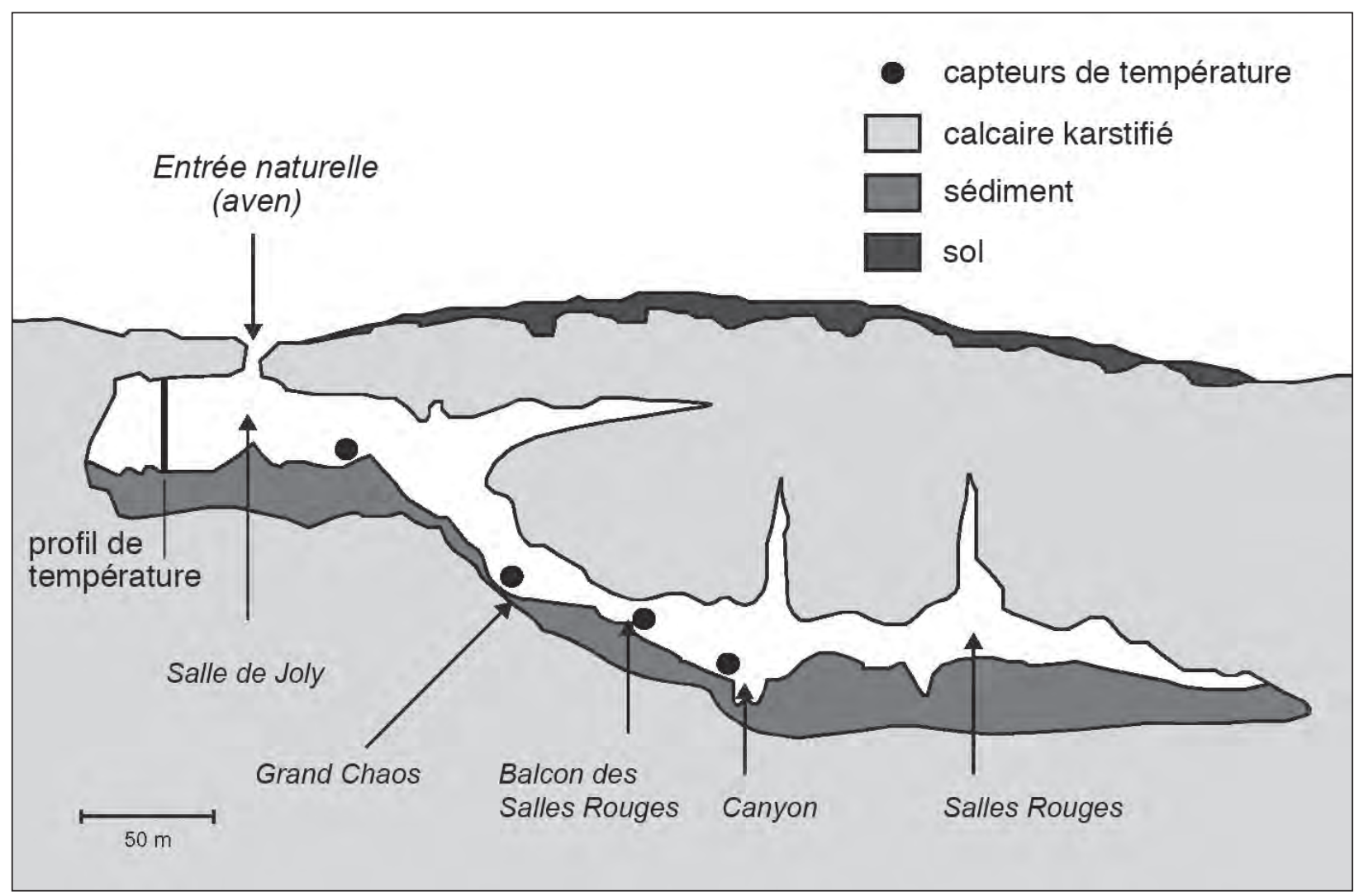


Les températures sont enregistrées dans les différentes salles du réseau souterrain (figure 1) depuis 1997. L'enregistrement a été arrêté pendant six mois en raison de la destruction du dispositif de mesure par l'inondation qui a suivi l'événement pluvieux centennal de septembre 2002. Les mesures ont repris depuis mars 2003, avec seulement trois capteurs thermiques : deux en Salle de Joly, un au Grand chaos. Afin de définir la stratification thermique à l'intérieur des salles, trois profils verticaux ont été réalisés en 2002, deux en Salle de Joly (entre le 24 janvier et le 25 janvier et entre le 7 août et le 8 août), un troisième dans la Salle Plane qui se trouve dans les parties lointaines du réseau (entre le 14 juin et le 19 juin).

Les données sont analysées avec différentes méthodes de traitement statistique du signal. Les analyses corrélatoires et spectrales (Mangin 1984) ${ }^{1}$ constituent le principal outil d'extraction de l'information, mais les transformations par ondelettes de Morlet ou de Meyer sont aussi couramment employées (figure $2 \mathrm{a}, \mathrm{b}$ ).

1 Mangin, A. 1984. Pour une meilleure connaissance des systèmes hydrologiques à partir d'analyses corrélatoires et spectrales. J. of Hydrol. 67: 27-43
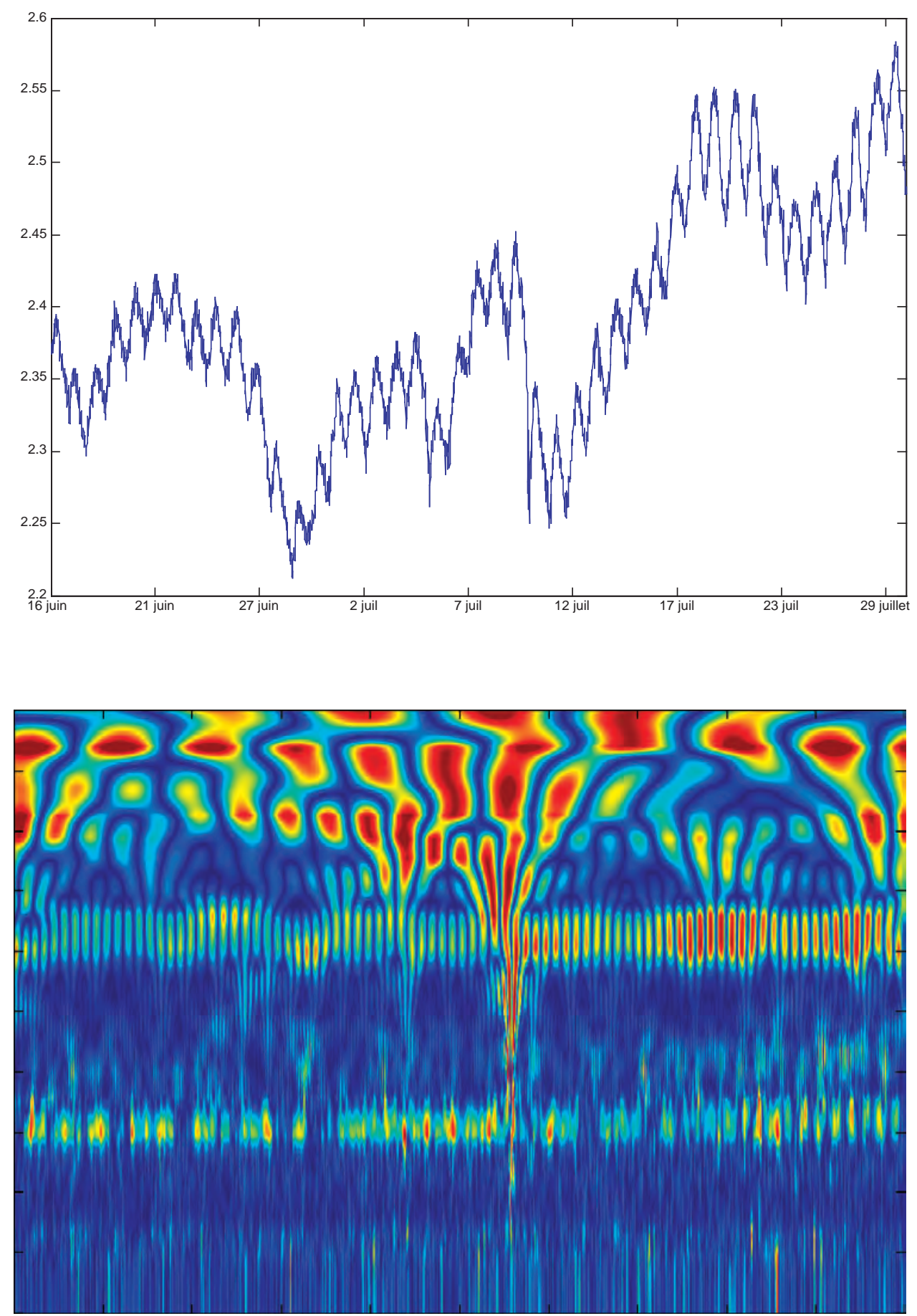

Figure 2

a) chronique des enregistrements du pourcentage volumique de $\mathrm{CO}_{2}$ dans l'atmosphère de la Salle de Joly à l'aven d'Orgnac $d u$ 16 juin au 29 juillet 2007 au pas du quart d'heure (4096 valeurs).

b) Décomposition en ondelettes de Morlet de cette chronique montrant que l'énergie du signal se répartit entre :

1) des variations de long terme (supérieur à 32 heures) qui sont associées à des effets météorologiques (variations thermiques ou évolution de la pression) influant essentiellement sur la ventilation de la Salle de Joly,

2) des variations de moyen terme (autour de 24 heures) dues également à des variations de la ventilation associées à l'effet thermique des alternances nuit-jour,

3) de petites variations de court terme (2,5 heures) attribuées à un effet de production par les groupes de visiteurs, ces variations sont invisibles sur la chronique brute. 


\title{
Annexe 8
}

\section{D ET RÉALITÉ VIRTUELLE}

\author{
par Estelle PLOYON
}

\section{OBJectiF}

L'étude des réseaux karstiques dans leur environnement topographique et géologique permet d'appréhender leurs contextes de développement et d'évolution. Cette approche est riche d'enseignements et contribue largement aux tentatives de reconstitutions paléogéographiques à l'échelle régionale. Les réseaux karstiques et la géologie ont pour spécificité de s'exprimer dans les trois dimensions de l'espace. Leur étude conjointe, intégrant cet aspect tri-dimensionnel, est aujourd'hui facilité par le développement des outils informatiques de conception et de visualisation 3D. Le site d'Orgnac a fait l'objet d'une étude autour des questions de 3D et de réalité virtuelle. Celle-ci répondait à une volonté d'apporter de nouveaux regards sur l'organisation et la mise en place des réseaux karstiques.

\section{EléMENTS MÉTHOdOLOGIQUES}

Il existe de nombreuses contraintes inhérentes à l'approche tri-dimensionnelle. Tout d'abord, on peut souligner le fait qu'une telle approche requiert des données en trois dimensions, lesquelles font souvent défaut. Ensuite, il s'agit de pouvoir traiter ces données très particulières, ce qui ne peut se faire qu'avec des outils spécifiques.

La réalisation d'une visualisation 3D nécessite également un préalable important : celui de constituer une base de données spatialisée. L'objectif est ici d'intégrer dans un référentiel commun l'ensemble des données de manière à pouvoir les traiter conjointement et à créer de nouvelles informations en reconstituant notamment la dimension verticale des données lorsque celle-ci n'est pas directement disponible. Dans le cas de l'étude conduite sur le site d'Orgnac au sein du laboratoire EDYTEM, différentes données de surface ont été rassemblées et intégrées dans un SIG (cartes géologiques, cartes topographiques, photographies aériennes, MNT). Quant aux données purement 3D, à savoir la géologie souterraine et le réseau karstique, elles ont été traitées directement à partir de logiciels de conception 3D (autocad, 3dsmax) mais mises en relation avec les données du SIG.
Ainsi, des coupes géologiques classiques en deux dimensions (altitudes et longueur de coupe) ont été traitées et repositionnées sur les profils topographiques en $3 \mathrm{D}$, générés à partir du MNT de surface. À partir de ces coupes géologiques tri-dimensionnelles et d'affleurements géologiques en 3D (générés à partir des cartes géologiques et du MNT), des horizons géologiques ont été reconstitués à proximité du réseau souterrain d'Orgnac.

Quant à celui-ci, sa représentation en trois dimensions a nécessité de nombreux traitements compte tenu des données initiales disponibles. Partant du plan et de la coupe du réseau souterrain sous format papier, il a d'abord fallu informatiser ces données et trouver les correspondances entre le plan et la coupe pour les repositionner l'un par rapport à l'autre. Ensuite, la coupe a pu être projetée sur le plan par segments et ainsi retrouver sa position dans l'espace. À ce stade, le réseau souterrain se résumait simplement à des données filaires plan-coupe qu'il fallait encore mailler en 3 dimensions de manière à obtenir un objet plus facilement lisible et utilisable dans une visualisation 3D.

\section{VisUALISATION 3D EN RÉALITÉ VIRTUELLE}

Les étapes concernant la géologie décrites précédemment ont dès lors permis d'envisager une représentation 3D de la géologie simplifiée autour du site d'Orgnac, et ce, en réalité virtuelle (figure 1).

Le réseau karstique a ensuite été replacé dans cet espace géologique souterrain de manière à considérer leur positionnement relatif (horizons géologiquesréseau souterrain). Cette confrontation des données n'a été possible qu'en raison du respect de l'unité du référentiel spatial tout au long du travail (figure 2).

Enfin, les potentialités des visualisations en réalité virtuelle ont été investiguées en ne travaillant pas simplement sur la confrontation des données mais également sur le rendu et son réalisme (figure 3).

La visualisation 3D apporte indéniablement de nouveaux regards sur les objets étudiés mais nécessite néanmoins des outils et des données spécifiques et dédiés à cette approche. 
Figure 1 : Surfaces géologiques reconstituées et Modèle Numérique de Terrain.

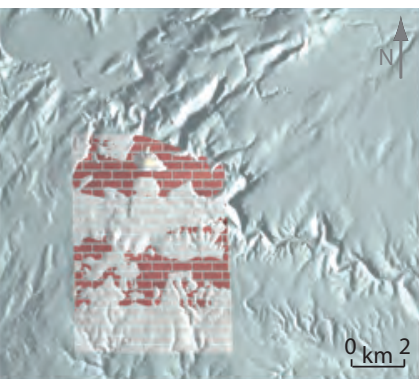

Vue de dessus

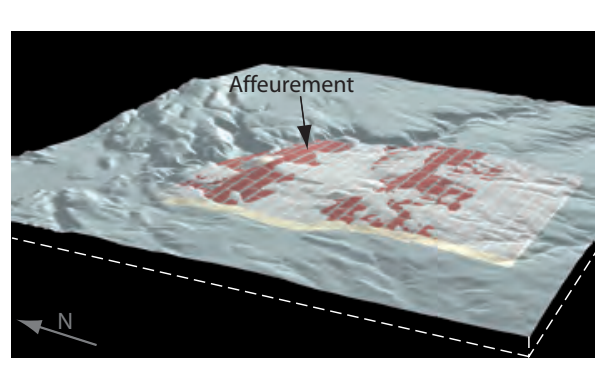

Vue en perspective et par transparence
Surfaces géologiques de l'Urgonien niveau inférieur et supérieur

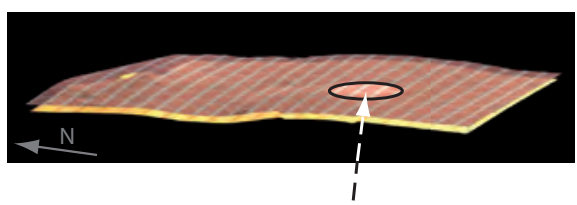

Emplacement des réseaux souterrains

Figure 2

Positionnement relatif du réseau souterrain et de des horizons géologiques.

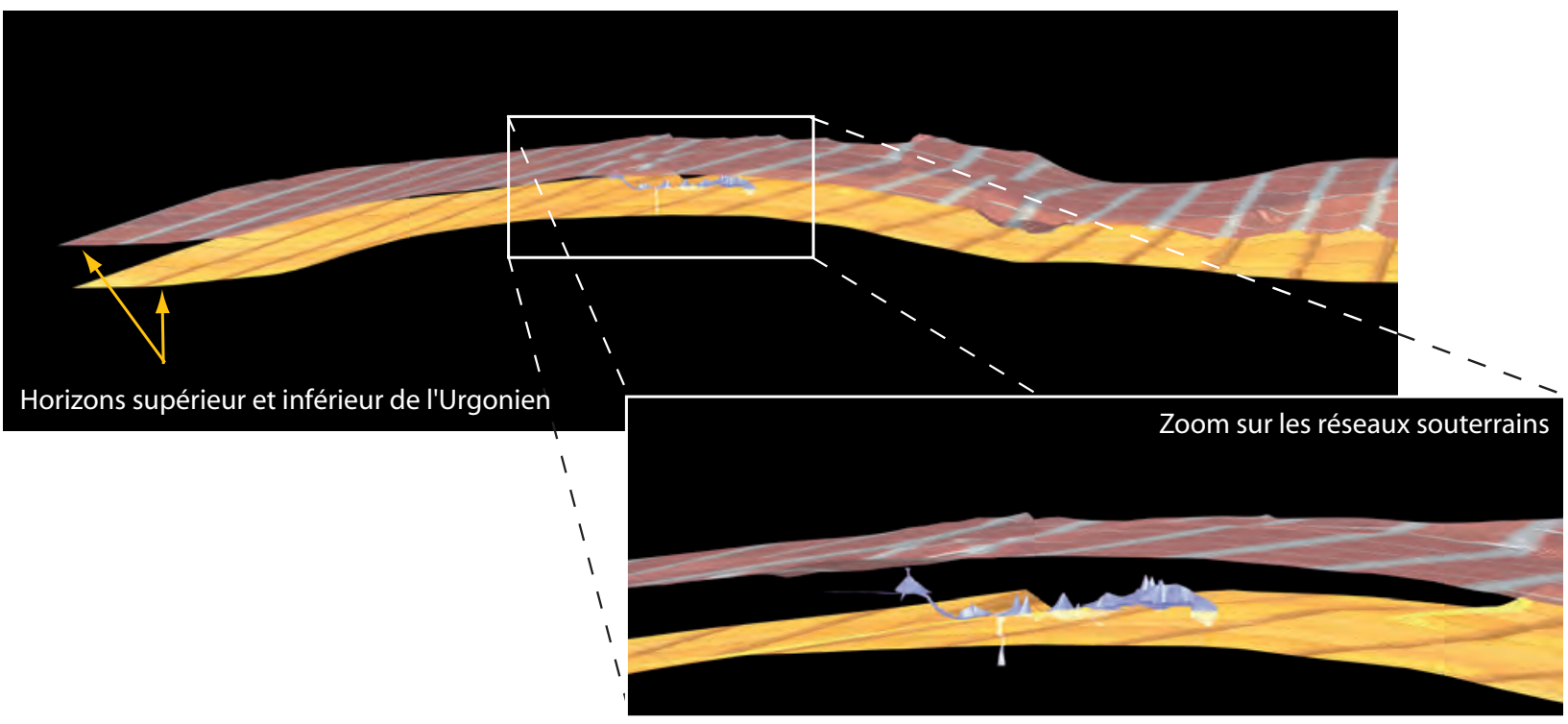

Figure 3

Photographies aériennes en $3 D$ avec un rendu d'éclairage différent
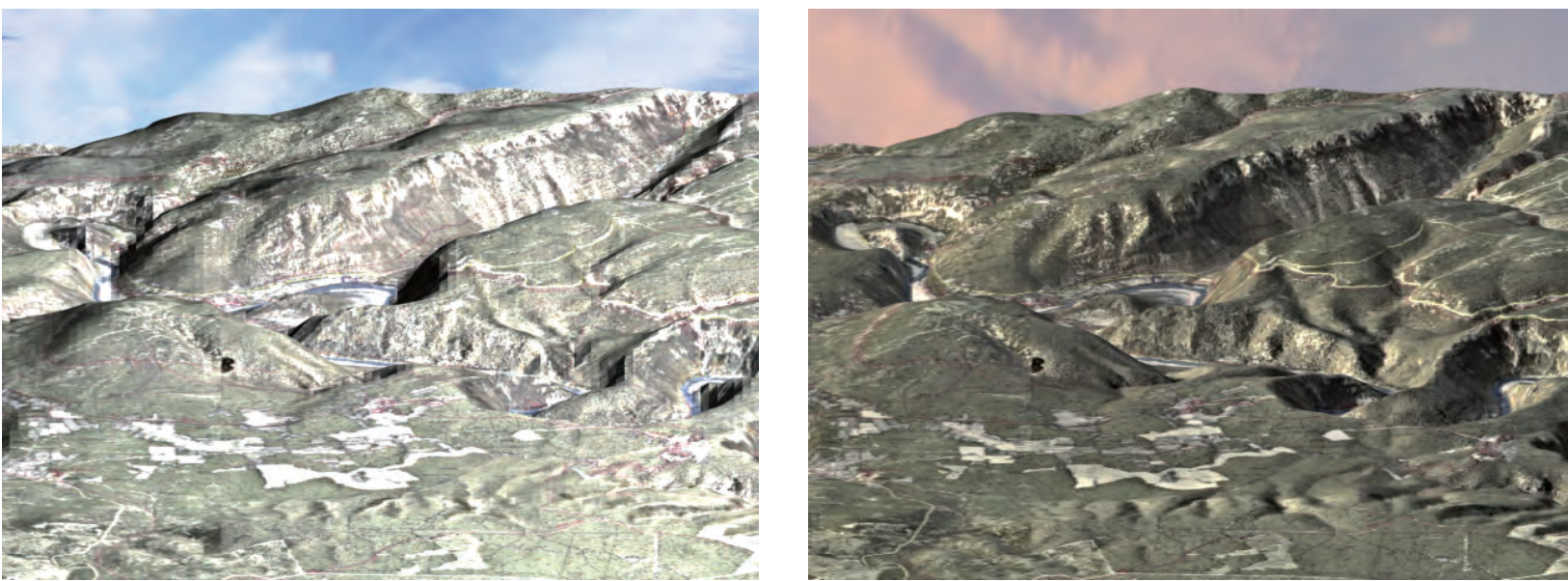


\section{LES AUTEURS}

Jean-Loïc BERSIHAND - Laboratoire EDYTEM, UMR 5204 CNRS

Université de Savoie, CISM, F 73376 Le-Bourget-du-Lac cedex

Vincent BIOT - Laboratoire EDYTEM, UMR 5204 CNRS

Séquence Nature Rhône-Alpes, Orée d'Ecully, 5 chemin de la Forestière, 69130 Écully - vincent.biot@free.fr

François BOURGES - Géologie-Environnement-Conseil,

30, rue de la République, 09200 St-Girons - geconseil@wanadoo.fr

Jean-Jacques DELANNOY - Laboratoire EDYTEM, UMR 5204 CNRS

Université de Savoie, CISM, F 73376 Le-Bourget-du-Lac cedex - jean-jacques.delannoy@univ-savoie.fr

Dominique D’HULST - Laboratoire de Moulis

CNRS, 09200 St-Girons

Mélanie DUVAL - Laboratoire EDYTEM, UMR 5204 CNRS

Université de Savoie, CISM, F 73376 Le-Bourget-du-Lac cedex - melanie.duval@univ-savoie.fr

Serge FUDRAL - Laboratoire EDYTEM, UMR 5204 CNRS

Université de Savoie, CISM, F 73376 Le-Bourget-du-Lac cedex - serge.fudral@univ-savoie.fr

Dominique GASQUET - Laboratoire EDYTEM, UMR 5204 CNRS

Université de Savoie, CISM, F 73376 Le-Bourget-du-Lac cedex - dominique.gasquet@univ-savoie.fr

Christophe GAUCHON - Laboratoire EDYTEM, UMR 5204 CNRS

Université de Savoie, CISM, F 73376 Le-Bourget-du-Lac cedex - christophe.gauchon@univ-savoie.fr

Françoise GAUQUELIN - Ministère de l'Écologie, du développement et de l'aménagement durables, CERTU, 9 rue Juliette Récamier 69456 Lyon cedex 06.

Pierre GENTHON - IRD Hydrosciences

Maison des Sciences de l'Eau, 34000 Montpellier - genthon@msem.univ-montp2.fr

Stéphane JAILLET - Laboratoire EDYTEM, UMR 5204 CNRS

Université de Savoie, CISM, F 73376 Le-Bourget-du-Lac cedex - stephane.jaillet@univ-savoie.fr

Olivier KAUFMANN

Faculté polytechnique de Mons, rue de Houdain 9, B-7000 Mons - olivier.kaufmann@fpms.ac.be

Alain MANGIN - Laboratoire de Moulis

CNRS, 09200 St-Girons - mangin.cnrs@free.fr

Matthieu NOURY - Laboratoire EDYTEM, UMR 5204 CNRS

Université de Savoie, CISM, F 73376 Le-Bourget-du-Lac cedex - noury.matthieu@caramail.com

Yves PERRETTE - Laboratoire EDYTEM, UMR 5204 CNRS

Université de Savoie, CISM, F 73376 Le-Bourget-du-Lac cedex - yves.perrette@univ-savoie.fr

Anne-Sophie PERROUX - Laboratoire EDYTEM, UMR 5204 CNRS

Université de Savoie, CISM, F 73376 Le-Bourget-du-Lac cedex- anne-sophie.perroux@univ-savoie.fr

Estelle PLOYON - Laboratoire EDYTEM, UMR 5204 CNRS

Université de Savoie, CISM, F 73376 Le-Bourget-du-Lac cedex - estelle.ployon@univ-savoie.fr

Françoise PRUD’HOMME - Musée régional de Préhistoire

Orgnac - Grand Site de France ${ }^{\circledR}, 07150$ ORGNAC-L'AVEN - f.prud'homme@orgnac.com

Yves QUINIF - CERAK (Centre d'études et de recherches appliquées au karst)

Faculté polytechnique de Mons, rue de Houdain 9, B-7000 Mons - yves.quinif@fpms.ac.be

Benjamin SADIER- Laboratoire EDYTEM, UMR 5204 CNRS

Université de Savoie, CISM, F 73376 Le-Bourget-du-Lac cedex - benjamin.sadier@univ-savoie.fr

Stéphane TOCINO - SIVU Orgnac-Issirac

Orgnac - Grand Site de France ${ }^{\circledR}, 07150$ ORGNAC-L’AVEN - infos@orgnac.com 


\section{COMPLETEZ VOTRE COLLECTION}

\section{CAHIERS SAVOISIENS DE GÉOGRAPHIE}

Numéro 1 (1997):

Transports et développement en Pays de Savoie

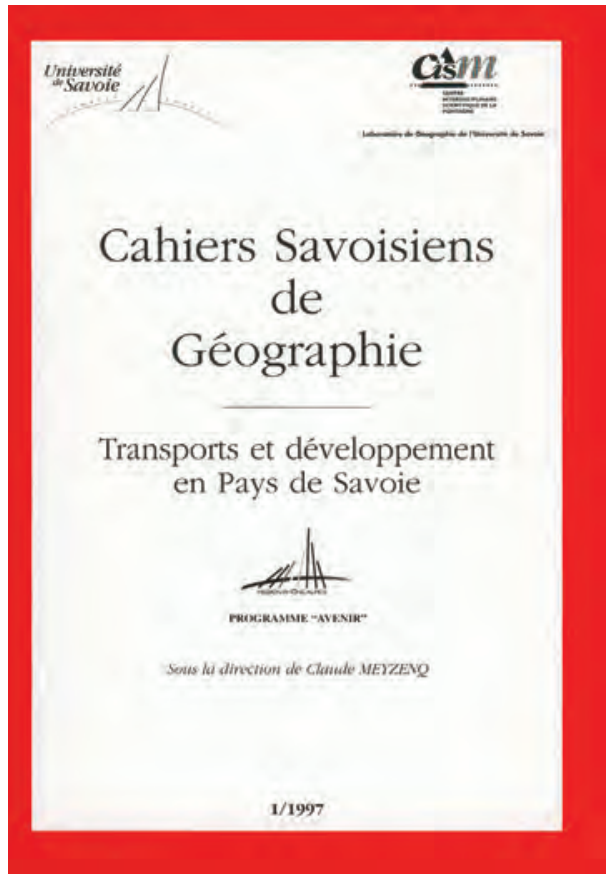

Transports, géographie et développement en Rhône-Alpes, et plus spécialement en Pays de Savoie par Claude MeyzenQ.

Les transports et Chambéry: de l'atavisme du carrefour à la nodalité européenne? par LiONEL LASLAZ.

La localisation des acteurs économiques dans la vallée de lArve depuis la construction de l'Autoroute Blanche par JEAN-FrançoIS DonQue.

Transport et développement urbain: un lien ancien devenu clé de l'avenir. L'exemple dAix-les-Bains (Savoie, France) par FABRICE MaUCCI.

La Maurienne: permanence et évolution d'un passage alpin par MichĖLE BoIs.

Les transports express régionaux: une nouvelle façon de concevoir le transport public. L'exemple de Rhône-Alpes par DaVID NAVET.

Le funiculaire «Arc-en-Ciel » de Bourg-Saint-Maurice - Les Arcs (Savoie). Un essai de reterritorialisation d'un espace-ski par un bourg traditionnel par SYLVAIN JAILLET.

Vers une spécificité de l'aéroport d'Annecy? par YanNick Roux.

Le rôle des transports et des échanges dans la formation historique du territoire savoyard par JEAN-LOUIS ARNAUD.

Numéro 2 (1999):

Livret guide des excursions Grands Causses - Vercors, 10-15 septembre 1999. Des paysages du karst au géosystème kartisque. Dynamiques, structures et en registrements karstiques.

Excursion 1: Le Valdonnez et ses marges (Lozère) par PhILIPPE Martin \& Albert Colas

Excursion 2: Le Larzac nord et le Causse de Campestre par LaURENT Bruxelles, Paul Ambert \& Jean-Louis Guendon

Excursion 3: Le Causse de Blandas, le Larzac sud et la Séranne par Hubert CAmus.

Excursion 4 : Le Vercors par Jean-Jacques Delannoy, Yves Perrette, Jean-Luc Destombes \& Jean-Luc Peiry

Numéro épuisé, disponible sur le web au format pdf http://www.univ-savoie.fr/labos/edytem/publilabo/cs/CSG.html

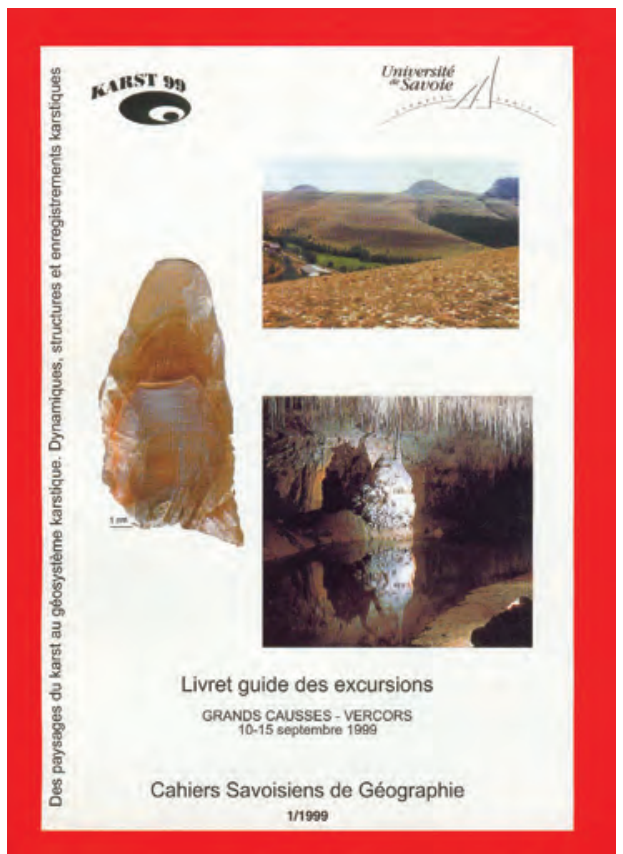


Numéro 3 (2000):

La géographie des risques dits «naturels» entre géographie fondamentale et géographie appliquée.

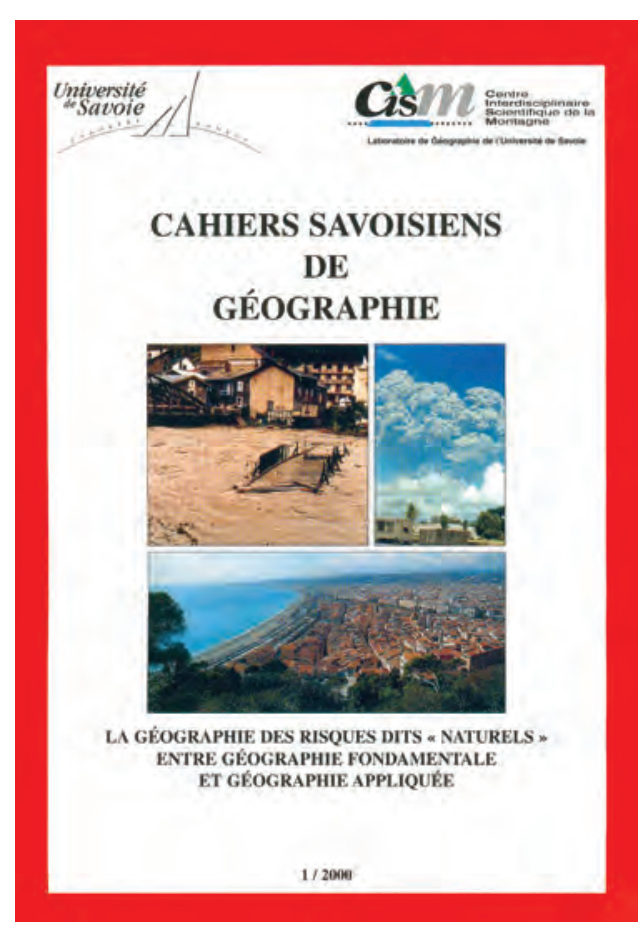

De l'intérêt de la démarche phénoménologique en géographie des risques par Patrick Pigeon.

Le système urbain niçois face à un séisme: Analyse des enjeux et dysfonctionnements potentiels par CÉLINE LUTOFF.

L'évaluation du risque à l'échelle internationale; Méthodologie et application aux diagnostics préalables aux actions de préparation et de prévention des catastrophes par RoBert D'ERCole \& PATRICK Pigeon, contribution de Claudine Misson

La vulnérabilité de Quito (Equateur) face à l'activité du Guagua Pichincha. Les premières leçons d'une crise volcanique durable par Robert D’Ercole \& Pascale Metzger

Implications territoriales de l'éruption du Mont Pinatubo pour la minorité autochtone aeta. Cas des bassins-versants des rivières Pasig et Sacobia (provinces de Pampanga et Tarlac, Philippines) par Jean-Christophe Gaillard, \& Frédéric Leone.

L'activité touristique face au risque cyclonique en " Guadeloupe Continentale. Approche de la vulnérabilité d'un secteur économique par MAUD LEREIN.

Aléas et risques dans un espace naturel: Le cas du parc national des Lacs Waterton (Alberta, Rocheuses canadiennes) par StÉPHANE HERITIER.

Gestion des risques et développement métropolitain: L'exemple de la forêt de l'Hautil (Ile-de-France) par Patrick Pigeon

L'Autoroute de Maurienne (A 43) et la prise en compte des risques naturels par Alain Marnezy \& CATHerine Pla.

\section{Numéro 4 (2001): \\ Identités et territoires.}

Et si on parlait enfin de territoire ! Territoires, identité et patrimoine, espaces images et représentations, ou comment réactualiser la géographie régionale par Claude MeyzenQ.

Patrimoine paysager, territoire viticole et périurbanisation: l'exemple du versant du Mont Granier par Lionel LasLaz.

Toponymie, tourisme et identité dans les Alpes du Nord par CHRISTOPHE GAUCHON.

La mise en valeur du patrimoine archéologique en Haute-Maurienne : le cas des gravures rupestres d'Aussois par Alain MARNEZY ET BERTRAND COFFY.

L'identité dans les topologies interurbaines. La structuration réelle et idéelle du réseau urbain dans le Valenciennois par Damien RATAJCZAK.

Une étude du concept d'ile linguistique: le cas de la langue Kapampangan (Central Luzon, Philippines) par Lino L. Dizon \& JeAn-Christophe Gaillard.

Identité et Territoire au Canada: La place des parcs nationaux des montagnes dans la construction identitaire nationale par STÉPHANE HÉRITIER.

L'identité savoyarde : Défense ou recherche d'une identité ? L'examen des mouvements identitaires par BENOÎT BRASSOU

Etude géographique des symboles identitaires extra-territoriaux en Savoie par Olivier SeVESSAND.

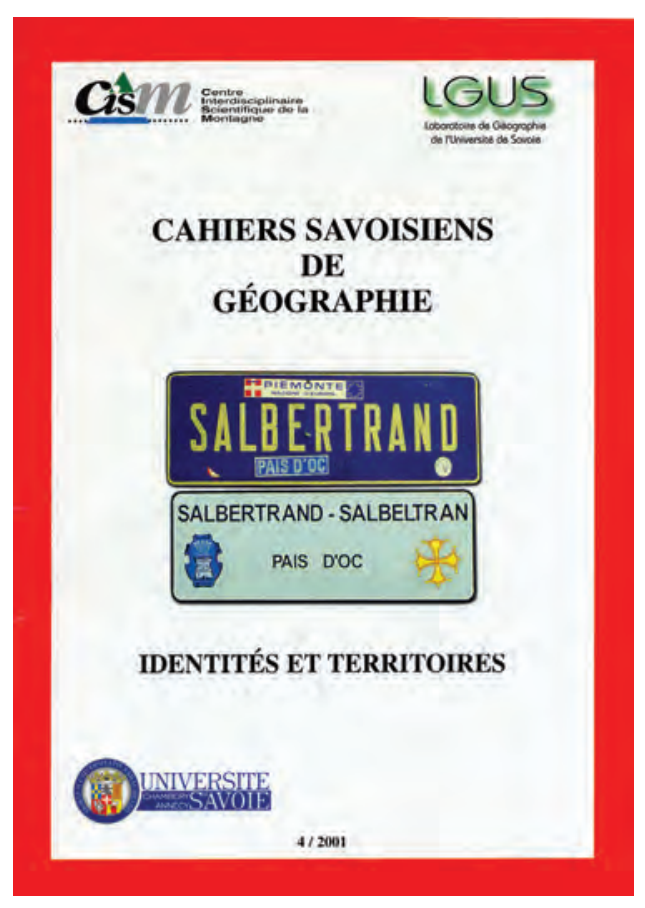




\title{
COMPLETEZ VOTRE COLLECTION
}

\section{Collection EDYTEM \\ Environnements, Dynamiques et Territoires de la Montagne}

\section{Cahiers de Géographie}

\author{
Numéro 1 (2003): \\ Dynamique et vulnérabilités des milieux montagnards méditerranéens et alpins. \\ Mélanges offerts au Professeur René Lhénaff.
}

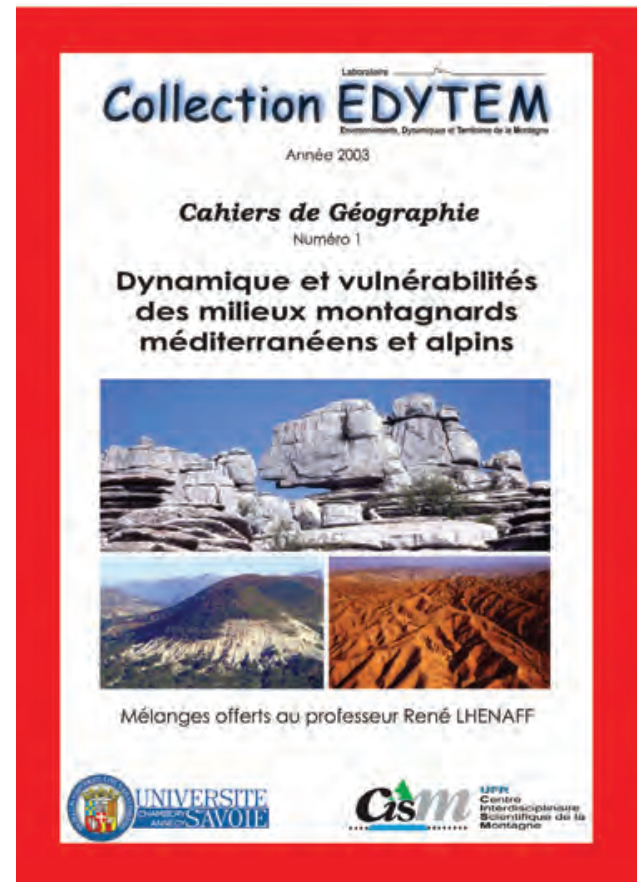

Jean-Jacques DELANNOY, Les planéités «karstiques », genèse et intérêts morphogéniques: application au bassin de Ronda (Andalousie)

Marc CALVET et Bertrand LEMARTINEL, Vieilles formes et vieux versants: le paradoxe des paysages méditerranéens

Jean-Jacques DUFAURE, Regard sur les bassins intramontagnards sudbalkaniques: morphogenèse, milieux, sociétés

Jean NICOD, Le Velebit (Croatie occidentale), une chaîne typique du karst dinarique - mise au point d'après des articles récents

Khadidja REMAOUN, Le bassin versant de l'Oued Tafna (Algérie occidentale): mise en place du réseau hydrographique et processus morphogéniques à l'origine de l'organisation du bassin

Jean SOMME, Cap Blanc-Nez, falaise de Sangatte et Calaisis : un tournant géomorphologique à l'Holocène récent

Alain MARNEZY, Essai de détermination d'un bilan global d'érosion, application au cas du bassin versant de l'Arc (Savoie)

Georges ROVERA, Christophe CORONA et Lise WLERICK, Processus d'érosion et mesure de l'ablation sur les versants gypseux du Petit Mont Blanc de Pralognan, vers 2500 m. (Vanoise, Alpes du Nord, France)

Grégoire THEVENET, Laurent ASTRADE et Jean-Paul BRAVARD, La métamorphose des lits torrentiel à la fin du XIXe siècle :un effet du changement climatique ou du reboisement (bassin du Haut-Bez-Drôme)

Stéphane BALLANDRAS, Réalité et logique des géosystèmes montagnards alpins : principes de fonctionnement morphodynamique

Jean VAUDOUR, Approche systémique et analyse séquentielle des carbonates continentaux dans les milieux méditerranéens Philippe AUDRA, Les valeurs record d'ablation karstique dans les montagnes Nakanaï (Nouvelle-Bretagne, Papouasie-Nouvelle-Guinée Robert d'ERCOLE et Florent DEMORAES, Risques et réponses institutionnelles en Equateur: cartes et méthodes

Philip DELINE, Les grands écroulements rocheux de 1920 et de 1997 sur le glacier de la Brenva (massif du Mont-Blanc): un vecteur géomorphologique pour la reconstitution de l'histoire holocène d'un bassin glaciaire de la haute montagne alpine

Michel CHARDON, Les récents écroulements de parois en Oisans : observations et réflexions

Philippe LAHOUSSE, Gilles GARITTE et Lucas THENARD, Aléa et risque torrentiel dans le Briançonnais (Alpes françaises du Sud)

Anne LACAMBRE, Stanislas WICHEREK et Jean-Pierre PEULVAST, Connaissance et perception des risques naturels face à une réalité érosive. L'apport d'une enquête auprès de la population dans les communes d'Orcières et de Champoléon (HautesAlpes, France)

Stéphanie BARAILLE, Prévision des crues graves en haute Durance : typologie des situations météorologiques à risque

Céline LUTOFF, L'évaluation des enjeux : base de l'analyse de la vulnérabilité des systèmes urbains. Conditions de reproduction de l'expérience niçoise

Richard LAGANIER, Claude KERGOMARD et Monique DACHARRY, Les inondations en région Nord-Pas de Calais: essai de synthèse régionale

Alain MOREL et Ibrahim BOUZOU-MOUSSA, Erosion et lutte anti-érosive dans les milieux sahélo-soudaniens 


\section{COMPLETEZ VOTRE COLLECTION}

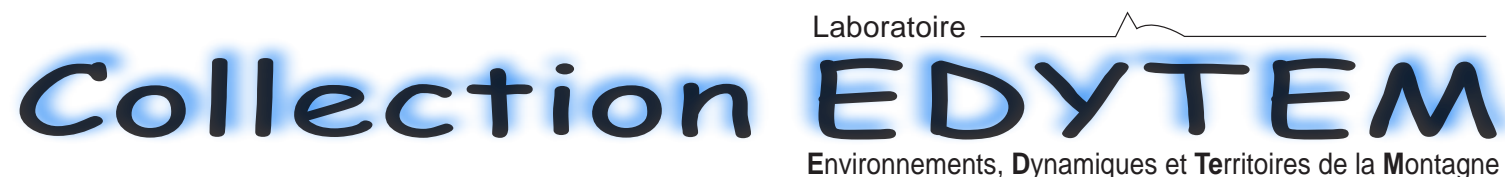

Cahiers de Géographie

Numéro 2 (2004) :

Traverser les montagnes.

Actes du colloque organisé par Montanéa, 3 \& 4 octobre 2002 à Chambéry.

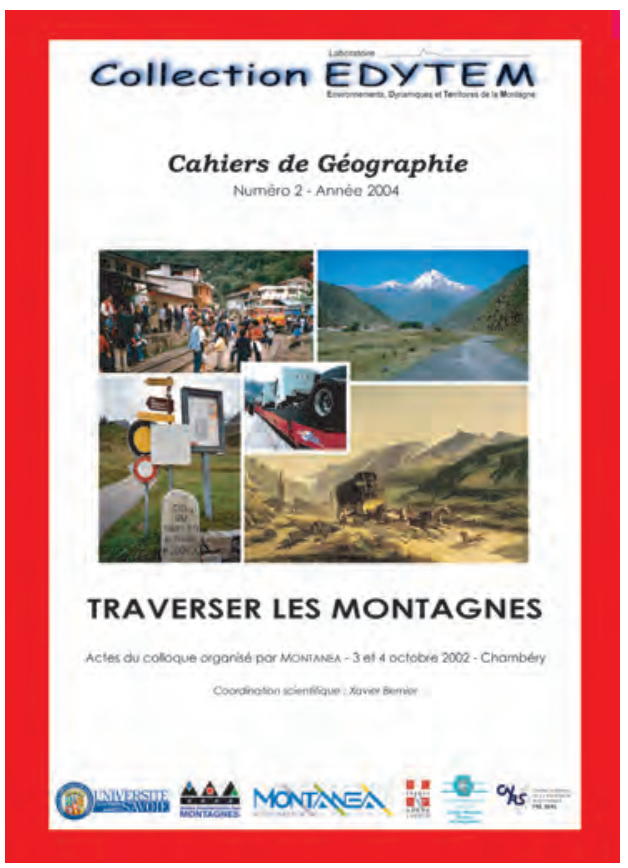

1 - Les conditions du passage et les marqueurs du franchissement

Emmanuel LE ROY LADURIE, La nécessaire prise en compte de l'histoire du climat

Jean-Daniel CANDAUX, Voyages et représentations - La littérature de voyage, les cols par plaisir

Jean-Jacques REY-BELLET, Une politique du passage: le Valais

Louis FRESCHI, L'axe du Brenner

Christophe GAUCHON, Les monuments du passage

2 - Les enjeux liés à la maîtrise du passage et aux dynamiques d'ouverture et de fermeture

Yves CROZET, Traversées alpines - Comment conjuguer fluidité et respect de l'environnement?

Jean VARLET, Traverser le Massif Central - Dynamiques d'ouverture et de fermeture

Xavier BERNIER, Les cols routiers dans la traversée des montagnes françaises - Contribution à une définition plurivalente et dynamique

André PALLUEL-GUILLARD, L'épopée des chemins de fer à travers les Rocheuses de la ruée vers l'or à nos jours Stéphane MOURLANE, Le tunnel du Mont-Blanc - Un projet à travers un siècle de relations franco-italiennes (1860-1965)

3 - Réorganisations des flux et recompositions territoriales dans la traversée des montagnes

Anne-Laure AMILHAT-SZARY, Les nouvelles traversées andines - De la montagne-obstacle à la montagne-interface?

Bartolomé BENASSAR, La traversée des Andes à l'époque moderne

Pierre THOREZ, Flux et déplacements dans le Caucase

Julien THOREZ, Montagnes et espaces nationaux post-soviétiques en Asie Centrale (Kirghizstan, Tadjikistan, Ouzbékistan)

Patrick PIGEON, Gestion des risques et peuplements helvétiques - L'exemple du Gothard 164 pages, ISBN 2-9520432-1-3 ; ISSN 1762-4304 


\section{COMPLETEZ VOTRE COLLECTION}

\section{Collection EDYTEM \\ Environnements, Dynamiques et Territoires de la Montagne}

\section{Cahiers de Géographie}

Numéro 3 (2005) :

Le Quaternaire des vallées alpines. Fronts glaciaires, mouvements de versants et comblements alluviaux dans les vallées de l'Arve, d'Aoste et de Suse. Livret-guide de l'excursion organisée par l'AFEQ du 2 au 4 juin 2005.

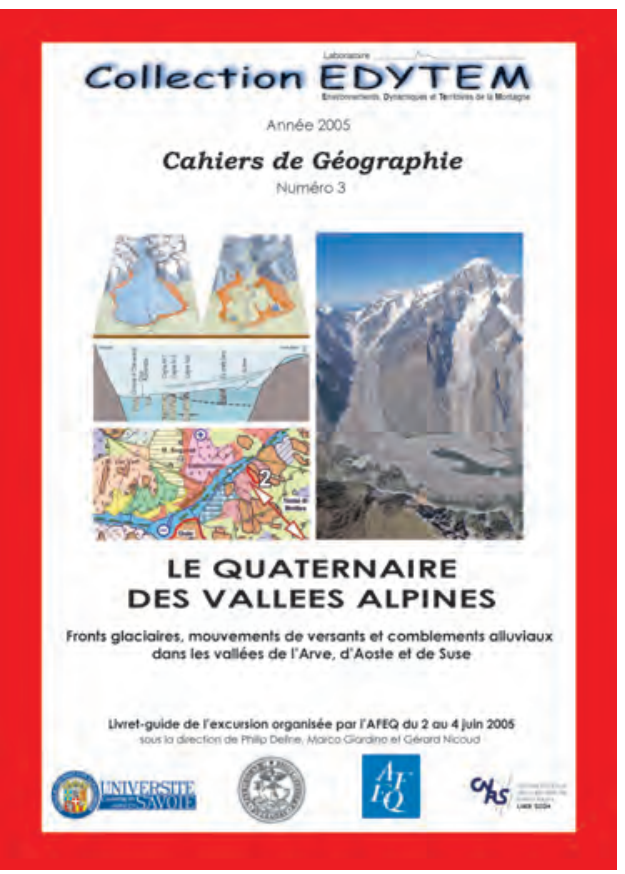

Première demi-journée - La déglaciation de la vallée de l'Arve par G. NICOUD, S. COUTTERAND, F. AMELOT, C. BURNIER et L. MOREAU

Le bassin de Bonneville - L'ombilic de Sallanches / Le Fayet et le complexe morainique des stades de Magland - Les graniteurs - Le complexe morainique des stades du Fayet - Les écroulements du Dérochoir et les mouvements de terrain du versant méridional du Désert de Platé - L'ombilic de Chamonix / Les Houches.

Deuxième demi-journée - Le Val Veny (Vallée d'Aoste) :

Héritages post-LGM, formes et processus actuels de la haute montagne alpine englacée (par P. DELINE et S. COUTTERAND)Un glacier noir remarquable, le Miage - Amphithéâtre morainique du lac du Miage : reconstituer la dynamique du Miage pendant l'Holocène - Les écroulements holocènes sur la Brenva - Reconstitution de la région du massif du Mont Blanc pendant le LGM.

Troisième demi-journée - Comblement alluvial et dynamique des versants de la vallée d'Aoste par M. GIARDINO, G. MARTINOTTI, F. MEZZENA, G. NICOUD et E. DALBARD

L'ombilic d'Aoste, une dynamique lacustre complexe - Formes et dépôts de la glaciation pléistocène dans la moyenne Vallée d'Aoste Dynamique géomorphologique et évolution d'un site archéologique : la nécropole de Vollein - Sédimentation et néotectonique post-glaciaires dans la moyenne Vallée d'Aoste - Les mouvements de terrain entre Bard et Donnas (basse Vallée d'Aoste).

Quatrième demi-journée - Formes et dépôts glaciaires dans l'Amphithéâtre morainique d'Ivrea (AMI) par F. GIANOTTI, M. GIARDINO, G. FORNO et F. GROSSO

Serra d'Ivrea et Petite Serra - Stratigraphie de la Serra d'Ivrea - Les Collines d'Ivrea : affleurements rocheux à modelé glaciaire - L'amphithéâtre morainique d'Ivrée vu par les anciens auteurs.

Cinquième demi-journée - L’Amphithéâtre Morainique de Rivoli - Avigliana par M. GIARDINO, F. CARRARO, G. F. FIORASO et S. LUCCHESI

Dépôts glaciaires de l'amphitéâtre morainique de Rivoli / Avigliana - Sols fossiles et surfaces de base des unités glaciaires de l'amphithéâtre - Moraine et till du Mont Musinè - Vue panoramique sur l'amphithéâtre et la basse Vallée de Suse et la Sacra di San Michele : histoire, architecture et légende.

Sixième demi-journée - Mouvements de masse post-glaciaires dans la vallée de Suse par F. CARRARO, M. GIARDINO et G. F. FIORASO

Observations en route : la basse Vallée de Suse ; la région de Suse - La glaciation locale du Val Clarea (moyenne Vallée de Suse) - Le lit épigénique de la Doire Ripaire et la dynamique des versants dans la moyenne Vallée de Suse - La déformation gravitaire profonde de versant de Serre La Voute - Néotectonique et contrôle lithostructural sur les formes de la moyenne et haute Vallée de Suse. 


\title{
COMPLETEZ VOTRE COLLECTION
}

\section{Collection EDYTEM}

\section{Cahiers de Géographie}

\author{
Numéro 4 (2006) : Transport et Tourisme.
}

\section{Actes du colloque organisé à Chambéry du 13 au 15 septembre 2006.}

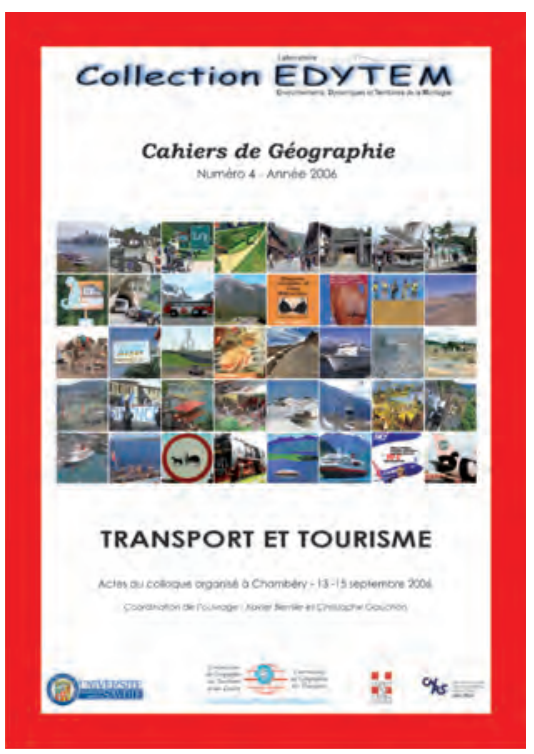

Première partie - Les interactions entre transport et tourisme RÉFLEXIONS

Transport et mise en tourisme du Monde par JEAn-Christophe GAY.

De la relation entre transport et lieux touristiques par PHILIPPE DUHAMEL.

Tourisme et enclavement: l'exemple du Massif Central français par CHRISTIAN JAMOT.

\section{DEUXIÈME PARTIE - L'ACCÈS AUX DESTINATIONS TOURISTIQUES}

Le transport, entre nécessité et plaisir : les perspectives d'ouverture des espaces touristiques de la Roumanie par MinAELA AXENTE-BUDILEANU.

Les compagnies aériennes à bas prix et le tourisme en Europe : état des lieux et perspectives par Pierre THOREZ et Pierre ZEMBRI.

Éléments pour une géographie de l'offre charter européenne face à la concurrence des compagnies low-cost par FréDÉRIC DOBRUSZKES, VINCENT SCHEPENS et JEAN-Michel DECROLY.

Le Point Afrique, acteur majeur du transport aérien et du développement touristique en Afrique saharo-sahélienne par BRUNo LECOQUIERRE.

Accessibilité et mobilité aux îles du Cap-Vert par NADÈGE KOKEL.

\section{TroisièME PARTIE - LES DÉPLACEMENTS DANS LES ESPACES TOURISTIQUES}

Transports par câbles et sports d'hiver : approche géographique de la dynamique territoriale du tourisme et des loisirs en espace montagnard par CHRISTIAN HELION.

Les domaines skiables reliés dans les Alpes françaises par Alain MARNEZY et Christophe GAUCHON.

Nature mobile et touriste transporté... Enjeux et problèmes liés aux déplacements touristiques dans les parcs nationaux des montagnes de l'Ouest canadien par STÉPHANE HÉRITIER.

Pour une différenciation des déplacements dans l'espace touristique : l'analyse des excursions à l'île Maurice par FRANK PARIS.

\section{QUATRIÈME PARTIE - LES RÉSEAUX DE TRANSPORT COMME ÉLÉMENTS DE LA RESSOURCE TOURISTIQUE}

Une voie de transport devenue ressource touristique: le cas très particulier de l'Express côtier norvégien par JAcQuES GUILLAUME.

Structuration et dynamiques du tourisme de croisière dans le Bassin caraïbe par THIERRY HARTOG et CoLETTE RANÉLY VERGÉDÉPRÉ.

L'émergence du tourisme fluvial en Europe par RAYMOND WOESSNER.

Véloroutes et voies vertes : supports, ou objets touristiques? par AnNE HECKER.

Le rôle du chemin de fer dans la mise en valeur touristique : Le cas d'une moyenne montagne française, le Massif Central par MARIE-Eve FEREROL.

Le voyage sur la Nakasendô (Japon) par SyLvie GUICHARD-ANGUIS.

Manger sur l'autoroute en France : Les pratiques alimentaires des touristes par GILLES FUMEY.

\section{CinquiÈME PARTIE - TrANSPORT, DÉVELOPPEMENT TOURISTIQUE ET TERRITOIRES - SyNERGIES ET CONFLITS}

Autoroutes et dynamique du tourisme par Anne GRIFFOND-BOITIER.

Ressource touristique et enjeux territoriaux évolution et re-définition de la route touristique des gorges de l'Ardèche par Mélanie DUVAL.

Pas feutrés et pneus crantés... Les Alpes françaises entre pratiques de «nature » et loisirs motorisés, une approche des conflits d'usages autour de la mobilité touristique par Lionel LASLAZ.

Les transports, facteurs de développement touristique au sud du Maroc par Mohamed OUDADA. 


\section{Publications en vente}

\section{Cahiers Savoisiens de Géographie}

Prix du $\mathrm{N}^{\circ} \quad$ Frais de port

No 1 (1997): Transports et développement en Pays de Savoie

$10 €$

$\mathrm{N}^{\circ} 2$ (1999) : Livret guide des excursions Grands Causses - Vercors

épuisé

$\mathrm{N}^{\circ} 3$ (2000) : La géographie des risques dits «naturels» entre géographie fondamentale et géographie appliquée

$10 €$

$\mathrm{N}^{\circ} 4$ (2001) : Identités et territoires

$10 €$

\section{Collection EDYTEM - Cahiers de GÉographie}

$\mathrm{N}^{\circ} 1$ (2003) : Dynamique et vulnérabilités des milieux montagnards méditerranéens et alpins

$\mathrm{N}^{\circ} 2$ (2004) : Traverser les Montagnes

$15 € \quad 3 €$

№3 (2005): Le Quaternaire des vallées alpines

$15 €$ $3 €$

$\mathrm{N}^{\circ} 4$ (2006) : Transport et Tourisme

$15 €$

Pour recevoir ces publications :

Adressez votre commande à :

Laboratoire EDYTEM, secrétariat,

Université de Savoie,

CISM, Campus scientifique,

F 73376 Le Bourget du Lac Cedex.

accompagnée d'un chèque (à l'ordre de M. l'Agent Comptable de l'Université de Savoie), ou d'un mandat administratif. 
Imprimé sur les presses de SVI Publicep (Label Imprim'Vert), avec des encres végétales, sur du papier blanchi sans chlore, provenant de forêts gérées durablement (garantis PEFC). 




\section{Sommaire}

Éditorial

René UGHETTO, maire d'Orgnac-l'Aven

Introduction

Problématique d'étude

Jean-Jacques DELANNOY

Chapitre 1

L'aven d'Orgnac : identification d'un haut lieu du tourisme souterrain

Vincent BIOT, Mélanie DUVAL et Christophe GAUCHON

La gestion des réseaux d'Orgnac-Issirac : un exemple original de valorisation

Stéphane TOCINO

Chapitre 2

L'aven d'Orgnac : une caverne privilégiée pour l'élaboration des connaissances karstologiques

Christophe GAUCHON et Françoise PRUD'HOMME

Bibliographie scientifique sur l'aven d'Orgnac.

Françoise PRUD'HOMME

Chapitre 3

L’aven d'Orgnac : un grand réseau paragénétique, étude spéléogénétique des grands volumes karstifiés

Stéphane JAILLET, Jean Jacques DELANNOY, Jean-Loïc BERSIHAND, Matthieu NOURY, Benjamin SADIER et Stéphane TOCINO

\section{Chapitre 4}

L'aven d'Orgnac : étude des remplissages, mémoires des dynamiques spéléogéniques post-paragénétiques

Benjamin SADIER, Anne-Sophie PERRROUX, Yves PERRETTE, Jean-Jacques DELANNOY, Yves QUINIF et Olivier KAUFMANN

Chapitre 5

L'aven d'Orgnac : suivi environnemental et modèle de fonctionnement actuel du milieu souterrain karstique au service du développement durable.

François BOURGES, Alain MANGIN, Pierre GENTHON, Dominique D’HULST et Françoise GAUQUELIN

Chapitre 6

L'aven d'Orgnac : un jalon karstique pour la reconstitution paléogéographique de l'interfluve Ardèche/Cèze

Jean-Jacques DELANNOY, Stéphane JAILLET, Serge FUDRAL, Dominique GASQUET, Olivier KAUFMANN, Maxime SABAUT et Estelle PLOYON

Conclusion

Perspectives pluridisciplinaires

Jean-Jacques DELANNOY

Annexes

1 -Topographie et Modèle Numérique de Terrain 2,5D par Benjamin SADIER

2 - Volume souterrain 3D et laserscanning par Stéphane JAILLET

3 - Cartographie géomorphologique des sols par Jean-Jacques DELANNOY

4 - Sédimentologie endokarstique par Anne-Sophie PERROUX

5 - Datations U / Th des stalagmites par Yves QUINIF

6 - Tomographie électrique par Olivier KAUFMANN

7 - Métrologie et climatologie souterraine par François BOURGES

Prix à la vente 15 euros

ISBN 2-9520432-4-8 